Universidad deValladolid

PROGRAMA DE DOCTORADO EN QUÍMICA: QUÍMICA DE SÍNTESIS, CATÁLISIS Y MATERIALES AVANZADOS

TESIS DOCTORAL

\title{
DESARROLLO DE MÉTODOS IN VITRO PARA LA DETERMINACIÓN DE LA PENETRACIÓN EN EL SISTEMA NERVIOSO CENTRAL Y NUEVOS HÍBRIDOS ANTI-ALZHEIMER DERIVADOS DE TACRINA O DE DIBENCILMETILAMINA
}

Presentada por Beatriz López Iglesias para optar al grado de Doctora por la Universidad de Valladolid

Dirigida por

Dra. María Isabel Rodríguez Franco

Instituto de Química Médica

Consejo Superior de Investigaciones Científicas

Valladolid 2018 



\section{AUTORIZACIÓN DE LA DIRECTORA DE TESIS}

Dña. María Isabel Rodríguez Franco, con D.N.I. № 50.417.234-S, Investigadora Científica del Instituto de Química Médica del Consejo Superior de Investigaciones Científicas, como Directora de la Tesis Doctoral titulada "Desarrollo de métodos in vitro para la determinación de la penetración en el sistema nervioso central y nuevos híbridos anti-Alzheimer derivados de tacrina o de dibencilmetilamina", presentada por Dña. Beatriz López Iglesias, alumna del programa de doctorado: “Doctorado en Química: Química de síntesis, catálisis y materiales avanzados" impartido por el Instituto Universitario CINQUIMA, autoriza la presentación de la misma, considerando que cumple todos los requisitos para ello.

Valladolid, 7 de junio de2018

La Directora de la Tesis

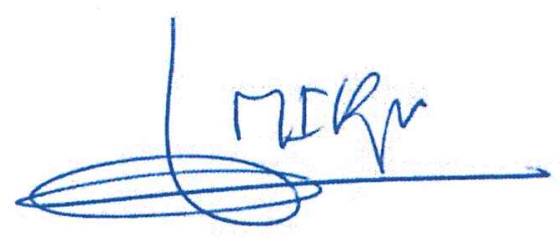

Fdo. María Isabel Rodríguez Franco 



\section{$\frac{\text { CIN: }: \text { it: }}{\text { QUIMA }}$}
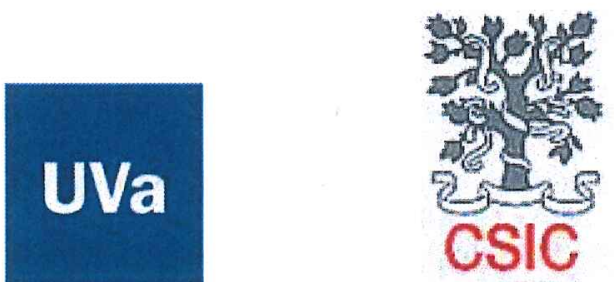

La Tesis Doctoral titulada "Desarrollo de métodos in vitro para la determinación de la penetración en el sistema nervioso central y nuevos híbridos anti-Alzheimer derivados de tacrina o de dibencilmetilamina" ha sido realizada gracias al apoyo económico del Plan Nacional de I+D (SAF2012-31035 y SAF2015-64948-C2-1-R), de la Comunidad de Madrid (Programa de Biomedicina B2017/BMD-3827) y del CSIC (PIE-201580E109).

Se agradece la colaboración del grupo de los Drs. Antonio G. García y Manuela G. López (Facultad de Medicina de la Universidad Autónoma de Madrid) en la realización de los estudios de neuroprotección y en el modelo in vivo de pérdida de memoria. Asimismo, se agradecen los estudios de neurogénesis en células madre neuronales, realizados por el grupo de la Dra. Ana Pérez-Castillo (Instituto de Investigaciones Biomédicas "Alberto Sols" - CSIC). Sin su desinteresada colaboración, esta Tesis no hubiera podido realizarse. 

Índice 



\section{Capítulo 1. MÉTODOS IN VITRO PARA LA DETERMINACIÓN DE LA} PENETRACIÓN DE MOLÉCULAS EN EL SISTEMA NERVIOSO CENTRAL (SNC)

\subsection{INTRODUCCIÓN}

1.1.1. Desarrollo farmacéutico y propiedades ADME 1

1.1.2. Penetración de fármacos en el SNC. Barrera hematoencefálica 4

1.1.3. Métodos in vitro para determinar la penetración de fármacos en el SNC 6

1.1.3.1. Penetración de fármacos en el SNC. Barrera hematoencefálica 6

$\begin{array}{ll}\text { 1.1.3.2. Desarrollo farmacéutico y propiedades ADME } & 7\end{array}$

1.1.4. Permeabilidad a través de lípidos (difusión horizontal y PAMPA) 9

\subsection{OBJETIVOS 12}

\subsection{DISCUSIÓN DE RESULTADOS}

1.3.1. Modelo predictivo de la penetración en el SNC empleando celdas de difusión horizontal

1.3.2. Modelo predictivo de la penetración en el SNC empleando la metodología PAMPA (Parallel Artificial Membrane Permeation Assay) 16

1.3.2.1. Descripción general del método y de las fórmulas empleadas 16

1.3.2.2. Validación de condiciones experimentales con fármacos patrón 18

1.3.2.3. Estudio del empleo de cosolventes 20

1.3.3. Moléculas evaluadas empleando la metodología PAMPA 24

1.3.3.1. Neuroprotectores multifuncionales derivados del ácido L-glutámico 24

1.3.3.2. N-Acilaminofenotiazinas y 5,6-dihidro-1,4,5-dibenzo[b,f]tiadiazepinas .26

1.3.3.3 Tacripirinas 28

1.3.3.4. Sulfato de condroitina 30

1.3.3.5. Antioxidantes comerciales $\quad 32$

1.4. CONCLUSIONES 34

1.5. PARTE EXPERIMENTAL 35 


\section{Capítulo 2. NUEVOS HÍBRIDOS ANTI-ALZHEIMER DERIVADOS DE TACRINA O DE N,N-DIBENCIL(N-METIL)AMINA}

\subsection{INTRODUCCIÓN}

2.1.1. Neuropatología de la enfermedad de Alzheimer

2.1.1.1. Lesiones características de la EA: placas amiloides y ovillos neurofibrilares .41

2.1.1.2. Alteraciones en los sistemas de neurotransmisión

2.1.1.3. Estrés oxidativo

2.1.2. Estrategias terapéuticas contra la enfermedad de Alzheimer $\quad 50$

2.1.2.1. Fármacos comercializados y ejemplos de moléculas en fases clínicas $\quad 50$

2.1.2.2. Fármacos multi-diana (MTL, multi-targeted ligands) 52

\subsection{OBJETIVOS 55}

\subsection{HÍBRIDOS DERIVADOS DE TACRINA}

2.3.1. Híbridos tacrina - neuroaminas

2.3.1.1. Síntesis de los híbridos tacrina - neuroaminas 60

2.3.1.2. Inhibición de acetil y butirilcolinesterasa de los híbridos tacrina - neuroaminas

2.3.1.3. Predicción in vitro de la penetración en el SNC de los híbridos tacrina $\begin{array}{ll}\text { neuroaminas } & 64\end{array}$

2.3.2. Híbridos tacrina - ferúlico 65

2.3.2.1. Síntesis de los híbridos tacrina - ferúlico 66

2.3.2.2. Inhibición de acetil- y butirilcolinesterasa de los híbridos tacrina - ferúlico .68

2.3.2.3. Predicción de la penetración en el SNC de los híbridos tacrina - ferúlico $\quad 70$

2.3.3. Híbridos tacrina - fenol 71

2.3.3.1. Síntesis de los híbridos tacrina - fenol 72

2.3.3.2. Inhibición de acetil y butirilcolinesterasa de los híbridos tacrina - o-fenol .75

2.3.3.3. Predicción de la penetración en el SNC de los híbridos tacrina - o-fenol 77

2.3.3.4. Estudio de unión al PAS de la AChE de híbridos tacrina - o-fenol 78

2.3.3.5. Ensayos de toxicidad y de neuroprotección frente al estrés oxidativo mitocondrial 


\subsection{HÍBRIDOS N,N-DIBENCIL(N-METIL)AMINA - NEUROAMINAS Y N,N- DIBENCIL(N-METIL)AMINA - PIRIDINA / PIRIDINOL}

2.4.1. Síntesis de los híbridos DBMA - neuroaminas y DBMA - piridina/piridinol 85

2.4.2. Medida de la actividad como inhibidores de acetil y butirilcolinesterasa $\quad 89$

2.4.3. Estudio de unión al PAS de la AChE mediante desplazamiento de propidio ......92

2.4.4. Predicción in vitro de la penetración en el SNC de los híbridos DBMA neuroaminas y DBMA - piridina / piridinol 93

2.4.5. Ensayos de toxicidad y de neuroprotección frente al estrés oxidativo mitocondrial

2.4.6. Neuroprotección del híbrido DBMA - homoveratrilamina (61) frente a otros estímulos tóxicos relacionados con la enfermedad de Alzheimer en la línea celular de neuroblastoma humano SH-SY5Y

2.4.7. Estudio de neuroprotección del híbrido DBMA - homoveratrilamina (61) en un modelo tisular de isquemia cerebral

2.4.8. Evaluación del híbrido DBMA - homoveratrilamina (61) en un modelo in vivo de pérdida de memoria por escopolamina

\subsection{HÍBRIDOS N,N-DIBENCIL(N-METIL)AMINA - MELATONINA}

2.5.1. Síntesis de los híbridos DBMA - melatonina

2.5.2. Inhibición de acetil y butirilcolinesterasa humanas de los híbridos DBMA melatonina

2.5.3. Ensayos enzimáticos de desplazamiento de propidio del PAS de la AChE $\quad 110$

2.5.4. Predicción in vitro del paso de la barrera hematoencefálica 112

2.5.5. Evaluación de la capacidad de captura de radicales de oxígeno 114

2.5.6. Ensayos de neuroprotección y viabilidad celular en neuroblastoma humano 114

2.5.7. Estudios neurogénicos de los híbridos DBMA - melatonina 115

2.6. CONCLUSIONES 121

2.7. PARTE EXPERIMENTAL 124

2.7.1. Derivados de tacrina $\quad 125$

2.7.1.1. Procedimiento general para la síntesis de 8,9-dicloro-, 6,8,9-tricloro- y 9-cloro-

7-flúor-1,2,3,4-tetrahidroacridina (2-4) 126

2.7.1.2. Procedimiento general para la síntesis de los ácidos (5-11) 128

2.7.1.3. Síntesis de los híbridos tacrina - neuroaminas (12-24). Procedimiento general 
2.7.1.4. Procedimiento general para la síntesis de tioamidas derivadas de los híbridos tacrina - neuroaminas (25 y 26$)$

2.7.1.5. Síntesis de N-(1,2,3,4-tetrahidroacridin-9-il)]-1,N-alcanodiaminas (27-30).

Procedimiento general

2.7.1.6. Síntesis de los híbridos tacrina - ferúlico (31-34) y tacrina - fenol (35-47) .147

2.7.2. Híbridos derivados de N,N-dibencil(N-metil)amina

2.7.2.1. Procedimiento general para la síntesis de los benzonitrilos precursores (49-52)

2.7.2.2. Procedimiento general para la síntesis de los ácidos precursores (53-57) 161

2.7.2.3. Síntesis de N-(4-(aminometil)bencil)-N-metil-1-fenilmetanamina (58) 164

2.7.2.4. Síntesis de los híbridos N,N-dibencil(N-metil)amina - neuroaminas (59-68) y

N,N-dibencil(N-metil)amina - piridina / piridinol (69-76). Procedimiento general 164

2.7.3. Síntesis de los híbridos N,N-dibencil(N-metil)amina - melatonina (77-90) 175

2.7.4. Ensayos biológicos 183

2.7.4.1. Inhibición de AChE y BuChE 183

2.7.4.2. Ensayos de desplazamineto de propidio del PAS de la AChE 184

2.7.4.3. Evaluación de la capacidad antioxidante mediante el método ORAC $\quad 184$

2.7.4.4. Cultivo de la línea celular de neuroblastoma humano SH-SY5Y 185

2.7.4.5. Neuroprotección contra el estrés oxidativo 185

2.7.4.6. Neuroprotección contra la sobrecarga de calcio 186

2.7.4.7. Neuroprotección contra la toxicidad inducida por $\mathrm{A} \beta_{1-42} \quad 186$

2.7.4.8. Neuroprotección contra la toxicidad inducida por ácido okadaico 186

2.7.4.9. Medida de la actividad de lactato deshidrogenasa (LDH) 186

2.7.4.10. Medida de la viabilidad celular mediante MTT 186

2.7.4.11. Preparación de rodajas de hipocampo de rata e inducción de toxicidad mediante la falta de oxígeno y glucosa seguida de re-oxigenación (OGD/Reox) 188

2.7.4.12. Cuantificación de la viabilidad celular en rodajas de hipocampo por MTT 189

2.7.4.13. Estudios de un modelo in vivo de pérdida de memoria por escopolamina 189

2.7.4.14. Ensayos de Neurogénesis. Animales y cultivo de neuroesferas 190

2.7.4.15. Inmunocitoquímica y determinaciones estadísticas 191

2.8. TABLAS (DATOS DE ${ }^{1} \mathrm{H}-\mathrm{RMN}$ Y ${ }^{13} \mathrm{C}-\mathrm{RMN}$ ) 


Abreviaturas 

13C-RMN Resonancia magnética nuclear de carbono

1H-RMN Resonancia magnética nuclear de protón

ACh Acetilcolina

AChE Acetilcolinesterasa

AChE-h: Acetilcolinesterasa humana

AcOEt Acetato de etilo

ADME Absorción, Distribución, Metabolismo y Excreción

BHE Barrera hematoencefálica

BOP Hexafluorofosfato de (benzotriazol-1-loxi)trisdimetilaminolidinofosfonio

bov-AChE: Acetilcolinesterasa bovina

BuChE Butirilcolinesterasa

BuChE-h Butirilcolinesterasa humana

CAS: Centro activo

$\mathrm{CI}_{50}$ Concentración inhibitoria al 50\%

COSY Correlación homonuclear de protón

DBMA: $N, N$-dibencil( $N$-metil)amina

DCC: diciclohexilcarbodiimida

DMF $N, N$-Dimetilformamida

DMSO Dimetilsulfóxido

EA Enfermedad de Alzheimer

EA: enfermedad de Alzheimer

EM Espectroscopía de masas

EN Enfermedades neurodegenerativas

eq-BuChE: Acetilcolinesterasa equina

ES Electrospray

EtOH Etanol

Glu Ácido glutámico

HMBC Correlación heteronuclear a larga distancia

HPLC-MS: High performance liquid chromatography-mass spectrometry

HSQC Correlación heteronuclear a un enlace

IE Impacto electrónico

IR Espectroscopia de infrarrojo

LDH: lactato deshidrogenasa 
MAP Proteína asociada a microtúbulos

$\mathrm{MHz}$ Megahercios

MTT: bromuro de 3-(4,5-dimetiltiazol-2-il)-2,5-difeniltetrazolio

NBS $N$-Bromosuccinimida

NO Óxido nítrico

NOS Sintasa del óxido nítrico

ON Ovillos neurofibrilares

ONOO: peroxinitrilo

ORAC-FL: oxygen radical absorbance capacity - fluorescein

PAMPA Parallel Artificial Membrane Permeation Assay

PAS sitio aniónico periférico

PBS phosphate buffered saline

$P_{\mathrm{e}}$ Permeabilidad experimental

PEG: Polietilenglicol

Ph Fenilo

PPA Proteína precursora del péptido amiloide

PS Placas seniles

PVDF Polifluoruro de vinildeno

Py Piridina

PyBOP Hexafluorofosfato de (benzotriazol-1-iloxi)tripirrolidinofosfonio

RMN Resonancia magnética nuclear

RMN: Resonancia magnética nuclear

ROS Especies reactivas de oxígeno

Ser Serina

SNC: Sistema nervioso central

TFA Ácido trifluoroacético

THF Tetrahidrofurano

TLC Cromatografía en placa fina

$t_{R}$ : Tiempo de retención

Trp Triptófano

Tyr Tirosina

UV-vis: Espectroscopia ultravioleta-visible

$\beta$ A péptido amiloide 
Capítulo 1

Métodos in vitro para la determinación de la penetración de moléculas en el SNC 



\section{MÉTODOS IN VITRO PARA LA DETERMINACIÓN DE LA PENETRACIÓN DE MOLÉCULAS EN EL SISTEMA NERVIOSO CENTRAL (SNC)}

\subsection{INTRODUCCIÓN}

\subsubsection{Desarrollo farmacéutico y propiedades ADME}

El desarrollo clásico de un fármaco es un proceso largo y complejo que consta de diversas etapas, agrupadas en cuatro grandes bloques (Figura 1):

1. Investigación básica en Química Médica, que comprende desde el diseño o encuentro fortuito de una estructura química interesante y el estudio de sus actividades biológicas in vitro, hasta su optimización estructural. Esta etapa suele tener una duración aproximada de dos o tres años y los costes se pueden considerar moderados.

2. Ensayos preclínicos en animales de experimentación, donde se estudian los aspectos de farmacología y toxicidad in vivo, con una duración de tres a cinco años, y donde los costes aumentan de manera exponencial.

3. Ensayos clínicos en humanos, divididos a su vez en tres fases. En la primera se estudia la seguridad y las pautas más adecuadas para la administración del producto, empleando voluntarios sanos. En la fase clínica II se estudia la eficacia real del fármaco frente a la patología a tratar y las relaciones dosis-respuesta con un número limitado de enfermos. En la fase clínica III se realizan estudios multicentro en hospitales, donde se prueba la eficacia y seguridad del fármaco en las condiciones de uso habituales, comparándolo con las alternativas terapéuticas previamente existentes. Los ensayos clínicos constituyen la etapa de mayor duración, entre 5 y 8 años, y en la que los costes son mayores.

4. Aprobación del fármaco por las autoridades sanitarias competentes y comercialización del medicamento. 
Después de la comercialización se inicia el periodo de farmacovigilancia, comúnmente denominado fase clínica IV, en la que se estudian posibles incompatibilidades del medicamento y efectos secundarios a largo plazo. En algunos casos, también se investigan aplicaciones del producto en otras enfermedades, relacionadas o no con la patología inicial para la que se había desarrollado.

Se estima que el tiempo medio necesario para lanzar un nuevo producto en el mercado oscila entre 10 y 18 años y la inversión es muy elevada, entre 500 y 2.000 millones de euros, dependiendo del medicamento y de la categoría terapéutica de la que se trate (Figura $1)^{1,2}$. Aunque en las primeras etapas del desarrollo farmacéutico, concretamente en las que se refieren a la investigación básica, los costes pueden considerarse moderados, éstos sufren un incremento exponencial ${ }^{3}$ a partir del inicio de los ensayos preclínicos, que no dejan de aumentar hasta la comercialización del medicamento. La razón la podremos entender fácilmente, considerando la mayor cuantía de los ensayos in vivo, ya sean realizados en animales de experimentación o en pacientes, frente a las pruebas in vitro.

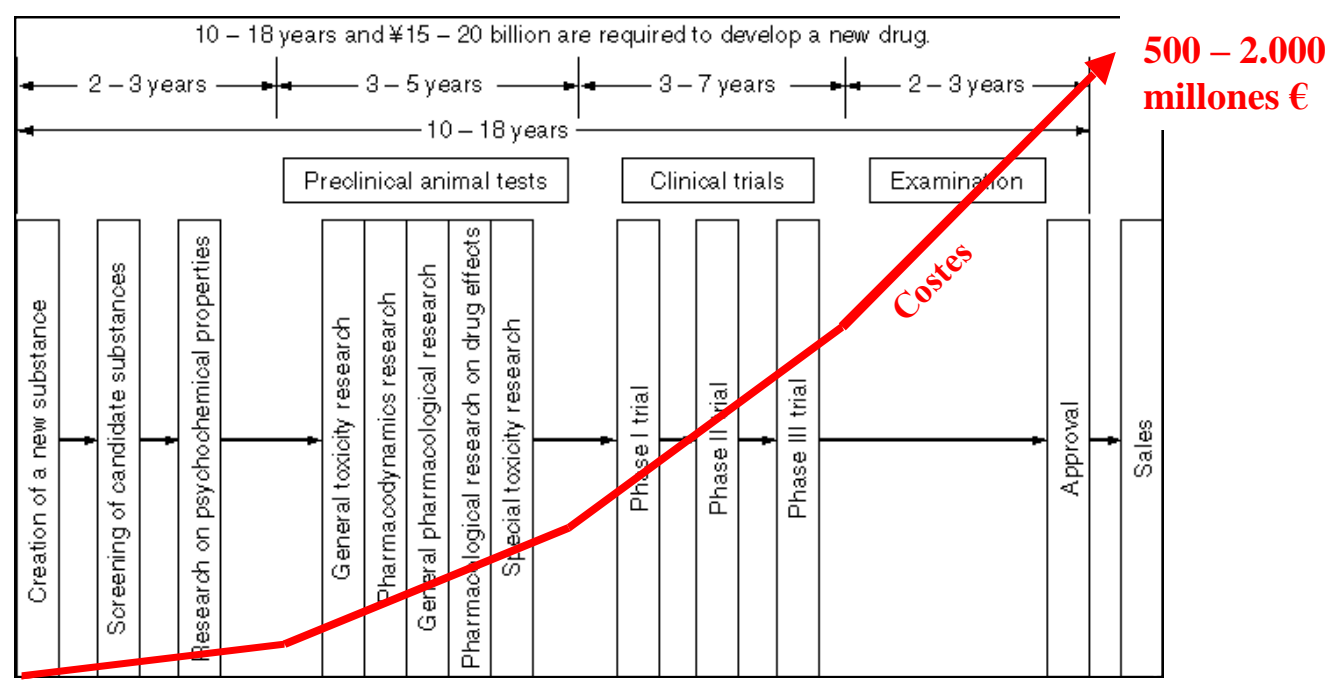

Figura 1. Esquema general del desarrollo de un fármaco.

Es importante señalar que estos enormes costes se refieren a situaciones de éxito, es decir a los casos en los que se consigue comercializar un nuevo medicamento. Pero la

\footnotetext{
${ }^{1}$ Adams, C.; Brantner, V. Estimating the cost of new drug development: is it really 802 million dollars? Health Aff. (Millwood) 2006, 25, 420-428.

${ }^{2}$ Riggs, T. L. Research and development costs for drugs. Lancet 2004, 363, 184.

${ }^{3}$.DiMasi, J. A; Grabowski, H.G.; Hansen, R. W. Innovation in the pharmaceutical industry: New estimates of R\&D costs. Journal of Health Economics. 2016, 47, 20-33.
} 
realidad es muy distinta, porque desafortunadamente no todos los productos que se incorporan al desarrollo farmacéutico llegan finalmente al mercado, y muchos de ellos son eliminados en algunas de las fases debido a la aparición de diferentes problemas. Un estudio sobre los motivos de los fracasos ha puesto de manifiesto que en un $11 \%$ de los casos éstos se deben a efectos tóxicos observados en animales de experimentación, toxicidad que no había sido detectada previamente en los estudios in vitro. En los ensayos en humanos, la retirada de un candidato se debe fundamentalmente a una falta de eficacia real $(30 \%)$ o a la aparición de efectos secundarios no deseados (10\%). En algunos casos, existen razones comerciales o de política empresarial. Sin embargo el mayor porcentaje, con un 39\% de los fracasos, corresponde a problemas en la adsorción, distribución, metabolismo y excreción (ADME) de los candidatos (Figura 2) ${ }^{4}$.

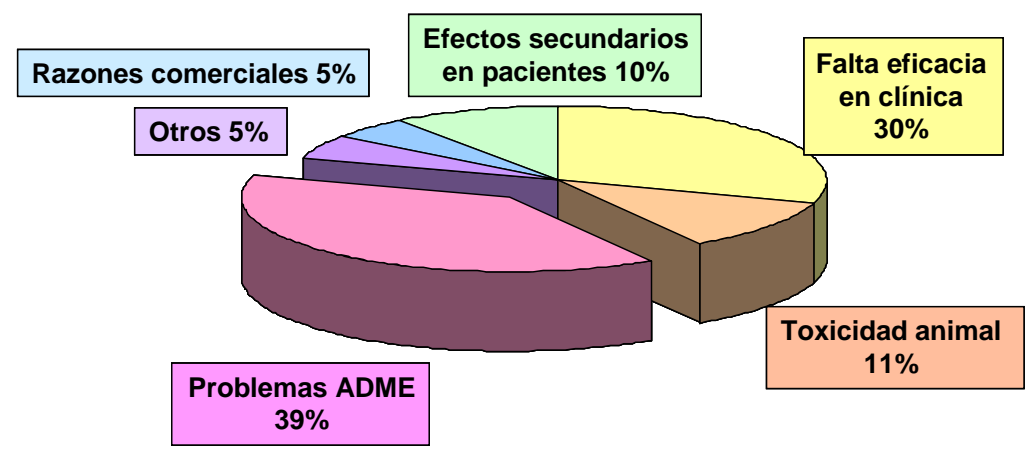

Figura 2. Razones por la que un candidato a fármaco no llega al mercado.

Por este motivo, es de gran importancia poder hacer una estimación lo más fidedigna posible de las propiedades ADME de los productos susceptibles de desarrollo farmacéutico, para poder detectar estos problemas en las fases iniciales del proceso, cuando la inversión realizada ha sido menor.

Además, la aparición en los últimos años de la química combinatoria para la síntesis masiva de productos y de los sistemas de high-throughput screening (HTS) para la evaluación de las propiedades biológicas, ha hecho aumentar el número de candidatos para desarrollo farmacéutico. Por lo tanto, la puesta en marcha de métodos de alto rendimiento para estudiar el ADME preliminar será de gran ayuda para obtener un fármaco que realmente cumpla con los requerimientos deseados en cuanto a potencia, selectividad, toxicidad, absorción, distribución, metabolismo y excreción. Por este motivo, en los

\footnotetext{
${ }^{4}$ Kubinyi, H. Drug research: myths, hype and reality. Nat. Rev. Drug Discov. 2003, 2, 665-668.
} 
últimos años se viene trabajando intensamente en el desarrollo de métodos, tanto teóricos como experimentales, para la determinación de propiedades $\mathrm{ADME}^{5}$, como la absorción oral, la penetración en el sistema nervioso central (SNC), el metabolismo hepático, etc.

\subsubsection{Penetración de fármacos en el SNC. Barrera hematoencefálica}

Aunque una buena actividad biológica es fundamental para el desarrollo de un nuevo fármaco, existen otros factores como la biodisponibilidad y la distribución entre diferentes tejidos que son igualmente importantes. Por ejemplo, el conocimiento del grado de penetración de un producto en el sistema nervioso central (SNC) es de vital importancia. Así, cuando se trabaja en enfermedades relacionadas con el SNC, como es la enfermedad de Alzheimer, es imprescindible que la molécula sea capaz de atravesar la barrera hematoencefálica (BHE) para alcanzar sus dianas terapéuticas situadas en el cerebro. Por el contrario, cuando lo que se pretende es desarrollar medicamentos que actúen en otros órganos, su penetración en el cerebro no es deseable porque disminuye la concentración efectiva del fármaco que llega a la diana terapéutica y porque frecuentemente aparecen efectos secundarios, debido a interacciones no deseadas con receptores cerebrales.

El concepto de BHE se remonta a finales del siglo XIX y principios del XX. En 1885 Paul Ehrlich inyectó un colorante derivado de anilina en la sangre de una rata y observó que todos los órganos del animal se teñían de azul, excepto el cerebro que mantenía su color original. Inicialmente, el resultado se atribuyó a que el tejido cerebral no tenía afinidad por el colorante. Posteriormente, en 1913 Edwin Goldmann, un discípulo de Ehrlich, hizo el experimento contrario. Inyectó el colorante directamente en el fluido cefalorraquídeo y observó que en este caso el cerebro se teñía con el colorante, mientras que el resto del cuerpo permanecía inalterado. Estos experimentos pusieron de manifiesto la existencia de algún tipo de compartimentación para proteger el SNC, el órgano más importante del organismo, de sustancias nocivas que pudieran encontrarse en la sangre. Aunque se desconocía su naturaleza, ya en esos momentos se pensó que los propios vasos sanguíneos eran los responsables de dicha barrera, pasando a denominarse BHE a propuesta de la bióloga y fisióloga rusa Lina Stern en 1921. Sin embargo, no fue hasta la

\footnotetext{
${ }^{5}$ Hop, C. E.; Cole, M. J.; Davidson, R. E.; Duignan, D. B.; Federico, J.; Janiszewski, J. S.; Jenkins, K.; Krueger, S.; Lebowitz, R.; Liston, T. E.; Mitchell, W.; Snyder, M.; Steyn, S. J.; Soglia, J. R.; Taylor, C.; Troutman, M. D.; Umland, J.; West, M.;Whalen, K. M.; Zelesky, V.; Zhao, S. X. High throughput ADME screening: practical considerations, impact on the portfolio and enabler of ADME models. Curr. Drug Metab. 2008, 9, 847-53.
} 
introducción de las técnicas de imagen por microscopía electrónica en la década de 1960, que se pudo comprender realmente la naturaleza de la BHE.

La BHE es una barrera física y metabólica que aísla al SNC del resto del organismo, localizada en el sistema vascular y más concretamente en los capilares (Figura 3). Está constituida por tejido endotelial rodeado por pies de astrocitos que actúan principalmente como soporte del capilar. Las células endoteliales están fuertemente unidas, sin fisuras, lo que impide que las moléculas solubles en agua puedan pasar entre ellas mediante difusión paracelular. La membrana lipídica de dichas células constituye una barrera adicional al paso de moléculas hidrófilas. En la BHE existen transportadores específicos y canales iónicos, que regulan el paso de las especies químicas necesarias para el metabolismo cerebral, así como sistemas enzimáticos que metabolizan sustancias tóxicas y transportadores activos que eliminan desechos e impiden el paso de moléculas lipófilas perjudiciales.

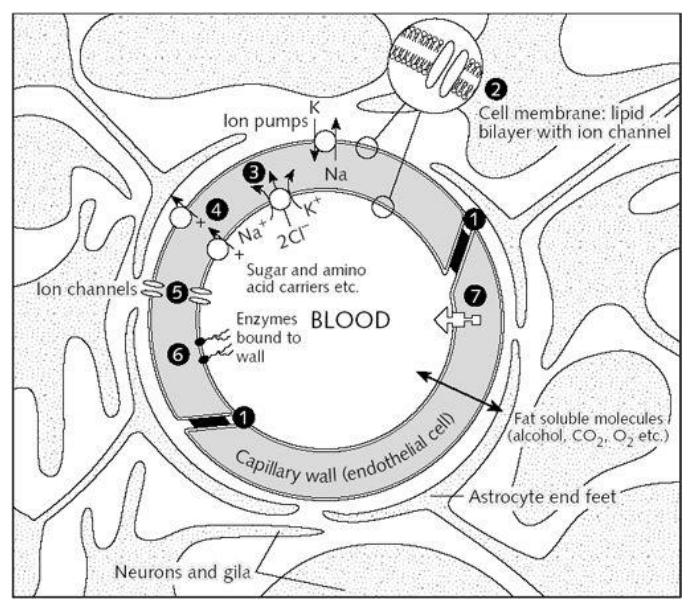

Figura 3. Características de la BHE: (1) Fuertes uniones entre células endoteliales. (2) Membranas lipídicas. (3), (4), y (5) Transportadores específicos y canales iónicos.(6) Barrera enzimática. (7) Sistemas anti-transporte.

La BHE es una estructura plástica capaz de responder rápidamente a cambios en el cerebro o en la sangre y que en condiciones normales tiene cuatro funciones principales ${ }^{6}$ :

\footnotetext{
${ }^{6}$ Huber, J. D.; Egleton, R. D.; Davis, T. P. Molecular Physiology and pathophysiology of tight junctions in the blood-brain barrier. Trends Neurosci. 2001, 24, 719-725.
} 
1. Proteger al cerebro de sustancias tóxicas y de patógenos, que puedan encontrarse en la sangre.

2. Transportar de forma selectiva los nutrientes necesarios para el metabolismo cerebral, como glucosa y oxígeno.

3. Detectar cambios en la sangre y comunicar estos cambios al cerebro, desencadenando cascadas de señalización.

4. Metabolizar y eliminar sustancias nocivas para el cerebro.

\subsubsection{Métodos in vitro para determinar la penetración de fármacos en el SNC}

Dada la importancia de conocer si un determinado candidato a fármaco será capaz de penetrar en el SNC, en los últimos años se viene trabajando activamente en el desarrollo de métodos in vitro, tanto computacionales como experimentales, para la predicción del paso de la BHE.

\subsubsection{Modelos computacionales para la predicción de la penetración en el SNC}

Los modelos predictivos computacionales emplean diferentes propiedades moleculares (lipofilia, peso molecular, número de dadores y aceptores de enlace de hidrógeno, distribución de cargas, etc.) que se correlacionan con el $\log \mathrm{BB}^{7}$. Empleando un conjunto de productos con propiedades conocidas se establece el algoritmo matemático que correlaciona los descriptores teóricos con el grado de penetración en el SNC. Una vez validado el modelo, éste se puede aplicar a los productos de interés para predecir si serán capaces o no de atravesar la BHE. A modo de ejemplo, un método predictivo para la penetración en SNC descrito en $2008^{8}$ propone el empleo de 4 descriptores cuánticos, obtenidos mediante cálculos ab initio, junto con otros descriptores clásicos, como el número de átomos de carbono, el $\log \mathrm{P}^{9}$, el momento dipolar y el área de la superficie polar $(\mathrm{PSA})^{10}$.

\footnotetext{
${ }^{7}$ Log BB se define como la relación de concentración del fármaco distribuida entre el cerebro y la sangre $\left[\log \mathrm{BB}=\log \left(\mathrm{C}_{\text {cerebro }} / \mathrm{C}_{\text {sangre }}\right)\right]$.

${ }^{8}$ Van Damme, S.; Langenaeker, W.; Bultinck, P. Prediction of blood-brain partitioning: a model based on $a b$ initio calculated quantum chemical descriptors. J. Mol. Graph. Model. 2008, 26, 1223-1236.

${ }^{9} \log$ P es el coeficiente de partición octanol / agua, empleado para medir la lipofilia de un compuesto.

${ }^{10}$ PSA es el acrónimo en inglés de Polar Surface Area, que se define como la superficie polar accesible al disolvente y está relacionada con el número de átomos capaces de formar enlaces de hidrógeno.
} 
Los métodos computacionales presentan la ventaja de poder predecir las propiedades de una molécula, antes incluso de ser sintetizada. Pero también presentan inconvenientes, como es que requieren cálculos complicados, con el consiguiente elevado gasto de tiempo de ordenador. Además, el hecho de que la conformación activa de un fármaco no siempre es la más estable termodinámicamente, complica enormemente los cálculos para moléculas con libertad conformacional.

Un método computacional que trata de obviar los inconvenientes anteriores es el desarrollado en el Instituto de Química Médica, que emplea el software CODES ${ }^{\circledR}$ (ideado por el Prof. Manfred Stud) y redes neuronales artificiales. El programa CODES codifica las moléculas desde un punto de vista topológico teniendo en cuenta tanto la naturaleza de los átomos como el tipo de enlace, la conectividad con el resto de la molécula, así como la carga atómica y los centros estereogénicos. Para la predicción del paso de la BHE, se eligieron 108 productos con estructuras muy diversas, de conocida penetración en el SNC. Las moléculas fueron codificadas mediante CODES, obteniendo un conjunto de parámetros numéricos (matriz dinámica) para cada producto. Estos parámetros fueron los datos de entrada de una red neuronal, mientras que los valores de $\log$ BB fueron los de salida. La red neuronal fue entrenada hasta alcanzar el equilibrio, al cabo del cual ésta es capaz de predecir con un $73 \%$ de aciertos si una molécula será capaz o no de atravesar la $\mathrm{BHE}^{11,12}$.

\subsubsection{Modelos experimentales para la predicción de la penetración en el SNC}

Los métodos experimentales para la predicción del paso de la BHE están basados en diferentes técnicas de mayor o menor dificultad. El más clásico consiste en la medida del coeficiente de reparto entre dos fases inmiscibles (octanol / agua o liposomas / agua) ${ }^{13}$. También se ha empleado la medida del tiempo de retención en HPLC usando membranas artificiales inmovilizadas, que contienen fosfatidilcolina inmovilizada sobre el relleno de

${ }^{11}$ Dorronsoro, I.; Chana, A.; Abasolo, M. I.; Castro, A.; Gil, C.; Stud, M.; Martinez, A. CODES/Neural network model: a useful tool for in silico prediction of oral absorption and blood-brain barrier permeability of structurally diverse drugs. QSAR Comb. Sci. 2004, 23, 89-98.

12 Guerra, A.; Páez, J. A.; Campillo, N. E. Artificial neural networks in ADMET modeling: Prediction of blood-brain barrier permeation. QSAR Comb. Sci. 2008, 27, 586-594.

${ }^{13}$ Gulyaeva, N.; Zaslavsky, A.; Lechner, P.; Chlenov, M.; McConnell, O.; Chait, A.; Kipnis, V.; Zaslavsky, B. Relative hydrophobicity and lipophilicity of drugs measured by aqueous two-phase partitioning, octanol-buffer partitioning and HPLC. A simple model for predicting blood-brain distribution. Eur. J. Med. Chem. 2003, 38, 391-396. 
sílice ${ }^{14,15}$. Estos métodos presentan como ventaja su sencillez y como desventaja que se precisa realizar un elevado número de ensayos para obtener resultados fiables y estadísticamente significativos.

Los métodos experimentales más sofisticados para evaluar el paso de la BHE consisten en la medida de la permeabilidad de las moléculas a través de cultivos celulares. En 2002 se describió un modelo que empleaba un cocultivo de células endoteliales y astrocitos de rata $^{16}$ y posteriormente (2008) se publicó la aplicación de la línea celular hCMEC/D3, compuesta por células endoteliales procedentes de capilares cerebrales humanos, al estudio del transporte de diversos sustratos naturales y fármacos ${ }^{17}$. Se ha comprobado que la línea hCMEC/D3 expresa varias proteínas de membrana implicadas en el transporte activo de nutrientes y en la eliminación de sustancias nocivas del cerebro. También se ha encontrado que estas células expresan el receptor de transferrina, encargado de mantener la homeostasis del hierro, de vital importancia para el metabolismo cerebral. Este último modelo tiene como ventaja que es el que más se aproxima a la realidad, proporcionando resultados muy fiables, pero tiene como desventaja su elevado coste y su dificultad experimental.

En una situación intermedia se encuentran las metodologías basadas en la medida de la permeabilidad a través de un lípido, como el transporte por difusión horizontal o el método PAMPA (Parallel Artificial Membrane Permeation Assay). Estos procedimientos presentan un alto grado de predicción, su coste es moderado y los experimentos son rápidos, fiables y asequibles. Estas razones han hecho que la metodología PAMPA sea el método de elección en numerosas empresas farmacéuticas para la selección de candidatos a estudios farmacológicos avanzados. En esta Tesis Doctoral, se ha empleado la permeabilidad a través de lípidos, por lo que esta tecnología será explicada con mayor detalle en el siguiente apartado.

14 Salminen, T.; Pulli, A.; Taskinen, J. Relationship between immobilised artificial membrane chromatographic retention and the brain penetration of structurally diverse drugs. J. Pharm. Biomed. Anal. 1997, 15, 469-477.

15 Stewart, B. H.; Chan, O. H. Use of immobilized artificial membrane chromatography for drug transport applications. J. Pharm. Sci. 1998, 87, 1471-1478.

${ }^{16}$ Demeuse, P.; Kerkhofs, A.; Struys-Ponsar, C.; Knoops, B.; Remacle, C.; van den Bosch de Aguilar, P. Compartmentalized coculture of rat brain endothelial cells and astrocytes: a syngenic model to study the blood-brain barrier. J. Neurosci. Methods 2002, 121, 21-31.

${ }^{17}$ Poller, B.; Gutmann, H.; Krähenbühl, S.; Weksler, B.; Romero, I.; Couraud, P. O.; Tuffin, G.; Drewe, J.; Huwyler, J. The human brain endothelial cell line hCMEC/D3 as a human blood-brain barrier model for drug transport studies. J. Neurochem. 2008, 107, 1358-1368. 


\subsubsection{Permeabilidad a través de lípidos (difusión horizontal y PAMPA)}

El interés por los lípidos como modelos de membranas celulares se inicia en las últimas décadas del siglo XX. Así en 1962 Müeller y col. descubrieron que una pequeña cantidad de un fosfolípido disuelto en un alcano, colocada en un orificio de pequeño diámetro $(0.5$ $\mathrm{mm}$ ) perforado en una lámina de Teflón o polietileno (10-25 micras de grosor), formaba una bicapa lipídica ${ }^{18}$. Estos autores demostraron que el sistema poseía algunas de las propiedades de las membranas biológicas y que los lípidos adecuados para la formación de bicapas eran los aislados de fuentes naturales, como fosfatidilcolina, fosfatidiletanolamina, etc. El método fue empleado como modelo de membranas biológicas, más sencillas que las naturales, pero tenía como desventaja la dificultad experimental para formarlas y su gran inestabilidad.

Posteriormente, dos investigadores del Massachusetts Institute of Technology (MIT, USA), Bromberg y Klibanov publicaron en 1995 un interesante trabajo en el que utilizaban lípidos naturales (lecitina, colesterol, etc.) soportados sobre celulosa, como un modelo biomimético de membrana celular ${ }^{19}$. Empleando un aparato de transporte de difusión horizontal, como el representado en la figura 4, estos autores estudiaron la permeabilidad de diferentes proteínas (hormona del crecimiento, lisozima, mioglobina, etc.) a través de estas membranas artificiales que, al estar soportadas sobre un filtro, eran mucho más estables que los modelos previos.
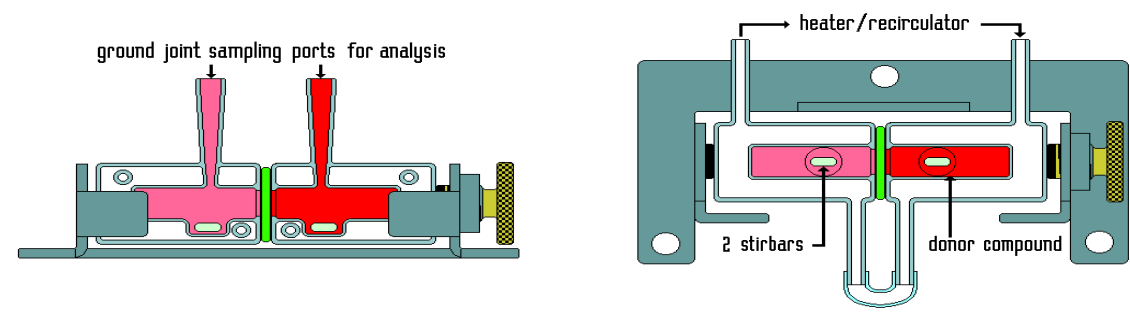

Figura 4. Aparato de transporte compuesto por celdas de difusión horizontal.

La metodología PAMPA, que puede considerarse como una miniaturización de la anterior técnica de difusión horizontal, fue inicialmente desarrollada en 1998 por Kansy y

\footnotetext{
${ }^{18}$ Müeller, P.; Rudin, D. O.; Tien, H. T.; Wescott, W. C. Reconstitution of cell membrane structure in vitro and its transformation into an excitable system. Nature 1962, 194, 979-980.

${ }^{19}$ Bromberg, L. E.; Klibanov, A. M. Transport of proteins dissolved in organic solvents across biomimetic membranes. Proc. Natl. Acad. Sci. U S A 1995, 92, 1262-1266.
} 
col. de la compañía Hoffmann - La Roche (Suiza) para la determinación de la absorción oral $^{20}$. Empleando dos placas de 96 pocillos situadas una sobre la otra con un filtro entre ambas, estos autores eligieron como barrera lipídica la lecitina de huevo, por su composición similar a las de las membranas naturales de mamíferos. En los pocillos superiores situaron 25 fármacos comerciales disueltos en tampón fosfato y en los inferiores, el mismo tampón puro (Figura 5). Después de 15 horas de incubación, midieron la permeabilidad de cada uno de los productos ensayados a través del lípido, determinando su concentración en los pocillos inferiores mediante un lector UV de microplacas. La representación gráfica de la permeabilidad frente al grado de absorción oral en humanos proporcionó unas curvas, a partir de las cuales estos autores fueron capaces de predecir la absorción oral de una molécula dada.
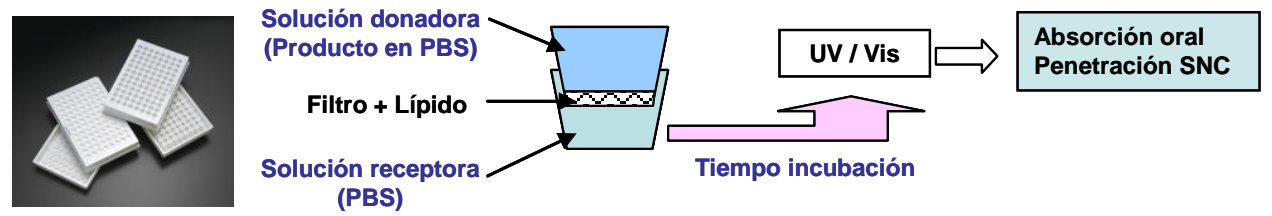

Figura 5. Descripción gráfica de la metodología PAMPA.

A partir de este trabajo pionero de Kansy y col., se han publicado numerosas contribuciones encaminadas al perfeccionamiento de la técnica. Así Sugano y col. (Chugai Pharmaceutical Co., Japón) mejoraron la predicción de la absorción oral, empleando una membrana artificial biomimética compuesta por una mezcla de lípidos (fosfatidilcolina, fosfatidiletanolamina, fosfatidilserina, fosfatidilinositol, esfingomielina y colesterol), en proporciones semejantes a las encontradas en el epitelio intestinal ${ }^{21}$. También caben destacar los trabajos de Avdeef y col. (pION Biopharma Services, USA) en los que se

${ }^{20}$ Kansy, M.; Senner, F.; Gubernator, K. Physicochemical high throughput screening: parallel artificial membrane permeation assay in the description of passive absorption processes. J. Med. Chem. 1998, 41, 1007-1010.

${ }^{21}$ Sugano, K.; Takata, N.; Machida, M.; Saitoh, K.; Terada, K. Prediction of passive intestinal absorption using bio-mimetic artificial membrane permeation assay and the paracellular pathway model. Int. J. Pharm. 2002, 241, 241-251. 
predice la absorción oral, variando el $\mathrm{pH}$ del experimento entre 2 y 10 para mimetizar las condiciones del sistema digestivo ${ }^{22,23}$.

Un avance importante para la metodología PAMPA fue el trabajo de Di y col. (Wyeth Pharmaceuticals, USA) publicado en 2003, en el que se desarrollaba el método para la predicción de la permeabilidad en el SNC. Empleando un extracto lipídico de cerebro de cerdo, el ensayo fue puesto a punto empleando 30 fármacos comerciales de los que se conocía su grado de penetración en el SNC y validado con 14 productos de la propia compañía, también de conocido coeficiente de reparto sangre-cerebro ${ }^{24}$.

Como ya se ha comentado anteriormente, los métodos basados en la permeabilidad a través de lípidos presentan ventajas frente a los cultivos celulares, derivadas de su sencillez. Son fiables, rápidos, reproducibles y asequibles para un laboratorio de Química Médica. Su coste es moderado y permiten evaluar quimiotecas en poco tiempo. Además, los que se realizan en microplacas, requieren poca cantidad de producto: entre 1 y 3 mg suelen ser suficientes, dependiendo de la absorción UV-vis del compuesto a ensayar.

Pero los métodos basados en la permeabilidad a través de lípidos también tienen limitaciones. Únicamente se puede determinar difusión pasiva, ya que el sistema carece de los transportadores activos y de los canales iónicos característicos de las membranas biológicas. Sin embargo, ésta no es una gran limitación puesto que, aunque para algunas sustancias y medicamentos se ha identificado un trasportador activo (por ej., la cafeína ${ }^{25}$, el relajante muscular baclofeno ${ }^{26}$ y el antiepiléptico gabapentina ${ }^{27}$ ) la mayoría de las moléculas capaces de atravesar una barrera biológica lo hacen mediante difusión pasiva (por encima del $90-95 \%$ de los productos permeables).

\footnotetext{
${ }^{22}$ Nielsen, P. E.; Avdeef, A. PAMPA-a drug absorption in vitro model 8. Apparent filter porosity and the unstirred water layer. Eur. J. Pharm. Sci. 2004, 22, 33-41.

${ }^{23}$ Avdeef, A.; Bendels, S.; Di, L.; Faller, B.; Kansy, M.; Sugano, K.; Yamauchi, Y. PAMPA-critical factors for better predictions of absorption. J. Pharm. Sci. 2007, 96, 2893-909.

${ }^{24}$ Di, L.; Kerns, E. H.; Fan, K.; McConnell, O. J.; Carter, G. T. High throughput artificial membrane permeability assay for blood-brain barrier. Eur. J. Med. Chem. 2003, 38, 223-232.

${ }^{25}$ McCall, A. L.; Millington, W. R.; Wurtman, R. J. Blood-brain barrier transport of caffeine: dose-related restriction of adenine transport. Life Sci. 1982, 31, 2709-2715.

${ }^{26}$ van Bree, J. B.; Audus, K. L.; Borchardt, R. T. Carrier-mediated transport of baclofen across monolayers of bovine brain endothelial cells in primary culture. Pharm. Res. 1988, 5, 369-371.

${ }^{27}$ Luer, M. S.; Hamani, C.; Dujovny, M.; Gidal, B.; Cwik, M.; Deyo, K.; Fischer, J. H. Saturable transport of gabapentin at the blood-brain barrier. Neurol. Res. 1999, 21, 559-562.
} 


\subsection{OBJETIVOS}

Dentro de los objetivos de nuestro grupo de investigación, involucrado desde hace más de una década en el diseño, síntesis y evaluación de nuevos fármacos para el tratamiento de la enfermedad de Alzheimer y de otros procesos neurodegenerativos, nos propusimos poner en marcha métodos experimentales in vitro para la predicción del paso de la BHE para poder aplicarlos a moléculas de nuestro interés. Se buscaban ensayos que fueran fiables, pero de coste y dificultad experimental asequibles a nuestros medios humanos y materiales, éstos últimos referidos principalmente al equipamiento científico disponible en nuestro Instituto. Después de un estudio bibliográfico, parte del cual ha sido expuesto en la introducción, nos decidimos por ensayos de permeabilidad a través de lípidos. Por otra parte, con frecuencia nos encontramos con productos de reducida solubilidad acuosa, por lo que sería necesario adaptar y validar las condiciones experimentales previamente descritas para poder evaluar estas moléculas. Por lo tanto, los objetivos de este primer capítulo se pueden enunciar de la siguiente manera:

1. Poner en marcha métodos experimentales sencillos para la determinación de la penetración en SNC, sin emplear cultivos celulares ni animales de experimentación.

2. Validar nuevas condiciones experimentales para poder evaluar moléculas de limitada solubilidad acuosa. 


\subsection{DISCUSIÓN DE RESULTADOS}

\subsubsection{Modelo predictivo de la penetración en el SNC empleando celdas de difusión horizontal}

Al inicio de este trabajo, en nuestro Instituto no existía un lector UV de microplacas y únicamente se disponía de un espectrofotómetro UV-vis de cubetas. Por ese motivo, para desarrollar un método experimental predictivo de la permeabilidad en el SNC se decidió utilizar un aparato de difusión horizontal, que permite el uso de volúmenes en torno a 3 $\mathrm{mL}$, lo que era perfectamente compatible con el sistema de medida del que se disponía en esos momentos.

Se decidió emplear un extracto lipídico de cerebro de cerdo, de composición similar a la de las células endoteliales del cerebro (Tabla 1), soportado sobre celulosa.

Tabla 1. Composición del extracto lipídico de cerebro

de cerdo

\begin{tabular}{lc}
\hline Componente & $\%$ Peso $^{\mathrm{a}}$ \\
\hline Fosfatidiletanolamina & 33.1 \\
Fosfatidilserina & 18.5 \\
Fosfatidilcolina & 12.6 \\
Fosfatidilinositol & 4.1 \\
Otros & 31.7 \\
\hline
\end{tabular}

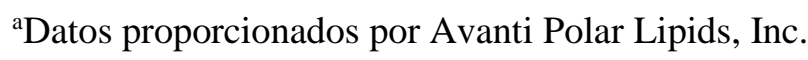

Para la validación del método se escogieron 14 productos comerciales, cuyo grado de penetración en el SNC era conocido. Para que el modelo predictivo estuviera equilibrado, se tomaron 7 productos que pasaban a cerebro (testosterona, verapamilo, imipramina, progesterona, promazina, clorpromazina y clonidina) y 7 que no lo hacían (lomefloxacino, ofloxacino, atenolol, isoxicam, dopamina, teofilina y cimetidina).

El aparato de difusión horizontal consiste en dos celdas de vidrio que se mantienen unidas mediante un sistema de anclaje externo para evitar pérdidas (ver Figura 4). Cada 
recipiente $(3.4 \mathrm{~mL})$ tiene una ventana circular $\left(\mathrm{de} 0.5 \mathrm{~cm}^{2}\right.$ de superficie) que sirve para comunicar ambas celdas y donde se coloca el papel de celulosa impregnado con el lípido. En una de las celdas se pone una disolución acuosa del producto que se va a evaluar, mientras que la otra se rellena con disolución acuosa pura. El sistema se mantiene a $37{ }^{\circ} \mathrm{C}$ y se agita a una velocidad lenta y constante con ayuda de una pequeña barra magnética recubierta de teflón en cada uno de los recipientes. A intervalos regulares de tiempo, se toma una alícuota de la fase receptora, se mide la concentración de producto mediante UVvis y rápidamente se reintegra la alícuota al sistema para evitar pérdidas de volumen y para no perturbar la cinética del transporte. La representación de la absorbancia de cada producto frente al tiempo proporcionó gráficas como las de la figura 6 , donde se puede apreciar que el transporte se produce de una forma lineal en los primeros 40-60 minutos, para después descender a medida que el gradiente de concentración entre ambas cubetas disminuye.
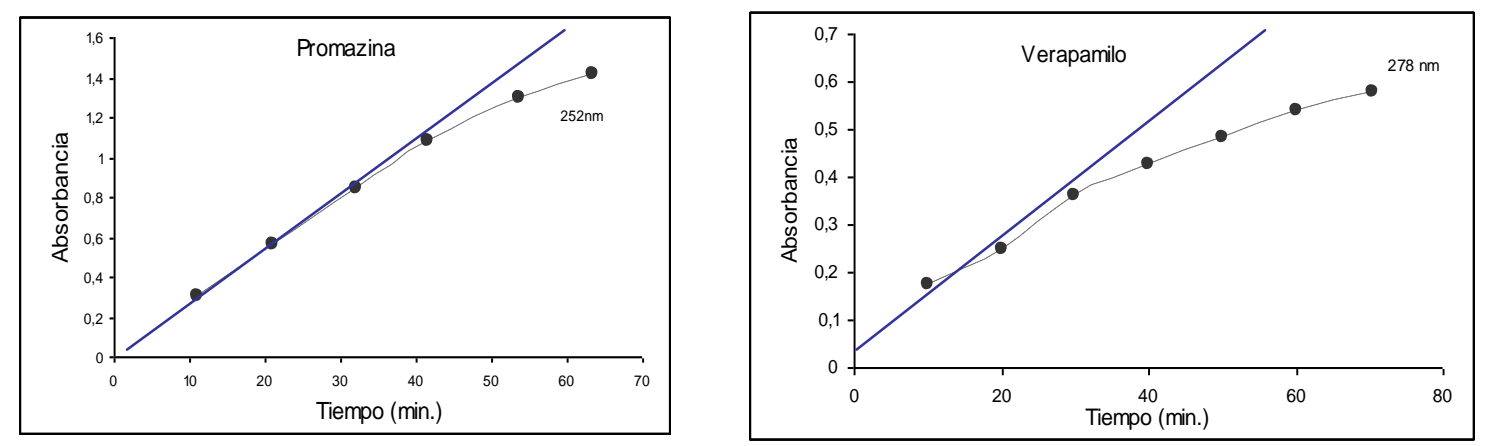

Figura 6. Representación gráfica de la absorbancia frente al tiempo para promazina y verapamilo.

A partir de las gráficas absorbancia/tiempo se calculó para cada uno de los fármacos comerciales el porcentaje inicial de compuesto transportado por segundo $\% T_{\mathrm{i}}\left(\mathrm{s}^{-1}\right)$, que compararon con la permeabilidad descrita en la bibliografía ${ }^{24}$ para estos mismos productos (Tabla 2). 
Tabla 2. Resultados experimentales del porcentaje inicial de producto transportado por segundo $\left(\% T_{i}, \mathrm{~s}^{-1}\right)$, comparados con la permeabilidad descrita $\left(P_{a}, 10^{-6} \mathrm{~cm} \mathrm{~s}^{-1}\right)$ de los 14 fármacos patrón.

\begin{tabular}{|c|c|c|c|c|c|}
\hline Producto & $\% \mathrm{~T}_{\mathrm{i}} \exp ^{\mathrm{a}}$ & $P_{\mathrm{a}}$ bibl. $^{\mathrm{b}}$ & Producto & $\% \mathrm{~T}_{\mathrm{i}} \exp ^{\mathrm{a}}$ & $P_{\mathrm{a}}$ bibl. $^{\mathrm{b}}$ \\
\hline Testosterona & $20.1 \pm 0.9$ & 17.0 & Lomefloxacino & $3.2 \pm 0.2$ & 1.1 \\
\hline Verapamilo & $27.1 \pm 1.0$ & 16.0 & Ofloxacino & $4.4 \pm 0.2$ & 0.8 \\
\hline Imipramina & $21.0 \pm 0.9$ & 13.0 & Atenolol & $5.7 \pm 0.3$ & 0.8 \\
\hline Progesterona & $11.7 \pm 0.5$ & 9.3 & Isoxicam & $3.2 \pm 0.1$ & 0.3 \\
\hline Promazina & $16.8 \pm 0.6$ & 8.8 & Dopamina & $3.6 \pm 0.1$ & 0.2 \\
\hline Clorpromazina & $12.3 \pm 0.5$ & 6.5 & Teofilina & $5.9 \pm 0.2$ & 0.1 \\
\hline Clonidina & $12.5 \pm 0.7$ & 5.3 & Cimetidina & $2.7 \pm 0.1$ & 0.0 \\
\hline
\end{tabular}

${ }^{\mathrm{a}}$ Media de tres experimentos \pm desviación estándar. ${ }^{\mathrm{b}}$ Datos tomados de la ref. 24

La representación gráfica del porcentaje inicial de producto transportado frente a la permeabilidad descrita proporcionó una recta de ecuación \% $\mathrm{T}_{\mathrm{i}}(\exp )=.1.2243 P_{\mathrm{a}}(\mathrm{bibl})+$. 3.7997 , con un buen coeficiente de correlación $\mathrm{R}^{2}$ (0.9161) (Figura 7).

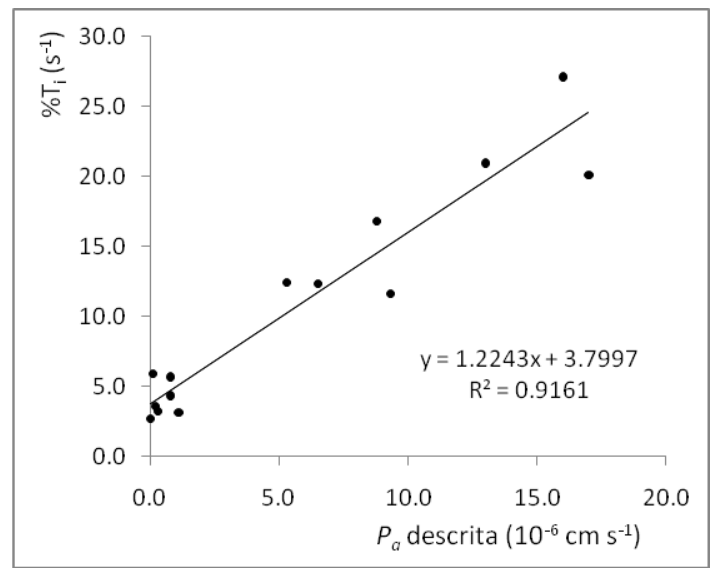

Figura 7. Correlación entre el porcentaje inicial de producto transportado y la permeabilidad descrita para los 14 fármacos patrón.

A partir de la ecuación de esta recta y teniendo en cuenta los límites establecidos en la bibliografía, se pudieron definir los límites de este experimento. Los productos con un 
porcentaje de transporte inicial superior al $8.7 \% \mathrm{~s}^{-1}$ serían capaces de atravesar la BHE, mientras que los que mostraran un $\mathrm{T}_{\mathrm{i}}<6.2 \% \mathrm{~s}^{-1}$ no la atravesarían.

Como puede apreciarse en la tabla 2, todos los productos comerciales fueron correctamente predichos por el modelo, lo que demuestra su utilidad para la predicción del paso de la BHE.

El método de difusión horizontal permite realizar estudios cinéticos y es versátil, ya que se pueden emplear una gran variedad de filtros (celulosa, fluoruro de polivinilideno, etc.), lípidos, etc. Pero también tiene sus inconvenientes, entre las que cabría destacar la lentitud, ya que se pueden realizar unas 6 cinéticas / persona / día. Teniendo en cuenta que los resultados se expresan como la media de tres experimentos independientes, para evaluar 14 productos patrón y tan sólo 10 productos desconocidos se necesitarían 10 jornadas de trabajo. Por otra parte, se precisan cantidades relativamente altas de producto, entre 20 y $50 \mathrm{mg}$ dependiendo del peso molecular de la molécula y de su coeficiente de extinción molar en UV.

\subsubsection{Modelo predictivo de la penetración en el SNC empleando la metodología PAMPA (Parallel Artificial Membrane Permeation Assay)}

Aprovechando la experiencia adquirida con el método anterior, a continuación se decidió poner a punto la metodología PAMPA para la predicción del paso de la barrera hematoencefálica (PAMPA-BHE), coincidiendo con la adquisición de un lector de microplacas de 96-pocillos en nuestros laboratorios.

\subsubsection{Descripción general del método y de las fórmulas empleadas}

En el método PAMPA se emplean dos microplacas de 96 pocillos situadas una sobre otra, en un montaje tipo sandwich. En el fondo de cada uno de los pocillos de la placa superior se encuentra un microfiltro donde se deposita el lípido que simula la membrana biológica, en este caso un extracto lipídico de cerebro de cerdo disuelto en dodecano (20 $\mathrm{mg} \mathrm{mL} \mathrm{m}^{-1}$ ) En los pocillos superiores se sitúan los productos que se van a ensayar disueltos en una solución acuosa tamponada a una concentración aproximada de $1 \mu \mathrm{M}$, mientras que la parte inferior se compone de tampón puro como fase receptora (ver Figura 5). El sistema se deja a $25^{\circ} \mathrm{C}$ durante un cierto tiempo. Después del periodo de incubación, se separan las 
placas y en cada uno de los pocillos de la placa inferior se mide la cantidad de producto que ha sido capaz de pasar a través del lípido mediante un lector UV-vis de microplacas. Para ello se mide la absorbancia de la fase receptora a cinco longitudes de onda, previamente escogidas empleando la disolución inicial de cada uno de los productos del ensayo, de tal manera que la absorbancia en dichas longitudes de onda esté comprendida entre 0.8 y 1.2. Junto con los productos que se deseen probar, en el mismo experimento se evalúan entre 15 y 20 fármacos patrón, de los que se conoce la propiedad que se quiera valorar, en este caso, la penetración en el SNC. Una vez establecida la ecuación entre los valores descritos y los experimentales, se puede determinar la propiedad de la que se trate para los productos de interés.

El porcentaje de transporte para cada uno de los productos ensayados es el cociente de concentraciones entre las dos fases y puede expresarse en función de la absorbancia a una determinada longitud de onda según la fórmula (1)

$$
\% T=\frac{[\operatorname{prod}]_{R}}{[\operatorname{prod}]_{D}} 100=\frac{A b s_{R} V_{R}}{A b s_{D} V_{D}} 100
$$

donde $A b s_{R}$ y $A b s_{D}$ son las absorbancias observadas, $V_{R}$ y $V_{D}$ son los volúmenes empleados y los subíndices $R$ y $D$ se refieren a las fases receptora y donadora, respectivamente.

A partir del porcentaje de producto transportado $(\% T)$ se puede calcular la permeabilidad aparente $\left(P_{a}\right)$ aplicando la fórmula (2)

$$
P_{a}=\frac{V_{D} \cdot V_{R}}{\left(V_{D}+V_{R}\right) S \cdot t} \ln \frac{100 V_{D}}{100 V_{D}-\% T\left(V_{D}+V_{R}\right)}
$$

donde $S$ es el área de la superficie de la membrana artificial y $t$ es el tiempo de incubación. La ecuación (2) procede de la integración de la primera ley de difusión de Fick antes de que el sistema alcance el equilibrio, ya que ningún producto ensayado es capaz de equilibrar su concentración a ambos lados de la membrana en el tiempo de incubación ${ }^{28}$.

${ }^{28}$ Zhu, C.; Jiang, L.; Chen, T. M.; Hwang, K. K. A comparative study of artificial membrane permeability assay for high throughput profiling of drug absorption potential. Eur. J. Med. Chem. 2002, 37, 399-407. 


\subsubsection{Validación de condiciones experimentales con fármacos patrón}

En primer lugar, se realizó un experimento empleando 16 productos comerciales disueltos en tampón fosfato salino a pH 7.4 (PBS), con el fin de determinar si era posible reproducir en nuestros laboratorios el experimento descrito por Di y col. ${ }^{24}$ Únicamente se modificó el tiempo del experimento, pasando de las 18 horas del trabajo original a 4 horas, un periodo que permite realizar un mayor número de experimentos por día. La temperatura se mantuvo constante a $25^{\circ} \mathrm{C}$.

Tabla 3. Permeabilidad descrita y experimental $\left(P_{a}, 10^{-6} \mathrm{~cm} \mathrm{~s}^{-1}\right)$, clasificación descrita y predicción experimental de 16 productos comerciales, empleando PBS ( $p H$ 7.4)como disolvente y 4 horas de incubación a $25^{\circ} \mathrm{C}$.

\begin{tabular}{|c|c|c|c|c|}
\hline & \multirow{2}{*}{$\begin{array}{c}\text { Clasificación } \\
\text { bibl. }^{\mathrm{a}}\end{array}$} & \multicolumn{2}{|c|}{$P_{\mathrm{a}}\left(10^{-6} \mathrm{~cm} \mathrm{~s}^{-1}\right)$} & \multirow{2}{*}{ Predicción } \\
\hline & & Bibl. ${ }^{\mathrm{a}}$ & Experimental $^{\mathrm{b}}$ & \\
\hline Verapamilo & snct & 16.0 & $8.0 \pm 0.2$ & snct \\
\hline Imipramina & snct & 13.0 & $5.5 \pm 0.0$ & snct \\
\hline Desipramina & snct & 12.0 & $7.3 \pm 0.1$ & snct \\
\hline Estradiol & snct & 12.0 & $5.9 \pm 0.4$ & snct \\
\hline Astemizol & snct & 11.0 & $5.4 \pm 0.2$ & snct \\
\hline Promazina & snct & 8.8 & $5.4 \pm 0.1$ & snct \\
\hline Clorpromazina & snct & 6.5 & $2.7 \pm 0.1$ & snct \\
\hline Clonidina & snct & 5.3 & $3.4 \pm 0.2$ & snct \\
\hline Corticosterona & snct & 5.1 & $2.1 \pm 0.0$ & snct \\
\hline Hidrocortisona & snc- & 1.9 & $0.6 \pm 0.01$ & snc- \\
\hline Cafeina & snc- & 1.3 & $0.7 \pm 0.01$ & snc- \\
\hline Aldosterona & snc- & 1.2 & $0.3 \pm 0.03$ & snc- \\
\hline Lomefloxacina & snc- & 1.1 & $0.1 \pm 0.00$ & snc- \\
\hline Enoxacino & snc- & 0.9 & $0.2 \pm 0.02$ & snc- \\
\hline Atenolol & snc- & 0.8 & $0.1 \pm 0.01$ & snc- \\
\hline Ofloxacino & snc- & 0.8 & $0.2 \pm 0.01$ & snc- \\
\hline
\end{tabular}

${ }^{\mathrm{a}}$ Datos tomados de la ref. $24 .{ }^{\mathrm{b}}$ Media de tres experimentos con cuatro repeticiones de producto en cada placa \pm desviación estándar. 
La representación de la permeabilidad experimental frente a la descrita proporcionó una recta de ecuación $P_{\mathrm{a}}(\exp )=.0.5253 P_{\mathrm{a}}$ (bibl.) -0.2171 , con un coeficiente de correlación $\mathrm{R}^{2}$ de 0.9577 (Figura 8).

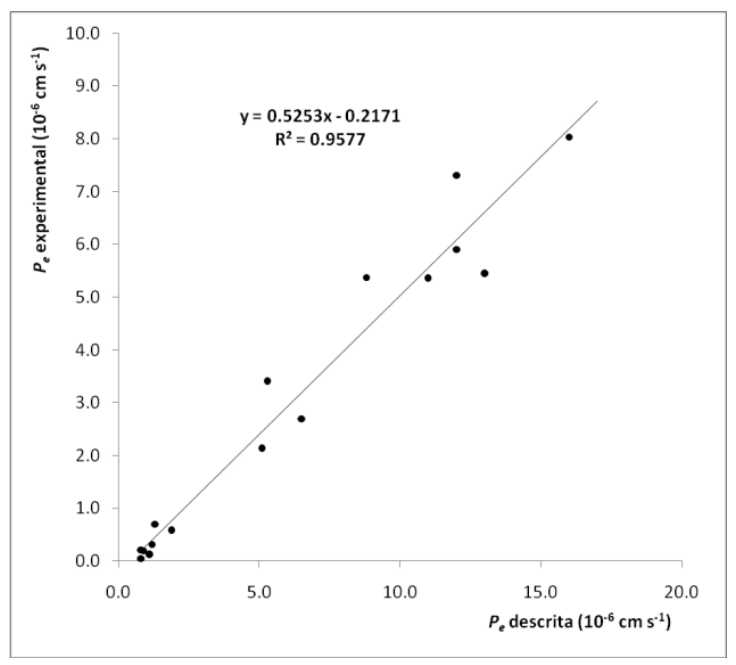

Figura 8. Correlación entre la permeabilidad experimental y la descrita de 16 fármacos patrón, empleando $\mathrm{PBS}$ ( $\mathrm{pH}$ 7.4) como disolvente y 4 horas de incubación a $25^{\circ} \mathrm{C}$.

Por lo tanto, existe una alta linealidad entre la permeabilidad experimental y la descrita. Haciendo una correlación entre los límites establecidos en la bibliografía para la metodología PAMPA con los resultados experimentales, se pudo establecer que en nuestro experimento los productos con $P_{\mathrm{a}}>1.910^{-6} \mathrm{~cm} \mathrm{~s}^{-1}$ serían capaces de atravesar la BHE y los que presentaran una $P_{\mathrm{a}}<0.810^{-6} \mathrm{~cm} \mathrm{~s}^{-1}$ no lo serían. Como puede apreciarse en la tabla 2 , todos los productos comerciales fueron correctamente predichos por el modelo, lo que demuestra su utilidad para la predicción del paso de la BHE.

Cabe destacarse que los valores obtenidos en nuestro experimento son aproximadamente la mitad que los descritos, como indica la pendiente de 0.5. Este hecho puede ser debido a que en nuestro caso se empleó un menor tiempo de incubación: 4 horas frente a las 18 del trabajo original. Puesto que en las condiciones ensayadas en nuestro laboratorio el método demostró ser predictivo, en los siguientes experimentos se emplearon 4 horas de incubación a $25^{\circ} \mathrm{C}$, salvo que se indique lo contrario. 


\subsubsection{Estudio del empleo de cosolventes}

En numerosas ocasiones, los productos que se pretenden evaluar no son lo suficientemente solubles en agua. Por ese motivo, nos propusimos comprobar si el método PAMPA seguía siendo predictivo empleando diferentes cosolventes, como etanol, polietilenglicol (PEG-400) o acetonitrilo. Los resultados experimentales están recogidos en la tabla 4 y gráficamente representados en las figuras 9 y 10.

Cuando el experimento se realizó con una mezcla de tampón fosfato y etanol al 10, 20 ó 30\% se mantuvo la linealidad entre los resultados experimentales y los descritos (Figura 9). Sin embargo, cuando se aumentó la proporción del alcohol al 50\% no se pudo establecer ninguna correlación. En el rango comprendido entre el 0 y el 30\% de etanol, la pendiente de la recta aumenta a medida que aumenta la proporción del cosolvente (Figura 9). Consecuentemente, los límites para establecer el paso o no de la barrera hematoencefálica también van aumentando su valor, como queda reflejado en la parte inferior de la tabla 4. Así, la condición para que un producto pase al SNC es que su permeabilidad sea superior a 1.9, 4.4, 6.1 y 6.9, según se trate de un experimento realizado en PBS, PBS:EtOH (10\%), PBS:EtOH (20\%) o PBS:EtOH (30\%). Es importante señalar que en cada una de las condiciones experimentales, el comportamiento de los productos patrón fue predicho correctamente, lo que avala el empleo de etanol en estas proporciones para la evaluación de productos cuya baja solubilidad acuosa pueda ser resuelta con la adición de este cosolvente. 
Tabla 4. Permeabilidad descrita y experimental $\left(P_{a}, 10^{-6} \mathrm{~cm} \mathrm{~s}^{-1}\right)$ de 20 productos comerciales, empleando mezclas de PBS y EtOH (10, 20 y 30\%), PBS y PEG-400 (10 y $20 \%)$ y PBS y acetonitrilo $(10 \%)^{a}$.

\begin{tabular}{lcrrrrrrrr}
\hline & Clasif. & Bibl. & PBS & $\begin{array}{r}\text { EtOH } \\
(10 \%)\end{array}$ & $\begin{array}{r}\text { EtOH } \\
(20 \%)\end{array}$ & $\begin{array}{r}\text { EtOH } \\
(30 \%)\end{array}$ & $\begin{array}{r}\text { PEG } \\
(10 \%)\end{array}$ & $\begin{array}{c}\text { PEG } \\
(20 \%)\end{array}$ & $\begin{array}{c}\text { MeCN } \\
(10 \%)\end{array}$ \\
\hline Testosterona & snc+ & 17.0 & n.d. & 13.5 & 17.8 & 24.5 & 12.4 & 9.1 & 17.6 \\
Verapamilo & snc+ & 16.0 & 8.0 & 13.0 & 14.6 & 20.2 & 11.3 & 7.8 & 15.5 \\
Imipramina & snc+ & 13.0 & 5.5 & 9.1 & 13.1 & 14.4 & 10.4 & 6.9 & 14.0 \\
Desipramina & snc+ & 12.0 & 7.3 & 11.3 & 13.2 & 16.2 & 9.7 & 5.1 & 10.8 \\
Astemizol & snc+ & 11.0 & 5.4 & 10.9 & 18.2 & n.d. & 6.8 & 4.2 & 9.1 \\
Progesterona & snc+ & 9.3 & n.d. & 8.6 & 11.3 & n.d. & 5.9 & 4.6 & 9.9 \\
Promazina & snc+ & 8.8 & 5.4 & 7.3 & 9.7 & 17.7 & 4.7 & 4.6 & 9.9 \\
Clorpromazina & snc+ & 6.5 & 2.7 & 6.1 & 7.8 & 15.5 & 4.1 & 2.9 & 6.5 \\
Clonidina & snc+ & 5.3 & 3.4 & 6.8 & 6.9 & 11.0 & 4.6 & 3.3 & 7.3 \\
Corticosterone & snc+ & 5.1 & 2.1 & 7.2 & 6.7 & 9.5 & 4.5 & 3.4 & 6.2 \\
Piroxicam & snc- & 2.5 & n.d. & 2.3 & 4.0 & 4.4 & 2.0 & 1.0 & 3.0 \\
Hidrocortisona & snc- & 1.9 & 0.6 & 2.8 & 3.9 & 3.7 & n.d. & 1.9 & 3.0 \\
Aldosterona & snc- & 1.2 & 0.3 & 2.7 & 3.5 & 5.0 & 1.8 & 1.5 & 2.8 \\
Lomefloxazina & snc- & 1.1 & 0.1 & 1.3 & 3.3 & 4.3 & 1.7 & 1.3 & 2.5 \\
Enoxacino & snc- & 0.9 & 0.2 & 1.7 & 3.3 & n.d. & n.d. & 1.5 & 2.5 \\
Atenolol & snc- & 0.8 & 0.1 & 2.0 & 4.0 & 2.5 & 1.8 & 0.8 & 2.0 \\
Ofloxazino & snc- & 0.8 & 0.2 & 1.8 & 3.3 & 2.6 & 1.5 & 1.2 & 2.5 \\
Isoxicam & snc- & 0.3 & n.d. & 1.6 & 3.8 & 2.3 & 1.0 & 0.8 & 2.0 \\
Teofilina & snc- & 0.1 & n.d. & 1.5 & 2.2 & n.d. & 1.1 & 0.2 & 0.6 \\
Cimetidina & snc- & 0.0 & n.d. & 1.2 & 2.0 & n.d. & 0.8 & 0.1 & n.d. \\
\hline \multicolumn{1}{c}{ Límites } & snc+ & $>4.0$ & $>1.9$ & $>4.4$ & $>6.1$ & $>6.9$ & $>3.4$ & $>2.4$ & $>5.0$ \\
\multicolumn{1}{c}{ predictivos } & snc- & $<2.0$ & $<0.8$ & $<2.9$ & $<4.3$ & $<4.5$ & $<2.1$ & $<1.5$ & $<3.2$ \\
\hline & & & & & & & & &
\end{tabular}

${ }^{a}$ Condiciones experimentales: 4 horas de incubación a $25^{\circ} \mathrm{C}$. Los resultados se expresan como la media de tres experimentos independientes, conteniendo cada uno de ellos cuatro repeticiones de cada producto. En todos los casos el coeficiente de variación estuvo por debajo del 10\%. ${ }^{\mathrm{b}}$ Datos tomados de la ref. 24 


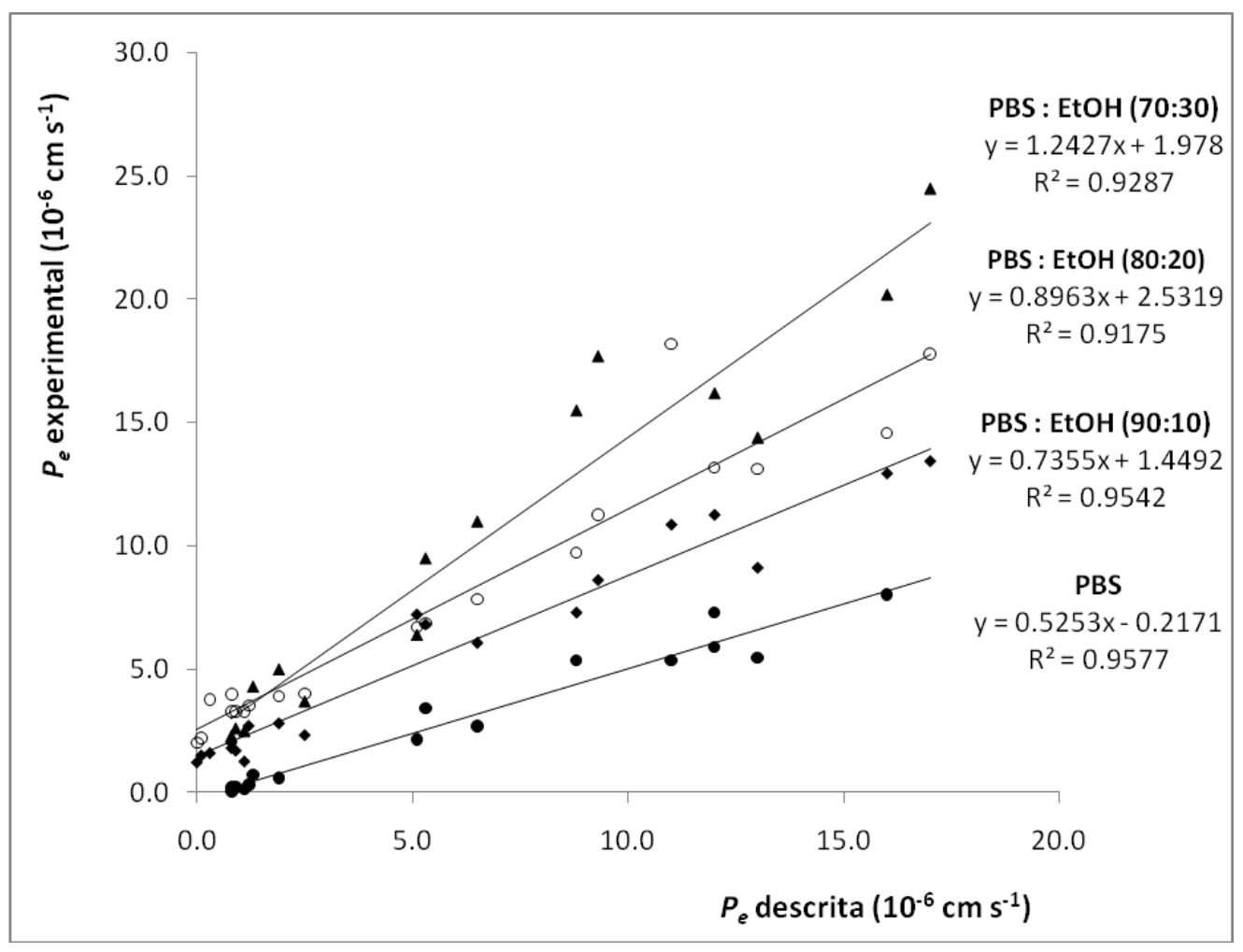

Figura 9. Correlación entre la permeabilidad experimental y la descrita empleando etanol como cosolvente en proporciones que varían entre el 10 y el $30 \%$.

El PEG-400 es una mezcla de polietilenglicoles con una masa molecular en torno a los $400 \mathrm{~g} \mathrm{~mol}^{-1}$, muy empleado en formulaciones farmacéuticas dada su compatibilidad con medios acuosos y su escasa toxicidad ${ }^{29}$. Por este motivo, se decidió probarlo en los ensayos PAMPA-BHE. Cuando se empleó en proporciones del $10 \%$ o del $20 \%$, de nuevo se observaron buenas correlaciones lineales entre la permeabilidad experimental y la descrita (Figura 10). Es curioso señalar que, al contrario de lo que ocurría con el etanol, el aumento de la proporción de PEG-400 hace disminuir la pendiente de la recta, pasando del 0.7 para el $10 \%$ al 0.4 para el $20 \%$. Este hecho puede ser debido a la mayor viscosidad de este cosolvente que hace que el transporte resulte más lento. Precisamente, por este motivo no se siguió aumentando la proporción de PEG-400, ya que una menor pendiente en la recta de calibración conduciría a un margen menor entre los límites para determinar si un producto pasa o no la BHE, con la consiguiente incertidumbre en la predicción.

\footnotetext{
${ }^{29}$ Handbook of Pharmaceutical Excipients. $5^{\text {th }}$ Edition, 2006. Eds. Rowe, R. C.; Sheskey, P. J.; Owen, S. C.
} Pharmaceutical Press (London, Chicago). 
Por último, se ensayó el acetonitrilo al 10\% como cosolvente, obteniendo también buenos resultados (Tabla 4 y Figura 10). Cuando se aumentó su proporción al $20 \%$ se observó que el material plástico de las microplacas se volvía algo opaco, por lo que se descartó este último experimento.

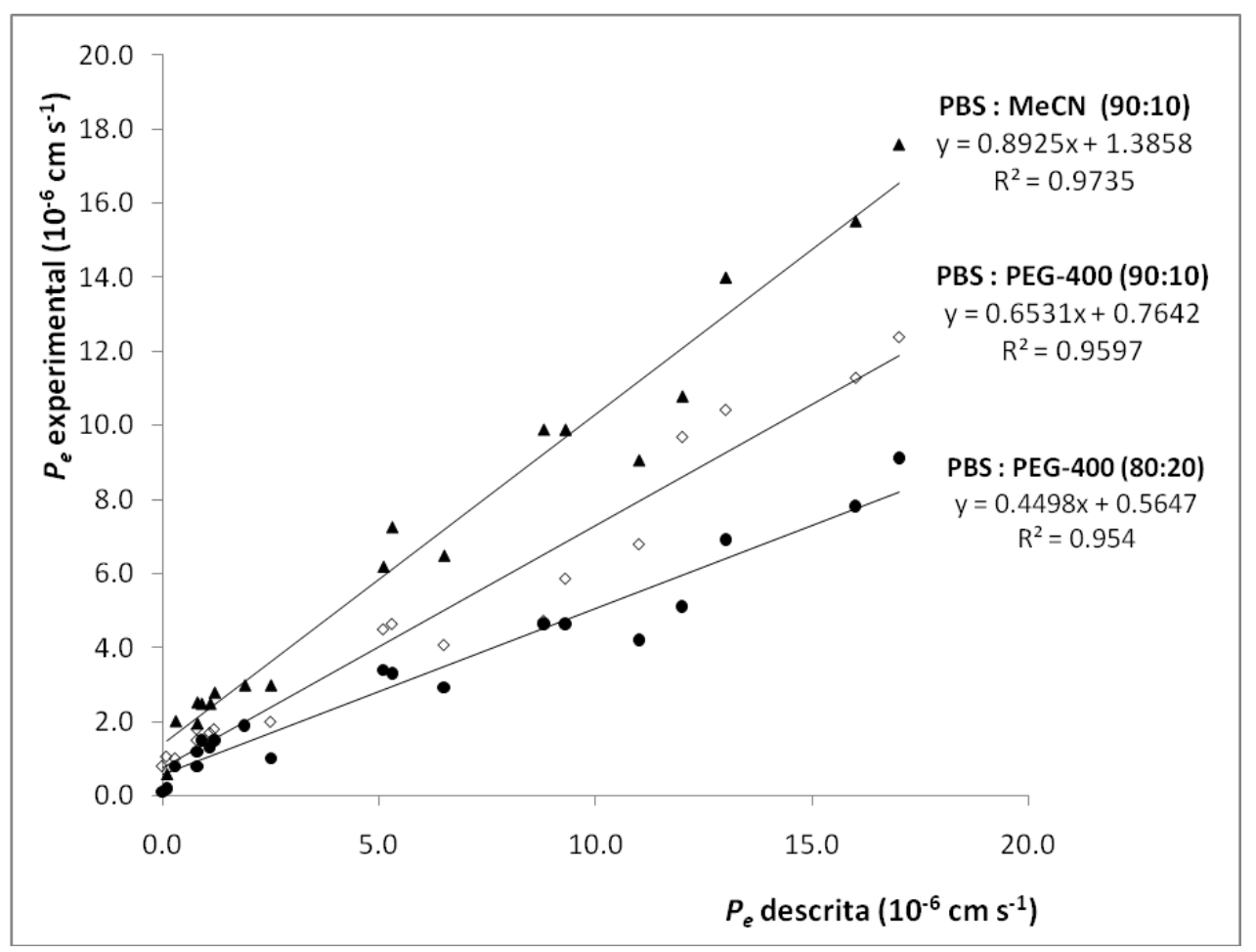

Figura 10. Correlación entre la permeabilidad experimental y la descrita empleando PEG-400 al 10 y al 20\% ó acetonitrilo al $10 \%$.

En esta Tesis Doctoral se ha predicho el comportamiento de numerosos productos en cuanto a su posible penetración en el SNC. Estas moléculas proceden de nuestro propio grupo de investigación así como de otros equipos académicos. También se han evaluado productos para empresas farmacéuticas, cuyos resultados no pueden ser expuestos en esta memoria por motivos de confidencialidad.

En lo que se sigue, se expondrán los resultados de moléculas sintetizadas en nuestro grupo y en otros equipos de investigación. Las predicciones PAMPA-BHE de los productos directamente derivados de esta Tesis Doctoral serán explicadas en el capítulo 2, junto con su diseño, síntesis y resto de evaluación biológica. 


\subsubsection{Moléculas evaluadas empleando la metodología PAMPA (Parallel Artificial Membrane Permeation Assay)}

\subsubsection{Neuroprotectores multifuncionales derivados del ácido L-glutámico}

En nuestro grupo de investigación se había patentado una nueva familia de $\mathrm{N}$ bencilpiperidinas derivadas del ácido L-glutámico que presentaban varias propiedades de interés para la enfermedad del Alzheimer: inhibición submicromolar de AChE humana, desplazamiento de propidio del sitio periférico de la $\mathrm{AChE}$ y neuroprotección de un cultivo de células SH-SY5Y de neuroblastoma humano frente a radicales libres exógenos y mitocondriales, sobrecarga de $\mathrm{Ca}^{2+}$, péptido beta-amiloide y ácido okadaico ${ }^{30}$. También muestran neuroprotección en rodajas de hipocampo de rata sometidas a privación de oxígeno y glucosa. En ensayos in vivo, reducen la muerte neuronal producida por la inyección intrahipocampal de kainato ${ }^{31}$.

Una selección de los derivados más interesantes de la serie fue evaluada en el experimento PAMPA-BHE, empleando una mezcla de PBS:EtOH (70:30) y los resultados están recogidos en la tabla 5. Todos los productos ensayados presentan una permeabilidad superior a $6.910^{-6} \mathrm{~cm} \mathrm{~s}^{-1}$, límite inferior establecido para los productos capaces de atravesar la BHE cuando se emplea esa proporción de etanol (ver tabla 4). Por lo tanto, estos neuroprotectores multifuncionales serían capaces de penetrar en el SNC y llegar a sus dianas terapéuticas situadas en cerebro ${ }^{32}$, como lo corroboran diferentes ensayos in vivo que se están realizando en la actualidad. Concretamente, se ha comprobado que la administración intraperitoneal de una $N$-bencilpiperidina derivada del ácido L-glutámico

\footnotetext{
${ }^{30}$ Conde, S.; Rodríguez-Franco, M. I.; Arce, M. P.; González-Muñoz, G. C.; Villarroya, M.; López, M. G.; García, A. G. Nuevos derivados de aminoácidos dicarboxílicos y su aplicación en el tratamiento de enfermedades neurodegenerativas. ES Pat. P200703264 (10.12.2007); PCT/ES2008/070221 (27/11/2008); WO 2009/074706 A1 (2009).

${ }^{31}$ Lorrio, S.; Negredo, P.; Romero, A.; Egea, J.; del Barrio, L.; Martín de Saavedra, M. D.; Rodríguez-Franco, M. I.; Conde, S.; Arce, M. P.; Villarroya, M.; López, M. G. Perfil neuroprotector del compuesto MPA9.21 (ITH 12233). XXX Reunión Anual del Grupo Español de Neurotransmisión y Neuroprotección. Santo Domingo de Silos (Burgos), 2009.

${ }^{32}$ Arce, M. P.; Rodríguez-Franco, M. I.; González-Muñoz, G. C.; Pérez, C.; López, B.; Villarroya, M.; López, M. G.; García, A. G.; Conde, S. Neuroprotective and Cholinergic Properties of Multifunctional Glutamic Acid Derivatives for the Treatment of Alzheimer's Disease. J. Med. Chem. 2009, 52, 7249-7257.
} 
reduce el volumen de infarto cerebral cortical producido por fototrombosis en ratón, lo que demuestra su capacidad para atravesar la barrera hematoencefálica ${ }^{33}$.

Tabla 5. Permeabilidad $P_{e}\left(10^{-6} \mathrm{~cm} \mathrm{~s}^{-1}\right)$ de $N$-bencilpiperidinas derivadas del ácido L-glutámico, empleando PBS:EtOH (70:30).<smiles>[Y]C(=O)NCCC(=O)NCCC1CCN(Cc2ccccc2)CC1</smiles>

R: 1a: $t$ BuO

1d:<smiles>Cc1cc2cccnc2s1</smiles>

1c:<smiles>Cc1cccs1</smiles>

1f:<smiles>Cc1cc2ccsc2s1</smiles>

\begin{tabular}{rrc}
\hline Comp. & $P_{\mathrm{e}}\left(10^{-6} \mathrm{~cm} \mathrm{~s}^{-1}\right)^{a}$ & Predicción \\
\hline $\mathbf{1 a}$ & $11.6 \pm 0.8$ & $\mathrm{CNS}+$ \\
$\mathbf{1 b}$ & $18.7 \pm 1.6$ & $\mathrm{CNS}+$ \\
$\mathbf{1 c}$ & $20.9 \pm 1.8$ & $\mathrm{CNS}+$ \\
$\mathbf{1 d}$ & $25.6 \pm 1.3$ & $\mathrm{CNS}+$ \\
$\mathbf{1 e}$ & $18.8 \pm 0.9$ & $\mathrm{CNS}+$ \\
$\mathbf{1 f}$ & $28.5 \pm 2.0$ & $\mathrm{CNS}+$ \\
\hline
\end{tabular}

${ }^{\mathrm{a}}$ Media \pm DS de tres experimentos independientes, conteniendo cada uno cuatro repeticiones.

${ }^{33}$ García, A. G.; Rodríguez-Franco, M. I.; Conde, S.; Lorrio, S.; Negredo, P.; Egea, J.; Romero, A.; Roda, J. M.; Arce, M.P.; González, G.; Villarroya M.; López, M. G. A la búsqueda de un medicamento neuroprotector: MPA 9.21 - ITH33. Reunión Red RENEVAS. Salamanca, 2010. 
1.3.3.2. N-Acilaminofenotiazinas y 5,6-dihidro-1,4,5-dibenzo[b,f]tiadiazepinas, potentes protectores neuronales

A partir de una quimioteca de nuestro grupo de investigación, se encontraron dos series de potentes protectores neuronales derivadas respectivamente de $N$-acilaminofenotiazina y de 5,6-dihidro-1,4,5-dibenzo[b,f]tiadiazepina. Estas series fueron protegidas mediante sendas patentes españolas con extensión PCT, debido a sus interesantes perfiles farmacológicos de posible aplicación para el tratamiento de la enfermedad de Alzheimer y otras dolencias neurodegenerativas ${ }^{34,35}$.

Las $N$-acilaminofenotiazinas presentan inhibición selectiva de butirilcolinesterasa en los rangos micro- y submicromolar, neuroprotección frente a radicales libres exógenos y mitocondriales, capacidad de captación de radicales libres en neuroblastoma humano y modulación de canales de calcio. Además, muestran neuroprotección en un modelo de isquemia cerebral y no son tóxicos. Dentro de los estudios farmacológicos, se evaluó su capacidad para atravesar la BHE empleando PAMPA-BHE y una mezcla de PBS:EtOH (90:10). Como puede apreciarse en la tabla 6 , todas las $N$-acilaminofenotiazinas son capaces de penetrar en el SNC, ya que presentan una permeabilidad superior a $4.410^{-6} \mathrm{~cm}$ $\mathrm{s}^{-1}$, valor mínimo establecido para los productos capaces de atravesar la BHE cuando se emplea un $10 \%$ de etanol.

${ }^{34}$ Conde, S.; Rodríguez-Franco, M. I.; González-Muñoz, G. C.; Arce, M. P.; Villarroya, M.; López, M. G.; García, A. G. Uso de hidrazidas de sistemas heterocíclicos en el tratamiento de enfermedades neurodegenerativas. ES Pat. P200801900 (25/06/2008); PCT/ES2009/070229 (16/06/2009); WO 2009/156535 A1 (2009).

${ }^{35}$ Conde, S.; Rodríguez-Franco, M. I.; González-Muñoz, G. C.; Villarroya, M.; López, M. G.; García, A. G. Derivados de 1,4,5-dibenzo[b,f]tiadiazepinas 5,6-dihidro y su uso en el tratamiento de enfermedades neurodegenerativas. ES Pat. 200803413 (01/12/2008); PCT/ES2009/070522 (23/11/2009). 
Tabla 6. Permeabilidad $P_{e}\left(10^{-6} \mathrm{~cm} \mathrm{~s}^{-1}\right)$ de $\mathrm{N}$-acilaminofenotiazinas (PBS:EtOH, 90:10)

\begin{tabular}{|c|c|c|c|c|}
\hline Comp. & $X$ & $\mathrm{R}$ & $P_{\mathrm{e}}\left(10^{-6} \mathrm{~cm} \mathrm{~s}^{-1}\right)^{a}$ & Predicción \\
\hline $2 \mathbf{a}$ & $3-\mathrm{Cl}$ & $\mathrm{R}^{1}$ & $9.1 \pm 0.3$ & $\mathrm{SNC}+$ \\
\hline $2 b$ & $\mathrm{H}$ & $\mathrm{R}^{2}$ & $18.3 \pm 0.6$ & $\mathrm{SNC}+$ \\
\hline $2 c$ & $3-\mathrm{Cl}$ & $\mathrm{R}^{2}$ & $15.5 \pm 0.1$ & $\mathrm{SNC}+$ \\
\hline $2 d$ & $2-\mathrm{Cl}$ & $\mathrm{R}^{3}$ & $9.1 \pm 0.3$ & SNC+ \\
\hline $2 e$ & $3-\mathrm{Cl}$ & $\mathrm{R}^{4}$ & $4.9 \pm 0.1$ & $\mathrm{SNC}+$ \\
\hline $2 f$ & $4-\mathrm{Cl}$ & $\mathrm{CH}_{3}$ & $7.8 \pm 0.2$ & $\mathrm{SNC}+$ \\
\hline $2 \mathrm{~g}$ & $\mathrm{H}$ & $\mathrm{R}^{5}$ & $7.0 \pm 0.2$ & $\mathrm{SNC}+$ \\
\hline $2 \mathbf{h}$ & $3-\mathrm{Cl}$ & $\mathrm{R}^{5}$ & $13.8 \pm 0.3$ & $\mathrm{SNC}+$ \\
\hline $2 \mathbf{i}$ & $3-\mathrm{OCH}_{3}$ & $\mathrm{R}^{5}$ & $6.8 \pm 0.2$ & $\mathrm{SNC}+$ \\
\hline $2 \mathbf{j}$ & $3-\mathrm{NO}_{2}$ & $\mathrm{R}^{5}$ & $14.6 \pm 0.3$ & $\mathrm{SNC}+$ \\
\hline $2 \mathbf{k}$ & $\mathrm{H}$ & $\mathrm{R}^{6}$ & $7.3 \pm 0.2$ & $\mathrm{SNC}+$ \\
\hline 21 & $3-\mathrm{Cl}$ & $\mathrm{R}^{6}$ & $16.4 \pm 0.4$ & $\mathrm{SNC}+$ \\
\hline $2 \mathrm{~m}$ & $3-\mathrm{OCH}_{3}$ & $\mathrm{R}^{6}$ & $8.7 \pm 0.3$ & $\mathrm{SNC}+$ \\
\hline
\end{tabular}

${ }^{\mathrm{a}}$ Media \pm DS de tres experimentos independientes y cuatro repeticiones por ensayo

La familia de las dibenzo[ $b, f]$ tiadiazepinas se caracteriza por un elevado poder neuroprotector de la línea celular de neuroblastoma humano frente a radicales libres mitocondriales, que roza el $100 \%$ cuando los productos se pre-incuban durante 24 horas. Su mecanismo de acción incluye su capacidad directa para neutralizar radicales libres y la disminución de la concentración de calcio citosólico, lo que a su vez promueve mecanismos endógenos de supervivencia celular. Su evaluación en el experimento PAMPA-BHE, empleando PBS:EtOH (90:10) proporcionó los resultados de la tabla 7. Con la excepción de 3e, 3f y 3i que tendrían dificultades para entrar en cerebro, el resto de las dibenzotiadiazepinas atravesarían la barrera hematoencefálica y serían capaces de alcanzar sus dianas terapéuticas situadas en el sistema nervioso central. 
Tabla 7. Evaluación in vitro de la penetración en el SNC de dibenzo[b,f]tiadiazepinas, empleando PBS:EtOH (90:10).
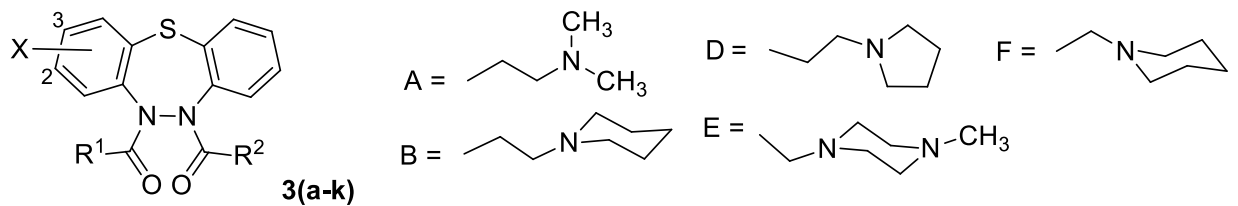

\begin{tabular}{|c|c|c|c|c|c|}
\hline Comp. & $\mathrm{X}$ & $\mathrm{R}^{1}$ & $\mathrm{R}^{2}$ & $\mathrm{P}_{\mathrm{e}} \exp \cdot\left(10^{-6} \mathrm{~cm} \mathrm{~s}^{-1}\right)$ & Predicción ${ }^{\mathrm{b}}$ \\
\hline $3 \mathbf{a}$ & $1-\mathrm{Cl}$ & $\mathrm{CH}_{3}$ & $\mathrm{CH}_{3}$ & $6.7 \pm 0.2$ & $\mathrm{SNC}+$ \\
\hline $3 \mathbf{b}$ & $2-\mathrm{Cl}$ & $\mathrm{CH}_{3}$ & $\mathrm{CH}_{3}$ & $10.1 \pm 0.1$ & $\mathrm{SNC}+$ \\
\hline $3 c$ & $3-\mathrm{Cl}$ & $\mathrm{CH}_{3}$ & $\mathrm{CH}_{3}$ & $12.3 \pm 0.5$ & $\mathrm{SNC}+$ \\
\hline 3d & $3-\mathrm{OCH}_{3}$ & $\mathrm{CH}_{3}$ & $\mathrm{CH}_{3}$ & $12.6 \pm 0.3$ & $\mathrm{SNC}+$ \\
\hline $3 e$ & $3-\mathrm{NO}_{2}$ & $\mathrm{H}$ & $\mathrm{CH}_{3}$ & $3.9 \pm 0.1$ & $\mathrm{SNC}+/-$ \\
\hline $3 f$ & $3-\mathrm{CF}_{3}$ & $\mathrm{CH}_{3}$ & $\mathrm{CH}_{3}$ & $3.0 \pm 0.1$ & $\mathrm{SNC}+/-$ \\
\hline $3 g$ & $2-\mathrm{Cl}$ & A & A & $14.2 \pm 0.1$ & $\mathrm{SNC}+$ \\
\hline $3 \mathbf{h}$ & $2-\mathrm{Cl}$ & $\mathrm{B}$ & $\mathrm{B}$ & $5.3 \pm 0.2$ & $\mathrm{SNC}+$ \\
\hline $3 \mathbf{i}$ & $2-\mathrm{Cl}$ & $\mathrm{D}$ & $\mathrm{D}$ & $3.7 \pm 0.1$ & $\mathrm{SNC}+/-$ \\
\hline $3 \mathbf{j}$ & $2-\mathrm{Cl}$ & $\mathrm{E}$ & $\mathrm{E}$ & $5.9 \pm 0.2$ & $\mathrm{SNC}+$ \\
\hline $3 \mathbf{k}$ & $2-\mathrm{Cl}$ & $\mathrm{F}$ & $\mathrm{F}$ & $7.3 \pm 0.2$ & SNC+ \\
\hline
\end{tabular}

${ }^{a}$ Media \pm DS de tres experimentos independientes, conteniendo cada uno cuatro repeticiones.

\subsubsection{Tacripirinas}

Las tacripirinas son híbridos tacrina - dihidropiridina, desarrollados por el equipo del Dr. J. L. Marco, que combinan inhibición de acetilcolinesterasa y antagonismo de calcio. En esta Tesis Doctoral, se colaboró con este grupo evaluando una serie de tacripirinas en el ensayo PAMPA-BHE, empleando PBS:EtOH (80:20) (Tabla 8). 
Tabla 8. Evaluación in vitro de la penetración en el SNC de tacripirinas, empleando PBS:EtOH (80:20).

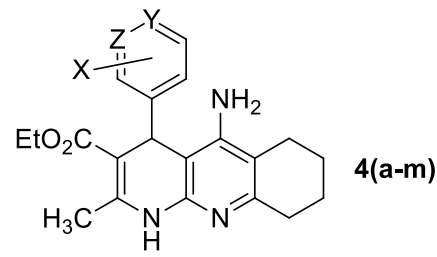

\begin{tabular}{cccccc}
\hline Comp. & $\mathrm{X}$ & $\mathrm{Y}$ & $\mathrm{Z}$ & $P_{\mathrm{e}}\left(10^{-6} \mathrm{~cm} \mathrm{~s}^{-1}\right)^{a}$ & Predicción \\
\hline $\mathbf{4 a}$ & $\mathrm{H}$ & $\mathrm{CH}$ & $\mathrm{CH}$ & $12.6 \pm 0.2$ & $\mathrm{CNS}+$ \\
$\mathbf{4 b}$ & $4^{\prime}-\mathrm{F}$ & $\mathrm{C}$ & $\mathrm{CH}$ & $9.6 \pm 0.1$ & $\mathrm{CNS}+$ \\
$\mathbf{4 c}$ & $2^{\prime}-\mathrm{CF}_{3}$ & $\mathrm{CH}$ & $\mathrm{CH}$ & $4.4 \pm 0.1$ & $\mathrm{CNS}+/-$ \\
$\mathbf{4 d}$ & $2^{\prime}-\mathrm{NO}_{2}$ & $\mathrm{CH}$ & $\mathrm{CH}$ & $8.6 \pm 0.2$ & $\mathrm{CNS}+$ \\
$\mathbf{4 e}$ & $3^{\prime}-\mathrm{NO}_{2}$ & $\mathrm{CH}$ & $\mathrm{CH}$ & $7.0 \pm 0.1$ & $\mathrm{CNS}+$ \\
$\mathbf{4 f}$ & $4^{\prime}-\mathrm{NO}_{2}$ & $\mathrm{C}$ & $\mathrm{CH}$ & $6.8 \pm 0.1$ & $\mathrm{CNS}+$ \\
$\mathbf{4 g}$ & $4^{\prime}-\mathrm{Me}^{\prime}$ & $\mathrm{C}$ & $\mathrm{CH}$ & $4.8 \pm 0.1$ & $\mathrm{CNS}+/-$ \\
$\mathbf{4 h}$ & $2^{\prime}-\mathrm{OMe}$ & $\mathrm{CH}$ & $\mathrm{CH}$ & $7.1 \pm 0.1$ & $\mathrm{CNS}+$ \\
$\mathbf{4 i}$ & $3^{\prime}-\mathrm{OMe}$ & $\mathrm{CH}$ & $\mathrm{CH}$ & $6.5 \pm 0.1$ & $\mathrm{CNS}+$ \\
$\mathbf{4 j}$ & $4^{\prime}-\mathrm{OMe}$ & $\mathrm{C}$ & $\mathrm{CH}$ & $12.8 \pm 0.2$ & $\mathrm{CNS}+$ \\
$\mathbf{4 k}$ & $3^{\prime}, 4^{\prime}-\mathrm{di}-\mathrm{OMe}$ & $\mathrm{C}$ & $\mathrm{CH}$ & $9.4 \pm 0.1$ & $\mathrm{CNS}+$ \\
$\mathbf{4 l}$ & $\mathrm{H}$ & $\mathrm{CH}$ & $\mathrm{N}$ & $7.2 \pm 0.4$ & $\mathrm{CNS}+$ \\
$\mathbf{4 m}$ & $\mathrm{H}$ & $\mathrm{N}$ & $\mathrm{CH}$ & $6.2 \pm 0.1$ & $\mathrm{CNS}+$ \\
\hline
\end{tabular}

${ }^{\mathrm{a}}$ Media \pm DS de tres experimentos independientes, conteniendo cada uno cuatro repeticiones.

La mayoría de las tacripirinas atravesarían la barrera hematoencefálica. Sólo dos compuestos, el $\mathbf{4 c}$ y $\mathbf{4 g}$, derivados de 2'-trifluorometilfenilo y de 4'-metilfenilo, respectivamente, muestran una permeabilidad dentro del rango de incertidumbre (CNS+/). Estos resultados han quedado plasmados en una publicación conjunta ${ }^{36}$.

${ }^{36}$ Marco-Contelles, J.; León, R.; de los Ríos, C.; Samadi, A.; Bartolini, M.; Andrisano, V.; Huertas, O.; Barril, X.; Luque, F. J.; Rodríguez-Franco, M. I.; López, B.; López, M. G.; García, A. G.; Carreiras, M. C.; Villarroya, M. Tacripyrines, the first tacrine-dihydropyridine hybrids, as multitarget-directed ligands for the treatment of Alzheimer's disease. J. Med. Chem. 2009, 52, 2724-2732. 


\subsubsection{Sulfato de condroitina}

El sulfato de condroitina o condroitín sulfato (CS) está compuesto por una cadena de disacáridos de $N$-acetilgalactosamina y $N$-ácido glucurónico alternados (Figura 11). Una molécula de CS puede estar constituida por más de 100 azúcares individuales, cada uno de los cuales puede estar sulfatado en diferentes posiciones. Es un componente importante de los tejidos conectivos del cuerpo, cartílago, piel, vasos sanguíneos, así como de los ligamentos y los tendones. El CS aporta al cartílago sus propiedades mecánicas y elásticas, proporcionándole mucha resistencia a la compresión.

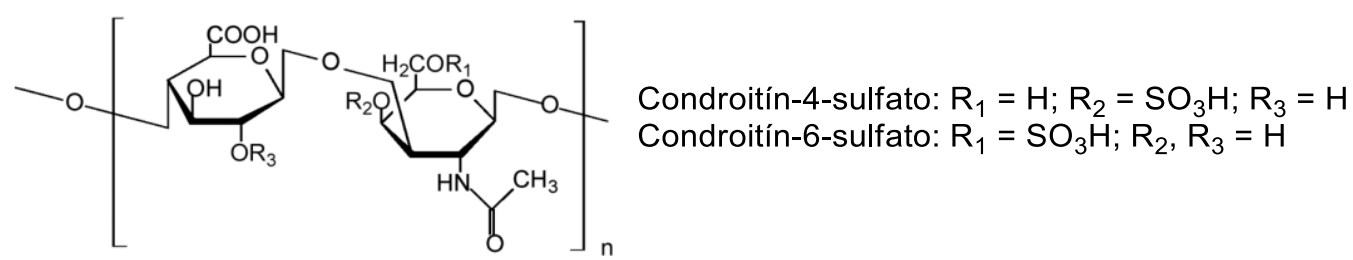

Figura 11. Estructura del sulfato de condroitina

El sulfato de condroitina está aprobado en más de 22 países europeos para el tratamiento de la artrosis, debido a sus propiedades antiinflamatorias y antiapoptóticas. Nuevas evidencias han puesto de manifiesto que estos efectos del CS pueden ser de utilidad terapéutica en enfermedades del SNC. Así, se ha descubierto que la red perineuronal, formada por proteínas altamente glicosiladas con condroitín sulfato, ejerce un papel neuroprotector frente al estrés oxidativo ${ }^{37}$. Además, se ha demostrado que el CS tiene efectos antioxidantes y neuroprotectores en cultivos neuronales ${ }^{38,39}$ y que un disacárido derivado de la proteólisis endógena del CS también tiene efectos neuroprotectores tanto in vitro como in vivo ${ }^{40}$.

37 Egea, J.; García, A. G.; Vergés, J.; Montell, E.; López, M. G. Antioxidant, antiinflammatory and neuroprotective actions of chondroitin sulfate and proteoglycans. Osteoarthritis Cartilage 2010, 000 doi:10.1016/j.joca.2010.01.016.

${ }^{38}$ Cañas, N.; Valero, T.; Villarroya, M.; Montell, E.; Vergés, J.; García, A. G.; López, M. G. Chondroitin sulfate protects SH-SY5Y cells from oxidative stress by inducing heme oxygenase-1 via phosphatidylinositol 3-kinase/Akt. J. Pharmacol. Exp. Ther. 2007, 323, 946-953.

${ }^{39}$ Cañas, N.; Gorina, R.; Planas, A. M.; Vergés, J.; Montell, E.; García, A. G.; López, M. G. Chondroitin sulfate inhibits lipopolysaccharide-induced inflammation in rat astrocytes by preventing nuclear factor kappa B activation. Neuroscience 2010, 167, 872-879.

${ }^{40}$ Rolls, A.; Avidan, H.; Cahalon, L.; Schori, H.; Bakalash, S.; Litvak, V.; Lev, S.; Lider, O.; Schwartz, M. A disaccharide derived from chondroitin sulphate proteoglycan promotes central nervous system repair in rats and mice. Eur. J. Neurosci. 2004, 20, 1973-1983. 
En colaboración con el grupo del Dr. Antonio G. García del Instituto Teófilo Hernando (Facultad de Medicina de la Universidad Autónoma) se estudió in vitro la penetración en el SNC del condroitín sulfato y del disacárido CS-frag-4,6. Ambos productos únicamente presentan absorción en la zona más extrema del UV, zona en la que el material de la microplaca de 96-pocillos también absorbe, lo que interferiría en las medidas. Por esta razón, las longitudes de onda analíticas se tomaron a 210, 212 y $214 \mathrm{~nm}$, ya que a longitudes de onda superiores a $210 \mathrm{~nm}$ las interferencias con el material de la microplaca se minimizan (Figura 12a). Por otra parte, y teniendo en cuenta que los productos son polisacáridos, se buscó un revelador específico que absorbiera en la zona del visible, como es la mezcla fenol / ácido sulfúrico con una banda en torno a $475 \mathrm{~nm}$. En este caso, se emplearon las siguientes longitudes de onda analíticas: 465, 470, 475, 480 y $485 \mathrm{~nm}$ (Figura 12b).

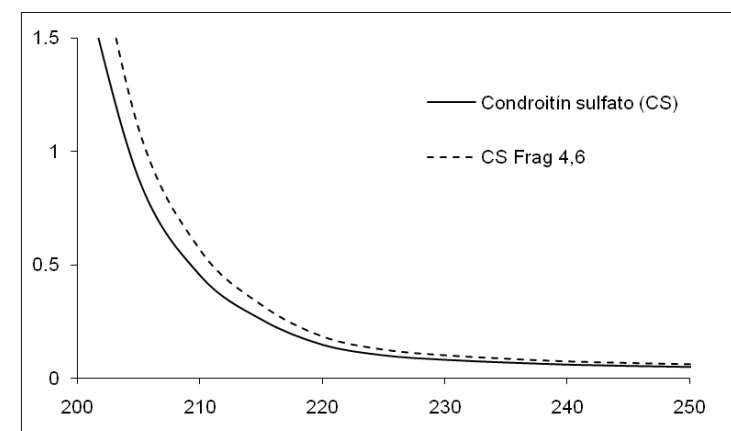

(a)

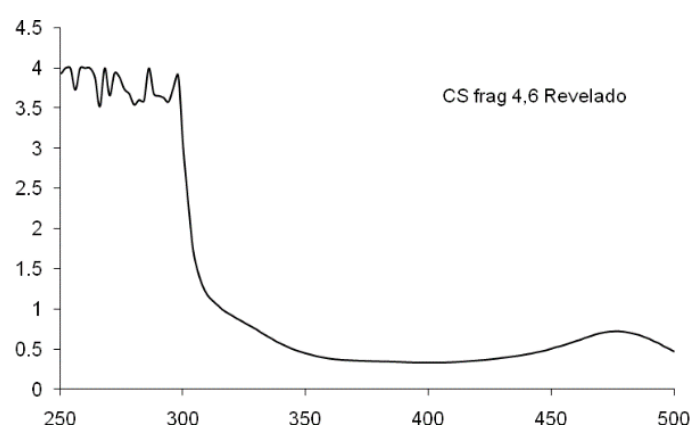

(b)

Figura 12. Espectros de absorción UV-vis de: (a) condroitín sulfato y el disacárido CS-frag4,6 en PBS:EtOH (90:10); (b) CS-frag-4,6 después del tratamiento con fenol / ácido sulfúrico.

El CS se evaluó de forma directa, mientras que el disacárido se evaluó además por revelado posterior al proceso de transporte, tratando la solución receptora con la mezcla de fenol y ácido sulfúrico. Como puede apreciarse en la tabla 9, donde se han recogido las longitudes de onda empleadas en el experimento, así como los resultados del mismo, ninguno de los dos productos sería capaz de atravesar la BHE, al menos mediante difusión pasiva. 
Tabla 9. Evaluación in vitro de la penetración en el SNC de condroitín sulfato (CS) y CSfrag-4,6, empleando PBS:EtOH (90:10)

\begin{tabular}{lccc}
\multicolumn{1}{c}{ Comp. } & $\lambda$ analíticas (Abs. Inicial) & $P_{\mathrm{e}}\left(10^{-6} \mathrm{~cm} \mathrm{~s}^{-1}\right)^{a}$ & Predicción \\
CS & $210(0.72), 212(0.63), 214(0.42)$ & $0.1 \pm 0.06$ & CNS - \\
CS-frag-4,6 & $210(0.94), 212(0.67), 214(0.51)$ & $0.2 \pm 0.01$ & CNS - \\
$\begin{array}{l}\text { CS-frag-4,6 } \\
\text { revelado) }\end{array}$ & $465(0.62), 470(0.66), 475(0.69)$, & $0.3 \pm 0.01$ & CNS - \\
\hline
\end{tabular}

${ }^{a}$ Media \pm DS de tres experimentos independientes, conteniendo cada uno cuatro repeticiones.

Es conocido que en el cerebro existen varios transportadores activos de carbohidratos, fundamentalmente GLUT-1 y GLUT-3, que suministran glucosa al SNC. Debido al elevado peso molecular del CS, no parece que pueda ser sustrato dichos carriers. Sin embargo, el CS-frag-4,6 es un disacárido, por lo que cabe la posibilidad de que este producto pueda unirse a alguno de estos transportadores debido al parecido estructural con los sustratos naturales, y llegar al SNC mediante transporte activo.

\subsubsection{Antioxidantes comerciales}

Con el fin de conocer si una serie de antioxidantes comerciales, tales como sulforafano, tert-butilhidroquinona y oltipraz, podrían pasar o no al SNC, se evaluaron en el ensayo PAMPA-BHE empleando PBS con un 30\% de etanol. Como queda recogido en la tabla 10 , la tert-butilhidroquinona y el oltipraz serían capaces de atravesar la BHE, mientras que el sulforafano presentaría más dificultades, ya que su permeabilidad experimental queda en la zona de incertidumbre del ensayo.

El sulforafano es un isotiocianato que se encuentra en vegetales de la familia de las coles, especialmente en el brécol. Este producto posee propiedades citoprotectoras frente al estrés oxidativo, debido a sus propiedades antioxidantes ${ }^{41}$. Recientemente, se ha demostrado que la inyección intraperitoneal de sulforafano reduce el volumen de infarto

\footnotetext{
${ }^{41}$ Niso-Santano, M.; González-Polo, R. A.; Bravo-San Pedro, J. M.; Gómez-Sánchez, R.; Lastres-Becker, I.; Ortiz-Ortiz, M. A.; Soler, G.; Morán, J. M.; Cuadrado, A.; Fuentes, J. M. Activation of apoptosis signalregulating kinase 1 is a key factor in paraquat-induced cell death: modulation by the Nrf2/Trx axis. Free Radic. Biol. Med. 2010, 48, 1370-1381.
} 
cerebral en un modelo murino de hipoxia-isquemia ${ }^{42}$. Estos resultados farmacológicos, junto con nuestra estimación en el ensayo PAMPA-BHE, sugieren que el sulforafano sería capaz de llegar al cerebro mediante transporte facilitado por una proteína de membrana y no por difusión pasiva.

Tabla 10. Evaluación in vitro de la penetración en el SNC de antioxidantes comerciales, empleando PBS:EtOH (70:30)

\begin{tabular}{lcc} 
& \\
\multicolumn{1}{c}{ Sulforafano } & $P_{a}\left(10^{-6} \mathrm{~cm} \mathrm{~s}^{-1}\right)^{\mathrm{a}}$ & Predicción \\
\hline Comp. & $1.3 \pm 0.1$ & $\mathrm{SNC}+/-$ \\
tert-Butilhidroquinona & $6.1 \pm 0.2$ & $\mathrm{SNC}+$ \\
Oltipraz & $10.0 \pm 0.1$ & $\mathrm{SNC}+$ \\
\hline
\end{tabular}

${ }^{\mathrm{a} M e d i a} \pm$ DS de tres experimentos independientes, conteniendo cada uno cuatro repeticiones.

La tert-butilhidroquinona es un antioxidante utilizado en la industria alimenticia como conservante de aceites vegetales y grasas animales. Por su parte, el oltipraz posee un alto potencial terapéutico como antiparasitario, en la prevención de ciertos tumores, como protector mitocondrial y como citoprotector frente al estrés oxidativo ${ }^{43}$. El hecho de que ambos productos sean capaces de llegar fácilmente a cerebro mediante difusión pasiva, hace que puedan ser considerados fragmentos valiosos para el diseño de nuevos fármacos que combatan el estrés oxidativo para el tratamiento de enfermedades neurodegenerativas.

\footnotetext{
${ }^{42}$ Ping, Z.; Liu, W.; Kang, Z.; Cai, J.; Wang, Q.; Cheng, N.; Wang, S.; Wang, S.; Zhang, J. H.; Sun, X. Sulforaphane Protects Brains against Hypoxic-Ischemic Injury through Induction of Nrf2-Dependent Phase 2 Enzyme. Brain Res. 2010 (doi: 10.1016/j.brainres.2010.04.036).

${ }^{43}$ Choi, S. H.; Kim, Y. M.; Lee, J. M.; Kim, S.G. Antioxidant and mitochondrial protective effects of oxidized metabolites of oltipraz. Expert Opin. Drug Metab. Toxicol. 2010, 6, 213-224.
} 


\subsection{CONCLUSIONES}

En la primera parte de esta Tesis Doctoral se han puesto en marcha dos tipos de experimentos in vitro para evaluar la penetración de moléculas en el SNC: difusión horizontal a través de membranas artificiales y la metodología PAMPA. En ambos, la barrera biológica se ha simulado empleando un extracto lipídico de cerebro de cerdo soportado en un filtro. El método de difusión horizontal tiene como ventaja que permite realizar estudios cinéticos, pero su principal inconveniente es su lentitud y que se necesitan cantidades relativamente elevadas de producto.

El método PAMPA es más rápido, reproducible y de menor coste que el anterior. Permite la evaluación de series en poco tiempo y requiere poca cantidad de producto, entre 1 y $5 \mathrm{mg}$ suelen ser suficientes para la evaluación in vitro de la penetración en el SNC.

Empleando la metodología PAMPA, se ha optimizado el empleo de diferentes cosolventes en varias proporciones para poder evaluar moléculas de limitada solubilidad acuosa. Concretamente, se ha validado el empleo de mezclas PBS : etanol (90:10, 80:20 y 70:30), PBS : PEG-400 (90:10 y 80:20) y PBS : MeCN (90:10).

El método PAMPA es actualmente el método de elección en nuestro grupo para hacer la determinación in vitro de la permeabilidad de nuestras moléculas en el SNC. Prueba de ello, es la incorporación de estas técnicas en todas nuestras líneas de investigación, como queda reflejado en las publicaciones y patentes realizadas en los últimos años. 


\subsection{EXPERIMENTAL}

Los ensayos de permeabilidad a través de membranas artificiales, PAMPA (Parallel Artificial Membrane Permeation Assay), se realizaron empleando dos microplacas de 96 pocillos (Millipore). La microplaca donadora contiene un filtro de PVDF con un tamaño de poro de $0.45 \mu \mathrm{m}$, mientras que la microplaca aceptora tiene forma de lágrima. Los fármacos empleados para validar el método se compraron en Sigma, Aldrich, Acros y Fluka. Los filtros Millex (membrana de PVDF), empleados para filtrar las muestras, poseen un diámetro de $25 \mathrm{~mm}$ y un tamaño de poro de $0.45 \mu \mathrm{m}$. El extracto lipídico de cerebro de cerdo (porcine brain lipid, PBL), empleado para simular la barrera biológica, se obtuvo de la casa Avanti Polar Lipids. El protocolo experimental es el siguiente:

1. Se preparan disoluciones $\approx 1 \mu \mathrm{M}(5 \mathrm{~mL})$ de cada producto en tampón fosfato salino de pH 7.4, sólo o con un cosolvente dependiendo de la solubilidad de los productos, y se filtran. A continuación se registra un espectro UV para determinar las longitudes de onda analíticas. Idealmente, se eligen 5 longitudes de onda diferentes con una absorción en torno a $1(0.8-1.2)$.

2. Se mide la absorción inicial por triplicado o cuadriplicado a las longitudes de onda seleccionadas.

3. Se disuelven $8 \mathrm{mg}$ de PLB (porcine brain lipid) en $0.4 \mathrm{~mL}$ de dodecano y se sonica para la completa disolución del lípido. Esta pesada se debe realizar con la mayor rapidez posible para evitar que el lípido se estropee.

4. Se pone $180 \mu \mathrm{L}$ de buffer $\mathrm{pH} 7.4$ en cada pocillo de la placa receptora tipo lágrima.

5. Se añaden $4 \mu \mathrm{L}$ de la disolución del lípido en el filtro de todos los pocillos de la placa donadora. La disolución ha de caer en el centro del material polimérico y la pipeta no debe rozarlo.

6. Se pone $180 \mu \mathrm{L}$ de la solución del producto por triplicado (para los productos comerciales) o por cuadriplicado (para los productos a evaluar) según la distribución que se indica en la figura 13. 


\begin{tabular}{|c|c|c|c|c|c|c|c|c|c|c|c|c|}
\hline & 1 & 2 & 3 & 4 & 5 & 6 & 7 & 8 & 9 & 10 & 11 & 12 \\
\hline$\overline{\mathbf{A}}$ & \multicolumn{3}{|c|}{ Hidrocortisona } & \multicolumn{3}{|c|}{ Corticosterona } & \multicolumn{3}{|c|}{ Aldosterona } & \multicolumn{3}{|c|}{ Promazina } \\
\hline B & \multicolumn{3}{|c|}{ Clorpromazina } & \multicolumn{3}{|c|}{ Progesterora } & \multicolumn{3}{|c|}{ Testosterona } & \multicolumn{3}{|c|}{ Desipramina } \\
\hline $\mathrm{C}$ & \multicolumn{3}{|c|}{ Imipramina } & \multicolumn{3}{|c|}{ Atenolol } & \multicolumn{3}{|c|}{ Clonidina } & \multicolumn{3}{|c|}{ Astemizol } \\
\hline D & \multicolumn{3}{|c|}{ Verapamilo } & \multicolumn{3}{|c|}{ Cafeína } & \multicolumn{3}{|c|}{ Lomefloxacina } & \multicolumn{3}{|c|}{ Piroxican } \\
\hline $\mathbf{E}$ & \multicolumn{3}{|c|}{ Ofloxacina } & \multicolumn{3}{|c|}{ Enoxacina } & \multicolumn{3}{|c|}{ Estradiol } & \multicolumn{3}{|c|}{ Blanco } \\
\hline $\mathbf{F}$ & \multicolumn{4}{|c|}{ Producto 1} & \multicolumn{4}{|c|}{ Producto 2} & \multicolumn{4}{|c|}{ Producto 3} \\
\hline $\mathbf{G}$ & \multicolumn{4}{|c|}{ Producto 4} & \multicolumn{4}{|c|}{ Producto 5} & \multicolumn{4}{|c|}{ Producto 6} \\
\hline H & \multicolumn{4}{|c|}{ Producto 7} & \multicolumn{4}{|c|}{ Producto 8} & \multicolumn{4}{|c|}{ Producto 9} \\
\hline
\end{tabular}

Figura 13. Distribución habitual de los productos en un ensayo PAMPA-BHE en la microplaca de 96 pocillos

7. Se coloca la placa donadora sobre la receptora y se incuba a temperatura ambiente durante 4 horas. Para evitar la evaporación de las muestras hay que colocar el montaje dentro de un recipiente cerrado a temperatura constante $\left(25^{\circ} \mathrm{C}\right)$. Se emplea un cronómetro para medir exactamente el tiempo del experimento.

8. Después de la incubación se retira inmediatamente la fase donadora y se toman $130 \mu \mathrm{L}$ de cada uno de los pocillos de la fase receptora (placa con forma de lágrima), que se trasvasan a otra placa que, a diferencia de la anterior, sí es compatible con el UV-vis. Se determina la absorbancia de cada producto a las longitudes de onda previamente determinadas.

9. A partir de las absorbancias iniciales de las disoluciones preparadas, y las finales después de la incubación a una determinada longitud de onda, se calcula el porcentaje de producto transportado T $(\%)$, mediante la fórmula que se muestra a continuación:

$$
\% T=\frac{[\text { prod }]_{R}}{[\text { prod }]_{D}} 100=\frac{A b s_{R} V_{R}}{A b s_{D} V_{D}} 100
$$

donde, Abs: absorbancia, V: volumen, R: fase receptora, D: fase donadora.

10. La permeabilidad del producto a través del lípido $\mathrm{Pa}(\mathrm{cm} \mathrm{s}-1)$ se calcula a partir del porcentaje de transporte mediante la siguiente ecuación: 


$$
P_{a}=\frac{V_{D} \cdot V_{R}}{\left(V_{D}+V_{R}\right) S \cdot t} \ln \frac{100 V_{D}}{100 V_{D}-\% T\left(V_{D}+V_{R}\right)}
$$

donde, S: superficie de contacto entre las dos fases $\left(0.2642 \mathrm{~cm}^{2}\right)$; t: tiempo de incubación en segundos.

Cada una de las condiciones experimentales ensayadas fue validada comparando los datos obtenidos para los productos comerciales con los descritos por Di y col. ${ }^{24}$, obteniendo rectas con buen coeficiente de correlación. A partir de la ecuación de cada recta y teniendo en cuenta los límites establecidos por los autores anteriores para la predicción de la penetración en el SNC, se establecen los límites para cada uno de los ensayos.

Con el fin de comparar ensayos realizados en las mismas condiciones experimentales pero con rectas de calibración diferentes, se puede proceder a su normalización. Para ello, los valores experimentales de $P_{\mathrm{e}}$ se re-calculan aplicando su recta de calibración y los valores de los productos patrón se representan frente a los datos bibliográficos (Figura 14). Esta nueva correlación lineal proporciona una pendiente próxima a 1 y una ordenada en el origen próxima a 0 , por lo que en estos casos los límites para la predicción de la penetración en el SNC coinciden con los inicialmente descritos por Li y $\operatorname{col}^{24}: \mathrm{SNC}+: P_{\mathrm{e}}>4.010^{-6} \mathrm{~cm}$ $\mathrm{s}^{-1} / \mathrm{SNC}-: P_{\mathrm{e}}<2.010^{-6} \mathrm{~cm} \mathrm{~s}^{-1}$.

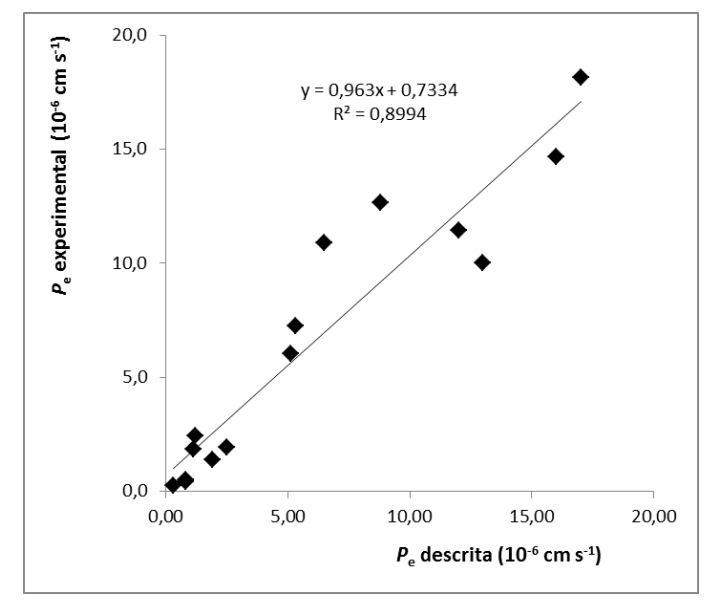

Figura 14. Correlación entre la permeabilidad experimental normalizada y la descrita empleando PBS:EtOH (70:30) 

Capítulo 2

Nuevos híbridos anti-Alzheimer derivados de tacrina o de dibencilamina 



\section{NUEVOS HÍBRIDOS ANTI-ALZHEIMER DERIVADOS DE TACRINA O DE $N, N$-DIBENCIL( $N$-METIL)AMINA}

\subsection{INTRODUCCIÓN}

\subsubsection{Neuropatología de la enfermedad de Alzheimer}

La esperanza media de vida en los países desarrollados, que rondaba los 45 años a principios del siglo XX, se ha duplicado en los últimos 100 años, debido a las vacunas, a los antibióticos, al saneamiento de las aguas y a la higiene en todos los ámbitos. Este incremento de la esperanza de vida ha conducido a una mayor incidencia de las enfermedades ligadas al envejecimiento. Entre ellas, se encuentran las enfermedades neurodegenerativas, que provocan un enorme deterioro de la calidad de vida de los pacientes y unos gastos sanitarios muy elevados. Las demencias asociadas a la edad afectan a unos 47 millones de personas a nivel mundial y se prevé que este número aumente a cerca de 75 millones en 2030 y a casi el triple en 2050 (132 millones $)^{44}$. La enfermedad de Alzheimer (EA) es la demencia más frecuente en personas de más de 65 años, representando entre el 60-70\% del total de los casos.

La Organización Mundial de la Salud define a la EA como "un síndrome debido a una patología del cerebro, generalmente de naturaleza crónica o progresiva, en la que hay déficits de múltiples funciones corticales superiores que repercuten en la actividad cotidiana del enfermo" ${ }^{45}$.

La enfermedad se caracteriza clínicamente por un deterioro progresivo e irreversible de las funciones cerebrales superiores o cognitivas, con pérdida de memoria, juicio, lenguaje, etc. Aunque la progresión de la enfermedad puede ser muy variable, en general se distinguen tres fases. En los primeros años aparecen alteraciones de la memoria, dificultad de aprendizaje, desorientación espacial, cambios de humor y depresión por apatía. En la fase moderada se producen alteraciones intelectuales más importantes como

\footnotetext{
${ }^{44}$ Organización Mundial de la Salud (http://www.who.int/mediacentre/factsheets/fs362/es/).

${ }^{45}$ Fundación Alzheimer España (http://www.alzfae.org/fundacion/135)
} 
dificultades en el lenguaje y la pérdida de la capacidad de reconocimiento. En la etapa más severa, el paciente llega a desconectarse del entorno y se produce un grave deterioro de las capacidades motrices, siendo incapaz de controlar las funciones fisiológicas básicas.

Los estudios postmorten de los cerebros de enfermos de Alzheimer reflejan atrofia generalizada de la corteza cerebral, disminución del peso y volumen del cerebro, así como aumento del tamaño de los ventrículos y de la profundidad de los surcos. Los primeros cambios se producen en la corteza entorrinal y en el hipocampo, zonas esenciales para la formación y consolidación de la memoria, que comienzan a atrofiarse disminuyendo su tamaño. Estos cambios probablemente empiezan entre 10 y 20 años antes de que se observen las primeras alteraciones de la memoria. A medida que la enfermedad avanza, el hipocampo y la corteza cerebral pierden volumen y las lesiones se extienden a otras zonas de la corteza cerebral, agravando los síntomas (Figura 15).
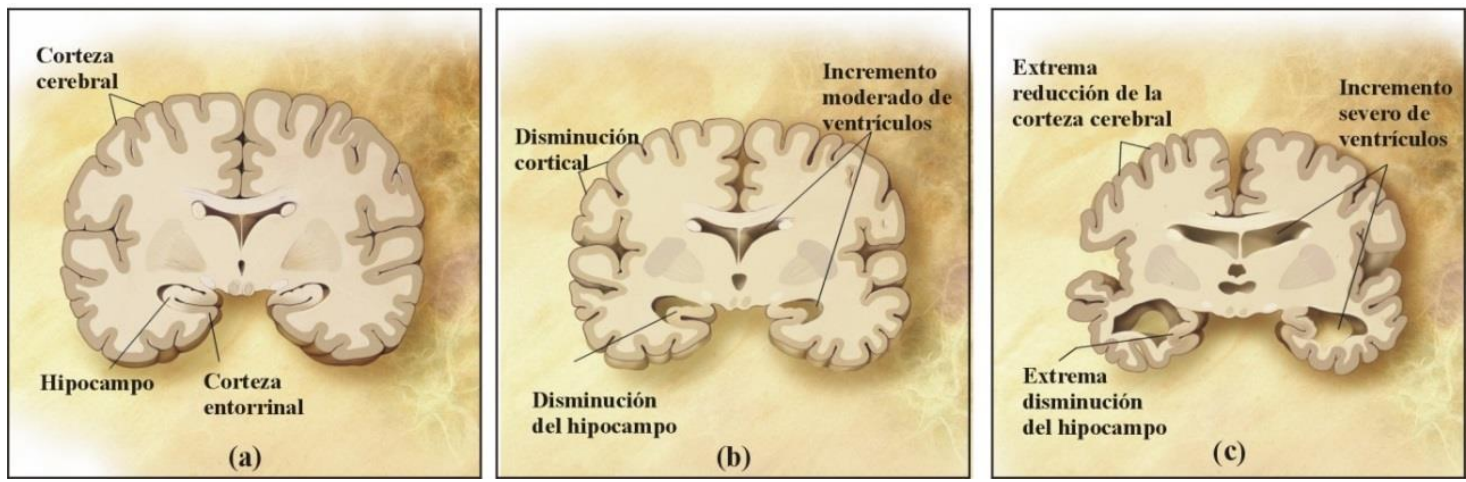

Figura 15. Comparación de la morfología del cerebro sano (a) y del afectado por la enfermedad de Alzheimer de forma leve (b) o severa $(c)^{46}$.

\footnotetext{
${ }^{46}$ Imágenes tomadas de Alzheimer's disease: unraveling the mystery. Ed. U. S. Department of Health and Human Services, National Institutes of Health, NIH Publication Number: 02-3782. Diciembre, 2003.
} 


\subsubsection{Lesiones características de la EA: placas amiloides y ovillos neurofibrilares}

A nivel histológico, se observan dos lesiones características que sirven para diagnosticar de forma definitiva la enfermedad: las placas seniles ${ }^{47}$ y los ovillos neurofibrilares $^{48}$ (Figura 16). También se observa una reducción en el número de neuronas, que afecta principalmente al sistema colinérgico. Concretamente, los exámenes postmorten de enfermos de Alzheimer han demostrado que existe una pérdida superior al $75 \%$ de las neuronas colinérgicas de la corteza cerebral ${ }^{49}$.

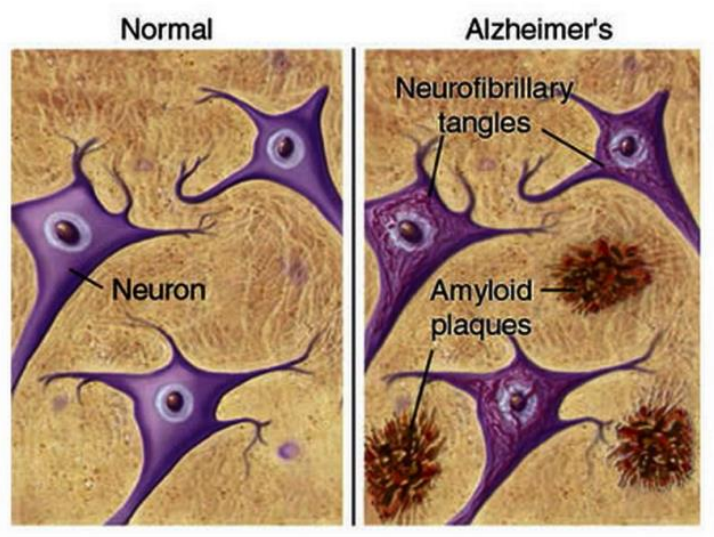

Figura 16. (a) Placas amiloides. (b) Ovillos neurofibrilares ${ }^{50}$.

Las placas seniles, también denominadas placas amiloides, son agregados insolubles de tamaño variable de 10 a $120 \mu \mathrm{m}$ de diámetro, localizados en el espacio extracelular. Se trata de conglomerados anulares de cuerpos y prolongaciones neuronales degeneradas, en torno a un depósito central de un péptido de longitud variable (de 40-42 aminoácidos)

\footnotetext{
${ }^{47}$ (a) Neve, R. L.; McPhie, D. L.; Chen, Y. Alzheimer's disease: a dysfunction of the amyloid precursor protein. Brain Res. 2000, 886, 54-66. (b) Egensperger, R.; Weggen, S.; Ida, N.; Multhayp, G. Reverse relationship between $\beta$-amyloid precursor protein and $\beta$-amyloid peptide plaques in Down's syndrome versus sporadic/familial Alzheimer's disease. Acta Neuropathol. 1999, 2, 113-118.

48 (a) Crowther, R. A.; Goedert, M. Abnormal tau-containing filaments in neurodegenerative disease. $J$. Struct. Biol. 2000, 130, 271-279. (b) Iqbal, K.; Alonso, A. D.; Gondal, J. A.; Gong, C. X.; Haque, N.; Katoon, S.; Segupta, A.; Wang, J. Z.; Grundke-Iqbal, I. Mechanism of neurofibrillary degeneration and pharmacologic therapeutic approach. J. Neural Trasm. Suppl. 2000, 59, 213-222.

${ }^{49}$ Whitehouse, P.; Priece, D.; Struble, R.; Clarke, A.; Coyle, J.; Delong, M. Alzheimer's disease in senile dementia: loss of neurons in the basal forebrain. Science. 1982, 215, 1237-1239.

${ }^{50}$ Fundación Española para la Ciencia y la Tecnología (FECYT) (www.tecnociencia.es/especiales/alzheimer/causas.htm).
} 
llamado péptido amiloide $(\beta \mathrm{A})^{51}$. Este péptido es un subproducto del metabolismo normal de una glicoproteína de transmembrana denominada proteína precursora del amiloide, $\mathrm{PPA}^{52}$ (amyloid precursor protein). Esta proteína presenta un gran segmento $N$-terminal en el espacio extracelular, un dominio de transmembrana y un pequeño segmento $C$ terminal en el espacio intracelular ${ }^{53,54}$ y es degradada por tres proteasas: $\alpha-, \beta-$ y $\gamma$ secretasa $^{55}$ (Figura 17).

En la llamada ruta no-amiloidogénica, que corresponde con un estado no-patológico, la PPA es inicialmente degradada por la $\alpha$-secretasa, generando el fragmento soluble sPPA $\alpha$ y un residuo de 83 aminoácidos (C83). Posteriormente, C83 es degradado por la $\gamma$-secretasa originando un péptido pequeño de $3 \mathrm{kDa}(\mathrm{p} 3$ ), que contiene la región $\mathrm{C}$ terminal del $\beta \mathrm{A}^{56}$. El fragmento sPPA $\alpha$ presenta conformación de hélice $\alpha$, y tiene efectos neuroprotectores y neurotróficos ${ }^{57}$.

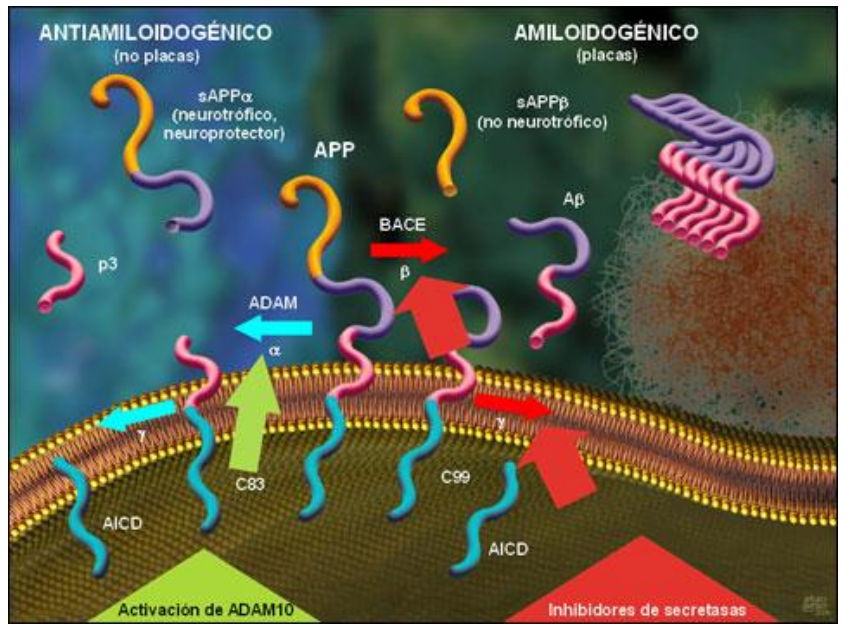

Figura 17. Metabolismo de la PPA por las enzimas $\alpha$ -

, $\beta$ - y $\gamma$-secretasas

${ }^{51}$ Gorman, P. M.; Chakrabartty, A. Alzheimer beta-amyloid peptides: structures of amyloid fibrils and alternate aggregation products. Biopolymers. 2001, 60, 381-94.

${ }^{52}$ Wolfe, M. S.; Guénette, S. Y. APP at a glance. J. Cell. Sci. 2007, 120, 3157-61.

${ }^{53}$ Numan, J.; Small, D. H. Regulation of APP cleavage by alpha-, beta- and gamma-secretases. FEBS Lett. 2000, 483, 6-10.

${ }^{54}$ Mills, J.; Reiner, P. B. Regulation of amyloid precursor protein cleavage. J. Neurochem. 1999, 72, 443460.

${ }^{55}$ Gralle, M.; Ferreira, S. T. Structure and functions of the human amyloid precursor protein: the whole is more than the sum of its parts. Prog. Neurobiol. 2007, 82, 11-32.

${ }^{56}$ Russo, C.; Venezia, V.; Repetto, E.; Nizzari, M.; Violani, E.; Carlo, P.; Schettini, G. The amyloid precursor protein and its network of interacting proteins: physiological and pathological implications. Brain Res. Rev. 2005, 48, 257-264.

${ }^{57}$ Hooper, N. M. Roles of proteolysis and lipid rafts in the processing of the amyloid precursor protein and prion protein. Biochem. Soc. Trans. 2005, 33, 335-338. 
Sin embargo, en condiciones patológicas, la llamada ruta amiloidogénica aumenta su importancia en detrimento de la hidrólisis vía $\alpha$-secretasa. La PPA es degradada en el extremo $N$-terminal por la $\beta$-secretasa (también denominada BACE-1, Asp2 o memapsina 2$)^{58}$ generando el fragmento soluble de sPPA $\beta$ y un fragmento de 99 aminoácidos (C99). Posteriormente, C99 es sustrato de la $\gamma$-secretasa, enzima capaz de degradarlo en diferentes puntos originando fragmentos heterogéneos de péptidos $\beta \mathrm{A}$ de longitud variable (entre 39-43 aminoácidos) y dominios intracelulares de la proteína precursora del amiloide ${ }^{59}$. Las presenilinas PS1 y PS2 se encuentran fundamentalmente en sitio catalítico de la $\gamma$-secretasa, y son las responsables de la producción de los $\beta$ A de longitud variable ${ }^{60}$. Por último, los fragmentos de $\beta \mathrm{A}$ de 42 y 43 aminoácidos tienden a agregarse originando las placas amiloides ${ }^{61}$. Cuando el $\beta$ A se deposita en las arterias de mediano y pequeño calibre se origina la angiopatía amiloide.

Estos hallazgos han dado lugar a la denominada "Hipótesis Amiloide de la EA", que propugna que las placas amiloides provocan efectos neurotóxicos que desencadenan cascadas patológicas neurodegenerativas ${ }^{62}$. Posteriormente, se descubrió que la toxicidad del $\beta \mathrm{A}$ se encuentra principalmente en formas intermedias prefibrilares, oligómeros solubles y protofibrillas, de forma que los grandes agregados de proteínas podrían ser simplemente inactivos o incluso un intento por parte de la neurona de inactivar las especies neurotóxicas y deshacerse de ellas ${ }^{63}$ (Figura 18).

${ }^{58}$ Citron, M, Beta secretase inhibition for the treatment of Alzheimer's disease - promise and challenge. Trends Pharmacol. Sci. 2004, 25, 92-97.

${ }^{59}$ Passer, B.; Pellegrini, L.; Russo, C.; Siegel, M. R.; Lenardo, M. J.; Schettini, G.; Bachmann, M.; Tabaton, M.; D’Adamio, L. Generation of an apoptotic intracellular peptide by gamma-secretase cleavage of Alzheimer's amyloid beta protein precursor. J. Alzheimer's Dis. 2000, 2, 289-301.

${ }^{60}$ Hardy, J.; Selkoe, D. J. The amyloid hypothesis of Alzheimer's disease: progress and problem on the road to therapeutics. Science 2002, 297, 353-356.

${ }^{61}$ Small, D. H.; McLean, C. A. Alzheimer's disease and the amyloid beta protein: What is the role of amyloid? J. Neurochem. 1999, 73, 443-449.

62 Hardy, J.; Allsop, D. Amyloid deposition as the central event in the aetiology of Alzheimer's disease.Trends. Pharmacol. Sci. 1991, 12, 383-8.

${ }^{63}$ Lannfelt, L.;Möller, C.; Basun, H.; Osswald, G.;Sehlin, D.; Satlin, A. Logovinsky, V.; Gellerfors, P. Perspectives on future Alzheimer therapies:amyloid- $\beta$ protofibrils - a new target for immunotherapy with BAN2401 in Alzheimer's disease. Alzheimers Res. Ther. 2014, 6(2):16. 


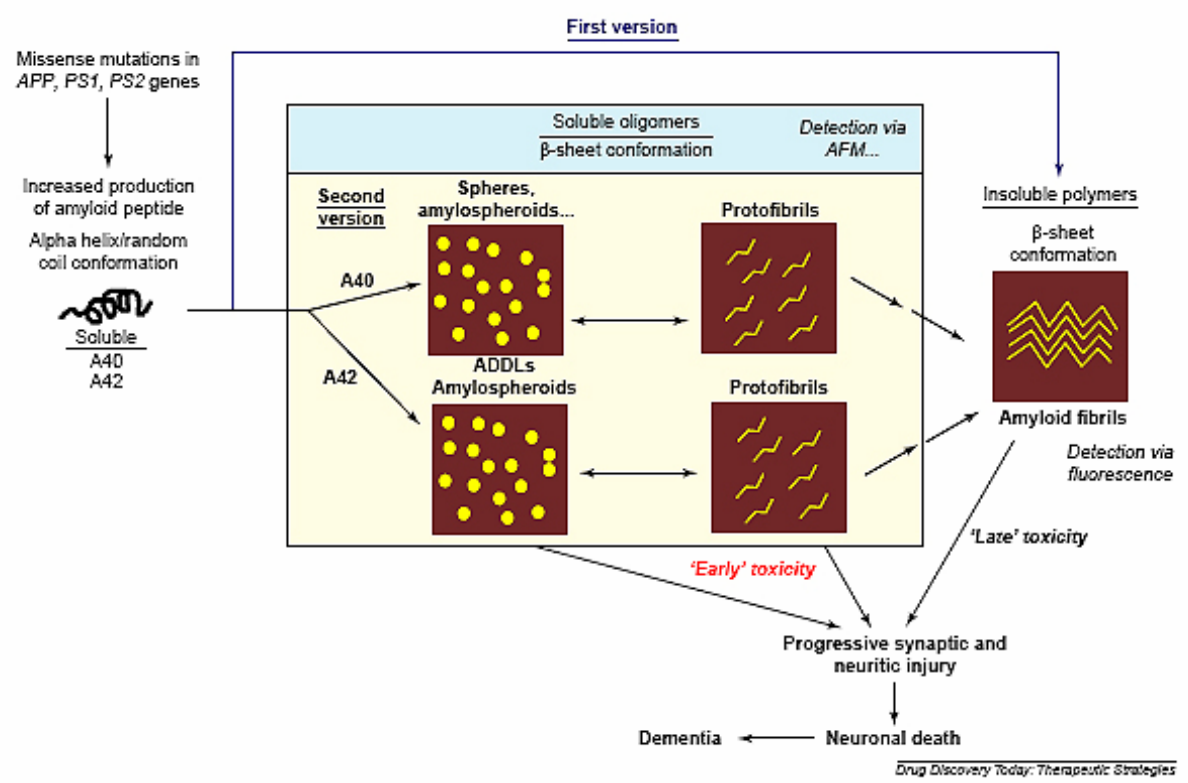

Figura 18. Actualización de la hipótesis de la cascada amiloide

En resumen, el $\beta \mathrm{A}$ parece ser un producto natural presente en cerebro y líquido cefalorraquídeo en individuos sanos y su simple presencia no causa neurodegeneración, sino que la autoasociación o agregación de las moléculas de $\beta$ A es esencial para su toxicidad ${ }^{64}$. Los oligómeros de $\beta \mathrm{A}$ parecen estar implicados en diferentes procesos tóxicos, tales como la alteración de la homeostasis del $\mathrm{Ca}^{2+}$, apoptosis, intercalación directa en la membrana celular, generación de radicales libres, inflamación de la microglía o la inducción de la formación de ovillos neurofibrilares ${ }^{65,66}$.

Otra lesión característica de la EA son los ovillos neurofibrilares, que están compuestos por restos de neuronas muertas y agregados de proteína tau en un estado anómalo de hiperfosforilación. En condiciones normales, tau es una proteína importante para mantener la integridad y la estabilidad del citoesqueleto neuronal. Es una proteína asociada a los microtúbulos, polímeros que constituyen la arquitectura celular y que son esenciales en numerosos procesos de transporte y división mitótica. Sin embargo, en situaciones patológicas tau aparece anormalmente hiperfosforilada y deja de cumplir su

${ }^{64}$ Ma, Q. L.; Lim, G. P.; Harris-White, M. E.; Yang, F.; Ambegaokar, S. S.; Ubeda, O. J.; Glabe, C. G.; Teter, B.; Frautschy, S. A.; Cole, G. M. Antibodies against beta-amyloid reduce Abeta oligomers, glycogen synthase kinase-3beta activation and tau phosphorylation in vivo and in vitro. J. Neurosci. Res. 2006, 83, 374-84.

${ }^{65}$ Walsh, D. M.; Selkoe, D. J. Abeta oligomers - a decade of discovery. J. Neurochem. 2007, 101, 117284.

${ }^{66}$ Small, D. H.; Mok, S. S.; Bornstein, J. C. Alzheimer's disease and Abeta toxicity: from top to bottom. Nat. Rev. Neurosci. 2001, 2, 595-8. 
papel en el mantenimiento de la estabilidad del citoesqueleto, transformándose en una proteína con gran capacidad de asociarse consigo misma para formar polímeros intracelulares ${ }^{67}$ (Figura 19). Estos conglomerados proteicos se encuentran principalmente en los cuerpos neuronales y dendritas apicales, provocando serios trastornos en la actividad celular normal e impidiendo la transmisión nerviosa. Un porcentaje elevado de neuronas con ovillos neurofibrilares pierden su funcionalidad y mueren, pasando a formar parte de los agregados insolubles.

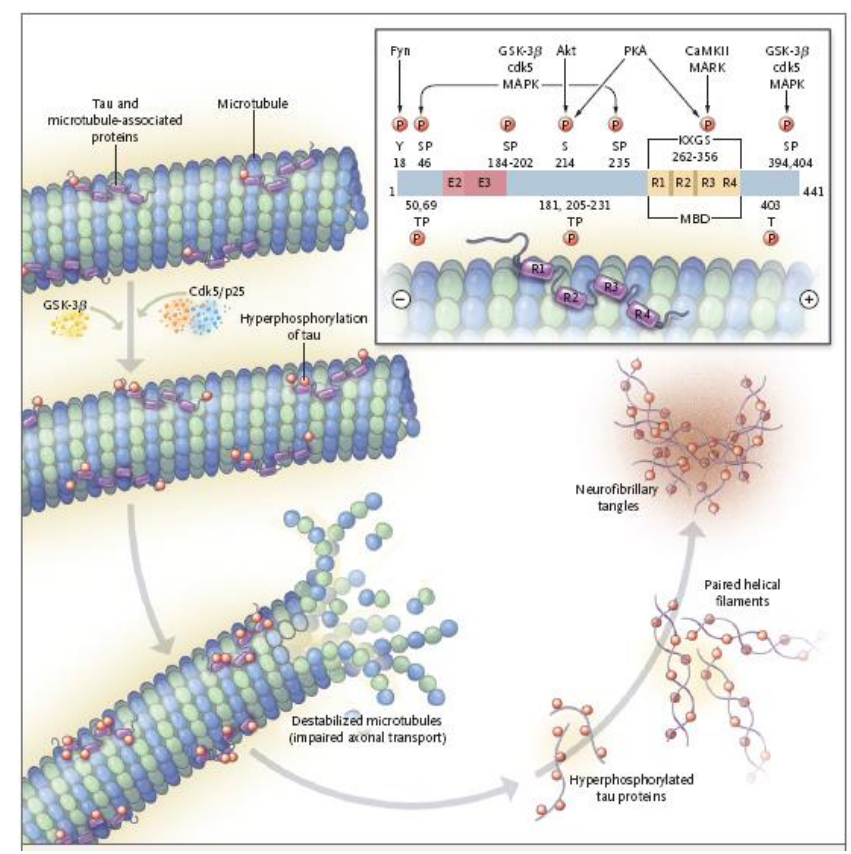

Figura 19. Estructura y función de tau ${ }^{46}$.

El buen funcionamiento de tau viene regulado por un equilibrio de fosforilación desfosforilación, regulado por quinasas y fosfatasas, respectivamente ${ }^{68}$. Sin embargo, en situaciones patológicas dicho equilibrio se rompe y tau es hiperfosforilada de manera aberrante por una serie de quinasas, especialmente la glicógeno sintasa kinasa-3 beta (GSK-3 $\beta$ ) y pierde su función estabilizadora de los microtúbulos. La neurona responde a la pérdida de niveles de tau aumentando la producción de otras proteínas asociadas a microtúbulos, como MAP1A/MPA1B y MAP2, pero el problema es que la nueva tau disfuncional hiperfosforilada es tóxica. Así, la neurona afectada intenta defenderse de esta

\footnotetext{
${ }^{67}$ Mandelkow, E.-M.; Mandelkow, E. Tau in Alzheimer's disease. Trends Cell. Biol. 1998, 8, 425-427.

${ }^{68} \mathrm{Mi}, \mathrm{K}$; Johnson, G. V. The role of tau phosphorylation in the pathogenesis of Alzheimer's disease. Curr. Alzheimer Res. 2006, 3, 449-63.
} 
tau tóxica sintetizando nuevas cantidades de tau normal y empaquetando la tau fosforilada en polímeros inertes, los ovillos neurofibrilares. Pero inevitablemente la neurona sufre una lenta y progresiva degeneración.

Las placas amiloides y los ovillos neurofibrilares parecen estar relacionados de una manera aún no bien definida pese a que es un tema de estudio desde hace bastante tiempo $^{69}$. Es un campo de máxima actualidad, fomentado por la cada vez más amplia disponibilidad de ratones transgénicos y que ha dado lugar a diferentes hipótesis basadas en algunos resultados experimentales, como la formación de un complejo soluble entre $\beta$ A y $\operatorname{tau}^{70}$ o la activación de GSK-3 $\beta$ por óxido nítrico ${ }^{71}$. Sin duda es un aspecto que, cuando esté descifrado, supondrá un gran avance en el conocimiento de la EA y sus posibles tratamientos.

\subsubsection{Alteraciones en los sistemas de neurotransmisión}

Además de la formación de agregados proteicos, en la EA existen alteraciones en la neurotransmisión, en especial en el sistema colinérgico. Se ha observado una disminución de los niveles de neurotransmisores que constituyen la comunicación sináptica, en especial de acetilcolina (ACh) ${ }^{72}$. Teniendo en cuenta que la ACh es hidrolizada por la enzima acetilcolinesterasa (AChE), los inhibidores de esta enzima mejorarían la neurotransmisión y con ello la capacidad cognitiva de los pacientes. También se han hallado alteraciones en otros sistemas de neurotransmisores, como los regulados por glutamato $^{73}$ dopamina $^{74}$ y serotonina ${ }^{75}$.

${ }^{69}$ Busciglio, J.; Lorenzo, A.; Yeh, J.; Yankner, B. A. beta-amyloid fibrils induce tau phosphorylation and loss of microtubule binding. Neuron, 1995, 14, 879-88.

${ }^{70}$ Guo, J. P.; Arai, T.; Miklossy, J.; McGeer, P. L. Abeta and tau form soluble complexes that may promote self aggregation of both into the insoluble forms observed in Alzheimer's disease. Proc. Natl. Acad. Sci. 2006, 103, 1953-8.

${ }^{71}$ Zhang, Y. J.; Xu, Y. F.; Liu, Y. H.; Yin, J.; Wang, J. Z. Nitric oxide induces tau hyperphosphorylation via glycogen synthase kinase-3beta activation. FEBS Lett. 2005, 579, 6230-6.

${ }^{72}$ Bowen, D. M.; Smith, C. B.; White, P.; Davison, A. N. Neurotransmitter-related enzymes and indices of hypoxia in senile dementia and other abiotropies. Brain 1976, 99, 459-496.

${ }^{73}$ Clarke, N. A.; Francis, P. T. Cholinergic and glutamatergic drugs in Alzheimer's disease. Expert Rev. Neurother. 2005, 5, 671-682.

${ }^{74}$ Palmer, A. M.; Wilcock, G. K.; Erisi, M. M.; Francis, P. T.; Bowen, D. M. Monoaminergic innervation of the frontal and temporal lobes in Alzheimer's disease. Brain Res. 1987, 401, 231-238.

${ }^{75}$ Palmer, A. M.; Francis, P. T.; Benton, J. S.; Sims, N. R.; Mann, D. M.; Neary, D.; Snowden, J. S.; Bowen, P. R. Presynaptic serotonergic dysfunction in patients with Alzheimer's disease. J. Neurochem. 1987, 48, 8-15. 


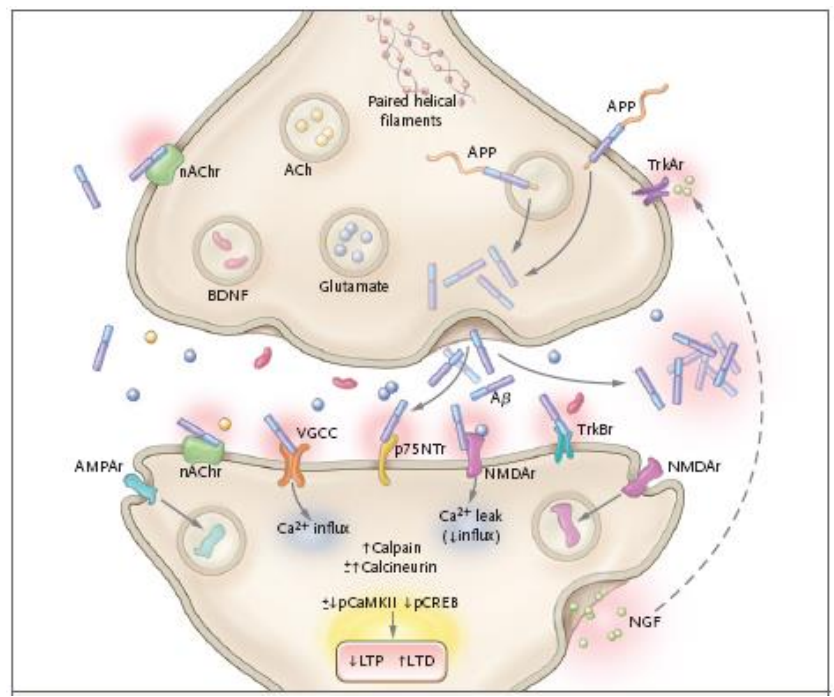

Figura 20. Disfunción sináptica en la enfermedad de

\section{Alzheimer}

La ACh se produce en el citosol por acción de la enzima colinacetilasa, también conocida como colín-acetil-transferasa (CAT), siendo posteriormente almacenada en vesículas sinápticas desde las que, mediante un proceso de exocitosis dependiente de calcio, se libera al espacio sináptico. Allí ejerce su acción como neurotransmisor, uniéndose a los receptores muscarínicos y nicotínicos a ambos niveles, pre- y postsinápticos. Una vez ejercida su acción sobre los diferentes receptores colinérgicos, la ACh es hidrolizada a colina mediante la acción de la acetilcolinesterasa (AChE). Una segunda enzima también implicada en la neurotransmisión colinérgica es la butirilcolinesterasa $(\mathrm{BuChE})^{76}$. En cerebros sanos la AChE se encarga de hidrolizar del orden del $80 \%$ de la $\mathrm{ACh}$, mientras que la BuChE juega un papel secundario. Sin embargo, en cerebros afectados por la EA la actividad de la AChE se ve disminuida mientras se incrementa la de BuChE en un intento de las neuronas por mantener los niveles de $\mathrm{ACh}^{77}$.

Además de su papel en la transmisión del impulso nervioso, la AChE desempeña otras funciones no colinérgicas, incluido un papel importante en el procesamiento del $\beta \mathrm{A}$. Varios estudios han indicado que la AChE aumenta la formación de fibrillas $\beta \mathrm{A}$ in vitro ${ }^{78}$

\footnotetext{
${ }^{76}$ Darvesh, S.; Hopkins, D. A.; Geula, C. Neurobiology of butyrylcholinesterase. Nat. Rev. Neurosci. 2003, 4, 131-138.

77 Scarpini, E.; Scheltens, P.; Feldman, H. Treatment of Alzheimer's disease: current status and new perspectives. Lancet Neurol. 2003, 2, 539-47.

${ }^{78}$ Inestrosa, N. C.; Dinamarca, M. C.; Alvarez, A. Amyloid-cholinesterase interactions. Implications for Alzheimer's disease. FEBS J. 2008, 275, 625-632.
} 
y de placas amiloides en la corteza cerebral de modelos de ratones transgénicos de la $\mathrm{EA}^{79}$. Estos efectos parecen estar mediados por interacciones entre el $\beta \mathrm{A}$ y el sitio aniónico periférico (PAS) de la enzima, apoyado por el hecho de que el propidio, un inhibidor de AChE no-competitivo que se une puramente a PAS, disminuye significativamente la agregación del $\beta \mathrm{A}$ inducida por $\mathrm{AChE}^{80}$. Sin embargo, el edrofonio, un inhibidor competitivo puro que se une al centro activo (CAS), no muestra ningún efecto sobre la fibrilogénesis de $\beta \mathrm{A}$ inducida por $\mathrm{AChE}^{81}$. Por lo tanto, parece existir una estrecha relación entre la actividad catalítica de la AChE y la precipitación del péptido $\beta A$.

\subsubsection{Estrés oxidativo}

Es conocido que el cerebro es especialmente vulnerable al daño oxidativo, debido al elevado consumo de oxígeno (utiliza el $20 \%$ del oxígeno basal a pesar de constituir solamente el 2-3\% de la masa corporal total), al alto contenido en ácidos grasos poliinsaturados fácilmente oxidables y a la presencia de iones metálicos activos en procesos redox, capaces de generar radicales libres. Además, la relativa escasez de sistemas de defensa antioxidante hace que el SNC sea particularmente propenso a patologías oxidativas $^{82}$. Es un hecho contrastado que el estrés oxidativo aumenta con la edad y existen claras evidencias de la participación del desequilibrio oxidativo en diferentes patologías. Por ejemplo, un estudio de la corteza frontal postmortem de pacientes con EA demostró un aumento significativo dependiente de la enfermedad en marcadores oxidativos que se correlacionaba con bajas puntuaciones en el "Mini-Mental Status Examination" 83 . Además, en un modelo de ratón de EA se descubrió que el daño oxidativo es un evento que precede la aparición de otras características patológicas de la

\footnotetext{
${ }^{79}$ Rees, T.; Hammond, P. I.; Soreq, H.; Younkin, S.; Brimijoin, S. Acetylcholinesterase promotes betaamyloid plaques in cerebral cortex. Neurobiol. Aging 2003, 24, 777-787.

${ }^{80}$ De Ferrari, G. V.; Canales, M. A.; Shin, I.; Weiner, L. M.; Silman, I.; Inestrosa, N. C. A structural motif of acetylcholinesterase that promotes amyloid beta-peptide fibril formation. Biochemistry 2001, 40, 10447-10457.

${ }^{81}$ Bartolini, M.; Bertucci, C.; Cavrini, V.; Andrisano, V. beta-Amyloid aggregation induced by human acetylcholinesterase: inhibition studies. Biochem. Pharmacol. 2003, 65, 407-416.

${ }^{82}$ Casetta, I.; Govoni, V.; Granieri, E. "Oxidative stress, antioxidants and neurodegenerative diseases" Curr. Pharm. Design 2005, 11, 2033-2052.

${ }^{83}$ Ansari, M. A.; Scheff, S. W. Oxidative stress in the progression of Alzheimer disease in the frontal cortex. J. Neuropathol. Exp. Neurol. 2010, 69, 155-167.
} 
$\mathrm{EA}^{84}$. Estos hallazgos señalan la participación temprana del estrés oxidativo mitocondrial en la patogénesis y la progresión de esta enfermedad ${ }^{85}$. Por lo tanto, los fármacos que protegen a las neuronas del estrés oxidativo mitocondrial podrían ser útiles para la prevención o el tratamiento de $\mathrm{EA}^{86}$.

La fosforilación oxidativa mitocondrial es la fuente principal de radicales libres endógenos y de entidades químicas relacionadas, entre las que se encuentran el peróxido de hidrógeno $\left(\mathrm{H}_{2} \mathrm{O}_{2}\right)$, el radical hidroxilo $(\cdot \mathrm{OH})$ y el radical superóxido $\left(\mathrm{O}_{2}{ }^{-}\right)$. El peróxido de hidrógeno, en presencia de metales de transición reducidos se puede convertir en el radical tóxico $\cdot \mathrm{OH}$ a través de las reacciones de Fenton y/o de Haber Weiss, procesos que se localizan en las placas amiloides y en los ovillos neurofibrilares de la EA ${ }^{87}$. Además, en presencia de óxido nítrico (NO), generado durante la conversión de arginina en citrulina por la sintasa del óxido nítrico (NOS), el radical superóxido puede generar el potente radical oxidante peroxinitrilo (ONOO·). Normalmente, existe un equilibrio entre la generación de ROS y su neutralización. Pero si la cantidad de radicales libres sobrepasa la capacidad de las neuronas para neutralizar estas especies tóxicas, se produce el estrés oxidativo, seguido de la disfunción mitocondrial y del daño neuronal.

Existe una estrecha relación entre el $\beta$ A, los procesos oxidativos y la disfunción de la homeostasis de $\mathrm{Ca}^{+}$, que confirma el papel central de $\beta$ A en la patología de EA y la estrecha relación entre los distintos procesos patológicos de la EA (Figura 21) ${ }^{88}$. El péptido $\beta$ A muestra una doble personalidad: en principio posee una serie de propiedades tróficas, derivadas de que pertenece al grupo de proteínas capaces de complejar metales redox, en especial cobre, controlando su concentración y evitando que dichos metales participen en procesos redox patológicos ${ }^{89}$. Por otra parte, el estrés oxidativo promueve

\footnotetext{
${ }^{84} \mathrm{Gu}$, F.; Zhu, M.; Shi, J.; Hu, Y.; Zhao, Z. Enhanced oxidative stress is an early event during development of Alzheimer-like pathologies in presenilin conditional knock-out mice. Neurosci. Lett. 2008, 440, 4448.

${ }^{85}$ Caldeira, G. L.; Ferreira, I. L.; Rego, A. C. Impaired transcription in Alzheimer's disease: key role in mitochondrial dysfunction and oxidative stress. J. Alzheimers Dis. 2013, 34, 115-131.

${ }^{86}$ Huang, Q.; Aluise, C. D.; Joshi, G.; Sultana, R.; St Clair, D. K.; Markesbery, W. R.; Butterfield, D. A. Potential in vivo amelioration by $\mathrm{N}$-acetyl-L-cysteine of oxidative stress in brain in human double mutant APP/PS-1 knock-in mice: toward therapeutic modulation of mild cognitive impairment. $J$. Neurosci. Res. 2010, 88, 2618-2629.

${ }^{87}$ Sayre, L. M.; Perry, G.; Harris, P. L.; Liu, Y.; Schubert, K. A.; Smith, M. A. In situ oxidative catalysis by neurofibrillary tangles and senile plaques in Alzheimer's disease: a central role for bound transition metals. J. Neurochem. 2000, 74, 270-279.

${ }^{88}$ Mattson, M. Pathways towards and away from Alzheimer's disease. Nature. 2004. 420, 631-639.

89 Kasper P. Kepp; Alzheimer's disease: How metal ions define $\beta$-amyloid function. Coordination Chemistry Reviews. 2017, 351, 127-159.
} 
la formación de más $\beta \mathrm{A}$ del fisiológicamente aceptable, de forma que cuando los mecanismos antioxidantes no son capaces de controlar las especies radicálicas aparece un aumento de $\beta \mathrm{A}$, posiblemente como un intento de eliminar el exceso de $\operatorname{ROS}^{90}$.

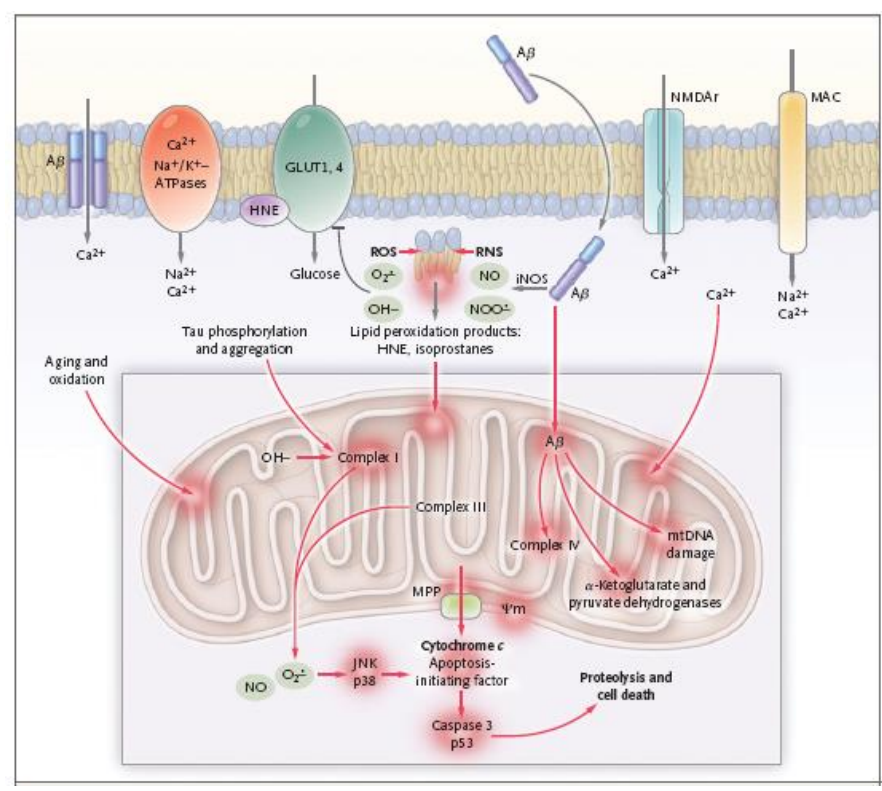

Figura 21. Estrés oxidativo y fallo mitocondrial

\subsubsection{Estrategias terapéuticas contra la enfermedad de Alzheimer}

\subsubsection{Fármacos comercializados y ejemplos de moléculas en fases clínicas}

En la actualidad, las opciones terapéuticas para el tratamiento de la EA están limitadas a tres inhibidores de la AChE: donepezilo, rivastigmina y galantamina ${ }^{91}$, ya que la tacrina se retiró del mercado dada su hepatoxicidad; y a un antagonista del receptor de $N$-metil-D-aspartato, la memantina ${ }^{92}$ (Figura 22). Estos fármacos tienen efectos beneficiosos sobre las funciones cognitivas de los pacientes durante los primeros 6-12 meses de tratamiento y en algunos casos, retrasan el decline degenerativo. Sin embargo, ninguno de ellos es capaz de bloquear o revertir la neurodegeneración.

${ }^{90}$ Atwood, C. S.; Obrenovich, M. E.; Liu, T.; Chan, H.; Perry, G.; Smith, M. A.; Martins, R. N. Amyloidbeta: a chameleon walking in two worlds: a review of the trophic and toxic properties of amyloid-beta. Brain Res Rev. 2003, 43, 1-16.

${ }^{91}$ Bond, M.; Rogers, G.; Peters, J.; Anderson, R.; Hoyle, M.; Miners, A.; Moxham, T.; Davis, S.; Thokala, P.; Wailoo, A.; Jeffreys, M.; Hyde, C. The effectiveness and cost-effectiveness of donepezil, galantamine, rivastigmine and memantine for the treatment of Alzheimer's disease (review of Technology Appraisal No. 111): a systematic review and economic model. Health Technol. Assess. 2012, 16, 1-470.

92 Wilkinson, D.; Wirth, Y.; Goebel, C. Memantine in Patients with Moderate to Severe Alzheimer's Disease: Meta-Analyses Using Realistic Definitions of Response. Dement. Geriatr. Cogn. Disord. 2013, 37, 71-85 


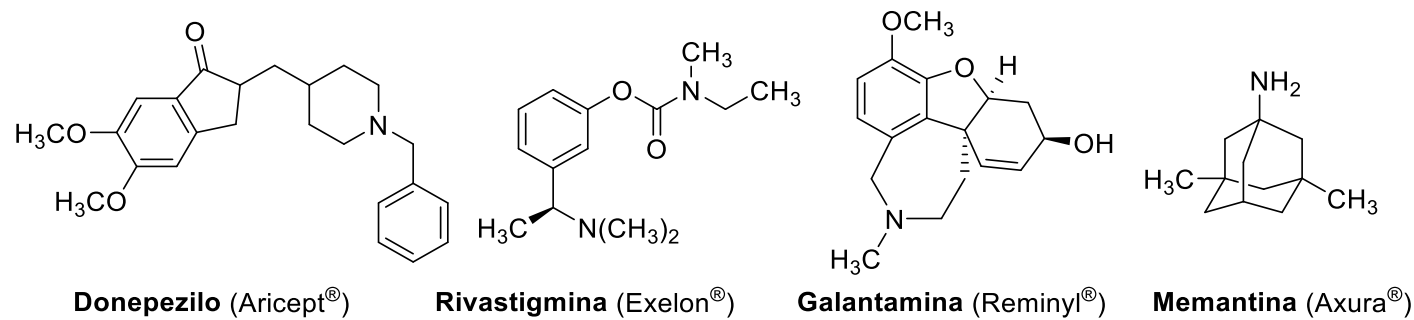

Figura 22. Fármacos actualmente comercializados para el tratamiento paliativo de la EA

A pesar del esfuerzo investigador que se viene desarrollando en las últimas décadas, desde 2003 no se ha comercializado ningún nuevo medicamento contra la EA. Sin embargo, hay numerosas moléculas en ensayos clínicos ${ }^{93,94}$ : inhibidores de AChE, BACE-1 y $\gamma$-secretasa, agonistas y antagonistas de receptores de neurotransmisores, anticuerpos para eliminar agregados proteicos de $\beta \mathrm{A}$ y tau, antiinflamatorios, etc. Algunos ejemplos de fármacos que se encuentran en avanzadas fases clínicas para el tratamiento de la $\mathrm{EA}^{95}$ son: dextrometorfano (antagonista NMDA y agonista de receptores sigma- $1^{96}$ ), prazosin y carvedilol (antagonistas de receptores adrenérgicos ${ }^{97}$ ), simvastatina (inhibidor de $\mathrm{HMG}-\mathrm{CoA}$ reductasa ${ }^{98}$ ), intepirdina (antagonista de los receptores de serotonina de tipo $5-\mathrm{HT}_{6}{ }^{99}$ ), elenbecestat, lanabecestat y verubecestat (inhibidores de BACE-1 ${ }^{100}$ ), y TRx0237 o azul de metileno (inhibidor de la agregación de $\operatorname{tau}^{101}$ ) (Figura 23).

\footnotetext{
${ }^{93}$ Pogacic Kramp, V. List of drugs in development for neurodegenerative diseases: update October 2011. Neurodegener. Dis. 2012, 9, 210-283.

${ }^{94}$ Hung, S. Y.; Fu, W. M. Drug candidates in clinical trials for Alzheimer's disease. J. Biomed. Sci. 2017, $24,47$.

${ }^{95}$ Alzorum https://www.alzforum.org/ (consultado el 1 junio de 2018).

${ }^{96}$ Porsteinsson, A. P.; Antonsdottir, I. M. An update on the advancements in the treatment of agitation in Alzheimer's disease. Expert Opin. Pharmacother. 2017, 18, 611-620.

${ }^{97}$ Dunn, K. M.; Nelson, M. T. Neurovascular signaling in the brain and the pathological consequences of hypertension. Am. J. Physiol. Heart Circ. Physiol. 2014, 306, H1-14.

${ }^{98}$ Li, G.; Mayer, C. L.; Morelli, D.; Millard, S. P.; Raskind, W. H.; Petrie, E. C.; Cherrier, M.; Fagan, A. M.; Raskind, M. A.; Peskind, E. R. Effect of simvastatin on CSF Alzheimer disease biomarkers in cognitively normal adults. Neurology 2017, 89, 1251-1255.

${ }^{99}$ Khoury, R.; Grysman, N.; Gold, J.; Patel, K.; Grossberg, G. T. The Role of 5 HT6-Receptor Antagonists in Alzheimer's Disease: An Update. Expert Opin. Investig. Drugs 2018, 10.1080/13543784.2018.1483334.

${ }^{100}$ Kumar, D.; Ganeshpurkar, A.; Kumar, D.; Modi, G.; Gupta, S. K.; Singh, S. K. Secretase inhibitors for the treatment of Alzheimer's disease: Long road ahead. Eur. J. Med. Chem. 2018, 148, 436-452.

${ }^{101}$ Crowe, A.; James, M. J.; Lee, V. M.; Smith, A. B., 3rd; Trojanowski, J. Q.; Ballatore, C.; Brunden, K. R. Aminothienopyridazines and methylene blue affect Tau fibrillization via cysteine oxidation. J. Biol. Chem. 2013, 288, 11024-11037.
} 


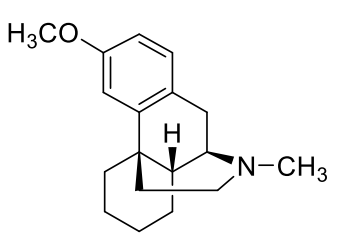

Dextrometorfano

(antagonista NMDA y agonista sigma-1, fase IV)<smiles>O=S(=O)(c1ccccc1)c1cnc2c(N3CCNCC3)cccc2c1</smiles>

Intepirdina

(antagonista $5-\mathrm{HT}_{6}$, fase III)<smiles>COc1cc2nc(N3CCN(C(=O)c4ccco4)CC3)nc(N)c2cc1OC</smiles>

Prazosin

(antagonista selectivo del receptor $\alpha-1$ adrenérgico, fase IV)<smiles></smiles>

Azul de metileno (inhibidor de la agregación de tau, fase III)<smiles>COc1ccccc1OCCNCC(O)COc1cccc2[nH]c3ccccc3c12</smiles>

Carvedilol (antagonista receptores $\alpha, \beta$ adrenérgicos, fase IV)<smiles>O=C1C[C@H](O)CCO1</smiles><smiles>CCC(C)(C)C(=O)O[C@H]1C[C@@H](C)C=C2C=C[C@H](C)[C@H](CCC(C)C)[C@H]21</smiles>

Simvastatina (inhibidor de HMG-CoA reductasa, fase IV)

Figura 23. Ejemplos de fármacos en avanzadas fases clínicas para el tratamiento de la EA

\subsubsection{Fármacos multi-diana (MTL, multi-targeted ligands)}

La complejidad de la patología de la EA ha fomentado el diseño de moléculas capaces de interactuar con dos o más dianas farmacológicas complementarias, esperando que estos ligandos multi-diana (MTL, por sus siglas en inglés) puedan representar ventajas importantes en el tratamiento de la enfermedad ${ }^{102}$. En los últimos años, se han desarrollado muchos MTL interesantes, como memoquin, ladostigil y huprina $\mathrm{X}$, entre otros (Figura 10). Memoquin es un inhibidor de AChE y $\beta$-secretasa-1 (BACE-1) con propiedades antiagregantes y antioxidantes adicionales, que recientemente ha demostrado su eficacia in vivo usando diferentes modelos de ratones de amnesia inducida ${ }^{103}$. Ladostigil es un inhibidor de colinesterasas (ChEs) y un inhibidor selectivo de monoaminoxidasas cerebrales (MAO-A y -B), con poco o ningún efecto inhibitorio de la

102 (a) Morphy, R.; Rankovic, Z. Designed multiple ligands. An emerging drug discovery paradigm. J. Med. Chem. 2005, 48, 6523-6543. (b) Cavalli, A.; Bolognesi, M. L.; Minarini, A.; Rosini, M.; Tumiatti, V.; Recanatini, M.; Melchiorre, C. Multi-targetdirected ligands to combat neurodegenerative diseases. $J$. Med. Chem. 2008, 51, 347-372. (c) León, R.; García, A. G.; Marco-Contelles, J. Recent advances in the multitarget-directed ligands approach for the treatment of Alzheimer's disease. Med. Res. Rev. 2013, 33, 139-189.

103 (a) Cavalli, A.; Bolognesi, M. L.; Capsoni, S.; Andrisano, V.; Bartolini, M.; Margotti, E.; Cattaneo, A.; Recanatini, M.; Melchiorre, C. A small molecule targeting the multifactorial nature of Alzheimer's disease. Angew. Chem. Int. Ed. Engl. 2007, 46, 3689-3692. (b) Capurro, V.; Busquet, P.; Lopes, J. P.; Bertorelli, R.; Tarozzo, G.; Bolognesi, M. L.; Piomelli, D.; Reggiani, A.; Cavalli, A. Pharmacological characterization of memoquin, a multi-target compound for the treatment of Alzheimer's disease. PLoS One 2013, 8, e56870. 
MAO periférica en experimentos in vivo ${ }^{104}$. Y la huprina X es un inhibidor sub-nanomolar de AChE con efectos adicionales, tales como inhibición de BACE-1, activación de $\alpha$ secretasas y estimulación de la señalización de la ruta de la proteína quinasa activada por mitógeno, que es capaz de mejorar el aprendizaje y la memoria en un modelo triple de ratones transgénicos de $\mathrm{AD}^{105}$.

En nuestro grupo también se han desarrollado varias familias de MTL derivadas de donepezilo ${ }^{106}$ o de tacrina ${ }^{107-110}$ (Figura 10), que combinan propiedades neuroprotectoras, colinérgicas y antioxidantes. Los derivados del ácido L-glutámico con fragmentos de donepezilo presentaron interesantes propiedades en modelos in vitro de EA y de isquemia cerebral $^{111,112}$. Y entre los derivados de tacrina, destacan los híbridos tacrina - clioquinol y tacrina - melatonina que han mostrado su eficacia in vivo en ratones transgénicos APP-

${ }^{104}$ Weinreb, O.; Amit, T.; Bar-Am, O.; Youdim, M. B. Ladostigil: a novel multimodal neuroprotective drug with cholinesterase and brain-selective monoamine oxidase inhibitory activities for Alzheimer's disease treatment. Curr. Drug Targets 2012, 13, 483-494

105 (a) Viayna, E.; Gómez, T.; Galdeano, C.; Ramírez, L.; Ratia, M.; Badía, A.; Clos, M. V.; Verdaguer, E.; Junyent, F.; Camins, A.; Pallas, M.; Bartolini, M.; Mancini, F.; Andrisano, V.; Arce, M. P.; RodríguezFranco, M. I.; Bidon-Chanal, A.; Luque, F. J.; Camps, P.; Muñoz-Torrero, D. Novel huprine derivatives with inhibitory activity toward beta-amyloid aggregation and formation as disease-modifying antiAlzheimer drug candidates. ChemMedChem 2010, 5, 1855-1870. (b) Ratia, M.; Giménez-Llort, L.; Camps, P.; Muñoz-Torrero, D.; Pérez, B.; Clos, M. V.; Badía, A. Huprine X and huperzine A improve cognition and regulate some neurochemical processes related with Alzheimer's disease in triple transgenic mice (3xTg-AD). Neurodegener. Dis. 2013, 11, 129-140.

106 Arce, M. P.; Rodríguez-Franco, M. I.; González-Muñoz, G. C.; Pérez, C.; López, B.; Villarroya, M.; López, M. G.; García, A. G.; Conde, S., Neuroprotective and cholinergic properties of multifunctional glutamic acid derivatives for the treatment of Alzheimer's disease. J. Med. Chem. 2009, 52 (22), 72497257.

${ }^{107}$ Rodríguez-Franco, M. I.; Fernández-Bachiller, M. I.; Pérez, C.; Hernández-Ledesma, B.; Bartolomé, B. Novel tacrine-melatonin hybrids as dual-acting drugs for Alzheimer disease, with improved acetylcholinesterase inhibitory and antioxidant properties. J. Med. Chem. 2006, 49, 459-462.

${ }^{108}$ Fernández-Bachiller, M. I.; Pérez, C.; Campillo, N. E.; Páez, J. A.; González-Muñoz, G. C.; Usán, P.; García-Palomero, E.; López, M. G.; Villarroya, M.; García, A. G.; Martínez, A.; Rodríguez-Franco, M. I. Tacrine-melatonin hybrids as multifunctional agents for Alzheimer's disease, with cholinergic, antioxidant, and neuroprotective properties. ChemMedChem 2009, 4, 828-841.

${ }^{109}$ Fernández-Bachiller, M. I.; Pérez, C.; González-Muñoz, G. C.; Conde, S.; López, M. G.; Villarroya, M.; García, A. G.; Rodríguez-Franco, M. I., Novel tacrine-8-hydroxyquinoline hybrids as multifunctional agents for the treatment of Alzheimer's disease, with neuroprotective, cholinergic, antioxidant, and copper-complexing properties. J. Med. Chem. 2010, 53 (13), 4927-4937.

${ }^{110}$ Fernández-Bachiller, M. I.; Pérez, C.; Monjas, L.; Rademann, J.; Rodríguez-Franco, M. I. New tacrine-4-oxo-4H-chromene hybrids as multifunctional agents for the treatment of Alzheimer's disease, with cholinergic, antioxidant, and beta-amyloid-reducing properties. J. Med. Chem. 2012, 55, 1303-1317.

${ }^{111}$ Maroto, M.; de Diego, A. M.; Albinana, E.; Fernández-Morales, J. C.; Caricati-Neto, A.; Jurkiewicz, A.; Yáñez, M.; Rodríguez-Franco, M. I.; Conde, S.; Arce, M. P.; Hernández-Guijo, J. M.; García, A. G., Multi-target novel neuroprotective compound ITH33/IQM9.21 inhibits calcium entry, calcium signals and exocytosis. Cell Calcium 2011, 50 (4), 359-369.

${ }^{112}$ Monjas, L.; Arce, M. P.; León, R.; Egea, J.; Pérez, C.; Villarroya, M.; López, M. G.; Gil, C.; Conde, S.; Rodríguez-Franco, M. I., Enzymatic and solid-phase synthesis of new donepezil-based L- and Dglutamic acid derivatives and their pharmacological evaluation in models related to Alzheimer's disease and cerebral ischemia. Eur. J. Med. Chem. 2017, 130, 60-72. 
Ps1, mejorando sus capacidades cognitivas y reduciendo la carga amiloide en cerebro $^{113,114}$.<smiles>CCCCCCNC1=CC(=O)C(NCCCCCCN(CC)Cc2ccccc2OC)=CC1=O</smiles>

(inhibidor dual de AChE y BACE-1)<smiles>C#CCNC1CCc2ccccc21</smiles>
(inhibidor dual de ChEs y MAOs)<smiles>[R]N[C@@H](CCC(=O)NCCC1CCN(Cc2ccccc2)CC1)C([R2])=O</smiles><smiles>[R]c1cccc2[nH]cc(CCNC(=O)C(C)NCc3c4c(nc5ccccc35)CCCC4)c12</smiles><smiles>[Z]NCc1cc([R])c2ccc([R])nc2c1O</smiles>

Híbridos tacrina - clioquinol

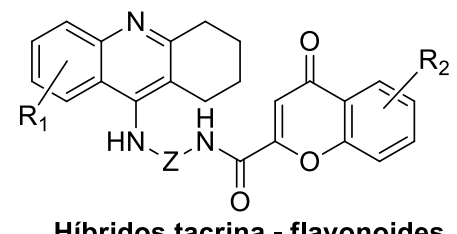

Híbridos tacrina - melatonina

Figura 24. Ejemplos de fármacos multidiana para la EA

${ }^{113}$ Spuch, C.; Antequera, D.; Fernández-Bachiller, M. I.; Rodríguez-Franco, M. I.; Carro, E., A new tacrinemelatonin hybrid reduces amyloid burden and behavioral deficits in a mouse model of Alzheimer's disease. Neurotox. Res. 2010, 17 (4), 421-431.

114 Antequera, D.; Bolos, M.; Spuch, C.; Pascual, C.; Ferrer, I.; Fernández-Bachiller, M. I.; RodríguezFranco, M. I.; Carro, E., Effects of a tacrine-8-hydroxyquinoline hybrid (IQM-622) on Abeta accumulation and cell death: involvement in hippocampal neuronal loss in Alzheimer's disease. Neurobiol. Dis. 2012, 46 (3), 682-691. 


\subsection{OBJETIVOS}

El objetivo general de esta Tesis Doctoral ha sido la síntesis y evaluación biológica de nuevos ligandos multifuncionales, diseñados para actuar en varias dianas biológicas de interés para la enfermedad de Alzheimer: inhibición de AChE y de la agregación del $\beta$-amiloide, propiedades antioxidantes, neuroprotectoras y neurogénicas. Sin perder de vista este objetivo general, a lo largo de la realización de esta Tesis los objetivos concretos han ido evolucionando de acuerdo con los resultados obtenidos.

Teniendo en cuenta la estructura cristalina de la $\mathrm{AChE}^{115,116}$, el diseño de las nuevas estructuras se realizó uniendo un ligando del centro activo (CAS) con fragmentos capaces de interaccionar con el centro aniónico periférico (PAS), a través de un espaciador lo suficientemente flexible para acomodarse a la estrecha garganta catalítica de la enzima (Figura 25). Es de esperar que los inhibidores duales de CAS y PAS presenten una buena inhibición de la AChE y que impidan la precipitación del $\beta$ A.
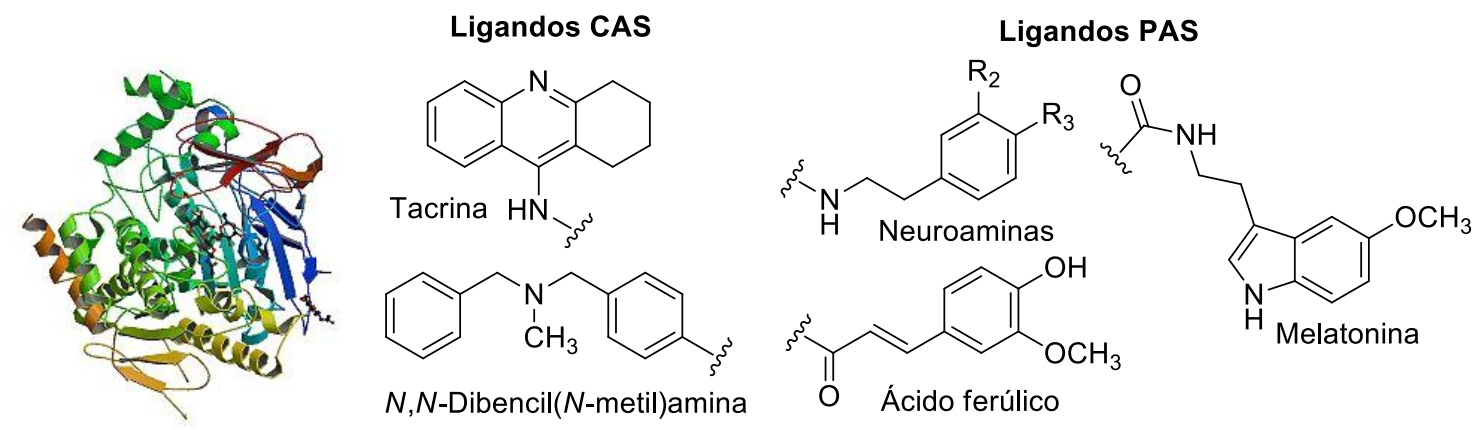

Figura 25. Diseño de estructuras

Partiendo de los trabajos previos del grupo de investigación sobre derivados de tacrina, con interesantes propiedades colinérgicas y antioxidantes, inicialmente se planteó la síntesis de nuevos híbridos de tacrina y neuroaminas, ácido ferúlico y fenoles. A la vista de los resultados obtenidos en estas series, se decidió sustituir el fragmento de

\footnotetext{
${ }^{115}$ Sussman, J. L.; Harel, M.; Frolow, F.; Oefner, C.; Goldman, A.; Toker, L.; Silman, I., Atomic structure of acetylcholinesterase from Torpedo californica: a prototypic acetylcholine-binding protein. Science 1991, 253 (5022), 872-879.

${ }^{116}$ Cheung, J.; Rudolph, M. J.; Burshteyn, F.; Cassidy, M. S.; Gary, E. N.; Love, J.; Franklin, M. C.; Height, J. J., Structures of human acetylcholinesterase in complex with pharmacologically important ligands. $J$. Med. Chem. 2012, 55 (22), 10282-10286.
} 
tacrina por el de $N, N$-dibencil( $N$-metil)amina (DBMA), obteniendo dos nuevas series: los híbridos DBMA - neuroaminas / piridina y DBMA - melatonina.

Todos los productos obtenidos serán evaluados en nuestro Grupo de Neurofármacos del Instituto de Química Médica (CSIC) como inhibidores de AChE y BuChE de origen animal y los más activos frente a las enzimas humanas, empleando el método colorimétrico de Ellman. Las propiedades antioxidantes se determinarán midiendo la capacidad de captura de radicales libres de oxígeno, empleando el método ORAC-FL (oxygen radical absorbance capacity - fluorescein). La penetración en el sistema nervioso central de las nuevas moléculas se evaluará siguiendo el método PAMPA-BBB (parallel artificial membrane permeation assay - blood-brain barrier), puesto a punto en el primer capítulo de esta memoria.

Los productos más interesantes serán evaluados en pruebas biológicas adicionales en colaboración con otros grupos de investigación: determinación de la unión a sitio periférico de la AChE, toxicidad y neuroprotección frente diferentes situaciones tóxicas (estrés oxidativo mitocondrial, sobrecarga de calcio, $\beta$ A, ácido okadaico), modelo tisular de isquemia cerebral, modelo in vivo de pérdida de memoria en ratón y estudios de neurogénesis in vitro. 


\subsection{HÍBRIDOS DERIVADOS DE TACRINA}

Como ya se ha comentado con anterioridad, el carácter complejo de la enfermedad de Alzheimer ha promovido el diseño de moléculas multifuncionales dotadas de dos o más actividades biológicas complementarias, como potenciales fármacos para el tratamiento de esta patología117,118. Continuando con el trabajo de nuestro grupo de investigación sobre diferentes familias heterocíclicas con potencial aplicación en el campo de las enfermedades neurodegenerativas ${ }^{119-122}$, con anterioridad a la realización de esta Tesis Doctoral se habían obtenido diferentes híbridos de tacrina, que demostraron unas interesantes propiedades multifuncionales. Estos híbridos se diseñaron por unión de un fragmento de tacrina, el primer fármaco comercializado para el tratamiento de la enfermedad de Alzheimer, con productos naturales (melatonina o flavonoides) o con fármacos en avanzados estudios clínicos (ej., clioquinol), dando lugar a los híbridos tacrina - melatonina ${ }^{107,108}$, tacrina - clioquinol $^{109}$ y tacrina - flavonoides ${ }^{110}$ (Figura 1).

Estas familias demostraron su capacidad para evitar la muerte de las neuronas sometidas a estrés oxidativo mitocondrial o a la exposición de péptido $\beta \mathrm{A}$, restablecer los niveles de neurotransmisores y detener la pérdida neuronal. Además, en estudios in vivo los híbridos tacrina - melatonina y tacrina - clioquinol, totalmente desarrollados en nuestro grupo de investigación, son capaces de reducir los déficits cognitivos, así como de disminuir la carga de beta-amiloide en el cerebro de ratones transgénicos APP/Ps1 $1^{113,114}$ empleados como modelo murino de la EA.

117 Cavalli, A.; Bolognesi, M. L.; Minarini, A.; Rosini, M.; Tumiatti, V.; Recanatini, M.; Melchiorre, C. Multi-target-directed ligands to combat neurodegenerative diseases. J. Med. Chem. 2008, 51, 347-372.

${ }^{118}$ Bolognesi, M. L.; Cavalli, A.; Melchiorre, C. Memoquin: a multi-target-directed ligand as an innovative therapeutic opportunity for Alzheimer's disease. Neurotherapeutics 2009, 6, 152-162.

${ }^{119}$ Rodríguez-Franco, M. I.; Fernández-Bachiller, M. I.; Pérez, C.; Castro, A.; Martínez, A. Design and synthesis of $N$-benzylpiperidine purine derivatives as new dual inhibitors of acetyl- and butyrylcholinesterase. Bioorg. Med. Chem. 2005, 13, 6795-6802.

${ }^{120}$ Rodríguez-Franco, M. I.; Dorronsoro, I.; Castro, A.; Martínez, A.; Badía, A.; Baños, J.-E. Synthesis and Muscarinic Activities of $O$-[(Benzyl- or Benzoyl-pyrazolyl)propynyl]-oximes of $N$ Methylpiperidinone, 3-Tropinone, and 3-Quinuclidinone. Bioorg. Med. Chem. 2003, 11, 2263-2268.

121 Rodríguez-Franco, M. I.; Dorronsoro, I.; Martínez, A. O-Pyrazolylpropynyl-Hydroxylamines as Versatile Intermediates in the Synthesis of Compounds of Pharmacological Interest. Synthesis 2001, 1711-1715.

${ }^{122}$ Rodríguez-Franco, M. I.; Dorronsoro, I.; Martínez, A.; Pérez, C.; Badía, A.; Baños, J.-E. Synthesis of New N-(4-Pyridyl)-1-Aminopyrazoles and their Muscarinic and Adrenergic Properties. Arch. Pharm. Pharm. Med. Chem. 2000, 333, 118-122. 


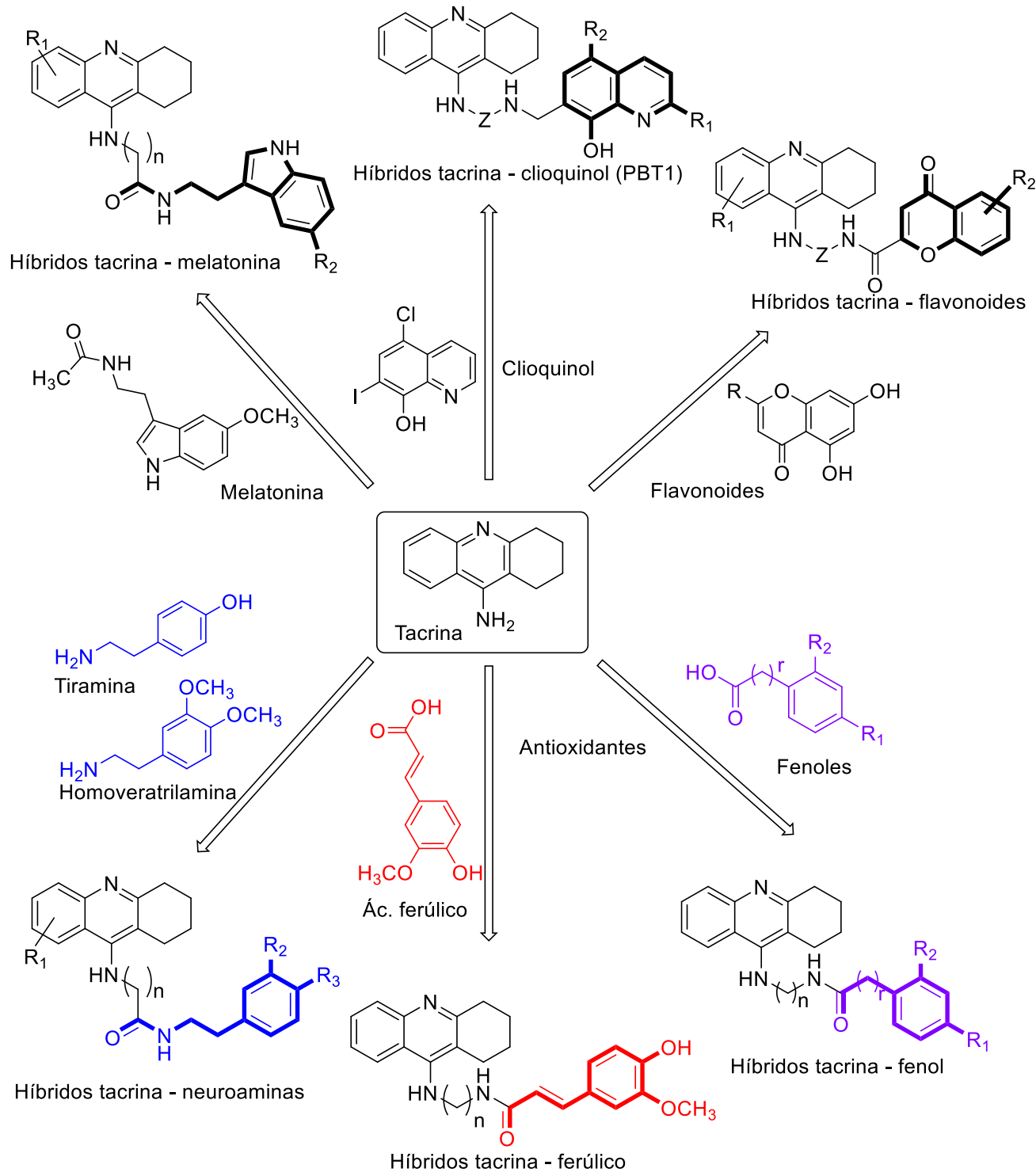

Figura 26. Híbridos de tacrina, obtenidos con anterioridad en el grupo (derivados de melatonina, clioquinol y flavonoides) y los desarrollados en esta Tesis Doctoral (derivados de neuroaminas, del ácido ferúlico y de fenoles).

A la vista de estos interesantes resultados, en esta Tesis Doctoral nos propusimos la obtención de nuevos híbridos, en los que a la estructura de tacrina se le unirían fragmentos de neuroaminas (como tiramina o homoveratrilamina) o de moléculas antioxidantes (como el ácido ferúlico y otros fenoles). En todos los casos, se buscaban moléculas multifuncionales con propiedades colinérgicas y neuroprotectoras, dirigidas a un potencial tratamiento de la EA (Figura 26). 


\subsubsection{Híbridos tacrina - neuroaminas}

En primer lugar, nos propusimos la síntesis de los híbridos tacrina - neuroaminas, con diferentes sustituyentes en el fragmento de tacrina $\left(\mathrm{R}_{1}=\mathrm{H}, 8-\mathrm{Cl}, 6,8-\mathrm{diCl}, 7-\mathrm{F}\right)$, diferentes longitudes en el espaciador $(n=5-7)$, con uniones de tipo amida o tioamida $(X$ $=\mathrm{O}, \mathrm{S}$ ) y empleando dos tipos de neuroaminas: tiramina y homoveratrilamina (Figura 27).

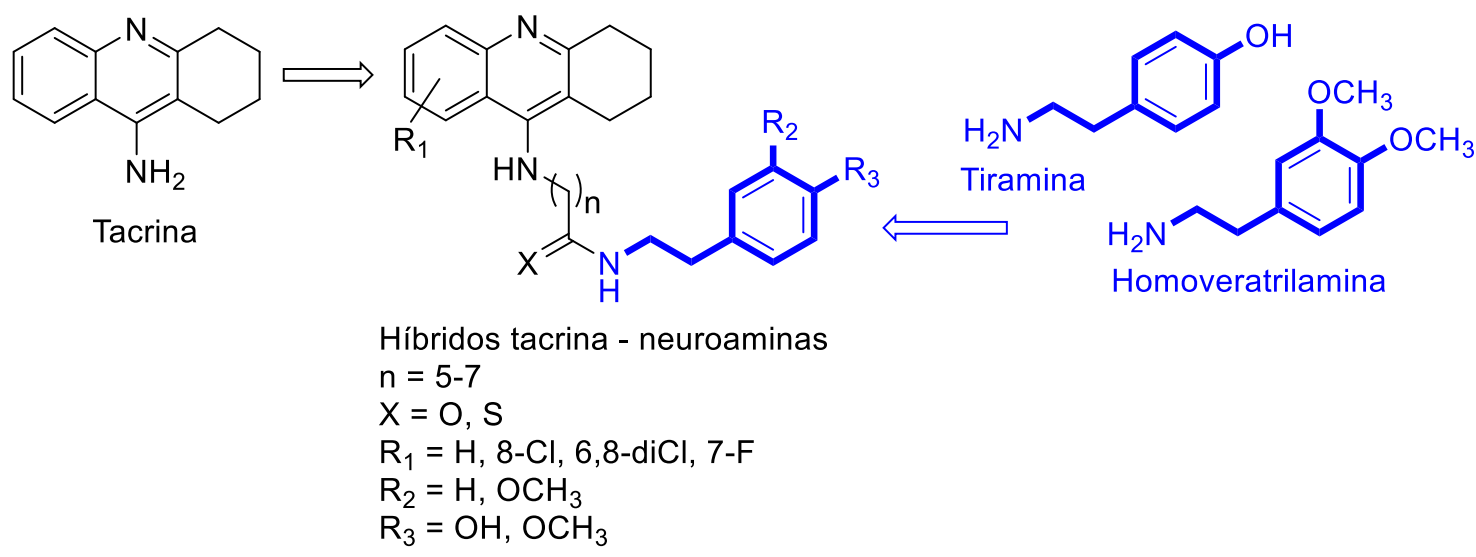

Figura 27. Diseño de los híbridos tacrina - neuroaminas

Las neuroaminas actúan como neurotransmisores y neuromoduladores y se caracterizan porque contienen un grupo amino conectado a un anillo aromático por una cadena de dos carbonos. Estas neuroaminas derivan de aminoácidos aromáticos como la fenilalanina y tirosina.

La tiramina es una neuroamina endógena que interviene como intermedio en la síntesis de dopamina y otras catecolaminas neurotransmisoras, y se produce por descarboxilación de L-tirosina. Además, la tiramina actúa directamente como un neuromodulador, como reveló el descubrimiento de un receptor acoplado a proteína $\mathrm{G}$ con alta afinidad por tiramina, llamado TAAR1 (trace amine-associated receptor 1) ${ }^{123,124}$, que está ampliamente expresado en SNC. Por otra parte, la homoveratrilamina es una catecolamina análoga del principal neurotransmisor humano la dopamina, donde los grupos hidroxi en las posiciones 3 y 4 de la dopamina han sido reemplazados por grupos metoxilo.

\footnotetext{
${ }^{123}$ Liberles, S. D.; Buck, L. B. A second class of chemosensory receptors in the olfactory epithelium. Nature 2006, 442, 645-650.

${ }^{124}$ Khan, M. Z.; Nawaz, W. The emerging roles of human trace amines and human trace amine-associated receptors (hTAARs) in central nervous system. Biomed. Pharmacother. 2016, 83, 439-449.
} 
Ambas neuroaminas se encuentran de forma natural en vegetales y, en especial la tiramina en alimentos fermentados (ej., queso maduro), en plantas (ej., nueces), en el hígado de pollo y en pescados (ej., sardinas), por lo que no es de esperar toxicidad en los híbridos propuestos.

\subsubsection{Síntesis de los híbridos tacrina - neuroaminas}

La obtención de los híbridos tacrina - neuroaminas se planteó según la ruta sintética recogida en el esquema 1. El tratamiento de la 9-(1,2,3,4-tetrahidro)acridona, de origen comercial, con oxicloruro de fósforo a reflujo durante 6 horas condujo a la 9-cloro(1,2,3,4-tetrahidro)acridina (1) con buen rendimiento (87\%), siguiendo el procedimiento experimental descrito en la bibliografía ${ }^{125}$. En el caso de las cloroacridinas análogas con diferentes sustituyentes $\mathbf{2 - 4}$, su síntesis se realizó mediante la ciclocondensación de diferentes anilinas sustituidas con 2-etoxicarbonilciclohexanona en presencia de oxicloruro de fósforo a reflujo durante 3 horas, obteniéndose rendimientos moderados (34-68\%). El tratamiento de estos intermedios con 1 equivalente del correspondiente $\alpha, \omega-$ aminoácido en pentanol a reflujo, permitió aislar los derivados 5-11, con rendimientos comprendidos entre el 30 y el $62 \%$.

El tratamiento de los ácidos intermedios 5-11 con tiramina [4-(2-aminoetil)fenol] o con homoveratrilamina [2-(3,4-dimetoxifenil)etan-1-amina] en presencia de BOP [hexafluorofosfato de (benzotriazol-1-iloxi)tris(dimetilamino)fosfonio] y trietilamina condujo a los híbridos deseados, derivados de tacrina y neuroaminas 12-24, con rendimientos comprendidos entre el 29 y el $70 \%$.

Finalmente, el tratamiento de las amidas $\mathbf{1 9}$ y 21 con el reactivo de Lawesson (2,4bis( $p$-metoxifenil)-1,3-ditiadifosfetano-2,4-disulfito $)^{126}$ en tolueno a reflujo durante 8 horas originó las tioamidas $\mathbf{2 5}$ y $\mathbf{2 6}$, con rendimientos del 87 y $88 \%$, respectivamente (Esquema 1).

\footnotetext{
${ }^{125}$ Carlier, P. R.; Han, Y. F.; Chow, E. S.; Li, C. P.; Wang, H.; Lieu, T. X.; Wong, H. S.; Pang, Y. P. Evaluation of short-tether bis-THA AChE inhibitors. A further test of the dual binding site hypothesis. Bioorg. Med. Chem. 1999, 7, 351-357.

126 Cava, M.P.; Lewinson, M.I. Thionation reactions of Lawenson's reagents. Tetrahedron 1985, 41, 50615087.
} 

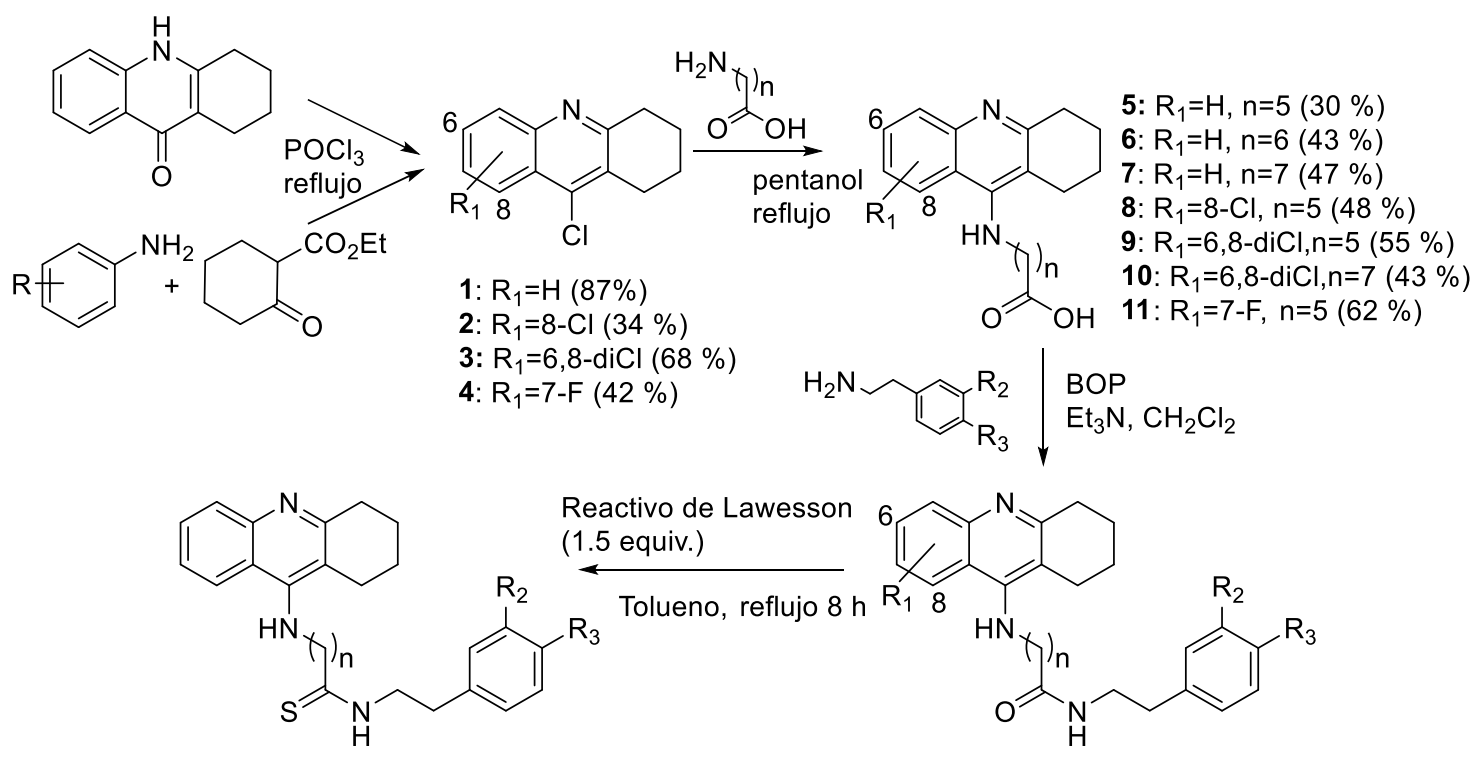

25: $\mathrm{R}_{2}=\mathrm{R}_{3}=\mathrm{OCH}_{3} \mathrm{n}=5 \quad(87 \%)$

26: $\mathrm{R}_{2}=\mathrm{R}_{3}=\mathrm{OCH}_{3} \mathrm{n}=7 \quad(88 \%)$

12: $\mathrm{R}_{1}=\mathrm{R}_{2}=\mathrm{H}, \mathrm{R}_{3}=\mathrm{OH} \mathrm{n}=5(52 \%)$

13: $\mathrm{R}_{1}=\mathrm{R}_{2}=\mathrm{H}, \mathrm{R}_{3}=\mathrm{OH} \mathrm{n}=6(45 \%)$

14: $\mathrm{R}_{1}=\mathrm{R}_{2}=\mathrm{H}, \mathrm{R}_{3}=\mathrm{OH} n=7(68 \%)$

15: $\mathrm{R}_{1}=8-\mathrm{Cl}, \mathrm{R}_{2}=\mathrm{H}, \mathrm{R}_{3}=\mathrm{OH} n=5(44 \%)$

16: $\mathrm{R}_{1}=6,8-\mathrm{diCl}, \mathrm{R}_{2}=\mathrm{H}, \mathrm{R}_{3}=\mathrm{OH} \mathrm{n}=5(39 \%)$

17: $\mathrm{R}_{1}=6,8-\mathrm{diCl}, \mathrm{R}_{2}=\mathrm{H}, \mathrm{R}_{3}=\mathrm{OH} \mathrm{n}=7(29 \%)$

18: $\mathrm{R}_{1}=7-\mathrm{F}, \mathrm{R}_{2}=\mathrm{H}, \mathrm{R}_{3}=\mathrm{OH} \mathrm{n}=5(48 \%)$

19: $\mathrm{R}_{1}=\mathrm{H}, \mathrm{R}_{2}=\mathrm{R}_{3}=\mathrm{OCH}_{3} \mathrm{n}=5(40 \%)$

20: $\mathrm{R}_{1}=\mathrm{H}, \mathrm{R}_{2}=\mathrm{R}_{3}=\mathrm{OCH}_{3} \mathrm{n}=6(52 \%)$

21: $R_{1}=H, R_{2}=R_{3}=\mathrm{OCH}_{3} n=7(61 \%)$

22: $\mathrm{R}_{1}=8-\mathrm{Cl}, \mathrm{R}_{2}=\mathrm{R}_{3}=\mathrm{OCH}_{3} \mathrm{n}=5(43 \%)$

23: $\mathrm{R}_{1}=6,8-\mathrm{diCl}, \mathrm{R}_{2}=\mathrm{R}_{3}=\mathrm{OCH}_{3} \mathrm{n}=5(70 \%)$

24: $R_{1}=7-F, R_{2}=R_{3}=O_{3} \quad n=5(40 \%)$

Esquema 1. Sintesis de los híbridos tacrina - neuroaminas 12-26

Todos los híbridos tacrina - neuroaminas 12-26 fueron purificados en columnas de cromatografía de media presión, empleando gel de sílice como fase estacionaria, y su pureza se determinó en un equipo de HPLC (ver detalles en la parte experimental). La estructura de todos los híbridos quedó demostrada a partir de sus datos espectroscópicos de ${ }^{1} \mathrm{H}-\mathrm{RMN},{ }^{13} \mathrm{C}-\mathrm{RMN}$ y EM. La asignación de los protones y carbonos se realizó mediante experimentos de correlación heteronuclear protón-carbono a un enlace (HSQC, Heteronuclear Multiple Quantum Correlation) y a 2-3 enlaces (HMBC, Heteronuclear Multiple Bond Correlation). 


\subsubsection{Inhibición de acetil y butirilcolinesterasa de los híbridos tacrina-neuroaminas}

Siguiendo el método de Ellman y usando tacrina como referencia interna ${ }^{127}$, se evaluó la capacidad de los híbridos tacrina - neuroaminas como inhibidores de AChE y BuChE. Debido a su menor coste y a su alto grado de homología con las enzimas humanas ${ }^{128}$, inicialmente se emplearon enzimas de mamífero, concretamente AChE de eritrocitos bovinos y BuChE de suero de caballo, y los resultados se encuentran recogidos en la tabla 11.

Todos los híbridos tacrina - neuroaminas 12-26 son potentes inhibidores de AChE y BuChE de mamífero, con valores de $\mathrm{CI}_{50}$ en el orden nanomolar para la mayoría de los compuestos. Concretamente, los valores de $\mathrm{CI}_{50}$ en la bov-AChE están comprendidos entre $7.5 \mathrm{nM}$ para el derivado más activo $\left(\mathbf{1 6}, \mathrm{n}=5, \mathrm{R}=6,8\right.$-diCl, $\mathrm{R}_{1}=\mathrm{H}, \mathrm{R}_{2}=\mathrm{OH}, \mathrm{X}=$ O) y $2000 \mathrm{nM}$ para el menos potente $\left(\mathbf{2 4}, \mathrm{n}=5, \mathrm{R}=7-\mathrm{F}, \mathrm{R}_{1}=\mathrm{R}_{2}=\mathrm{OCH}_{3}, \mathrm{X}=\mathrm{O}\right)$. En el caso de la eq-BuChE las variaciones en las $\mathrm{CI}_{50}$ s son menores: entre $1.0 \mathrm{nM}$ para $\mathbf{1 8}(\mathrm{n}=$ $\left.5, \mathrm{R}=7-\mathrm{F}, \mathrm{R}_{1}=\mathrm{H}, \mathrm{R}_{2}=\mathrm{OH}, \mathrm{X}=\mathrm{O}\right)$ y 350 para $23\left(\mathrm{n}=5, \mathrm{R}=6,8-\mathrm{diCl}, \mathrm{R}_{1}=\mathrm{R}_{2}=\mathrm{OCH}_{3}\right.$, $\mathrm{X}=\mathrm{O}$ ). En general, todos los híbridos tacrina - neuroaminas presentan una buena selectividad hacia la eq-BuChE frente a la bov-AChE, llegando a 100 veces para los derivados con un átomo de flúor en la posición 7 del anillo de tacrina, es decir, los híbridos $18\left(\mathrm{n}=5, \mathrm{R}=7-\mathrm{F}, \mathrm{R}_{1}=\mathrm{H}, \mathrm{R}_{2}=\mathrm{OH}, \mathrm{X}=\mathrm{O}\right)$ y $24\left(\mathrm{n}=5, \mathrm{R}=7-\mathrm{F}, \mathrm{R}_{1}=\mathrm{R}_{2}=\mathrm{OCH}_{3}, \mathrm{X}=\right.$ O). La introducción de un átomo de cloro en la posición 8 del resto de tacrina no modifica la selectividad, como puede comprobarse por la comparación de 12 con 15 y de 19 con 22. Sorprendentemente, la introducción de un segundo átomo de cloro, esta vez en la posición 6, invierte totalmente la selectividad a favor de la AChE, siendo los híbridos $\mathbf{1 6}$ ( $\mathrm{n}=5, \mathrm{R}=6,8$-diCl, $\mathrm{R}_{1}=\mathrm{H}, \mathrm{R}_{2}=\mathrm{OH}, \mathrm{X}=\mathrm{O}$ ), 17 ( $\mathrm{n}=7, \mathrm{R}=6,8-\mathrm{diCl}, \mathrm{R}_{1}=\mathrm{H}, \mathrm{R}_{2}=\mathrm{OH}$, $\mathrm{X}=\mathrm{O})$ y $23\left(\mathrm{n}=5, \mathrm{R}=6,8-\mathrm{diCl}, \mathrm{R}_{1}=\mathrm{R}_{2}=\mathrm{OCH}_{3}, \mathrm{X}=\mathrm{O}\right)$ un orden de magnitud más activos en bov-AChE que en eq-BuChE.

En lo que se refiere a las $\mathrm{CI}_{50} \mathrm{~s}$ en bov-AChE y eq-BuChE, y en los derivados con el fragmento de tacrina sin sustituir, no existen grandes diferencias entre los que tienen un fragmento de tiramina $\left(\mathrm{R}_{1}=\mathrm{H}, \mathrm{R}_{2}=\mathrm{OH}\right)$ o de homoveratrilamina $\left(\mathrm{R}_{1}=\mathrm{R}_{2}=\mathrm{OCH}_{3}\right)$. El cambio del agrupamiento amida por la tioamida tampoco supone un cambio en la

127 Ellman, G. L.; Courtney, K. D.; Andres, V., Jr.; Feather-Stone, R. M. A new and rapid colorimetric determination of acetylcholinesterase activity. Biochem. Pharmacol. 1961, 7, 88-95.

${ }^{128}$ Cygler, M.; Schrag, J. D.; Sussman, J. L.; Harel, M.; Silman, I.; Gentry, M. K.; Doctor, B. P. Relationship between sequence conservation and three-dimensional structure in a large family of esterases, lipases, and related proteins. Protein Sci. 1993, 2, 366-382. 
actividad de los compuestos, como puede comprobarse por la comparación de $\mathbf{1 9}$ ( $\mathrm{n}=5$, $\left.\mathrm{R}=\mathrm{H}, \mathrm{R}_{1}=\mathrm{R}_{2}=\mathrm{OCH}_{3}, \mathrm{X}=\mathrm{O}\right)$ con $25\left(\mathrm{n}=5, \mathrm{R}=\mathrm{H}, \mathrm{R}_{1}=\mathrm{R}_{2}=\mathrm{OCH}_{3}, \mathrm{X}=\mathrm{S}\right)$ y de 21 $\left(\mathrm{n}=7, \mathrm{R}=\mathrm{H}, \mathrm{R}_{1}=\mathrm{R}_{2}=\mathrm{OCH}_{3}, \mathrm{X}=\mathrm{O}\right) \operatorname{con} \mathbf{2 6}\left(\mathrm{n}=7, \mathrm{R}=\mathrm{H}, \mathrm{R}_{1}=\mathrm{R}_{2}=\mathrm{OCH}_{3}, \mathrm{X}=\mathrm{S}\right)$.

Sin embargo, en los híbridos con sustituyentes en el fragmento de tacrina (8-Cl, 6,8-diCl ó 7-F), los derivados de tiramina son un orden de magnitud más potentes que los de homoveratrilamina, tanto en bov-AChE como en eq-BuChE.

Tabla 11. Inhibición de AChE y BuChE de los híbridos tacrina - neuroaminas 12-26

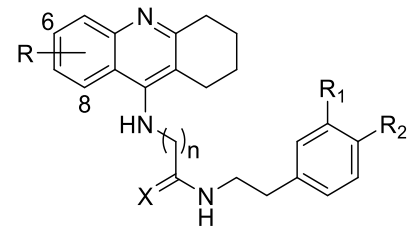

\begin{tabular}{|c|c|c|c|c|c|c|c|c|c|c|}
\hline & \multirow[b]{2}{*}{$\mathrm{n}$} & \multirow[b]{2}{*}{$\mathrm{R}_{1}$} & \multirow[b]{2}{*}{$\mathrm{R}_{2}$} & \multirow[b]{2}{*}{$\mathrm{R}$} & \multirow[b]{2}{*}{$\mathrm{X}$} & \multicolumn{3}{|c|}{$\mathrm{CI}_{50} \pm \mathrm{SEM}(\mathrm{nM})^{\mathrm{a}}$} & \multicolumn{2}{|c|}{$\begin{array}{l}\text { Selectividad }^{\mathrm{e}} \\
\text { eq-BuChE } v s .\end{array}$} \\
\hline & & & & & & bov-AChE ${ }^{\mathrm{b}}$ & eq-BuChE ${ }^{c}$ & $\mathrm{~h}-\mathrm{AChE}^{\mathrm{d}}$ & bov-AChE & h-AChE \\
\hline 12 & 5 & $\mathrm{H}$ & $\mathrm{OH}$ & $\mathrm{H}$ & $\mathrm{O}$ & $20 \pm 2$ & $8.0 \pm 0.1$ & nd & 2.5 & \\
\hline 13 & 6 & $\mathrm{H}$ & $\mathrm{OH}$ & $\mathrm{H}$ & $\mathrm{O}$ & $500 \pm 55$ & $17.5 \pm 0.9$ & nd & 29 & \\
\hline 14 & 7 & $\mathrm{H}$ & $\mathrm{OH}$ & $\mathrm{H}$ & $\mathrm{O}$ & $60 \pm 3$ & $3.0 \pm 0.2$ & nd & 20 & \\
\hline 15 & 5 & $\mathrm{H}$ & $\mathrm{OH}$ & $8-\mathrm{Cl}$ & $\mathrm{O}$ & $300 \pm 28$ & $85 \pm 7$ & $73.8 \pm 5.8$ & 3.5 & 0.9 \\
\hline 16 & 5 & $\mathrm{H}$ & $\mathrm{OH}$ & 6,8-diCl & $\mathrm{O}$ & $7.5 \pm 0.2$ & $40 \pm 3$ & $6.75 \pm 0.02$ & 0.2 & 0.2 \\
\hline 17 & 7 & $\mathrm{H}$ & $\mathrm{OH}$ & 6,8-diCl & $\mathrm{O}$ & $100 \pm 7$ & $250 \pm 23$ & $123 \pm 10$ & 0.4 & 0.5 \\
\hline 18 & 5 & $\mathrm{H}$ & $\mathrm{OH}$ & $7-\mathrm{F}$ & $\mathrm{O}$ & $100 \pm 8$ & $1.0 \pm 0.01$ & $237 \pm 16$ & 100 & 237 \\
\hline 19 & 5 & $\mathrm{OCH}_{3}$ & $\mathrm{OCH}_{3}$ & $\mathrm{H}$ & $\mathrm{O}$ & $50 \pm 5$ & $7.5 \pm 0.8$ & $7940 \pm 500$ & 6.7 & 1059 \\
\hline 20 & 6 & $\mathrm{OCH}_{3}$ & $\mathrm{OCH}_{3}$ & $\mathrm{H}$ & $\mathrm{O}$ & $36 \pm 4$ & $3.7 \pm 0.1$ & nd & 9.7 & \\
\hline 21 & 7 & $\mathrm{OCH}_{3}$ & $\mathrm{OCH}_{3}$ & $\mathrm{H}$ & $\mathrm{O}$ & $100 \pm 8$ & $1.5 \pm 0.1$ & $8.01 \pm 0.12$ & 67 & 5.3 \\
\hline 22 & 5 & $\mathrm{OCH}_{3}$ & $\mathrm{OCH}_{3}$ & $8-\mathrm{Cl}$ & $\mathrm{O}$ & $1000 \pm 120$ & $375 \pm 15$ & $863 \pm 70$ & 2.7 & 2.3 \\
\hline 23 & 5 & $\mathrm{OCH}_{3}$ & $\mathrm{OCH}_{3}$ & 6,8-diCl & $\mathrm{O}$ & $50 \pm 4$ & $350 \pm 21$ & $49.3 \pm 5.8$ & 0.1 & 0.1 \\
\hline 24 & 5 & $\mathrm{OCH}_{3}$ & $\mathrm{OCH}_{3}$ & $7-\mathrm{F}$ & $\mathrm{O}$ & $2000 \pm 150$ & $20 \pm 1$ & $574 \pm 47$ & 100 & 29 \\
\hline 25 & 5 & $\mathrm{OCH}_{3}$ & $\mathrm{OCH}_{3}$ & $\mathrm{H}$ & $\mathrm{S}$ & $75 \pm 5$ & $6.5 \pm 0.5$ & $93.6 \pm 2.5$ & 12 & 14 \\
\hline 26 & 7 & $\mathrm{OCH}_{3}$ & $\mathrm{OCH}_{3}$ & $\mathrm{H}$ & $\mathrm{S}$ & $75 \pm 4$ & $25 \pm 2$ & nd & 3.0 & \\
\hline \multicolumn{6}{|c|}{ Tacrina } & $40 \pm 2$ & $10 \pm 0.4$ & $350 \pm 10$ & 4.0 & 35.0 \\
\hline
\end{tabular}

${ }^{a}$ Los resultados se expresan como la media de tres experimentos independientes $(n=3) \pm$ error estándar de la media (SEM). ${ }^{\mathrm{b}} \mathrm{AChE}$ (EC 3.1.1.7) de eritrocitos bovinos. ${ }^{\mathrm{C}} \mathrm{BuChE}$ (EC 3.1.1.8) procedente de suero de caballo. ${ }^{\mathrm{d}} \mathrm{AChE}$ (EC 3.1.1.7) de eritrocitos humanos. ${ }^{\mathrm{e} S e l e c t i v i d a d ~ h a c i a ~}$ BuChE (equina) frente a $\mathrm{AChE}$ (bovina y humana), calculada como $\mathrm{CI}_{50}$ (bov-AChE o h-AChE) $/ \mathrm{CI}_{50}$ (eq-BuChE). 
Los híbridos tacrina - neuroaminas también fueron evaluados como inhibidores de AChE humana y los resultados están recogidos en la tabla 1. En este caso, los valores de $\mathrm{CI}_{50}$ son semejantes o algo mejores que en el caso de la AChE de mamífero. Cabe destacar la notable diferencia de la $\mathrm{CI}_{50}$ para la bov-AChE y la h-AChE en el híbrido 19 ( $\mathrm{n}=5, \mathrm{R}$ $=\mathrm{H}, \mathrm{R}_{1}=\mathrm{R}_{2}=\mathrm{OCH}_{3}, \mathrm{X}=\mathrm{O}$ ): hay una diferencia de tres órdenes de magnitud y por lo tanto un cambio muy grande en la selectividad hacia la eq-BuChE. El compuesto 19 presenta una selectividad hacia la eq-BuChE de 6.7-veces si la comparamos con la bovAChE, pero de 1059-veces comparándola con la h-AChE. Este hecho es bastante sorprendente, dada la alta homología estructural entre las AChEs animal y humana.

\subsubsection{Predicción in vitro de la penetración en el SNC de los híbridos tacrina -} neuroaminas

Con el fin de explorar si los híbridos tacrina - neuroaminas eran capaces de penetrar en el cerebro, se midió la permeabilidad de una selección de ellos a través de un extracto lipídico de cerebro de cerdo, empleando la metodología PAMPA-BBB como se ha descrito en el capítulo 1. Los experimentos se llevaron a cabo empleando una mezcla de tampón fosfato salino a pH 7.4 y etanol en proporción 70:30, evaluando en cada ensayo entre 10 y 12 patrones comerciales de los que se conocía su grado de penetración en el SNC. Los valores experimentales fueron normalizados a partir de la correlación lineal entre éstos y los descritos en la bibliografía. Los resultados experimentales de permeabilidad de los híbridos tacrina - neuroaminas 14, 18, 21 y 24, junto con su predicción para penetrar en el SNC por difusión pasiva se encuentran en la tabla 12.

De acuerdo con los límites establecidos para este tipo de ensayos, los productos con una permeabilidad superior a $410^{-6} \mathrm{~cm} \mathrm{~s}^{-1}$ serían capaces de atravesar la barrera hematoencefálica, mientras que los que presenten una $P_{\text {e }}$ por debajo de $210^{-6} \mathrm{~cm} \mathrm{~s}^{-1}$ no serían capaces de llegar al SNC. Como puede apreciarse, todos los compuestos evaluados presentan problemas para entrar en el SNC por difusión pasiva, por lo que no parecen buenos candidatos para continuar con su evaluación biológica. 
Tabla 12. Resultados de permeabilidad $\left(P_{\mathrm{e}}, 10^{-6} \mathrm{~cm} \mathrm{~s}^{-1}\right)^{\mathrm{a}}$ en experimentos PAMPA-BBB de híbridos tacrina - neuroaminas y su predicción para entrar en el SNC

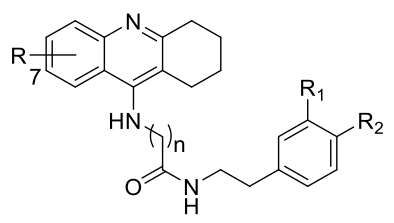

\begin{tabular}{ccccccc}
\hline Comp. & $\mathrm{R}$ & $\mathrm{n}$ & $\mathrm{R}_{1}$ & $\mathrm{R}_{2}$ & $P_{\mathrm{e}}\left(10^{-6} \mathrm{~cm} \mathrm{~s}^{-1}\right)$ & Predicción \\
\hline $\mathbf{1 4}$ & $\mathrm{H}$ & 7 & $\mathrm{H}$ & $\mathrm{OH}$ & $2.4 \pm 0.2$ & $\mathrm{snc}+/-$ \\
$\mathbf{1 8}$ & $7-\mathrm{F}$ & 5 & $\mathrm{H}$ & $\mathrm{OH}$ & $2.8 \pm 0.2$ & $\mathrm{snc}+/-$ \\
$\mathbf{2 1}$ & $\mathrm{H}$ & 7 & $\mathrm{OCH}_{3}$ & $\mathrm{OCH}_{3}$ & $1.6 \pm 0.1$ & $\mathrm{snc}-$ \\
$\mathbf{2 4}$ & $7-\mathrm{F}$ & 5 & $\mathrm{OCH}_{3}$ & $\mathrm{OCH}_{3}$ & $2.1 \pm 0.2$ & $\mathrm{snc}+/-$
\end{tabular}

${ }^{a}$ Los resultados se expresan como la media de tres experimentos independientes $(\mathrm{n}=3) \pm$ desviación estándar (DS).

\subsubsection{Híbridos tacrina - ferúlico}

A continuación, nos propusimos la síntesis de los híbridos tacrina - ferúlico que se muestran en la figura 28. El ácido ferúlico es un potente antioxidante natural, muy abundante en vegetales, que es fácilmente absorbido en el tracto gastrointestinal y es permeable en el $\mathrm{SNC}^{129}$, por lo que nos pareció un buen fragmento para emplearlo en nuestras moléculas.

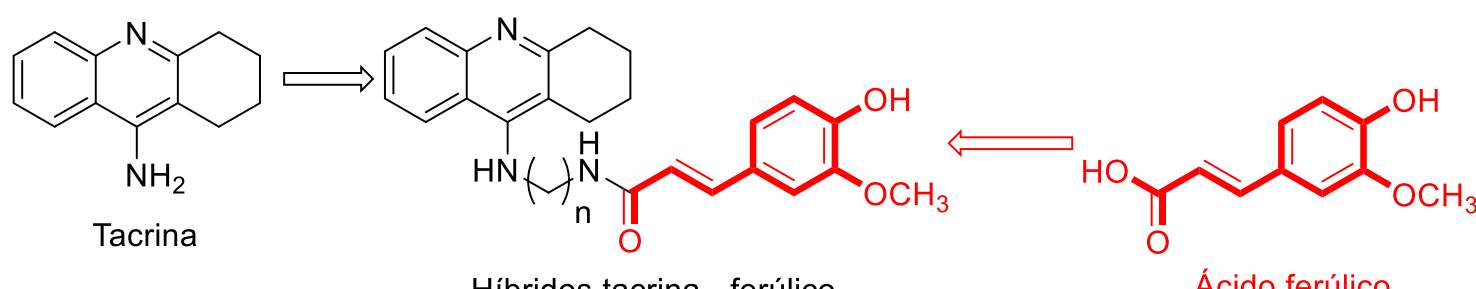

Figura 28. Diseño de los híbridos tacrina-ferúlico

${ }^{129}$ Zhao, Z.; Moghadasian, M. H. Chemistry, natural sources, dietary intake and pharmacokinetic properties of ferulic acid: A review. Food Chem. 2008, 109, 691-702. 


\subsubsection{Síntesis de los híbridos tacrina-ferúlico}

La síntesis de los híbridos derivados de tacrina y ácido ferúlico se llevó a cabo en varios pasos de reacción, como se indica en el esquema 2. El tratamiento de 9-cloro(1,2,3,4-tetrahidro)acridina (1) con 3 equivalentes de la correspondiente $\alpha, \omega$-diamina en pentanol a reflujo, permitió aislar las tacrindiaminas 27-30, con rendimientos comprendidos entre el 75 y el 85\%. Inicialmente, la reacción entre estas tacrindiaminas y el ácido ferúlico se ensayó empleando como agente acoplante hexafluorofosfato de ((1Hbenzo[ $d][1,2,3]$ triazol-1-il)oxi)tris(dimetilamino) fosfonio(V) (BOP), ya empleado con éxito en la síntesis de los híbridos tacrina - neuroaminas. Sin embargo, en este caso la reacción progresaba muy lentamente y tras 24 horas de reacción se obtuvo un rendimiento muy bajo. Además, el producto se encontraba impurificado por hexametilfosforamida (HMPA), resultante de la hidrólisis del BOP y de naturaleza tóxica ${ }^{130}$.

El segundo intento se realizó con un reactivo semejante al anterior, el hexafluorofosfato de (benzotriazol-1-iloxi)tris(pirrolidin)fosfonio (PyBOP), que habitualmente proporciona mejores rendimientos que el BOP y que además presenta la ventaja de que la fosforamida resultante (óxido de tris(pirrolidin-1-il)fosfina) es menos tóxica. Sin embargo, en nuestro caso los resultados no fueron completamente satisfactorios. Por HPLC-MS se vio que se obtenían mayores conversiones, pero los híbridos tacrina - antioxidante estaban impuros con la fosforamida, que tiene una polaridad parecida al producto buscado, lo que dificultaba la purificación de los productos deseados.

Finalmente, se optó por emplear otro tipo de agente acoplante, la diciclohexilcarbodiimida (DCC) en DMF a temperatura ambiente, que tras $24 \mathrm{~h}$ de reacción permitió aislar los híbridos tacrina-ferúlico 31-33 con rendimientos moderados (36-53\%). También en este caso la purificación de los híbridos fue complicada: aunque se separaron bien de los subproductos derivados de la DCC, en todos los casos se encontraban mezclados con otro producto de mayor masa molecular por HPLC-MS, por lo que se tuvieron que realizar varias separaciones cromatográficas consecutivas. En todos los casos, por HPLC se determinó que los híbridos tacrina - ferúlico presentaban una pureza final en torno al $80 \%$.

${ }^{130}$ Keller, D. A.; Marshall, C. E.; Lee, K. P. Subchronic nasal toxicity of hexamethylphosphoramide administered to rats orally for 90 days. Fundam. Appl. Toxicol. 1997, 40, 15-29. 


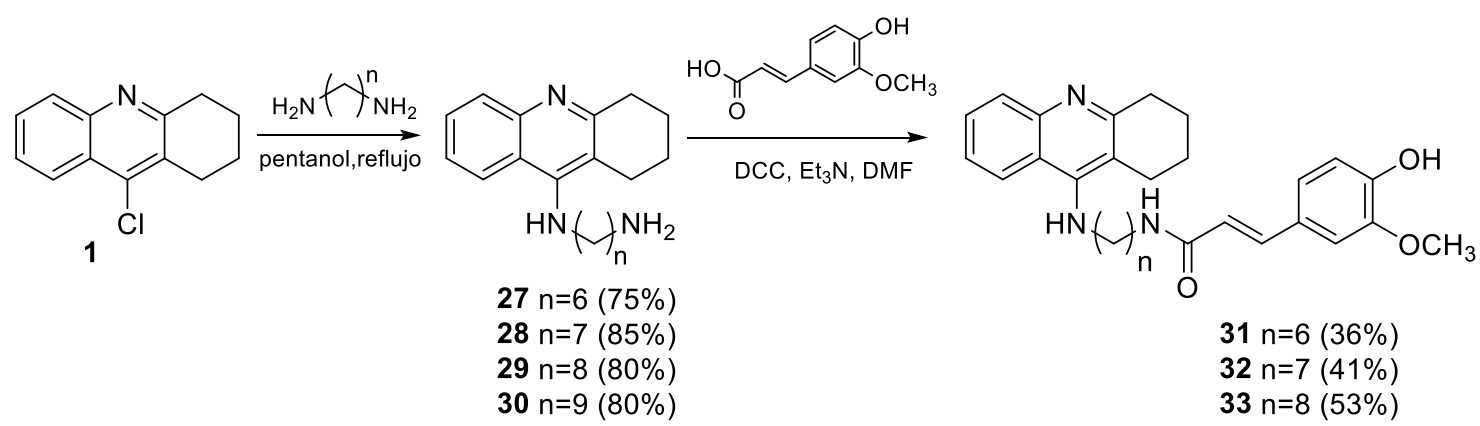

Esquema 2. Síntesis de los híbridos tacrina-ferúlico 31-33

Como ya se ha comentado, en todos los casos, además del producto deseado se obtenía otro de mayor peso molecular. En la síntesis del híbrido 32 se logró purificar dicho producto y determinar su estructura a partir de sus datos de HPLC-MS. Se trataba del producto resultante de un segundo acoplamiento entre el ácido ferúlico y la amina secundaria, para dar el híbrido $\mathbf{3 4}$ compuesto por un fragmento de tacrina y dos de ferúlico (Esquema 3).

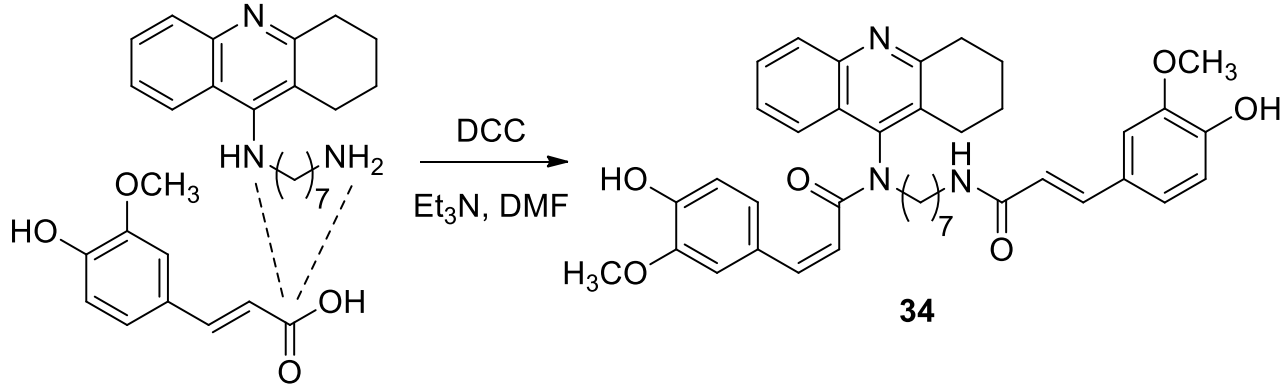

Esquema 3. Obtención del híbrido 34

El mecanismo de la reacción de acoplamiento empleando DCC $^{131}$ se refleja en el esquema 4. El primer paso implica una transferencia de protón para formar un par iónico intermedio, seguido de la adición del ácido carboxílico, lo que da lugar a la $O$-acilisourea A. Este intermedio es muy reactivo y puede sufrir distintos procesos: (i) Ataque del

131 a) De Tar, D.F.; Silverstein, R. Reactions of Carbodiimides. I. The Mechanisms of the Reactions of Acetic Acid with Dicyclohexylcarbodiimide. J. Am. Chem. Soc. 1966, 88, 1013. b) De Tar, D.F.; Silverstein, R. Reactions of Carbodiimides. II. The Reactions of Dicyclohexylcarbodiide with Carboxylic Acids in the Presence of Amines and Phenols. J. Am. Chem. Soc. 1966, 88, 1020. c) Merrified, R.B.; Vizioli, L.D.; Boman, H.G. Synthesis of the Antibacterial Peptide Cecropin A. Biochemistry 1982, 21, 5020. 
nitrógeno de la amina para formar la amida deseada C. (ii) Reordenamiento para dar lugar a la $\mathrm{N}$-acilurea $\mathbf{B}$ que no es reactiva y que contribuye a la disminución en el rendimiento del acoplamiento final. (iii) Reacción con otra molécula de ácido carboxílico, lo que conduce al anhídrido simétrico D.

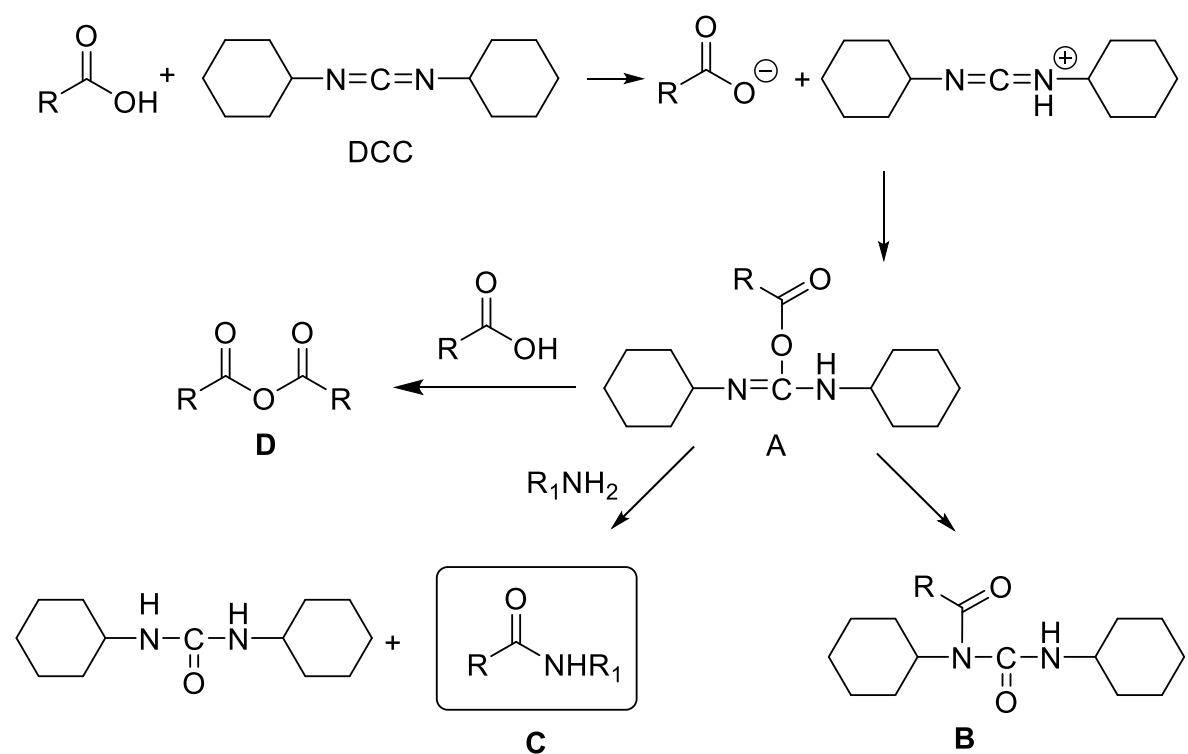

Esquema 4. Mecanismo de acoplamiento con DCC

\subsubsection{Inhibición de acetil- y butirilcolinesterasa de los híbridos tacrina-ferúlico}

Los híbridos tacrina-ferúlico 31-34 fueron ensayados como inhibidores de AChE y BuChE, siguiendo el método colorimétrico de Ellman y usando tacrina como referencia interna $^{127}$. Como en la familia anterior, primero se utilizaron enzimas de mamífero (bovAChE y eq-BuChE) debido a su menor coste y su alto grado de similitud con las enzimas humanas en cuanto a la secuencia de la cadena de aminoácidos ${ }^{128}$. Los resultados se encuentran en la tabla 13.

Los híbridos tacrina-ferúlico son buenos inhibidores de ambas enzimas, presentando $\mathrm{CI}_{50}$ s entre 240 y $400 \mathrm{nM}$ en AChE bovina y entre 3.7 y $6.3 \mathrm{nM}$ para la BuChE equina. Esto se traduce en buenas selectividades hacia la eq-BuChE, siendo entre 64 y 80 veces más potentes en la eq-BuChE que en la bov-AChE. Es interesante señalar que todos los híbridos tacrina - ferúlico 31-34 son más potentes en un orden de magnitud en la inhibición de eq-BuChE que el referente tacrina. 
Tabla 13. Inhibición de AChE y BuChE de los híbridos tacrina-ferúlico ( $\left.\mathrm{CI}_{50}, \mathrm{nM}\right)$<smiles>COc1cc(/C=C/C(=O)NC(=O)Nc2c3c(nc4ccccc24)CCCC3)ccc1O</smiles><smiles>COc1cc(/C=C/C(=O)N(CC(=O)NCc2c3c(nc4ccccc24)CCCC3)C(=O)/C=C/c2ccc(O)c(OC)c2)ccc1O</smiles>

$$
\mathrm{CI}_{50} \pm \mathrm{SEM}(\mathrm{nM})^{\mathrm{a}}
$$

Selectividad eq-BuChE $v s$.

\begin{tabular}{|c|c|c|c|c|c|c|}
\hline Comp. & $\mathrm{n}$ & bov-AChE ${ }^{b}$ & eq-BuChE $E^{c}$ & $h-A C h E^{d}$ & bov-AChE & h-AChE \\
\hline 31 & 6 & $280 \pm 20$ & $6.3 \pm 0.5$ & $87 \pm 8$ & 44.4 & 13.8 \\
\hline 32 & 7 & $400 \pm 35$ & $5.0 \pm 0.4$ & $75 \pm 6$ & 80.0 & 15.0 \\
\hline 33 & 8 & $240 \pm 20$ & $3.7 \pm 0.2$ & $43 \pm 5$ & 64.9 & 11.6 \\
\hline 34 & 7 & $350 \pm 30$ & $5.3 \pm 0.3$ & $40 \pm 4$ & 66.0 & 7.5 \\
\hline Tacrin & & $40 \pm 2$ & $10 \pm 0.4$ & $350 \pm 10$ & 4.0 & 35.0 \\
\hline
\end{tabular}

${ }^{a}$ Los resultados se expresan como la media de tres experimentos independientes $(n=3) \pm$ error estándar de la media (SEM). ${ }^{\mathrm{b}} \mathrm{AChE}$ (EC 3.1.1.7) de eritrocitos bovinos. ${ }^{\mathrm{c}} \mathrm{BuChE}$ (EC 3.1.1.8) procedente de suero de caballo. ${ }^{\mathrm{d}} \mathrm{AChE}$ (EC 3.1.1.7) de eritrocitos humanos. 'Selectividad hacia BuChE (equina) frente a AChE (bovina y humana), calculada como $\mathrm{CI}_{50}$ (bov-AChE o h-AChE) / CI 50 (eq-BuChE).

A la vista de estos resultados, decidimos probar nuestros compuestos como inhibidores de AChE humana y los resultados están también recogidos en la tabla 3. Sorprendentemente, y en contra de lo esperado por la similitud entre las enzimas bovina y humana, todos los híbridos 31-34 presentaron $\mathrm{CI}_{50}$ s más potentes en un orden de magnitud en AChE humana (40-87 nM) que en la enzima de mamífero (240-400 nM). Comparando con el referente, los híbridos tacrina - ferúlico son también un orden de magnitud más potentes en h-AChE que el fármaco tacrina.

En las tres enzimas ensayadas, la longitud de la cadena entre los dos anillos aromáticos de 31-34 no tiene gran influencia en su inhibición enzimática, lo que sugiere que todos ellos interaccionan de forma similar con las proteínas. 


\subsubsection{Predicción de la penetración en el SNC de los híbridos tacrina - ferúlico}

A continuación se evaluó la capacidad de penetración en el SNC de los híbridos tacrina - ferúlico 31-34, empleando el método in vitro PAMPA-BBB ya explicado con anterioridad (Tabla 14).

Tabla 14. Resultados de permeabilidad $\left(P_{\mathrm{e}}, 10^{-6} \mathrm{~cm} \mathrm{~s}^{-1}\right)^{\mathrm{a}}$ en experimentos PAMPA-BBB de los híbridos tacrina-ferúlico 3134 y su predicción para entrar en el SNC
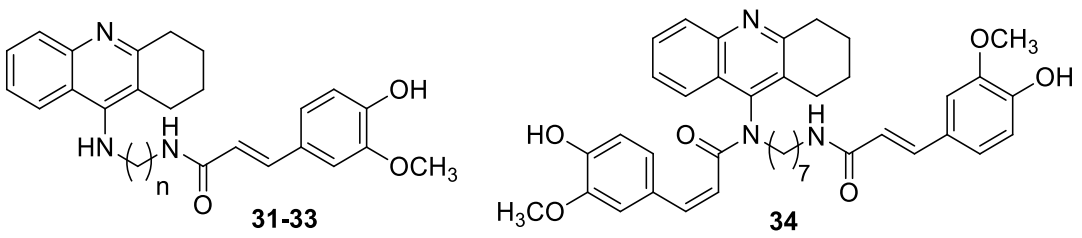

\begin{tabular}{cccc}
\hline Compuesto & $\mathrm{n}$ & $P_{\mathrm{e}}\left(10^{-6} \mathrm{~cm} \mathrm{~s}^{-1}\right)$ & Predicción \\
\hline $\mathbf{3 1}$ & 6 & $2.4 \pm 0.1$ & $\mathrm{snc}+/-$ \\
$\mathbf{3 2}$ & 7 & $2.6 \pm 0.1$ & $\mathrm{snc}+/-$ \\
$\mathbf{3 3}$ & 8 & $3.4 \pm 0.1$ & $\mathrm{snc}+/-$ \\
$\mathbf{3 4}$ & 7 & $3.5 \pm 0.1$ & $\mathrm{snc}+/-$
\end{tabular}

${ }^{a}$ Los resultados se expresan como la media de tres experimentos independientes $(\mathrm{n}=3) \pm$ desviación estándar (DS).

Como se recordará, los productos con una permeabilidad superior a $410^{-6} \mathrm{~cm} \mathrm{~s}^{-1}$ serían capaces de llegar al SNC, mientras que los que tengan una $P_{\text {e }}$ por debajo de $210^{-6}$ $\mathrm{cm} \mathrm{s}^{-1}$ no lo serían. Todos los híbridos tacrina - ferúlico 31-34 presentan permeabilidades entre ambos límites, lo que indica que tendrían dificultades para atravesar la barrera hematoencefálica.

Por otra parte, la existencia del doble enlace conjugado con la amida hace que los derivados del ácido ferúlico puedan comportarse como aceptores de Michael y reaccionen 
de manera indiscriminada con los numerosos grupos tiol presentes en las proteínas ${ }^{132,133}$, dando lugar a interacciones no deseadas con otras dianas biológicas (Esquema 5).

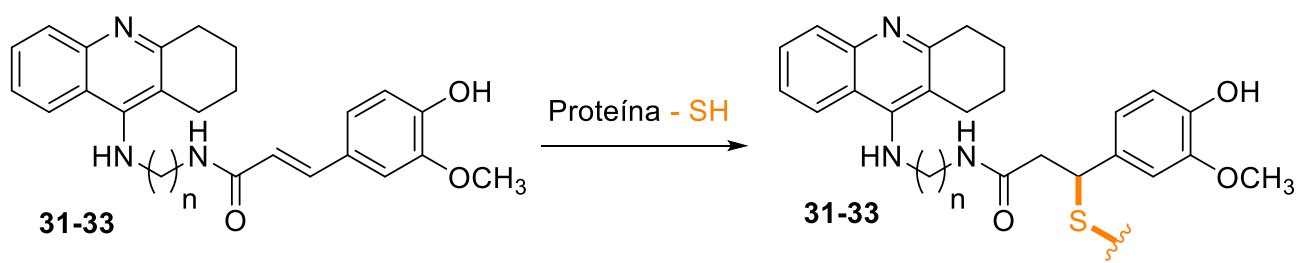

Esquema 5. Posible adición de Michael entre derivados del ácido ferúlico y grupos tiol de las proteínas

Estos potenciales inconvenientes como aceptores de Michael y su dudosa predicción para llegar al cerebro por difusión pasiva, junto con los problemas encontrados en la síntesis y purificación de los derivados del ácido ferúlico, nos indujeron a abordar la obtención de nuevos híbridos de tacrina con otros fragmentos antioxidantes como se explica a continuación.

\subsubsection{Híbridos tacrina - fenol}

Los fenoles y polifenoles naturales son metabolitos de la maquinaria celular de las plantas, que presentan potentes propiedades antioxidantes y que están involucrados en los mecanismos de autodefensa del organismo. Por ese motivo, en los últimos años ha aumentado el interés científico por este tipo de estructuras y sus potenciales beneficios en la prevención y tratamiento de enfermedades crónicas y degenerativas, como cáncer, enfermedades cardiovasculares, diabetes, Alzheimer, Parkinson, etc ${ }^{134}$.

132 Jackson, P. A.; Widen, J. C.; Harki, D. A.; Brummond, K. M. Covalent Modifiers: A Chemical Perspective on the Reactivity of alpha,beta-Unsaturated Carbonyls with Thiols via Hetero-Michael Addition Reactions. J. Med. Chem. 2017, 60, 839-885.

133 Brenk, R.; Schipani, A.; James, D.; Krasowski, A.; Gilbert, I. H.; Frearson, J.; Wyatt, P. G. Lessons learnt from assembling screening libraries for drug discovery for neglected diseases. ChemMedChem 2008, 3, 435-444.

134 Costa, C.; Tsatsakis, A.; Mamoulakis, C.; Teodoro, M.; Briguglio, G.; Caruso, E.; Tsoukalas, D.; Margina, D.; Dardiotis, E.; Kouretas, D.; Fenga, C. Current evidence on the effect of dietary polyphenols intake on chronic diseases. Food Chem. Toxicol. 2017, 110, 286-299. 
Como continuación de las familias anteriores, nos planteamos la síntesis de los híbridos tacrina - fenol que se muestran en el esquema 6.

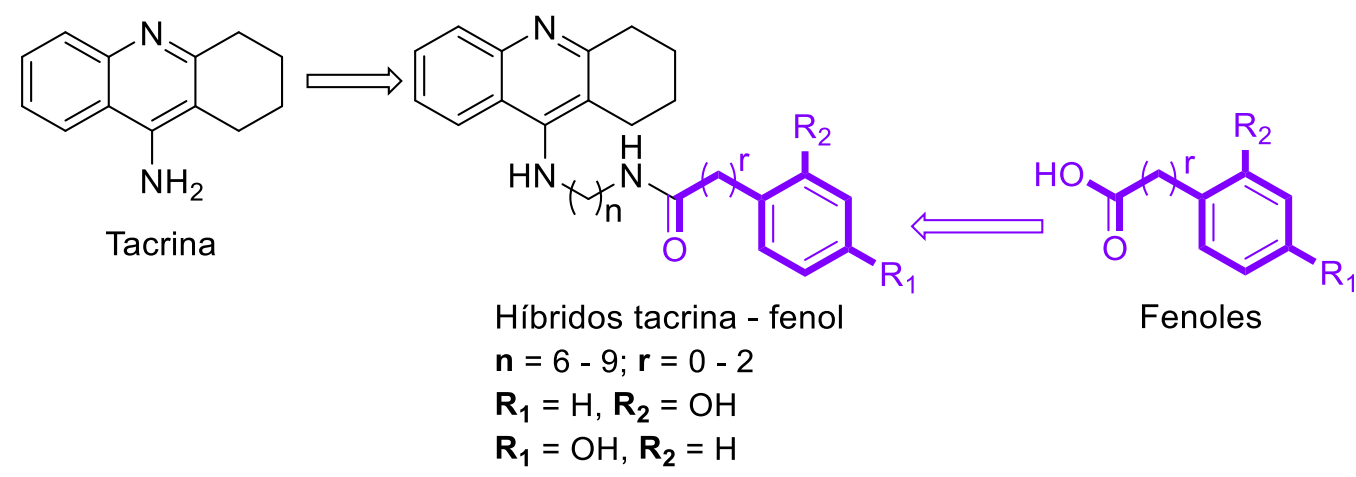

Esquema 6. Modificaciones estructurales planteadas para los híbridos tacrina-fenol

Con respecto a los anteriores híbridos tacrina - ferúlico, se plantearon cuatro tipos de modificaciones: (i) La longitud de cadena entre la amina del fragmento de tacrina y la amida, con distancias entre 6 y 9 metilenos $(n=6-9)$. (ii) Eliminación del doble enlace conjugado entre la amida y el anillo de benceno, para evitar que se comporten como aceptores de Michael. (iii) La distancia entre la amida y el anillo con el grupo fenol ( $\mathrm{r}=$ 0 -2). (iv) La posición orto- o meta- del grupo fenol.

\subsubsection{Síntesis de los híbridos tacrina - fenol}

Inicialmente, nos planteamos la síntesis de derivados con el grupo fenol en para- $\left(\mathrm{R}_{1}\right.$ $\left.=\mathrm{OH}, \mathrm{R}_{2}=\mathrm{H}\right)$ y con una longitud de cadena entre la amida y el fenol de 2 metilenos $(\mathrm{r}=$ 2). Para ello, se hicieron reaccionar las tacrinaminas 28-30 con el ácido 3-(4hidroxifenil)propanoico, empleando DCC y trietilamina en DMF. Desafortunadamente, dichas reacciones transcurrieron con muy bajo rendimiento, por lo que se intentaron optimizar modificando el agente acoplante (PyBOP) y los equivalentes de los distintos reactivos, sin conseguir mejorar los resultados. Sólo en el caso de $n=6$ se logró purificar la cantidad necesaria para identificar y evaluar el producto de interés 35 (Esquema 7). 


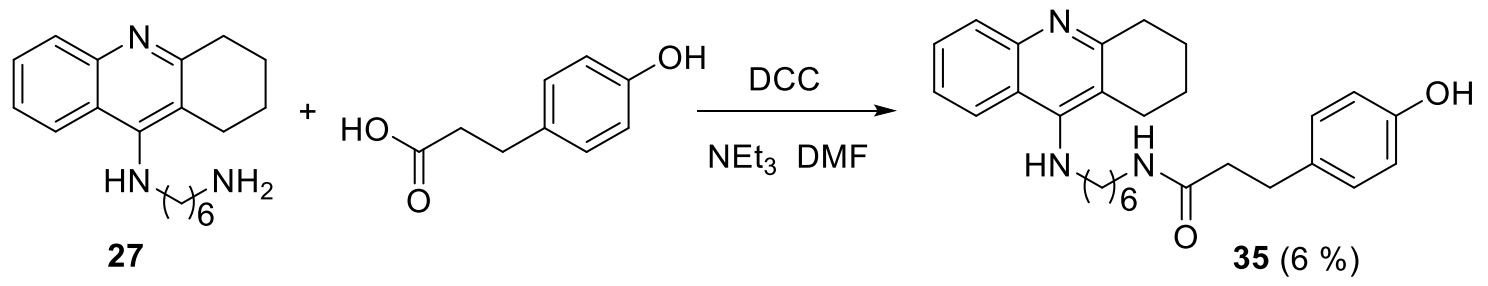

Esquema 7. Síntesis del híbrido 35

El cambio del grupo fenol de la posición para- a la orto- mejoró la obtención de los híbridos correspondientes 36-39. Así, cuando se empleó el ácido 3-(2hidroxifenil)propanoico en las condiciones anteriores, la reacciones trascurren con rendimientos superiores, comprendidos entre el 43y el 65\% (tabla 15). Este hecho probablemente se debe a que el cambio de la posición del grupo hidroxilo de la posición para- a la orto-, permite que se establezcan puentes de hidrógeno intramoleculares, aumentando así el carácter ácido y por tanto su reactividad con la correspondiente tacrindiamina.

Tabla 15. Híbridos derivados del ácido 3-(2-hidroxifenil)propanoico (36-39)

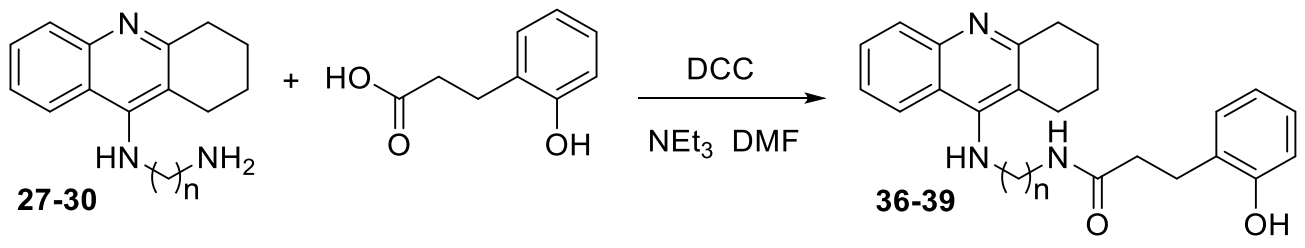

\begin{tabular}{cccc}
\hline Compuesto & $\mathrm{n}$ & Rendimiento $(\%)^{\mathrm{a}}$ & $\mathrm{t}_{\mathrm{R}(\min )} \mathrm{b}$ \\
\hline $\mathbf{3 6}$ & 6 & 43 & 10.5 \\
$\mathbf{3 7}$ & 7 & 60 & 10.8 \\
$\mathbf{3 8}$ & 8 & 65 & 11.1 \\
$\mathbf{3 9}$ & 9 & 55 & 11.3 \\
\hline
\end{tabular}

${ }^{a}$ Rendimiento de producto aislado. ${ }^{\text {b}}$ HPLC Alliance Waters 2690, detector de UV Photodiodo Array modelo Waters 2996 acoplado a un detector de masas modelo MicromassZQ de Waters, columna XBridgeTM C18, $3.5 \mu \mathrm{m}, 200 \AA$ (2.1 nm x $100 \mathrm{~mm})$. Eluyente $\left(\mathrm{CH}_{3} \mathrm{CN}: \mathrm{H}_{2} \mathrm{O}\right) / \mathrm{CF}_{3} \mathrm{CO}_{2} \mathrm{H}(0.05 \%)$. Flujo de $0.25 \mathrm{~mL} / \mathrm{min} . \mathrm{tg}=15$ 
Continuando con las modificaciones estructurales planteadas y a la vista de los buenos resultados sintéticos obtenidos con los derivados de $o$-fenol, a continuación se sintetizaron los derivados con un grupo metileno entre el fenol y la amida $(r=1)$. El acoplamiento de las distintas tacrinaminas con el ácido 2-(2-hidroxifenil)acético permitió obtener los híbridos $\mathbf{4 0 - 4 3}$ con moderados rendimientos (Tabla 16).

Tabla 16. Híbridos derivados del ácido 2-(2-hidroxifenil)acético (40-43)

\begin{tabular}{|c|c|c|c|}
\hline Compuesto & $\mathrm{n}$ & Rendimiento $(\%)^{\mathrm{a}}$ & $\mathrm{t}_{\mathrm{R}(\min )} \mathrm{b}^{\mathrm{s}}$ \\
\hline 40 & 6 & 17 & 10.7 \\
\hline 41 & 7 & 31 & 11.1 \\
\hline 42 & 8 & 55 & 11.4 \\
\hline 43 & 9 & 51 & 11.8 \\
\hline
\end{tabular}

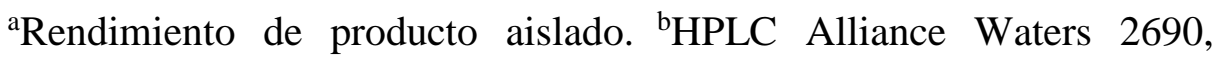
detector de UV Photodiodo Array modelo Waters 2996 acoplado a un detector de masas modelo MicromassZQ de Waters, columna XBridgeTM C18, $3.5 \mu \mathrm{m}, 200 \AA$ (2.1 nm x $100 \mathrm{~mm})$. Eluyente $\left(\mathrm{CH}_{3} \mathrm{CN}\right.$ : $\left.\mathrm{H}_{2} \mathrm{O}\right) / \mathrm{CF}_{3} \mathrm{CO}_{2} \mathrm{H}(0.05 \%)$. Flujo de $0.25 \mathrm{~mL} / \mathrm{min}$. tg=15

Finalmente, para obtener los derivados con $\mathrm{r}=0$ se hizo reaccionar el ácido 2hidroxibenzoico con las diferentes tacrinaminas, obteniendo los híbridos deseados 4447, aunque con menores rendimientos que en los casos anteriores (Tabla 17). 
Tabla 17. Híbridos derivados del ácido 2-hidroxibenzoico

\begin{tabular}{cccc} 
Compuesto & $\mathrm{n}$ & Rendimiento $(\%)^{\mathrm{a}}$ & $\mathrm{t}_{\mathrm{R}(\min )}^{\mathrm{b}}$ \\
$\mathbf{4 4}$ & 6 & 13 & 11.5 \\
$\mathbf{4 5}$ & 7 & 12 & 12.1 \\
$\mathbf{4 6}$ & 8 & 13 & 12.5 \\
$\mathbf{4 7}$ & 9 & 11 & 13.0 \\
\hline
\end{tabular}

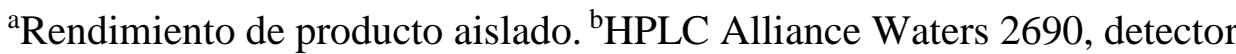
de UV Photodiodo Array modelo Waters 2996 acoplado a un detector de masas modelo MicromassZQ de Waters, columna XBridgeTM C18, 3.5 $\mu \mathrm{m}, 200 \AA(2.1 \mathrm{~nm} \times 100 \mathrm{~mm})$. Eluyente $\left(\mathrm{CH}_{3} \mathrm{CN}: \mathrm{H}_{2} \mathrm{O}\right) / \mathrm{CF}_{3} \mathrm{CO}_{2} \mathrm{H}$ $(0.05 \%)$. Flujo de $0.25 \mathrm{~mL} / \mathrm{min} . \mathrm{tg}=15$

\subsubsection{Inhibición de acetil y butirilcolinesterasa de los híbridos tacrina-o-fenol}

Los híbridos tacrina - o-fenol 36-47 fueron evaluados como inhibidores de colinesterasas, siguiendo el método de Ellman y empleando tacrina como patrón ${ }^{127}$. En este caso, se empleó AChE procedente de eritrocitos humanos (h-AChE) y BuChE de suero de caballo (eq-BuChE) y los resultados están recogidos en la tabla 18.

Todos los híbridos tacrina - $o$-fenol 36-47 son potentes inhibidores de AChE humana y BuChE equina, mejores que la anterior familia derivada de tacrina y ácido ferúlico. El mejor inhibidor de h-AChE es el híbrido $38(\mathrm{r}=2, \mathrm{n}=8)$ con una $\mathrm{CI}_{50}$ de $0.85 \mathrm{nM}, 412$ veces más potente que tacrina. En general, los híbridos tacrina - o-fenol presentan una clara selectividad por eq-BuChE con $\mathrm{CI}_{50} \mathrm{~s}$ en los rangos nanomolar bajo y subnanomolar, llegando a picomolar en los casos de los híbridos $36\left(\mathrm{r}=2, \mathrm{n}=6, \mathrm{CI}_{50}=74\right.$ $\mathrm{pM}), 38\left(\mathrm{r}=2, \mathrm{n}=8, \mathrm{CI}_{50}=77 \mathrm{pM}\right), 46\left(\mathrm{r}=0, \mathrm{n}=8, \mathrm{CI}_{50}=85 \mathrm{pM}\right)$ y $44(\mathrm{r}=0, \mathrm{n}=6$, $\mathrm{CI}_{50}=93 \mathrm{pM}$ ). Estos inhibidores son más de 107 veces más potentes que el referente tacrina. 
Tabla 18. Inhibición de h-AChE y eq-BuChE de los híbridos tacrina $-o$-fenol ${ }^{\mathrm{a}}$

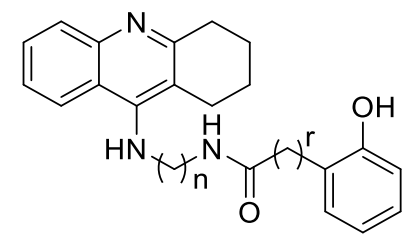

\begin{tabular}{cccccc}
\hline & & & \multicolumn{2}{c}{$\mathrm{CI}_{50} \pm \mathrm{SEM}(\mathrm{nM})^{\mathrm{a}}$} & $\begin{array}{c}\text { Selectividad } \\
\text { BuChE }^{\mathrm{d}}\end{array}$ \\
\cline { 5 - 6 } Comp. & $\mathrm{r}$ & $\mathrm{n}$ & $\mathrm{h}-\mathrm{AChE}^{\mathrm{b}}$ & eq-BuChEc & \\
\hline $\mathbf{3 6}$ & 2 & 6 & $5.31 \pm 0.50$ & $0.074 \pm 0.005$ & 71.8 \\
$\mathbf{3 7}$ & 2 & 7 & $5.21 \pm 0.49$ & $0.214 \pm 0.012$ & 24.3 \\
$\mathbf{3 8}$ & 2 & 8 & $0.85 \pm 0.05$ & $0.077 \pm 0.005$ & 11.0 \\
$\mathbf{3 9}$ & 2 & 9 & $13.9 \pm 1.10$ & $21.6 \pm 1.2$ & 0.64 \\
$\mathbf{4 0}$ & 1 & 6 & $4.97 \pm 0.38$ & $0.164 \pm 0.08$ & 30.3 \\
$\mathbf{4 1}$ & 1 & 7 & $1.10 \pm 0.09$ & $0.183 \pm 0.09$ & 6.0 \\
$\mathbf{4 2}$ & 1 & 8 & $5.73 \pm 0.42$ & $0.197 \pm 0.10$ & 29.1 \\
$\mathbf{4 3}$ & 1 & 9 & $40.4 \pm 2.1$ & $10.0 \pm 0.9$ & 4.0 \\
$\mathbf{4 4}$ & 0 & 6 & $10.5 \pm 0.8$ & $0.093 \pm 0.007$ & 112.9 \\
$\mathbf{4 5}$ & 0 & 7 & $1.77 \pm 0.09$ & $0.125 \pm 0.009$ & 14.2 \\
$\mathbf{4 6}$ & 0 & 8 & $11.2 \pm 0.08$ & $0.085 \pm 0.002$ & 131.8 \\
$\mathbf{4 7}$ & 0 & 9 & $336 \pm 20$ & $48.7 \pm 1.2$ & 6.9 \\
Tacrina & & $350 \pm 10$ & $10 \pm 0.4$ & 35.0 \\
& & & & & \\
\hline
\end{tabular}

${ }^{a}$ Los resultados son la media de tres experimentos independientes (n = 3) \pm error estándar de la media (SEM). ${ }^{\mathrm{b}} \mathrm{AChE}$ (EC 3.1.1.7) de eritrocitos humanos. ${ }^{\mathrm{c}} \mathrm{BuChE}$ (EC 3.1.1.8) procedente de suero de caballo. ${ }^{\mathrm{d} S e l e c t i v i d a d ~ h a c i a ~} \mathrm{BuChE}$ (equina) frente a $\mathrm{AChE}$ (humana), calculada como $\mathrm{CI}_{50}$ (h-AChE) / $\mathrm{CI}_{50}$ (eq-BuChE).

A partir de los datos recogidos en la tabla 18 se pueden establecer algunas correlaciones entre la estructura química y la actividad biológica (SAR, por sus siglas en inglés). Manteniendo constante la distancia entre el grupo amida y el anillo de $o$-fenol (r), en todas las series se comprueba que los mejores inhibidores de eq-BuChE son los derivados con 6 metilenos entre el fragmento de tacrina y el grupo amida $(n=6): 36\left(\mathrm{IC}_{50}\right.$ $=74 \mathrm{pM}), \mathbf{4 0}\left(\mathrm{IC}_{50}=164 \mathrm{pM}\right)$ y $44\left(\mathrm{IC}_{50}=93 \mathrm{pM}\right)$. En lo que se refiere a la inhibición de 
h-AChE los mejores resultados se obtuvieron cuando entre la tacrina y la amida había 8 metilenos $\left(\mathbf{3 8}, \mathrm{IC}_{50}=0.85 \mathrm{nM}\right)$ ó 7 metilenos $\left(41 \mathrm{y} \mathrm{45,} \mathrm{IC}_{50}=1.10\right.$ y $1.77 \mathrm{nM}$, respectivamente).

Finalmente, cabe destacar que los híbridos tacrina - o-fenol $44(\mathrm{r}=0, \mathrm{n}=6)$ y $46(\mathrm{r}$ $=0, \mathrm{n}=8$ ) son los inhibidores de BuChE más selectivos de toda la serie sintetizada, inhibiendo respectivamente 113- y 132-veces más a la eq-BuChE que a la h-AChE. Esta marcada selectividad por la BuChE puede ser interesante, puesto que a medida que la enfermedad de Alzheimer progresa, la actividad de la AChE cerebral disminuye paulatinamente, mientras que la de la BuChE se mantiene o incluso aumenta ligeramente $^{135}$. Como consecuencia, la regulación del neurotransmisor acetilcolina se va haciendo cada vez más dependiente de BuChE y, por lo tanto, los inhibidores selectivos de esta enzima mejoran más eficazmente la neurotransmisión colinérgica, proporcionando un mayor beneficio terapéutico en las fases avanzadas de la enfermedad de Alzheimer ${ }^{136}$.

\subsubsection{Predicción de la penetración en el SNC de los híbridos tacrina-o-fenol}

Los híbridos tacrina - $o$-fenol fueron evaluados en experimentos PAMPA-BBB para conocer su habilidad para penetrar en el SNC por difusión pasiva y los resultados están recogidos en la tabla 19.

Todos los híbridos evaluados presentaron buenos valores de permeabilidad en el $\mathrm{SNC}(\mathrm{snc}+)$, con la excepción del derivado 40 con 6 metilenos $(\mathrm{n}=6)$ entre el fragmento de tacrina y el grupo amida, que se encuentra en la zona de incertidumbre (snc + / -). A medida que aumenta este espaciador $(n \geq 7)$ aumenta progresivamente la permeabilidad de los híbridos, de acuerdo con el progresivo aumento en la lipofilia de las moléculas ${ }^{137}$.

En el caso de la serie de los híbridos tacrina - $o$-hidroxibenzoico $(\mathrm{r}=0)$ sólo se evaluaron en PAMPA-BBB los compuestos con menor y mayor número de carbonos en

\footnotetext{
${ }^{135}$ Giacobini, E. Cholinesterases: new roles in brain function and in Alzheimer's disease. Neurochem. Res. 2003, 28, 515-522.

${ }^{136}$ Lane, R. M.; Potkin, S. G.; Enz, A. Targeting acetylcholinesterase and butyrylcholinesterase in dementia. Int. J. Neuropsychopharmacol. 2006, 9, 101-124.

${ }^{137}$ Rutkowska, E.; Pajak, K.; Jozwiak, K. Lipophilicity--methods of determination and its role in medicinal chemistry. Acta Pol. Pharm. 2013, 70, 3-18.
} 
el espaciador ( 44 y 47, $\mathrm{n}=6$ y 9). Ambos atravesarían la BHE, y considerando su comportamiento, podemos pensar que los híbridos 45 y $46(n=7$ y 8) también lo harían.

Tabla 19. Resultados de permeabilidad $\left(P_{\mathrm{e}}, 10^{-6} \mathrm{~cm} \mathrm{~s}^{-1}\right)^{\mathrm{a}}$ en experimentos PAMPA-BBB de los híbridos tacrina $o$-fenol 36-47 y su predicción para entrar en el SNC

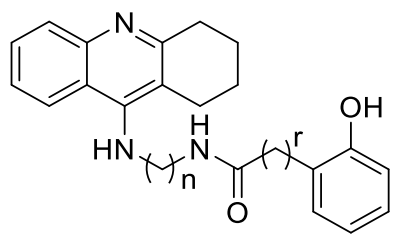

\begin{tabular}{ccccc}
\hline Compuesto & $\mathrm{r}$ & $\mathrm{n}$ & $P_{\mathrm{e}}\left(10^{-6} \mathrm{~cm} \mathrm{~s}^{-1}\right)$ & Predicción \\
\hline $\mathbf{3 6}$ & 2 & 6 & $4.3 \pm 0.1$ & $\mathrm{snc}+$ \\
$\mathbf{3 7}$ & 2 & 7 & $4.7 \pm 0.1$ & $\mathrm{snc}+$ \\
$\mathbf{3 8}$ & 2 & 8 & $6.0 \pm 0.2$ & $\mathrm{snc}+$ \\
$\mathbf{3 9}$ & 2 & 9 & $7.6 \pm 0.1$ & $\mathrm{snc}+$ \\
$\mathbf{4 0}$ & 1 & 6 & $3.7 \pm 0.1$ & $\mathrm{snc}+/-$ \\
$\mathbf{4 1}$ & 1 & 7 & $5.8 \pm 0.1$ & $\mathrm{snc}+$ \\
$\mathbf{4 2}$ & 1 & 8 & $7.1 \pm 0.2$ & $\mathrm{snc}+$ \\
$\mathbf{4 3}$ & 1 & 9 & $8.8 \pm 0.2$ & $\mathrm{snc}+$ \\
$\mathbf{4 4}$ & 0 & 6 & $6.5 \pm 0.1$ & $\mathrm{snc}+$ \\
$\mathbf{4 7}$ & 0 & 9 & $8.1 \pm 0.2$ & snc + \\
\end{tabular}

${ }^{\text {aLos }}$ resultados se expresan como la media de tres experimentos independientes $(\mathrm{n}=3) \pm$ desviación estándar (DS).

\subsubsection{Estudio de unión al PAS de la AChE de híbridos tacrina - o-fenol}

Como ya se comentó en la introducción, diferentes estudios han indicado que la enzima AChE presenta acciones no-colinérgicas relacionadas con procesos de adhesión celular. Esta enzima también interacciona con oligómeros y fibrillas del péptido $\beta$ amiloide $(\beta \mathrm{A})$, promoviendo su agregación en placas amiloides ${ }^{138}$. El punto de interacción entre AChE y $\beta$ A parece estar situado en el sitio aniónico periférico (PAS) en

${ }^{138}$ Cerpa, W.; Dinamarca, M. C.; Inestrosa, N. C. Structure-function implications in Alzheimer's disease: effect of Abeta oligomers at central synapses. Curr. Alzheimer Res. 2008, 5, 233-243. 
la entrada de la garganta catalítica de la AChE, puesto que los inhibidores selectivos de centro activo (CAS) no disminuyen la agregación de $\beta A$, mientras que propidio, un ligando selectivo de PAS, evita la oligomerización de fibrillas de $\beta \mathrm{A}^{139}$.

Cuando se encuentra unido al PAS de la enzima, el propidio emite fluorescencia y esta señal desciende cuando es desplazado de su sitio de unión por un inhibidor con mayor afinidad, siendo este descenso proporcional a la cantidad de propidio desplazado. Este ensayo ha sido empleado en experimentos competitivos para evaluar la interacción de diferentes inhibidores con el PAS de la AChE, siendo un método indirecto para estudiar el efecto de estas moléculas sobre la agregación del $\beta \mathrm{A}^{140}$.

Con el fin de estudiar la unión de los híbridos tacrina - o-fenol al PAS de la AChE, se realizó un estudio de desplazamiento de propidio con una selección de compuestos a tres concentraciones $(0.3,1.0$ y $3.0 \mu \mathrm{M})$ empleando donepezilo $(0.3 \mu \mathrm{M})$ como control positivo (Tabla 20).

Tabla 20. Desplazamiento de propidio (\%) de híbridos tacrina - o-fenol a las concentraciones indicadas. ${ }^{\mathrm{a}}$

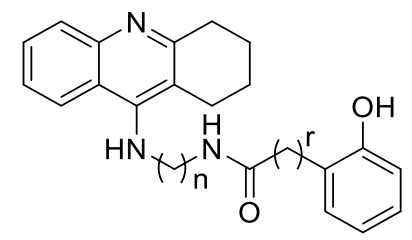

\begin{tabular}{cccccc}
\hline & & & \multicolumn{3}{c}{ Desplazamiento de propidio (\%) } \\
\cline { 4 - 6 } compuesto & $\mathrm{r}$ & $\mathrm{n}$ & $0.3 \mu \mathrm{M}$ & $1.0 \mu \mathrm{M}$ & $3.0 \mu \mathrm{M}$ \\
\hline $\mathbf{3 6}$ & 2 & 6 & $23.5 \pm 3.1$ & $13.0 \pm 0.8$ & $15.2 \pm 1.0$ \\
$\mathbf{4 0}$ & 1 & 6 & $11.2 \pm 1.0$ & $\mathrm{nd}$ & $\mathrm{nd}$ \\
$\mathbf{4 2}$ & 1 & 8 & $6.4 \pm 0.9$ & $12.4 \pm 1.1$ & $3.6 \pm 0.7$ \\
$\mathbf{4 4}$ & 0 & 6 & $23.8 \pm 3.1$ & $24.6 \pm 2.2$ & $10.0 \pm 0.8$ \\
$\mathbf{4 6}$ & 0 & 8 & $39.7 \pm 4.2$ & $46.1 \pm 4.1$ & $20.7 \pm 2.0$ \\
Donepezilo & & $19.4 \pm 2.0$ & $\mathrm{nd}$ & $\mathrm{nd}$
\end{tabular}

${ }^{\mathrm{a}}$ Los resultados son la media de tres experimentos independientes $(\mathrm{n}=3)$

\footnotetext{
${ }^{139}$ De Ferrari, G. V.; Canales, M. A.; Shin, I.; Weiner, L. M.; Silman, I.; Inestrosa, N. C. A structural motif of acetylcholinesterase that promotes amyloid beta-peptide fibril formation. Biochemistry 2001, 40, 10447-10457.

140 Taylor, P.; Lappi, S. Interaction of fluorescence probes with acetylcholinesterase: the site and specifity of propidium binding. Biochemistry 1975, 14, 1989-1997.
} 
En mayor o menor medida, todos los híbridos evaluados son capaces de desplazar propidio del PAS, en algunos casos con más eficacia que el propio donepezilo. Destaca el híbrido 46 derivado del ácido $o$-hidroxibenzoico $(r=0)$ con una cadena de 8 metilenos entre el fragmento de tacrina y el grupo amida $(\mathrm{n}=8)$, que a $1.0 \mu \mathrm{M}$ desplaza al propidio en un $46 \%$ del PAS de la enzima. Puesto que se sabe que el fragmento de tacrina se une preferentemente al CAS de la AChE, estos resultados apuntan a que el anillo de $o$-fenol probablemente esté interaccionando con el PAS. Por lo tanto, podríamos pensar que nuestros híbridos son capaces de interaccionar simultáneamente con el CAS y PAS de la enzima, mejorando la transmisión colinérgica e impidiendo la agregación del $\beta \mathrm{A}^{141}$.

\subsubsection{Ensayos de toxicidad y de neuroprotección frente al estrés oxidativo mitocondrial}

Con el fin de explorar el potencial terapéutico de los híbridos tacrina - fenol, a continuación se estudió la toxicidad y la capacidad neuroprotectora frente al estrés oxidativo mitocondrial de una pequeña selección de estos compuestos $(35,36$ y 47$)$ en la línea celular SH-SY5Y de neuroblastoma humano. Para evaluar la citotoxicidad, las células SH-SY5Y se trataron con cada uno de los híbridos a la concentración de $1.0 \mu \mathrm{M}$ durante 24 horas, al cabo de las cuales se midió el porcentaje de muerte celular a partir de la concentración de lactato deshidrogenasa ( $\mathrm{LDH})$, que es una proteína que se libera al medio extracelular cuando las células mueren ${ }^{142}$. En todos los casos, la concentración de LDH fue similar al valor basal, lo que indica que la viabilidad celular está en torno al $100 \%$ y que los productos no son tóxicos.

A continuación, se estudió el efecto neuroprotector de las moléculas frente al estrés oxidativo mitocondrial, empleando la línea celular SH-SY5Y y una mezcla tóxica compuesta por rotenona y oligomicina A. La combinación de dichos tóxicos provoca la generación de radicales libres de oxígeno (ROS) endógenos como consecuencia del bloqueo de los complejos I y $\mathrm{V}$ de la cadena respiratoria mitocondrial, por lo que se considera un buen modelo de estrés oxidativo mitocondrial ${ }^{143}$. Las células fueron

${ }^{141}$ Alvarez, A.; Opazo, C.; Alarcón, R.; Garrido, J.; Inestrosa, N. C. Acetylcholinesterase promotes the aggregation of amyloid-beta-peptide fragments by forming a complex with the growing fibrils. J. Mol. Biol. 1997, 272, 348-361.

${ }^{142}$ Cummings, B. S.; Wills, L. P.; Schnellmann, R. G. Measurement of cell death in Mammalian cells. Curr. Protoc. Pharmacol. 2012, Chapter 12, Unit12 18.

${ }^{143}$ González-Muñoz, G. C.; Arce, M. P.; López, B.; Pérez, C.; Villarroya, M.; López, M. G.; García, A. G.; Conde, S.; Rodríguez-Franco, M. I. Old phenothiazine and dibenzothiadiazepine derivatives for tomorrow's neuroprotective therapies against neurodegenerative diseases. Eur. J. Med. Chem. 2010, 45, 6152-6158. 
incubadas en presencia de $1 \mu \mathrm{M}$ de cada uno de los compuestos durante 24 horas antes de la adición de la mezcla de rotenona $(30 \mu \mathrm{M})$ y oligomicina A $(10 \mu \mathrm{M})$. Después se mantuvieron durante 24 horas adicionales con la mezcla tóxica y los productos a evaluar, midiéndose a continuación la concentración de LDH. En estos experimentos se empleó melatonina como control positivo, que a $0.3 \mu \mathrm{M}$ ejerció un $33 \%$ de protección, y los resultados se encuentran en la tabla 21 .

Tabla 21. Porcentaje de neuroprotección (\%) de los híbridos 35, 36 y $47(1 \mu \mathrm{M})$ en células SH-SY5Y frente a la mezcla de rotenona $(30 \mu \mathrm{M})$ y oligomicina $\mathrm{A}(10 \mu \mathrm{M}){ }^{\mathrm{a}}$

Comp. Neuroprotección (\%)

${ }^{a}$ Los resultados son la media \pm SEM de tres experimentos independientes

Los híbridos 35 y 36 presentan una moderada neuroprotección frente al estrés oxidativo mitocondrial, en torno al 20-24\%, mientras que el compuesto 47 protege tan sólo un $6 \%$ frente a la mezcla de rotenona y oligomicina A. El cambio de posición del grupo fenol desde la posición para- (compuesto 35) a la orto- (híbrido 36) se traduce en un significativo aumento de las propiedades neuroprotectoras, mientras que el alargamiento de la cadena de 6 a 9 metilenos va en detrimento de estas propiedades.

A modo de resumen, se han diseñado y sintetizado tres familias de híbridos por unión del fragmento de tacrina con tiramina y homoveratrilamina (12-26), con ácido ferúlico (31-34) y con fragmentos derivados de para- y orto-fenol (35-47). En las tres series se han obtenido potentes inhibidores de bov-AChE y eq-BuChE en el rango nanomolar. 
Sorprendentemente, los híbridos tacrina - ferúlico fueron un orden de magnitud más potentes en la $\mathrm{AChE}$ humana que en la enzima de origen animal, por lo que los siguientes derivados de $p$ - y $o$-fenol, éstos fueron ensayados en h-AChE y no en bov-AChE. De las tres familias, sólo los híbridos tacrina - $o$-fenol mostraron una aceptable permeabilidad en el SNC, según el método PAMPA-BBB, por lo que algunos de sus representantes fueron elegidos para posteriores estudios biológicos, como la medida del desplazamiento de propidio del PAS de la AChE y estudios de neuroprotección frente al estrés oxidativo mitocondrial en la línea celular de neuroblastoma humano SH- SY5Y.

Entre ellos, destaca el híbrido 36, que es un inhibidor nanomolar de colinesterasas, con selectividad hacia eq-BuChE frente a h-AChE $\left(\mathrm{CI}_{50} \mathrm{~S}=0.074\right.$ y $5.31 \mathrm{nM}$, respectivamente), lo que podría ser útil en las fases avanzadas de la enfermedad de Alzheimer, en las que la transmisión colinérgica se hace más dependiente de BuChE, como se explicó con anterioridad. Además, este híbrido es capaz de desplazar propidio del PAS de la AChE, por lo que podría impedir la agregación del péptido $\beta$ A patógeno y frenar de esta manera el proceso de degeneración neuronal. En los ensayos celulares protegió en un $24 \%$ al neuroblastoma del efecto tóxico de una mezcla de rotenona y oligomicina A, que un modelo del estrés oxidativo mitocondrial. Finalmente, el híbrido 36 presentó una aceptable permeabilidad in vitro en el sistema nervioso central, según el experimento PAMPA-BBB $\left(P_{\mathrm{e}}=4.310^{-6} \mathrm{~cm} \mathrm{~s}^{-1}\right)$, por lo que sería capaz de llegar al cerebro e interaccionar con sus dianas situadas en el SNC. 


\subsection{HÍBRIDOS $N, N$-DIBENCIL( $N$-METIL)AMINA - NEUROAMINAS Y $N, N$ - DIBENCIL( $N$-METIL)AMINA - PIRIDINA / PIRIDINOL}

El primer fármaco comercializado para el tratamiento de la EA (tacrina) fue posteriormente retirado del mercado debido a la toxicidad hepática observada en varias cohortes de pacientes ${ }^{144}$. Por ese motivo, en este trabajo se planteó reemplazar el fragmento de tacrina empleado en las series anteriores, por el de $N, N$-dibencil $(N$ metil)amina (DBMA) presente en varios fármacos multi-diana, como AP2238 y AP2469 (Figura 14). Estos compuestos son buenos inhibidores de AChE, debido a la interacción del fragmento de DBMA con el centro activo de la enzima (CAS). También presentan un interesante perfil multifuncional para el potencial tratamiento de la EA: inhiben la agregación del péptido $\beta$-amiloide y presentan propiedades neuroprotectoras $\mathrm{y}$ antiinflamatorias $^{145,146}$.

Por otra parte, actualmente existen claras evidencias de que el estrés oxidativo juega un papel determinante en el origen y desarrollo de la neurodegeneración ${ }^{147}$. Esta hipótesis está avalada por el descubrimiento de que las alteraciones oxidativas de numerosas estructuras celulares preceden a las lesiones características de la EA, como las placas amiloides y los ovillos neurofibrilares ${ }^{148}$. Como consecuencia, en los últimos años se ha estudiado con mucho interés la actividad antioxidante de fenoles de origen natural ${ }^{149}$ y su aplicación en la prevención y tratamiento de enfermedades asociadas con la edad.

${ }^{144}$ Watkins, P. B.; Zimmerman, H. J.; Knapp, M. J.; Gracon, S. I.; Lewis, K. W. Hepatotoxic effects of tacrine administration in patients with Alzheimer's disease. JAMA 1994, 271, 992-998.

${ }^{145}$ Piazzi, L.; Rampa, A.; Bisi, A.; Gobbi, S.; Belluti, F.; Cavalli, A.; Bartolini, M.; Andrisano, V.; Valenti, P.; Recanatini, M. 3-(4-[[Benzyl(methyl)amino]methyl]phenyl)-6,7-dimethoxy-2H-2-chromenone (AP2238) inhibits both acetylcholinesterase and acetylcholinesterase-induced beta-amyloid aggregation: a dual function lead for Alzheimer's disease therapy. J. Med. Chem. 2003, 46, 2279-2282.

146 Tarozzi, A.; Bartolini, M.; Piazzi, L.; Valgimigli, L.; Amorati, R.; Bolondi, C.; Djemil, A.; Mancini, F.; Andrisano, V.; Rampa, A. From the dual function lead AP2238 to AP2469, a multi-target-directed ligand for the treatment of Alzheimer's disease. Pharmacol. Res. Perspect. 2014, 2, e00023.

147 Zhu, X.; Lee, H. G.; Perry, G.; Smith, M. A. Alzheimer disease, the two-hit hypothesis: an update. Biochim. Biophys. Acta. 2007, 1772, 494-502.

${ }^{148}$ Nunomura, A., Perry, G., Pappolla, M. A., Friedland, R. P., Hirai, K., Chiba, S. ,Smith, M. A., Neuronal oxidative stress precedes amyloid-beta deposition in Down syndrome, J. Neuropathol. Exp. Neurol. 2000, 59, 1011-7.

149 Ordui, S.;Tsimidou, M., Crocin Bleaching Assay (CBA) in Structure-Radical Scavenging Activity Studies of Selected Phenolic Compounds, J. Agric. Food Chem. 2006, 54, 9347-9356 
A la vista de estos precedentes, decidimos emplear el fragmento de DBMA para desarrollar nuevas familias de inhibidores de $\mathrm{AChE}$ con propiedades neuroprotectoras adicionales, mediante su unión a fragmentos derivados de neuroaminas y de piridinol. Como se recordará de las series anteriores, las neuroaminas como la tiramina y la homoveratrilamina, actúan como neuromoduladores y se encuentran presentes en numerosos alimentos ${ }^{150}$. Por otra parte, se ha descrito que diferentes piridinoles poseen una capacidad antioxidante cien veces mayor que la vitamina $\mathrm{E}^{151}$, por lo que nos pareció muy interesante introducir este tipo de subestructuras en nuestros híbridos. Por lo tanto, nos planteamos la obtención de híbridos DBMA - neuroaminas y DBMA - piridina / piridinol, cuyas estructuras generales se representan en la figura 29.
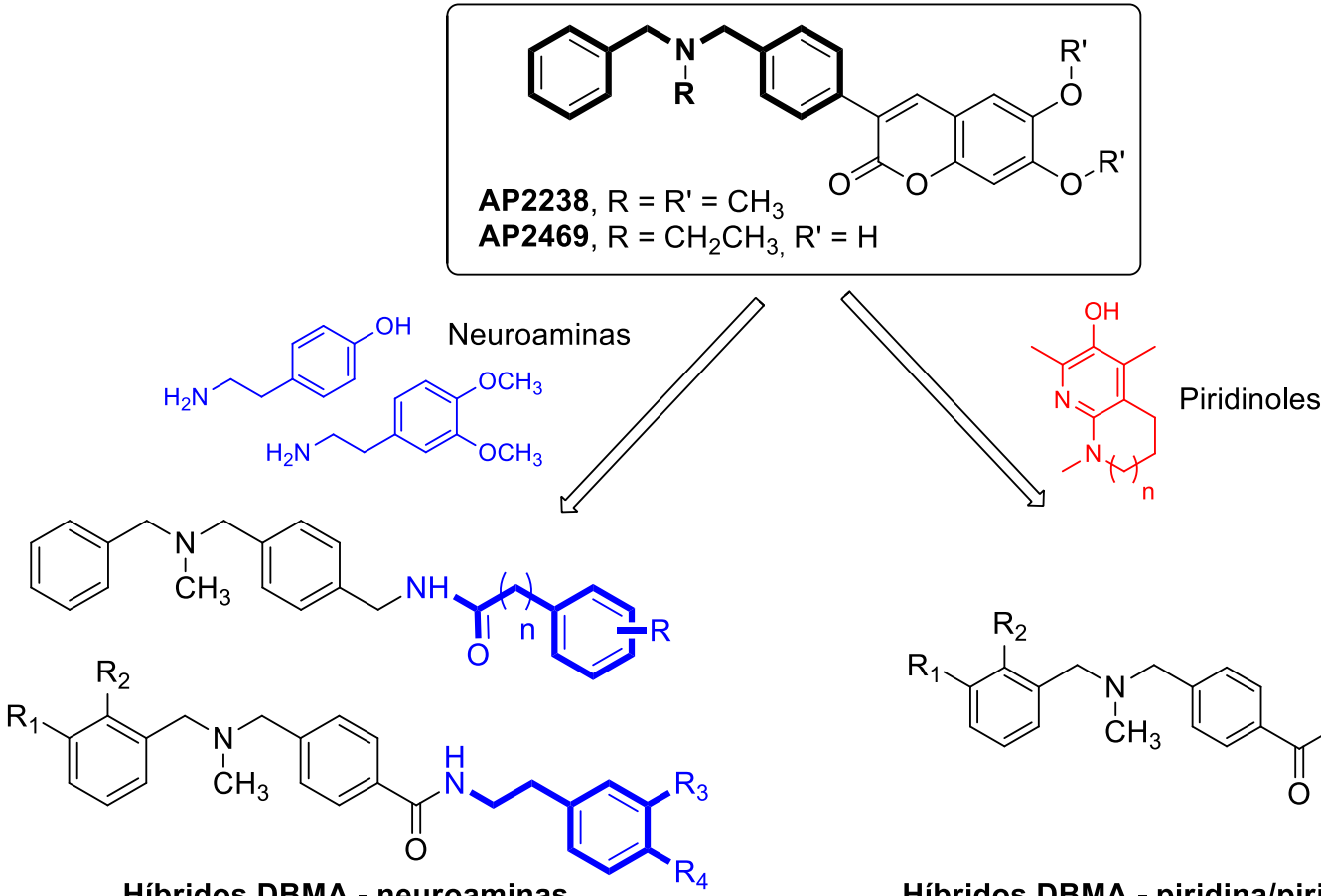<smiles>[R]c1ccccc1CN(C)Cc1ccc(C(=O)Nc2ncccc2[R])cc1</smiles>

Híbridos DBMA - neuroaminas

Híbridos DBMA - piridina/piridinol

Figura 29. Fórmulas generales de los híbridos DBMA - neuroaminas y DBMA-

$$
\text { piridina/piridinol planteados }
$$

${ }^{150}$ Khan, M. Z.; Nawaz, W. The emerging roles of human trace amines and human trace amine-associated receptors (hTAARs) in central nervous system. Biomed. Pharmacother. 2016, 83, 439-449.

151 a) Wijtmans, M. ; Derek A. ; Valgimigli L. ; DiLabio, G.A. ; Franco Pedulli, G. ;Porter, N.A.; 6-Amino3-Pyridinols: Towards Diffussion-Controlled Chain-Breaking Antioxidants, Angew. Chem. Int. Ed. 2003, 42, 4370-4373. b) Wijtmans, M.; Derek A. ; Brinkhorst, J.; Valgimigli L. ; Franco Pedulli, G. ;Porter, N.A,. Synthesis and Reactivity of Some 6-Substituted-2,4-dimethyl-3-pyridinols, a Novel Class of Chain-Breaking Antioxidants, J. Org. Chem. 2004, 69, 9215-9223. c ) Nam, T-G.;. Rector, C.L.; Hye-young K.; Sonnen, A.; Meyer, R.; Atkinson, J.; Rintoul, J.; Pratt, D.P.; Porter, N.A.; Tetrahydro1,8-naphthyridinol Analogues of r-Tocopherol as Antioxidants in Lipid Membranes and Low-Density Lipoproteins, J. Am. Chem. 2007, 129, 10211-10219.
} 


\subsubsection{Síntesis de los híbridos DBMA - neuroaminas y DBMA - piridina/piridinol}

La síntesis de todos los híbridos derivados de DBMA se planteó por acoplamiento peptídico entre un ácido, adecuadamente activado con hexafluorofosfato de benzotriazol1-il-oxitripirrolidinofosfonio (PyBOP), y la correspondiente amina en presencia de trietilamina en dimetilformamida a temperatura ambiente (Esquema 8). Para construir la parte derecha de nuestras estructuras existen numerosos ácidos y aminas comerciales, por lo que sólo fue necesario obtener los precursores del fragmento de DBMA, dotados con un grupo amina o con un ácido carboxílico.

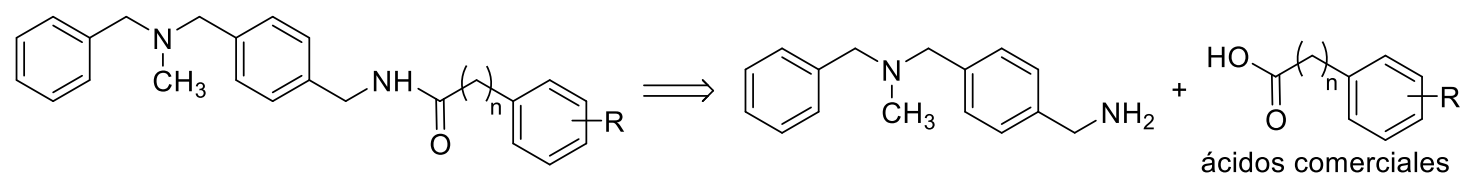

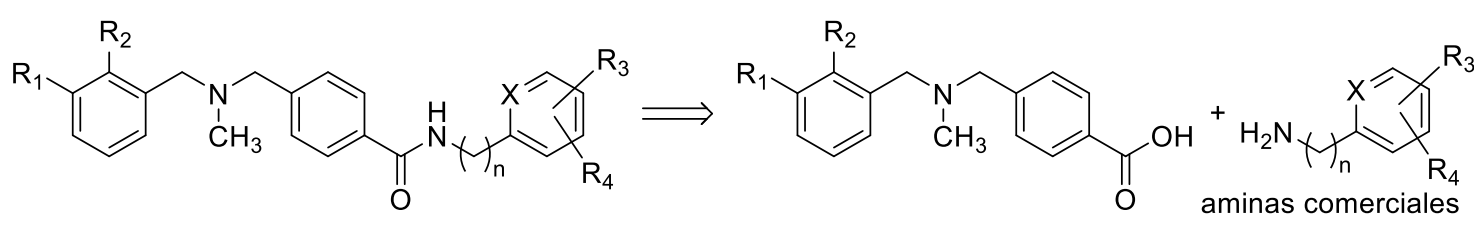

Esquema 8. Retrosíntesis de los híbridos de DBMA planteados

La síntesis de los precursores correspondientes al fragmento de DBMA se llevó a cabo como se muestra en el esquema 9. A una disolución de $p$-tolunitrilo en tetracloruro de carbono, se añade $N$-bromosuccinimida (NBS) en cantidad equimolar y peróxido de benzoilo como iniciador de radicales libres. Después de 4 horas a reflujo, se filtra el sólido que ha precipitado y se elimina el disolvente. El 4-(bromometil)benzonitrilo se purifica por recristalización en ciclohexano, obteniéndose un rendimiento del 57\%. Éste se hace reaccionar con $N, N$-bencilmetilaminas diferentemente sustituidas en éter etílico a reflujo durante 10 horas, obteniéndose los ciano-derivados intermedios $\mathbf{4 8 - 5 2}$ con buenos rendimientos, comprendidos entre el 68 y el 93\%. El tratamiento de éstos con una disolución de sosa $2 \mathrm{M}$ en etanol a reflujo durante 4 horas originó los ácidos 53-57 con rendimientos superiores al 69\% (Tabla 22). 


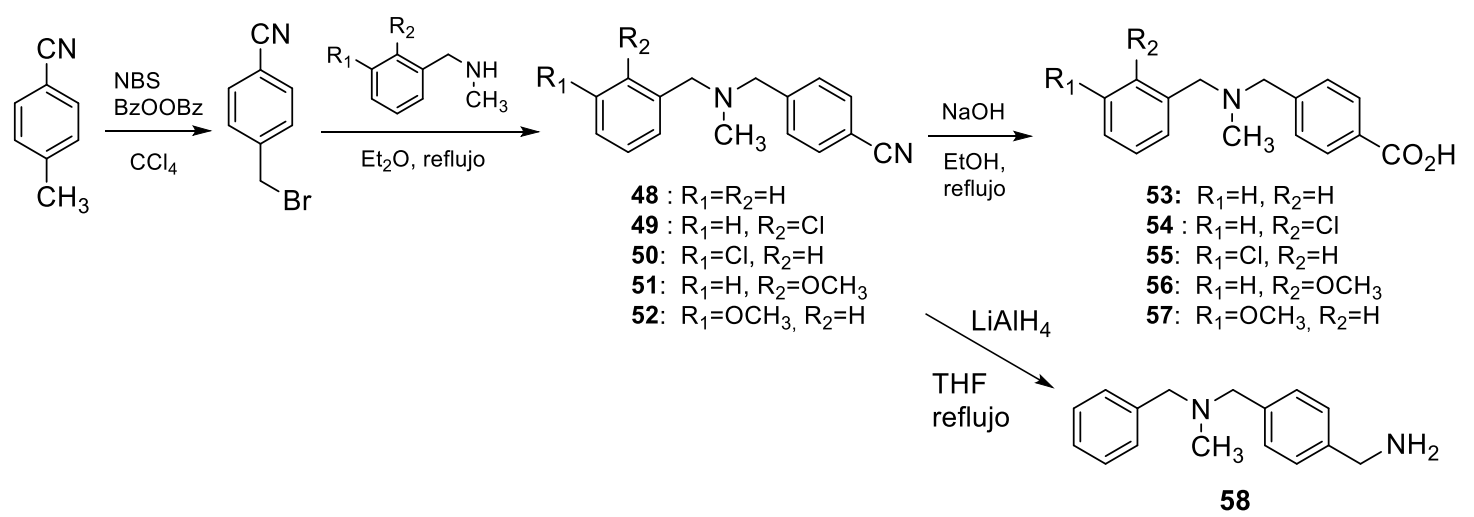

Esquema 9. Síntesis de los precursores de los híbridos derivados de DBMA

Tabla 22. Rendimientos y tiempo de retención en HPLC de nitrilos y ácidos precursores
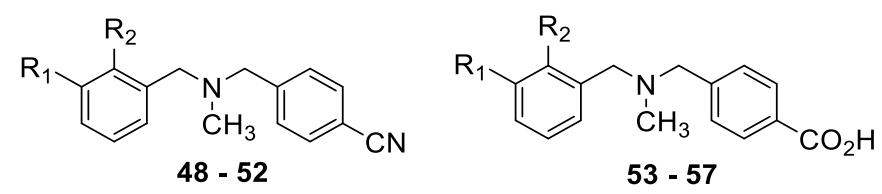

\begin{tabular}{lllcl}
\hline Comp. & $\mathrm{R}_{1}$ & $\mathrm{R}_{2}$ & $\mathrm{Rto}(\%)$ & $\mathrm{t}_{\mathrm{R}(\mathrm{min})}{ }^{\mathrm{a}}$ \\
\hline $\mathbf{4 8}$ & $\mathrm{H}$ & $\mathrm{H}$ & 68 & $\mathrm{n} . \mathrm{d}$. \\
$\mathbf{4 9}$ & $\mathrm{H}$ & $\mathrm{Cl}$ & 88 & 6.58 \\
$\mathbf{5 0}$ & $\mathrm{Cl}$ & $\mathrm{H}$ & 83 & 7.13 \\
$\mathbf{5 1}$ & $\mathrm{H}$ & $\mathrm{OCH}_{3}$ & 93 & 7.00 \\
$\mathbf{5 2}$ & $\mathrm{OCH}_{3}$ & $\mathrm{H}$ & 77 & 6.62 \\
$\mathbf{5 3}$ & $\mathrm{H}$ & $\mathrm{H}$ & 75 & 7.57 \\
$\mathbf{5 4}$ & $\mathrm{H}$ & $\mathrm{Cl}$ & 88 & 8.76 \\
$\mathbf{5 5}$ & $\mathrm{Cl}$ & $\mathrm{H}$ & 97 & 9.43 \\
$\mathbf{5 6}$ & $\mathrm{H}$ & $\mathrm{OCH}$ & 97 & 8.77 \\
$\mathbf{5 7}$ & $\mathrm{OCH}_{3}$ & $\mathrm{H}$ & 69 & 9.17 \\
\hline
\end{tabular}

${ }^{a}$ HPLC Alliance Waters 2690, detector de UV Photodiodo Array modelo Waters 2996 acoplado a un detector de masas modelo MicromassZQ de Waters, columna XBridgeTM C18, $3.5 \mu \mathrm{m}, 200 \AA$ (2.1 nm x 100 $\mathrm{mm})$. Eluyente $\left(\mathrm{CH}_{3} \mathrm{CN}: \mathrm{H}_{2} \mathrm{O}\right) / \mathrm{CF}_{3} \mathrm{CO}_{2} \mathrm{H}(0.05 \%)$. Flujo de $0.25 \mathrm{~mL} / \mathrm{min}$. 
Por otro lado, la reducción del ciano derivado 48 (ya descrito con anterioridad ${ }^{152}$ ) con hidruro de litio y aluminio permitió obtener la $N$-(4-(aminometil)bencil)- $N$-metil-1fenilmetanamina deseada 58 (Esquema 9). A continuación, el acoplamiento peptídico de esta amina con los ácidos comerciales 3,4,5-trimetoxibenzoico y 3-(3,4dimetoxifenil)propanoico en presencia de PyBOP y trietilamina proporcionó los productos 59 y $\mathbf{6 0}$ con buenos rendimientos (Esquema 10).

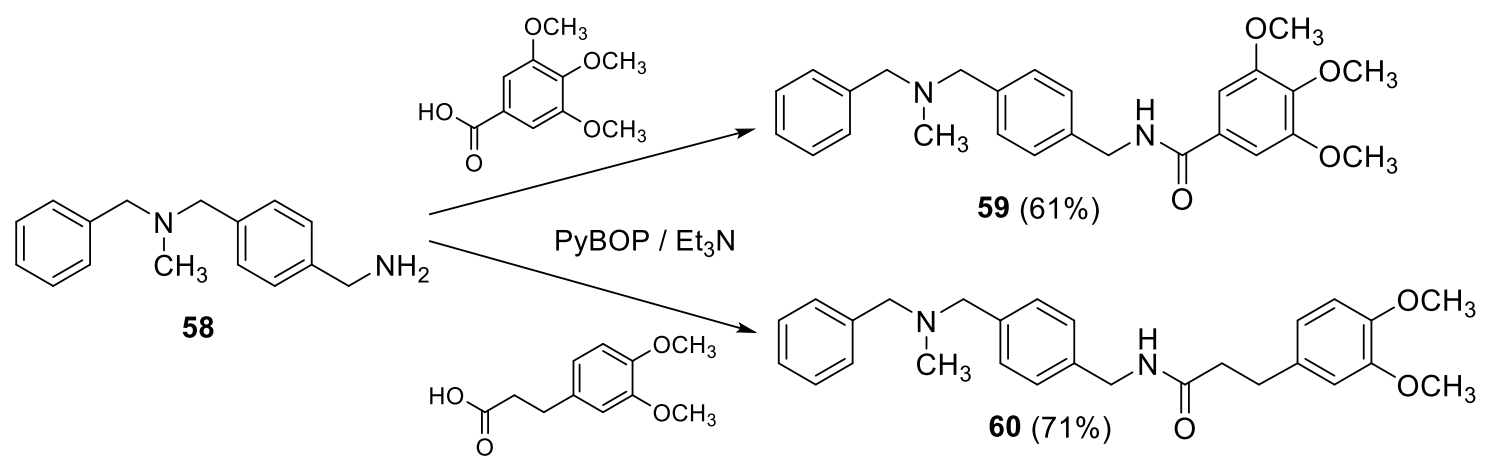

Esquema 10. Obtención de los híbridos 59 y 60

Por otra parte, la reacción del ácido 4-((bencil(metil)amino)metil)benzoico $\mathbf{5 3}$ y sus derivados cloro o metoxisustituidos previamente sintetizados (54-57) con aminas comerciales (fenetilamina y derivados) en las mismas condiciones de reacción conduce a los productos 61-68. De forma análoga, las reacciones de acoplamiento de los ácidos intermedios 53-57 con 2-amino-3-hidroxipiridina y 2-aminopiridina nos permitió obtener los productos 69-76. Es interesante señalar que cuando este mismo acoplamiento se realizó con la 2-amino-8-hidroxiquinolina y los ácidos $53\left(\mathrm{R}_{1}=\mathrm{R}_{2}=\mathrm{H}\right)$ y $56\left(\mathrm{R}_{1}=\mathrm{H}, \mathrm{R}_{2}\right.$ $=\mathrm{OCH}_{3}$ ), no se obtuvieron los productos deseados, por lo que este tipo de reacciones no se intentó con el resto de los ácidos intermedios (Esquema 11).

${ }^{152}$ Gilman, H.; Bailie, J. C. Relative reactivities of organometallic compounds. XVII. The azo linkage. J. Org. Chem. 1937, 2, 84-94. 


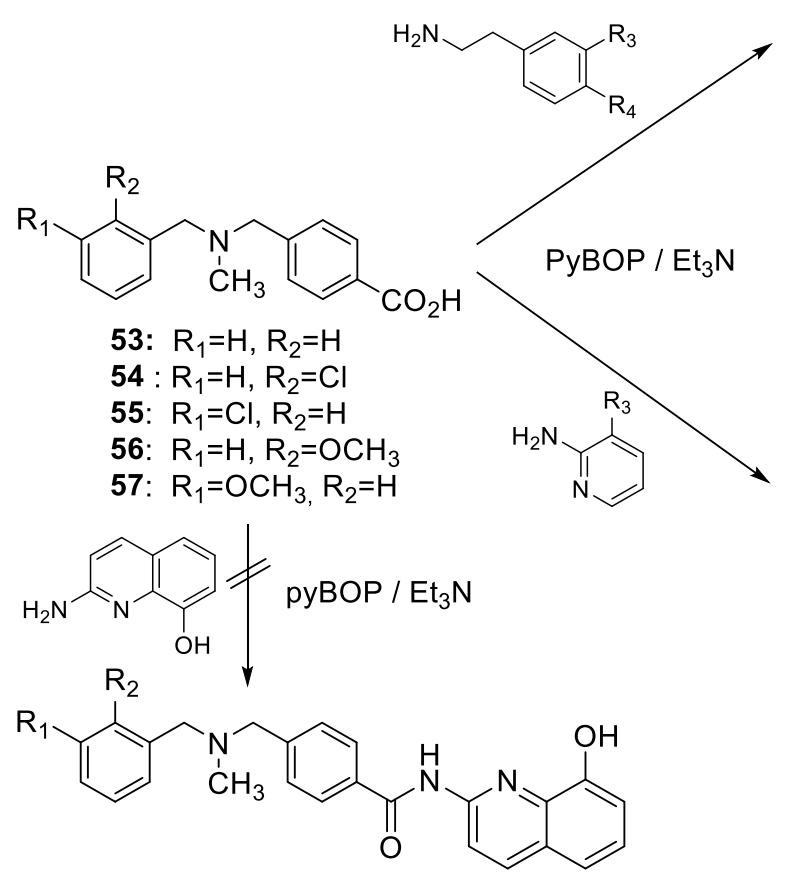<smiles>[R]c1ccc(CCNC(=O)c2ccc(CN(C)Cc3cccc([R])c3[R])cc2)cc1[R3]</smiles>

$62: \mathrm{R}_{1}=\mathrm{R}_{2}=\mathrm{H}$

63: $\mathrm{R}_{1}=\mathrm{R}_{3}=\mathrm{R}_{4}=\mathrm{H}, \mathrm{R}_{2}=\mathrm{OCH}_{3}$

64: $\mathrm{R}_{1}=\mathrm{R}_{2}=\mathrm{R}_{3}=\mathrm{H}, \mathrm{R}_{4}=\mathrm{OH}$

65: $\mathrm{R}_{1}=\mathrm{R}_{3}=\mathrm{H}, \mathrm{R}_{2}=\mathrm{Cl}, \mathrm{R}_{4}=\mathrm{OH}$

66: $\mathrm{R}_{1}=\mathrm{Cl}, \mathrm{R}_{2}=\mathrm{R}_{3}=\mathrm{H}, \mathrm{R}_{4}=\mathrm{OH}$

67: $\mathrm{R}_{1}=\mathrm{R}_{3}=\mathrm{H}, \mathrm{R}_{2}=\mathrm{OCH}_{3}, \mathrm{R}_{4}=\mathrm{OH}$

68: $\mathrm{R}_{1}=\mathrm{OCH}_{3}, \mathrm{R}_{2}=\mathrm{R}_{3}=\mathrm{H}, \mathrm{R}_{4}=\mathrm{OH}$<smiles>[R]c1cccnc1CN(C)Cc1ccc(C(=O)Nc2cccnc2[R])cc1</smiles>

70: $\mathrm{R}_{1}=\mathrm{R}_{2}=\mathrm{H}, \mathrm{R}_{3}=\mathrm{OH}$

71: $\mathrm{R}_{1}=\mathrm{Cl}, \mathrm{R}_{2}=\mathrm{H}, \mathrm{R}_{3}=\mathrm{OH}$

72: $\mathrm{R}_{1}=\mathrm{H}, \mathrm{R}_{2}=\mathrm{OCH}_{3}, \mathrm{R}_{3}=\mathrm{OH}$

73: $\mathrm{R}_{1}=\mathrm{OCH}_{3} \mathrm{R}_{2}=\mathrm{H}, \mathrm{R}_{3}=\mathrm{OH}$

74: $\mathrm{R}_{1}=\mathrm{R}_{2}=\mathrm{R}_{3}=\mathrm{H}$

75: $\mathrm{R}_{1}=\mathrm{H}, \mathrm{R}_{2}=\mathrm{Cl}, \mathrm{R}_{3}=\mathrm{H}$

76: $\mathrm{R}_{1}=\mathrm{Cl}, \mathrm{R}_{2}=\mathrm{R}_{3}=\mathrm{H}$

Esquema 11. Obtención de los híbridos 61-76

En la tabla 23 están recogidos los rendimientos y los tiempos de retención de HPLC de los híbridos 61-76. Es interesante señalar que los mejores rendimientos corresponden a los híbridos DBMA - neuroaminas 61-68, que están comprendidos entre el 61 y el 91\%, mientras que los rendimientos de los híbridos DBMA - piridinol 69-73 oscilan entre el 29 y el 66\%. Los peores rendimientos corresponden a los derivados DBMA - piridina 74$76(15-35 \%)$. 
Tabla 23. Rendimientos y tiempo de retención en HPLC de los híbridos 61-76<smiles>[R]c1ccc(CCNC(=O)c2ccc(CN(C)Cc3cccc([R])c3[R])cc2)cc1[R3]</smiles><smiles>[R]c1cccnc1NC(=O)c1ccc(CN(C)Cc2cccc([R])c2[R])cc1</smiles>

\begin{tabular}{lllllll}
\hline Comp. & $\mathrm{R}_{1}$ & $\mathrm{R}_{2}$ & $\mathrm{R}_{3}$ & $\mathrm{R}_{4}$ & $\mathrm{Rto}(\%)$ & $\mathrm{t}_{\mathrm{R}(\mathrm{min})^{\mathrm{a}}}$ \\
\hline $\mathbf{6 1}$ & $\mathrm{H}$ & $\mathrm{H}$ & $\mathrm{OCH}_{3}$ & $\mathrm{OCH}_{3}$ & 61 & 12.2 \\
$\mathbf{6 2}$ & $\mathrm{H}$ & $\mathrm{H}$ & $\mathrm{H}$ & $\mathrm{H}$ & 87 & 11.9 \\
$\mathbf{6 3}$ & $\mathrm{H}$ & $\mathrm{OCH}_{3}$ & $\mathrm{H}$ & $\mathrm{H}$ & 63 & 12.9 \\
$\mathbf{6 4}$ & $\mathrm{H}$ & $\mathrm{H}$ & $\mathrm{H}$ & $\mathrm{OH}$ & 85 & 9.3 \\
$\mathbf{6 5}$ & $\mathrm{H}$ & $\mathrm{Cl}$ & $\mathrm{H}$ & $\mathrm{OH}$ & 69 & $9.0^{\mathrm{b}}$ \\
$\mathbf{6 6}$ & $\mathrm{Cl}$ & $\mathrm{H}$ & $\mathrm{H}$ & $\mathrm{OH}$ & 91 & $9.3^{\mathrm{b}}$ \\
$\mathbf{6 7}$ & $\mathrm{H}$ & $\mathrm{OCH}$ & $\mathrm{H}$ & $\mathrm{OH}$ & 72 & 8.9 \\
$\mathbf{6 8}$ & $\mathrm{OCH}$ & $\mathrm{H}$ & $\mathrm{H}$ & $\mathrm{OH}$ & 81 & 10.5 \\
$\mathbf{6 9}$ & $\mathrm{H}$ & $\mathrm{H}$ & $\mathrm{OH}$ & --- & 48 & 7.2 \\
$\mathbf{7 0}$ & $\mathrm{H}$ & $\mathrm{Cl}$ & $\mathrm{OH}$ & --- & 58 & 7.6 \\
$\mathbf{7 1}$ & $\mathrm{Cl}$ & $\mathrm{H}$ & $\mathrm{OH}$ & --- & 66 & 8.1 \\
$\mathbf{7 2}$ & $\mathrm{H}$ & $\mathrm{OCH}$ & $\mathrm{OH}$ & --- & 36 & 7.7 \\
$\mathbf{7 3}$ & $\mathrm{OCH}$ & $\mathrm{H}$ & $\mathrm{OH}$ & --- & 29 & 7.63 \\
$\mathbf{7 4}$ & $\mathrm{H}$ & $\mathrm{H}$ & $\mathrm{H}$ & --- & 35 & 7.9 \\
$\mathbf{7 5}$ & $\mathrm{H}$ & $\mathrm{Cl}$ & $\mathrm{H}$ & --- & 15 & 8.4 \\
$\mathbf{7 6}$ & $\mathrm{Cl}$ & $\mathrm{H}$ & $\mathrm{H}$ & --- & 17 & 8.9 \\
\hline
\end{tabular}

${ }^{a}$ HPLC Alliance Waters 2690, detector de UV Photodiodo Array modelo Waters 2996 acoplado a un detector de masas modelo MicromassZQ de Waters, columna XBridgeTM C18, $3.5 \mu \mathrm{m}, 200 \AA$ (2.1 nm x $100 \mathrm{~mm})$. Eluyente $\left(\mathrm{CH}_{3} \mathrm{CN}: \mathrm{H}_{2} \mathrm{O}\right) / \mathrm{CF}_{3} \mathrm{CO}_{2} \mathrm{H}(0.05 \%)$. Flujo de $0.25 \mathrm{~mL} / \mathrm{min}$. $\operatorname{tg}=20^{\mathrm{b}} \operatorname{tg}=10$

\subsubsection{Medida de la actividad como inhibidores de acetil y butirilcolinesterasa}

A continuación, todos los híbridos obtenidos fueron evaluados como inhibidores de AChE humana y BuChE equina, siguiendo el método de Ellman ${ }^{127}$ y empleando tacrina como referencia interna (Tabla 24).

Dentro de los híbridos DBMA - neuroaminas (59-68), los que tenían el NH de la amida más cerca del fragmento de DBMA ( 59 y 60) resultaron ser más potentes que los 
que tenían el agrupamiento amida al revés (61-68). De hecho, el producto más activo de la serie es el híbrido 59, resultado de la unión de $N$-(4-(aminometil)bencil)- $N$-metil-1fenilmetanamina (58) con el ácido 3,4,5-trimetoxibenzoico, con $\mathrm{CI}_{50}$ s en el rango submicromolar para ambas enzimas y con una ligera selectividad hacia la $\mathrm{BuChE}\left(\mathrm{CI}_{50}=\right.$ $0.14 \mu \mathrm{M}$ ) en comparación con la $\mathrm{AChE}\left(\mathrm{CI}_{50}=0.88 \mu \mathrm{M}\right.$ ) (unas 6-veces más potente en BuChE que en AChE). Al aumentar la longitud de la cadena y eliminar uno de los grupos metoxilo del anillo de benceno obtenemos el híbrido 60, con peores propiedades que 59 en cuanto a potencia y selectividad frente a las dos colinesterasas.

En cuanto a los híbridos DBMA - neuroaminas con el grupo carbonilo más cercano al fragmento de DBMA (61-68), se observa que todos son moderados inhibidores de $\mathrm{AChE}$ y BuChE con $\mathrm{CI}_{50}$ s en el rango micromolar, sin una clara selectividad hacia ninguna de las dos enzimas. En este subgrupo, los productos más activos son 61 y 63 que contienen en su estructura sustituyentes metoxilo. Además, el híbrido DBMA homoveratrilamina $61\left(\mathrm{R}_{1}=\mathrm{R}_{2}=\mathrm{H}, \mathrm{R}_{3}=\mathrm{R}_{4}=\mathrm{OCH}_{3}\right)$ es 4-veces más activo en AChE $\left(\mathrm{CI}_{50}=5.0 \mu \mathrm{M}\right)$ que en $\mathrm{BuChE}\left(\mathrm{CI}_{50}=20.0 \mu \mathrm{M}\right)$.

En la serie DBMA - piridina / piridinol todos los híbridos son moderados inhibidores de $\mathrm{AChE}$ y BuChE con $\mathrm{CI}_{50}$ s por encima de $10 \mu \mathrm{M}$, con las excepciones de los compuestos 75 y 76 con un fragmento de piridina no-sustituida y un átomo de cloro en diferentes posiciones de la subunidad de DBMA. El híbrido 76, con un átomo de cloro en $\mathrm{R}_{1}$ inhibe 4-veces mejor la h-AChE $\left(\mathrm{CI}_{50}=2.5 \mu \mathrm{M}\right)$ que la eq-BuChE $\left(\mathrm{CI}_{50}=10.0 \mu \mathrm{M}\right)$. Curiosamente, cuando el átomo de cloro se sitúa en $\mathrm{R}_{2}$ esta selectividad se invierte, puesto que el híbrido 75 es más de 2.6-veces más potente frente a eq-BuChE $\left(\mathrm{CI}_{50}=3.76 \mu \mathrm{M}\right)$ que frente a h-AChE $\left(\mathrm{CI}_{50}>10 \mu \mathrm{M}\right)$. 
Tabla 24. Inhibición de AChE humana y BuChE equina de los híbridos 59-76

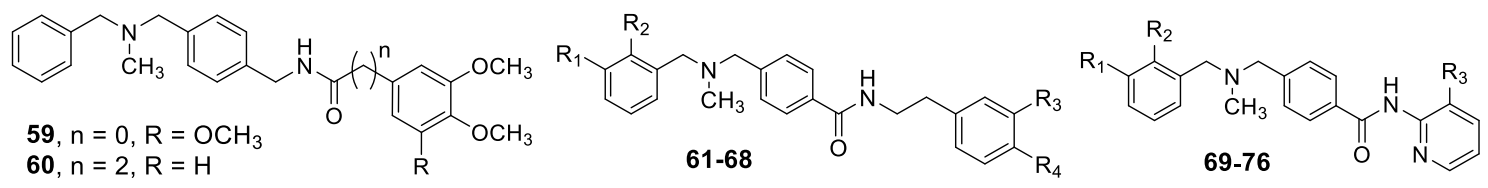

\begin{tabular}{|c|c|c|c|c|c|c|}
\hline \multirow[b]{2}{*}{ Comp. } & \multirow[b]{2}{*}{$\mathrm{R}_{1}$} & \multirow[b]{2}{*}{$\mathrm{R}_{2}$} & \multirow[b]{2}{*}{$\mathrm{R}_{3}$} & \multirow[b]{2}{*}{$\mathrm{R}_{4}$} & \multicolumn{2}{|c|}{$\mathrm{CI}_{50} \pm \operatorname{SEM}(\mu \mathrm{M})^{\mathrm{a}, \mathrm{b}}$} \\
\hline & & & & & $\mathrm{h}-\mathrm{AChE} \mathrm{E}^{\mathrm{c}}$ & eq-BuChE ${ }^{d}$ \\
\hline 59 & --- & --- & --- & --- & $0.88 \pm 0.001$ & $0.14 \pm 0.001$ \\
\hline 60 & --- & --- & --- & --- & $6.2 \pm 0.02$ & $6.1 \pm 0.03$ \\
\hline 61 & $\mathrm{H}$ & $\mathrm{H}$ & $\mathrm{OCH}_{3}$ & $\mathrm{OCH}_{3}$ & $5.0 \pm 0.3$ & $20.0 \pm 0.3$ \\
\hline 62 & $\mathrm{H}$ & $\mathrm{H}$ & $\mathrm{H}$ & $\mathrm{H}$ & $10.0 \pm 0.5$ & $>10(22 \%)$ \\
\hline 63 & $\mathrm{H}$ & $\mathrm{OCH}_{3}$ & $\mathrm{H}$ & $\mathrm{H}$ & $7.9 \pm 0.1$ & $5.8 \pm 0.4$ \\
\hline 64 & $\mathrm{H}$ & $\mathrm{H}$ & $\mathrm{H}$ & $\mathrm{OH}$ & $6.0 \pm 0.2$ & $>10(26 \%)$ \\
\hline 65 & $\mathrm{H}$ & $\mathrm{Cl}$ & $\mathrm{H}$ & $\mathrm{OH}$ & $>10(37 \%)$ & $>10(35 \%)$ \\
\hline 66 & $\mathrm{Cl}$ & $\mathrm{H}$ & $\mathrm{H}$ & $\mathrm{OH}$ & $9.5 \pm 0.1$ & $>10(47 \%)$ \\
\hline 67 & $\mathrm{H}$ & $\mathrm{OCH}_{3}$ & $\mathrm{H}$ & $\mathrm{OH}$ & $>10(36 \%)$ & $>10(46 \%)$ \\
\hline 68 & $\mathrm{OCH}_{3}$ & $\mathrm{H}$ & $\mathrm{H}$ & $\mathrm{OH}$ & $>10(25 \%)$ & $>10(25 \%)$ \\
\hline 69 & $\mathrm{H}$ & $\mathrm{H}$ & $\mathrm{OH}$ & --- & $17.3 \pm 0.7$ & $12.5 \pm 0.5$ \\
\hline 70 & $\mathrm{H}$ & $\mathrm{Cl}$ & $\mathrm{OH}$ & --- & $>10$ & $>10(34 \%)$ \\
\hline 71 & $\mathrm{Cl}$ & $\mathrm{H}$ & $\mathrm{OH}$ & --- & $>10$ & $>10(37 \%)$ \\
\hline 72 & $\mathrm{H}$ & $\mathrm{OCH}_{3}$ & $\mathrm{OH}$ & --- & $50.1 \pm 1.8$ & $79.3 \pm 2.5$ \\
\hline 73 & $\mathrm{OCH}_{3}$ & $\mathrm{H}$ & $\mathrm{OH}$ & --- & $>10$ & $>10(23 \%)$ \\
\hline 74 & $\mathrm{H}$ & $\mathrm{H}$ & $\mathrm{H}$ & --- & $10.0 \pm 0.2$ & $20.9 \pm 1.5$ \\
\hline 75 & $\mathrm{H}$ & $\mathrm{Cl}$ & $\mathrm{H}$ & --- & $>10$ & $3.76 \pm 0.1$ \\
\hline 76 & $\mathrm{Cl}$ & $\mathrm{H}$ & $\mathrm{H}$ & --- & $2.50 \pm 0.1$ & $10.0 \pm 0.4$ \\
\hline \multicolumn{2}{|c|}{ Tacrina } & & & & $0.35 \pm 0.01$ & $0.01 \pm 0.0004$ \\
\hline
\end{tabular}

${ }^{a}$ Los resultados son la media de tres experimentos independientes $(n=3) \pm$ error estándar de la media (SEM). ${ }^{\mathrm{b}}$ Cuando la $\mathrm{CI}_{50}$ es superior a $10 \mu \mathrm{M}$ entre paréntesis se da el porcentaje de inhibición a dicha concentración. ${ }^{\mathrm{c}} \mathrm{AChE}$ (EC 3.1.1.7) de eritrocitos humanos. ${ }^{\mathrm{d}} \mathrm{BuChE}$ (EC 3.1.1.8) procedente de suero de caballo. 


\subsubsection{Estudio de unión al PAS de la AChE mediante desplazamiento de propidio}

Para estudiar si los híbridos DBMA - neuroaminas y DBMA - piridina / piridinol eran capaces de interaccionar con el PAS de la AChE, se realizaron estudios de desplazamiento de propidio del PAS de la AChE. Los compuestos fueron evaluados a tres concentraciones $(0.3,1.0$ y $3.0 \mu \mathrm{M})$ empleando donepezilo a $0.3 \mu \mathrm{M}$ como referencia interna (Tabla 25).

Tabla 25. Desplazamiento de propidio (\%) del PAS de la AChE realizado por los híbridos ensayados a las concentraciones indicadas ${ }^{\mathrm{a}}$

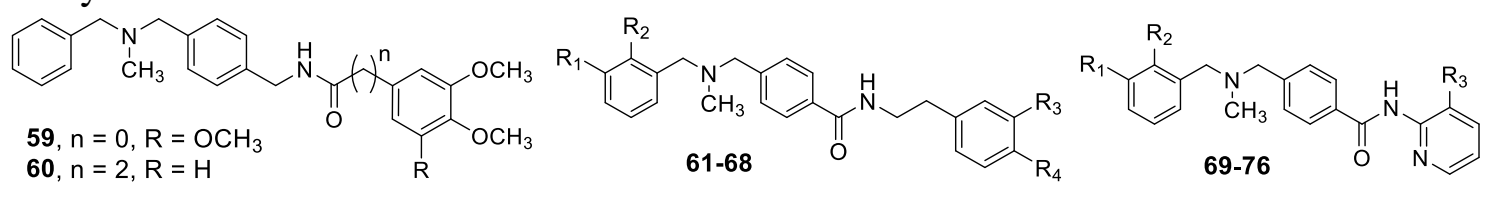

$\%$ Desplazamiento de propidio @

$\begin{array}{llllllll}\text { Comp. } & \mathrm{R}_{1} & \mathrm{R}_{2} & \mathrm{R}_{3} & \mathrm{R}_{4} & 0.3 \mu \mathrm{M} & 1.0 \mu \mathrm{M} & 3.0 \mu \mathrm{M}\end{array}$

\begin{tabular}{cccccccc}
\hline $\mathbf{5 9}$ & --- & --- & --- & --- & $7.4 \pm 0.2$ & $12.1 \pm 1.0$ & $39.2 \pm 2.1$ \\
$\mathbf{6 0}$ & --- & --- & --- & --- & $3.7 \pm 0.1$ & $46.5 \pm 2.2$ & $17.9 \pm 0.9$ \\
$\mathbf{6 1}$ & $\mathrm{H}$ & $\mathrm{H}$ & $\mathrm{OCH}_{3}$ & $\mathrm{OCH}_{3}$ & $11.2 \pm 0.8$ & $51.0 \pm 3.4$ & $52.7 \pm 3.4$ \\
$\mathbf{6 2}$ & $\mathrm{H}$ & $\mathrm{H}$ & $\mathrm{H}$ & $\mathrm{H}$ & $18.9 \pm 0.7$ & $22.0 \pm 0.9$ & $44.4 \pm 1.1$ \\
$\mathbf{6 3}$ & $\mathrm{H}$ & $\mathrm{OCH}_{3}$ & $\mathrm{H}$ & $\mathrm{H}$ & $18.7 \pm 0.8$ & $15.2 \pm 0.7$ & $46.1 \pm 1.4$ \\
$\mathbf{6 4}$ & $\mathrm{H}$ & $\mathrm{H}$ & $\mathrm{H}$ & $\mathrm{OH}$ & $<0.1$ & $<0.1$ & $<0.1$ \\
$\mathbf{6 5}$ & $\mathrm{H}$ & $\mathrm{Cl}$ & $\mathrm{H}$ & $\mathrm{OH}$ & $<0.1$ & $<0.1$ & $<0.1$ \\
$\mathbf{6 6}$ & $\mathrm{Cl}$ & $\mathrm{H}$ & $\mathrm{H}$ & $\mathrm{OH}$ & $<0.1$ & $<0.1$ & $<0.1$ \\
$\mathbf{6 7}$ & $\mathrm{H}$ & $\mathrm{OCH}$ & $\mathrm{H}$ & $\mathrm{OH}$ & $<0.1$ & $6.8 \pm 0.6$ & $<0.1$ \\
$\mathbf{6 8}$ & $\mathrm{OCH}$ & $\mathrm{H}$ & $\mathrm{H}$ & $\mathrm{OH}$ & $<0.1$ & $<0.1$ & $1.3 \pm 0.1$ \\
$\mathbf{6 9}$ & $\mathrm{H}$ & $\mathrm{H}$ & $\mathrm{OH}$ & --- & $32.1 \pm 2.6$ & $19.2 \pm 0.8$ & $<0.1$ \\
$\mathbf{7 0}$ & $\mathrm{H}$ & $\mathrm{Cl}$ & $\mathrm{OH}$ & --- & $34.4 \pm 1.2$ & $25.3 \pm 1.0$ & $20.2 \pm 1.2$ \\
$\mathbf{7 1}$ & $\mathrm{Cl}$ & $\mathrm{H}$ & $\mathrm{OH}$ & --- & $38.0 \pm 2.1$ & $23.4 \pm 0.8$ & $18.4 \pm 0.7$ \\
$\mathbf{7 2}$ & $\mathrm{H}$ & $\mathrm{OCH}$ & $\mathrm{OH}$ & --- & $28.3 \pm 1.4$ & $30.4 \pm 2.3$ & $16.2 \pm 0.8$ \\
$\mathbf{7 6}$ & $\mathrm{Cl}$ & $\mathrm{H}$ & $\mathrm{H}$ & --- & $11.2 \pm 0.6$ & $<0.1$ & $18.3 \pm 1.5$ \\
$\mathbf{D o n e p e z i l o ~}$ & & & & $19.4 \pm 2.0$ & $\mathrm{nd}$ & $\mathrm{nd}$ \\
\hline
\end{tabular}

${ }^{a}$ Los resultados son la media de tres experimentos independientes \pm error estándar de la media (SEM). 
Como puede apreciarse en la tabla 26, los híbridos DBMA - neuroaminas son por lo general más potentes que los DBMA - piridina / piridinol. En la serie de los híbridos DBMA - neuroaminas (59-68) la presencia de grupos metoxilo en cualquiera de las dos partes de la molécula mejora el desplazamiento de propidio del PAS, lo que indica que estos compuestos son capaces de interaccionar con el PAS de la AChE. Por el contrario, la presencia de un grupo $p$-fenol en el fragmento de neuroamina $\left(\mathrm{R}_{4}=\mathrm{OH}\right)$ lo perjudica, como puede deducirse de la falta de actividad en este ensayo de los derivados de tiramina 64-68 a todas las concentraciones ensayadas. Sin embargo, en la serie DBMA - piridinol 69-72 la presencia del fenol en la posición 2 no impide la interacción de estos híbridos con el PAS, que presentan mejores valores que el derivado de DBMA - piridina 76.

De entre todos los productos aquí ensayados, los mejores son los híbridos 59, 61-63, que presentan desplazamientos de propidio superiores al 39\% a la máxima concentración ensayada $(3.0 \mu \mathrm{M})$. Por lo tanto, estos compuestos son capaces de interaccionar con el PAS de la AChE y podrían evitar la agregación de $\beta$-amiloide, reduciendo así la formación de las placas seniles. Además, en los híbridos 59, 61 y 62 se observa que la unión al PAS es dependiente de la concentración de producto ensayado, como puede apreciarse en la figura 30.

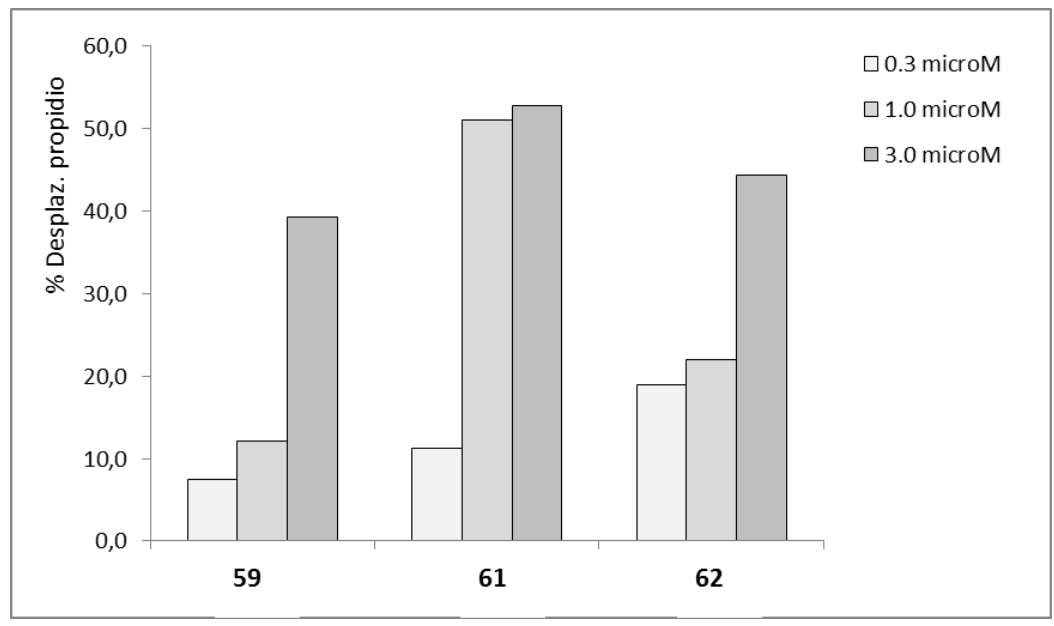

Figura 30. Concentración-dependencia en el desplazamiento de propidio de 59, 61 y 62 


\subsubsection{Predicción in vitro de la penetración en el SNC de los híbridos DBMA - neuroaminas y DBMA - piridina / piridinol}

A continuación, se evaluó la capacidad de los híbridos DBMA - neuroaminas y DBMA - piridina / piridinol para penetrar en el SNC, siguiendo el método in vitro PAMPA-BBB y empleando como disolvente una mezcla de tampón fosfato salino a pH 7.4 y etanol en proporción 70:30. Todos los compuestos evaluados presentan permeabilidades superiores a $410^{-6} \mathrm{~cm} \mathrm{~s}^{-1}$, por lo que serían capaces de llegar al SNC por difusión pasiva y actuar en sus dianas biológicas en el cerebro (Tabla 26).

Tabla 26. Resultados de permeabilidad $\left(P_{\mathrm{e}}, 10^{-6} \mathrm{~cm} \mathrm{~s}^{-1}\right)^{\mathrm{a}}$ en experimentos PAMPA-BBB de híbridos DBMA - neuroaminas y DBMA - piridina / piridinol. Predicción para entrar en el SNC

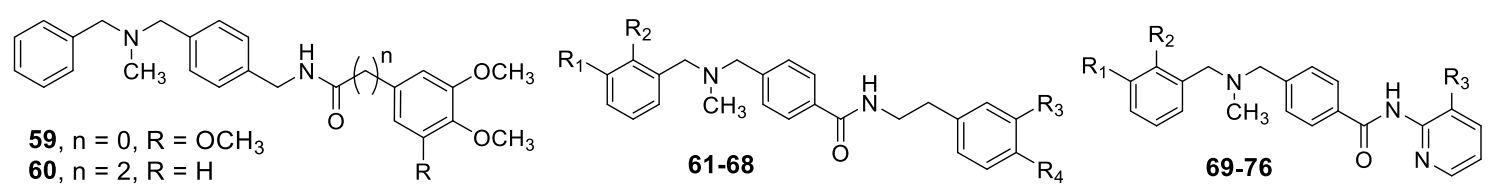

\begin{tabular}{ccccccc}
\hline Comp. & $\mathrm{R}_{1}$ & $\mathrm{R}_{2}$ & $\mathrm{R}_{3}$ & $\mathrm{R}_{4}$ & $\left(P_{\mathrm{e}}, 10^{-6} \mathrm{~cm} \mathrm{~s}^{-1}\right)$ & Predicción \\
\hline $\mathbf{5 9}$ & ---- & --- & --- & --- & $12.6 \pm 0.3$ & $\mathrm{snc}+$ \\
$\mathbf{6 0}$ & ---- & --- & --- & --- & $12.0 \pm 0.4$ & $\mathrm{snc}+$ \\
$\mathbf{6 1}$ & $\mathrm{H}$ & $\mathrm{H}$ & $\mathrm{OCH}_{3}$ & $\mathrm{OCH}_{3}$ & $24.2 \pm 0.5$ & $\mathrm{snc}+$ \\
$\mathbf{6 2}$ & $\mathrm{H}$ & $\mathrm{H}$ & $\mathrm{H}$ & $\mathrm{H}$ & $13.9 \pm 0.2$ & $\mathrm{snc}+$ \\
$\mathbf{6 3}$ & $\mathrm{H}$ & $\mathrm{OCH}_{3}$ & $\mathrm{H}$ & $\mathrm{H}$ & $16.8 \pm 0.2$ & $\mathrm{snc}+$ \\
$\mathbf{6 4}$ & $\mathrm{H}$ & $\mathrm{H}$ & $\mathrm{H}$ & $\mathrm{OH}$ & $8.0 \pm 0.1$ & $\mathrm{snc}+$ \\
$\mathbf{6 5}$ & $\mathrm{H}$ & $\mathrm{Cl}$ & $\mathrm{H}$ & $\mathrm{OH}$ & $13.1 \pm 0.1$ & $\mathrm{snc}+$ \\
$\mathbf{6 6}$ & $\mathrm{Cl}$ & $\mathrm{H}$ & $\mathrm{H}$ & $\mathrm{OH}$ & $9.2 \pm 0.2$ & $\mathrm{snc}+$ \\
$\mathbf{6 7}$ & $\mathrm{H}$ & $\mathrm{OCH}$ & $\mathrm{H}$ & $\mathrm{OH}$ & $5.2 \pm 0.4$ & $\mathrm{snc}+$ \\
$\mathbf{6 8}$ & $\mathrm{OCH}$ & $\mathrm{H}$ & $\mathrm{H}$ & $\mathrm{OH}$ & $6.6 \pm 0.1$ & $\mathrm{snc}+$ \\
$\mathbf{6 9}$ & $\mathrm{H}$ & $\mathrm{H}$ & $\mathrm{OH}$ & --- & $20.8 \pm 0.6$ & $\mathrm{snc}+$ \\
$\mathbf{7 1}$ & $\mathrm{Cl}$ & $\mathrm{H}$ & $\mathrm{OH}$ & --- & $8.6 \pm 0.3$ & snc + \\
$\mathbf{7 3}$ & $\mathrm{OCH}$ & $\mathrm{H}$ & $\mathrm{OH}$ & --- & $15.6 \pm 0.5$ & snc + \\
\hline
\end{tabular}

${ }^{a}$ Los resultados son la media de tres experimentos independientes $(n=3) \pm$ desviación estándar (DS). 


\subsubsection{Ensayos de toxicidad y de neuroprotección frente al estrés oxidativo mitocondrial}

Siguiendo con el estudio del potencial terapéutico de los híbridos DBMA neuroaminas y DBMA - piridina / piridinol, a continuación se estudió su toxicidad y su capacidad neuroprotectora frente al estrés oxidativo mitocondrial en la línea celular SHSY5Y de neuroblastoma humano. Para evaluar la citotoxicidad, las células SH-SY5Y se trataron con cada uno de los híbridos a la concentración de $1.0 \mu \mathrm{M}$ durante 24 horas, al cabo de las cuales se midió el porcentaje de muerte celular a partir de la concentración de lactato deshidrogenasa $(\mathrm{LDH})^{153}$. En todos los casos, la concentración de LDH fue similar al valor basal, lo que indica que la viabilidad celular está en torno al $100 \%$ y que los productos no son tóxicos.

A continuación, se estudió el efecto neuroprotector de las moléculas frente al estrés oxidativo mitocondrial, empleando la línea celular SH-SY5Y y la mezcla de rotenona y oligomicina A. Como se recordará, la combinación de estos tóxicos provoca la generación de radicales libres de oxígeno (ROS) endógenos como consecuencia del bloqueo de los complejos I y V de la cadena respiratoria mitocondrial, por lo que se considera un buen modelo de estrés oxidativo mitocondrial ${ }^{154}$. Las células fueron incubadas en presencia de $1.0 \mu \mathrm{M}$ de cada uno de los compuestos durante 24 horas antes de la adición de la mezcla de rotenona $(30.0 \mu \mathrm{M})$ y oligomicina $\mathrm{A}(10.0 \mu \mathrm{M})$. Después se mantuvieron durante 24 horas adicionales con la mezcla tóxica y los productos a evaluar, midiéndose a continuación la concentración de LDH en el medio. En estos experimentos se empleó melatonina como control positivo (Tabla 27).

${ }^{153}$ Cummings, B. S.; Wills, L. P.; Schnellmann, R. G. Measurement of cell death in Mammalian cells. Curr. Protoc. Pharmacol. 2012, Chapter 12, Unit12 18.

${ }^{154}$ González-Muñoz, G. C.; Arce, M. P.; López, B.; Pérez, C.; Villarroya, M.; López, M. G.; García, A. G.; Conde, S.; Rodríguez-Franco, M. I. Old phenothiazine and dibenzothiadiazepine derivatives for tomorrow's neuroprotective therapies against neurodegenerative diseases. Eur. J. Med. Chem. 2010, 45, 6152-6158. 
Tabla 27. Porcentaje de neuroprotección (\%) de híbridos DBMA - neuroaminas 59-68 y DBMA - piridina/piridinol 69-71, 75, 76 $(1.0 \mu \mathrm{M})$ en células SH-SY5Y frente a la mezcla de rotenona $(30.0 \mu \mathrm{M})$ y oligomicina $\mathrm{A}(10.0 \mu \mathrm{M})^{\mathrm{a}}$.

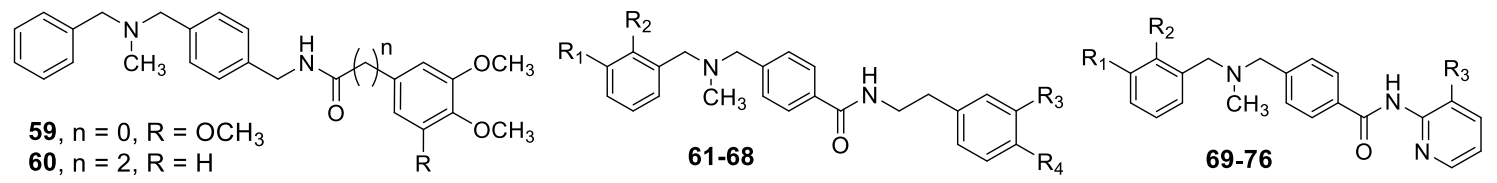

\begin{tabular}{cccccc}
\hline Comp. & $\mathrm{R}_{1}$ & $\mathrm{R}_{2}$ & $\mathrm{R}_{3}$ & $\mathrm{R}_{4}$ & Neuroprotección (\%) \\
\hline $\mathbf{5 9}$ & --- & --- & --- & --- & $33.6 \pm 2.1$ \\
$\mathbf{6 0}$ & --- & --- & --- & --- & $49.1 \pm 3.0$ \\
$\mathbf{6 1}$ & $\mathrm{H}$ & $\mathrm{H}$ & $\mathrm{OCH}_{3}$ & $\mathrm{OCH}_{3}$ & $52.3 \pm 3.5$ \\
$\mathbf{6 2}$ & $\mathrm{H}$ & $\mathrm{H}$ & $\mathrm{H}$ & $\mathrm{H}$ & $22.2 \pm 1.4$ \\
$\mathbf{6 3}$ & $\mathrm{H}$ & $\mathrm{OCH}_{3}$ & $\mathrm{H}$ & $\mathrm{H}$ & $42.4 \pm 2.2$ \\
$\mathbf{6 4}$ & $\mathrm{H}$ & $\mathrm{H}$ & $\mathrm{H}$ & $\mathrm{OH}$ & $29.1 \pm 1.5$ \\
$\mathbf{6 5}$ & $\mathrm{H}$ & $\mathrm{Cl}$ & $\mathrm{H}$ & $\mathrm{OH}$ & $36.4 \pm 2.0$ \\
$\mathbf{6 6}$ & $\mathrm{Cl}$ & $\mathrm{H}$ & $\mathrm{H}$ & $\mathrm{OH}$ & $30.2 \pm 1.8$ \\
$\mathbf{6 7}$ & $\mathrm{H}$ & $\mathrm{OCH}$ & $\mathrm{H}$ & $\mathrm{OH}$ & $39.6 \pm 2.0$ \\
$\mathbf{6 8}$ & $\mathrm{OCH}$ & $\mathrm{H}$ & $\mathrm{H}$ & $\mathrm{OH}$ & $31.8 \pm 1.7$ \\
$\mathbf{6 9}$ & $\mathrm{H}$ & $\mathrm{H}$ & $\mathrm{OH}$ & --- & $29.5 \pm 1.9$ \\
$\mathbf{7 0}$ & $\mathrm{H}$ & $\mathrm{Cl}$ & $\mathrm{OH}$ & --- & $3.3 \pm 0.3$ \\
$\mathbf{7 1}$ & $\mathrm{Cl}$ & $\mathrm{H}$ & $\mathrm{OH}$ & --- & $<0.5$ \\
$\mathbf{7 5}$ & $\mathrm{H}$ & $\mathrm{Cl}$ & $\mathrm{H}$ & --- & $2.6 \pm 0.1$ \\
$\mathbf{7 6}$ & $\mathrm{Cl}$ & $\mathrm{H}$ & $\mathrm{H}$ & --- & $32.7 \pm 2.2$ \\
$\mathbf{M e l a t o n i n a}(0.3 \mu \mathrm{M})$ & & & $33.0 \pm 2.1$ \\
\hline
\end{tabular}

${ }^{a}$ Los resultados son la media de tres experimentos independientes (n =3) \pm error estándar de la media (SEM).

En líneas generales, los híbridos DBMA - neuroaminas 59-68 son mejores neuroprotectores que los derivados de piridinol 69-71 y de piridina 75 y 76. Sin embargo, los derivados de 3-hidroxi-2-piridinilo (69) y de piridina con un cloro en $\mathrm{R}_{1}$ (76) presentan un buen porcentaje de neuroprotección, en torno al 30\%. 
En lo que se refiere a los híbridos DBMA - neuroaminas 59-68, el porcentaje de protección oscila entre el 22 y $52 \%$, lo que indica que todos ellos presentan una buena neuroprotección frente al daño producido por el estrés oxidativo mitocondrial.

Partiendo del híbrido 62 sin ningún sustituyente en su estructura $\left(\mathrm{R}_{1}=\mathrm{R}_{2}=\mathrm{R}_{3}=\mathrm{R}_{4}\right.$ $=\mathrm{H}$ ), la introducción de un hidroxilo en $\mathrm{R}_{4}$ para dar el derivado 64, mejora ligeramente la capacidad neuroprotectora, pasando del 22\% para 62 al 29\% para 64. La posterior introducción en $\mathrm{R}_{1} \mathrm{o}$ en $\mathrm{R}_{2}$ de un átomo de cloro o de un grupo metoxilo, sube la protección por encima del $30 \%$ con el siguiente orden de menor a mayor potencia: $\mathbf{6 6}\left(\mathrm{R}_{1}\right.$ $\left.=\mathrm{Cl}, \mathrm{R}_{2}=\mathrm{R}_{3}=\mathrm{H}, \mathrm{R}_{4}=\mathrm{OH}, 30 \%\right)<\mathbf{6 8}\left(\mathrm{R}_{1}=\mathrm{OCH}_{3}, \mathrm{R}_{2}=\mathrm{R}_{3}=\mathrm{H}, \mathrm{R}_{4}=\mathrm{OH}, 32 \%\right)<\mathbf{6 5}$ $\left(\mathrm{R}_{1}=\mathrm{R}_{3}=\mathrm{H}, \mathrm{R}_{2}=\mathrm{Cl}, \mathrm{R}_{4}=\mathrm{OH}, 36 \%\right)<\mathbf{6 7}\left(\mathrm{R}_{1}=\mathrm{R}_{3}=\mathrm{H}, \mathrm{R}_{2}=\mathrm{OCH}_{3}, \mathrm{R}_{4}=\mathrm{OH}, 40 \%\right)$.

Finalmente, los híbridos DBMA - neuroaminas con mejores valores de neuroprotección son los que contienen en su estructura exclusivamente sustituyentes metoxilo: $63\left(\mathrm{R}_{1}=\mathrm{R}_{3}=\mathrm{R}_{4}=\mathrm{H}, \mathrm{R}_{2}=\mathrm{OCH}_{3}, 42 \%\right), \mathbf{6 0}$ (derivado de 3,4-dimetoxibenceno, $49 \%$ ), llegando hasta una neuroprotección del 52\% para el híbrido DBMA homoveratrilamina $61\left(\mathrm{R}_{1}=\mathrm{R}_{2}=\mathrm{H}, \mathrm{R}_{3}=\mathrm{R}_{4}=\mathrm{OCH}_{3}\right)$.

Haciendo un análisis conjunto de los resultados obtenidos hasta el momento, podemos decir que el híbrido DBMA - homoveratrilamina $61\left(\mathrm{R}_{1}=\mathrm{R}_{2}=\mathrm{H}, \mathrm{R}_{3}=\mathrm{R}_{4}=\right.$ $\mathrm{OCH}_{3}$ ) presenta un equilibrado perfil farmacológico in vitro: (i) Inhibe selectivamente la h-AChE $(5.0 \pm 0.3 \mu \mathrm{M})$, 4-veces mejor que la eq-BuChE $(20.0 \pm 0.3 \mu \mathrm{M})$. (ii) Presenta buen desplazamiento de propidio del PAS de la AChE (desplazamiento máximo del 53\% a $3.0 \mu \mathrm{M}$ ), por lo que podría impedir la agregación y precipitación del péptido $\beta$-amiloide promovida por esta enzima. (iii) Posee buena penetración en el SNC por difusión pasiva $\left(P_{\mathrm{e}}=24.210^{-6} \mathrm{~cm} \mathrm{~s}^{-1}\right)$. (iv) En la línea de neuroblastoma humano, a la concentración de $1.0 \mu \mathrm{M}$ no presenta toxicidad durante 24 horas y protege al $52 \%$ del cultivo celular frente a la mezcla tóxica de rotenona $(30 \mu \mathrm{M})$ y oligomicina $\mathrm{A}(10 \mu \mathrm{M})$, tomado como modelo de estrés oxidativo mitocondrial. Debido a este conjunto de buenas propiedades, el híbrido DBMA - homoveratrilamina 61 fue elegido para ensayos farmacológicos adicionales: (i) Neuroprotección frente a otros estímulos tóxicos (agua oxigenada, sobrecarga de calcio, $\beta$-amiloide y ácido okadaico) en la línea celular SH-SY5Y. (ii) Protección en un modelo de isquemia cerebral de falta de oxígeno y glucosa en tejido cerebral (rodajas de hipocampo). (iii) Estudio in vivo en ratones frente a la pérdida de memoria provocada por escopolamina. 


\subsubsection{Neuroprotección del híbrido DBMA - homoveratrilamina (61) frente a otros estímulos tóxicos relacionados con la enfermedad de Alzheimer en la línea celular de neuroblastoma humano SH-SY5Y}

A continuación, se estudió el comportamiento de $\mathbf{6 1}$ en la línea celular de neuroblastoma humano SH-SY5Y frente a otros estímulos tóxicos relacionados con la patología de la EA: agua oxigenada, sobrecarga de calcio, $\beta$-amiloide y ácido okadaico.

La adición de agua oxigenada al cultivo celular es otro modelo de estrés oxidativo, ya que genera una gran cantidad de radicales libres que conduce a la muerte celular ${ }^{155}$. Las células fueron incubadas con el híbrido 61 a tres concentraciones $(0.3,1.0$ y $3.0 \mu \mathrm{M})$ 24 horas antes de la adición del peróxido de hidrógeno $(100 \mu \mathrm{M})$ y mantenidas durante otras 24 horas en presencia del compuesto. Después, se evaluó la viabilidad celular mediante el reactivo MTT, bromuro de 3-(4,5-dimetiltiazol-2-il)-2,5-difeniltetrazolio, midiendo su absorbancia a $540 \mathrm{~nm}$. Como control positivo se utilizó trolox $(30 \mu \mathrm{M})$, la parte aromática de la vitamina E y la responsable de la captura de radicales libres. Como puede apreciarse en la tabla 29, el híbrido 61 presentó una protección máxima del $86 \%$ a $1.0 \mu \mathrm{M}$, mucho mejor que la protección del trolox (58\%) a una concentración mucho mayor $(30 \mu \mathrm{M})$.

Es conocido que la sobrecarga de calcio en un cultivo neuronal provoca la entrada masiva de este catión a través de canales específicos, causando disfunción mitocondrial y muerte celular ${ }^{156}$. Estos efectos pueden ser contrarrestados con bloqueantes de canales de calcio de tipo L-, como por ejemplo el nimodipino, que producen neuroprotección al impedir la entrada masiva de calcio al interior de la célula.

A continuación, estudiamos el comportamiento del híbrido $\mathbf{6 1}$ en la línea celular de neuroblastoma humano SH-SY5Y, empleando condiciones de sobrecarga de calcio y nimodipino como control positivo. Para incrementar el daño provocado por la entrada masiva de calcio a través de canales dependientes de voltaje (VDCC) se empleó un

155 González-Muñoz, G. C.; Arce, M. P.; López, B.; Pérez, C.; Villarroya, M.; López, M. G.; García, A. G.; Conde, S.; Rodríguez-Franco, M. I. Old phenothiazine and dibenzothiadiazepine derivatives for tomorrow's neuroprotective therapies against neurodegenerative diseases. Eur. J. Med. Chem. 2010, 45, 6152-6158.

${ }^{156}$ Cano-Abad, M. F.; Villarroya, M.; García, A. G.; Gabilán, N. H.; López, M. G. Calcium entry through L-type calcium channels causes mitochondrial disruption and chromaffin cell death. J. Biol. Chem. 2001, 276, 39695-39704. 
agonista de los canales de calcio de tipo L- (FPL64176) ${ }^{157}$, en condiciones de despolarización $\left(\left[\mathrm{K}^{+}\right]=20 \mathrm{mM}\right)$ y en presencia de cloruro cálcico $(5 \mathrm{mM})$ en el medio durante 24 horas. El híbrido 61 se incubó a cuatro concentraciones $(0.3,1.0,3.0$ y 10.0 $\mu \mathrm{M})$ con las células de neuroblastoma durante 24 horas antes del tratamiento con FPL64176 y después se mantuvo durante 24 horas más después del estímulo tóxico. El híbrido DBMA - homoveratrilamina 61 presentó una protección máxima del 33\% a 1.0 $\mu \mathrm{M}$, siendo mejor que el nimodipino que necesitó una concentración mayor $(3.0 \mu \mathrm{M})$ para ejercer el mismo porcentaje de neuroprotección (32\%).

Tabla 28. Ensayos adicionales de neuroprotección (NP) del híbrido DBMA homoveratrilamina (61) en la línea celular SH-SY5Y ${ }^{\mathrm{a}}$.

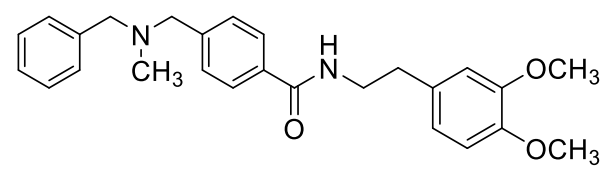

\begin{tabular}{lcccccc}
\hline & \multicolumn{3}{c}{ \% Neuroprotección (NP) de 61 @ } & \multicolumn{3}{l}{$\begin{array}{l}\text { \% NP de patrones a la } \\
\text { concentración } \\
\text { indicada }\end{array}$} \\
\cline { 2 - 6 } & $0.3 \mu \mathrm{M}$ & $1.0 \mu \mathrm{M}$ & $3.0 \mu \mathrm{M}$ & $10.0 \mu \mathrm{M}$ & \\
\hline $\begin{array}{l}\mathrm{H}_{2} \mathrm{O}_{2} \\
(100 \mu \mathrm{M})\end{array}$ & $66.3 \pm 1.2$ & $86.4 \pm 1.4$ & $60.4 \pm 0.9$ & nd & $\begin{array}{l}\text { Trolox } \\
(30.0 \mu \mathrm{M})\end{array}$ & 58 \\
$\begin{array}{l}\mathrm{CaCl} \\
(5 \mathrm{mM})\end{array}$ & $22.8 \pm 0.5$ & $33.1 \pm 0.9$ & $26.0 \pm 0.7$ & $28.1 \pm 1.0$ & $\begin{array}{l}\text { Nimodipino } \\
(3.0 \mu \mathrm{M})\end{array}$ & 32 \\
$\begin{array}{l}\beta \text {-amiloide } \\
(30 \mu \mathrm{M})\end{array}$ & $74.1 \pm 1.5$ & $75.8 \pm 1.4$ & $16.0 \pm 0.2$ & nd & $\begin{array}{l}\text { Melatonina } \\
(0.01 \mu \mathrm{M})\end{array}$ & 72 \\
$\begin{array}{l}\text { Ac. okadaico } \\
(30 \mathrm{nM})\end{array}$ & $45.4 \pm 0.9$ & $35.3 \pm 1.3$ & $51.0 \pm 1.5$ & nd & $\begin{array}{l}\text { Galantamina } \\
(0.3 \mu \mathrm{M})\end{array}$ & 36 \\
\hline
\end{tabular}

${ }^{a}$ Los resultados son la media de tres experimentos independientes $(n=3) \pm$ error estándar de la media (SEM).

Seguidamente, se estudió la actividad neuroprotectora de $\mathbf{6 1}$ frente a la toxicidad provocada por el fragmento $A \beta_{1-42}$ del péptido $\beta$-amiloide en la línea celular SH-SY5Y, puesto que este péptido es la isoforma con mayor tendencia a la formación de agregados proteicos $^{158}$. El tratamiento de las células SH-SY5Y con $30 \mu \mathrm{M}$ de A $\beta_{1-42}$ durante 24 horas

${ }^{157}$ Liu, L.; González, P. K.; Barrett, C. F.; Rittenhouse, A. R. The calcium channel ligand FPL 64176 enhances L-type but inhibits N-type neuronal calcium currents. Neuropharmacology 2003, 45, 281-292.

158 a) Jarrett, J. T.; Berger, E. P.; Lansbury, P. T., Jr. The C-terminus of the beta protein is critical in amyloidogenesis. Ann. N. Y. Acad. Sci. 1993, 695, 144-148. b) Jarrett, J. T.; Berger, E. P.; Lansbury, P. 
provoca un $42 \%$ de reducción de la viabilidad celular medida con MTT. Las células fueron pre-incubadas con concentraciones crecientes de $61(0.3,1.0$ y $3.0 \mu \mathrm{M})$ durante 24 horas antes y durante la exposición a $\mathrm{A} \beta_{1-42}(30 \mu \mathrm{M})$. Como puede observarse en la tabla 29, el híbrido 61 presentó una excelente protección máxima del 76\% a $1.0 \mu \mathrm{M}$. En este ensayo se empleó melatonina como control positivo, que dio una protección similar del $72 \%$, pero a una concentración 100 veces menor $(0.01 \mu \mathrm{M})$.

El ácido okadaico es una toxina aislada de algas marinas que provoca la hiperfosforilación de la proteína tau y su posterior agregación en ovillos neurofibrilares, tanto en modelos in vitro ${ }^{159}$ como in vivo ${ }^{160}$. Puesto que la agregación patológica de tau está relacionada con la EA y otras taupatías neurodegenerativas, el empleo del ácido okadaico como estímulo tóxico en líneas neuronales es un buen modelo in vitro para imitar la muerte celular relacionada con estas enfermedades ${ }^{161}$.

En este ensayo, las células SH-SY5Y expuestas a la acción del ácido okadaico (30 $\mathrm{nM}$ ) durante 24 horas mostraron un $61 \%$ de muerte celular con respecto al control, medido a partir del porcentaje de LDH liberada al medio extracelular. Las células fueron incubadas con el híbrido 61 a tres concentraciones $(0.3,1.0$ y $3.0 \mu \mathrm{M})$ durante 24 horas antes de la adición del ácido okadaico $(30 \mathrm{nM})$ y mantenidas durante un periodo adicional de 24 horas de exposición al tóxico. El híbrido DBMA - homoveratrilamina 61 presentó una protección máxima del $51 \%$ a $3.0 \mu \mathrm{M}$. Como control positivo se empleó galantamina, que proporcionó una protección del 36\% a $0.3 \mu \mathrm{M}$.

Por lo tanto, se demuestra que el híbrido DBMA - homoveratrilamina 61 tiene un equilibrado perfil neuroprotector en modelos celulares relacionados con la EA y otras enfermedades neurodegenerativas. En el rango micromolar bajo, 61 presenta buenos porcentajes de neuroprotección (33-86\%) de la línea de neuroblastoma humano SHSY5Y sometida a diferentes tóxicos: agua oxigenada, sobrecarga de calcio, $\beta$-amiloide y ácido okadaico.

T., Jr. The carboxy terminus of the beta amyloid protein is critical for the seeding of amyloid formation: implications for the pathogenesis of Alzheimer's disease. Biochemistry 1993, 32, 4693-4697.

${ }^{159}$ Uberti, D.; Rizzini, C.; Spano, P. F.; Memo, M. Characterization of tau proteins in human neuroblastoma SH-SY5Y cell line. Neurosci. Lett. 1997, 235, 149-153.

${ }^{160}$ Zhang, Z.; Simpkins, J. W. An okadaic acid-induced model of tauopathy and cognitive deficiency. Brain Res. 2010, 1359, 233-246.

${ }^{161}$ Zhang, Z.; Simpkins, J. W. Okadaic acid induces tau phosphorylation in SH-SY5Y cells in an estrogenpreventable manner. Brain Res. 2010, 1345, 176-181. 


\subsubsection{Estudio de neuroprotección del híbrido DBMA - homoveratrilamina 61 en un modelo tisular de isquemia cerebral}

Es conocido que durante el proceso de envejecimiento se producen micro-infartos cerebrales, que aceleran la pérdida cognitiva asociada con la edad y que agravan la patología asociada con la EA y otras enfermedades neurodegenerativas ${ }^{162}$. Por ese motivo, nos pareció interesante estudiar el comportamiento de nuestro híbrido seleccionado 61 en un modelo in vitro de isquemia cerebral. En este modelo se emplean rodajas de hipocampo de ratón que se someten a la privación de oxígeno y glucosa (OGD) durante 15 minutos, seguido de un periodo de re-oxigenación durante 2 horas (OGD/R). El deterioro funcional de las mitocondrias, provocado por el corte del suministro de oxígeno y glucosa, aumenta aún más en el periodo de reoxigenación, en el que se desencadena una producción masiva de especies reactivas de oxígeno (ROS) por la acción de la enzima NADPH oxidasa $(\mathrm{NOX})^{163}$.

La viabilidad celular, normalizada al $100 \%$ de las rodajas control, se redujo al 55\% después de OGD / R (Figura 16). Este daño se mitigó significativamente en presencia del híbrido 61 con un máximo de protección de $51 \pm 2 \%$ a la concentración de $3 \mu \mathrm{M}$. Es interesante señalar que este dato es muy próximo al de galantamina, empleada como patrón positivo en este tipo de ensayos, que arrojó una protección del 55\% a una concentración 5 veces mayor $(15 \mu \mathrm{M})$. Por lo tanto, se demuestra que nuestro híbrido DBMA - homoveratrilamina $\mathbf{6 1}$ es un buen protector en un modelo tisular de isquemia cerebral.

162 Kalaria, R. N. The role of cerebral ischemia in Alzheimer's disease. Neurobiol. Aging 2000, 21, 321330.

${ }^{163}$ Noraberg, J.; Poulsen, F. R.; Blaabjerg, M.; Kristensen, B. W.; Bonde, C.; Montero, M.; Meyer, M.; Gramsbergen, J. B.; Zimmer, J. Organotypic hippocampal slice cultures for studies of brain damage, neuroprotection and neurorepair. Curr. Drug Targets CNS Neurol. Disord. 2005, 4, 435-452. 

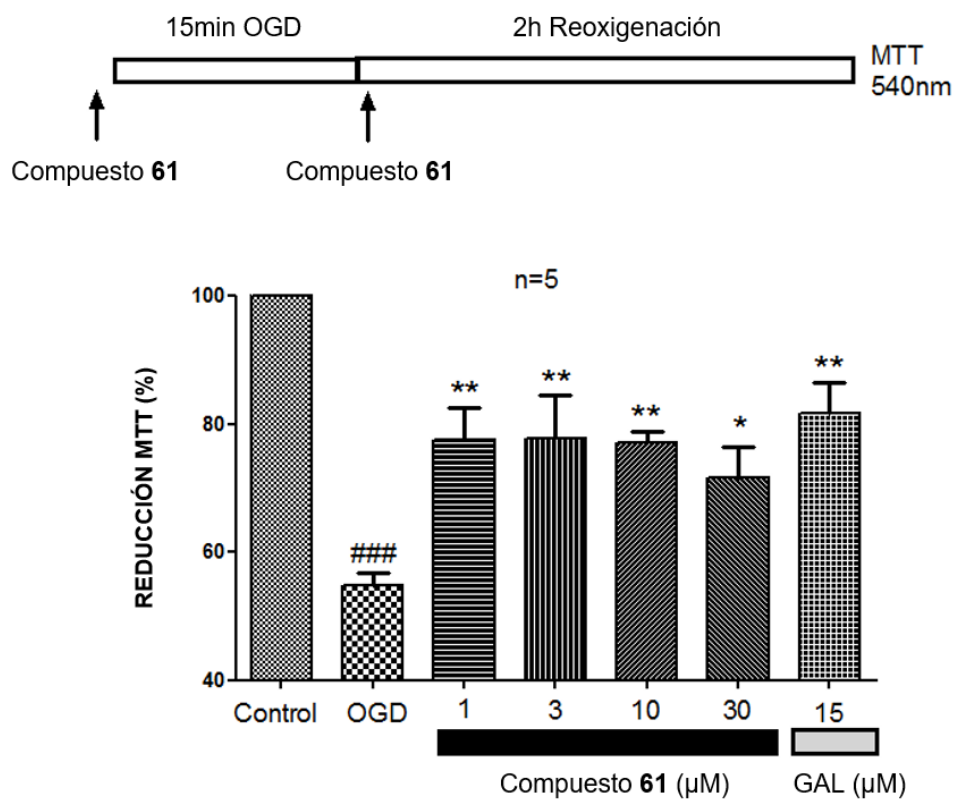

Figura 31. El híbrido DBMA - homoveratrilamina 61 aumenta la viabilidad de las rodajas de hipocampo sometidas a OGD / $R$. El protocolo experimental está ilustrado en la parte superior de la figura. Los resultados son la media \pm SEM de 5 experimentos independientes en triplicado.

\subsubsection{Evaluación del híbrido DBMA - homoveratrilamina 61 en un modelo in vivo de pérdida de memoria por escopolamina}

Dados los excelentes resultados encontrados para el híbrido 61 en modelos in vitro de EA y de isquemia cerebral, decidimos estudiarlo en un modelo in vivo de pérdida de memoria causada por escopolamina en ratón ${ }^{164}$. La escopolamina es un antagonista muscarínico, que impide la transmisión colinérgica y produce deterioro transitorio de la memoria, que en ratones puede cuantificarse mediante el test de reconocimiento de objetos. Varios trabajos han confirmado la correlación entre los efectos de la escopolamina con el déficit cognitivo de la EA en términos de memoria, recuerdo, reconocimiento y capacidad de aprendizaje ${ }^{165,166}$, por lo que se considera un modelo válido para estudiar el potencial terapéutico de un fármaco.

${ }^{164}$ Lorrio, S.; Romero, A.; González-Lafuente, L.; Lajarín-Cuesta, R.; Martínez-Sanz, F. J.; Estrada, M.; Samadi, A.; Marco-Contelles, J.; Rodríguez-Franco, M. I.; Villarroya, M.; López, M. G.; de los Ríos, C. PP2A ligand ITH12246 protects against memory impairment and focal cerebral ischemia in mice. ACS Chem. Neurosci. 2013, 4, 1267-1277.

${ }^{165}$ Gilles, C.; Ertle, S. Pharmacological models in Alzheimer's disease research. Dialogues Clin. Neurosci. 2000, 2, 247-255.

${ }^{166}$ More, S. V.; Kumar, H.; Cho, D. Y.; Yun, Y. S.; Choi, D. K. Toxin-Induced Experimental Models of Learning and Memory Impairment. Int. J. Mol. Sci. 2016, 17. 
Los ratones fueron divididos en 5 grupos dependiendo del tratamiento al que fueron sometidos mediante inyección intraperitoneal (i.p.): basal (suero salino), escopolamina, escopolomina $+2.5 \mathrm{mg} / \mathrm{kg}$ galantamina, escopolamina $+2.5 \mathrm{mg} / \mathrm{kg}$ híbrido $61 \mathrm{y}$ escopolamina $+10 \mathrm{mg} / \mathrm{kg}$ híbrido 61. El grupo de escopolamina mostró un índice de memoria (IM), medido como el índice de discriminación relativa entre un objeto nuevo y un objeto familiar para los ratones, significativamente reducido $(0.17 \pm 0.04)$ en comparación con el grupo basal no tratado $(0.42 \pm 0.04)$. Esta disminución en el IM se revirtió parcialmente por el híbrido 61, ya que los animales tratados con este compuesto, a la concentración de $10 \mathrm{mg} / \mathrm{kg}$ i.p., mostraron un IM de $0.26 \pm 0.03$ (Figura 17). La galantamina a $2.5 \mathrm{mg} / \mathrm{kg}$ i.p., usada como estándar ${ }^{167}$, también redujo la pérdida de memoria provocada por escopolamina con un IM de $0.34 \pm 0.02$. Estos datos demuestran que el híbrido DBMA - homoveratrilamina 61 mejora el rendimiento nemotécnico en ratones sometidos a la alteración de la memoria provocada por la escopolamina, aunque en menor medida que la galantamina, fármaco actualmente utilizado para el tratamiento de la EA.

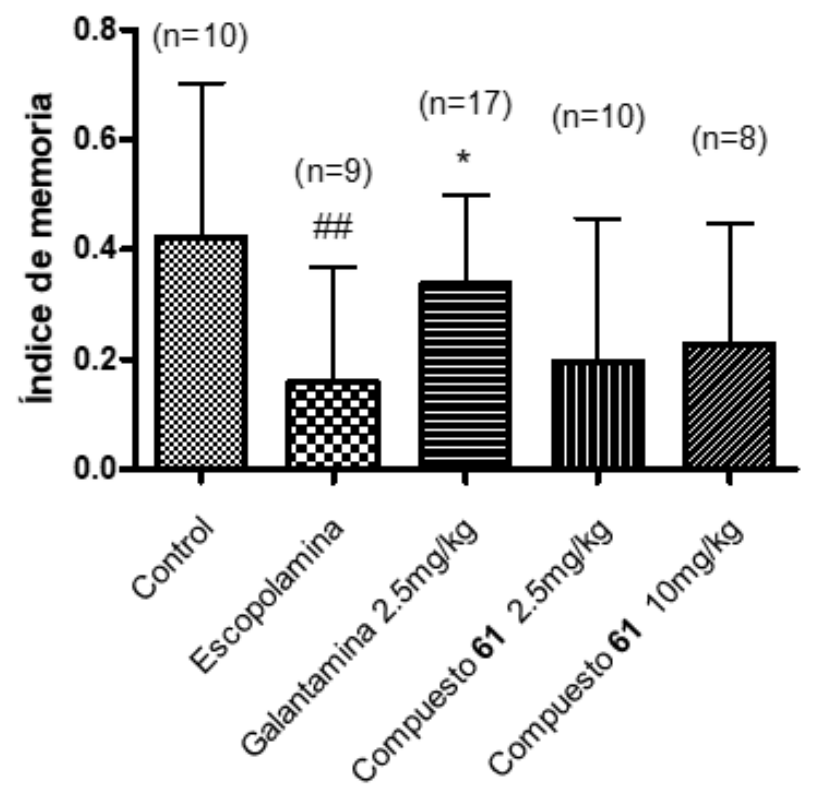

Figura 32. Índice de memoria (IM), medido como el indice de discriminación relativa entre un objeto nuevo y otro conocido por los ratones.

${ }^{167}$ de Bruin, N.; Pouzet, B. Beneficial effects of galantamine on performance in the object recognition task in Swiss mice: deficits induced by scopolamine and by prolonging the retention interval. Pharmacol. Biochem. Behav. 2006, 85, 253-260. 
Como resumen, se han diseñado y obtenido 10 híbridos DBMA - neuroaminas y 7 híbridos DBMA - piridina / piridinol, con propiedades colinérgicas y neuroprotectoras. La mayoría son inhibidores de AChE y BuChE en el rango micromolar bajo, desplazan propidio del PAS de la AChE, serían capaces de llegar al SNC y son protectores frente al estrés oxidativo mitocondrial en una línea neuronal. A partir de estos ensayos, se eligió al híbrido DBMA - homoveratrilamina 61 para realizar estudios farmacológicos adicionales, que han demostrado que este producto mantiene excelentes propiedades neuroprotectoras en modelos de daño neuronal provocado por estrés oxidativo, fallo mitocondrial (sobrecarga de calcio), $\beta$-amiloide (placas seniles) y ácido okadaico (ovillos neurofibrilares). También presenta interesantes efectos protectores en un modelo tisular de isquemia cerebral y en un modelo in vivo de pérdida de memoria por escopolamina.

Las interesantes propiedades mostradas por los híbridos DBMA - neuroaminas han conducido a la presentación de una patente española ${ }^{168}$ y su extensión a $\mathrm{PCT}^{169}$.

${ }^{168}$ Rodríguez-Franco, M. I.; Conde, S.; López-Iglesias, B.; Pérez, C.; Villarroya, M.; López, M. G.; García, A. G. Derivados de bis(aralquil)amino y sistemas (hetero)aromáticos de seis miembros y su uso en el tratamiento de patologías neurodegenerativas, incluida la enfermedad de Alzheimer. ES P200930931 (29/10/2009).

${ }^{169}$ Rodríguez-Franco, M. I.; Conde, S.; López-Iglesias, B.; Pérez, C.; Villarroya, M.; López, M. G.; García, A. G. Bis(aralkyl)amino - 6-membered aromatic derivatives as new drugs for the treatment of neurodegenerative pathologies, including Alzheimer's disease. PCT/2010/070702 (28/10/2010). 


\subsection{HÍBRIDOS $N, N$-DIBENCIL( $N$-METIL)AMINA - MELATONINA}

La melatonina es una neurohormona que se produce a partir del neurotransmisor serotonina, principalmente en la glándula pineal, pero también en la retina y en el tracto gastrointestinal. Desempeña numerosas funciones en el organismo, como la regulación del ciclo circadiano, del sistema inmune y la neutralización de radicales libres ${ }^{170}$. Es capaz de atravesar la barrera hematoencefálica, encontrándose en prácticamente todos los tejidos del organismo, donde ejerce sus acciones protectoras ${ }^{171}$. En lo que se refiere a su potencial aplicación en la EA, numerosos estudios han puesto de manifiesto las propiedades neuroprotectoras de la melatonina frente al daño producido por $\beta$ A tanto en experimentos in vitro ${ }^{172}$ como in vivo ${ }^{173}$.

Además de este gran conjunto de acciones, hay otra propiedad que nos llamó la atención de la melatonina: su capacidad para promover la neurogénesis endógena en el cerebro adulto ${ }^{174}$. La neurogénesis implica la generación, maduración e integración de nuevas neuronas en los circuitos neuronales, que es un fenómeno generalizado durante el desarrollo embrionario. Sin embargo, en el cerebro adulto la neurogénesis es un fenómeno residual y sólo dos nichos de células madre retienen una cierta capacidad de regeneración significativa, la zona subventricular (SVZ) y la zona subgranular (SGZ) en el giro dentado del hipocampo ${ }^{175}$. La neurogénesis parece modular procesos de aprendizaje y de integración de la memoria y es sensible a estímulos fisiológicos, patológicos y

${ }^{170}$ Hardeland, R.; Cardinali, D. P.; Srinivasan, V.; Spence, D. W.; Brown, G. M.; Pandi-Perumal, S. R. Melatonin--a pleiotropic, orchestrating regulator molecule. Prog. Neurobiol. 2011, 93, 350-384.

${ }^{171}$ Tan, D. X.; Reiter, R. J.; Manchester, L. C.; Yan, M. T.; El-Sawi, M.; Sainz, R. M.; Mayo, J. C.; Kohen, R.; Allegra, M.; Hardeland, R. Chemical and physical properties and potential mechanisms: melatonin as a broad spectrum antioxidant and free radical scavenger. Curr. Top. Med. Chem. 2002, 2, 181-197.

172 Feng, Z.; Zhang, J. T. Protective effect of melatonin on beta-amyloid-induced apoptosis in rat astroglioma C6 cells and its mechanism. Free Radic. Biol. Med. 2004, 37, 1790-1801.

173 Rosales-Corral, S.; Tan, D. X.; Reiter, R. J.; Valdivia-Velazquez, M.; Martinez-Barboza, G.; AcostaMartinez, J. P.; Ortiz, G. G. Orally administered melatonin reduces oxidative stress and proinflammatory cytokines induced by amyloid-beta peptide in rat brain: a comparative, in vivo study versus vitamin C and E. J. Pineal Res. 2003, 35, 80-84.

174 Ramírez-Rodríguez, G.; Klempin, F.; Babu, H.; Benítez-King, G.; Kempermann, G. Melatonin modulates cell survival of new neurons in the hippocampus of adult mice. Neuropsychopharmacology 2009, 34, 2180-2191.

175 Kempermann, G.; Jessberger, S.; Steiner, B.; Kronenberg, G. Milestones of neuronal development in the adult hippocampus. Trends Neurosci. 2004, 27, 447-452. 
farmacológicos ${ }^{176}$. Por ejemplo, el envejecimiento, la neurodegeneración y algunas enfermedades mentales están asociados con una disminución exponencial de la neurogénesis del hipocampo ${ }^{177}$. Por lo tanto, la estimulación farmacológica controlada de las células madre neurales endógenas de los nichos neurogénicos del cerebro adulto podría contrarrestar la pérdida de memoria relacionada con la edad y el deterioro cognitivo en algunos procesos patológicos ${ }^{178}$.

Los niveles plasmáticos de melatonina disminuyen con la edad, de manera similar a la capacidad neurogénica de los nichos de células madre neuronales ${ }^{179}$. No está demostrado que los dos fenómenos estén relacionados, pero lo que sí se sabe es que la melatonina modula positivamente la neurogénesis del hipocampo al aumentar la proliferación y la supervivencia de células precursoras de ratones senescentes ${ }^{180}$. Este comportamiento está de acuerdo con observaciones previas que concluyeron que la administración exógena de melatonina, además de un rendimiento cognitivo mucho mejor conservado, mejora el proceso de envejecimiento al retrasar la aparición de estados de salud deteriorados en ratones senescentes ${ }^{181}$.

Debido al potencial neurogénico de la melatonina y a nuestros resultados previos en híbridos tacrina - melatonina, que presentaron propiedades colinérgicas, antioxidantes y neuroprotectoras mejores que los fragmentos de los que derivan ${ }^{182,183}$, en esta Tesis nos propusimos la síntesis de nuevos híbridos de $N, N$-dibencil( $N$-metil)amina - melatonina

${ }^{176}$ Duman, R. S.; Malberg, J.; Nakagawa, S. Regulation of adult neurogenesis by psychotropic drugs and stress. J. Pharmacol. Exp. Ther. 2001, 299, 401-407.

${ }^{177}$ Rolando, C.; Taylor, V. Neural stem cell of the hippocampus: development, physiology regulation, and dysfunction in disease. Curr. Top. Dev. Biol. 2014, 107, 183-206.

${ }^{178}$ Herrera-Arozamena, C.; Martí-Marí, O.; Estrada, M.; de la Fuente Revenga, M.; Rodríguez-Franco, M. I. Recent advances in neurogenic small molecules as innovative treatments for neurodegenerative diseases. Molecules 2016, 21, 1165-1185.

${ }^{179}$ Iguichi, H.; Kato, K. I.; Ibayashi, H. Age-dependent reduction in serum melatonin concentrations in healthy human subjects. J. Clin. Endocrinol. Metab. 1982, 55, 27-29.

${ }^{180}$ Ramirez-Rodriguez, G.; Vega-Rivera, N. M.; Benitez-King, G.; Castro-Garcia, M.; Ortiz-Lopez, L. Melatonin supplementation delays the decline of adult hippocampal neurogenesis during normal aging of mice. Neurosci. Lett. 2012, 530, 53-58.

${ }^{181}$ Poeggeler, B. Melatonin, aging, and age-related diseases: perspectives for prevention, intervention, and therapy. Endocrine 2005, 27, 201-212.

${ }^{182}$ Rodríguez-Franco, M. I.; Fernández-Bachiller, M. I.; Pérez, C.; Hernández-Ledesma, B.; Bartolomé, B. Novel tacrine-melatonin hybrids as dual-acting drugs for Alzheimer disease, with improved acetylcholinesterase inhibitory and antioxidant properties. J. Med. Chem. 2006, 49, 459-462.

${ }^{183}$ Fernández-Bachiller, M. I.; Pérez, C.; Campillo, N. E.; Páez, J. A.; González-Muñoz, G. C.; Usán, P.; García-Palomero, E.; López, M. G.; Villarroya, M.; García, A. G.; Martínez, A.; Rodríguez-Franco, M. I. Tacrine-melatonin hybrids as multifunctional agents for Alzheimer's disease, with cholinergic, antioxidant, and neuroprotective properties. ChemMedChem 2009, 4, 828-841. 
(Figura 33) y el estudio de sus propiedades biológicas, incluida su capacidad para promover procesos de neurogénesis.

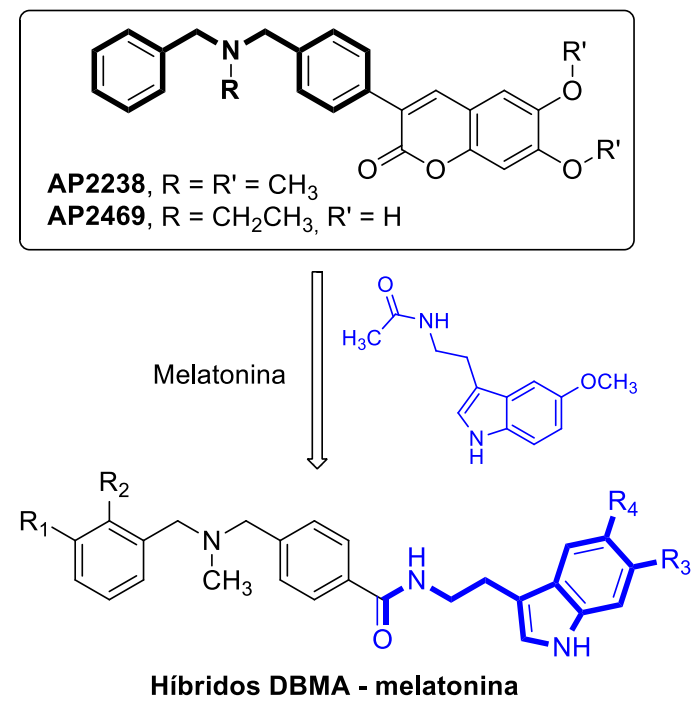

Figura 33. Híbridos $N, N$-dibencil(N-metil)amina - melatonina

\subsubsection{Síntesis de los híbridos DBMA - melatonina}

La síntesis de los híbridos DBMA - melatonina se realizó a partir de los ácidos 4((bencil(metil)amino)metil)benzoicos 53-57, ya descritos en el capítulo anterior, y derivados comerciales de triptamina, empleando PyBOP como reactivo de acoplamiento y Et ${ }_{3} \mathrm{~N}$ como base, en DMF a temperatura ambiente durante una noche (Esquema 12).

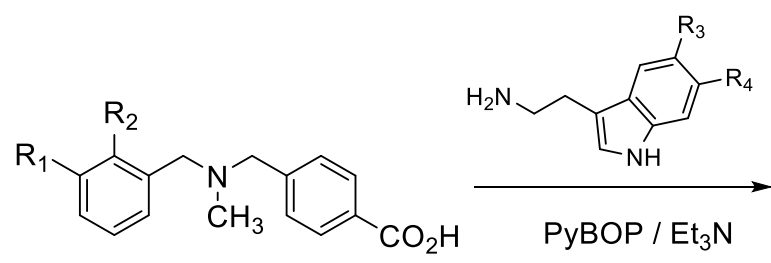

53: $\mathrm{R}_{1}=\mathrm{H}, \mathrm{R}_{2}=\mathrm{H}$

$54: \mathrm{R}_{1}=\mathrm{H}, \mathrm{R}_{2}=\mathrm{Cl}$

55: $\mathrm{R}_{1}=\mathrm{Cl}, \mathrm{R}_{2}=\mathrm{H}$

56: $\mathrm{R}_{1}=\mathrm{H}, \mathrm{R}_{2}=\mathrm{OCH}_{3}$

57: $\mathrm{R}_{1}=\mathrm{OCH}_{3}, \mathrm{R}_{2}=\mathrm{H}$<smiles>[R]c1cc2[nH]cc(CCNC(=O)c3ccc(CN(C)Cc4cccc([R])c4[R2])cc3)c2cc1[R3]</smiles>

78: $R_{1}=R_{2}=R_{4}=H, R_{3}=O H$

79: $\mathrm{R}_{1}=\mathrm{R}_{2}=\mathrm{R}_{4}=\mathrm{H}, \mathrm{R}_{3}=\mathrm{OCH}_{3}$

80: $\mathrm{R}_{1}=\mathrm{R}_{2}=\mathrm{R}_{3}=\mathrm{H}, \mathrm{R}_{4}=\mathrm{OCH}_{3}$

81: $R_{1}=R_{2}=R_{3}=H, R_{4}=F$

82: $\mathrm{R}_{1}=\mathrm{Cl}, \mathrm{R}_{2}=\mathrm{R}_{3}=\mathrm{R}_{4}=\mathrm{H}$

83: $\mathrm{R}_{1}=\mathrm{Cl}, \mathrm{R}_{2}=\mathrm{R}_{4}=\mathrm{H}, \mathrm{R}_{3}=\mathrm{OCH}_{3}$

84: $\mathrm{R}_{1}=\mathrm{Cl}, \mathrm{R}_{2}=\mathrm{R}_{3}=\mathrm{H}, \mathrm{R}_{4}=\mathrm{OCH}_{3}$

85: $\mathrm{R}_{1}=\mathrm{OCH}_{3}, \mathrm{R}_{2}=\mathrm{R}_{3}=\mathrm{R}_{4}=\mathrm{H}$

86: $\mathrm{R}_{1}=\mathrm{R}_{3}=\mathrm{OCH}_{3}, \mathrm{R}_{2}=\mathrm{R}_{4}=\mathrm{H}$

87: $\mathrm{R}_{1}=\mathrm{R}_{3}=\mathrm{R}_{4}=\mathrm{H}, \mathrm{R}_{2}=\mathrm{OCH}_{3}$

88: $R_{1}=R_{4}=H, R_{2}=R_{3}=O C H 3$

89: $\mathrm{R}_{1}=\mathrm{R}_{3}=\mathrm{R}_{4}=\mathrm{H}, \mathrm{R}_{2}=\mathrm{Cl}$

90: $\mathrm{R}_{1}=\mathrm{R}_{4}=\mathrm{H}, \mathrm{R}_{2}=\mathrm{Cl}, \mathrm{R}_{3}=\mathrm{OCH}_{3}$

Esquema 12. Obtención de los híbridos DBMA - melatonina 77-90 
Los híbridos DBMA - melatonina fueron purificados mediante cromatografía en columna, aislándose con rendimientos de moderados a buenos (Tabla 29). Es interesante destacar que cuando se empleó triptamina $\left(\mathrm{R}_{3}=\mathrm{R}_{4}=\mathrm{H}\right)$ ó serotonina $\left(\mathrm{R}_{3}=\mathrm{OH}, \mathrm{R}_{4}=\mathrm{H}\right)$, los rendimientos fueron moderados (30-61\%), mientras que con el resto de aminas se obtuvieron rendimientos siempre superiores al 65\%. Todos los compuestos fueron caracterizados a partir de sus datos analíticos (HPLC y microanálisis por combustión) y espectroscópicos $\left({ }^{1} \mathrm{H}-\mathrm{RMN},{ }^{13} \mathrm{C}-\mathrm{RMN}\right.$ y MS).

Tabla 29. Rendimientos y tiempo de retención en HPLC de los híbridos DBMA - melatonina 77-90

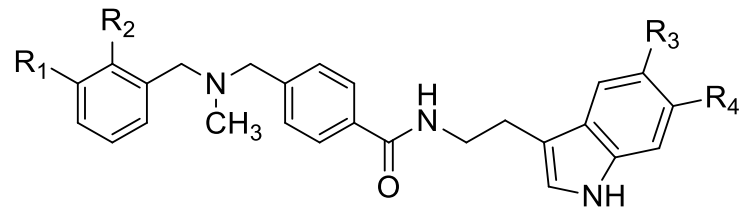

\begin{tabular}{ccccccc}
\hline Comp. & $\mathbf{R}_{\mathbf{1}}$ & $\mathbf{R}_{\mathbf{2}}$ & $\mathbf{R}_{\mathbf{3}}$ & $\mathbf{R}_{\mathbf{4}}$ & $\mathbf{R t o}(\boldsymbol{\%})$ & $\mathbf{t}_{\mathbf{R}(\mathbf{m i n})}{ }^{\mathbf{a}}$ \\
\hline $\mathbf{7 7}$ & $\mathrm{H}$ & $\mathrm{H}$ & $\mathrm{H}$ & $\mathrm{H}$ & 46 & 10.3 \\
$\mathbf{7 8}$ & $\mathrm{H}$ & $\mathrm{H}$ & $\mathrm{OH}$ & $\mathrm{H}$ & 30 & 9.2 \\
$\mathbf{7 9}$ & $\mathrm{H}$ & $\mathrm{H}$ & $\mathrm{OCH}_{3}$ & $\mathrm{H}$ & 72 & 9.7 \\
$\mathbf{8 0}$ & $\mathrm{H}$ & $\mathrm{H}$ & $\mathrm{H}$ & $\mathrm{OCH}_{3}$ & 65 & 10.0 \\
$\mathbf{8 1}$ & $\mathrm{H}$ & $\mathrm{H}$ & $\mathrm{H}$ & $\mathrm{F}$ & 65 & 9.4 \\
$\mathbf{8 2}$ & $\mathrm{Cl}$ & $\mathrm{H}$ & $\mathrm{H}$ & $\mathrm{H}$ & 55 & 12.9 \\
$\mathbf{8 3}$ & $\mathrm{Cl}$ & $\mathrm{H}$ & $\mathrm{OCH}_{3}$ & $\mathrm{H}$ & 82 & 11.7 \\
$\mathbf{8 4}$ & $\mathrm{Cl}$ & $\mathrm{H}$ & $\mathrm{H}$ & $\mathrm{OCH}$ & 80 & 11.9 \\
$\mathbf{8 5}$ & $\mathrm{OCH}$ & $\mathrm{H}$ & $\mathrm{H}$ & $\mathrm{H}$ & 78 & $9.7^{\mathrm{b}}$ \\
$\mathbf{8 6}$ & $\mathrm{OCH}$ & $\mathrm{H}$ & $\mathrm{OCH}_{3}$ & $\mathrm{H}$ & 63 & $9.5^{\mathrm{b}}$ \\
$\mathbf{8 7}$ & $\mathrm{H}$ & $\mathrm{OCH}_{3}$ & $\mathrm{H}$ & $\mathrm{H}$ & 61 & $9.9^{\mathrm{b}}$ \\
$\mathbf{8 8}$ & $\mathrm{H}$ & $\mathrm{OCH}$ & $\mathrm{OCH}_{3}$ & $\mathrm{H}$ & 76 & 12.3 \\
$\mathbf{8 9}$ & $\mathrm{H}$ & $\mathrm{Cl}$ & $\mathrm{H}$ & $\mathrm{H}$ & 49 & 12.3 \\
$\mathbf{9 0}$ & $\mathrm{H}$ & $\mathrm{Cl}$ & $\mathrm{OCH}_{3}$ & $\mathrm{H}$ & 57 & $9.5^{\mathrm{b}}$ \\
\hline
\end{tabular}

${ }^{a}$ HPLC Alliance Waters 2690, detector de UV Photodiodo Array modelo Waters 2996 acoplado a un detector de masas modelo MicromassZQ de Waters, columna XBridgeTM C18, $3.5 \mu \mathrm{m}, 200 \AA$ $(2.1 \mathrm{~nm} \times 100 \mathrm{~mm})$. Eluyente $\left(\mathrm{CH}_{3} \mathrm{CN}: \mathrm{H}_{2} \mathrm{O}\right) / \mathrm{CF}_{3} \mathrm{CO}_{2} \mathrm{H}(0.05 \%)$. Flujo de $0.25 \mathrm{~mL} / \mathrm{min}$. $\operatorname{tg}=20^{\mathrm{b}} \mathrm{tg}=10$ 


\subsubsection{Inhibición de acetil y butirilcolinesterasa humanas de los híbridos DBMA - melatonina}

Como en las familias anteriores, los nuevos híbridos DBMA - melatonina 77-90 fueron ensayados como inhibidores de $\mathrm{AChE}$ y $\mathrm{BuChE}$, empleando en este caso enzimas de origen humano, siguiendo el método colorimétrico de Ellman ${ }^{184}$ y empleando tacrina como referencia interna (Tabla 30).

Tabla 30. Inhibición de AChE y BuChE humanas de los híbridos 77-90

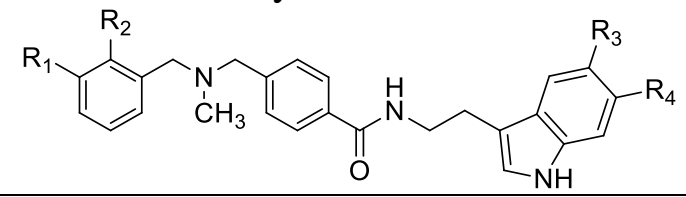

\begin{tabular}{ccccccc}
\hline & & & & & \multicolumn{2}{c}{$\mathrm{CI}_{50} \pm \mathrm{SEM}(\mu \mathrm{M})^{\mathrm{a}, \mathrm{b}}$} \\
\cline { 5 - 6 } Comp. & $\mathrm{R}_{1}$ & $\mathrm{R}_{2}$ & $\mathrm{R}_{3}$ & $\mathrm{R}_{4}$ & $\mathrm{~h}-\mathrm{AChE}^{\mathrm{c}}$ & $\mathrm{h}-\mathrm{BuChE}^{\mathrm{d}}$ \\
\hline $\mathbf{7 7}$ & $\mathrm{H}$ & $\mathrm{H}$ & $\mathrm{H}$ & $\mathrm{H}$ & $1.9 \pm 0.1$ & $3.7 \pm 0.1$ \\
78 & $\mathrm{H}$ & $\mathrm{H}$ & $\mathrm{OH}$ & $\mathrm{H}$ & $4.2 \pm 0.2$ & $9.5 \pm 0.5$ \\
$\mathbf{7 9}$ & $\mathrm{H}$ & $\mathrm{H}$ & $\mathrm{OCH}_{3}$ & $\mathrm{H}$ & $6.1 \pm 0.4$ & $7.8 \pm 0.5$ \\
$\mathbf{8 0}$ & $\mathrm{H}$ & $\mathrm{H}$ & $\mathrm{H}$ & $\mathrm{OCH}_{3}$ & $4.1 \pm 0.3$ & $50.0 \pm 2.1$ \\
$\mathbf{8 1}$ & $\mathrm{H}$ & $\mathrm{H}$ & $\mathrm{H}$ & $\mathrm{F}$ & $2.5 \pm 0.1$ & $7.0 \pm 0.1$ \\
$\mathbf{8 2}$ & $\mathrm{Cl}$ & $\mathrm{H}$ & $\mathrm{H}$ & $\mathrm{H}$ & $5.1 \pm 0.2$ & $>10(38 \%)$ \\
$\mathbf{8 3}$ & $\mathrm{Cl}$ & $\mathrm{H}$ & $\mathrm{OCH}_{3}$ & $\mathrm{H}$ & $5.6 \pm 0.4$ & $>10(38 \%)$ \\
$\mathbf{8 4}$ & $\mathrm{Cl}$ & $\mathrm{H}$ & $\mathrm{H}$ & $\mathrm{OCH}$ & $2.1 \pm 0.1$ & $>10(22 \%)$ \\
$\mathbf{8 5}$ & $\mathrm{OCH}$ & $\mathrm{H}$ & $\mathrm{H}$ & $\mathrm{H}$ & $3.8 \pm 0.1$ & $9.6 \pm 0.2$ \\
$\mathbf{8 6}$ & $\mathrm{OCH}$ & $\mathrm{H}$ & $\mathrm{OCH}_{3}$ & $\mathrm{H}$ & $6.8 \pm 0.2$ & $>10(45 \%)$ \\
$\mathbf{8 7}$ & $\mathrm{H}$ & $\mathrm{OCH}$ & $\mathrm{H}$ & $\mathrm{H}$ & $4.7 \pm 0.2$ & $8.2 \pm 0.4$ \\
$\mathbf{8 8}$ & $\mathrm{H}$ & $\mathrm{OCH}$ & $\mathrm{OCH}_{3}$ & $\mathrm{H}$ & $5.4 \pm 0.2$ & $>10(47 \%)$ \\
$\mathbf{8 9}$ & $\mathrm{H}$ & $\mathrm{Cl}$ & $\mathrm{H}$ & $\mathrm{H}$ & $3.8 \pm 0.2$ & $>10(38 \%)$ \\
$\mathbf{9 0}$ & $\mathrm{H}$ & $\mathrm{Cl}$ & $\mathrm{OCH}_{3}$ & $\mathrm{H}$ & $2.6 \pm 0.1$ & $>10(37 \%)$ \\
Tacrina & & & & $0.23 \pm 0.07$ & $0.040 \pm 0.002$ \\
& & & & & &
\end{tabular}

${ }^{a}$ Los resultados son la media de tres experimentos independientes $(n=3) \pm$ error

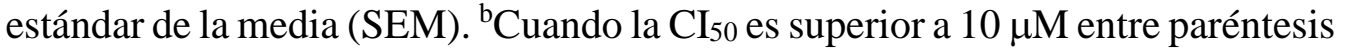
se da el porcentaje de inhibición a dicha concentración. ${ }^{\mathrm{c}} \mathrm{AChE}$ (EC 3.1.1.7) de eritrocitos humanos. ${ }^{\mathrm{d}} \mathrm{BuChE}$ (EC 3.1.1.8) de suero humano.

${ }^{184}$ Ellman, G. L.; Courtney, K. D.; Andres, V., Jr.; Feather-Stone, R. M. A new and rapid colorimetric determination of acetylcholinesterase activity. Biochem. Pharmacol. 1961, 7, 88-95. 
Todos los híbridos inhiben la h-AChE con $\mathrm{CI}_{50}$ s en el rango de micromolar bajo y muestran pequeñas variaciones al introducir diferentes sustituyentes en el anillo de benceno o de indol. Sin embargo, la inhibición de la h-BuChE muestra una alta dependencia de la presencia de sustituyentes: sólo el híbrido no-sustituido 77 inhibe la hBuChE en el rango micromolar bajo $\left(\mathrm{IC}_{50}=3.7 \mu \mathrm{M}\right)$, mientras que la introducción de algún sustituyente en 78-90 dificultan las interacciones híbrido-enzima en un orden de magnitud y muestran $\mathrm{CI}_{50}$ s alrededor de $10 \mu \mathrm{M}$ o peores.

\subsubsection{Ensayos enzimáticos de desplazamiento de propidio del PAS de la AChE}

Como se ha mencionado con anterioridad, la enzima AChE interacciona con los oligómeros de $\beta$-amiloide, induciendo cambios conformacionales que contribuyen a su agregación y precipitación en placas amiloides ${ }^{185}$. La región enzimática que provoca estas modificaciones anormales se ha localizado en la entrada del sitio aniónico periférico (PAS) de la AChE, puesto que el inhibidor selectivo de PAS propidio inhibe la agregación de $\beta$-amiloide inducida por $\mathrm{AChE}$, mientras que el inhibidor competitivo del centro activo (CAS) edrofonio no lo impide ${ }^{186}$. Por lo tanto, el ensayo de desplazamiento de propidio del PAS de la AChE se considera un método válido para estudiar la inhibición de la agregación de $\beta$-amiloide mediante ligandos del $\mathrm{PAS}^{187}$.

El yoduro de propidio experimenta un incremento de su fluorescencia de 10-veces cuando se encuentra unido al PAS de la AChE. Esta señal de fluorescencia desciende cuando el propidio es desplazado del PAS por un inhibidor con mayor afinidad, siendo este descenso proporcional a la cantidad de propidio desplazado y, por lo tanto, es una medida de la afinidad de dicho compuesto por el PAS de la $\mathrm{AChE}^{188}$. Así pues, se estudió la afinidad experimental de los híbridos DBMA - melatonina 77-90 por el PAS de la

${ }^{185}$ De Ferrari, G. V.; Canales, M. A.; Shin, I.; Weiner, L. M.; Silman, I.; Inestrosa, N. C. A structural motif of acetylcholinesterase that promotes amyloid beta-peptide fibril formation. Biochemistry 2001, 40, 10447-10457.

${ }^{186}$ Bartolini, M.; Bertucci, C.; Cavrini, V.; Andrisano, V. beta-Amyloid aggregation induced by human acetylcholinesterase: inhibition studies. Biochem. Pharmacol. 2003, 65, 407-416.

${ }^{187}$ Di Pietro, O.; Viayna, E.; Vicente-Garcia, E.; Bartolini, M.; Ramon, R.; Juarez-Jimenez, J.; Clos, M. V.; Perez, B.; Andrisano, V.; Luque, F. J.; Lavilla, R.; Munoz-Torrero, D. 1,2,3,4Tetrahydrobenzo[h][1,6]naphthyridines as a new family of potent peripheral-to-midgorge-site inhibitors of acetylcholinesterase: synthesis, pharmacological evaluation and mechanistic studies. Eur. J. Med. Chem. 2014, 73, 141-152.

188 Taylor, P.; Lappi, S. "Interaction of flurescence probes with acetylcholinesterase: the site and specifity of propidium binding” Biochemistry 1975, 14, 1989-1997. 
AChE mediante ensayos enzimáticos competitivos en presencia de yoduro de propidio como una medida indirecta de la agregación del péptido $\beta$ A.

Los nuevos híbridos 77-90 fueron evaluados a tres concentraciones $(0.3,1.0$, y 3.0 $\mu \mathrm{M}) \mathrm{y}$ los resultados se recogen en la tabla 30 .

Tabla 31. Desplazamiento de propidio (\%) del PAS de la AChE realizado por los híbridos ensayados a las concentraciones indicadas ${ }^{\mathrm{a}}$

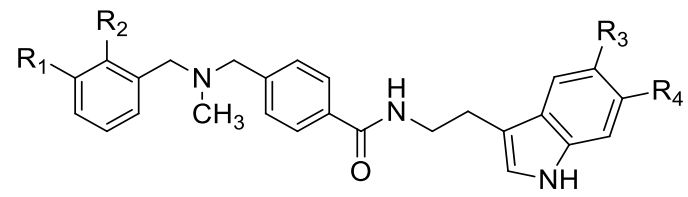

\begin{tabular}{|c|c|c|c|c|c|c|c|}
\hline \multirow[b]{2}{*}{ Comp. } & \multirow[b]{2}{*}{$\mathrm{R}_{1}$} & \multirow[b]{2}{*}{$\mathrm{R}_{2}$} & \multirow[b]{2}{*}{$\mathrm{R}_{3}$} & \multirow[b]{2}{*}{$\mathrm{R}_{4}$} & \multicolumn{3}{|c|}{ \% Desplazamiento de propidio @ } \\
\hline & & & & & $0.3 \mu \mathrm{M}$ & $1.0 \mu \mathrm{M}$ & $3.0 \mu \mathrm{M}$ \\
\hline 77 & $\mathrm{H}$ & $\mathrm{H}$ & $\mathrm{H}$ & $\mathrm{H}$ & $37.6 \pm 0.22$ & $5.6 \pm 0.11$ & $51.4 \pm 1.80$ \\
\hline 78 & $\mathrm{H}$ & $\mathrm{H}$ & $\mathrm{OH}$ & $\mathrm{H}$ & $8.0 \pm 0.54$ & $22.4 \pm 0.37$ & $25.3 \pm 0.70$ \\
\hline 79 & $\mathrm{H}$ & $\mathrm{H}$ & $\mathrm{OCH}_{3}$ & $\mathrm{H}$ & $45.2 \pm 1.80$ & $25.3 \pm 0.96$ & $67.3 \pm 0.08$ \\
\hline 80 & $\mathrm{H}$ & $\mathrm{H}$ & $\mathrm{H}$ & $\mathrm{OCH}_{3}$ & $24.1 \pm 1.01$ & $24.9 \pm 0.30$ & $17.8 \pm 0.31$ \\
\hline 81 & $\mathrm{H}$ & $\mathrm{H}$ & $\mathrm{H}$ & $\mathrm{F}$ & $8.1 \pm 0.87$ & n.d. & $34.5 \pm 0.29$ \\
\hline 82 & $\mathrm{Cl}$ & $\mathrm{H}$ & $\mathrm{H}$ & $\mathrm{H}$ & $10.9 \pm 0.30$ & $15.6 \pm 0.32$ & $29.9 \pm 0.60$ \\
\hline 83 & $\mathrm{Cl}$ & $\mathrm{H}$ & $\mathrm{OCH}_{3}$ & $\mathrm{H}$ & $4.1 \pm 0.70$ & $11.3 \pm 0.48$ & $31.8 \pm 0.37$ \\
\hline 84 & $\mathrm{Cl}$ & $\mathrm{H}$ & $\mathrm{H}$ & $\mathrm{OCH}_{3}$ & $16.8 \pm 0.06$ & $11.4 \pm 0.01$ & $33.4 \pm 0.38$ \\
\hline 85 & $\mathrm{OCH}_{3}$ & $\mathrm{H}$ & $\mathrm{H}$ & $\mathrm{H}$ & $21.8 \pm 0.56$ & $21.4 \pm 1.18$ & $43.7 \pm 1.10$ \\
\hline 87 & $\mathrm{H}$ & $\mathrm{OCH}_{3}$ & $\mathrm{H}$ & $\mathrm{H}$ & $11.5 \pm 0.32$ & $16.9 \pm 1.21$ & $37.9 \pm 1.23$ \\
\hline 88 & $\mathrm{H}$ & $\mathrm{OCH}_{3}$ & $\mathrm{OCH}_{3}$ & $\mathrm{H}$ & n.d. & n.d. & $30.4 \pm 0.76$ \\
\hline 89 & $\mathrm{H}$ & $\mathrm{Cl}$ & $\mathrm{H}$ & $\mathrm{H}$ & $7.7 \pm 0.08$ & $25.8 \pm 0.90$ & $34.7 \pm 0.61$ \\
\hline BW28 & & & & & & & $16.0 \pm 2.4$ \\
\hline
\end{tabular}

${ }^{a}$ Los resultados son la media de tres experimentos independientes \pm error estándar de la media (SEM). 
Todos los compuestos desplazan al catión propidio del PAS mejor que el dibromuro de 4,4'-(3-oxopentano-1,5-diil)bis( $N, N$-dimetil- $N$-prop-2-en-1-ilanilina) (BW248c51), un ligando PAS usado como referencia en este tipo de experimentos ${ }^{189}$. Estos resultados sugieren que los híbridos DBMA - melatonina son capaces de unirse al PAS-AChE y, por lo tanto, podrían prevenir la agregación del $\beta$ A estimulada por esta enzima. Para la mayoría de los compuestos, se obtiene una relación linear concentración - respuesta con máximos de desplazamiento a $3.0 \mu \mathrm{M}$, concentración próxima a los valores de $\mathrm{CI}_{50 \mathrm{~S}}$ observados para la inhibición de la h-AChE $(1.9-6.8 \mu \mathrm{M})$. Sin embargo, algunos compuestos $(\mathbf{7 7}, 79$ y 84) presentan una forma de $U$ en las gráficas concentración respuesta, que podría deberse que estos derivados multifuncionales podrían interaccionar con otros puntos de la garganta enzimática, dependiendo de su concentración.

A $3.0 \mu \mathrm{M}$ el híbrido 79, que es un derivado del 5-metoxiindol y un fragmento nosustituido de DBMA, muestra el mejor resultado de desplazamiento de propidio con un $67 \%$. Otros compuestos con desplazamientos excepcionales son 77 (51\%), 87 (38\%) y 85 $(44 \%)$.

\subsubsection{Predicción in vitro del paso de la barrera hematoencefálica}

El paso de la barrera hematoencefálica de los compuestos se evaluó empleando e 1 ensayo habitual de permeabilidad a través de una membrana artificial, PAMPA (Parallel Artificial Membrane Permeation Assay), siguiendo el procedimiento optimizado previamente en nuestro laboratorio, y descrito con anterioridad en esta tesis. Los resultados se expresan como el valor medio \pm desviación estándar de tres ensayos independientes.

Las permeabilidades in vitro $\left(P_{\mathrm{e}}\right)$ de los híbridos DBMA - melatonina 77-90 y de 10 fármacos comerciales a través de un extracto lipídico de cerebro porcino se determinaron usando una mezcla de PBS: EtOH (70:30). La validación del ensayo se realizó comparando la permeabilidad experimental con los valores descritos de estos fármacos comerciales, dando una buena correlación lineal, $P_{\mathrm{e}}(\exp )=.0.57 P_{\mathrm{e}}(\mathrm{bibl})+2.36\left(\mathrm{R}^{2}=\right.$ 0.919), y los valores fueron normalizados mediante esta correlación lineal. Como en

${ }^{189}$ Arce, M. P.; Rodríguez-Franco, M. I.; González-Muñoz, G. C.; Pérez, C.; López, B.; Villarroya, M.; López, M. G.; García, A. G.; Conde, S. Neuroprotective and cholinergic properties of multifunctional glutamic acid derivatives for the treatment of Alzheimer's disease. J. Med. Chem. 2009, 52, 7249-7257. 
casos anteriores, los productos con una permeabilidad superior a $410^{-6} \mathrm{~cm} \mathrm{~s}^{-1}$ serían capaces de atravesar la barrera hematoencefálica, mientras que los que presenten una $P_{\mathrm{e}}$ por debajo de $210^{-6} \mathrm{~cm} \mathrm{~s}^{-1}$ no serían capaces de llegar al SNC. Como puede apreciarse en la tabla 32, todos los híbridos DBMA - melatonina presentan valores de $P_{\text {e }}$ por encima de $410^{-6} \mathrm{~cm} \mathrm{~s}^{-1}$ y por lo tanto, serían capaces de penetrar en el SNC por difusión pasiva y llegar a sus dianas terapéuticas en el cerebro.

Tabla 32. Permeabilidad $\left(P_{\mathrm{e}}, 10^{-6} \mathrm{~cm} \mathrm{~s}^{-1}\right)^{\mathrm{a}}$ en PAMPA-BBB, predicción para entrar en el SNC y capacidad para capturar radicales libres (ORAC) de los híbridos 77-90.

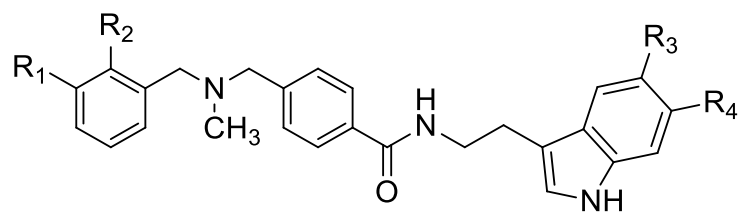

\begin{tabular}{|c|c|c|c|c|c|c|c|}
\hline \multirow[b]{2}{*}{ Comp } & \multirow[b]{2}{*}{$\mathrm{R}_{1}$} & \multirow[b]{2}{*}{$\mathrm{R}_{2}$} & \multirow[b]{2}{*}{$\mathrm{R}_{3}$} & \multirow[b]{2}{*}{$\mathrm{R}_{4}$} & \multicolumn{2}{|c|}{ PAMPA-BBB } & \multirow{2}{*}{$\begin{array}{c}\text { ORAC } \\
(\text { equiv. trolox) })^{\mathrm{a}}\end{array}$} \\
\hline & & & & & $P_{\mathrm{e}}\left(10^{-6} \mathrm{~cm} \mathrm{~s}^{-1}\right)^{i}$ & Predicción & \\
\hline 77 & $\mathrm{H}$ & $\mathrm{H}$ & $\mathrm{H}$ & $\mathrm{H}$ & $15.4 \pm 0.2$ & snct & $3.2 \pm 0.03$ \\
\hline 78 & $\mathrm{H}$ & $\mathrm{H}$ & $\mathrm{OH}$ & $\mathrm{H}$ & $10.0 \pm 0.5$ & snct & $4.3 \pm 0.1$ \\
\hline 79 & $\mathrm{H}$ & $\mathrm{H}$ & $\mathrm{OCH}_{3}$ & $\mathrm{H}$ & $14.1 \pm 0.4$ & snct & $2.5 \pm 0.04$ \\
\hline 80 & $\mathrm{H}$ & $\mathrm{H}$ & $\mathrm{H}$ & $\mathrm{OCH}_{3}$ & $14.2 \pm 0.1$ & snct & $1.5 \pm 0.01$ \\
\hline 81 & $\mathrm{H}$ & $\mathrm{H}$ & $\mathrm{H}$ & $\mathrm{F}$ & $12.6 \pm 0.2$ & snct & $2.1 \pm 0.04$ \\
\hline 82 & $\mathrm{Cl}$ & $\mathrm{H}$ & $\mathrm{H}$ & $\mathrm{H}$ & $14.1 \pm 0.1$ & snct & $2.9 \pm 0.1$ \\
\hline 83 & $\mathrm{Cl}$ & $\mathrm{H}$ & $\mathrm{OCH}_{3}$ & $\mathrm{H}$ & $14.9 \pm 0.2$ & snct & $2.6 \pm 0.1$ \\
\hline 84 & $\mathrm{Cl}$ & $\mathrm{H}$ & $\mathrm{H}$ & $\mathrm{OCH}_{3}$ & $14.9 \pm 0.1$ & snct & $1.8 \pm 0.04$ \\
\hline 85 & $\mathrm{OCH}_{3}$ & $\mathrm{H}$ & $\mathrm{H}$ & $\mathrm{H}$ & $16.8 \pm 0.1$ & snct & $2.7 \pm 0.04$ \\
\hline 86 & $\mathrm{OCH}_{3}$ & $\mathrm{H}$ & $\mathrm{OCH}_{3}$ & $\mathrm{H}$ & $16.7 \pm 0.4$ & snct & $2.5 \pm 0.04$ \\
\hline 87 & $\mathrm{H}$ & $\mathrm{OCH}_{3}$ & $\mathrm{H}$ & $\mathrm{H}$ & $16.8 \pm 0.3$ & snct & $2.9 \pm 0.1$ \\
\hline 88 & $\mathrm{H}$ & $\mathrm{OCH}_{3}$ & $\mathrm{OCH}_{3}$ & $\mathrm{H}$ & $18.9 \pm 0.3$ & snct & $2.4 \pm 0.1$ \\
\hline 89 & $\mathrm{H}$ & $\mathrm{Cl}$ & $\mathrm{H}$ & $\mathrm{H}$ & $10.8 \pm 0.1$ & snct & $2.8 \pm 0.02$ \\
\hline 90 & $\mathrm{H}$ & $\mathrm{Cl}$ & $\mathrm{OCH}_{3}$ & $\mathrm{H}$ & $10.9 \pm 0.4$ & snct & $2.5 \pm 0.2$ \\
\hline \multicolumn{3}{|c|}{ Melatonina } & & & nd & & $2.4 \pm 0.1$ \\
\hline
\end{tabular}

${ }^{a}$ Los resultados son la media de tres experimentos independientes $(\mathrm{n}=3) \pm$ desviación estándar (DS). 


\subsubsection{Evaluación de la capacidad de captura de radicales de oxígeno}

A continuación, se evaluó la capacidad de captura de radicales de oxígeno (Oxygen Radical Absorbance Capacity, ORAC) de los hibridos DBMA - melatonina 77-90 como una medida de sus propiedades antioxidantes siguiendo protocolo establecido ${ }^{190}$ (Tabla 34). En estos ensayos se usó trolox, la parte aromática de la vitamina E y la responsable de la captura de radicales, como estándar interno al que se le asignó el valor arbitrario de ORAC $=1.0$. Por lo tanto, los resultados se expresan como equivalentes de trolox (micromoles de trolox/micromoles de compuesto evaluado) en una escala comparativa que muestra si los compuestos son mejores (ORAC $>1)$ o peores $(\mathrm{ORAC}<1)$ que el trolox. Como control positivo se empleó melatonina, que dio un valor de ORAC de 2.4, muy próximo al valor descrito por Sǒfic et al. (2.0 equiv. trolox) ${ }^{191}$. Los compuestos evaluados muestran buenos valores de ORAC, comprendidos entre 1.5 y 4.3 equiv. trolox, por lo que pueden ser considerados como potentes agentes antioxidantes.

Como era de esperar, la capacidad de captura de radicales libres de estos compuestos está principalmente localizada en el fragmento de melatonina, donde la presencia de un grupo fenólico proporciona el mejor valor de ORAC (78, ORAC $=4.3$ equiv. trolox). Sin embargo, la introducción de un halógeno o un grupo metoxilo en el indol y/o en el fragmento de DBMA disminuye la capacidad ORAC entre 0.3 y 1.7 equiv. trolox, comparada con el híbrido no-sustituido 77 (ORAC $=3.2$ equiv. trolox). Es interesante mencionar que los derivado 5-metoxilindol 79 y 83 muestran mejores valores de ORAC ( 2.5 y 2.6 equiv. trolox, respectivamente) que sus análogos 6-metoxilo 80 y 84 (1.5 y 1.8 equiv. trolox), sugiriendo la participación de la posición indólica cinco en el mecanismo de captura de estos híbridos.

\subsubsection{Ensayos de neuroprotección y viabilidad celular en neuroblastoma humano}

Para explorar el potencial terapéutico de los híbridos DBMA - melatonina 77-90, se evaluó su toxicidad y su capacidad de neuroprotección frente al estrés oxidativo mitocondrial en la línea celular de neuroblastoma humano SH-SY5Y, usando la mezcla de rotenona y oligomicina A. La combinación de estos tóxicos induce radicales libres de

190 Dávalos, A.; Gómez-Cordovés, C.; Bartolomé, B. Extending applicability of the oxygen radical absorbance capacity (ORAC-fluorescein) assay. J. Agric. Food Chem. 2004, 52, 48-54.

191 Sofic, E.; Rimpapa, Z.; Kundurovic, Z.; Sapcanin, A.; Tahirovic, I.; Rustembegovic, A.; Cao, G. Antioxidant capacity of the neurohormone melatonin. J. Neural Transm. 2005, 112, 349-358. 
oxígeno debido al bloqueo de los complejos I y V de la cadena electrónica mitocondrial, por lo que es un buen modelo de estrés oxidativo endógeno ${ }^{192}$. En estos experimentos, los compuestos fueron evaluados a $1.0 \mu \mathrm{M}$, una concentración próxima a sus $\mathrm{CI}_{50}$ s en la inhibición de h-AChE. El porcentaje de muerte celular fue determinado por la concentración de lactato deshidrogenasa (LDH), una enzima que es liberada al medio extracelular cuando las neuronas mueren ${ }^{193}$.

En primer lugar, se estudiaron los posibles efectos citotóxicos de 77-90 por exposición de las células SH-SY5Y a los compuestos a una concentración de $1.0 \mu \mathrm{M}$ durante 24 h. En todos los casos, el porcentaje de LDH es menor o igual que la medida basal, lo que indica que la viabilidad celular está próxima al 100\%. A continuación, las células fueron incubadas con los híbridos 77-90 a $1.0 \mu \mathrm{M}$ durante 24 h antes de la adición de la mezcla de rotenona $(30 \mu \mathrm{M})$ y oligomicina $\mathrm{A}(10 \mu \mathrm{M})$ y después se mantienen otras 24h en presencia de los híbridos. Se empleó melatonina como referencia interna y los resultados se muestran en la figura 34 .

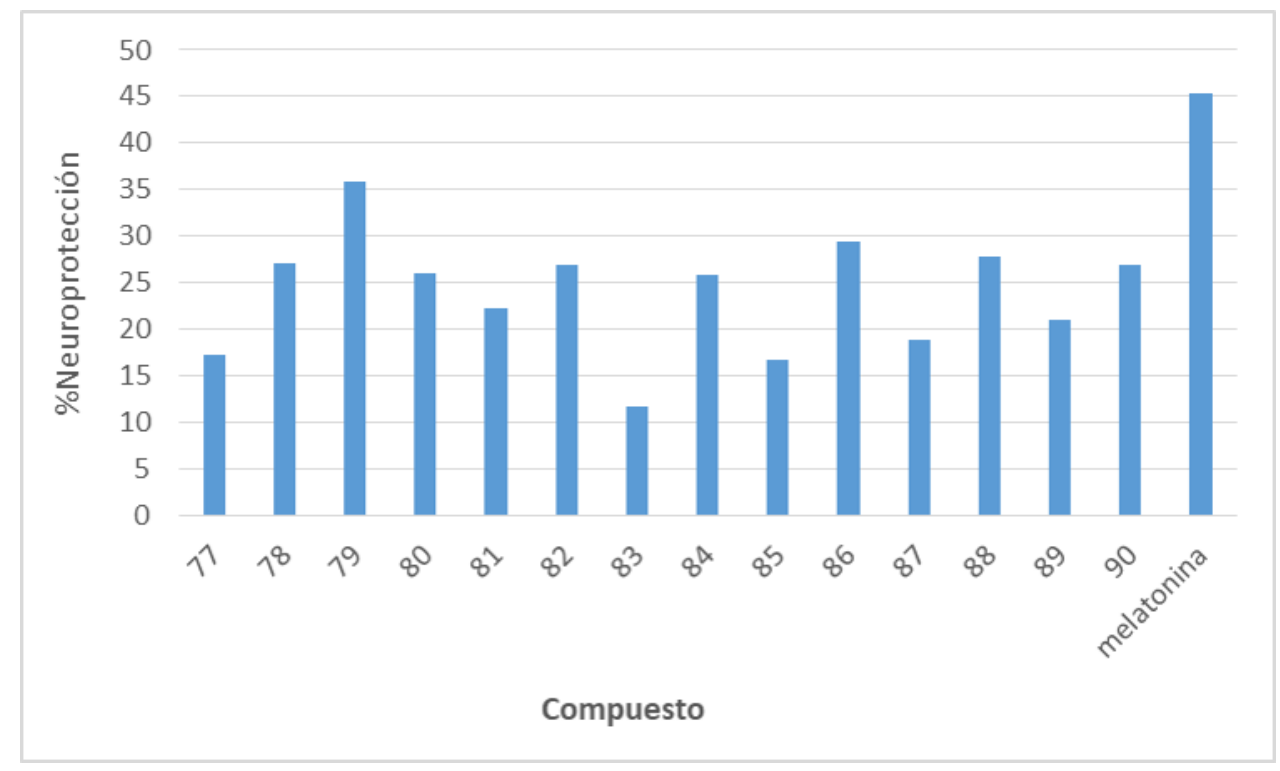

Figura 34. Efecto de los híbridos 77-90 (1.0 $\mu M)$ sobre la muerte celular inducida por la combinación de rotenona $(30 \mu \mathrm{M})$ y oligomicina $\mathrm{A}(10 \mu \mathrm{M})$. La viabilidad celular se evaluó mediante la liberación de LDH en el medio.

192 Egea, J.; Rosa, A. O.; Cuadrado, A.; García, A. G.; López, M. G. Nicotinic receptor activation by epibatidine induces heme oxygenase- 1 and protects chromaffin cells against oxidative stress. $J$. Neurochem. 2007, 102, 1842-1852.

${ }^{193}$ Maroto, R.; De la Fuente, M. T.; Artalejo, A. R.; Abad, F.; López, M. G.; García-Sancho, J.; García, A. $\mathrm{G}$. Effects of $\mathrm{Ca} 2+$ channel antagonists on chromaffin cell death and cytosolic $\mathrm{Ca} 2+$ oscillations induced by veratridine. Eur. J. Pharmacol. 1994, 270, 331-339. 
Todos los híbridos DBMA - melatonina muestran buenos niveles de protección, comprendidos entre el 12 y el 36\%, en algunos casos próximos al valor de la propia melatonina (45\%). Entre los híbridos con un fragmento no-sustituido de DBMA 77-81, la introducción de un sustituyente en posición 5- o 6- en el anillo de indol, incrementa el porcentaje de protección. De hecho, el híbrido 79, derivado de 5-metoxiindol y el fragmento de DBMA no-sustituida, es el mejor agente neuroprotector, salvando al $36 \%$ de las células del daño inducido por radicales libres mitocondriales.

Con respecto a los derivados de 5-metoxiindol $\left(\mathrm{R}_{3}=\mathrm{OCH}_{3}\right)$ la introducción de un átomo de cloro en el fragmento de DBMA tiene un efecto perjudicial en la neuroprotección, reduciendo los valores desde el más alto del $36 \%$ para el fragmento nosustituido de DBMA (79, $\left.\mathrm{R}_{1}=\mathrm{R}_{2}=\mathrm{H}\right)$ al $27 \%\left(\mathbf{9 0}, \mathrm{R}_{1}=\mathrm{H}, \mathrm{R}_{2}=\mathrm{Cl}\right)$ y $12 \%\left(\mathbf{8 3}, \mathrm{R}_{1}=\mathrm{Cl}\right.$, $\mathrm{R}_{2}=\mathrm{H}$ ). Sin embargo, la introducción de un segundo grupo metoxilo en $\mathrm{R}_{1}$ mantiene la neuroprotección en el $30 \%\left(\mathbf{8 6}, \mathrm{R}_{1}=\mathrm{OCH}_{3}\right)$.

\subsubsection{Estudios neurogénicos de los híbridos DBMA - melatonina}

Para evaluar la capacidad de los nuevos híbridos para reparar el daño cerebral, se realizaron estudios de neurogénesis in vitro. Teniendo en cuenta la estructura de la melatonina, que es un derivado del 5-metoxiindol, para estos experimentos se seleccionaron híbridos que llevaran uno o dos grupos metoxilo en diferentes posiciones. Concretamente, se eligieron los siguientes compuestos: $79\left(\mathrm{R}_{1}=\mathrm{R}_{2}=\mathrm{R}_{4}=\mathrm{H}, \mathrm{R}_{3}=\right.$ $\left.\mathrm{OCH}_{3}\right), 86\left(\mathrm{R}_{1}=\mathrm{R}_{2}=\mathrm{OCH}_{3}, \mathrm{R}_{3}=\mathrm{R}_{4}=\mathrm{H}\right)$ y $87\left(\mathrm{R}_{1}=\mathrm{R}_{3}=\mathrm{R}_{4}=\mathrm{H}, \mathrm{R}_{2}=\mathrm{OCH}_{3}\right)$.

A partir de la zona subgranular del giro dentado del hipocampo de ratas Wistar adultas se obtuvieron células madre neuronales primarias, en las que se indujo su proliferación siguiendo protocolos establecidos ${ }^{194,195,196}$. A continuación, se analizó si la adición de diferentes compuestos podría promover estados tempranos de neurogénesis y de maduración neuronal, mediante la tinción de las células con $\beta$-tubulina (clon TuJ1) y

${ }^{194}$ Ferrón, S. R.; Andreu-Agullo, C.; Mira, H.; Sánchez, P.; Marqués-Torrejón, M. A.; Farinas, I. A combined ex/in vivo assay to detect effects of exogenously added factors in neural stem cells. Nat. Protoc. 2007, 2, 849-859.

${ }^{195}$ Morales-García, J. A.; Luna-Medina, R.; Alfaro-Cervello, C.; Cortes-Canteli, M.; Santos, A.; GarcíaVerdugo, J. M.; Pérez-Castillo, A. Peroxisome proliferator-activated receptor gamma ligands regulate neural stem cell proliferation and differentiation in vitro and in vivo. Glia 2011, 59, 293-307.

${ }^{196}$ Morales-García, J. A.; Luna-Medina, R.; Alonso-Gil, S.; Sanz-Sancristóbal, M.; Palomo, V.; Gil, C.; Santos, A.; Martínez, A.; Pérez-Castillo, A. Glycogen synthase kinase 3 inhibition promotes adult hippocampal neurogenesis in vitro and in vivo. ACS Chem. Neurosci. 2012, 3, 963-971. 
MAP-2 (proteína 2 asociada a microtúbulos) respectivamente. Todos los compuestos evaluados, incluidas los referentes, fueron usados a una concentración de $10 \mu \mathrm{M}$.

En primer lugar, se hicieron estudios de citotoxicidad para los compuestos 79, 86 y 87 a $10 \mu \mathrm{M}$ usando células de la línea de neuroblastoma humano. Ninguno de los compuestos evaluados causó una significativa reducción de la viabilidad celular (medida como reducción de MTT) o muerte celular (medido como aumento de LDH) después de exponer a las células SH-SY5Y a los compuestos a $10 \mu \mathrm{M}$ durante 48h (Tabla 33). Estos resultados indican que los híbridos 79, 86 y 87 no son tóxicos a la concentración usada en los ensayos de neurogénesis.

Tabla 33. Porcentaje de reducción de MTT y de liberación de LDH en presencia de los compuestos seleccionados en la línea celular SH-SY5Y

\begin{tabular}{ccc}
\hline Comp. & $\%$ MTT & $\%$ LDH \\
\hline $\mathbf{7 9}$ & $98 \pm 1$ & $12.4 \pm 0.5$ \\
$\mathbf{8 6}$ & $96 \pm 1$ & $12.9 \pm 0.1$ \\
$\mathbf{8 7}$ & $100 \pm 2$ & $10.5 \pm 0.4$ \\
Basal & $100 \pm 1$ & $11.5 \pm 0.2$ \\
\hline
\end{tabular}

Los datos son la media \pm SEM $(n=5)$. Todos los compuestos se ensayaron a $10 \mu \mathrm{M}$ durante $48 \mathrm{~h} \mathrm{y}$ no mostraron diferencias significativas con respecto al basal (DMSO al $0.1 \%$ como vehículo).

Las figuras 35 y 36 muestran los efectos neurogénicos de los compuestos 79, 86 y 87 a $10 \mu \mathrm{M}$ en cultivos de células madre neuronales, comparados con el efecto del vehículo (basal), de la melatonina (agonista endógeno de los receptores melatoninérgicos) y del luzindol (antagonista de estos mismos receptores). En las gráficas de barras se han cuantificado las células marcadas con $\mathrm{TuJ}^{+}$o con MAP-2 ${ }^{+}$usando 5 neuroesferas para cada producto y condición. 


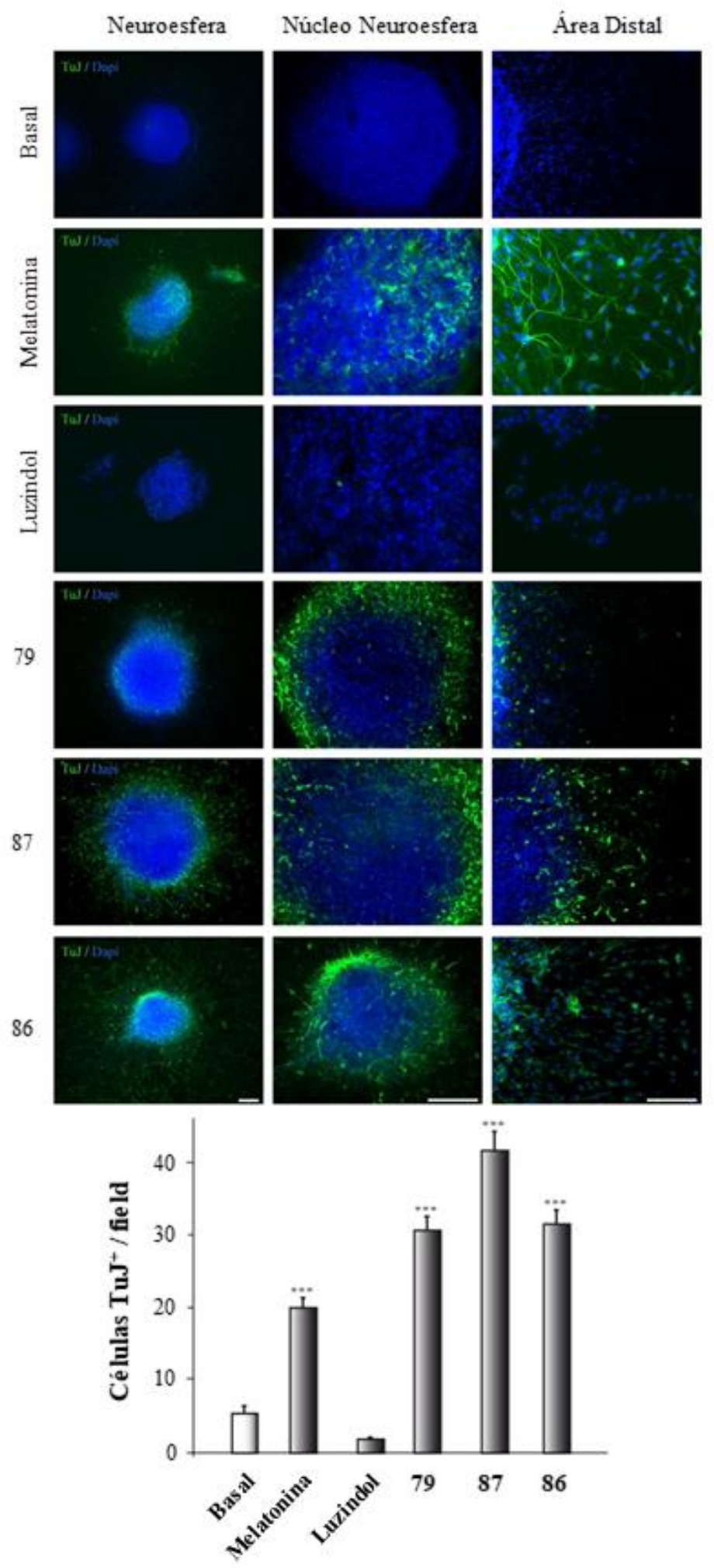

Figura 35. Cultivos de células madre neurales tratadas con vehículo (basal), melatonina, luzindol (antagonista de MTRs), 79, 87 y 86 a $10 \mu \mathrm{M}$ durante 48h. Las células neuronales se detectaron utilizando un anticuerpo de anti- $\beta$-tubulina (clon TuJl, verde) como marcador de neurogénesis temprana. DAPI (azul) se usó para tinción nuclear. Barra de escala, $200 \mu \mathrm{m}$. Se muestra la cuantificación de células TuJ ${ }^{+}$en neuroesferas. Los valores son la media \pm desviación estándar de cinco neuroesferas. $* * * P \leq 0.001$. 


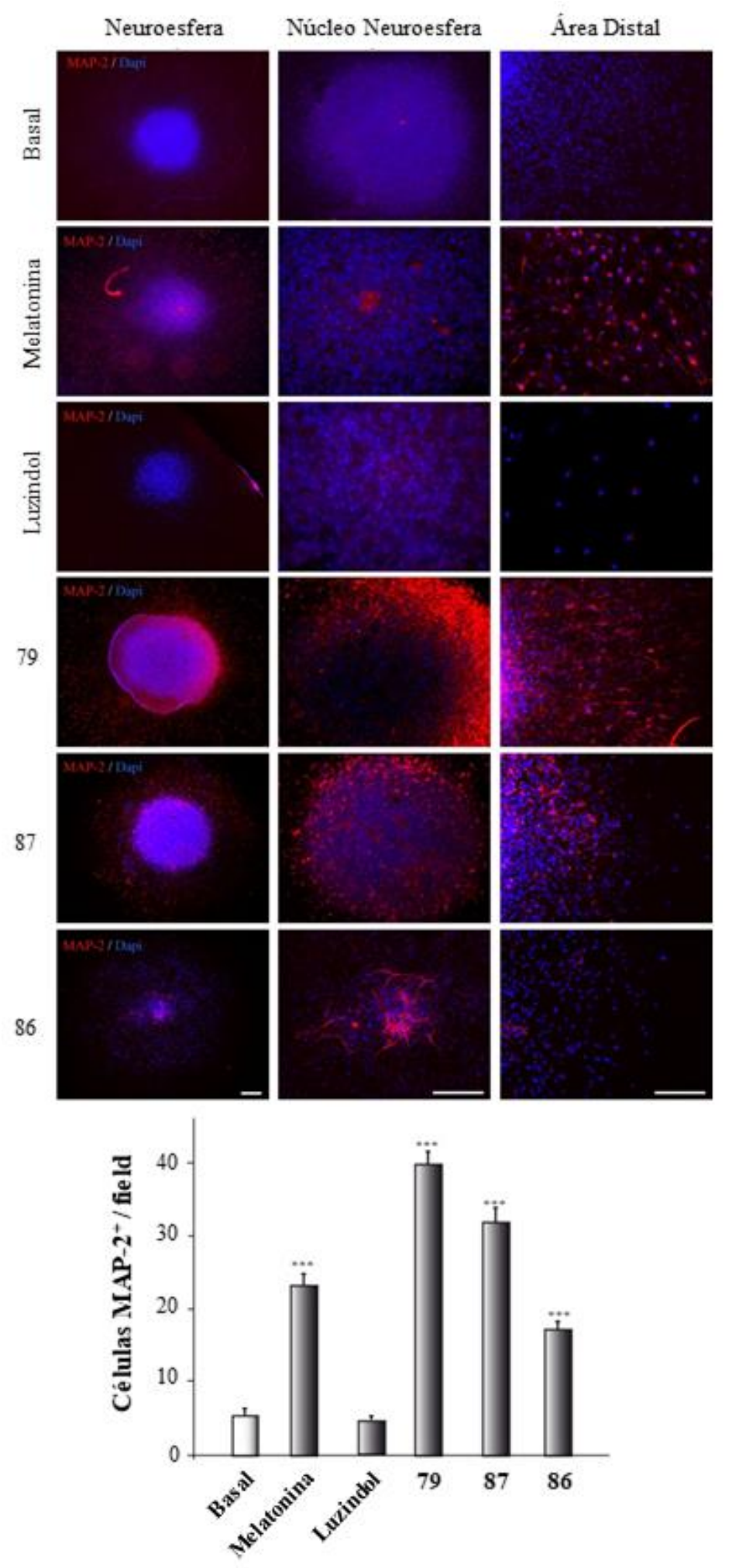

Figura 36. Cultivos de células madre neurales tratadas con vehículo (basal), melatonina, luzindol (antagonista de MTRs), 79, 87 y 86 a 10 MM durante 48h. Se usó MAP-2 (proteína 2 asociada a microtúbulos, rojo) como marcador asociado con la maduración neuronal y se usó DAPI (azul) para tinción nuclear. Barra de escala, $200 \mu \mathrm{m}$. Se muestra la cuantificación de células MAP-2 + en neuroesferas. Los valores son la media \pm desviación estándar de cinco neuroesferas. $* * * P \leq 0.001$. 
Como era de esperar, la melatonina indujo tanto la neurogénesis temprana como la maduración celular, mientras que el luzindol no fue capaz de promover ninguno de estos dos procesos. Todos los híbridos de DBMA - melatonina 79, 86 y 87, fueron capaces de estimular la neurogénesis temprana y la maduración a un fenotipo neuronal, siendo más eficaces que la propia melatonina. Empleando TuJ1, se encontró que el compuesto 87 era el híbrido más eficaz en la neurogénesis temprana, siendo dos veces más potente que la melatonina (Figura 35). Pero en los experimentos de maduración celular, el agente más eficiente fue el híbrido 79, derivado del 5-metoxiindol y la $N, N$-dibencil( $N$-metil)amina no-sustituida, que era casi dos veces mejor que la melatonina. Además, el híbrido 79 mostró una densa corona de células marcadas con TuJ1 y MAP-2 alrededor del núcleo de la neurosfera y células positivas hacia la parte externa, lo que sugiere la migración fuera de la neurosfera (Figura 36).

Como resumen, se han obtenido híbridos DBMA - melatonina que presentan un perfil biológico equilibrado. A concentraciones micromolares bajas, estimulan las etapas tempranas de la neurogénesis de células madre neurales y su maduración hacia un fenotipo neuronal, inhiben la h-AChE, desplazan propidio del PAS de la AChE y protegen a una línea celular de neuroblastoma humano contra el daño causado por radicales libres mitocondriales. Además, son compuestos permeables al SNC con baja toxicidad celular y muestran buenas propiedades antioxidantes.

Por lo tanto, es de esperar que estos nuevos híbridos DBMA - melatonina puedan promover procesos de auto-reparación de células madre neurales en el SNC, proteger las neuronas del estrés oxidativo mitocondrial, aumentar la memoria del paciente y reducir el formación de placas amiloides. Estas propiedades biológicas, junto con su capacidad para penetrar en el SNC, hacen de estos nuevos híbridos interesantes prototipos multifuncionales en la búsqueda de nuevos fármacos regenerativos para el tratamiento de la enfermedad del Alzheimer y otras patologías neurodegenerativas.

Los híbridos DBMA - melatonina fueron primero protegidos mediante una Patente ${ }^{197}$ y posteriormente publicados en una de las mejores revistas del área de Química Médica, como es el Journal of Medicinal Chemistry ${ }^{198}$.

\footnotetext{
${ }^{197}$ Rodríguez-Franco, M. I.; Conde, S.; López-Iglesias, B.; Pérez, C.; Villarroya, M.; López, M. G.; García, A. G. Derivados de bis(aralquil)amino y sistemas [6+5]-heteroaromáticos y su uso en el tratamiento de patologías neurodegenerativas, incluida la enfermedad de Alzheimer. ES P200930936 (30/10/2009).

${ }^{198}$ López-Iglesias, B.; Pérez, C.; Morales-García, J. A.; Alonso-Gil, S.; Pérez-Castillo, A.; Romero, A.; López, M. G.; Villarroya, M.; Conde, S.; Rodríguez-Franco, M. I. New melatonin- $N, N$-dibenzyl $(N$ -
} 


\subsection{CONCLUSIONES}

En este capítulo se han obtenido varias familias de moléculas multifuncionales con propiedades colinérgicas, antioxidantes, neuroprotectoras y neurogénicas, dirigidas a un potencial tratamiento de la enfermedad de Alzheimer. Empleando fragmentos de conocidos inhibidores de $\mathrm{AChE}$, se han diseñado híbridos derivados de tacrina y de $N, N$ dibencil( $N$-metil)amina, que en algunos casos han mostrado mejores propiedades biológicas que los fragmentos que los componen. Se han optimizado métodos de síntesis y se ha realizado la asignación de los datos espectroscópicos de ${ }^{1} \mathrm{H}-\mathrm{y}{ }^{13} \mathrm{C}-\mathrm{RMN}$ de los productos obtenidos.

A continuación, se resumen los puntos más importantes y las conclusiones de este capítulo:

1. Se han diseñado y sintetizado tres familias de híbridos por unión del fragmento de tacrina con tiramina y homoveratrilamina (12-26), con ácido ferúlico (31-34) y con fragmentos derivados de para- y orto-fenol (35-47).

1.1. Se han obtenido inhibidores nanomolares de bov-AChE y eq-BuChE en las tres series derivadas de tacrina.

1.2. Los híbridos tacrina - ferúlico fueron un orden de magnitud más potentes en la AChE humana que en la enzima de origen animal, por lo que los siguientes derivados de $p$ - y $o$-fenol, éstos fueron ensayados en h-AChE y no en bov-AChE.

1.3. Sólo los híbridos tacrina - $o$-fenol mostraron una aceptable permeabilidad en el SNC, según el método PAMPA-BBB, por lo que algunos de sus representantes fueron elegidos para posteriores estudios biológicos: desplazamiento de propidio del PAS de la AChE y estudios de neuroprotección frente al estrés oxidativo mitocondrial en una línea celular de neuroblastoma humano.

1.4. Entre los híbridos tacrina - o-fenol, destaca 3-(2-hidroxifenil)- $N-(6-((1,2,3,4-$ tetrahidroacridin-9-il)amino)hexil)propanamida (36), que es un inhibidor nanomolar de colinesterasas, con selectividad hacia eq-BuChE frente a h-AChE $\left(\mathrm{CI}_{50 \mathrm{~s}}=0.074\right.$ 
y $5.31 \mathrm{nM}$, respectivamente), lo que podría ser útil en las fases avanzadas de la enfermedad de Alzheimer, en las que la transmisión colinérgica se hace más dependiente de BuChE.

1.5. En ensayos adicionales, el híbrido 36 es capaz de desplazar propidio del PAS de la $\mathrm{AChE}$, por lo que podría impedir la agregación del péptido $\beta$ A patógeno y frenar de esta manera el proceso de degeneración neuronal. En los ensayos celulares protegió en un $24 \%$ al neuroblastoma del efecto tóxico de una mezcla de rotenona y oligomicina A, que es un modelo del estrés oxidativo mitocondrial.

1.6. Los resultados anteriores, junto con su positiva predicción de penetración en el SNC (PAMPA-BBB, $P_{\mathrm{e}}=4.310^{-6} \mathrm{~cm} \mathrm{~s}^{-1}$ ) perfilan al híbrido tacrina $-o$-fenol 36 como un prototipo útil en la búsqueda de nuevos fármacos contra la EA.

2. Se han diseñado y obtenido híbridos DBMA - neuroaminas e híbridos DBMA piridina / piridinol, con propiedades colinérgicas y neuroprotectoras.

2.1. La mayoría de los híbridos derivados de DBMA son inhibidores de AChE y BuChE en el rango micromolar bajo, desplazan propidio del PAS de la AChE, serían capaces de llegar al SNC y son protectores frente al estrés oxidativo mitocondrial en una línea neuronal de neuroblastoma humano.

2.2. A partir de estos ensayos, se eligió al híbrido DBMA - homoveratrilamina 61 para realizar estudios farmacológicos adicionales, que han demostrado que este producto mantiene excelentes propiedades neuroprotectoras en modelos de daño neuronal provocado por estrés oxidativo, fallo mitocondrial (sobrecarga de calcio), $\beta$-amiloide (placas seniles) y ácido okadaico (ovillos neurofibrilares).

2.3. En un modelo tisular de isquemia cerebral, el híbrido DBMA homoveratrilamina $\mathbf{6 1}$ presenta interesantes propiedades protectoras.

2.4. En un modelo in vivo de pérdida de memoria por escopolamina en ratón, el híbrido DBMA - homoveratrilamina 61 mejora el rendimiento nemotécnico de los animales, aunque en menor medida que la galantamina. 
3. Se han diseñado y obtenido híbridos DBMA - melatonina, con un equilibrado perfil multifuncional que incluye propiedades neurogénicas, neuroprotectoras, colinérgicas y antioxidantes.

3.1. Los híbridos DBMA - melatonina son buenos inhibidores de AChE humana, en el rango micromolar bajo y desplazan propidio del PAS de la AChE.

3.2. En neuroblastoma humano los híbridos DBMA - melatonina, empleados en concentraciones de micromolar-bajo, protegen a la línea celular del daño provocado por radicales libres mitocondriales.

3.3. Los híbridos DBMA - melatonina presentan buenas propiedades antioxidantes.

3.4. Estos compuestos son permeables al SNC, con baja toxicidad celular.

3.5. A concentraciones micromolares bajas, los híbridos DBMA - melatonina estimulan las etapas tempranas de la neurogénesis de células madre neurales y su maduración hacia un fenotipo neuronal.

3.6. Por lo tanto, es de esperar que estos nuevos híbridos DBMA - melatonina puedan promover procesos de auto-reparación de células madre neurales en el SNC, proteger las neuronas del estrés oxidativo mitocondrial, aumentar la memoria del paciente y reducir el formación de placas amiloides. Estas propiedades biológicas, junto con su capacidad para penetrar en el SNC, hacen de estos nuevos híbridos interesantes prototipos multifuncionales en la búsqueda de nuevos fármacos regenerativos para el tratamiento de la enfermedad del Alzheimer y otras patologías neurodegenerativas. 


\subsection{PARTE EXPERIMENTAL}

Las separaciones cromatográficas se realizaron empleando columnas de cromatografía a presión sobre gel de sílice (Kieselgel 60 Merck de 230-400). El eluyente se especifica en cada caso y las proporciones de mezcla van siempre indicadas en volumen. Los compuestos se detectaron mediante UV (254 nm) o mediante el empleo de reveladores químicos como yodo o ninhidrina. Las cromatografías en capa fina, se realizaron en cromatofolios de aluminio de gel de sílice tipo 60 F-254 Merck, de $0.2 \mathrm{~mm}$ de espesor. Los puntos de fusión se determinaron en un aparato Reichert-Jung Thermovar y no están corregidos. Los análisis elementales de los compuestos están en el rango de \pm 0.4 respecto de los valores teóricos calculados para las fórmulas moleculares y se han realizado en el Departamento de Análisis y Técnicas Instrumentales del Centro Nacional de Química Orgánica “Lora Tamayo”, con un analizador Heraeus CHN-O-rapid.

Los espectros de resonancia magnética nuclear se obtuvieron en espectrómetros Varian Unity-500, Varian Unity Inova-400 y Varian XL-300. Los valores de los desplazamientos químicos $(\delta)$ se expresan en ppm, relativos al tetrametilsilano empleado como referencia interna. Los valores de las constantes de acoplamiento se indican en Herzios (Hz). Los parámetros esectroscópicos empleados habitualmente en los espectros de ${ }^{1} \mathrm{H}-\mathrm{RMN}$ fueron: anchura espectral $10 \mathrm{ppm}$, anchura de pulso $9 \mathrm{~ms}\left(57^{\circ}\right)$ y en los espectros de ${ }^{13} \mathrm{C}-\mathrm{RMN}$ : anchura espectral $16 \mathrm{KHz}$, tiempo de adquisición $0.99 \mathrm{~s}$ y anchura de pulso $9 \mathrm{~ms}\left(57^{\circ}\right)$. Para los experimentos bidimensionales de correlación heteronuclear protón-carbono, HSQC (Heteronuclear Single Quantum Coherance) y HMBC (Heteronuclear Multiple Bond Correlation), se emplearon las condiciones estándar, mediante detección inversa. Las multiplicidades se indican como s (singlete), d (doblete), t (triplete), c (cuadruplete), y m (multiplete). Los espectros de masas (EM) se obtuvieron por impacto electrónico a $70 \mathrm{eV}$ (IE) en un espectrómetro Hewlett-Packard 5973 (inserción directa de muestra), mediante ionización química a presión atmosférica (APCI) o ionización por electronebulización (electrospray ionization, ESI) en modo positivo en un espectrómetro Hewlett-Packard MSD 1100.

La pureza de los productos se determinó utilizando equipos de cromatografía líquida de alta resolución (HPLC). Por una parte, se empleó un equipo Waters 6000 con detector de UV (214-272 nm) utilizando una columan Delta PaK Symmetry $\mathrm{C}_{18}, 5 \mu \mathrm{m}, 300 \AA$ (3.9 
$\mathrm{nm} \times 150 \mathrm{~mm}$ ). Los compuestos se eluyeron con un flujo de $1.0 \mathrm{~mL} / \mathrm{min}$, empleando mezclas de $\mathrm{CH}_{3} \mathrm{CN}$ (eluyente $\mathrm{A}$ ) y $\mathrm{H}_{2} \mathrm{O}$ con $0.05 \%$ de ácido trifluoroacético (eluyente $\mathrm{B}$ ) como se indica en cada caso. El segundo equipo de HPLC era un Alliance Waters 2690 con un detector de UV Photodiodo Array modelo Waters 2996 acoplado a un detector de masas modelo MicromassZQ de Waters, utilizando una columna XBridgeTM C18, 3.5 $\mu \mathrm{m}, 200 \AA$ ( $2.1 \mathrm{~nm}$ x $100 \mathrm{~mm})$ y empleando en todos los casos el gradiente 5/95 ó 5/80 $\left(\mathrm{CH}_{3} \mathrm{CN}: \mathrm{H}_{2} \mathrm{O}\right) / \mathrm{CF}_{3} \mathrm{CO}_{2} \mathrm{H}(0.05 \%)$ hasta $100 \%$ de $\mathrm{CH}_{3} \mathrm{CN}$ empleando un tiempo de gradiente de 15 minutos con un flujo de $0.25 \mathrm{~mL} / \mathrm{min}$.

\subsubsection{Derivados de tacrina}

\section{9-Cloro-1,2,3,4-tetrahidroacridina (1)}<smiles>Clc1c2c(nc3ccccc13)CCCC2</smiles>

Una mezcla de 9-(1,2,3,4-tetrahidro)acridona (1.0 g, $50 \mathrm{mmol}) \mathrm{y}$ $\mathbf{P O C l}_{3}(25 \mathrm{~mL})$ se refluyó durante 6 horas. Posteriormente, la reacción se trató con una disolución acuosa de $\mathrm{KOH} 10 \mathrm{~N}$ hasta alcanzar un pH $\approx 8$, enfriando externamente con un baño de hielo. La mezcla resultante se extrajo con $\mathrm{Et}_{2} \mathrm{O}(3 \times 100 \mathrm{~mL})$, y los extractos orgánicos se secaron sobre $\mathrm{Na}_{2} \mathrm{SO}_{4}$, se filtraron, y el disolvente se evaporó a sequedad. El residuo se purificó mediante recristalización en éter de petróleo, aislándose $950 \mathrm{mg}(87 \%)$ de 1 como un sólido amarillo de p. f. $=65^{\circ} \mathrm{C}$ (bibl. $\left.{ }^{199} 68-70{ }^{\circ} \mathrm{C}\right) . \mathrm{EM}(\mathrm{IE}), m / z=182(73), 217\left(100, \mathrm{M}^{+}\right), 219\left(35, \mathrm{M}^{+}+2\right) .{ }^{1} \mathrm{H}-\mathrm{RMN}$ $\left[\mathrm{CDCl}_{3}, 300 \mathrm{MHz}\right], \delta(\mathrm{ppm}): 8.16(\mathrm{dd}, 1 \mathrm{H}, J=8.3 \mathrm{~Hz}, J=1,2 \mathrm{~Hz}), 7.98(\mathrm{dd}, 1 \mathrm{H}, J=8.3$ $\mathrm{Hz}, J=1.2 \mathrm{~Hz}), 7.67(\mathrm{ddd}, 1 \mathrm{H}, J=8.3 \mathrm{~Hz}, J=6.9 \mathrm{~Hz}, J=1.2 \mathrm{~Hz}), 7.54(\mathrm{ddd}, 1 \mathrm{H}, J=8.3$ $\mathrm{Hz}, J=6.9 \mathrm{~Hz}, J=1.2 \mathrm{~Hz}), 3.15(\mathrm{~m}, 2 \mathrm{H}), 3.03(\mathrm{~m}, 2 \mathrm{H}), 1.96(\mathrm{~m}, 4 \mathrm{H}) .{ }^{13} \mathrm{C}-\mathrm{RMN}\left[\mathrm{CDCl}_{3}\right.$, $75 \mathrm{MHz}], \delta$ (ppm): 159.4, 146.5, 141.3, 129.3, 128.7, 128.5, 126.3, 125.2, 123.6, 27.3, 22.6, 22.5. ${ }^{1} \mathrm{H}$ y ${ }^{13} \mathrm{C}-\mathrm{RMN}$ : Los datos se recogen en las Tablas $I$ y II (ver apartado 2.8 Tablas). Análisis (\%): Calculado para $\mathrm{C}_{13} \mathrm{H}_{12} \mathrm{ClN}$ : C, 71.72, H, 5.56, N, 6.43. Encontrado: C, 71.87, H, 5.66, N, 6.54.

199 Hu, M. -K.; Wu, L. -J.; Hsiao, G.; Yen, M. -H. "Homodimeric tacrine congeners as acetylcholinesterase inhibitors" J. Med. Chem. 2002, 45, 2277-2282. 
2.7.1.1. Procedimiento general para la síntesis de 8,9-dicloro-, 6,8,9-tricloro-y 9-cloro7-flúor-1,2,3,4-tetrahidroacridina (2-4).

Enfriando con un baño de hielo, sobre $30 \mathrm{~mL}$ de $\mathrm{POCl}_{3}$ se añadieron de forma sucesiva la correspondiente cloroanilina $(1.0 \mathrm{mmol})$ y 2-etoxicarbonilciclohexanona $(1.0$ mmol) y la mezcla resultante se calentó a reflujo durante 8 horas. Posteriormente, se añadió una disolución acuosa de $\mathrm{KOH} 10 \mathrm{~N}$ hasta un $\mathrm{pH}=8$ enfriando externamente con un baño de hielo. La fase acuosa se extrajo con $\mathrm{Et}_{2} \mathrm{O}(3 \mathrm{x} 100 \mathrm{~mL})$ y los extractos orgánicos se secaron sobre $\mathrm{Na}_{2} \mathrm{SO}_{4}$, se filtraron y el disolvente se eliminó a sequedad. El residuo se purificó mediante columna de cromatografía a presión sobre gel de sílice empleando como eluyente mezclas de disolventes de polaridad creciente de hexanoAcOEt (desde $10: 1$ hasta $3: 1$ ).

\section{8,9-Dicloro-1,2,3,4-tetrahidroacridina (2)}<smiles>Clc1cccc2nc3c(c(Cl)c12)CCCC3</smiles>

A partir de 3-cloroanilina $(3.0 \mathrm{~g}, 23.5 \mathrm{mmol}, \rho=1.20 \mathrm{~g} / \mathrm{mol}), 2$ etoxicarbonilciclohexanona $(4,0 \mathrm{~g}, 23,5 \mathrm{mmol}, \rho=1,07 \mathrm{~g} / \mathrm{mol}) \mathrm{se}$ obtuvo una mezcla de dos productos que se separaron siguiendo el procedimiento general descrito anteriormente. De las fracciones de $R_{f}=0.2$ (hexano : AcOEt, $10: 1)$ se aisló 2 (2,0 g, 34\%) como un sólido amarillo, p. f. = 83-85 ${ }^{\circ} \mathrm{C}$. EM (IE), $m / z=216(60), 251\left(100, \mathrm{M}^{+}\right), 253\left(67, \mathrm{M}^{+}+2\right), 255\left(12, \mathrm{M}^{+}+4\right) .{ }^{1} \mathrm{H}-\mathrm{RMN}\left[\mathrm{CDCl}_{3}, 300\right.$ MHz], $\delta(\mathrm{ppm}): 7.87(\mathrm{dd}, 1 \mathrm{H}, J=8.2 \mathrm{~Hz}, J=1,2 \mathrm{~Hz}), 7.54(\mathrm{dd}, 1 \mathrm{H}, J=8.2 \mathrm{~Hz}, J=$ $1.2 \mathrm{~Hz}), 7.46(\mathrm{t}, 1 \mathrm{H}, J=8.2 \mathrm{~Hz}), 3.11(\mathrm{~m}, 2 \mathrm{H}), 2.95(\mathrm{~m}, 2 \mathrm{H}), 1.92(\mathrm{~m}, 4 \mathrm{H}) .{ }^{13} \mathrm{C}-\mathrm{RMN}$ $\left[\mathrm{CDCl}_{3}, 75 \mathrm{MHz}\right], \delta$ (ppm): 159.6, 148.4, 140.3, 131.9, 130.0, 129.1, 128.9, 128.3, 122.6, 34.0, 28.1, 22.7, 22.3. ${ }^{1} \mathrm{H}$ y ${ }^{13} \mathrm{C}-\mathrm{RMN}$ : Los datos se recogen en las Tablas $I$ y II (ver apartado 2.8 Tablas). Análisis (\%): Calculado para $\mathrm{C}_{13} \mathrm{H}_{11} \mathrm{Cl}_{2} \mathrm{~N}$ : C, 61.93, H, 4.40, N, 5.56. Encontrado: C, 62.30, H, 4.74, N, 5.90. 


\section{6,8,9-Tricloro-1,2,3,4-tetrahidroacridina $(3)^{200}$}<smiles>Clc1cc(Cl)c2c(Cl)c3c(nc2c1)CCCC3</smiles>

De acuerdo con el procedimiento general, la reacción de 3,5dicloroanilina (4.0 g, $24.7 \mathrm{mmol})$ con 2-etoxicarbonilciclohexanona $(3.9 \mathrm{~mL}, 24.7 \mathrm{mmol})$ en $\mathrm{POCl}_{3}(70 \mathrm{~mL})$ proporcionó 3 ( $4,8 \mathrm{~g}, 68 \%$ ) como un sólido amarillo, p. f. $=118-120^{\circ} \mathrm{C} . R_{f}=0.2$ (hexano : AcOEt, 10 : 1). EM (IE), $m / z=284\left(100, \mathrm{M}^{+}\right), 286\left(97, \mathrm{M}^{+}+2\right), 288\left(32, \mathrm{M}^{+}+4\right), 290$ $\left(4, \mathrm{M}^{+}+6\right) .{ }^{1} \mathrm{H}-\mathrm{RMN}\left[\mathrm{CDCl}_{3}, 300 \mathrm{MHz}\right], \delta(\mathrm{ppm}): 7.48(\mathrm{~d}, 1 \mathrm{H}, J=2.2 \mathrm{~Hz}), 7.81(\mathrm{~d}, 1 \mathrm{H}$, $J=2.2 \mathrm{~Hz}), 3.01(\mathrm{~m}, 2 \mathrm{H}), 2.90(\mathrm{~m}, 2 \mathrm{H}), 1.89(\mathrm{~m}, 4 \mathrm{H}) .{ }^{13} \mathrm{C}-\mathrm{RMN}\left[\mathrm{CDCl}_{3}, 75 \mathrm{MHz}\right], \delta$ (ppm): 160.8, 147.3, 140.4, 133.5, 131.8, 130.3, 130.1, 127.8, 121.0, 33.9, 28.1, 22.6, 22.1. ${ }^{1} \mathrm{H}$ y ${ }^{13} \mathrm{C}-\mathrm{RMN}$ : Los datos se recogen en las Tablas I y II (ver apartado 2.8 Tablas). Análisis (\%): Calculado para $\mathrm{C}_{13} \mathrm{H}_{10} \mathrm{Cl}_{3} \mathrm{~N}$ : C, 55.48, H, 3.52, N, 4.89. Encontrado: $\mathrm{C}$, $55.60, \mathrm{H}, 3.72, \mathrm{~N}, 4.99$.

\section{9-Cloro-7-flúor-1,2,3,4-tetrahidroacridina (4)}<smiles>Fc1ccc2nc3c(c(Cl)c2c1Cl)CCCC3</smiles>

Siguiendo el procedimiento general descrito en el apartado 2.7.1.2., a partir de 4-flúoranilina (444 mg, $4.0 \mathrm{mmol}, \rho=1.157 \mathrm{~g} / \mathrm{L}$ ), 2etoxicarbonilciclohexanona (680 mg, $4.0 \mathrm{mmol}, \rho=1.071 \mathrm{~g} / \mathrm{L})$ en $\mathrm{POCl}_{3}(4 \mathrm{~mL})$ se aisló 4 (397 mg, 42\%) como un sólido amarillo, p. f. $=61-63{ }^{\circ} \mathrm{C} . R_{f}=$ 0.3 (hexano : AcOEt, $6: 1$ ). EM (ESI), $m / z=236[\mathrm{M}+\mathrm{H}]^{+} .{ }^{1} \mathrm{H}-\mathrm{RMN}\left[\mathrm{CDCl}_{3}, 300 \mathrm{MHz}\right]$, $\delta(\mathrm{ppm}): 7.95$ (dd, 1H, $J=9.1 \mathrm{~Hz}, J=5.3 \mathrm{~Hz}), 7.75(\mathrm{dd}, 1 \mathrm{H}, J=9.7 \mathrm{~Hz}, J=2.7 \mathrm{~Hz}), 7.41$ (ddd, $1 \mathrm{H}, J=9.1 \mathrm{~Hz}, J=8.2 \mathrm{~Hz}, J=2.7 \mathrm{~Hz}), 3.08(\mathrm{~m}, 2 \mathrm{H}), 3.00(\mathrm{~m}, 2 \mathrm{H}), 1.94(\mathrm{~m}, 4 \mathrm{H})$. ${ }^{13} \mathrm{C}-\mathrm{RMN}\left[\mathrm{CDCl}_{3}, 75 \mathrm{MHz}\right], \delta$ (ppm): 160.6, 158.7, 143.7, 140.6, 131.1, 129.6, 126.1, 119.4, 107.4, 33.9, 27.5, 22.6, 22.5. ${ }^{1} \mathrm{H}$ y ${ }^{13} \mathrm{C}-\mathrm{RMN}$ : Los datos se recogen en las Tablas $I$ y II (ver apartado 2.8 Tablas). Análisis (\%): Calculado para $\mathrm{C}_{13} \mathrm{H}_{11} \mathrm{ClFN}$ : C, 66.25, H, 4.70, N, 5.94. Encontrado: C, 66.55, H, 4.50, N, 6.24.

200 Savini, L.; Gaeta A., Fattorusso, C.; Catalanotti, B.;Campiani, G.;Chiasserini, L.; Pellerano, C.;Novellino, E.; McKissic, D.;Saxena, A. Specific targeting of acetylcholinesterase and butyrylcholinesterase recognition sites Rational desing of novel, selective, and highly potent cholinesterase inhisbitors. J. Med. Chem. 2003, 46, 1-4. 


\subsubsection{Procedimiento general para la síntesis de los ácidos 5-11}

Sobre una disolución del correspondiente $\alpha, \omega$-aminoácido (1.0 mmol) en 1-pentanol (20 mL) se añadieron las diferentes 9-cloro-(1,2,3,4-tetrahidro)acridinas $\mathbf{1}, \mathbf{2 - 3}$ y 4 (1,0 mmol). La mezcla resultante se calentó a reflujo durante toda la noche. Después de enfriar a temperatura ambiente, la mezcla de reacción se diluyó con $\mathrm{CH}_{2} \mathrm{Cl}_{2}(50 \mathrm{~mL})$ y se lavó de forma sucesiva con una disolución acuosa de $\mathrm{NaOH}$ al $10 \%$ (3 x $30 \mathrm{~mL}$ ) y con $\mathrm{H}_{2} \mathrm{O}(3$ x $30 \mathrm{~mL}$ ). Los extractos orgánicos se juntaron, se secaron sobre $\mathrm{Na}_{2} \mathrm{SO}_{4}$, se filtraron y el disolvente se evaporó a sequedad. Los ésteres intermedios se purificaron mediante cromatografía a presión en columna sobre gel de sílice empleando como eluyente mezclas de disolventes $\mathrm{CH}_{2} \mathrm{Cl}_{2}: \mathrm{CH}_{3} \mathrm{OH}$ y posteriormente se hidrolizaron empleando hidróxido sódico $(4,0 \mathrm{mmol})$ en un mezcla de dioxano : $\mathrm{H}_{2} \mathrm{O}(1: 1$, v/v). Después de calentar a reflujo durante 18 horas, la mezcla de reacción se enfrió a temperatura ambiente, se acidificó con una disolución acuosa de $\mathrm{HCl} 2 \mathrm{~N}$ y el disolvente se evaporó a sequedad. El residuo se purificó mediante columna de cromatografía a presión sobre gel de sílice empleando como eluyente la mezcla de disolventes AcOEt : $\mathrm{CH}_{3} \mathrm{OH}: \mathrm{NH}_{3}$ en las proporciones que se indican en cada caso. El ácido aislado empleando estas condiciones presenta una elevada pureza para poder definir el rendimiento de la reacción y para ser empleado en el siguiente paso sintético. Una pequeña cantidad de este ácido se purificó de nuevo mediante cromatografía en columna sobre gel de sílice empleando como eluyente mezclas de $\mathrm{CH}_{2} \mathrm{Cl}_{2}: \mathrm{CH}_{3} \mathrm{OH}$, obteniéndose un sirupe que se empleó para registrar los espectros de resonancia magnética nuclear y para análisis elemental.

\section{Ácido 6-(1,2,3,4-tetrahidroacridin-9-il)amino]hexanoico (5)}

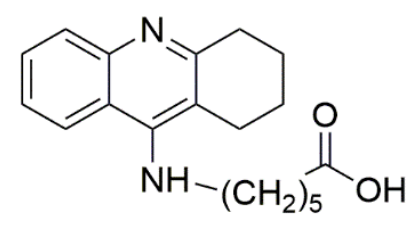

De acuerdo con el procedimiento general, a partir de $400 \mathrm{mg}$ (1.84 mmol) de 9-cloro-1,2,3,4-tetrahidroacridina (1) y de 268 $\mathrm{mg}(2.00 \mathrm{mmol})$ de ácido 6-aminohexanoico de obtuvieron $210 \mathrm{mg}(30 \%)$ de 6-[(1,2,3,4-tetrahidroacridin-9il)amino] hexanoato de pentilo como un aceite incoloro, $R_{f}=0.6\left(\mathrm{CH}_{2} \mathrm{Cl}_{2}: \mathrm{CH}_{3} \mathrm{OH}, 9: 1\right.$ : 0,1), después de eluir con $\mathrm{CH}_{2} \mathrm{Cl}_{2}: \mathrm{CH}_{3} \mathrm{OH}$ (desde $15: 1$ hasta $9: 1$ ). $\mathrm{EM}(\mathrm{ESI}), \mathrm{m} / z=$ $383[\mathrm{M}+\mathrm{H}]^{+} .{ }^{1} \mathrm{H}-\mathrm{RMN}\left[\mathrm{CD}_{3} \mathrm{OD}, 300 \mathrm{MHz}\right], \delta(\mathrm{ppm}): 8.56(\mathrm{dd}, 1 \mathrm{H}, J=8.3 \mathrm{~Hz}, J=1,4$ $\mathrm{Hz}), 7.94(\mathrm{dd}, 1 \mathrm{H}, J=8.3 \mathrm{~Hz}, J=1.4 \mathrm{~Hz}), 7.78(\mathrm{ddd}, 1 \mathrm{H}, J=8.3 \mathrm{~Hz}, J=6.8 \mathrm{~Hz}, J=1.4$ $\mathrm{Hz}), 8.01(\mathrm{ddd}, 1 \mathrm{H}, J=8.3 \mathrm{~Hz}, J=6.8 \mathrm{~Hz}, J=1.4 \mathrm{~Hz}), 4.14(\mathrm{t}, 2 \mathrm{H}, J=7.3 \mathrm{~Hz}), 3.20(\mathrm{~m}$, 
2H), $2.88(\mathrm{~m}, 2 \mathrm{H}), 2.44(\mathrm{t}, 2 \mathrm{H}, J=7.3 \mathrm{~Hz}), 2.14(\mathrm{~m}, 4 \mathrm{H}), 2.04(\mathrm{q}, 2 \mathrm{H}, J=7.3 \mathrm{~Hz}), 1.84$ $(\mathrm{q}, 2 \mathrm{H}, J=7.3 \mathrm{~Hz}), 1.65(\mathrm{q}, 2 \mathrm{H}, J=7.3 \mathrm{~Hz}) .{ }^{13} \mathrm{C}-\mathrm{RMN}\left[\mathrm{CD}_{3} \mathrm{OD}, 75 \mathrm{MHz}\right], \delta(\mathrm{ppm}):$ 175.4, 158.9, 153.3, 147.7, 129.8, 127.8, 124.7, 124.4, 121.2, 116.7, 65.5, 48.6, 34.9, 34.1, 29.4, 29.2, 27.4, 26.1, 25.7, 24.1, 23.8, 23.3, 14.1. La hidrólisis de $180 \mathrm{mg}(0.47$ $\mathrm{mmol})$ de 6-[(1,2,3,4-tetrahidroacridin-9-il)amino]hexanoato de pentilo y $65.6 \mathrm{mg}(2.62$ mmol) de $\mathrm{NaOH}$ porporcionó $117 \mathrm{mg}$ (80\%) de 5 como un aceite después de eluir con AcOEt : $\mathrm{CH}_{3} \mathrm{OH}: \mathrm{NH}_{3}, 2: 1: 0.2$. A partir de las fracciones de $R_{f}=0,6\left(\mathrm{CH}_{2} \mathrm{Cl}_{2}: \mathrm{CH}_{3} \mathrm{OH}\right.$, $8: 1)$ recogidas de la segunda columna se obtuvo 5 como un aceite amarillento. EM (ESI), $m / z=313[\mathrm{M}+\mathrm{H}]^{+} .{ }^{1} \mathrm{H}$ y ${ }^{13} \mathrm{C}-\mathrm{RMN}$ : Los datos se recogen en las Tablas III y $I V$ (ver apartado 2.8 Tablas). Análisis (\%): Calculado para $\mathrm{C}_{19} \mathrm{H}_{24} \mathrm{~N}_{2} \mathrm{O}_{2}: \mathrm{C}, 73.05, \mathrm{H}, 7.74, \mathrm{~N}$, 8.97. Encontrado: C, 73.01, H, 7.72, N, 8.96.

\section{Ácido 7-[(1,2,3,4-tetrahidroacridin-9-il)amino]heptanoico (6)}

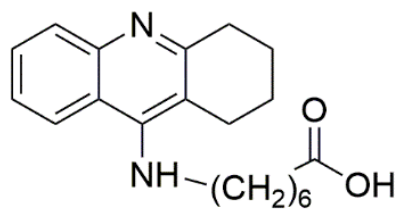

Empleando $600 \mathrm{mg}(2.76 \mathrm{mmol})$ de 9-cloro-(1,2,3,4tetrahidro)acridina (1) y $400 \mathrm{mg}(2.76 \mathrm{mmol})$ de ácido 7aminoheptanoico, como materiales de partida, se obtuvieron $470 \quad \mathrm{mg} \quad(43 \%)$ de 7-[(1,2,3,4-tetrahidroacridin-9il)amino] heptanoato de pentilo como un aceite incoloro, $R_{f}=0.4\left(\mathrm{CH}_{2} \mathrm{Cl}_{2}: \mathrm{CH}_{3} \mathrm{OH}, 7\right.$ : 1), después de eluir con mezclas de $\mathrm{CH}_{2} \mathrm{Cl}_{2}: \mathrm{CH}_{3} \mathrm{OH}$ (desde $12: 1$ hasta $6: 1$ ). EM (ESI), $m / z=396[\mathrm{M}+\mathrm{H}]^{+} .{ }^{1} \mathrm{H}-\mathrm{RMN}\left[\mathrm{CD}_{3} \mathrm{OD}, 300 \mathrm{MHz}\right], \delta(\mathrm{ppm}): 8.56(\mathrm{dd}, 1 \mathrm{H}, J=8.5 \mathrm{~Hz}, J$ $=1.5 \mathrm{~Hz}), 7.97(\mathrm{dd}, 1 \mathrm{H}, J=8.5 \mathrm{~Hz}, J=1.5 \mathrm{~Hz}), 8.03(\mathrm{ddd}, 1 \mathrm{H}, J=8.5 \mathrm{~Hz}, J=6.6 \mathrm{~Hz}, J$ $=1.5 \mathrm{~Hz}), 7.76(\mathrm{ddd}, 1 \mathrm{H}, J=8.5 \mathrm{~Hz}, J=6.6 \mathrm{~Hz}, J=1.5 \mathrm{~Hz}), 4.14(\mathrm{t}, 2 \mathrm{H}, J=7.3 \mathrm{~Hz})$, $3.20(\mathrm{~m}, 2 \mathrm{H}), 2.89(\mathrm{~m}, 2 \mathrm{H}), 2.46(\mathrm{t}, 2 \mathrm{H}, J=7.3 \mathrm{~Hz}), 2.15(\mathrm{~m}, 4 \mathrm{H}), 2.03(\mathrm{q}, 2 \mathrm{H}, J=7.3$ $\mathrm{Hz}), 1.85(\mathrm{~m}, 4 \mathrm{H}), 1.60(\mathrm{q}, 2 \mathrm{H}, J=7.3 \mathrm{~Hz}) .{ }^{13} \mathrm{C}-\mathrm{RMN}\left[\mathrm{CD}_{3} \mathrm{OD}, 75 \mathrm{MHz}\right], \delta(\mathrm{ppm}): 175.5$, 157.3, 152.5, 140.7, 133.5, 126.2, 126.1, 121.1, 117.5, 113.0, 65.4, 49.1, 34.9, 31.5, 30,0, 29.7, 29.4, 29.2 , 27.4, 26.0, 25.0, 23.1 (2C), 22.1, 14.3. Posteriormente, la hidrólisis 7[(1,2,3,4-tetrahidroacridin-9-il)amino]heptanoato de pentilo $(470 \mathrm{mg}, 1.19 \mathrm{mmol}) \mathrm{con}$ $\mathrm{NaOH}$ (190 mg, $4.75 \mathrm{mmol}$ ) proporcionó 6 (314 mg, 81\%) como un aceite después de eluir con AcOEt : $\mathrm{CH}_{3} \mathrm{OH}: \mathrm{NH}_{3}(3: 1: 0.2)$. A partir de las fracciones de $R_{f}=0.7\left(\mathrm{CH}_{2} \mathrm{Cl}_{2}\right.$ : $\left.\mathrm{CH}_{3} \mathrm{OH}, 14: 1\right)$ recogidas de la segunda columna se obtuvo 6 como un aceite incoloro. $\mathrm{EM}(\mathrm{ESI}), \mathrm{m} / z=327[\mathrm{M}+\mathrm{H}]^{+} .{ }^{1} \mathrm{H}$ y ${ }^{13} \mathrm{C}-\mathrm{RMN}$ : Los datos se recogen en las Tablas III y $I V$ (ver apartado 2.8 Tablas). Análisis (\%): Calculado para $\mathrm{C}_{20} \mathrm{H}_{26} \mathrm{~N}_{2} \mathrm{O}_{2}: \mathrm{C}, 73.59, \mathrm{H}, 8.03$, N, 8.58. Encontrado: C, 73.55, H, 7.99, N, 8.54. 


\section{Ácido 8-[(1,2,3,4-tetrahidroacridin-9-il)amino]octanóico (7)}

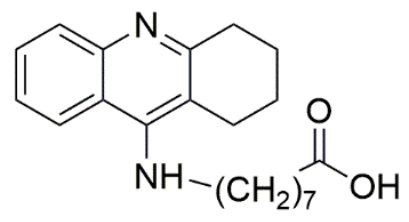

Siguiendo el procedimiento general, a partir de $430 \mathrm{mg}$ (1.97 mmol) de 9-cloro-(1,2,3,4-tetrahidro)acridina (1) y de $314 \mathrm{mg}$ (1.97 mmol) de ácido 8-aminooctanoico se aislaron $430 \mathrm{mg}$

$(47 \%)$ de 8-[(1,2,3,4-tetrahidroacridin-9-il)amino]octanoato de pentilo como un aceite incoloro, $R_{f}=0.4\left(\mathrm{CH}_{2} \mathrm{Cl}_{2}: \mathrm{CH}_{3} \mathrm{OH}, 8: 1\right)$, después de eluir con mezclas de $\mathrm{CH}_{2} \mathrm{Cl}_{2}: \mathrm{CH}_{3} \mathrm{OH}$ (desde $16: 1$ hasta $8: 1$ ). $\mathrm{EM}(\mathrm{ESI}), \mathrm{m} / z=411[\mathrm{M}+$ $\mathrm{H}]^{+} .{ }^{1} \mathrm{H}-\mathrm{RMN}\left[\mathrm{CD}_{3} \mathrm{OD}, 300 \mathrm{MHz}\right], \delta(\mathrm{ppm}): 8.58(\mathrm{dd}, 1 \mathrm{H}, J=8.4 \mathrm{~Hz}, J=1.2 \mathrm{~Hz}), 8.04$ $(\mathrm{ddd}, 1 \mathrm{H}, J=8.4 \mathrm{~Hz}, J=7.1 \mathrm{~Hz}, J=1.2 \mathrm{~Hz}), 7.77(\mathrm{ddd}, 1 \mathrm{H}, J=8.4 \mathrm{~Hz}, J=7.1 \mathrm{~Hz}, J=$ $1.2 \mathrm{~Hz}), 7,95(\mathrm{dd}, 1 \mathrm{H}, J=8.4 \mathrm{~Hz}, J=1.2 \mathrm{~Hz}), 4.14(\mathrm{t}, 2 \mathrm{H}, J=7.2 \mathrm{~Hz}), 3,20(\mathrm{t}, 2 \mathrm{H}, J=$ $5.4 \mathrm{~Hz}), 2.88(\mathrm{t}, 2 \mathrm{H}, J=5.4 \mathrm{~Hz}), 2.45(\mathrm{t}, 2 \mathrm{H}, J=7.3 \mathrm{~Hz}), 2.16(\mathrm{~m}, 4 \mathrm{H}), 2.02(\mathrm{q}, 2 \mathrm{H}, J=$ $7.3 \mathrm{~Hz}), 1.77(\mathrm{q}, 2 \mathrm{H}, J=7.3 \mathrm{~Hz}), 1.58(\mathrm{~m}, 6 \mathrm{H}) .{ }^{13} \mathrm{C}-\mathrm{RMN}\left[\mathrm{CD}_{3} \mathrm{OD}, 75 \mathrm{MHz}\right], \delta(\mathrm{ppm})$ : $175.9,155.9,154.9,143.4,132.2,128.2,125.6,123.6,118.9,114.6,65.8,49.2,35.4$, 35.0, 30.4 (3C), 29.8, 29,6, 28.1, 26.5, 26.3, 24.5, 24.1, 23.7, 14.3. La hidrólisis de 8[(1,2,3,4-tetrahidroacridin-9-il)amino]octanoato de pentilo $(381 \mathrm{mg}, 0.93 \mathrm{mmol})$ con $\mathrm{NaOH}$ (149 mg, $3.71 \mathrm{mmol}$ ) proporcionó 7 (240 mg, 76\%) como un aceite después de eluir con AcOEt : $\mathrm{CH}_{3} \mathrm{OH}: \mathrm{NH}_{3}(2: 1: 0.2)$. A partir de las fracciones de $R_{f}=0.6\left(\mathrm{CH}_{2} \mathrm{Cl}_{2}\right.$ : $\left.\mathrm{CH}_{3} \mathrm{OH}, 13: 1\right)$ se obtuvo 7 como un aceite incoloro. EM (ESI), $m / z=341[\mathrm{M}+\mathrm{H}]^{+}$. ${ }^{1} \mathrm{H}$ y ${ }^{13} \mathrm{C}-\mathrm{RMN}$ : Los datos se recogen en las Tablas III y IV (ver apartado 2.8 Tablas). Análisis (\%): Calculado para $\mathrm{C}_{21} \mathrm{H}_{28} \mathrm{~N}_{2} \mathrm{O}_{2}$ : C, 74.08, H, 8.29, N, 8.23. Encontrado: $\mathrm{C}$, $74.55, \mathrm{H}, 8.52$, N. 8.89.

\section{Ácido 6-[(8-cloro-1,2,3,4-tetrahidroacridin-9-il)amino]hexanoico (8)}

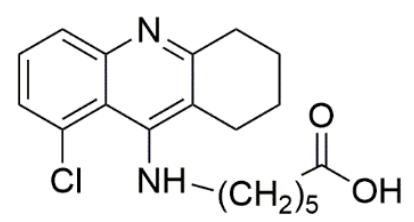

Siguiendo el procedimiento general, de la reacción de 8,9dicloro-(1,2,3,4-tetrahidro)acridina (2) (1.5 g, $5.95 \mathrm{mmol})$ con el ácido 6-aminohexanoico (779 $\mathrm{mg}, 5.95 \mathrm{mmol})$ se aislaron $1.2 \mathrm{~g}(48 \%)$ de 6-[(8-Cloro-1,2,3,4-tetrahidroacridin-9il)amino]hexanoato de pentilo como un aceite incoloro, $R_{f}=0.3\left(\mathrm{CH}_{2} \mathrm{Cl}_{2}: \mathrm{CH}_{3} \mathrm{OH}, 15\right.$ :1), después de eluir con mezclas de $\mathrm{CH}_{2} \mathrm{Cl}_{2}: \mathrm{CH}_{3} \mathrm{OH}$ (desde $16: 1$ hasta $7: 1$ ). EM (ESI), $m / z=417[\mathrm{M}+\mathrm{H}]^{+} .{ }^{1} \mathrm{H}-\mathrm{RMN}\left[\mathrm{CD}_{3} \mathrm{OD}, 300 \mathrm{MHz}\right], \delta(\mathrm{ppm}): 7.94(\mathrm{dd}, 1 \mathrm{H}, J=8.0 \mathrm{~Hz}, J$ $=1.8 \mathrm{~Hz}), 7.86(\mathrm{t}, 1 \mathrm{H}, J=8.0 \mathrm{~Hz}), 7.73(\mathrm{dd}, 1 \mathrm{H}, J=8.0 \mathrm{~Hz}, J=1.8 \mathrm{~Hz}), 3.94(\mathrm{t}, 2 \mathrm{H}, J=$ 
$7.0 \mathrm{~Hz}), 3,20(\mathrm{t}, 2 \mathrm{H}, J=6.2 \mathrm{~Hz}), 3.02(\mathrm{t}, 2 \mathrm{H}, J=6.2 \mathrm{~Hz}), 2.48(\mathrm{t}, 2 \mathrm{H}, J=7.0 \mathrm{~Hz}), 2.14$ $(\mathrm{m}, 4 \mathrm{H}), 1.91(\mathrm{q}, 2 \mathrm{H}, J=7.0 \mathrm{~Hz}), 1.75(\mathrm{q}, 2 \mathrm{H}, J=7.0 \mathrm{~Hz}), 1.48(\mathrm{q}, 2 \mathrm{H}, J=7.0 \mathrm{~Hz}) .{ }^{13} \mathrm{C}-$ $\mathrm{RMN}\left[\mathrm{CD}_{3} \mathrm{OD}, 75 \mathrm{MHz}\right], \delta$ (ppm): 175.3, 160.7, 154.5, 149.2, 131.9, 129.3, 128.6, 127.9, 120.7, 117.8, 65.5, 50.1, 34.9, 33.6, 31.5, 29.4, 29.2, 27.7, 27.5, 25.7, 24.0, 23.5, 23.4, 14.8. Posteriormente, la hidrólisis de $1.0 \mathrm{~g}(2.40 \mathrm{mmol})$ de 6-[(8-Cloro-1,2,3,4tetrahidroacridin-9-il)amino]hexanoato de pentilo con $384 \mathrm{mg}(9.60 \mathrm{mmol}) \mathrm{de} \mathrm{NaOH}$ proporcionó $600 \mathrm{mg}$ (72\%) 8 como un aceite después de eluir con AcOEt : $\mathrm{CH}_{3} \mathrm{OH}: \mathrm{NH}_{3}$ (6: $1: 0.2)$. A partir de las fracciones de $R_{f}=0.4\left(\mathrm{CH}_{2} \mathrm{Cl}_{2}: \mathrm{CH}_{3} \mathrm{OH}, 16: 1\right)$ recogidas de la segunda columna se obtuvo 8 como un aceite incoloro. EM (ESI), $m / z=347[\mathrm{M}+\mathrm{H}]^{+}$. ${ }^{1} \mathrm{H}$ y ${ }^{13} \mathrm{C}-\mathrm{RMN}$ : Los datos se recogen en las Tablas III y $I V$ (ver apartado 2.8 Tablas). Análisis (\%): Calculado para $\mathrm{C}_{19} \mathrm{H}_{23} \mathrm{ClN}_{2} \mathrm{O}_{2}: \mathrm{C}, 65.79, \mathrm{H}, 6.68, \mathrm{~N}, 8.08$. Encontrado: $\mathrm{C}$, $66.78, \mathrm{H}, 6.65, \mathrm{~N}, 8.06$.

\section{Ácido 6-[(6,8-dicloro-1,2,3,4-tetrahidroacridin-9-il)amino]hexanoico (9)}

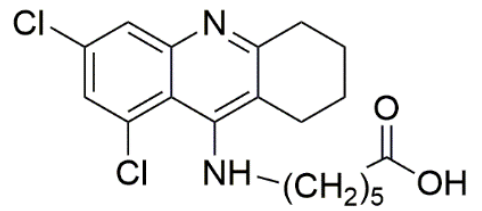

De acuerdo con el procedimiento general, la reacción de 6,8,9-tricloro-(1,2,3,4-tetrahidro)acridina (3) (1.50 g, 5.24 $\mathrm{mmol}$ ) con 6-aminohexanoico (686 $\mathrm{mg}, 5.24 \mathrm{mmol}$ ) proporcionó 6-[(6,8-Dicloro-1,2,3,4-tetrahidroacridin-9il)amino]hexanoato de pentilo $(1.78 \mathrm{~g}, 55 \%)$ como un aceite incoloro, $R_{f}=0.7\left(\mathrm{CH}_{2} \mathrm{Cl}_{2}\right.$ : $\mathrm{CH}_{3} \mathrm{OH}, 9: 1$ ), después de eluir con mezclas de $\mathrm{CH}_{2} \mathrm{Cl}_{2}: \mathrm{CH}_{3} \mathrm{OH}$ (desde $15: 1$ hasta 6 : 1). $\mathrm{EM}(\mathrm{ESI}), m / z=451[\mathrm{M}+\mathrm{H}]^{+} .{ }^{1} \mathrm{H}-\mathrm{RMN}\left[\mathrm{CD}_{3} \mathrm{OD}, 300 \mathrm{MHz}\right], \delta(\mathrm{ppm}): 7.92(\mathrm{~d}, 1 \mathrm{H}$, $J=2.2 \mathrm{~Hz}), 7.68(\mathrm{~d}, 1 \mathrm{H}, J=2.2 \mathrm{~Hz}), 3.67(\mathrm{t}, 2 \mathrm{H}, J=7.1 \mathrm{~Hz}), 3.17(\mathrm{t}, 2 \mathrm{H}, J=6.4 \mathrm{~Hz})$, $2.97(\mathrm{t}, 2 \mathrm{H}, J=6.4 \mathrm{~Hz}), 2.34(\mathrm{t}, 2 \mathrm{H}, J=7.1 \mathrm{~Hz}), 2.05(\mathrm{~m}, 4 \mathrm{H}), 1.84(\mathrm{q}, 2 \mathrm{H}, J=7.1$ $\mathrm{Hz}), 1.74(\mathrm{q}, 2 \mathrm{H}, J=7.1 \mathrm{~Hz}), 1.50(\mathrm{q}, 2 \mathrm{H}, J=7.1 \mathrm{~Hz}){ }^{13} \mathrm{C}-\mathrm{RMN}\left[\mathrm{CD}_{3} \mathrm{OD}, 75 \mathrm{MHz}\right], \delta$ (ppm): 175.5, 161.3, 153.9, 149.3, 134.1, 130.5, 128.1, 126.9, 120.9, 117.7, 65.5, 50.3, 34.8, 33.9, 31.7, 29.4, 29.2, 27.5, 27.4, 25.7, 23.9, 23.4, 23.3, 14.4. Posteriormente, la hidrólisis de 6-[(6,8-Dicloro-1,2,3,4-tetrahidroacridin-9-il)amino]hexanoato de pentilo (80 mg, $0.18 \mathrm{mmol})$ con $\mathrm{NaOH}(29 \mathrm{mg}, 0.72 \mathrm{mmol})$ proporcionó 9 (50 mg, 74\%) como un aceite después de eluir con AcOEt : $\mathrm{CH}_{3} \mathrm{OH}: \mathrm{NH}_{3}(3: 1: 0.2)$. A partir de las fracciones de $R_{f}=0.8\left(\mathrm{CH}_{2} \mathrm{Cl}_{2}: \mathrm{CH}_{3} \mathrm{OH}, 16: 1\right)$ recogidas de la segunda columna se obtuvo 9 como un aceite incoloro puro. EM (ESI), $m / z=381[\mathrm{M}+\mathrm{H}]^{+}$. ${ }^{1} \mathrm{H}$ y ${ }^{13} \mathrm{C}-\mathrm{RMN}$ : Los datos se recogen en las Tablas III y IV (ver apartado 2.8 Tablas). Análisis (\%): 
Calculado para $\mathrm{C}_{19} \mathrm{H}_{22} \mathrm{Cl}_{2} \mathrm{~N}_{2} \mathrm{O}_{2}$ : C, 59.85, H, 5.82, N, 7.35. Encontrado: C, 59.84, H, 5.81, N, 7.32.

\section{Ácido 8-[(6,8-dicloro-1,2,3,4-tetrahidroacridin-9-il)amino]octanoico (10)}<smiles>CNc1c2c(nc3cc(Cl)cc(Cl)c13)CCCC2</smiles>

De acuerdo con el procedimiento general descrito anteriormente, a partir de $400 \mathrm{mg}(1.40 \mathrm{mmol}) \mathrm{de}$ 6,8,9tricloro-(1,2,3,4-tetrahidro)acridina (3) y de $286 \mathrm{mg}(43 \%)$ 8-[(6,8-Dicloro-1,2,3,4-tetrahidroacridin-9-il)amino]octanoato de pentilo como un aceite incoloro, $R_{f}=0.5\left(\mathrm{CH}_{2} \mathrm{Cl}_{2}: \mathrm{CH}_{3} \mathrm{OH}, 9: 1\right)$, después de eluir con mezclas de $\mathrm{CH}_{2} \mathrm{Cl}_{2}$ : $\mathrm{CH}_{3} \mathrm{OH}$ (desde $15: 1$ hasta $9: 1$ ). EM (ESI), $m / z=479[\mathrm{M}+\mathrm{H}]^{+} .{ }^{1} \mathrm{H}-\mathrm{RMN}\left[\mathrm{CD}_{3} \mathrm{OD}, 300\right.$ MHz], $\delta$ (ppm): 7.98 (d, 1H, $J=2.3 \mathrm{~Hz}), 7.77(\mathrm{~d}, 1 \mathrm{H}, J=2.3 \mathrm{~Hz}), 3.91(\mathrm{t}, 2 \mathrm{H}, J=7.2$ $\mathrm{Hz}), 3.97$ (t, 2H, $J=6.4 \mathrm{~Hz}), 3.19(\mathrm{t}, 2 \mathrm{H}, J=6.4 \mathrm{~Hz}), 2.39$ (t, 2H, $J=7.3 \mathrm{~Hz}), 2.09$ (m, $4 \mathrm{H}), 1.87(\mathrm{q}, 4 \mathrm{H}, J=7.0 \mathrm{~Hz}), 1.72(\mathrm{q}, 4 \mathrm{H}, J=7.0 \mathrm{~Hz}), 1.46(\mathrm{~m}, 6 \mathrm{H}) \cdot{ }^{13} \mathrm{C}-\mathrm{RMN}\left[\mathrm{CD}_{3} \mathrm{OD}\right.$, $75 \mathrm{MHz}], \delta$ (ppm): 175.5, 161.1, 154.4, 149.3, 134.4, 130.7, 128.1, 126.5, 120.4, 117.6, 65.4, 50.5, 35.0, 33.7, 31.9, 30.0, 29.9, 29.5, 29.3, 27.7, 27.4, 25.8, 23.9, 23.4, 23.3, 14.3. Siguiendo el procedimiento general, de la hidrólisis de $668 \mathrm{mg}(1.39 \mathrm{mmol})$ de 8-[(6,8Dicloro-1,2,3,4-tetrahidroacridin-9-il)amino]octanoato de pentilo con $223 \mathrm{mg}$ (5.58 mmol) de $\mathrm{NaOH}$ se obtuvieron $449 \mathrm{mg}$ (79\%) de 10 como un aceite después de eluir con AcOEt : $\mathrm{CH}_{3} \mathrm{OH}: \mathrm{NH}_{3}(4: 1: 0.2)$. A partir de las fracciones de $R_{f}=0.5\left(\mathrm{CH}_{2} \mathrm{Cl}_{2}\right.$ : $\left.\mathrm{CH}_{3} \mathrm{OH}, 15: 1\right)$ recogidas de la segunda columna se obtuvo 10 como un aceite incoloro. EM (ESI), $m / z=409[\mathrm{M}+\mathrm{H}]^{+} .{ }^{1} \mathrm{H}$ y ${ }^{13} \mathrm{C}-\mathrm{RMN}$ : Los datos se recogen en las Tablas III y $I V$ (ver apartado 2.8 Tablas). Análisis (\%): Calculado para $\mathrm{C}_{21} \mathrm{H}_{26} \mathrm{Cl}_{2} \mathrm{~N}_{2} \mathrm{O}_{2}: \mathrm{C}, 61.62, \mathrm{H}$, 6.40, N, 6.84. Encontrado: C, 61.99, H, 6.75, N, 6.43.

\section{Ácido 6-[(7-fluor-1,2,3,4-tetrahidroacridin-9-il)amino]hexanoico (11)}

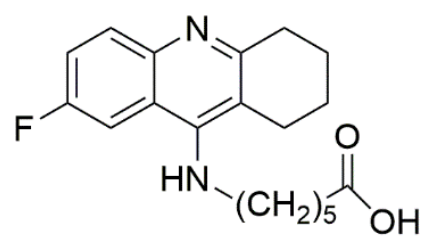

Siguiendo el procedimiento general, la reacción de 1.0 g $(4,25$ mmol) de 9-cloro-7-flúor-(1,2,3,4-tetrehidro)acridina (4) con $557 \mathrm{mg}$ (4.25 mmol) del 6-aminohexanoico proporcionó 1.05

$(62 \%)$ de 6-[(7-fluor-1,2,3,4-tetrahidroacridin-9il)amino]hexanoato de pentilo como un aceite incoloro, $R_{f}=0.4\left(\mathrm{CH}_{2} \mathrm{Cl}_{2}: \mathrm{CH}_{3} \mathrm{OH}, 9\right.$ : 1), después de eluir con mezclas de $\mathrm{CH}_{2} \mathrm{Cl}_{2}: \mathrm{CH}_{3} \mathrm{OH}$ (desde $18: 1$ hasta $7: 1$ ). EM (ESI), 
$m / z=401[\mathrm{M}+\mathrm{H}]^{+} .{ }^{1} \mathrm{H}-\mathrm{RMN}\left[\mathrm{CD}_{3} \mathrm{OD}, 300 \mathrm{MHz}\right], \delta(\mathrm{ppm}): 8.25(\mathrm{dd}, 1 \mathrm{H}, J=2.4 \mathrm{~Hz}$, $\left.J_{\mathrm{H}, \mathrm{F}}=10.7 \mathrm{~Hz}\right), 8.05\left(\mathrm{dd}, 1 \mathrm{H}, J_{\mathrm{H}, \mathrm{F}}=5.1, \mathrm{~Hz}, J=8.5 \mathrm{~Hz}\right), 7.85\left(\mathrm{ddd}, 1 \mathrm{H}, J_{\mathrm{H}, \mathrm{F}}=10.0 \mathrm{~Hz}\right.$, $J=8.5 \mathrm{~Hz}, J=2.4 \mathrm{~Hz}), 4.08(\mathrm{t}, 2 \mathrm{H}, J=7.2 \mathrm{~Hz}), 3.22(\mathrm{~m}, 2 \mathrm{H}), 2.40$ (t, 2H, $J=7.2 \mathrm{~Hz})$, $2.13(\mathrm{~m}, 4 \mathrm{H}), 2.02(\mathrm{q}, 4 \mathrm{H}, J=7.2 \mathrm{~Hz}), 1,84(\mathrm{q}, 2 \mathrm{H}, J=7.2 \mathrm{~Hz}), 1.64(\mathrm{~m}, 2 \mathrm{H}) .{ }^{13} \mathrm{C}-\mathrm{RMN}$ $\left[\mathrm{CD}_{3} \mathrm{OD}, 75 \mathrm{MHz}\right], \delta(\mathrm{ppm}): 175.4,160.2\left(\mathrm{~d},{ }^{1} J_{\mathrm{C}, \mathrm{F}}=242.7 \mathrm{~Hz}\right), 158.7,152.7,144.7,130.4$ $\left(\mathrm{d},{ }^{3} J_{\mathrm{C}, \mathrm{F}}=9.0 \mathrm{~Hz}\right), 121.8\left(\mathrm{~d},{ }^{3} J_{\mathrm{C}, \mathrm{F}}=9.0 \mathrm{~Hz}\right), 119.5\left(\mathrm{~d},{ }^{2} J_{\mathrm{C}, \mathrm{F}}=25.6 \mathrm{~Hz}\right), 117.3,107.8(\mathrm{~d}$, $\left.{ }^{2} J_{\mathrm{C}, \mathrm{F}}=23.6 \mathrm{~Hz}\right), 65.5,49.1,34.9,34.0,31.8,29.4,29.2,27.4,26.2,25.7,23.7,23.5,23.3$, 14.3. La hidrólisis de $980 \mathrm{mg}(2.45 \mathrm{mmol})$ de 6-[(7-fluor-1,2,3,4-tetrahidroacridin-9il)amino]hexanoato de pentilo con $392 \mathrm{mg}(9.80 \mathrm{mmol})$ de $\mathrm{NaOH}$ proporcionó $646 \mathrm{mg}$ (80\%) de 11 como un aceite después de eluir con AcOEt : $\mathrm{CH}_{3} \mathrm{OH}: \mathrm{NH}_{3}(6: 1: 0.2)$. A partir de las fracciones de $R_{f}=0.6\left(\mathrm{CH}_{2} \mathrm{Cl}_{2}: \mathrm{CH}_{3} \mathrm{OH}, 14: 1\right)$ recogidas de la segunda columna se obtuvo 11 como un aceite incoloro. EM (ESI), $m / z=331[\mathrm{M}+\mathrm{H}]^{+}$. ${ }^{1} \mathrm{H}$ y ${ }^{13} \mathrm{C}-$ RMN: Los datos se recogen en las Tablas III y IV (ver apartado 2.8 Tablas). Análisis (\%): Calculado para $\mathrm{C}_{19} \mathrm{H}_{23} \mathrm{FN}_{2} \mathrm{O}_{2}$ : C, 69.07, H, 7.02, N, 8.48. Encontrado: C, 69.37, H, 7.33, N, 8.14.

\subsubsection{Síntesis de los híbridos tacrina - neuroaminas 12-24. Procedimiento general}

A una disolución de los ácidos 5-11 $(1.0 \mathrm{mmol})$ en diclorometano $(20 \mathrm{~mL})$ se añadieron los reactivos en el siguiente orden: BOP $(1.3 \mathrm{mmol})$, el correspondiente derivado de 2-aminoetilfenol) $(1.0 \mathrm{mmol})$, y por último trietilamina $(2.6 \mathrm{mmol})$. La mezcla se dejó agitando a temperatura ambiente entre 6-18 horas. Transcurrido este tiempo, el bruto de reacción se diluyó con diclorometano $(50 \mathrm{~mL})$ y se lavó con una disolución acuosa de ácido cítrico al 10\% (3 x $30 \mathrm{~mL})$, con una disolución acuosa de bicarbonato sódico al 10\% ( 3 x $30 \mathrm{~mL})$ y, por último con agua destilada ( 3 x $30 \mathrm{~mL})$. Los extractos orgánicso se secaron sobre sulfato sódico, se filtraron y el disolvente se evaporó a presión reducida. El residuo se purificó mediante columna de cromatografía a presión sobre gel de sílice empleando como eluyente, mezclas de disolventes de polaridad creciente, como se indica en cada caso. El tratamiento posterior de las correspondientes amidas con una disolución de metanol saturada con cloruro de hidrógeno gas proporcionó el correspondiente hidrocloruro de forma cuantitativa. 


\section{$N$-(4-Hidroxifenetil)-6-(1,2,3,4-tetrahidroacridin-9-ilamino)hexanamida (12)}<smiles>CCCCCCNc1c2c(nc3ccccc13)CCCC2</smiles>

Siguiendo el procedimiento general, el tratamiento del ácido-[6-(1,2,3,4tetrahidroacridin-9-il)amino]-hexanóico 5 (70 $\mathrm{mg}, 0.22 \mathrm{mmol})$ con BOP $(128.2 \mathrm{mg}, 0.29$ $\mathrm{mmol})$, hidrocloruro de tiramina $(51.5 \mathrm{mg}, 0.29 \mathrm{mmol})$ y $\mathrm{Et}_{3} \mathrm{~N}(80 \mu \mathrm{L}, 0.58 \mathrm{mmol})$ durante 16 horas condujo a un aceite, que se purificó mediante cromatografía a presión en columna sobre gel de sílice empleando como eluyente mezclas de disolventes de polaridad creciente de acetato de etilo : metanol : hidróxido amónico, desde $12: 1: 0,1$ hasta $7: 1: 0,3$. Se aislaron $50 \mathrm{mg}(52 \%)$ de 12 como un aceite amarillento. MS (ESI $\left.{ }^{+}\right)$ $\mathrm{m} / \mathrm{z}=432[\mathrm{M}+\mathrm{H}]^{+} .{ }^{1} \mathrm{H}-\mathrm{RMN}\left[\mathrm{CDCl}_{3}, 400 \mathrm{MHz}\right], \delta(\mathrm{ppm}): 8.48\left(\mathrm{dd}, \mathrm{H}_{8}, \mathrm{~J}_{8.6}=1.1 ; \mathrm{J}_{8,7}=\right.$ $8.5 \mathrm{~Hz}$ ), 7.95 (ddd, , $\left.\mathrm{H}_{6}, \mathrm{~J}_{6.8}=1.1, \mathrm{~J}_{6.7}=7.0, \mathrm{~J}_{5,6}=8.5 \mathrm{~Hz}\right), 7.94\left(\mathrm{dd}, \mathrm{H}_{5,} \mathrm{~J}_{5,7}=1.1, \mathrm{~J}_{5,6}=\right.$ $8.5 \mathrm{~Hz}$ ), $7.70\left(\mathrm{ddd}, \mathrm{H}_{7,} \mathrm{~J}_{7,5}=1.1, \mathrm{~J}_{7,8}=8.5 \mathrm{~Hz}, \mathrm{~J}_{7,6}=7.0 \mathrm{~Hz}\right.$ ), $7.17\left(\mathrm{~d}, \mathrm{H}_{2}^{\prime}, \mathrm{J}=8.5 \mathrm{~Hz}\right.$ ), 6 $.85\left(\mathrm{~d}, \mathrm{H}_{3}^{\prime}, \mathrm{J}=8.5 \mathrm{~Hz}\right), 3.99(\mathrm{t}, 2 \mathrm{H} \mathrm{J}=7.2 \mathrm{~Hz}), 3.51(\mathrm{t}, 2 \mathrm{H \alpha}, \mathrm{J}=7.2 \mathrm{~Hz}), 3.17(\mathrm{~m}, 2 \mathrm{H})$, $2.89(\mathrm{~m}, 1 \mathrm{H}), 2.82\left(\mathrm{t}, 2 \mathrm{H}_{\beta}, \mathrm{J}=7.2 \mathrm{~Hz}\right), 2.33(\mathrm{t}, 2 \mathrm{H}, \mathrm{J}=7.2 \mathrm{~Hz}), 2.13(\mathrm{~m}, 4 \mathrm{H}), 1.96(\mathrm{q}$. $2 \mathrm{H} . \mathrm{J}=7.5), 1.79$ q. $2 \mathrm{H} . \mathrm{J}=7.5), 1.60-1.42$ (m. $2 \mathrm{H}) .{ }^{13} \mathrm{C}-\mathrm{RMN}\left[\mathrm{CDCl}_{3}, 100 \mathrm{MHz}\right], \delta$ (ppm): 175.8, 156.9, 156.2, 153.9, 142.3, 132.7, 131.2, 130.7, 125.8, 125.8, 122.5, 118.4, 116.2, 114.0, 49.4, 42.1, 36.8, 35.7, 31.4, 30.8, 27.2, 26.5, 25.2, 23.3, 22.4. Ver tablas $V$ y VI. 12·HCl: sólido amarillo, p. f. 97 - $99{ }^{\circ} \mathrm{C}$. Análisis (\%): Calculado para $\mathrm{C}_{27} \mathrm{H}_{34} \mathrm{ClN}_{3} \mathrm{O}_{2}$ : C, 69.29, H, 7.32, N, 8.98. Encontrado: C, 69.30, H, 7.30, N, 8.98.

\section{$N$-(4-Hidroxifenetil)-7-(1,2,3,4-tetrahidroacridin-9-ilamino)heptanamida (13)}<smiles>CCCCCCNc1c2c(nc3ccccc13)CCCC2</smiles>

Siguiendo el procedimiento general, la reacción del ácido-[7-(1,2,3,4-tetrahidroacridin-9-il)amino]-heptanóico 6 (50 mg, $0.15 \mathrm{mmol}$ ), BOP (88.2 $\mathrm{mg}, 0.20 \mathrm{mmol})$, hidrocloruro de tiramina ( $26.5 \mathrm{mg}, 0.15 \mathrm{mmol})$ y $\mathrm{Et}_{3} \mathrm{~N}(20 \mu \mathrm{L}, 0.39 \mathrm{mmol})$ durante 18 horas proporcionó un aceite, que se purificó mediante cromatografía a presión en columna sobre gel de sílice empleando como eluyente mezclas de disolventes de polaridad creciente de acetato de etilo : metanol : hidróxido amónico, desde $10: 1: 0,1$ hasta $6: 1: 0,3$. Se aislaron 30.6 $\mathrm{mg}(45 \%)$ de 13 como un aceite amarillento. MS $\left(\mathrm{ESI}^{+}\right) \mathrm{m} / \mathrm{z}=446[\mathrm{M}+\mathrm{H}]^{+} .{ }^{1} \mathrm{H}-\mathrm{RMN}$ $\left[\mathrm{CDCl}_{3}, 400 \mathrm{MHz}\right], \delta(\mathrm{ppm}): 8.42\left(\mathrm{~d}, \mathrm{H}_{8}, \mathrm{~J}_{8.6}=1.5 ; \mathrm{J}_{8,7}=8.5 \mathrm{~Hz}\right), 7.87$ (ddd, , $\mathrm{H}_{6}, \mathrm{~J}_{6.8}=$ 
$\left.1.5, \mathrm{~J}_{6.7}=6.9, \mathrm{~J}_{5,6}=8.5 \mathrm{~Hz}\right), 7.94\left(\mathrm{~d}, \mathrm{H}_{5}, \mathrm{~J}_{5,7}=1.5, \mathrm{~J}_{5,6}=8.5 \mathrm{~Hz}\right), 7.65\left(\mathrm{ddd}, \mathrm{H}_{7}, \mathrm{~J}_{7,5}=1.5\right.$, $\left.\mathrm{J}_{7,8}=8.5 \mathrm{~Hz}, \mathrm{~J}_{7,6}=6.9 \mathrm{~Hz}\right), 7.18\left(\mathrm{~d}, \mathrm{H}_{2}{ }^{\prime}, \mathrm{J}=8.6 \mathrm{~Hz}\right), 6.87\left(\mathrm{~d}, \mathrm{H}_{3}{ }^{\prime}, \mathrm{J}=8.6 \mathrm{~Hz}\right), 3.91(\mathrm{t}, 2 \mathrm{H}$ $\mathrm{J}=7.2 \mathrm{~Hz}), 3.52(\mathrm{t}, 2 \mathrm{H \alpha}, \mathrm{J}=7.2 \mathrm{~Hz}), 3.18(\mathrm{~m}, 2 \mathrm{H}), 2.92(\mathrm{~m}, 1 \mathrm{H}), 2.84\left(\mathrm{t}, 2 \mathrm{H}_{\beta}, \mathrm{J}=7.2\right.$ Hz), 2.34 (t, 2H, J = 7.2 Hz), 2.12 (m, 4H), 1.90 (q. 2H. J = 7.2), 1.76 (q, 2H. J = 7.2), $1.60-1.40$ (m. 2H). ${ }^{13} \mathrm{C}-\mathrm{RMN}\left[\mathrm{CDCl}_{3}, 100 \mathrm{MHz}\right], \delta$ (ppm): 175.9, 156.9, 156.2, 154.3, 143.3, 131.9, 131.6, 130.7, 125.8, 125.6, 122.8, 119.4, 116.3, 115.0, 49.9, 42.3, 36.9, 35.9, 31.4, 30.9, 27.2, 26.5, 25.7, 23.8, 22.9. Ver tablas $V y$ VI. ${ }^{1} \mathrm{H}$ y ${ }^{13} \mathrm{C}-\mathrm{RMN}$ : ver tablas $V$ y VI . 13·HCl: sólido amarillo, p. f. $91-93^{\circ} \mathrm{C}$. Análisis (\%): Calculado para $\mathrm{C}_{28} \mathrm{H}_{36} \mathrm{ClN}_{3} \mathrm{O}_{2}$ : C, 69.76, H, 7.53, N, 8.72. Encontrado: C, 69.75, H, 7.56, N, 8.71.

\section{$N$-(4-Hidroxifenetil)-8-(1,2,3,4-tetrahidroacridin-9-ilamino)octanamida (14)}<smiles>CCCCCCNc1c2c(nc3ccccc13)CCCC2</smiles>

Siguiendo el procedimiento general, el tratamiento del ácido-[8-(1,2,3,4-tetrahidroacridin-9-il)amino]-octanóico 7 (90 mg, 0.26 mmol) con BOP (150.2 mg, $0.34 \mathrm{mmol})$,

hidrocloruro de tiramina (45.9 mg, $0.26 \mathrm{mmol})$ y $\mathrm{Et}_{3} \mathrm{~N}(90 \mu \mathrm{L}, 0.69 \mathrm{mmol})$ durante 18 horas permitió obtener un aceite, que se purificó mediante cromatografía a presión en columna sobre gel de sílice empleando como eluyente mezclas de disolventes de polaridad creciente de acetato de etilo : metanol : hidróxido amónico, desde $10: 1: 0,1$ hasta $7: 1: 0,3$. Se aislaron $83 \mathrm{mg}(68 \%)$ de 14 como un aceite amarillento. MS (ESI $\left.{ }^{+}\right)$ $\mathrm{m} / \mathrm{z}=460[\mathrm{M}+\mathrm{H}]^{+} .{ }^{1} \mathrm{H}-\mathrm{RMN}\left[\mathrm{CDCl}_{3}, 400 \mathrm{MHz}\right], \delta(\mathrm{ppm}): 8.13\left(\mathrm{~d}, \mathrm{H}_{8}, \mathrm{~J}_{8.6}=1.2 ; \mathrm{J}_{8,7}=\right.$ $8.5 \mathrm{~Hz}), 7.58\left(\mathrm{ddd}, \mathrm{H}_{6}, \mathrm{~J}_{6.8}=1.2, \mathrm{~J}_{6.7}=6.9, \mathrm{~J}_{5,6}=8.5 \mathrm{~Hz}\right), 7.71\left(\mathrm{~d}, \mathrm{H}_{5,} \mathrm{~J}_{5,7}=1.2, \mathrm{~J}_{5,6}=8.5\right.$ $\mathrm{Hz}$ ), $7.38\left(\mathrm{ddd}, \mathrm{H}_{7}, \mathrm{~J}_{7,5}=1.2, \mathrm{~J}_{7,8}=8.5 \mathrm{~Hz}, \mathrm{~J}_{7,6}=6.9 \mathrm{~Hz}\right), 6.96\left(\mathrm{~d}, \mathrm{H}_{2}{ }^{\prime}, \mathrm{J}=8.5 \mathrm{~Hz}\right), 6.66$ $\left(\mathrm{d}, \mathrm{H}_{3}{ }^{\prime}, \mathrm{J}=8.5 \mathrm{~Hz}\right), 3.60$ (t, 2H J = 7.2 Hz), $3.30(\mathrm{t}, 2 \mathrm{H \alpha}, \mathrm{J}=7.2 \mathrm{~Hz}), 2.94(\mathrm{~m}, 2 \mathrm{H}), 2.68$ (m, 1H), 2.65 (t, 2H, $\mathrm{J}=7.2 \mathrm{~Hz}), 2.08$ (t, 2H, J = $7.2 \mathrm{~Hz}), 1.87$ (m, 4H), 1.64 (q. 2H. J = 7.3), 1.49 (q, 2H. J = 7.3), $1.38-1.18$ (m. 2H). ${ }^{13} \mathrm{C}-\mathrm{RMN}\left[\mathrm{CDCl}_{3}, 100 \mathrm{MHz}\right], \delta(\mathrm{ppm})$ : 176.6, 157.4, 157.4, 155.0, 146.2, 131.6, 131.4, 131.2, 125.5, 125.6, 126.3, 120.6, 116.1, $116.1,50.1,42.6,37.4,36.1,33.3,32.5,30.6,30.5,28.2,27.4,26.2,24.2,23.7 .{ }^{1} \mathrm{H} \mathrm{y}{ }^{13} \mathrm{C}-$ RMN: ver tablas $V$ y VI . 14·HCl: sólido Amarillo, p. f. 94 - $96{ }^{\circ} \mathrm{C}$. Análisis (\%): Calculado para $\mathrm{C}_{29} \mathrm{H}_{38} \mathrm{ClN}_{3} \mathrm{O}_{2}: \mathrm{C}, 70.21, \mathrm{H}, 7.72, \mathrm{~N}$, 8.47. Encontrado: C, 70.20, H, 7.71, N, 8.45. 


\section{6-(8-Cloro-1,2,3,4-tetrahidroacridin-9-ilamino)- $N$-(4-hidroxifenetil)hexanamida}<smiles>CCCCCCNc1c2c(nc3cccc(Cl)c13)CCCC2</smiles>

Siguiendo el procedimiento general, la reacción durante 18 horas del ácido-[6-(8-cloro-1,2,3,4tetrahidroacridin-9-il)amino]-hexanoico 8 (70 $\mathrm{mg}, 0.20 \mathrm{mmol})$, BOP (116.4 mg, $0.26 \mathrm{mmol})$, hidrocloruro de tiramina $(27.9 \mathrm{mg}, 0.22 \mathrm{mmol})$ y $\mathrm{Et}_{3} \mathrm{~N}(73 \mu \mathrm{L}, 0.52 \mathrm{mmol})$ proporcionó un aceite, que se purificó mediante cromatografía a presión en columna sobre gel de sílice empleando como eluyente mezclas de disolventes de polaridad creciente de acetato de etilo : metanol : hidróxido amónico, desde $9: 1: 0,1$ hasta $6: 1: 0,3$. Se aislaron $32.4 \mathrm{mg}$ $(44 \%)$ de 15 como un aceite amarillento. MS $\left(\mathrm{ESI}^{+}\right) \mathrm{m} / \mathrm{z}=466[\mathrm{M}+\mathrm{H}]^{+} .{ }^{1} \mathrm{H}-\mathrm{RMN}$ $\left[\mathrm{CDCl}_{3}, 400 \mathrm{MHz}\right], \delta(\mathrm{ppm}): 7.89\left(\mathrm{t}, \mathrm{H}_{6}, \mathrm{~J}_{6,5} \mathrm{~J}_{7,6}=8.1 \mathrm{~Hz}\right), 7.78\left(\mathrm{dd}, \mathrm{H}_{5,} \mathrm{~J}_{5,7}=1.5, \mathrm{~J}_{5,6}=\right.$ $8.1 \mathrm{~Hz}), 7.82\left(\mathrm{dd}, \mathrm{H}_{7}, \mathrm{~J}_{7,5}=1.5, \mathrm{~J}_{7,8}=8.1 \mathrm{~Hz}\right), 7.17\left(\mathrm{~d}, \mathrm{H}_{2}{ }^{\prime}, \mathrm{J}=8.4 \mathrm{~Hz}\right), 6.85\left(\mathrm{~d}, \mathrm{H}_{3}{ }^{\prime}, \mathrm{J}=\right.$ $8.4 \mathrm{~Hz}), 3.92(\mathrm{t}, 2 \mathrm{H} \mathrm{J}=7.0 \mathrm{~Hz}), 3.48(\mathrm{t}, 2 \mathrm{H \alpha}, \mathrm{J}=7.2 \mathrm{~Hz}), 3.17\left(\mathrm{t}, 2 \mathrm{H}_{4}, \mathrm{~J}=5.9 \mathrm{~Hz}\right), 3.02$ $\left(\mathrm{t}, 2 \mathrm{H}_{1}, \mathrm{~J}=5.9 \mathrm{~Hz}\right), 2.81\left(\mathrm{t}, 2 \mathrm{H}_{\beta}, \mathrm{J}=7.2 \mathrm{~Hz}\right), 2.29(\mathrm{t}, 2 \mathrm{H}, \mathrm{J}=7.1 \mathrm{~Hz}), 2.20(\mathrm{~m}, 2 \mathrm{H}), 2.00$ $(\mathrm{m}, 2 \mathrm{H}), 1.87$ (q, 2H. J = 7.4), $1.72(\mathrm{q}, 2 \mathrm{H} . \mathrm{J}=7.4), 1.43-1.38(\mathrm{~m} .2 \mathrm{H}) .{ }^{13} \mathrm{C}-\mathrm{RMN}$ $\left[\mathrm{CDCl}_{3}, 100 \mathrm{MHz}\right], \delta(\mathrm{ppm}): 175.7,156.9,159.8,157.4,152.8,141.2,133.6,130.9$, $129.5,131.2,130.9,119.2,116.1,115.0,114.2$, 50.6, 42.1, 36.6, 35.6, 31.4, 28.9, 27.0, 26.7, 26.4, 23.0, 21.6. ${ }^{1} \mathrm{H}$ y ${ }^{13} \mathrm{C}-\mathrm{RMN}$ : ver tablas $V$ y VI . 15.HCl: sólido amarillo, p. f. 74 - $76{ }^{\circ} \mathrm{C}$. Análisis (\%): Calculado para $\mathrm{C}_{27} \mathrm{H}_{33} \mathrm{Cl}_{2} \mathrm{~N}_{3} \mathrm{O}_{2}$ : C, 64.54, H, 6.62, N, 8.36. Encontrado: C, 64.53, H, 6.63, N, 8.34.

\section{6-(6,8-Dicloro-1,2,3,4-tetrahidroacridin-9-ilamino)- $N$-(4-hidroxifenetil)hexanamida} (16)<smiles>CCCCCCNc1c2c(nc3cc(Cl)cc(Cl)c13)CCCC2</smiles>

Siguiendo el procedimiento general, la reacción del ácido-[6-(6,8-dicloro-1,2,3,4tetrahidroacridin-9-il)amino]-hexanoico 9 (50 mg, $0.13 \mathrm{mmol})$ con BOP $(75.5 \mathrm{mg}$, $0.17 \mathrm{mmol}$ ), hidrocloruro de tiramina (22.7 mg, $0.13 \mathrm{mmol})$ y Et $\mathrm{E}_{3} \mathrm{~N}(40 \mu \mathrm{L}, 0.34 \mathrm{mmol})$ durante 18 horas condujo a un aceite, que se purificó mediante cromatografía a presión en columna sobre gel de sílice empleando como eluyente mezclas de disolventes de polaridad creciente de acetato de etilo : metanol : hidróxido amónico, desde $9: 1: 0,1$ 
hasta $6: 1$ : 0,3. Se aislaron $25.5 \mathrm{mg}(39 \%)$ de 16 como un aceite amarillento. MS (ESI $\left.{ }^{+}\right)$ $\mathrm{m} / \mathrm{z}=500[\mathrm{M}+\mathrm{H}]^{+} .{ }^{1} \mathrm{H}-\mathrm{RMN}\left[\mathrm{CDCl}_{3}, 400 \mathrm{MHz}\right], \delta(\mathrm{ppm}): 7.85\left(\mathrm{~d}, \mathrm{H}_{5,} \mathrm{~J}_{5,7}=2.2\right), 7.60$ $\left(\mathrm{d}, \mathrm{H}_{7}, \mathrm{~J}_{7,5}=2.2 \mathrm{~Hz}\right), 7.17$ (d, $\left.\mathrm{H}_{2}{ }^{\prime}, \mathrm{J}=8.3 \mathrm{~Hz}\right), 6.86\left(\mathrm{~d}, \mathrm{H}_{3^{\prime}}, \mathrm{J}=8.3 \mathrm{~Hz}\right), 3.53$ (t, 2H J = $7.1 \mathrm{~Hz}), 3.47$ (t, 2Ha, J =7.2 Hz), $3.14\left(\mathrm{t}, 2 \mathrm{H}_{4}, \mathrm{~J}=6.1 \mathrm{~Hz}\right), 2.94\left(\mathrm{t}, 2 \mathrm{H}_{1}, \mathrm{~J}=6.1 \mathrm{~Hz}\right), 2.83$ $\left(\mathrm{t}, 2 \mathrm{H}_{\beta}, \mathrm{J}=7.2 \mathrm{~Hz}\right), 2.28(\mathrm{t}, 2 \mathrm{H}, \mathrm{J}=7.2 \mathrm{~Hz}), 2.12(\mathrm{~m}, 2 \mathrm{H}), 2.02(\mathrm{~m}, 2 \mathrm{H}), 1.78(\mathrm{q}, 2 \mathrm{H} . \mathrm{J}=$ 7.3), 1.72 (q, 2H. J = 7.3), $1.52-1.38(\mathrm{~m} .2 \mathrm{H}) .{ }^{13} \mathrm{C}-\mathrm{RMN}\left[\mathrm{CDCl}_{3}, 100 \mathrm{MHz}\right], \delta(\mathrm{ppm})$ : $175.8,160.8,156.9,154.7,148.7,134.8,131.2$, 130.8, 130.7 , 128.3, 125.9, 120.1, 117.6, 116.2, 50.5, 42.1 , 36.8, 35.7, 33.4, 31.7, 27.4, 27.3, 26.6, 23.8, 23.2, 26.6. ${ }^{1} \mathrm{H}$ y ${ }^{13} \mathrm{C}-\mathrm{RMN}$ : ver tablas $V$ y VI . 16·HCl: sólido amarillo, p. f. 179 - $181^{\circ} \mathrm{C}$. Análisis (\%): Calculado para $\mathrm{C}_{27} \mathrm{H}_{32} \mathrm{Cl}_{3} \mathrm{~N}_{3} \mathrm{O}_{2}$ : C, 60.40, H, 6.01, N, 7.83. Encontrado: C, 60.38, H, 6.02, N, 7.80.

\section{8-(6,8-Dicloro-1,2,3,4-tetrahidroacridin-9-ilamino)- $N$-(4-hidroxifenetil)octanamida} (17)

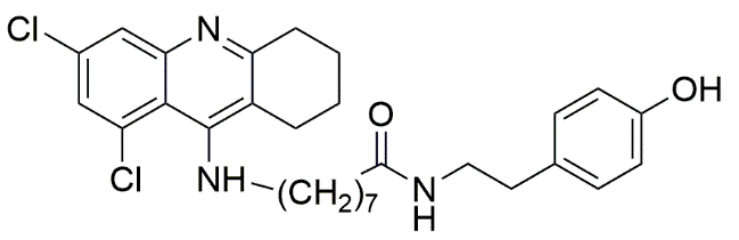

Siguiendo el procedimiento general, el tratamiento del ácido-[8-(6,8-dicloro1,2,3,4-tetrahidroacridin-9-il)-amino]octanóico 10 (60 mg, $0.15 \mathrm{mmol})$ con BOP (84.4 mg, $0.19 \mathrm{mmol})$, hidrocloruro de tiramina $(25.5 \mathrm{mg}, 0.15 \mathrm{mmol})$ y Et ${ }_{3} \mathrm{~N}(50$ $\mu \mathrm{L}, 0.38 \mathrm{mmol}$ ) durante 15 horas proporcionó un aceite, que se purificó mediante cromatografía a presión en columna sobre gel de sílice empleando como eluyente mezclas de disolventes de polaridad creciente de acetato de etilo : metanol : hidróxido amónico, desde $12: 1: 0,1$ hasta $6: 1: 0,3$. Se aislaron $22.1 \mathrm{mg}(29 \%)$ de 17 como un aceite amarillento. MS $\left(\mathrm{ESI}^{+}\right) \mathrm{m} / \mathrm{z}=528[\mathrm{M}+\mathrm{H}]^{+} .{ }^{1} \mathrm{H}-\mathrm{RMN}\left[\mathrm{CDCl}_{3}, 400 \mathrm{MHz}\right], \delta(\mathrm{ppm}): 7.84$ $\left(\mathrm{d}, \mathrm{H}_{5}, \mathrm{~J}_{5,7}=1.8 \mathrm{~Hz}\right), 7.82\left(\mathrm{~d}, \mathrm{H}_{7}, \mathrm{~J}_{7,5}=1.8 \mathrm{~Hz}\right), 7.18\left(\mathrm{~d}, \mathrm{H}_{2}{ }^{\prime}, \mathrm{J}=8.5 \mathrm{~Hz}\right), 6.85\left(\mathrm{~d}, \mathrm{H}_{3}{ }^{\prime}, \mathbf{J}\right.$ $=8.5 \mathrm{~Hz}), 3.93(\mathrm{t}, 2 \mathrm{H} \mathrm{J}=7.1 \mathrm{~Hz}), 3.53(\mathrm{t}, 2 \mathrm{H \alpha}, \mathrm{J}=7.2 \mathrm{~Hz}), 3.15\left(\mathrm{t}, 2 \mathrm{H}_{4}, \mathrm{~J}=5.8 \mathrm{~Hz}\right), 2.99$ $\left(\mathrm{t}, 2 \mathrm{H}_{1}, \mathrm{~J}=5.8 \mathrm{~Hz}\right), 2.85\left(\mathrm{t}, 2 \mathrm{H}_{\beta}, \mathrm{J}=7.2 \mathrm{~Hz}\right), 2.29(\mathrm{t}, 2 \mathrm{H}, \mathrm{J}=7.3 \mathrm{~Hz}), 2.20(\mathrm{~m}, 2 \mathrm{H}), 2.00$ $(\mathrm{m}, 2 \mathrm{H}), 1.87(\mathrm{q}, 2 \mathrm{H} . \mathrm{J}=7.2), 1.68(\mathrm{q}, 2 \mathrm{H} . \mathrm{J}=7.2), 1.55-1.35(\mathrm{~m} .6 \mathrm{H}) .{ }^{13} \mathrm{C}-\mathrm{RMN}$ $\left[\mathrm{CDCl}_{3}, 100 \mathrm{MHz}\right], \delta(\mathrm{ppm}): 176.6,162.7,157.3,156.5,153.7,133.3,131.7,131.2$, 130.7, 129.6, 125.9, 118.7, 116.6, 115.1, 50.1, 42.6, 37.4, 36.1, 32.1, 30.8, 30.2, 29.4, 27.8, 26.7, 27.2, 23.3, 22.1. ${ }^{1} \mathrm{H}$ y ${ }^{13} \mathrm{C}-\mathrm{RMN}$ : ver tablas $V$ y VI . 17.HCl: sólido amarillo, p. f. 195 - $197{ }^{\circ} \mathrm{C}$. Análisis (\%): Calculado para $\mathrm{C}_{29} \mathrm{H}_{36} \mathrm{Cl}_{3} \mathrm{~N}_{3} \mathrm{O}_{2}: \mathrm{C}, 61.65, \mathrm{H}, 6.42, \mathrm{~N}$, 7.44. Encontrado: C, 61.62, H, 6.40, N, 7.42. 


\section{6-(7-Fluoro-1,2,3,4-tetrahidroacridin-9-ilamino)- $N$-(4-hidroxifenetil)hexanamida} (18)<smiles>CCCCCCCCCCCNc1c2c(nc3ccc(F)cc13)CCCC2</smiles>

Siguiendo el procedimiento general, la reacción del ácido-[6-(7-fluor-1,2,3,4tetrahidroacridin-9-il)amino]-hexanoico 11 (90 mg, $0.27 \mathrm{mmol})$, BOP (156.8 mg, 0.35 mmol), hidrocloruro de tiramina $(47.2 \mathrm{mg}, 0.27 \mathrm{mmol})$ y $\mathrm{Et}_{3} \mathrm{~N}(90 \mu \mathrm{L}, 0.70 \mathrm{mmol})$ durante 16 horas condujo a un aceite, que se purificó mediante cromatografía a presión en columna sobre gel de sílice empleando como eluyente mezclas de disolventes de polaridad creciente de acetato de etilo : metanol : hidróxido amónico, desde $10: 1: 0.2$ hasta $6: 1$ : 0.2.). Se aislaron $58.6 \mathrm{mg}(48 \%)$ de 18 como un aceite amarillento. MS (ESI $\left.{ }^{+}\right)$ $\mathrm{m} / \mathrm{z}=528[\mathrm{M}+\mathrm{H}]^{+} .\left[\mathrm{CDCl}_{3}, 400 \mathrm{MHz}\right], \delta(\mathrm{ppm}): 8.24\left(\mathrm{dd}, \mathrm{H}_{8,} \mathrm{~J}_{8, \mathrm{~F}}=10.0 ; \mathrm{J}_{8,6}=2.4 \mathrm{~Hz}\right)$, $7.85\left(\mathrm{ddd}, \mathrm{H}_{6}, \mathrm{~J}_{6.8}=2.4, \mathrm{~J}_{6, \mathrm{~F}}=10.0, \mathrm{~J}_{5,6}=9.3 \mathrm{~Hz}\right), 7.95\left(\mathrm{dd}, \mathrm{H}_{5,} \mathrm{~J}_{5, \mathrm{~F}}=5.1, \mathrm{~J}_{5,6}=9.3 \mathrm{~Hz}\right)$, $7.16\left(\mathrm{~d}, \mathrm{H}_{2}{ }^{\prime}, \mathrm{J}=8.5 \mathrm{~Hz}\right), 6.84\left(\mathrm{~d}, \mathrm{H}_{3}^{\prime}, \mathrm{J}=8.5 \mathrm{~Hz}\right), 4.07(\mathrm{t}, 2 \mathrm{H} \mathrm{J}=7.2 \mathrm{~Hz}), 3.52(\mathrm{t}, 2 \mathrm{H \alpha}$, $\mathrm{J}=7.2 \mathrm{~Hz}), 3.16(\mathrm{~m}, 2 \mathrm{H}), 2.88(\mathrm{~m}, 2 \mathrm{H}), 2.78\left(\mathrm{t}, 2 \mathrm{H}_{\beta}, \mathrm{J}=7.2 \mathrm{~Hz}\right), 2.35(\mathrm{t}, 2 \mathrm{H}, \mathrm{J}=7.3 \mathrm{~Hz})$, $2.20(\mathrm{~m}, 2 \mathrm{H}), 2.03(\mathrm{~m}, 2 \mathrm{H}), 1.98$ (q. 2H. J = 7.2), 1.80 (q. 2H. J = 7.2), $1.60-1.50$ (m. 2H). ${ }^{13} \mathrm{C}-\mathrm{RMN}\left[\mathrm{CDCl}_{3}, 100 \mathrm{MHz}\right], \delta$ (ppm): 175.9, 173.1, 160.1, 152.1, 136.4, 156.8, 131.2, 123.6, 123.3, 123.0, 116.1, 113.2, 110.3, 31.1, 25.0, 22.8, 21.6, 49.7, 42.1, 36.8, 35.6, 31.1, 27.0, 26.5, ${ }^{1} \mathrm{H}$ y ${ }^{13} \mathrm{C}-\mathrm{RMN}$ : ver tablas $V$ y VI . 18·HCl: sólido amarillo, p. f. 169 - $171{ }^{\circ} \mathrm{C}$. Análisis (\%): Calculado para $\mathrm{C}_{27} \mathrm{H}_{33} \mathrm{ClFN}_{3} \mathrm{O}_{2}: \mathrm{C}, 66.72, \mathrm{H}, 6.84, \mathrm{~N}$, 8.65. Encontrado: C, 66.70, H, 6.82, N, 8.63.

\section{$N$-(3,4-Dimetoxifenetil)-6-(1,2,3,4-tetrahidroacridin-9-ilamino)hexanamida (19)}<smiles>CCCCCCNc1c2c(nc3ccccc13)CCCC2</smiles>

Siguiendo el procedimiento general, la reacción durante 12 horas del ácido-[6(1,2,3,4-tetrahidroacridin-9-il)amino]hexanoico 5 (70 $\mathrm{mg}, 0.22 \mathrm{mmol})$, BOP (128,2 $\mathrm{mg}, 0.29 \mathrm{mmol})$, homoveratrilamina $\left(37 \mu \mathrm{L}, 0.29 \mathrm{mmol}^{2}\right) \mathrm{y} \mathrm{Et}_{3} \mathrm{~N}(80 \mu \mathrm{L}, 0.58$ mmol) proporcionó un aceite, que se purificó mediante cromatografía a presión en columna sobre gel de sílice empleando como eluyente mezclas de disolventes de polaridad creciente de acetato de etilo : metanol : hidróxido amónico, desde $10: 1: 0.2$ 
hasta $6: 1$ : 0.2. Se aislaron $44.0 \mathrm{mg}(40 \%)$ de 19 como un aceite amarillento. MS (ESI $\left.{ }^{+}\right)$ $\mathrm{m} / \mathrm{z}=476[\mathrm{M}+\mathrm{H}]^{+} .{ }^{1} \mathrm{H}-\mathrm{RMN}\left[\mathrm{CDCl}_{3}, 400 \mathrm{MHz}\right], \delta(\mathrm{ppm}): 8.40\left(\mathrm{dd}, \mathrm{H}_{8,} \mathrm{~J}_{8.6}=1.2 ; \mathrm{J}_{8,7}=\right.$ $8.4 \mathrm{~Hz}), 7.85\left(\mathrm{ddd}, \mathrm{H}_{6}, \mathrm{~J}_{6.8}=1.2, \mathrm{~J}_{6.7}=7.0, \mathrm{~J}_{5,6}=8.4 \mathrm{~Hz}\right), 7.94\left(\mathrm{dd}, \mathrm{H}_{5,} \mathrm{~J}_{5,7}=1.2, \mathrm{~J}_{5,6}=8.4\right.$ $\mathrm{Hz}$ ), $7.64\left(\mathrm{ddd}, \mathrm{H}_{7}, \mathbf{J}_{7,5}=1.2, \mathbf{J}_{7,8}=8.4 \mathrm{~Hz}, \mathbf{J}_{7,6}=7.0 \mathrm{~Hz}\right), 7.00\left(\mathrm{~d}, \mathrm{H}_{5^{\prime}}, \mathrm{J}=8.0 \mathrm{~Hz}\right), 6.99$ $\left(\mathrm{d}, \mathrm{H}_{2}{ }^{\prime}, \mathrm{J}=1.9 \mathrm{~Hz}\right), 6.89$ (d, H, $\mathrm{H}^{\prime}, \mathrm{J}=8.0 \mathrm{~Hz}$ ), 3.97 (s, 3H), 3.93(s, 3H), 3.87 (t, 2H, J =

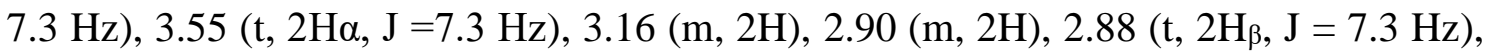
2.34 (t, 2H, J = $7.2 \mathrm{~Hz}$ ), 2.13 (m, 2H), 2.03 (m, 2H), 1.89 (q, 2H. J = 7.3), 1.77 (q. 2H. J = 7.3), $1.55-1.50$ (m. 2H). ${ }^{13} \mathrm{C}-\mathrm{RMN}\left[\mathrm{CDCl}_{3}, 100 \mathrm{MHz}\right], \delta(\mathrm{ppm}): 176.4,156.5,155.7$, 150.9, 149.5, 133.9, 132.1, 125.9, 125.8, 125.1, 122.7, 120.0, 115.6, 114.3, 113.6, 57.0, 56.9, 42.4, 37.4, 36.5, 32.6, 32.1, 27.8, 27.1, 26.1, 24.1, 23.4. ${ }^{1} \mathrm{H}$ y ${ }^{13} \mathrm{C}-\mathrm{RMN}$ : ver tablas VII y VIII . 19.HCl: sólido amarillo, p. f. 96 - $98{ }^{\circ} \mathrm{C}$. Análisis (\%): Calculado para $\mathrm{C}_{29} \mathrm{H}_{38} \mathrm{ClN}_{3} \mathrm{O}_{3}$ : C, 68.02, H, 7.48, N, 8.21. Encontrado: C, 68.00, H, 7.45, N, 8.20.

\section{$N$-(3,4-Dimetoxifenetil)-7-(1,2,3,4-tetrahidroacridin-9-ilamino)heptanamida (20)}<smiles>CCCCCNc1c2c(nc3ccccc13)CCCC2</smiles>

Siguiendo el procedimiento general, el tratamiento del ácido-[7-(1,2,3,4-tetrahidroacridin-9-il)amino]-heptanoico $6(76.5 \mathrm{mg}$, $0.23 \mathrm{mmol})$ con BOP (134.9 mg, $0.30 \mathrm{mmol})$,

homoveratrilamina $(39 \mu \mathrm{L}, 0.23 \mathrm{mmol})$ y $\mathrm{Et}_{3} \mathrm{~N}(84 \mu \mathrm{L}, 0.60 \mathrm{mmol})$ durante 12 horas condujo a un aceite, que se purificó mediante cromatografía a presión en columna sobre gel de sílice empleando como eluyente mezclas de disolventes de polaridad creciente de acetato de etilo : metanol : hidróxido amónico, desde $10: 1: 0.2$ hasta $6: 1: 0.2$. Se aislaron $59.6 \mathrm{mg}(52 \%)$ de 20 como un aceite amarillento. $\mathrm{MS}\left(\mathrm{ESI}^{+}\right) \mathrm{m} / \mathrm{z}=492[\mathrm{M}+$ $\mathrm{H}]^{+} .{ }^{1} \mathrm{H}-\mathrm{RMN}\left[\mathrm{CDCl}_{3}, 400 \mathrm{MHz}\right], \delta(\mathrm{ppm}): 8.32\left(\mathrm{dd}, \mathrm{H}_{8}, \mathrm{~J}_{8.6}=1.1 ; \mathrm{J}_{8,7}=8.4 \mathrm{~Hz}\right), 7.77$ $\left(\mathrm{ddd}, \mathrm{H}_{6}, \mathrm{~J}_{6.8}=1.1, \mathrm{~J}_{6.7}=6.9, \mathrm{~J}_{5,6}=8.4 \mathrm{~Hz}\right), 7.95\left(\mathrm{dd}, \mathrm{H}_{5,} \mathrm{~J}_{5,7}=1.1, \mathrm{~J}_{5,6}=8.4 \mathrm{~Hz}\right), 7.58$ $\left(\mathrm{ddd}, \mathrm{H}_{7}, \mathrm{~J}_{7,5}=1.1, \mathrm{~J}_{7,8}=8.4 \mathrm{~Hz}, \mathrm{~J}_{7,6}=6.9 \mathrm{~Hz}\right), 7.01\left(\mathrm{~d}, \mathrm{H}_{5}{ }^{\prime}, \mathrm{J}=8.2 \mathrm{~Hz}\right), 7.00\left(\mathrm{~d}, \mathrm{H}_{2}{ }^{\prime}, \mathrm{J}=\right.$

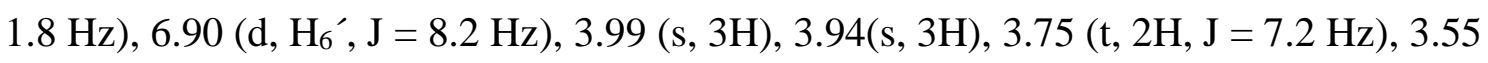
$(\mathrm{t}, 2 \mathrm{H \alpha}, \mathrm{J}=7.2 \mathrm{~Hz}), 3.17(\mathrm{~m}, 2 \mathrm{H}), 2.96(\mathrm{~m}, 2 \mathrm{H}), 2.89\left(\mathrm{t}, 2 \mathrm{H}_{\beta}, \mathrm{J}=7.2 \mathrm{~Hz}\right), 2.29(\mathrm{t}, 2 \mathrm{H}, \mathrm{J}=$ $7.2 \mathrm{~Hz}$ ), $2.12(\mathrm{~m}, 2 \mathrm{H}), 2.08(\mathrm{~m}, 2 \mathrm{H}), 1.82$ (q, 2H. J = 7.2), 1.74 (q. 2H. J = 7.2), $1.58-$ $1.40(\mathrm{~m}, 4 \mathrm{H}) .{ }^{13} \mathrm{C}-\mathrm{RMN}\left[\mathrm{CDCl}_{3}, 100 \mathrm{MHz}\right], \delta$ (ppm): 176.5, 156.5, 152.2, 150.8, 149.5, 143.6, 133.9, 132.8, 126.1, 126.0, 123.7, 122.6, 119.9, 114.9, 114.3, 113.6, 57.0, 56.9, 49.1, 42.3, 37.4, 36.5, 32.1, 31.8, 28.0, 27.3, 25.8, 23.9. ${ }^{1} \mathrm{H}$ y ${ }^{13} \mathrm{C}-\mathrm{RMN}$ : ver tablas VII $y$ 
VIII . 20·HCl: sólido amarillo, p. f. 89 - $92{ }^{\circ} \mathrm{C}$. Análisis (\%): Calculado para $\mathrm{C}_{30} \mathrm{H}_{40} \mathrm{ClN}_{3} \mathrm{O}_{3}: \mathrm{C}, 68.49, \mathrm{H}, 7.66, \mathrm{~N}, 7.99$. Encontrado: C, 68.50, H, 7.65, N, 7.98.

\section{$N$-(3,4-Dimetoxifenetil)-8-(5,6,7,8-tetrahidroacridin-9-ilamino)octanamida (21)}<smiles>CNc1c2c(nc3ccccc13)CCCC2</smiles>

Siguiendo el procedimiento general, la reacción del ácido-[8-(1,2,3,4-tetrahidroacridin-9-il)amino]-octanoico 7 (90 mg, 0.26 mmol) con BOP (151.8 mg, $0.34 \mathrm{mmol}$ ), homoveratrilamina (40 $\mu \mathrm{L}, 0.26 \mathrm{mmol})$ y $\mathrm{Et}_{3} \mathrm{~N}(90 \mu \mathrm{L}, 0.69 \mathrm{mmol})$ durante 18 horas proporcionó un aceite, que se purificó mediante cromatografía a presión en columna sobre gel de sílice empleando como eluyente mezclas de disolventes de polaridad creciente de acetato de etilo : metanol : hidróxido amónico, desde $10: 1: 0.2$ hasta $6: 1: 0.2$. Se aislaron $81.2 \mathrm{mg}(61 \%)$ de 21 como un aceite amarillento. MS $\left(\mathrm{ESI}^{+}\right) \mathrm{m} / \mathrm{z}=504[\mathrm{M}+$ $\mathrm{H}]^{+} .{ }^{1} \mathrm{H}-\mathrm{RMN}\left[\mathrm{CDCl}_{3}, 400 \mathrm{MHz}\right], \delta(\mathrm{ppm}): 8.30\left(\mathrm{dd}, \mathrm{H}_{8}, \mathrm{~J}_{8.6}=1.0 ; \mathrm{J}_{8,7}=8.4 \mathrm{~Hz}\right), 7.76$ $\left(\mathrm{ddd}, \mathrm{H}_{6}, \mathrm{~J}_{6.8}=1.0, \mathrm{~J}_{6.7}=6.9, \mathrm{~J}_{5,6}=8.4 \mathrm{~Hz}\right), 7.93\left(\mathrm{dd}, \mathrm{H}_{5,} \mathrm{~J}_{5,7}=1.0, \mathrm{~J}_{5,6}=8.4 \mathrm{~Hz}\right), 7.56$ $\left(\right.$ ddd, $\left.\mathrm{H}_{7}, \mathrm{~J}_{7,5}=1.0, \mathrm{~J}_{7,8}=8.4 \mathrm{~Hz}, \mathrm{~J}_{7,6}=6.9 \mathrm{~Hz}\right), 7.00\left(\mathrm{~d}, \mathrm{H}_{5}{ }^{\prime}, \mathrm{J}=8.0 \mathrm{~Hz}\right), 6.99\left(\mathrm{~d}, \mathrm{H}_{2}{ }^{\prime}, \mathrm{J}=\right.$ $1.9 \mathrm{~Hz}), 6.90\left(\mathrm{~d}, \mathrm{H}_{6}{ }^{\prime}, \mathrm{J}=8.0 \mathrm{~Hz}\right), 3.97(\mathrm{~s}, 3 \mathrm{H}), 3.93$ (s, 3H), 3.75 (t, 2H, J = 7.2 Hz), 3.56 (t, $2 \mathrm{H \alpha}, \mathrm{J}=7.3 \mathrm{~Hz}), 3.12(\mathrm{~m}, 2 \mathrm{H}), 2.89(\mathrm{~m}, 2 \mathrm{H}), 2.85\left(\mathrm{t}, 2 \mathrm{H}_{\beta}, \mathrm{J}=7.3 \mathrm{~Hz}\right), 2.29(\mathrm{t}, 2 \mathrm{H}, \mathrm{J}=$ $7.3 \mathrm{~Hz}), 2.12(\mathrm{~m}, 2 \mathrm{H}), 2.02(\mathrm{~m}, 2 \mathrm{H}), 1.82$ (q, 2H. J = 7.1), 1.69 (q. 2H. J = 7.1), $1.54-$ $1.38(\mathrm{~m}, 6 \mathrm{H}) .{ }^{13} \mathrm{C}-\mathrm{RMN}\left[\mathrm{CDCl}_{3}, 100 \mathrm{MHz}\right], \delta(\mathrm{ppm}): 176.1,157.8,154.0,150.4,148.9$, 146.6, 133.3, 130.4, 126.6, 124.9, 124.7, 122.1, 120.6, 116.0, 113.7, 113.0, 56.4, 56.4, 49.2, 41.9, 37.0, 36.0, 33.4, 32.1, 30.1, 30.0, 27.7, 26.7, 25.9, 23.9, 23.4. ${ }^{1} \mathrm{H}$ y ${ }^{13} \mathrm{C}-\mathrm{RMN}$ : ver tablas VII y VIII. 21·HCl: sólido Amarillo, p. f. 108 - $110{ }^{\circ} \mathrm{C}$. Análisis (\%): Calculado para $\mathrm{C}_{31} \mathrm{H}_{42} \mathrm{ClN}_{3} \mathrm{O}_{3}: \mathrm{C}, 68.93, \mathrm{H}, 7.84, \mathrm{~N}$, 7.78. Encontrado: C, 68.90, H, 7.82, N, 7.80. 


\section{6-(8-Cloro-1,2,3,4-tetrahidroacridin-9-ilamino)- $N$-(3,4-dimetoxifenetil)hexanamida}<smiles>CCCCCNc1c2c(nc3cccc(Cl)c13)CCCC2</smiles>

Siguiendo el procedimiento general, la reacción del ácido-[6-(8-cloro-1,2,3,4tetrahidro-acridin-9-il)amino]-hexanoico $\quad \mathbf{8}$

(70 mg, $0.20 \mathrm{mmol})$ con BOP (116.2 mg, 0.26 mmol), homoveratrilamina ( $34 \mu \mathrm{L}, 0.20 \mathrm{mmol})$ y $\mathrm{Et}_{3} \mathrm{~N}(73 \mu \mathrm{L}, 0.52 \mathrm{mmol})$ durante 18 horas condujo a un aceite, que se purificó mediante cromatografía a presión en columna sobre gel de sílice empleando como eluyente mezclas de disolventes de polaridad creciente de acetato de etilo : metanol : hidróxido amónico, desde $10: 1: 0.2$ hasta $6: 1$ : 0.2. Se aislaron $44.5 \mathrm{mg}(43 \%)$ de 22 como un aceite amarillento. $\mathrm{MS}\left(\mathrm{ESI}^{+}\right) \mathrm{m} / \mathrm{z}=510$ $[\mathrm{M}+\mathrm{H}]^{+} .{ }^{1} \mathrm{H}-\mathrm{RMN}\left[\mathrm{CDCl}_{3}, 400 \mathrm{MHz}\right], \delta(\mathrm{ppm}): 7.85\left(\mathrm{t}, \mathrm{H}_{6}, \mathrm{~J}_{6.5}=\mathrm{J}_{6.7}=8.0 \mathrm{~Hz}\right), 7.80(\mathrm{dd}$, $\left.\mathrm{H}_{5,} \mathrm{~J}_{5,7}=1.8, \mathrm{~J}_{5,6}=8.0 \mathrm{~Hz}\right), 7.72\left(\mathrm{dd}, \mathrm{H}_{7}, \mathrm{~J}_{7,5}=1.8, \mathrm{~J}_{7,6}=8.0 \mathrm{~Hz}\right), 7.01\left(\mathrm{~d}, \mathrm{H}_{5}{ }^{\prime}, \mathrm{J}=8.1 \mathrm{~Hz}\right)$, $6.99\left(\mathrm{~d}, \mathrm{H}_{2}^{\prime}, \mathrm{J}=1.8 \mathrm{~Hz}\right), 6.89$ (d, $\left.\mathrm{H}_{6}^{\prime}, \mathrm{J}=8.1 \mathrm{~Hz}\right), 3.97$ (s, 3H), 3.94 (s, 3H), 3.78 (t, 2H, $\mathrm{J}=7.0 \mathrm{~Hz}$ ), $3.53(\mathrm{t}, 2 \mathrm{H \alpha}, \mathrm{J}=7.2 \mathrm{~Hz}), 3.16(\mathrm{t}, 2 \mathrm{H}, \mathrm{J}=6.1 \mathrm{~Hz}), 2.99(\mathrm{t}, 2 \mathrm{H}, \mathrm{J}=6.1 \mathrm{~Hz}), 2.87$ $\left(\mathrm{t}, 2 \mathrm{H}_{\beta}, \mathrm{J}=7.2 \mathrm{~Hz}\right), 2.30$ (t, 2H, J = 7.2 Hz), 2.19 (m, 2H), 2.05 (m, 2H), 1.84 (q, 2H. J = 7.3), 1.72 (q, 2H. J = 7.3), $1.48-1.37(\mathrm{~m}, 2 \mathrm{H}) .{ }^{13} \mathrm{C}-\mathrm{RMN}\left[\mathrm{CDCl}_{3}, 100 \mathrm{MHz}\right], \delta(\mathrm{ppm})$ : 175.7, 158.0, 154.8, 150.4, 149.0, 143.3, 133.4, 132.5, 130.4, 129.3, 122.1, 121.6, 116.1, $115.9,113.8,113.1,56.5,56.4,50.5,41.8,36.9,36.0,32.1,30.2$, 27.8, 27.1, 26.5, 23.3, 22.1. ${ }^{1} \mathrm{H}$ y ${ }^{13} \mathrm{C}-\mathrm{RMN}$ : ver tablas VII y VIII . 22.HCl: sólido amarillo, p. f. $181-183{ }^{\circ} \mathrm{C}$. Análisis (\%): Calculado para $\mathrm{C}_{29} \mathrm{H}_{37} \mathrm{Cl}_{2} \mathrm{~N}_{3} \mathrm{O}_{3}: \mathrm{C}, 63.73, \mathrm{H}, 6.82, \mathrm{~N}, 7.69$. Encontrado: $\mathrm{C}$, 63.70, H, 6.80, N, 7.68.

\section{6-(6,8-Dicloro-1,2,3,4-tetrahidroacridin-9-ilamino)- $N$-(3,4-dimetoxifenetil) hexanamida (23)}<smiles>CCCCCNc1c2c(nc3cc(Cl)cc(Cl)c13)CCCC2</smiles>

Siguiendo el procedimiento general, la reacción durante 18 horas del ácido-[6(6,8-dicloro-1,2,3,4-tetrahidroacridin-9il)amino]-hexanoico $\quad 9 \quad(50 \quad \mathrm{mg}, \quad 0.13$ mmol) con BOP (75.3 mg, $0.17 \mathrm{mmol})$, homoveratrilamina ( $22 \mu \mathrm{L}, 0.13 \mathrm{mmol})$ y Et $_{3} \mathrm{~N}$ (47 $\mu \mathrm{L}, 0.34 \mathrm{mmol}$ ) proporcionó un aceite, que se purificó mediante cromatografía a presión en columna sobre gel de sílice empleando como eluyente mezclas de disolventes 
de polaridad creciente de acetato de etilo : metanol : hidróxido amónico, desde $10: 1$ : 0.2 hasta $6: 1: 0.2$. Se aislaron $49.6 \mathrm{mg}(70 \%)$ de 23 como un aceite amarillento. MS $\left(\mathrm{ESI}^{+}\right) \mathrm{m} / \mathrm{z}=544[\mathrm{M}+\mathrm{H}]^{+} .1 \mathrm{H}-\mathrm{RMN}[\mathrm{CDCl} 3,400 \mathrm{MHz}], \delta(\mathrm{ppm}): 7.80\left(\mathrm{~d}, \mathrm{H}_{5}, \mathrm{~J}_{5,7}=1.9\right.$

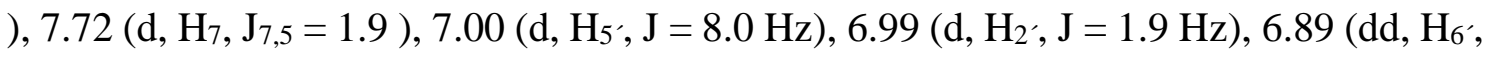
$\mathrm{J}=8.1 \mathrm{~Hz}, \mathrm{~J}=1.9 \mathrm{~Hz}), 3.98(\mathrm{~s}, 3 \mathrm{H}), 3.95(\mathrm{~s}, 3 \mathrm{H}), 3.75(\mathrm{t}, 2 \mathrm{H}, \mathrm{J}=7.2 \mathrm{~Hz}), 3.53(\mathrm{t}, 2 \mathrm{H \alpha}$, $\mathrm{J}=7.3 \mathrm{~Hz}), 3.14(\mathrm{t}, 2 \mathrm{H}, \mathrm{J}=6.1 \mathrm{~Hz}), 2.97(\mathrm{t}, 2 \mathrm{H}, \mathrm{J}=6.1 \mathrm{~Hz}), 2.86\left(\mathrm{t}, 2 \mathrm{H}_{\beta}, \mathrm{J}=7.3 \mathrm{~Hz}\right), 2.29$ (t, 2H, J = 7.2 Hz), $2.13(\mathrm{~m}, 2 \mathrm{H}), 2.04(\mathrm{~m}, 2 \mathrm{H}), 1.83(\mathrm{q}, 2 \mathrm{H} . \mathrm{J}=7.3), 1.72$ (q, 2H. J = 7.3), $1.45-1.42(\mathrm{~m}, 2 \mathrm{H}) .{ }^{13} \mathrm{C}-\mathrm{RMN}\left[\mathrm{CDCl}_{3}, 100 \mathrm{MHz}\right], \delta(\mathrm{ppm}): 175.8,157.6,155.8,150.3$, 148.9, 144.2, 137.3, 133.4, 131.9, 128.7,122.1, 121.0, 116.7,115.1, 113.7, 113.0, 56.5, 56.4, 50.7, 41.9, 36.7, 36.0, 31.5, 27.1, 26.7, 26.5, 23.2 , 22.1. ${ }^{1} \mathrm{H}$ y ${ }^{13} \mathrm{C}-\mathrm{RMN}$ : ver tablas VII y VIII. 23·HCl: sólido amarillo, p. f. 192 - $193{ }^{\circ} \mathrm{C}$. Análisis (\%): Calculado para $\mathrm{C}_{29} \mathrm{H}_{36} \mathrm{Cl}_{3} \mathrm{~N}_{3} \mathrm{O}_{3}:$ C, 59.95, H, 6.25, N, 7.23. Encontrado: C, 59.93, H, 6.22, N, 7.21.

\section{6-(7-Fluoro-1,2,3,4-tetrahidroacridin-9-ilamino)- $N$-(3,4-dimetoxifenetil) hexanamida (24)}<smiles>COc1ccc(CCNC(=O)OCc2ccc(F)cc2)cc1NCc1cccc(F)c1</smiles>

Siguiendo el procedimiento general, el tratamiento del ácido-[6-(7-fluoro-1,2,3,4tetrahidroacridin-9-il)-amino]-hexanoico 11 (90 mg, $0.27 \mathrm{mmol})$ con BOP (156.8 $\mathrm{mg}, 0.35 \mathrm{mmol})$, homoveratrilamina $(45 \mu \mathrm{L}, 0.27 \mathrm{mmol})$ y Et $3 \mathrm{~N}(98 \mu \mathrm{L}, 0.71 \mathrm{mmol})$ durante 18 horas condujo a un aceite, que se purificó mediante cromatografía a presión en columna sobre gel de sílice empleando como eluyente mezclas de disolventes de polaridad creciente de acetato de etilo : metanol : hidróxido amónico, desde $10: 1: 0.2$ hasta $6: 1: 0.2$. Se aislaron $54.1 \mathrm{mg}(40 \%)$ de 24 como un aceite amarillento. MS (ESI $\left.{ }^{+}\right)$ $\mathrm{m} / \mathrm{z}=494[\mathrm{M}+\mathrm{H}]^{+} .1 \mathrm{H}-\mathrm{RMN}[\mathrm{CDCl} 3,400 \mathrm{MHz}], \delta(\mathrm{ppm}): 8.26\left(\mathrm{dd}, \mathrm{H}_{8}, \mathrm{~J}_{8, \mathrm{~F}}=10.7, \mathrm{~J}_{8,6}\right.$ $=2.5 \mathrm{~Hz}), 7.96\left(\mathrm{dd}, \mathrm{H}_{5}, \mathrm{~J}_{5, \mathrm{~F}}=4.9 \mathrm{~Hz}, \mathrm{~J}_{5,6}=7.6 \mathrm{~Hz}\right), 7.87\left(\mathrm{ddd}, \mathrm{H}_{6}, \mathrm{~J}_{6, \mathrm{~F}}=9.3 \mathrm{~Hz}, \mathrm{~J}_{6,5}=7.6\right.$ $\left.\mathrm{Hz}, \mathrm{J}_{6,8}=2.5 \mathrm{~Hz}\right), 7.00$ (d, $\left.\mathrm{H}_{5^{\prime}}, \mathrm{J}=8.2 \mathrm{~Hz}\right), 6.99$ (d, $\left.\mathrm{H}_{2}, \mathrm{~J}=2.1 \mathrm{~Hz}\right), 6.89$ (dd, $\mathrm{H}_{6^{\prime}}, \mathrm{J}=8.2$

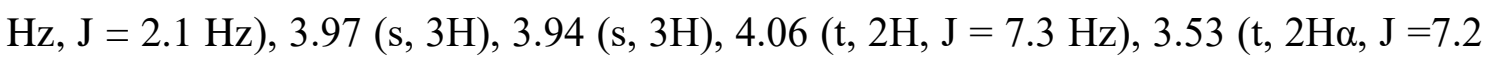
$\mathrm{Hz}), 3.17$ (m, 2H ), $2.91(\mathrm{~m}, 2 \mathrm{H}), 2.86\left(\mathrm{t}, 2 \mathrm{H}_{\beta}, \mathrm{J}=7.2 \mathrm{~Hz}\right), 2.35$ (t, 2H, J = 7.2 Hz), 2.18 (m, 2H), $2.08(\mathrm{~m}, 2 \mathrm{H}), 1.97$ (q, 2H. J = $7.3 \mathrm{~Hz}), 1.80$ (q, 2H. J = 7.3), $1.60-1.50$ (m, 2H). ${ }^{13} \mathrm{C}-\mathrm{RMN}\left[\mathrm{CDCl}_{3}, 100 \mathrm{MHz}\right], \delta$ (ppm): 175.8, 160.5, 157.4, 152.0, 150.3, 148.9, 136.4, $133.4,123.4,122.8,118.0,113.1,122.1,113.7,113.1,56.5,56.4,49.8,41.9,36.8,36.0$, 
31.5, 31.1, 26.5, 25.0, 22.9, 21.6. ${ }^{1} \mathrm{H}$ y ${ }^{13} \mathrm{C}-\mathrm{RMN}$ : ver tablas VII y VIII. 24·HCl: sólido amarillo, p. f. $165-167^{\circ} \mathrm{C}$. Análisis (\%): Calculado para $\mathrm{C}_{29} \mathrm{H}_{37} \mathrm{ClFN}_{3} \mathrm{O}_{3}$ : C, 65.71, H, 7.04, N, 7.93. Encontrado: C, 65.70, H, 7.02, N, 7.91.

2.7.1.4. Procedimiento general para la síntesis de tioamidas derivadas de los híbridos tacrina-neuroaminas (25 y 26)

Sobre una disolución de la correspondiente amida 19, 21 (1.0 mmol) en tolueno anhidro $(10 \mathrm{~mL})$ se añadió el reactivo de Lawesson $(\mathrm{RL})(1.5 \mathrm{mmol})$ y se calentó a reflujo durante 8 horas. Después de enfriar a temperatura ambiente, el disolvente se evaporó a presión reducida y el residuo resultante se purificó mediante columna de cromatografía gel de sílice empleando como eluyente mezclas de $\mathrm{AcOEt}$ : $\mathrm{CH}_{3} \mathrm{OH}: \mathrm{NH}_{3}$ como se indica en cada caso. El posterior tratamiento de las amidas con una disolución de $\mathrm{MeOH}$ saturada con $\mathrm{HCl}$ (gas) permitió aislar los correspondientes hidrocloruros mediante filtración de forma cuantitativa.

\section{$N$-(3,4-Dimetoxifenetil)-6-(1,2,3,4-tetrahidroacridin-9-ilamino)hexanetioamida (25)}<smiles>CNc1c2c(nc3ccccc13)CCCC2</smiles>

Siguiendo el procedimiento general, la reacción de $N$-(3,4-dimetoxifenetil)-6(1,2,3,4-tetrahidroacridin-9-ilamino)hexanamida 19 (47 mg, $0.10 \mathrm{mmol})$ y RL (60.0 mg, $0.15 \mathrm{mmol}$ ) a reflujo durante 12 horas proporcionó un aceite, que se purificó mediante cromatografía a presión en columna sobre gel de sílice empleando como eluyente mezclas de disolventes de polaridad creciente de acetato de etilo : metanol : hidróxido amónico, desde $14: 1: 0.2$ hasta $6: 1: 0.2$. Se aislaron $42.0 \mathrm{mg}(87 \%)$ de 25 como un aceite amarillento. MS $\left(\mathrm{ESI}^{+}\right) \mathrm{m} / \mathrm{z}=492[\mathrm{M}+\mathrm{H}]^{+} .{ }^{1} \mathrm{H}-\mathrm{RMN}\left[\mathrm{CDCl}_{3}, 400 \mathrm{MHz}\right], \delta(\mathrm{ppm}): 8.30$ $\left(\mathrm{dd}, \mathrm{H}_{8}, \mathrm{~J}_{8.6}=1.0 ; \mathrm{J}_{8,7}=8.3 \mathrm{~Hz}\right), 7.94\left(\mathrm{dd}, \mathrm{H}_{5}, \mathrm{~J}_{5,7}=1.0, \mathrm{~J}_{5,6}=8.3 \mathrm{~Hz}\right), 7.77\left(\mathrm{ddd}, \mathrm{H}_{6,} \mathrm{~J}_{6.8}=\right.$ $\left.1.0, \mathrm{~J}_{6.7}=6.9, \mathrm{~J}_{5,6}=8.3 \mathrm{~Hz}\right), 7.59\left(\mathrm{ddd}, \mathrm{H}_{7}, \mathrm{~J}_{7,5}=1.0, \mathrm{~J}_{7,8}=8.3 \mathrm{~Hz}, \mathrm{~J}_{7,6}=6.9 \mathrm{~Hz}\right), 7.01(\mathrm{~d}$,

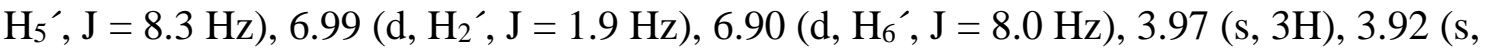

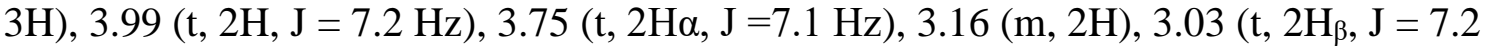
Hz), $2.93(\mathrm{~m}, 2 \mathrm{H}), 2.73(\mathrm{t}, 2 \mathrm{H}, \mathrm{J}=7.2 \mathrm{~Hz}), 2.16(\mathrm{~m}, 2 \mathrm{H}), 2.06(\mathrm{~m}, 2 \mathrm{H}), 1.88(\mathrm{q}, 2 \mathrm{H} . \mathrm{J}=$ 
7.3), 1.83 (q. $2 \mathrm{H} . \mathrm{J}=7.3$ ), $1.54-1.44$ (m. 2H). ${ }^{13} \mathrm{C}-\mathrm{RMN}\left[\mathrm{CDCl}_{3}, 100 \mathrm{MHz}\right], \delta$ (ppm): 209.8, 150.9, 158.7, 154.2, 149.6, 147.5, 133.6, 130.7, 127.5, 125.4, 125.2, 122.6, 121.3, $116.8,114.2,113.6,56.9,49.9,48.5,47.1,34.5,30.7,32.4,27.4,26.5,24.5,23.9 .{ }^{1} \mathrm{H} \mathrm{y}$ ${ }^{13} \mathrm{C}-\mathrm{RMN}$ : ver tablas VII y VIII. 25.HCl: sólido amarillo, p. f. $80-82{ }^{\circ} \mathrm{C}$. Análisis (\%): Calculado para $\mathrm{C}_{29} \mathrm{H}_{38} \mathrm{ClN}_{3} \mathrm{O}_{2} \mathrm{~S}: \mathrm{C}, 65.95, \mathrm{H}, 7.25, \mathrm{~N}, 7.96$. Encontrado: $\mathrm{C}, 65.93, \mathrm{H}$, 7.26, N, 7.94 .

\section{$N$-(3,4-Dimetoxifenetil)-8-(5,6,7,8-tetrahidroacridin-9-ilamino)octanotioamida (26)}<smiles>COc1ccc(CCNC(=S)NCc2c3c(nc4ccccc24)CCCC3)cc1OC</smiles>

Siguiendo el procedimiento general, el reflujo durante 12 horas de $N$-(3,4-dimetoxifenetil)-8(1,2,3,4-tetrahidroacridin-9-ilamino)octanamida 21 (21 mg, $0.04 \mathrm{mmol})$ y RL (25,5 mg, $0.06 \mathrm{mmol}$ ) condujo a un aceite, que se purificó mediante cromatografía a presión en columna sobre gel desílice empleando como eluyente mezclas de disolventes de polaridad creciente de acetato de etilo : metanol : hidróxido amónico, desde $14: 1: 0.2$ hasta $6: 1$ : 0.2. Se aislaron $19.0 \mathrm{mg}(88 \%)$ de 26 como un aceite amarillento. $\mathrm{MS}\left(\mathrm{ESI}^{+}\right) \mathrm{m} / \mathrm{z}=520$ $[\mathrm{M}+\mathrm{H}]^{+} .{ }^{1} \mathrm{H}-\mathrm{RMN}\left[\mathrm{CDCl}_{3}, 400 \mathrm{MHz}\right], \delta(\mathrm{ppm}): 8.21\left(\mathrm{dd}, \mathrm{H}_{8}, \mathrm{~J}_{8.6}=1.0 ; \mathrm{J}_{8,7}=8.4 \mathrm{~Hz}\right)$, $7.94\left(\mathrm{dd}, \mathrm{H}_{5}, \mathrm{~J}_{5,7}=1.0, \mathrm{~J}_{5,6}=8.4 \mathrm{~Hz}\right), 7.69\left(\mathrm{ddd}, \mathrm{H}_{6}, \mathrm{~J}_{6.8}=1.0, \mathrm{~J}_{6.7}=6.9, \mathrm{~J}_{5,6}=8.4 \mathrm{~Hz}\right)$, $7.51\left(\mathrm{ddd}, \mathrm{H}_{7}, \mathrm{~J}_{7,5}=1.0, \mathrm{~J}_{7,8}=8.4 \mathrm{~Hz}, \mathrm{~J}_{7,6}=6.9 \mathrm{~Hz}\right), 7.00\left(\mathrm{~d}, \mathrm{H}_{5^{\prime}}, \mathrm{J}=8.1 \mathrm{~Hz}\right), 6.99(\mathrm{~d}$, $\left.\mathrm{H}_{2}{ }^{\prime}, \mathrm{J}=1.8 \mathrm{~Hz}\right), 6.90\left(\mathrm{~d}, \mathrm{H}_{6}{ }^{\prime}, \mathrm{J}=8.1 \mathrm{~Hz}\right), 3.97(\mathrm{~s}, 3 \mathrm{H}), 3.93(\mathrm{~s}, 3 \mathrm{H}), 3.89$ (t, 2H, J = 7.2

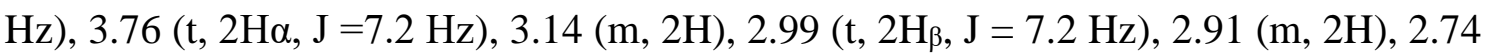
$(\mathrm{t}, 2 \mathrm{H}, \mathrm{J}=7.2 \mathrm{~Hz}), 2.13(\mathrm{~m}, 2 \mathrm{H}), 2.04(\mathrm{~m}, 2 \mathrm{H}), 1.82$ (q, 2H. J = 7.2), 1.71 (q. 2H. J = 7.2), $1.54-1.41$ (m. 6H). ${ }^{13} \mathrm{C}-\mathrm{RMN}\left[\mathrm{CDCl}_{3}, 100 \mathrm{MHz}\right], \delta$ (ppm): 209.6, 150.3, 158.6, 154.4, 149.1, 146.1, 133.4, 130.0, 127.5, 124.8, 124.5, 122.3, 120.9, 116.5, 114.3, 113.1, 56.4, 56.3, 49.2, 48.2, 47.1, 34.6, 34.4, 32.4, 30.9, 27.4, 26.1, 24.0, 23.6. ${ }^{1} \mathrm{H}$ y ${ }^{13} \mathrm{C}-\mathrm{RMN}$ : tablas VII y VIII. 26·HCl: sólido amarillo, p. f. 83 - $85{ }^{\circ} \mathrm{C}$. Análisis (\%): Calculado para $\mathrm{C}_{31} \mathrm{H}_{42} \mathrm{ClN}_{3} \mathrm{O}_{2} \mathrm{~S}$ : C, 66.94, H, 7.61, N, 7.55. Encontrado: C, 66.92, H, 7.60, N, 7.49. 
2.7.1.5. Síntesis de N-(1,2,3,4-tetrahidroacridin-9-il)]-1,N-alcanodiaminas (27-30). Procedimiento general

A una disolución de $\alpha, \omega$-diamina (3.0 mmol) en 1-pentanol anhidro se añadió 9-cloro(1,2,3,4-tetrahidro)acridina $1(1.0 \mathrm{mmol})$ y la mezcla resultante se calentó a reflujo durante 24 horas. Después de enfriar a temperatura ambiente, la mezcla de reacción se diluyó con $\mathrm{CH}_{2} \mathrm{Cl}_{2}(50 \mathrm{~mL})$, se lavó con una disolución acuosa de $\mathrm{NaOH}$ al $10 \%$ (3 x 30 mL) y con una disolución saturada de $\mathrm{NaCl}(3$ x $30 \mathrm{~mL})$. Los extractos orgánicos se secaron sobre $\mathrm{Na}_{2} \mathrm{SO}_{4}$, se filtraron y el disolvente se evaporó a sequedad, obteniéndose un aceite coloreado que se purificó mediante columna de cromatografía a presión sobre gel de sílice empleando como eluyente las mezclas de disolventes en las proporciones que se indican en cada caso.

\section{$N$-(1,2,3,4-Tetrahidroacridin-9-il)-1,6-hexanodiamina $(27)^{201}$}<smiles>NNc1c2c(nc3ccccc13)CCCC2</smiles>

La reacción de 1,7-hexanodiamina (491 mg, $4.14 \mathrm{mmol}$ ) con 1 (300 mg, $1.38 \mathrm{mmol}$ ) proporcionó un residuo que se purificó empleando como eluyente $\mathrm{CH}_{2} \mathrm{Cl}_{2}: \mathrm{CH}_{3} \mathrm{OH}: \mathrm{NH}_{3}$ (desde $10: 1$ : 0.2 hasta $5: 1: 0.2)$. De las fracciones de $R_{f}=0.3\left(\mathrm{CH}_{2} \mathrm{Cl}_{2}\right.$ : $\left.\mathrm{CH}_{3} \mathrm{OH}: \mathrm{NH}_{3}, 7: 1: 0.2\right)$ se aisló 27 (306 mg, 75\%) como un aceite amarillo. EM (ESI), $m / z=298,[\mathrm{M}+\mathrm{H}]^{+} .{ }^{1} \mathrm{H}-\mathrm{RMN}\left[\mathrm{CD}_{3} \mathrm{OD}, 300 \mathrm{MHz}\right], \delta(\mathrm{ppm}): 7.94\left(\mathrm{dd}, \mathrm{H}_{8}, \mathrm{~J}_{8.6}=1.0 ; \mathrm{J}_{8,7}\right.$ $=8.5 \mathrm{~Hz}), 7.90\left(\mathrm{dd}, \mathrm{H}_{5}, \mathrm{~J}_{5,7}=1.0, \mathrm{~J}_{5,6}=8.5 \mathrm{~Hz}\right), 7.54\left(\mathrm{ddd}, \mathrm{H}_{6}, \mathrm{~J}_{6.8}=1.0, \mathrm{~J}_{6.7}=7.0, \mathrm{~J}_{5,6}=\right.$ $8.5 \mathrm{~Hz}$ ), 7.33 (ddd, $\mathrm{H}_{7}, \mathrm{~J}_{7,5}=1.0, \mathrm{~J}_{7,8}=8.5 \mathrm{~Hz}, \mathrm{~J}_{7,6}=7.0 \mathrm{~Hz}$ ), $3.48(\mathrm{t}, 2 \mathrm{H \alpha}, \mathrm{J}=7.2 \mathrm{~Hz}$ ), $3.03(\mathrm{~m}, 2 \mathrm{H}), 2.69(\mathrm{~m}, 2 \mathrm{H}), 2.65(\mathrm{t}, 2 \mathrm{H} \omega, \mathrm{J}=7.0 \mathrm{~Hz}), 1.91(\mathrm{~m}, 4 \mathrm{H}), 1,62(\mathrm{~m}, 4 \mathrm{H}) ; 1,30$ $(\mathrm{m}, 4 \mathrm{H}) .{ }^{13} \mathrm{C}-\mathrm{RMN}\left[\mathrm{CD}_{3} \mathrm{OD}, 75 \mathrm{MHz}\right]: 158.1,151.3,147.1,129.9,127.1,124.7,124.5$, 120.3, 116.1, 49.5, 41.3, 33.5 32.0, 30.4, 29.9, 27.8, 26.0, 24.2, 23.7, ${ }^{1} \mathrm{H}$ y ${ }^{13} \mathrm{C}-\mathrm{RMN}$ : Los datos se recogen en las Tablas $I X$ y $X$ (ver apartado 2.8 Tablas). Análisis (\%): Calculado para $\mathrm{C}_{19} \mathrm{H}_{27} \mathrm{~N}_{3}$ : C, 76.72, H, 9.15, N, 14.13. Encontrado: C, 76.98, H, 9.43, N, 14.44.

${ }^{201}$ Carlier, P.R.; Chow, E.S.-H..; Han, Y.; Liu, J.;Yazal, J. E.; Pang, Y.-H. Heterodimeric tacrine-based acetylcholisterase inhibitors: investigating ligand-peripheral site interactions. J. Med. Chem. 1999, 42, 4225-4231. 


\section{$N$-(1,2,3,4-Tetrahidroacridin-9-il)-1,7-heptanodiamina $(28)^{7}$}<smiles>Nc1c2c(nc3ccccc13)CCCC2</smiles>

La reacción de 1,7-heptanodiamina (719 mg, $5.52 \mathrm{mmol})$ con 1 (400 mg, $1.84 \mathrm{mmol}$ ) proporcionó un residuo que se purificó empleando como eluyente $\mathrm{CH}_{2} \mathrm{Cl}_{2}: \mathrm{CH}_{3} \mathrm{OH}: \mathrm{NH}_{3}$ (desde $10: 1$ : 0.2 hasta $5: 1: 0.2)$. De las fracciones de $R_{f}=0.4\left(\mathrm{CH}_{2} \mathrm{Cl}_{2}\right.$ :

$\left.\mathrm{CH}_{3} \mathrm{OH}: \mathrm{NH}_{3}, 7: 1: 0.2\right)$ se aisló 28 (506 mg, 85\%) como un aceite amarillo. EM (ESI), $m / z=312 \quad[\mathrm{M}+\mathrm{H}]^{+} .{ }^{1} \mathrm{H}-\mathrm{RMN}\left[\mathrm{CD}_{3} \mathrm{OD}, 300 \mathrm{MHz}\right], \delta(\mathrm{ppm}): 8.32\left(\mathrm{dd}, \mathrm{H}_{8}, \mathrm{~J}_{8.6}=1.2 ;\right.$ $\left.\mathrm{J}_{8,7}=8.6 \mathrm{~Hz}\right), 7.96\left(\mathrm{dd}, \mathrm{H}_{5}, \mathrm{~J}_{5,7}=1.2, \mathrm{~J}_{5,6}=8.6 \mathrm{~Hz}\right), 7.77\left(\mathrm{ddd}, \mathrm{H}_{6,} \mathrm{~J}_{6.8}=1.2, \mathrm{~J}_{6.7}=7.0, \mathrm{~J}_{5,6}\right.$ $=8.6 \mathrm{~Hz}), 7.58\left(\mathrm{ddd}, \mathrm{H}_{7}, \mathrm{~J}_{7,5}=1.2, \mathrm{~J}_{7,8}=8.6 \mathrm{~Hz}, \mathrm{~J}_{7,6}=7.0 \mathrm{~Hz}\right), 3.77(\mathrm{t}, 2 \mathrm{H \alpha}, \mathrm{J}=7.2 \mathrm{~Hz})$, $3.17(\mathrm{~m}, 2 \mathrm{H}), 2.94(\mathrm{~m}, 2 \mathrm{H}), 2.93(\mathrm{t}, 2 \mathrm{H} \omega, \mathrm{J}=7.2 \mathrm{~Hz}), 2.11(\mathrm{~m}, 4 \mathrm{H}), 1,85$ (q, 2H, $J=7,2)$; $1,71(\mathrm{q}, 2 \mathrm{H}, J=7,2) ; 1,50(\mathrm{~m}, 6 \mathrm{H}) .{ }^{13} \mathrm{C}-\mathrm{RMN}$ [CD $\left.3 \mathrm{OD}, 75 \mathrm{MHz}\right]: 158.4,151.4,147.2$, 130.2, 127.2, 124.8, 124.6, 120.9, 116.4, 49.7, 41.4, 33.7, 32.1, 30.7, 30.0, 27.8, 27.5, 26.1, 24.0, 23.5. ${ }^{1} \mathrm{H}$ y ${ }^{13} \mathrm{C}-\mathrm{RMN}$ : Los datos se recogen en las Tablas IX y $X$ (ver apartado 2.8 Tablas). Análisis (\%): Calculado para $\mathrm{C}_{20} \mathrm{H}_{29} \mathrm{~N}_{3}$ : C, 77.12, $\mathrm{H}, 9.38, \mathrm{~N}, 13.49$. Encontrado: C, 77.42, H, 9.63, N, 13.64 .

\section{$N$-(1,2,3,4-Tetrahidroacridin-9-il)-1,8-octanodiamina $(29)^{7}$}<smiles>NNc1c2c(nc3ccccc13)CCCC2</smiles>

A partir de la reacción de 1,8-octanodiamina $(810 \mathrm{mg}, 5.52$ mmol) y 1 (400 mg, $1.84 \mathrm{mmol}$ ) se obtuvo un residuo que se purificó empleando como eluyente $\mathrm{CH}_{2} \mathrm{Cl}_{2}: \mathrm{CH}_{3} \mathrm{OH}: \mathrm{NH}_{3}$ (desde $10: 1: 0.2$ hasta $5: 1: 0.2$ ). De las fracciones de $R_{f}=0.3$ $\left(\mathrm{CH}_{2} \mathrm{Cl}_{2}: \mathrm{CH}_{3} \mathrm{OH}: \mathrm{NH}_{3}, 7: 1: 0,1\right)$ se aisló 29 (479 mg, 80\%) como un aceite amarillo. $\mathrm{EM}(\mathrm{ESI}), m / z=326[\mathrm{M}+\mathrm{H}]^{+} .{ }^{1} \mathrm{H}-\mathrm{RMN}\left[\mathrm{CD}_{3} \mathrm{OD}, 300 \mathrm{MHz}\right], \delta(\mathrm{ppm}): 8.30\left(\mathrm{dd}, \mathrm{H}_{8}\right.$, $\left.\mathrm{J}_{8.6}=1.0 ; \mathrm{J}_{8,7}=8.5 \mathrm{~Hz}\right), 7.95\left(\mathrm{dd}, \mathrm{H}_{5,} \mathrm{~J}_{5,7}=1.0, \mathrm{~J}_{5,6}=8.5 \mathrm{~Hz}\right), 7.75\left(\mathrm{ddd}, \mathrm{H}_{6}, \mathrm{~J}_{6.8}=1.0, \mathrm{~J}_{6.7}\right.$ $\left.=7.0, \mathrm{~J}_{5,6}=8.5 \mathrm{~Hz}\right), 7.58\left(\mathrm{ddd}, \mathrm{H}_{7}, \mathrm{~J}_{7,5}=1.0, \mathrm{~J}_{7,8}=8.5 \mathrm{~Hz}, \mathrm{~J}_{7,6}=7.0 \mathrm{~Hz}\right), 3.77(\mathrm{t}, 2 \mathrm{H \alpha}, \mathrm{J}$ $=7.2 \mathrm{~Hz}), 3.17(\mathrm{~m}, 2 \mathrm{H}), 2.94(\mathrm{~m}, 2 \mathrm{H}), 2.93(\mathrm{t}, 2 \mathrm{H \omega}, \mathrm{J}=7.2 \mathrm{~Hz}), 2.10(\mathrm{~m}, 4 \mathrm{H}), 1,81(\mathrm{q}$, $2 \mathrm{H}, J=7,2) ; 1,71(\mathrm{~m}, 2 \mathrm{H}) ; 1,45(\mathrm{~m}, 8 \mathrm{H}) .{ }^{13} \mathrm{C}-\mathrm{RMN}$ [CD $\left.3 \mathrm{OD}, 75 \mathrm{MHz}\right]: 159.2,153.2$, 148.1, 129.6, 128.1, 124.6, 124.4, 121.4, 116.7, 49.8, 42.4, 34.2, 33.5, 32.3, 30.4, 30.3, 27.8, 26.2, 24.1, 23.7. ${ }^{1} \mathrm{H}$ y ${ }^{13} \mathrm{C}-\mathrm{RMN}$ : Los datos se recogen en las Tablas $I X$ y $X$ (ver apartado 2.8 Tablas). Análisis (\%): Calculado para $\mathrm{C}_{21} \mathrm{H}_{31} \mathrm{~N}_{3}$ : C, 77.49, H, 9.60, N, 12.91 . Encontrado: C, 77.79, H, 9.84, N, 12.78 . 


\section{$N$-(1,2,3,4-Tetrahidroacridin-9-il)-1,9-nonanodiamina $(30)^{7}$}<smiles>NNc1c2c(nc3ccccc13)CCCC2</smiles>

Siguiendo el procedimiento general, la reacción de 1,9nonanodiamina ( $810 \mathrm{mg}, 5.52 \mathrm{mmol})$ con 1 (400 mg, $1.84 \mathrm{mmol})$ proporcionó un residuo que se purificó empleando como eluyente $\mathrm{CH}_{2} \mathrm{Cl}_{2}: \mathrm{CH}_{3} \mathrm{OH}: \mathrm{NH}_{3}$ (desde $10: 1: 0.2$ hasta $5: 1: 0.2$ ). De las fracciones de $R_{f}=0.3\left(\mathrm{CH}_{2} \mathrm{Cl}_{2}: \mathrm{CH}_{3} \mathrm{OH}: \mathrm{NH}_{3}, 7: 1: 0,1\right)$ se aisló 31 (479 $\left.\mathrm{mg}, 80 \%\right)$ como un aceite amarillo. EM (ESI), $\left.m / z=340[\mathrm{M}+\mathrm{H}]^{+}.\right]^{+} .{ }^{1} \mathrm{H}-\mathrm{RMN}\left[\mathrm{CDCl}_{3}, 300 \mathrm{MHz}\right]$, $\delta(\mathrm{ppm}): 8.26\left(\mathrm{dd}, \mathrm{H}_{8}, \mathrm{~J}_{8.6}=1.0 ; \mathrm{J}_{8,7}=8.5 \mathrm{~Hz}\right), 7.94\left(\mathrm{dd}, \mathrm{H}_{5,} \mathrm{~J}_{5,7}=1.0, \mathrm{~J}_{5,6}=8.5 \mathrm{~Hz}\right), 7.74$ $\left(\mathrm{ddd}, \mathrm{H}_{6,} \mathrm{~J}_{6.8}=1.0, \mathrm{~J}_{6.7}=7.0, \mathrm{~J}_{5,6}=8.5 \mathrm{~Hz}\right), 7.56\left(\mathrm{ddd}, \mathrm{H}_{7,} \mathrm{~J}_{7,5}=1.0, \mathrm{~J}_{7,8}=8.5 \mathrm{~Hz}, \mathrm{~J}_{7,6}=\right.$

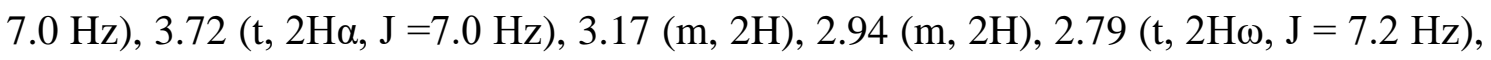
$2.11(\mathrm{~m}, 4 \mathrm{H}), 1,82(\mathrm{q}, 2 \mathrm{H}, J=7,2) ; 1,45(\mathrm{~m}, 12 \mathrm{H}) .{ }^{13} \mathrm{C}-\mathrm{RMN}$ [CD $\left.{ }_{3} \mathrm{OD}, 75 \mathrm{MHz}\right]: 158.4$, 148.0, 151.1, 129.2, 128.6, 123.9, 123.2, 120.7, 116.3, 34.1, 32.2, 31.1, 29.8, 29.7, 29.6, 27.5, 26.4, 25.2, 23.5, 23.2, ${ }^{1} \mathrm{H}$ y ${ }^{13} \mathrm{C}-\mathrm{RMN}$ : Los datos se recogen en las Tablas IX y $X$ (ver apartado 2.8 Tablas). Análisis (\%): Calculado para $\mathrm{C}_{22} \mathrm{H}_{33} \mathrm{~N}_{3}: \mathrm{C}, 77.83, \mathrm{H}, 9.80, \mathrm{~N}$, 12.38. Encontrado: C, 77.98, H, 9.60, N, 12.62 .

\subsubsection{Síntesis de los híbridos tacrina - ferúlico (31-34) y tacrina-fenol (35-47)}

Una mezcla del ácido derivado del compuesto antioxidante $(0.46 \mathrm{mmol})$ con $\mathrm{Et}_{3} \mathrm{~N}$ $(0.92 \mathrm{mmol})$ y la diamina derivada de tacrina $(0.46 \mathrm{mmol})$ en $8 \mathrm{~mL}$ de DMF anhidra, se agita a $0^{\circ} \mathrm{C}$ durante 10 minutos. Se adicionó DCC $(0.60 \mathrm{mmol})$, dejándolo reaccionar durante 24 horas a temperatura ambiente bajo atmósfera de $\mathrm{N}_{2}{ }^{202}$. Transcurrido ese tiempo se eliminó el disolvente a sequedad a presión reducida obteniéndose un residuo, que se redisolvió en metanol formándose un precipitado blanco que se eliminó por filtración. El metanol de la fase líquida se eliminó a sequedad, obteniéndose un crudo, que fue purificado mediante columna de cromatografía a presión sobre gel de sílice empleando como eluyente mezclas de acetato de etilo : metanol.

\footnotetext{
${ }^{202}$ Gao, M.; Mock, B. -H.; Hutchins, G. -D; Zheng, Q. -H. "Synthesis and initial PET imaging of new potential dopamine D3 receptor radioligands $(\mathrm{E})-4,3,2-[11 \mathrm{C}] \mathrm{methoxy}-\mathrm{N}-4-(4-(2-)$ methoxyphenyl)piperazin-1-yl)butyl-cinnamoylamides "Bioorg.Med.. Chem. 2005, 13, 6233-6243.
} 


\section{(E)-3-(4-Hidroxi-3-metoxifenil)- $N$-[6-(1,2,3,4-tetrahidroacridin-9-ilamino)hexil] acrilamida (31)}

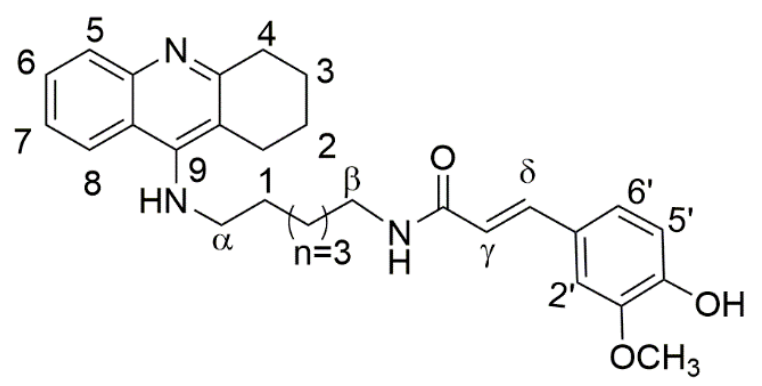

Siguiendo el procedimiento general, a partir del ácido ferúlico $(89.3 \mathrm{mg}, 0.46$ mmol), DCC (124 mg, $0.60 \mathrm{mmol}), \mathrm{N}$ (1,2,3,4-tetrahidroacridin-9-il)-1,6-hexanodiamina (137 mg, $0.46 \mathrm{mmol})$ y $\mathrm{Et}_{3} \mathrm{~N}$ (120 $\mu \mathrm{L}, 0.92 \mathrm{mmol}$ ), después de 24 horas se obtuvo un aceite que se purificó mediante cromatografía a presión en columna sobre gel de sílice empleando como eluyente una mezcla de acetato de etilo : metanol (10:1). Se aislaron $78.4 \mathrm{mg}(36 \%)$ de 31 como un sólido amarillo. p. f. 110 - $112{ }^{\circ} \mathrm{C}$ HPLC: pureza (80.5\%). MS: $\mathrm{m} / \mathrm{z}=474[\mathrm{M}+\mathrm{H}]^{+} .{ }^{1} \mathrm{H}-\mathrm{RMN}\left(500 \mathrm{MHz}, \mathrm{CD}_{3} \mathrm{OD}\right), \delta(\mathrm{ppm}): 8.20$ $\left(\mathrm{dd}, 1 \mathrm{H}_{8}, \mathrm{~J}=8.6, \mathrm{~J}=1.2\right), 7.75\left(\mathrm{dd}, 1 \mathrm{H}_{5}, \mathrm{~J}=8.6, \mathrm{~J}=1.2\right), 7.64\left(\mathrm{ddd}, 1 \mathrm{H}_{6}, \mathrm{~J}=8.6, \mathrm{~J}=7.7, \mathrm{~J}=\right.$ 1.2), $7.43\left(\mathrm{ddd}, 1 \mathrm{H}_{7}, \mathrm{~J}=8.6, \mathrm{~J}=7.7, \mathrm{~J}=1.2\right), 7.42$ (d, $\left.\mathrm{H}_{\gamma}, \mathrm{J}=15.8\right), 7.10\left(\mathrm{~d}, 1 \mathrm{H}_{2}, \mathrm{~J}=1.7\right.$ ),

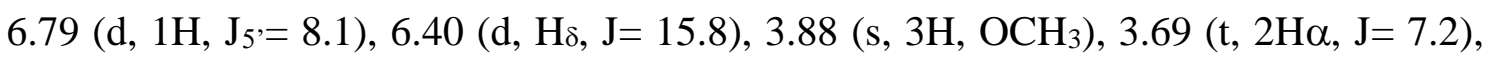
$3.27\left(\mathrm{t}, 2 \mathrm{H}_{\beta}, \mathrm{J}=7.0\right), 2.98(\mathrm{~m}, 2 \mathrm{H}), 2.73(\mathrm{~m}, 2 \mathrm{H}), 1.92(\mathrm{~m}, 4 \mathrm{H}), 1.73(\mathrm{q}, 2 \mathrm{H}, \mathrm{J}=7.2), 1.55$ $(\mathrm{q}, 2 \mathrm{H}, \mathrm{J}=7.2), 1.42(\mathrm{~m}, 4 \mathrm{H}) .{ }^{13} \mathrm{C}-\mathrm{RMN}\left(125 \mathrm{MHz}, \mathrm{CD}_{3} \mathrm{OD}\right), \delta(\mathrm{ppm}): 169.2(\mathrm{CONH})$, 156.5 (C), 154.8 (C), 150.1 (C), 149.3 (C), 145.1 (C), 142.1(C $), 131.2$ (CH), 128.0 (C), $125.3(\mathrm{CH}), 125.2(\mathrm{CH}), 125.2(\mathrm{CH}), 123.2(\mathrm{CH}), 119.8(\mathrm{C}), 118.5(\mathrm{C} \gamma \mathrm{H}), 116.5(\mathrm{CH})$, 115.4(C), $111.4(\mathrm{CH}), 56.3\left(\mathrm{OCH}_{3}\right), 49.5\left(\mathrm{C \alpha H}_{2}\right), 40.3\left(\mathrm{C}_{2} \mathrm{H}_{2}\right), 32.5\left(\mathrm{CH}_{2}\right), 31.9\left(\mathrm{CH}_{2}\right)$, $30.3\left(\mathrm{CH}_{2}\right), 27.6\left(\mathrm{CH}_{2}\right), 27.5\left(\mathrm{CH}_{2}\right), 25.7\left(\mathrm{CH}_{2}\right), 23.7\left(\mathrm{CH}_{2}\right), 23.0\left(\mathrm{CH}_{2}\right)$. Los datos se recogen en las Tablas XII y XII (ver apartado 2.8 Tablas).

\section{(E)-3-(4-Hidroxi-3-metoxifenil)- $N$-[7-(1,2,3,4-tetrahidroacridin-9-ilamino)heptil]} acrilamida (32)

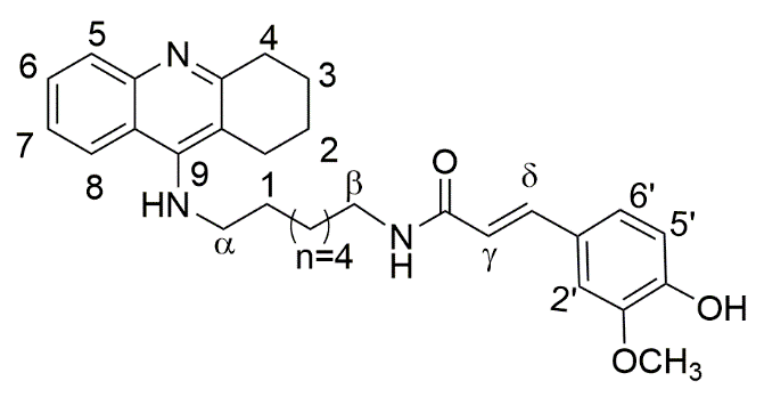

Siguiendo el procedimiento general, a partir del ácido ferúlico $(89.3 \mathrm{mg}, 0.46$ mmol), DCC (124 mg, $0.60 \mathrm{mmol}), \mathrm{N}$ (1,2,3,4-tetrahidroacridin-9-il)-1,7-heptanodiamina (143 mg, $0.46 \mathrm{mmol}$ ) y $\mathrm{Et}_{3} \mathrm{~N}$ (120 $\mu \mathrm{L}, 0.92 \mathrm{mmol})$, después de 24 horas se obtuvo un aceite que se purificó mediante cromatografía a presión en columna sobre 
gel de sílice empleando como eluyente una mezcla de acetato de etilo : metanol (10:1). Se aislaron $94.0 \mathrm{mg}(41 \%)$ de 32 como un sólido amarillo. p. f. 140 - $142{ }^{\circ} \mathrm{C}$ HPLC: pureza $(71 \%)$. MS : m/z $=488[\mathrm{M}+\mathrm{H}]^{+} .{ }^{1} \mathrm{H}-\mathrm{RMN}\left(500 \mathrm{MHz}, \mathrm{CD}_{3} \mathrm{OD}\right), \delta(\mathrm{ppm}): 8.12$ $\left(\mathrm{dd}, 1 \mathrm{H}_{8}, \mathrm{~J}=8.7, \mathrm{~J}=1.2\right), 7.75\left(\mathrm{dd}, 1 \mathrm{H}_{5}, \mathrm{~J}=8.6, \mathrm{~J}=1.2\right), 7.58\left(\mathrm{ddd}, 1 \mathrm{H}_{6}, \mathrm{~J}=8.6, \mathrm{~J}=7.7, \mathrm{~J}=\right.$ 1.2), $7.42(\mathrm{~d}, \mathrm{H} \delta, \mathrm{J}=15.7), 7.38\left(\mathrm{ddd}, 1 \mathrm{H}_{7}, \mathrm{~J}=8.7, \mathrm{~J}=7.7, \mathrm{~J}=1.2\right), 7.09$ (d, $1 \mathrm{H}_{2}, \mathrm{~J}=1.8$ ), $7.01\left(\mathrm{dd}, 1 \mathrm{H}_{6}, \mathrm{~J}=8.3, \mathrm{~J}=1.8\right), 6.78\left(\mathrm{~d}, 1 \mathrm{H}_{5}, \mathrm{~J}=8.3\right), 6.40\left(\mathrm{~d}, \mathrm{H}_{\gamma}, \mathrm{J}=15.7\right), 3.87(\mathrm{~s}, 3 \mathrm{H}$, $\left.\mathrm{OCH}_{3}\right), 3.59$ (t, 2H $\left.\alpha, \mathrm{J}=7.2\right), 3.25\left(\mathrm{t}, 2 \mathrm{H}_{\beta}, \mathrm{J}=7.1\right), 2.97(\mathrm{~m}, 2 \mathrm{H}), 2.72(\mathrm{~m}, 2 \mathrm{H}), 1.90(\mathrm{~m}$, $4 \mathrm{H}), 1.66(\mathrm{q}, 2 \mathrm{H}, \mathrm{J}=6.8), 1.55(\mathrm{q}, 2 \mathrm{H}, \mathrm{J}=6.8), 1.35(\mathrm{~m}, 6 \mathrm{H}) .{ }^{13} \mathrm{C}-\mathrm{RMN}(125$ MHz,CD $\left.{ }_{3} \mathrm{OD}\right), \delta(\mathrm{ppm}): 169.1(\mathrm{CONH}), 157.7$ (C), 153.9 (C), 150.5 (C), $149.4(\mathrm{C}), 146.5$ (C),142.0 (Cঠ), $130.5(\mathrm{CH}), 127.7(\mathrm{C}), 126.6(\mathrm{CH}), 124.9(\mathrm{CH}), 124.7(\mathrm{CH}), 123.3(\mathrm{CH})$, $120.5(\mathrm{C}), 118.4(\mathrm{C} \gamma \mathrm{H}), 116.5(\mathrm{CH}), 115.9(\mathrm{C}), 111.3(\mathrm{CH}), 56.3\left(\mathrm{OCH}_{3}\right), 49.5\left(\mathrm{CaH}_{2}\right)$, $40.4\left(\mathrm{C} \mathrm{H}_{2}\right), 33.3\left(\mathrm{CH}_{2}\right), 32.1\left(\mathrm{CH}_{2}\right), 30.3\left(\mathrm{CH}_{2}\right), 30.0\left(\mathrm{CH}_{2}\right), 27.8\left(\mathrm{CH}_{2}\right), 27.8\left(\mathrm{CH}_{2}\right)$, $25.8\left(\mathrm{CH}_{2}\right), 23.8\left(\mathrm{CH}_{2}\right), 23.4\left(\mathrm{CH}_{2}\right)$. Los datos se recogen en las Tablas XII y XII (ver apartado 2.8 Tablas).

\section{(E)-3-(4-Hidroxi-3-metoxifenil)- $N$-[8-(1,2,3,4-tetrahidroacridin-9-ilamino)octil] acrilamida (33)}

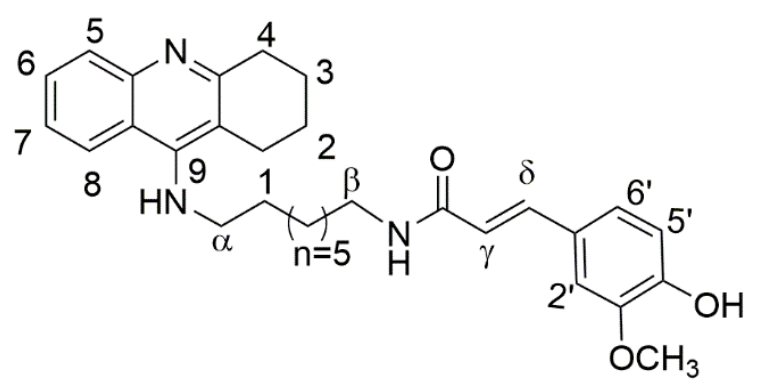

Siguiendo el procedimiento general, a partir del ácido ferúlico $(89.3 \mathrm{mg}, 0.46$ mmol), DCC (124 mg, $0.60 \mathrm{mmol}), \mathrm{N}$ -

(1,2,3,4-tetrahidroacridin-9-il)-1,8-octanodiamina (150 mg, $0.46 \mathrm{mmol})$ y $\mathrm{Et}_{3} \mathrm{~N}$ (120 $\mu \mathrm{L}, 0.92 \mathrm{mmol})$, después de 24 horas se obtuvo un aceite que se purificó mediante cromatografía a presión en columna sobre gel de sílice empleando como eluyente una mezcla de acetato de etilo : metanol (10:1). Se aislaron $122.3 \mathrm{mg}(53 \%)$ de 33 como un sólido amarillo. p. f. 80 - $82^{\circ} \mathrm{C}$ HPLC: pureza (83\%). MS : m/z = $502[\mathrm{M}+\mathrm{H}]^{+} .{ }^{1} \mathrm{H}-\mathrm{RMN}\left(500 \mathrm{MHz}, \mathrm{CD}_{3} \mathrm{OD}\right), \delta(\mathrm{ppm}): 8.11\left(\mathrm{dd}, 1 \mathrm{H}_{8}\right.$, $\mathrm{J}=8.6, \mathrm{~J}=1.2), 7.76\left(\mathrm{dd}, 1 \mathrm{H}_{5}, \mathrm{~J}=8.6, \mathrm{~J}=1.2\right), 7.57\left(\mathrm{ddd}, 1 \mathrm{H}_{6}, \mathrm{~J}=8.6, \mathrm{~J}=7.7, \mathrm{~J}=1.2\right), 7.42$

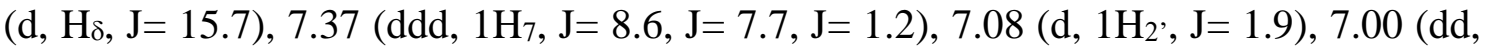
$\left.1 \mathrm{H}_{6}, \mathrm{~J}=8.1, \mathrm{~J}=1.9\right), 6.77\left(\mathrm{~d}, 1 \mathrm{H}_{5}, \mathrm{~J}=8.1\right), 6.41\left(\mathrm{~d}, \mathrm{H}_{\gamma}, \mathrm{J}=15.7\right), 3.86\left(\mathrm{~s}, 3 \mathrm{H}, \mathrm{OCH}_{3}\right), 3.57$ (t, 2H $\alpha, \mathrm{J}=7.2), 3.25\left(\mathrm{t}, 2 \mathrm{H}_{\beta}, \mathrm{J}=7.1\right), 2.97(\mathrm{~m}, 2 \mathrm{H}), 2.72(\mathrm{~m}, 2 \mathrm{H}), 1.90(\mathrm{~m}, 4 \mathrm{H}), 1.65$ (q, $2 \mathrm{H}, \mathrm{J}=7.2), 1.51(\mathrm{q}, 2 \mathrm{H}, \mathrm{J}=6.5), 1.35(\mathrm{~m}, 8 \mathrm{H}) .{ }^{13} \mathrm{C}-\mathrm{RMN}\left(125 \mathrm{MHz}, \mathrm{CD}_{3} \mathrm{OD}\right), \delta(\mathrm{ppm})$ : 
$169.1(\mathrm{CONH}), 157.9$ (C), 153.9 (C), 150.4 (C), $149.4(\mathrm{C}), 146.7$ (C),142.0 (C $\delta), 130.3$ (CH), $127.8(\mathrm{C}), 126.8(\mathrm{CH}), 124.9(\mathrm{CH}), 124.7(\mathrm{CH}), 123.2(\mathrm{CH}), 120.6(\mathrm{C}), 118.5$ $(\mathrm{C} \gamma \mathrm{H}), 116.6(\mathrm{CH}), 116.1(\mathrm{C}), 111.3(\mathrm{CH}), 56.3\left(\mathrm{OCH}_{3}\right), 49.6\left(\mathrm{C} \alpha H_{2}\right), 40.5\left(\mathrm{C}_{3} \mathrm{H}_{2}\right), 33.5$ $\left(\mathrm{CH}_{2}\right), 32.1\left(\mathrm{CH}_{2}\right), 30.4\left(\mathrm{CH}_{2}\right), 30.3\left(\mathrm{CH}_{2}\right), 30.2\left(\mathrm{CH}_{2}\right), 27.9\left(\mathrm{CH}_{2}\right), 27.8\left(\mathrm{CH}_{2}\right), 25.9$ $\left(\mathrm{CH}_{2}\right), 23.9\left(\mathrm{CH}_{2}\right), 23.4\left(\mathrm{CH}_{2}\right)$. Los datos se recogen en las Tablas XII y XII (ver apartado 2.8 Tablas).

\section{3-(4-HidroxifenII)- $N$-(4-(1,2,3,4-tetrahidroacridin-9-ilamino)butil)propanamida} (35)

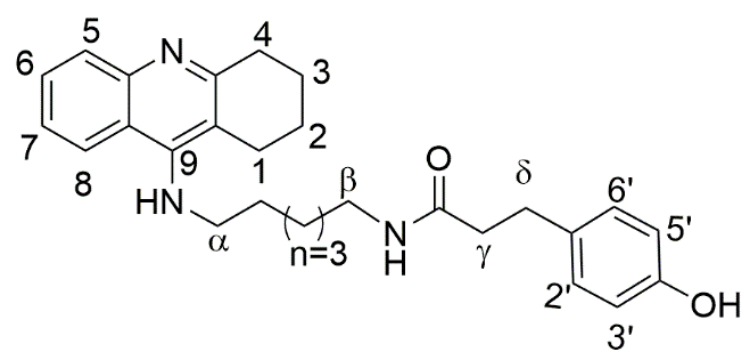

Siguiendo el procedimiento general, a partir del ácido 3-(4-hidroxifenil)propanoico $(75.5 \mathrm{mg}, 0.46 \mathrm{mmol}), \mathrm{DCC}$ (124 mg, $0.60 \mathrm{mmol}), \quad N-(1,2,3,4-$ tetrahidroacridin-9-il)-1,6-hexanodiamina (137 mg, $0.46 \mathrm{mmol})$ y Et ${ }_{3} \mathrm{~N}(120 \mu \mathrm{L}, 0.92$

mmol), después de 24 horas se obtuvo un aceite que se purificó mediante cromatografía a presión en columna sobre gel de sílice empleando como eluyente una mezcla de acetato de etilo : metanol (6:1). Se aislaron $12.3 \mathrm{mg}$ (6\%) de 35 como un sólido blanco. p. f. 60 $62{ }^{\circ} \mathrm{C}$ HPLC: pureza (99.8\%). MS : m/z $=446[\mathrm{M}+\mathrm{H}]^{+} .{ }^{1} \mathrm{H}-\mathrm{RMN}\left(400 \mathrm{MHz}, \mathrm{CD}_{3} \mathrm{OD}\right)$, $\delta(\mathrm{ppm}): 8.11\left(\mathrm{dd}, 1 \mathrm{H}_{8}, \mathrm{~J}=8.6, \mathrm{~J}=1.2\right), 7.76\left(\mathrm{dd}, 1 \mathrm{H}_{5}, \mathrm{~J}=8.6, \mathrm{~J}=1.2\right), 7.56\left(\mathrm{ddd}, 1 \mathrm{H}_{6}, \mathrm{~J}=\right.$ 8.6, $\mathrm{J}=7.8, \mathrm{~J}=1.2), 7.37\left(\mathrm{ddd}, 1 \mathrm{H}_{7}, \mathrm{~J}=8.6, \mathrm{~J}=7.8, \mathrm{~J}=1.2\right), 6.98(\mathrm{~d}, 2 \mathrm{H}, \mathrm{J}=8.6), 6.66(\mathrm{~d}$, $2 \mathrm{H}, \mathrm{J}=8.6), 3.54(\mathrm{t}, 2 \mathrm{H} \alpha, \mathrm{J}=7.2), 3.06\left(\mathrm{t}, 2 \mathrm{H}_{\beta}, \mathrm{J}=6.8\right), 2.97(\mathrm{~m}, 2 \mathrm{H}), 2.78\left(\mathrm{t}, 2 \mathrm{H}_{\gamma}, \mathrm{J}=7.6\right)$, $2.74(\mathrm{~m}, 2 \mathrm{H}), 2.38\left(\mathrm{t}, 2 \mathrm{H}_{\delta}, \mathrm{J}=7.6\right), 1.91(\mathrm{~m}, 4 \mathrm{H}), 1.62(\mathrm{q}, 2 \mathrm{H}, \mathrm{J}=7.2), 1.30(\mathrm{~m}, 6 \mathrm{H}),{ }^{13} \mathrm{C}$ -RMN (100 MHz, CD 3 OD), $\delta(\mathrm{ppm}): 175.3$ (CONH), $158.6(\mathrm{C}), 156.8(\mathrm{C}), 153.6$ (C), $147.4(\mathrm{C}), 132.8(\mathrm{C}), 130.4(2 \mathrm{CH}), 130.1(\mathrm{CH}), 127.4,(\mathrm{CH}), 124.8(\mathrm{CH}), 124.6(\mathrm{CH})$, $121.1(\mathrm{C}), 116.5(\mathrm{C}), 116.2(2 \mathrm{CH}), 49.7\left(\mathrm{CH}_{2}\right), 40.1\left(\mathrm{CH}_{2}\right), 39.3\left(\mathrm{CH}_{2}\right), 33.9\left(\mathrm{CH}_{2}\right), 32.2$ $\left(\mathrm{CH}_{2}\right), 32.2\left(\mathrm{CH}_{2}\right), 30.3\left(\mathrm{CH}_{2}\right), 27.6\left(\mathrm{CH}_{2}\right), 27.5\left(\mathrm{CH}_{2}\right), 26.1\left(\mathrm{CH}_{2}\right), 24.0\left(\mathrm{CH}_{2}\right), 23.6$ $\left(\mathrm{CH}_{2}\right)$. Análisis (\%): Calculado para $\mathrm{C}_{28} \mathrm{H}_{35} \mathrm{~N}_{3} \mathrm{O}_{2}: \mathrm{C}, 75.47$, H, 7.92, N, 9.43. Encontrado: C, 75.61, H, 7.77, N, 9.62. 


\section{3-(2-Hidroxifenil)- $N$-(4-(1,2,3,4-tetrahidroacridin-9-ilamino)hexil)propanamida}

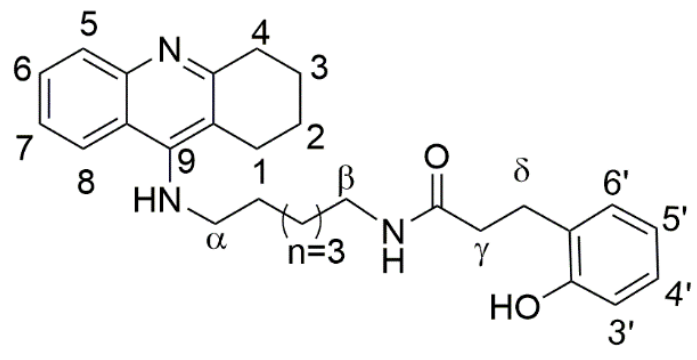

Siguiendo el procedimiento general, a partir del ácido 3-(2-hidroxifenil)propanoico (75.5 $\mathrm{mg}, 0.46 \mathrm{mmol})$, DCC (124 mg, $0.60 \mathrm{mmol})$,

$N$-(1,2,3,4-tetrahidroacridin-9-il)-1,6-hexanodiamina (137 mg, $0.46 \mathrm{mmol}) \mathrm{y} \mathrm{Et}_{3} \mathrm{~N}(120$ $\mu \mathrm{L}, 0.92 \mathrm{mmol})$, después de 24 horas se obtuvo un aceite que se purificó mediante cromatografía a presión en columna sobre gel de sílice empleando como eluyente una mezcla de acetato de etilo : metanol (6:1). Se aislaron $88.1 \mathrm{mg}$ (43\%) de 36 como un sólido blanco. p. f. 108 - $110{ }^{\circ} \mathrm{C}$ HPLC: pureza (99.7\%). MS : m/z = $446[\mathrm{M}+\mathrm{H}]^{+} .{ }^{1} \mathrm{H}-\mathrm{RMN}\left(400 \mathrm{MHz}, \mathrm{DMSO}-\mathrm{d}_{6}\right), \delta(\mathrm{ppm}): 9.31$ (s, $\mathrm{NH}), 8.10\left(\mathrm{dd}, 1 \mathrm{H}_{8}, \mathrm{~J}=8.6, \mathrm{~J}=1.2\right), 7.73(\mathrm{t}, \mathrm{NH}, \mathrm{J}=5.6), 7.68\left(\mathrm{dd}, 1 \mathrm{H}_{5}, \mathrm{~J}=8.6, \mathrm{~J}=1.2\right)$, $7.51\left(\mathrm{ddd}, 1 \mathrm{H}_{6}, \mathrm{~J}=8.6, \mathrm{~J}=7.8, \mathrm{~J}=1.2\right), 7.32$ (ddd, $1 \mathrm{H}_{7}, \mathrm{~J}=8.6, \mathrm{~J}=7.8, \mathrm{~J}=1.2$ ), 6.98 (dd, $1 \mathrm{H}, \mathrm{J}=7.6, \mathrm{~J}=1.5), 6.93(\mathrm{ddd}, 1 \mathrm{H}, \mathrm{J}=7.9, \mathrm{~J}=7.4, \mathrm{~J}=1.5), 6.72(\mathrm{dd}, 1 \mathrm{H}, \mathrm{J}=7.9, \mathrm{~J}=1.1)$, $6.62(\mathrm{ddd}, 1 \mathrm{H}, \mathrm{J}=7.6, \mathrm{~J}=7.4, \mathrm{~J}=1.1), 2.95(\mathrm{c}, 2 \mathrm{H} \alpha, \mathrm{J}=6.6), 2.88\left(\mathrm{t}, 2 \mathrm{H}_{\beta}, \mathrm{J}=6.0\right), 2.69$ (m, 2H), $2.68\left(\mathrm{t}, 2 \mathrm{H}_{\gamma}, \mathrm{J}=7.8\right), 2.74(\mathrm{~m}, 2 \mathrm{H}), 2.27(\mathrm{t}, 2 \mathrm{H} \delta, \mathrm{J}=7.8), 1.79(\mathrm{~m}, 4 \mathrm{H}), 1.59$ (m, 4H), $1.24(\mathrm{~m}, 4 \mathrm{H}) .{ }^{13} \mathrm{C}-\mathrm{RMN}$ (100 MHz, DMSO-d $)$ ), $(\mathrm{ppm}): 171.7$ (CONH), $156.7(\mathrm{C})$, $155.1(\mathrm{C}), 150.8(\mathrm{C}), 146.8(\mathrm{C}), 129.6(2 \mathrm{CH}), 128.3(\mathrm{C}), 127.5(\mathrm{CH}), 126.9(\mathrm{CH}), 123.4$ $(\mathrm{CH}), 123.2(\mathrm{CH}), 119.9(\mathrm{C}), 118.8(\mathrm{CH}), 115.5(\mathrm{C}), 114.9(\mathrm{CH}), 47.9\left(\mathrm{CH}_{2}\right), 38.3\left(\mathrm{CH}_{2}\right)$, $35.4\left(\mathrm{CH}_{2}\right), 33.4\left(\mathrm{CH}_{2}\right), 30.6\left(\mathrm{CH}_{2}\right), 29.1\left(\mathrm{CH}_{2}\right), 26.2\left(\mathrm{CH}_{2}\right), 26.1\left(\mathrm{CH}_{2}\right), 25.8\left(\mathrm{CH}_{2}\right), 25.4$ $\left(\mathrm{CH}_{2}\right), 24.5\left(\mathrm{CH}_{2}\right), 22.7\left(\mathrm{CH}_{2}\right), 22.3\left(\mathrm{CH}_{2}\right)$. Análisis (\%). $\mathrm{C}_{28} \mathrm{H}_{35} \mathrm{~N}_{3} \mathrm{O}_{2}: \mathrm{C}, 75.47, \mathrm{H}, 7.92$, N, 9.43. Encontrado: C, 75.49, H, 7.82, N, 9.52.

\section{3-(2-Hidroxifenil)- $N$-(4-(1,2,3,4-tetrahidroacridin-9-ilamino)heptil)propanamida}

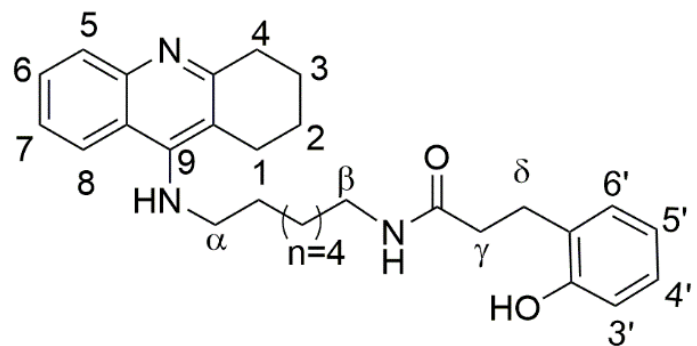

Siguiendo el procedimiento general, a partir del ácido 3-(2-hidroxifenil)propanoico (75.5 $\mathrm{mg}, 0.46 \mathrm{mmol}), \mathrm{DCC}$ (124 mg, $0.60 \mathrm{mmol})$, $N$-(1,2,3,4-tetrahidroacridin-9-il)-1,7-heptanodiamina (143 mg, $0.46 \mathrm{mmol})$ y Et $_{3} \mathrm{~N}$ (120 $\mu \mathrm{L}, 0.92 \mathrm{mmol}$ ), después de 24 horas se 
obtuvo un aceite que se purificó mediante cromatografía a presión en columna sobre gel de sílice empleando como eluyente una mezcla de acetato de etilo : metanol (6:1). Se aislaron $126.8 \mathrm{mg}(60 \%)$ de 37 como un sólido blanco. p. f. $100-102^{\circ} \mathrm{C}$ HPLC: pureza (99.9\%). MS : m/z = $460[\mathrm{M}+\mathrm{H}]^{+} .{ }^{1} \mathrm{H}-\mathrm{RMN}$ (400 MHz, DMSO-d 6 ), $\delta(\mathrm{ppm}): 9.32$ (s,

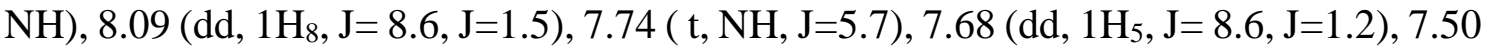
(ddd, $\left.1 \mathrm{H}_{6}, \mathrm{~J}=8.6, \mathrm{~J}=7.6, \mathrm{~J}=1.5\right), 7.30$ (ddd, 1H7, J=8.6, J=7.6, J=1.2), 7.00 (dd, 1H, J= 7.8, $\mathrm{J}=1.6$ ), 6.95 (ddd, 1H, $\mathrm{J}=7.8, \mathrm{~J}=7.4, \mathrm{~J}=1.6$ ), 6.73 (dd, $1 \mathrm{H}, \mathrm{J}=7.8, \mathrm{~J}=1.2$ ), 6.65 (ddd, 1H, J= 7.8, J= 7.4, J= 1.2), 2.96 (c, 2H $\alpha, \mathrm{J}=6.6$ ), 2.88 (t, 2H $\beta$, J=6.0), 2.69 (m, 2H), $2.68\left(\mathrm{t}, 2 \mathrm{H}_{\gamma}, \mathrm{J}=7.6\right), 2.49(\mathrm{~m}, 2 \mathrm{H}), 2.28\left(\mathrm{t}, 2 \mathrm{H}_{\delta}, \mathrm{J}=7.6\right), 1.84(\mathrm{~m}, 4 \mathrm{H}), 1.52(\mathrm{~m}, 2 \mathrm{H}), 1.24$ $(\mathrm{m}, 8 \mathrm{H}) .{ }^{13} \mathrm{C}-\mathrm{RMN}\left(100 \mathrm{MHz}, \mathrm{DMSO}-\mathrm{d}_{6}\right), \delta(\mathrm{ppm}): 171.6(\mathrm{CONH}), 157.7(\mathrm{C}), 155.1(\mathrm{C})$, $150.5(\mathrm{C}), 146.7(\mathrm{C}), 129.6(\mathrm{CH}), 128.1(\mathrm{CH}), 128.0(\mathrm{C}), 127.5(\mathrm{C}), 126.9(\mathrm{CH}), 123.2$ $(\mathrm{CH}), 123.1(\mathrm{CH}), 120.2(\mathrm{C}), 118.8(\mathrm{CH}), 115.7(\mathrm{C}), 114.9(\mathrm{CH}), 47.9\left(\mathrm{CH}_{2}\right), 38.4\left(\mathrm{CH}_{2}\right)$, $35.4\left(\mathrm{CH}_{2}\right), 33.4\left(\mathrm{CH}_{2}\right), 30.6\left(\mathrm{CH}_{2}\right), 29.1\left(\mathrm{CH}_{2}\right), 28.5\left(\mathrm{CH}_{2}\right), 26.3\left(2 \mathrm{CH}_{2}\right), 25.8\left(\mathrm{CH}_{2}\right)$, $25.1\left(\mathrm{CH}_{2}\right), 22.7\left(\mathrm{CH}_{2}\right), 22.5\left(\mathrm{CH}_{2}\right), 22.4\left(\mathrm{CH}_{2}\right)$. Análisis (\%): Calculado para $\mathrm{C}_{29} \mathrm{H}_{37} \mathrm{~N}_{3} \mathrm{O}_{2}$ : C, 75.78, H, 8.11, N, 9.14. Encontrado: C, 75.66, H, 8.02, N, 9.22.

\section{3-(2-Hidroxifenil)- $N$-(4-(1,2,3,4-tetrahidroacridin-9-ilamino)octil)propanamida(38)}

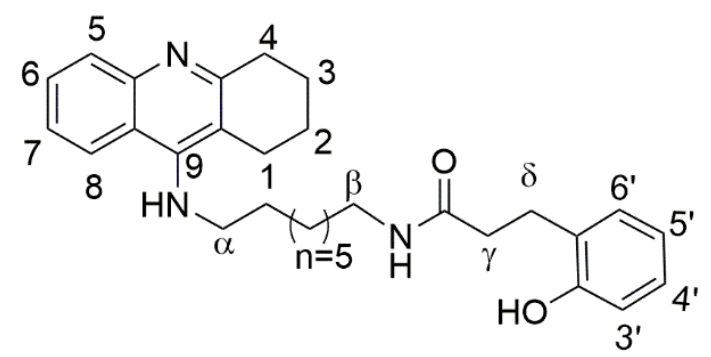

Siguiendo el procedimiento general, a partir del ácido 3-(2-hidroxifenil)propanoico (75.5 $\mathrm{mg}, 0.46 \mathrm{mmol}), \mathrm{DCC}(124 \mathrm{mg}, 0.60 \mathrm{mmol})$, $N$-(1,2,3,4-tetrahidroacridin-9-il)-1,8-octanodiamina (150 mg, $0.46 \mathrm{mmol}) \mathrm{y} \mathrm{Et}_{3} \mathrm{~N}$ (120 $\mu \mathrm{L}, 0.92 \mathrm{mmol}$ ), después de 24 horas se obtuvo un aceite que se purificó mediante cromatografía a presión en columna sobre gel de sílice empleando como eluyente una mezcla de acetato de etilo : metanol (6:1). Se aislaron $141.6 \mathrm{mg}(65 \%)$ de 38 como un sólido blanco. p. f. $96-98{ }^{\circ} \mathrm{C}$ HPLC: pureza (99.7\%). MS : m/z = $474[\mathrm{M}+\mathrm{H}]^{+} .{ }^{1} \mathrm{H}-\mathrm{RMN}$ (400 MHz, CD $\left.{ }_{3} \mathrm{OD}\right), \delta(\mathrm{ppm}): 8.07$ (dd, $\left.1 \mathrm{H}_{8}, \mathrm{~J}=8.6, \mathrm{~J}=1.0\right), 7.75\left(\mathrm{dd}, 1 \mathrm{H}_{5}, \mathrm{~J}=8.6, \mathrm{~J}=1.0\right), 7.53\left(\mathrm{ddd}, 1 \mathrm{H}_{6}, \mathrm{~J}=8.6, \mathrm{~J}=7.7, \mathrm{~J}=1.0\right)$, $7.34\left(\mathrm{ddd}, 1 \mathrm{H}_{7}, \mathrm{~J}=8.6, \mathrm{~J}=7.7, \mathrm{~J}=1.0\right), 7.02(\mathrm{dd}, 1 \mathrm{H}, \mathrm{J}=7.5, \mathrm{~J}=1.6), 6.96(\mathrm{ddd}, 1 \mathrm{H}, \mathrm{J}=$ 8.0, $\mathrm{J}=7.0, \mathrm{~J}=1.6$ ), $6.72(\mathrm{dd}, 1 \mathrm{H}, \mathrm{J}=8.0, \mathrm{~J}=1.0$ ), $6.68(\mathrm{ddd}, 1 \mathrm{H}, \mathrm{J}=7.5, \mathrm{~J}=7.0, \mathrm{~J}=1.0$ ), $3.50(\mathrm{t}, 2 \mathrm{H \alpha}, \mathrm{J}=7.2), 3.07\left(\mathrm{t}, 2 \mathrm{H}_{\beta}, \mathrm{J}=7.1\right), 2.96(\mathrm{~m}, 2 \mathrm{H}), 2.86\left(\mathrm{t}, 2 \mathrm{H}_{\gamma}, \mathrm{J}=7.6\right), 2.72(\mathrm{~m}$, $2 \mathrm{H}), 2.45(\mathrm{t}, 2 \mathrm{H} \delta, \mathrm{J}=7.6), 1.86(\mathrm{~m}, 2 \mathrm{H}), 1.66(\mathrm{~m}, 2 \mathrm{H}), 1.57(\mathrm{~m}, 2 \mathrm{H}), 1.24(\mathrm{~m}, 10 \mathrm{H}) .{ }^{13} \mathrm{C}-$ 
RMN (100 MHz, CD 3 OD), $\delta(\mathrm{ppm}): 175.7$ (CONH), 159.1 (C), $156.4(\mathrm{C}), 153.2$ (C), $147.9(\mathrm{C}), 131.1(\mathrm{CH}), 129.7(\mathrm{CH}), 128.4(\mathrm{C}), 128.3(\mathrm{CH}), 128.0(\mathrm{CH}), 124.6(\mathrm{CH}), 124.4$ $(\mathrm{CH}), 121.3(\mathrm{C}), 120.5(\mathrm{CH}), 116.7(\mathrm{C}), 116.1(\mathrm{CH}), 49.7\left(\mathrm{CH}_{2}\right), 40.3\left(\mathrm{CH}_{2}\right), 37.4\left(\mathrm{CH}_{2}\right)$, $34.8\left(\mathrm{CH}_{2}\right), 34.2\left(\mathrm{CH}_{2}\right), 30.3\left(\mathrm{CH}_{2}\right), 30.2\left(\mathrm{CH}_{2}\right), 27.8\left(\mathrm{CH}_{2}\right), 27.7\left(2 \mathrm{CH}_{2}\right), 26.7\left(\mathrm{CH}_{2}\right)$, $26.2\left(\mathrm{CH}_{2}\right), 26.1\left(\mathrm{CH}_{2}\right), 24.1\left(\mathrm{CH}_{2}\right), 23.7\left(\mathrm{CH}_{2}\right)$. Análisis (\%): Calculado para $\mathrm{C}_{30} \mathrm{H}_{39} \mathrm{~N}_{3} \mathrm{O}_{2}$ : C, 76.07, H, 8.30, N, 8.87. Encontrado: C, 75.83, H, 8.03, N, 8.75.

\section{3-(2-Hidroxifenil)- $N$-(4-(1,2,3,4-tetrahidroacridin-9-ilamino)nonil)propanamida} (39)

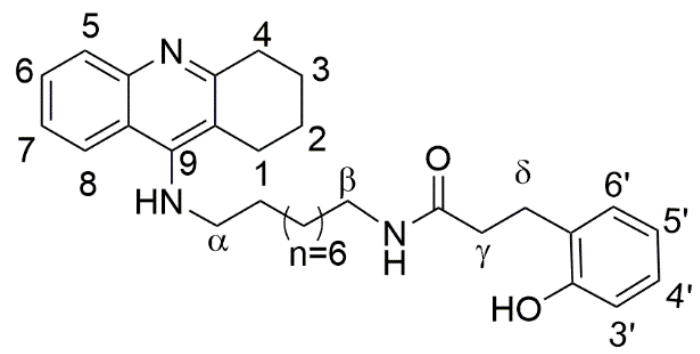

Siguiendo el procedimiento general, , a partir del ácido 3-(2-hidroxifenil)propanoico (75.5 $\mathrm{mg}, 0.46 \mathrm{mmol}), \mathrm{DCC}$ (124 mg, $0.60 \mathrm{mmol})$,

$N$-(1,2,3,4-tetrahidroacridin-9-il)-1,9-nonanodiamina (156 mg, $0.46 \mathrm{mmol}) \mathrm{y} \mathrm{Et}_{3} \mathrm{~N}$ (120 $\mu \mathrm{L}, 0.92 \mathrm{mmol}$ ), después de 24 horas se obtuvo un aceite que se purificó mediante cromatografía a presión en columna sobre gel de sílice empleando como eluyente una mezcla de acetato de etilo : metanol (6:1). Se aislaron $123.4 \mathrm{mg}(55 \%)$ de 39 como un sólido blanco. p. f. $38-40{ }^{\circ} \mathrm{C}$ HPLC: pureza (99.6\%). MS : m/z = $488[\mathrm{M}+\mathrm{H}]^{+} .{ }^{1} \mathrm{H}-\mathrm{RMN}$ (400 MHz, CD $\left.{ }_{3} \mathrm{OD}\right), \delta(\mathrm{ppm}): 8.10$ (dd, $\left.1 \mathrm{H}_{8}, \mathrm{~J}=8.6, \mathrm{~J}=0.8\right), 7.74\left(\mathrm{dd}, 1 \mathrm{H}_{5}, \mathrm{~J}=8.6, \mathrm{~J}=1.2\right), 7.56\left(\mathrm{ddd}, 1 \mathrm{H}_{6}, \mathrm{~J}=8.6, \mathrm{~J}=7.6, \mathrm{~J}=0.8\right)$, $7.36\left(\mathrm{ddd}, 1 \mathrm{H}_{7}, \mathrm{~J}=8.6, \mathrm{~J}=7.6, \mathrm{~J}=1.2\right), 7.02(\mathrm{dd}, 1 \mathrm{H}, \mathrm{J}=8.0, \mathrm{~J}=1.7), 6.96$ (ddd, 1H, J= $8.0, \mathrm{~J}=7.5, \mathrm{~J}=1.7), 6.72(\mathrm{dd}, 1 \mathrm{H}, \mathrm{J}=8.0, \mathrm{~J}=1.2), 6.68(\mathrm{ddd}, 1 \mathrm{H}, \mathrm{J}=8.0, \mathrm{~J}=7.5, \mathrm{~J}=1.2$ ), $3.56(\mathrm{t}, 2 \mathrm{H \alpha}, \mathrm{J}=7.2), 3.08\left(\mathrm{t}, 2 \mathrm{H}_{\beta}, \mathrm{J}=7.0\right), 2.93(\mathrm{~m}, 2 \mathrm{H}), 2.86\left(\mathrm{t}, 2 \mathrm{H}_{\gamma}, \mathrm{J}=7.4\right), 2.69$ (m, $2 \mathrm{H}), 2.45(\mathrm{t}, 2 \mathrm{H} \delta, \mathrm{J}=7.4), 1.91(\mathrm{~m}, 4 \mathrm{H}), 1.63(\mathrm{~m}, 2 \mathrm{H}), 1.57(\mathrm{~m}, 2 \mathrm{H}), 1.30(\mathrm{~m}, 12 \mathrm{H}) .{ }^{13} \mathrm{C}-$ RMN (100 MHz, CD 3 OD), $\delta(\mathrm{ppm}): 175.7$ (CONH), 157.7 (C), 156.4 (C), 154.1 (C), $146.4(\mathrm{C}), 131.1(\mathrm{CH}), 130.5(\mathrm{CH}), 128.4(2 \mathrm{CH}), 128.1(\mathrm{C}), 124.9(\mathrm{CH}), 124.8(\mathrm{CH})$, $120.8(\mathrm{C}), 120.5(\mathrm{CH}), 117.1(\mathrm{C}), 116.1(\mathrm{CH}), 49.6\left(\mathrm{CH}_{2}\right), 40.3\left(\mathrm{CH}_{2}\right), 37.4\left(\mathrm{CH}_{2}\right), 33.3$ $\left(\mathrm{CH}_{2}\right), 32.2\left(\mathrm{CH}_{2}\right), 30.5\left(\mathrm{CH}_{2}\right), 30.3\left(2 \mathrm{CH}_{2}\right), 30.2\left(\mathrm{CH}_{2}\right), 27.8\left(2 \mathrm{CH}_{2}\right), 27.7\left(\mathrm{CH}_{2}\right), 25.9$ $\left(\mathrm{CH}_{2}\right), 23.9\left(\mathrm{CH}_{2}\right), 23.4\left(\mathrm{CH}_{2}\right)$. Análisis (\%): Calculado para $\mathrm{C}_{31} \mathrm{H}_{41} \mathrm{~N}_{3} \mathrm{O}_{2}: \mathrm{C}, 76.35, \mathrm{H}$, 8.47, N, 8.62. Encontrado: C, 76.41, H, 8.53, N, 8.77. 


\section{2-(2-Hidroxifenil)- $N$-(6-(1,2,3,4-tetrahidroacridin-9-ilamino)hexil)acetamida (40)}

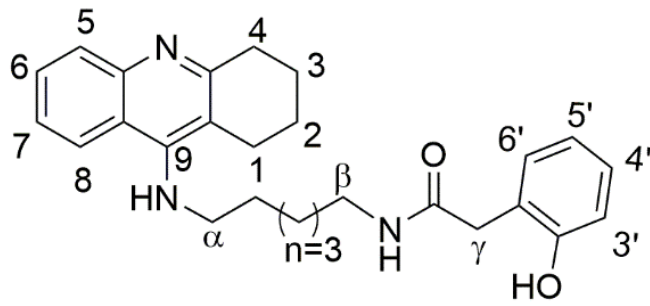

Siguiendo el procedimiento general, a partir del ácido 2-(2-hidroxifenil)acetico (70.0 mg, 0.46 mmol), DCC (124 mg, $0.60 \mathrm{mmol}), N-(1,2,3,4-$ tetrahidroacridin-9-il)-1,6-hexanodiamina (137 $\mathrm{mg}, 0.46 \mathrm{mmol})$ y $\mathrm{Et}_{3} \mathrm{~N}(120 \mu \mathrm{L}, 0.92 \mathrm{mmol})$, después de 24 horas se obtuvo un aceite que se purificó mediante cromatografía a presión en columna sobre gel de sílice empleando como eluyente una mezcla de acetato de etilo : metanol (6:1). Se aislaron $33.7 \mathrm{mg}$ (17\%) de 40 como un sólido blanco. p. f. $58-60{ }^{\circ} \mathrm{C}$ HPLC: pureza (99.7\%). MS : m/z = $432[\mathrm{M}+\mathrm{H}]^{+} .{ }^{1} \mathrm{H}-\mathrm{RMN}\left(400 \mathrm{MHz}, \mathrm{CD}_{3} \mathrm{OD}\right)$, $\delta(\mathrm{ppm}): 8.22\left(\mathrm{~d}, 1 \mathrm{H}_{8}, \mathrm{~J}=8.6\right), 7.75\left(\mathrm{~d}, 1 \mathrm{H}_{5}, \mathrm{~J}=8.4\right), 7.71\left(\mathrm{dd}, 1 \mathrm{H}_{6}, \mathrm{~J}=8.4, \mathrm{~J}=7.6\right), 7.47$ $\left(\mathrm{dd}, 1 \mathrm{H}_{7}, \mathrm{~J}=8.6, \mathrm{~J}=7.6\right), 7.08(\mathrm{~d}, 1 \mathrm{H}, \mathrm{J}=8.0), 7.02(\mathrm{dd}, 1 \mathrm{H}, \mathrm{J}=8.2, \mathrm{~J}=7.5), 6.76(\mathrm{~d}, 1 \mathrm{H}$, $\mathrm{J}=8.2), 6.72(\mathrm{dd}, 1 \mathrm{H}, \mathrm{J}=8.0, \mathrm{~J}=7.5), 3.71(\mathrm{t}, 2 \mathrm{H \alpha}, \mathrm{J}=7.2), 3.48\left(\mathrm{~s}, 2 \mathrm{H}_{\gamma}\right), 3.15\left(\mathrm{t}, 2 \mathrm{H}_{\beta}, \mathrm{J}=\right.$ 7.0), $2.98(\mathrm{~m}, 2 \mathrm{H}), 2.69(\mathrm{~m}, 2 \mathrm{H}),, 1.91(\mathrm{~m}, 4 \mathrm{H}), 1.70(\mathrm{~m}, 2 \mathrm{H}), 1.47(\mathrm{~m}, 2 \mathrm{H}), 1.33(\mathrm{~m}$, $4 \mathrm{H}) .{ }^{13} \mathrm{C}-\mathrm{RMN}\left(100 \mathrm{MHz}, \mathrm{CD}_{3} \mathrm{OD}\right), \delta(\mathrm{ppm}): 174.8$ (CONH), $156.8(\mathrm{C}), 155.9(\mathrm{C}), 154.1$ (C), $143.3(\mathrm{C}), 132.2(\mathrm{CH}), 131.8(\mathrm{CH}), 131.5(\mathrm{CH}), 129.4(\mathrm{CH}), 128.7(\mathrm{CH}), 125.6(\mathrm{CH})$, $123.4(\mathrm{C}), 120.7(\mathrm{CH}), 118.9(\mathrm{C}), 117.9(\mathrm{C}), 116.5(\mathrm{CH}), 49.6\left(\mathrm{CH}_{2}\right), 40.2\left(\mathrm{CH}_{2}\right), 39.3$ $\left(\mathrm{CH}_{2}\right), 31.7\left(\mathrm{CH}_{2}\right), 31.4\left(\mathrm{CH}_{2}\right), 30.1\left(\mathrm{CH}_{2}\right), 27.3\left(2 \mathrm{CH}_{2}\right), 25.4\left(\mathrm{CH}_{2}\right), 23.5\left(\mathrm{CH}_{2}\right), 22.6$ $\left(\mathrm{CH}_{2}\right)$. Análisis (\%): Calculado para $\mathrm{C}_{27} \mathrm{H}_{33} \mathrm{~N}_{3} \mathrm{O}_{2}$ : C, 75.14, H, 7,71, N,9.74. Encontrado: C, 75.31, H, 7,77, N, 9.62.

\section{2-(2-Hidroxifenil)- $N$-(6-(1,2,3,4-tetrahidroacridin-9-ilamino)heptil)acetamida (41)}

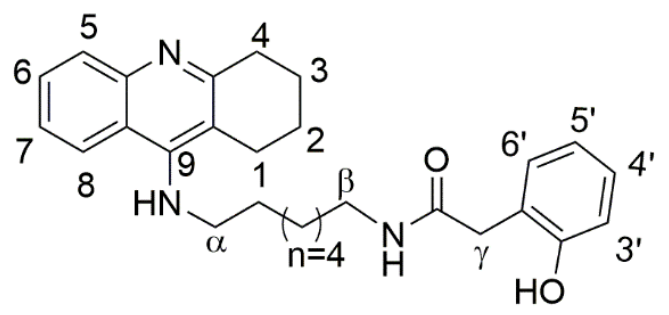

Siguiendo el procedimiento general, a partir del ácido 2-(2-hidroxifenil)acetico (70.0 mg, 0.46 mmol), DCC (124 mg, $0.60 \mathrm{mmol}), N-(1,2,3,4-$ tetrahidroacridin-9-il)-1,7-heptanodiamina (143 mg, $0.46 \mathrm{mmol})$ y $\mathrm{Et}_{3} \mathrm{~N}(120 \mu \mathrm{L}, 0.92$ mmol), después de 24 horas se obtuvo un aceite que se purificó mediante cromatografía a presión en columna sobre gel de sílice empleando como eluyente una mezcla de acetato de etilo : metanol (6:1). Se aislaron $63.5 \mathrm{mg}$ (31\%) de 41 como un sólido blanco. p. f. 114 - $116{ }^{\circ} \mathrm{C}$ HPLC: pureza (99.9\%). MS : m/z = $446[\mathrm{M}+\mathrm{H}]^{+} .{ }^{1} \mathrm{H}-\mathrm{RMN}(400 \mathrm{MHz}$, $\left.\mathrm{CD}_{3} \mathrm{OD}\right), \delta(\mathrm{ppm}): 8.09\left(\mathrm{dd}, 1 \mathrm{H}_{8}, \mathrm{~J}=8.6, \mathrm{~J}=1.0\right), 7.75\left(\mathrm{dd}, 1 \mathrm{H}_{5}, \mathrm{~J}=8.6, \mathrm{~J}=1.0\right), 7.56$ (ddd, 
$\left.1 \mathrm{H}_{6}, \mathrm{~J}=8.6, \mathrm{~J}=7.7, \mathrm{~J}=1.0\right), 7.36\left(\mathrm{ddd}, 1 \mathrm{H}_{7}, \mathrm{~J}=8.6, \mathrm{~J}=7.7, \mathrm{~J}=1.0\right), 7.08(\mathrm{~d}, 1 \mathrm{H}, \mathrm{J}=7.4, \mathrm{~J}=$ 1.6), 7.04 (ddd, 1H, J= 8.0, J= 7.8, J= 1.6), 6.78 (dd, 1H, J=8.0, J=1.2), 6.75 (ddd, $1 \mathrm{H}$, $\mathrm{J}=7.8, \mathrm{~J}=7.4, \mathrm{~J}=1.2), 3.53(\mathrm{t}, 2 \mathrm{H} \alpha, \mathrm{J}=7.2), 3.48\left(\mathrm{~s}, 2 \mathrm{H}_{\gamma}\right), 3.12\left(\mathrm{t}, 2 \mathrm{H}_{\beta}, \mathrm{J}=7.0\right), 2.97(\mathrm{~m}$, 2H), 2.72 (m, 2H), , 1.90 (m, 4H), 1.60 (q, 2H, J= 7.0), 1.42 (q, 2H, J= 7.0), 1.27 (m, 6H). ${ }^{13} \mathrm{C}-\mathrm{RMN}\left(100 \mathrm{MHz}, \mathrm{CD}_{3} \mathrm{OD}\right), \delta(\mathrm{ppm}): 174.8$ (CONH), $158.5(\mathrm{C}), 156.9(\mathrm{C}), 153.6(\mathrm{C})$, $147.3(\mathrm{C}), 131.8(\mathrm{CH}), 130.1(\mathrm{CH}), 129.4(\mathrm{CH}), 127.4(\mathrm{CH}), 124.8(\mathrm{CH}), 124.6(\mathrm{CH})$, $123.5(\mathrm{C}), 121.0(\mathrm{C}), 120.7(\mathrm{CH}), 116.6(\mathrm{CH}), 116.5(\mathrm{C}), 49.9\left(\mathrm{CH}_{2}\right), 40.4\left(\mathrm{CH}_{2}\right), 39.3$ $\left(\mathrm{CH}_{2}\right), 33.8\left(\mathrm{CH}_{2}\right), 32.1\left(\mathrm{CH}_{2}\right), 30.1\left(\mathrm{CH}_{2}\right), 29.9\left(\mathrm{CH}_{2}\right), 27.8\left(\mathrm{CH}_{2}\right), 27.6\left(\mathrm{CH}_{2}\right), 26.0$ $\left(\mathrm{CH}_{2}\right)$, $24.0\left(\mathrm{CH}_{2}\right), 23.6\left(\mathrm{CH}_{2}\right)$ Análisis (\%): Calculado para $\mathrm{C}_{28} \mathrm{H}_{35} \mathrm{~N}_{3} \mathrm{O}_{2}: \mathrm{C}, 75.47, \mathrm{H}$, 7,92, N, 9.43. Encontrado: C, 75.53, H, 7,76, N, 9.52.

\section{2-(2-Hidroxifenil)- $N$-(6-(1,2,3,4-tetrahidroacridin-9-ilamino)octil)acetamida (42)}

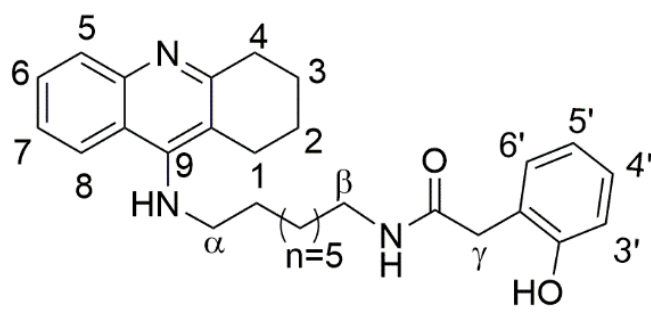

después de 24 horas se obtuvo un aceite que se purificó mediante cromatografía a presión en columna sobre gel de sílice empleando como eluyente una mezcla de acetato de etilo : metanol (6:1). Se aislaron $116.2 \mathrm{mg}$ (55\%) de 42 como un sólido blanco. p. f. $40-42{ }^{\circ} \mathrm{C}$ HPLC: pureza (99.6\%). MS : m/z $=460[\mathrm{M}+\mathrm{H}]^{+} .{ }^{1} \mathrm{H}-\mathrm{RMN}\left(400 \mathrm{MHz}, \mathrm{CD}_{3} \mathrm{OD}\right)$, $\delta(\mathrm{ppm}): 8.16\left(\mathrm{dd}, 1 \mathrm{H}_{8}, \mathrm{~J}=8.0, \mathrm{~J}=1.2\right), 7.75\left(\mathrm{dd}, 1 \mathrm{H}_{5}, \mathrm{~J}=8.6, \mathrm{~J}=1.2\right), 7.62\left(\mathrm{ddd}, 1 \mathrm{H}_{6}, \mathrm{~J}=\right.$ 8.6, $\mathrm{J}=7.8, \mathrm{~J}=1.2), 7.41\left(\mathrm{ddd}, 1 \mathrm{H}_{7}, \mathrm{~J}=8.0, \mathrm{~J}=7.8, \mathrm{~J}=1.2\right), 7.09(\mathrm{dd}, 1 \mathrm{H}, \mathrm{J}=8.2, \mathrm{~J}=1.5)$, 7.04 (ddd, 1H, J= 8.2, J= 7.6, J= 1.5), 6.78 (dd, 1H, J= 8.2, J= 1.2), 6.74 (ddd, 1H, J=8.2, $\mathrm{J}=7.6, \mathrm{~J}=1.2), 3.62(\mathrm{t}, 2 \mathrm{H} \alpha, \mathrm{J}=7.2), 3.35\left(\mathrm{~s}, 2 \mathrm{H}_{\gamma}\right), 3.13\left(\mathrm{t}, 2 \mathrm{H}_{\beta}, \mathrm{J}=7.0\right), 2.97(\mathrm{~m}, 2 \mathrm{H})$, $2.72(\mathrm{~m}, 2 \mathrm{H}),, 1.92(\mathrm{~m}, 4 \mathrm{H}), 1.66$ (q, 2H, J= 7.2), 1.43 (q, 2H, J=6.9), $1.29(\mathrm{~m}, 8 \mathrm{H}) .{ }^{13} \mathrm{C}$ -RMN (100 MHz, CD 3 OD), $\delta(\mathrm{ppm}): 174.8$ (CONH), $157.1(\mathrm{C}), 156.8(\mathrm{C}), 154.5(\mathrm{C})$, $148.8(\mathrm{C}), 131.8(\mathrm{CH}), 131.5(\mathrm{CH}), 130.9(\mathrm{CH}), 129.4(\mathrm{CH}), 125.1(\mathrm{CH}), 125.0(\mathrm{CH})$, $123.4(\mathrm{C}), 120.8(\mathrm{CH}), 120.2(\mathrm{C}), 117.9(\mathrm{C}), 116.5(\mathrm{CH}), 49.7\left(\mathrm{CH}_{2}\right), 40.4\left(\mathrm{CH}_{2}\right), 39.3$ $\left(\mathrm{CH}_{2}\right), 32.9\left(\mathrm{CH}_{2}\right), 32.0\left(\mathrm{CH}_{2}\right), 30.2\left(2 \mathrm{CH}_{2}\right), 30.1\left(\mathrm{CH}_{2}\right), 27.7\left(\mathrm{CH}_{2}\right), 27.6\left(\mathrm{CH}_{2}\right), 25.8$ $\left(\mathrm{CH}_{2}\right), 23.8\left(\mathrm{CH}_{2}\right), 23.2\left(\mathrm{CH}_{2}\right)$. Análisis (\%): Calculado para $\mathrm{C}_{29} \mathrm{H}_{37} \mathrm{~N}_{3} \mathrm{O}_{2}: \mathrm{C}, 75.78, \mathrm{H}$, 8.11, N, 9.14. Encontrado: C, 75.53, H, 8.33, N, 8.89. 


\section{2-(2-Hidroxifenil)- $N$-(6-(1,2,3,4-tetrahidroacridin-9-ilamino)nonil)acetamida (43)}

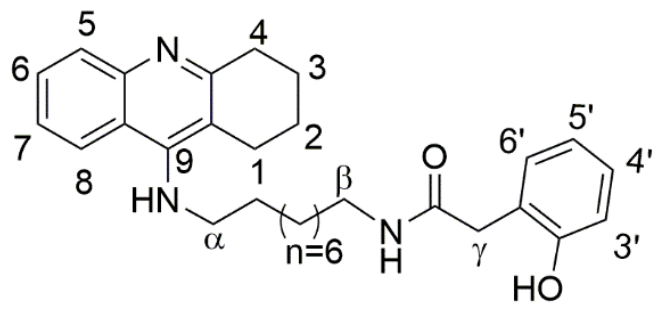

Siguiendo el procedimiento general, a partir del ácido 2-(2-hidroxifenil)acetico (70.0 mg, 0.46 mmol), DCC (124 mg, $0.60 \mathrm{mmol}), N-(1,2,3,4-$ tetrahidroacridin-9-il)-1,9-nonanodiamina (156 $\mathrm{mg}, 0.46 \mathrm{mmol})$ y Et ${ }_{3} \mathrm{~N}(120 \mu \mathrm{L}, 0.92 \mathrm{mmol})$, después de 24 horas se obtuvo un aceite que se purificó mediante cromatografía a presión en columna sobre gel de sílice empleando como eluyente una mezcla de acetato de etilo : metanol (6:1). Se aislaron $111.1 \mathrm{mg}(51 \%)$ de 43 como un sólido blanco. p. f. ${ }^{\circ} \mathrm{C}$ HPLC: pureza (99.6\%). MS : m/z = $474[\mathrm{M}+\mathrm{H}]^{+} .{ }^{1} \mathrm{H}-\mathrm{RMN}$ (400 MHz, CD $\left.3 \mathrm{OD}\right), \delta(\mathrm{ppm}): 8.06$ $\left(\mathrm{dd}, 1 \mathrm{H}_{8}, \mathrm{~J}=8.2, \mathrm{~J}=1.2\right), 7.75\left(\mathrm{dd}, 1 \mathrm{H}_{5}, \mathrm{~J}=8.2, \mathrm{~J}=1.2\right), 7.52\left(\mathrm{ddd}, 1 \mathrm{H}_{6}, \mathrm{~J}=8.2, \mathrm{~J}=7.6, \mathrm{~J}=\right.$ 1.2), 7.33 (ddd, $1 \mathrm{H}_{7}, \mathrm{~J}=8.6, \mathrm{~J}=7.6, \mathrm{~J}=1.2$ ), 7.08 (dd, 1H, $\mathrm{J}=8.0, \mathrm{~J}=1.6$ ), 7.04 (ddd, $1 \mathrm{H}$, $\mathrm{J}=8.2, \mathrm{~J}=7.5, \mathrm{~J}=1.6), 6.78(\mathrm{dd}, 1 \mathrm{H}, \mathrm{J}=8.2, \mathrm{~J}=1.2), 6.74(\mathrm{ddd}, 1 \mathrm{H}, \mathrm{J}=8.0, \mathrm{~J}=7.5, \mathrm{~J}=1.2$ ), $3.49(\mathrm{t}, 2 \mathrm{H} \alpha, \mathrm{J}=7.2), 3.48\left(\mathrm{~s}, 2 \mathrm{H}_{\gamma}\right), 3.11\left(\mathrm{t}, 2 \mathrm{H}_{\beta}, \mathrm{J}=7.0\right), 2.95(\mathrm{~m}, 2 \mathrm{H}), 2.69(\mathrm{~m}, 2 \mathrm{H}), 1.85$ $(\mathrm{m}, 4 \mathrm{H}), 1.58$ (q, 2H, J=7.4), 1.40 (q, 2H, J= 7.0), 1.24 (m, 10H). ${ }^{13} \mathrm{C}-\mathrm{RMN}(100 \mathrm{MHz}$, $\left.\mathrm{CD}_{3} \mathrm{OD}\right), \delta(\mathrm{ppm}): 173.6(\mathrm{CONH}), 157.7(\mathrm{C}), 155.8(\mathrm{C}), 152.2(\mathrm{C}), 146.6(\mathrm{C}), 130.6(\mathrm{CH})$, $128.7(\mathrm{CH}), 128.3(\mathrm{CH}), 126.6(\mathrm{CH}), 123.5(\mathrm{C}), 123.3(\mathrm{CH}), 122.3(\mathrm{CH}), 120.0(\mathrm{C}), 119.5$ $(\mathrm{CH}), 115.5(\mathrm{CH}), 115.4(\mathrm{C}), 48.5\left(\mathrm{CH}_{2}\right), 39.3\left(\mathrm{CH}_{2}\right), 38.2\left(\mathrm{CH}_{2}\right), 33.6\left(\mathrm{CH}_{2}\right), 32.9\left(\mathrm{CH}_{2}\right)$, $31.1\left(\mathrm{CH}_{2}\right), 29.3\left(\mathrm{CH}_{2}\right), 29.1\left(\mathrm{CH}_{2}\right), 29.0\left(\mathrm{CH}_{2}\right), 26.7\left(\mathrm{CH}_{2}\right), 26.6\left(\mathrm{CH}_{2}\right), 25.0\left(\mathrm{CH}_{2}\right), 22.9$ $\left(\mathrm{CH}_{2}\right)$, 22.6. $\left(\mathrm{CH}_{2}\right)$. Análisis (\%): Calculado para $\mathrm{C}_{30} \mathrm{H}_{93} \mathrm{~N}_{3} \mathrm{O}_{2}: \mathrm{C}, 76.07, \mathrm{H}, 8.30, \mathrm{~N}, 8.87$. Encontrado: C, 75.96, H, 8.32, N, 8.92.

\section{2-Hidroxi- $N$-(6-(1,2,3,4-tetrahidroacridin-9-ilamino)hexil)benzamida (44)}

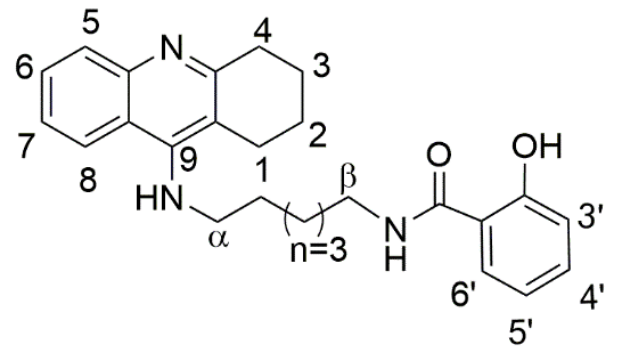

Siguiendo el procedimiento general, a partir del ácido 2-hidroxibenzoico (63.5 mg, $0.46 \mathrm{mmol})$, DCC $\quad(124 \quad \mathrm{mg}, \quad 0.60 \mathrm{mmol}), \quad N-(1,2,3,4-$ tetrahidroacridin-9-il)-1,6-hexanodiamina $\mathrm{mg}, 0.46 \mathrm{mmol})$ y $\mathrm{Et}_{3} \mathrm{~N}(120 \mu \mathrm{L}, 0.92 \mathrm{mmol})$, después de 24 horas se obtuvo un aceite que se purificó mediante cromatografía a presión en columna sobre gel de sílice empleando como eluyente una mezcla de acetato de etilo : metanol (6:1). Se aislaron $26.1 \mathrm{mg}$ (13\%) 
de 44 como un sólido blanco. p. f.68 - $70{ }^{\circ} \mathrm{C}$ HPLC: pureza (99.2\%). MS : m/z $=418$ [M $+\mathrm{H}]^{+} .{ }^{1} \mathrm{H}-\mathrm{RMN}\left(400 \mathrm{MHz}, \mathrm{CD}_{3} \mathrm{OD}\right), \delta(\mathrm{ppm}): 8.12\left(\mathrm{~d}, 1 \mathrm{H}_{8}, \mathrm{~J}=8.8\right), 7.71\left(\mathrm{~d}, 1 \mathrm{H}_{5}, \mathrm{~J}=8.0\right)$, $7.73\left(\mathrm{~d}, 1 \mathrm{H}_{3}, \mathrm{~J}=8.0\right), 7.57\left(\mathrm{dd}, 1 \mathrm{H}_{6}, \mathrm{~J}=8.0, \mathrm{~J}=7.1\right), 7.37\left(\mathrm{dd}, 1 \mathrm{H}_{7}, \mathrm{~J}=8.8, \mathrm{~J}=7.1\right), 7.25$ $\left(\mathrm{dd}, 1 \mathrm{H}_{5}, \mathrm{~J}=8.2 \mathrm{~J}=7.8\right), 6.81\left(\mathrm{~d}, 1 \mathrm{H}_{6}, \mathrm{~J}=8.2\right), 6.72\left(\mathrm{dd}, 1 \mathrm{H}_{4}, \mathrm{~J}=8.0, \mathrm{~J}=7.8\right), 3.59(\mathrm{t}$, $2 \mathrm{H} \alpha, \mathrm{J}=7.2), 3.34(\mathrm{t}, 2 \mathrm{H} \beta, \mathrm{J}=7.0), 2.94(\mathrm{~m}, 2 \mathrm{H}), 2.69(\mathrm{~m}, 2 \mathrm{H}), 1.90(\mathrm{~m}, 4 \mathrm{H}), 1.67(\mathrm{q}, 2 \mathrm{H}$, $\mathrm{J}=7.0), 1.58(\mathrm{q}, 2 \mathrm{H}, \mathrm{J}=6.8), 1.33(\mathrm{~m}, 4 \mathrm{H}) .{ }^{13} \mathrm{C}-\mathrm{RMN}\left(100 \mathrm{MHz}, \mathrm{CD}_{3} \mathrm{OD}\right), \delta(\mathrm{ppm}): 171.1$ (CONH), $163.7(\mathrm{C}), 157.2(\mathrm{C}), 155.3(\mathrm{C}), 145.9(\mathrm{C}), 134.3(\mathrm{CH}), 130.8(\mathrm{CH}), 129.2(\mathrm{CH})$, $126.0(\mathrm{CH}), 125.1(\mathrm{CH}), 124.9(\mathrm{CH}), 120.2(\mathrm{C}), 119.7(\mathrm{CH}), 118.4(\mathrm{C}), 117.8(\mathrm{CH}), 115.8$ (C), $49.6\left(\mathrm{CH}_{2}\right), 40.1\left(\mathrm{CH}_{2}\right), 33.0\left(\mathrm{CH}_{2}\right), 32.0\left(\mathrm{CH}_{2}\right), 30.4\left(\mathrm{CH}_{2}\right), 27.7\left(\mathrm{CH}_{2}\right), 27.5\left(\mathrm{CH}_{2}\right)$, $25.8\left(\mathrm{CH}_{2}\right), 23.8\left(\mathrm{CH}_{2}\right), 23.2\left(\mathrm{CH}_{2}\right)$. Análisis (\%): Calculado para $\mathrm{C}_{26} \mathrm{H}_{31} \mathrm{~N}_{3} \mathrm{O}_{2}: \mathrm{C}, 74.79$, H, 7,48, N, 10.06. Encontrado: C, 74.63, H, 7.51, N, 9.72.

\section{2-Hidroxi- $N$-(6-(1,2,3,4-tetrahidroacridin-9-ilamino)heptil)benzamida (45)}

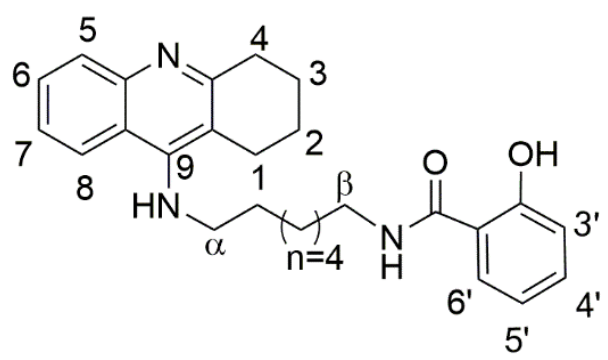

purificó mediante cromatografía a presión en columna sobre gel de sílice empleando como eluyente una mezcla de acetato de etilo : metanol (6:1). Se aislaron $23.8 \mathrm{mg}$ (12\%) de 45 como un sólido blanco. p. f. 42 - $44{ }^{\circ} \mathrm{C}$ HPLC: pureza (99.2\%). MS : m/z = 432 [M $+\mathrm{H}]^{+} .{ }^{1} \mathrm{H}-\mathrm{RMN}\left(400 \mathrm{MHz}, \mathrm{CD}_{3} \mathrm{OD}\right), \delta(\mathrm{ppm}): 8.08$ (dd, $\left.1 \mathrm{H}_{8}, \mathrm{~J}=8.6, \mathrm{~J}=1.2\right), 7.70$ (dd, $\left.1 \mathrm{H}_{5}, \mathrm{~J}=8.6, \mathrm{~J}=1.2\right), 7.73\left(\mathrm{dd}, 1 \mathrm{H}_{3}, \mathrm{~J}=8.2, \mathrm{~J}=1.6\right), 7.54\left(\mathrm{ddd}, 1 \mathrm{H}_{6}, \mathrm{~J}=8.6, \mathrm{~J}=7.6, \mathrm{~J}=\right.$ 1.2), 7.34 (ddd, $1 \mathrm{H}_{7}, \mathrm{~J}=8.6, \mathrm{~J}=7.6, \mathrm{~J}=1.2$ ), $7.24\left(\mathrm{ddd}, 1 \mathrm{H}_{5}, \mathrm{~J}=8.2, \mathrm{~J}=7.7, \mathrm{~J}=1.6\right), 6.80$ $\left(\mathrm{dd}, 1 \mathrm{H}_{6}, \mathrm{~J}=8.2, \mathrm{~J}=1.2\right), 6.71\left(\mathrm{ddd}, 1 \mathrm{H}_{4}, \mathrm{~J}=8.2, \mathrm{~J}=7.7, \mathrm{~J}=1.2\right), 3.94(\mathrm{t}, 2 \mathrm{H} \alpha, \mathrm{J}=7.4)$, $3.55\left(\mathrm{t}, 2 \mathrm{H}_{\beta}, \mathrm{J}=7.4\right), 2.92(\mathrm{~m}, 2 \mathrm{H}), 2.65(\mathrm{~m}, 2 \mathrm{H}), 1.89(\mathrm{~m}, 4 \mathrm{H}), 1.62(\mathrm{q}, 2 \mathrm{H}, \mathrm{J}=6.6), 1.53$ $(\mathrm{q}, 2 \mathrm{H}, \mathrm{J}=6.6), 1.13(\mathrm{~m}, 6 \mathrm{H}) .{ }^{13} \mathrm{C}-\mathrm{RMN}\left(100 \mathrm{MHz}, \mathrm{CD}_{3} \mathrm{OD}\right), \delta(\mathrm{ppm}): 171.0(\mathrm{CONH})$, $163.6(\mathrm{C}), 157.3(\mathrm{C}), 154.3(\mathrm{C}), 146.0(\mathrm{C}), 134.3(\mathrm{CH}), 130.7(\mathrm{CH}), 129.2(\mathrm{CH}), 126.1$ $(\mathrm{CH}), 125.0(\mathrm{CH}), 124.9(\mathrm{CH}), 120.3(\mathrm{C}), 119.6(\mathrm{CH}), 118.5(\mathrm{CH}), 117.8(\mathrm{C}), 115.8(\mathrm{C})$, $49.6\left(\mathrm{CH}_{2}\right), 40.2\left(\mathrm{CH}_{2}\right), 33.0\left(\mathrm{CH}_{2}\right), 32.0\left(\mathrm{CH}_{2}\right), 30.4\left(\mathrm{CH}_{2}\right), 30.0\left(\mathrm{CH}_{2}\right), 27.9\left(\mathrm{CH}_{2}\right), 27.7$ 
$\left(\mathrm{CH}_{2}\right), 25.8\left(\mathrm{CH}_{2}\right), 23.8\left(\mathrm{CH}_{2}\right)$. Análisis (\%): Calculado para $\mathrm{C}_{27} \mathrm{H}_{33} \mathrm{~N}_{3} \mathrm{O}_{2}: \mathrm{C}, 75.14, \mathrm{H}$, 7.71, N, 9.74. Encontrado: C, 75.11, H, 7,52, N, 9.81.

\section{2-Hidroxi- $N$-(6-(1,2,3,4-tetrahidroacridin-9-ilamino)octil)benzamida (46)}

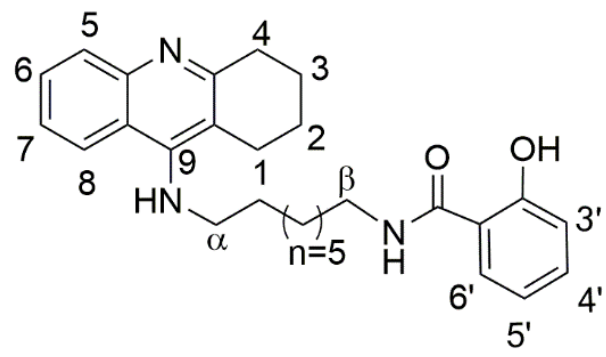

purificó mediante cromatografía a presión en columna sobre gel de sílice empleando como eluyente una mezcla de acetato de etilo : metanol (6:1). Se aislaron $26.6 \mathrm{mg}$ (13\%) de 46 como un sólido blanco. p. f. 48 - $50^{\circ} \mathrm{C}$ HPLC: pureza (100\%). MS : m/z = 446 [M $+\mathrm{H}]^{+} .{ }^{1} \mathrm{H}-\mathrm{RMN}\left(400 \mathrm{MHz}, \mathrm{CD}_{3} \mathrm{OD}\right), \delta(\mathrm{ppm}): 8.11$ (dd, $\left.1 \mathrm{H}_{8}, \mathrm{~J}=8.6, \mathrm{~J}=1.2\right), 7.73$ (dd, $\left.1 \mathrm{H}_{5}, \mathrm{~J}=8.2, \quad \mathrm{~J}=0.8\right), 7.72\left(\mathrm{dd}, 1 \mathrm{H}_{3}, \mathrm{~J}=8.2, \mathrm{~J}=1.6\right), 7.57\left(\mathrm{ddd}, 1 \mathrm{H}_{6}, \mathrm{~J}=8.2, \mathrm{~J}=7.6, \mathrm{~J}=\right.$ 1.2), $7.37\left(\mathrm{ddd}, 1 \mathrm{H}_{7}, \mathrm{~J}=8.6, \mathrm{~J}=7.6, \mathrm{~J}=0.8\right), 7.26\left(\mathrm{ddd}, 1 \mathrm{H}_{5}, \mathrm{~J}=8.2, \mathrm{~J}=7.5, \mathrm{~J}=1.6\right), 6.81$ $\left(\mathrm{dd}, 1 \mathrm{H}_{6}, \mathrm{~J}=8.2, \mathrm{~J}=1.2\right), 6.73\left(\mathrm{ddd}, 1 \mathrm{H}_{4}, \mathrm{~J}=8.2, \mathrm{~J}=7.5, \mathrm{~J}=1.2\right), 3.58(\mathrm{t}, 2 \mathrm{H} \alpha, \mathrm{J}=7.2)$, $3.36\left(\mathrm{t}, 2 \mathrm{H}_{\beta}, \mathrm{J}=7.0\right), 2.95(\mathrm{~m}, 2 \mathrm{H}), 2.70(\mathrm{~m}, 2 \mathrm{H}), 1.89(\mathrm{~m}, 4 \mathrm{H}), 1.64(\mathrm{q}, 2 \mathrm{H}, \mathrm{J}=7.0), 1.56$ $(\mathrm{q}, 2 \mathrm{H}, \mathrm{J}=7.0), 1.31(\mathrm{~m}, 8 \mathrm{H}) .{ }^{13} \mathrm{C}-\mathrm{RMN}\left(100 \mathrm{MHz}, \mathrm{CD}_{3} \mathrm{OD}\right), \delta(\mathrm{ppm}): 171.0(\mathrm{CONH})$, $163.5(\mathrm{C}), 157.5(\mathrm{C}), 154.3(\mathrm{C}), 146.2(\mathrm{C}), 134.3(\mathrm{CH}), 130.6(\mathrm{CH}), 129.2(\mathrm{CH}), 126.3$ $(\mathrm{CH}), 125.0(\mathrm{CH}), 124.9(\mathrm{CH}), 120.4(\mathrm{C}), 119.6(\mathrm{CH}), 118.6(\mathrm{CH}), 117.8(\mathrm{C}), 115.9(\mathrm{C})$, $49.6\left(\mathrm{CH}_{2}\right), 40.3\left(\mathrm{CH}_{2}\right), 33.1\left(\mathrm{CH}_{2}\right), 32.1\left(\mathrm{CH}_{2}\right), 30.4\left(\mathrm{CH}_{2}\right), 30.2\left(2 \mathrm{CH}_{2}\right), 27.9\left(\mathrm{CH}_{2}\right)$, $27.7\left(\mathrm{CH}_{2}\right), 25.9\left(\mathrm{CH}_{2}\right), 23.9\left(\mathrm{CH}_{2}\right), 23.3\left(\mathrm{CH}_{2}\right)$. Análisis (\%): Calculado para $\mathrm{C}_{28} \mathrm{H}_{35} \mathrm{~N}_{3} \mathrm{O}_{2}$ : C, 75.47, H, 7.92, N, 9.43. Encontrado: C, 75.66, H, 78.02, N, 9.21. 


\section{2-Hidroxi-N-(6-(1,2,3,4-tetrahidroacridin-9-ilamino)nonil)benzamida (47)}<smiles>O=C(NC(=O)C1CNc2c3c(nc4ccccc24)CCCC31)C1C=CCCC1</smiles>

$5^{\prime}$

Siguiendo el procedimiento general, a partir del ácido 2-hidroxibenzoico (63.5 mg, $0.46 \mathrm{mmol})$, DCC $\quad(124 \mathrm{mg}, \quad 0.60 \mathrm{mmol}), \quad N-(1,2,3,4-$ tetrahidroacridin-9-il)-1,6-nonanodiamina (156 $\mathrm{mg}, 0.46 \mathrm{mmol})$ y $\mathrm{Et}_{3} \mathrm{~N}(120 \mu \mathrm{L}, 0.92 \mathrm{mmol})$, después de 24 horas se obtuvo un aceite que se purificó mediante cromatografía a presión en columna sobre gel de sílice empleando como eluyente una mezcla de acetato de etilo : metanol (6:1). Se aislaron $23.3 \mathrm{mg}$ (11\%) de 47 como un sólido blanco. p. f. ${ }^{\circ} \mathrm{C}$ HPLC: pureza (99\%). MS : m/z $=460[\mathrm{M}+\mathrm{H}]^{+}$. ${ }^{1} \mathrm{H}-\mathrm{RMN}\left(400 \mathrm{MHz}, \mathrm{CD}_{3} \mathrm{OD}\right), \delta(\mathrm{ppm}): 8.13\left(\mathrm{dd}, 1 \mathrm{H}_{8}, \mathrm{~J}=8.6, \mathrm{~J}=1.2\right), 7.75\left(\mathrm{dd}, 1 \mathrm{H}_{5}, \mathrm{~J}=\right.$ 8.2, $\mathrm{J}=1.2), 7.74\left(\mathrm{dd}, 1 \mathrm{H}_{3}, \mathrm{~J}=8.2, \mathrm{~J}=1.2\right), 7.58\left(\mathrm{ddd}, 1 \mathrm{H}_{6}, \mathrm{~J}=8.2, \mathrm{~J}=7.6, \mathrm{~J}=1.2\right), 7.38$ $\left(\mathrm{ddd}, 1 \mathrm{H}_{7}, \mathrm{~J}=8.6, \mathrm{~J}=7.6, \mathrm{~J}=1.2\right), 7.26\left(\mathrm{ddd}, 1 \mathrm{H}_{5}, \mathrm{~J}=8.2, \mathrm{~J}=7.5, \mathrm{~J}=1.2\right), 6.82\left(\mathrm{dd}, 1 \mathrm{H}_{6}\right.$, $\mathrm{J}=8.2, \mathrm{~J}=0.8), 6.74\left(\mathrm{ddd}, 1 \mathrm{H}_{4}, \mathrm{~J}=8.2, \mathrm{~J}=7.5, \mathrm{~J}=0.8\right), 3.59(\mathrm{t}, 2 \mathrm{H} \alpha, \mathrm{J}=7.0), 3.35\left(\mathrm{t}, 2 \mathrm{H}_{\beta}\right.$, $\mathrm{J}=7.0), 2.95(\mathrm{~m}, 2 \mathrm{H}), 2.71(\mathrm{~m}, 2 \mathrm{H}), 1.90(\mathrm{~m}, 4 \mathrm{H}), 1.62(\mathrm{~m}, 4 \mathrm{H}), 1.32(\mathrm{~m}, 10 \mathrm{H}) .{ }^{13} \mathrm{C}-$ RMN (100 MHz, CD 3 OD), $\delta(\mathrm{ppm}): 171.1$ (CONH), 163.4 (C), 157.5 (C), 154.3 (C), $146.2(\mathrm{C}), 134.4(\mathrm{CH}), 130.7(\mathrm{CH}), 129.2(\mathrm{CH}), 126.3(\mathrm{CH}), 125.0(\mathrm{CH}), 124.9(\mathrm{CH})$, $120.4(\mathrm{C}), 119.6(\mathrm{CH}), 118.6(\mathrm{CH}), 117.8(\mathrm{C}), 115.9(\mathrm{C}), 49.6\left(\mathrm{CH}_{2}\right), 40.3\left(\mathrm{CH}_{2}\right), 34.8$ $\left(\mathrm{CH}_{2}\right), 32.1\left(\mathrm{CH}_{2}\right), 30.5\left(\mathrm{CH}_{2}\right), 30.4\left(\mathrm{CH}_{2}\right), 30.2\left(\mathrm{CH}_{2}\right), 28.0\left(\mathrm{CH}_{2}\right), 26.8\left(\mathrm{CH}_{2}\right), 26.1$ $\left(\mathrm{CH}_{2}\right), 25.9\left(\mathrm{CH}_{2}\right), 23.9\left(\mathrm{CH}_{2}\right), 23.3\left(\mathrm{CH}_{2}\right)$. Análisis (\%): Calculado para $\mathrm{C}_{29} \mathrm{H}_{37} \mathrm{~N}_{3} \mathrm{O}_{2}: \mathrm{C}$, 75.78, H, 8.11, N, 9.14. Encontrado: C, 75.63, H, 8.31, N, 9.26.

\subsubsection{Híbridos derivados de $N, N$-dibencil( $N$-metil)amina}

\subsubsection{Procedimiento general para la síntesis de los benzonitrilos precursores 49-52}

Sobre una disolución de la amina $(14.3 \mathrm{mmol})$ en $94 \mathrm{~mL}$ de éter dietílico se añadieron $4.8 \mathrm{mmol}$ de 4-bromometilbenzonitrilo, y la mezcla se calentó a reflujo durante 10 horas. Después de enfriar a temperatura ambiente, se eliminó por filtración un sólido blanco. Se evaporó el disolvente a sequedad, obteniéndose un aceite que se purificó por cromatografía a presión sobre gel de sílice empleando como eluyente mezclas de polaridad creciente de Hexano: AcOEt. 


\section{4-(((2-Clorobencil)(metil)amino)metil)benzonitrilo (49)}

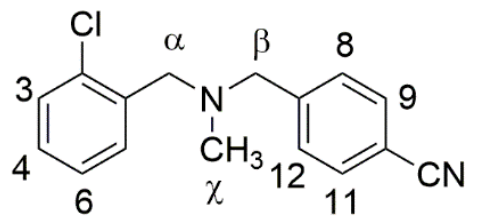

Siguiendo el procedimiento general, a partir de la 2-cloroN-metilbencilamina (2.23 g, $14.3 \mathrm{mmol})$, y del 4bromometilbenzonitrilo (941 mg, $4.8 \mathrm{mmol}$ ), se aislaron $1.146 \mathrm{~g}(88 \%)$ de 48 como un aceite .HPLC: pureza (100\%). MS: $\mathrm{m} / \mathrm{z}=271[\mathrm{M}+\mathrm{H}]^{+} .{ }^{1} \mathrm{H}-\mathrm{RMN}\left(500 \mathrm{MHz}, \mathrm{CDCl}_{3}\right), \delta(\mathrm{ppm}): 7.60\left(\mathrm{~d}, 2 \mathrm{H}_{9,11}\right.$, $\mathrm{J}=8.4), 7.51\left(\mathrm{dd}, 1 \mathrm{H}_{3}, \mathrm{~J}=7.6, \mathrm{~J}=1.5\right), 7.49\left(\mathrm{~d}, 2 \mathrm{H}_{8,12}, \mathrm{~J}=8.4\right), 7.36\left(\mathrm{dd}, 1 \mathrm{H}_{6}, \mathrm{~J}=7.6, \mathrm{~J}=\right.$ 1.2) $7.26\left(\mathrm{td}, 1 \mathrm{H}_{4}, \mathrm{~J}=7.6, \mathrm{~J}=1.2\right), 7.20\left(\mathrm{td}, 1 \mathrm{H}_{5}, \mathrm{~J}=7.6, \mathrm{~J}=1.5\right), 3.67\left(\mathrm{~s}, 2 \mathrm{H}_{\alpha}\right), 3.63(\mathrm{~s}$, 2H $\left.\mathrm{H}_{\alpha}\right), 2.22\left(\mathrm{~s}, 3 \mathrm{H}_{\chi}\right) .{ }^{13} \mathrm{C}-\mathrm{RMN}\left(125 \mathrm{MHz}, \mathrm{CDCl}_{3}\right), \delta(\mathrm{ppm}): 145.1(\mathrm{C}), 136.3(\mathrm{C}), 134.3$ (C), $132.1(2 \mathrm{CH}), 130.6(\mathrm{CH}), 129.6(\mathrm{CH}), 129.3(2 \mathrm{CH}), 128.3(2 \mathrm{CH}), 126.6(\mathrm{CH}), 119.0$ (C),110.7 (C), $61.5\left(\mathrm{CH}_{2}\right), 58.7\left(\mathrm{CH}_{2}\right), 42.3\left(\mathrm{CH}_{3}\right)$. Análisis $(\%)$ : Calculado para $\mathrm{C}_{16} \mathrm{H}_{15} \mathrm{ClN}_{2}$ : C, 70.98, H, 5.58, N, 10.35. Encontrado: C, 70.81, H, 5.42, N, 10.33.

\section{4-(((3-Clorobencil)(metil)amino)metil)benzonitrilo (50)}

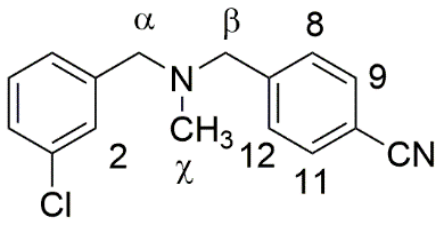

Siguiendo el procedimiento general, a partir de la 3-cloro- $N$ metilbencilamina $(2.23 \mathrm{~g}, \quad 14.3 \mathrm{mmol}), \quad \mathrm{y}$ del $4-$ bromometilbenzonitrilo (941 $\mathrm{mg}, 4.8 \mathrm{mmol}) \mathrm{se}$ aislaron $1.288 \mathrm{~g}(83 \%)$ de 49 como un aceite .HPLC: pureza (100\%). MS: $\mathrm{m} / \mathrm{z}=271[\mathrm{M}+\mathrm{H}]^{+} .{ }^{1} \mathrm{H}-\mathrm{RMN}\left(500 \mathrm{MHz}, \mathrm{CDCl}_{3}\right), \delta(\mathrm{ppm}): 7.60\left(\mathrm{~d}, 2 \mathrm{H}_{9,11}, \mathrm{~J}=8.4\right)$, $7.47\left(\mathrm{~d}, 2 \mathrm{H}_{8,12}, \mathrm{~J}=8.4\right), 7.36\left(\mathrm{~s}, 1 \mathrm{H}_{2}\right), 7.26(\mathrm{~m}, 3 \mathrm{H}), 3.55\left(\mathrm{~s}, 2 \mathrm{H}_{\beta}\right), 3.50\left(\mathrm{~s}, 2 \mathrm{H}_{\alpha}\right), 2.17(\mathrm{~s}$, $\left.3 \mathrm{H}_{\chi}\right) \cdot{ }^{13} \mathrm{C}-\mathrm{RMN}\left(125 \mathrm{MHz}, \mathrm{CDCl}_{3}\right), \delta(\mathrm{ppm}): 145.2(\mathrm{C}), 141.3(\mathrm{C}), 134.5(\mathrm{C}), 132.4$ $(2 \mathrm{CH}), 129.9(\mathrm{CH}), 129.5(2 \mathrm{CH}), 129.0(\mathrm{CH}), 127.6(\mathrm{CH}), 127.1(\mathrm{CH}), 119.2(\mathrm{C}), 111.1$ (C), $61.7\left(\mathrm{CH}_{2}\right), 61.6\left(\mathrm{CH}_{2}\right), 42.6\left(\mathrm{CH}_{3}\right)$. Análisis (\%). $\mathrm{C}_{16} \mathrm{H}_{15} \mathrm{ClN}_{2}: \mathrm{C}, 70.98, \mathrm{H}, 5.58, \mathrm{~N}$, 10.35. Encontrado: C, 70.88, H, 5.61, N, 10.29.

\section{4-(((2-Metoxibencil)(metil)amino)metil)benzonitrilo (51)}

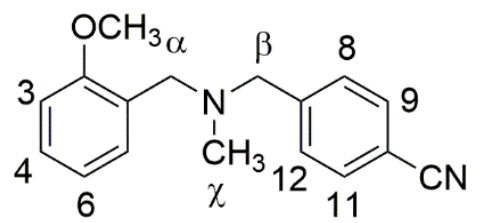

Siguiendo el procedimiento general, a partir de la 2metoxi-N-metilbencilamina (1.96 g, $14.3 \mathrm{mmol})$, y del 4bromometilbenzonitrilo (941 $\mathrm{mg}, 4.8 \mathrm{mmol}$ ) se aislaron $1.577 \mathrm{~g}(93 \%)$ de $\mathbf{5 0}$ como un aceite .HPLC: pureza (100\%). MS : m/z = $267[\mathrm{M}+\mathrm{H}]^{+} .{ }^{1} \mathrm{H}-\mathrm{RMN}\left(500 \mathrm{MHz}, \mathrm{CDCl}_{3}\right), \delta(\mathrm{ppm}): 7.60\left(\mathrm{~d}, 2 \mathrm{H}_{9,11}\right.$, 
$\mathrm{J}=8.2), 7.50\left(\mathrm{~d}, 2 \mathrm{H}_{8,12}, \mathrm{~J}=8.2\right), 7.40\left(\mathrm{dd}, 1 \mathrm{H}_{6}, \mathrm{~J}=7.9, \mathrm{~J}=1.6\right), 7.25\left(\mathrm{td}, 1 \mathrm{H}_{4}, \mathrm{~J}=7.9, \mathrm{~J}=\right.$ 1.6), $6.96\left(\mathrm{td}, 1 \mathrm{H}_{5}, \mathrm{~J}=7.9, \mathrm{~J}=0.7\right), 6.87\left(\mathrm{dd}, 1 \mathrm{H}_{3}, \mathrm{~J}=7.9, \mathrm{~J}=0.7\right), 3.81(\mathrm{~s}, 3 \mathrm{H}), 3.60$ (s, $\left.2 \mathrm{H}_{\beta}\right), 3.57\left(\mathrm{~s}, 2 \mathrm{H}_{\alpha}\right), 2.24\left(\mathrm{~s}, 3 \mathrm{H}_{\chi}\right) .{ }^{13} \mathrm{C}-\mathrm{RMN}\left(125 \mathrm{MHz}, \mathrm{CDCl}_{3}\right), \delta(\mathrm{ppm}): 158.0(\mathrm{C})$, $145.8(\mathrm{C}), 132.3(2 \mathrm{CH}), 130.5(\mathrm{CH}), 129.6(2 \mathrm{CH}), 128.4(\mathrm{CH}), 126.9(\mathrm{C}), 120.6(\mathrm{CH})$, $119.4(\mathrm{C}), 110.8(\mathrm{C}), 110.6(\mathrm{CH}), 61.9\left(\mathrm{CH}_{2}\right), 55.6\left(\mathrm{CH}_{3}\right), 55.5\left(\mathrm{CH}_{2}\right), 42.8\left(\mathrm{CH}_{3}\right)$. Análisis (\%): Calculado para $\mathrm{C}_{17} \mathrm{H}_{18} \mathrm{~N}_{2} \mathrm{O}: \mathrm{C}, 76.66, \mathrm{H}, 6.81, \mathrm{~N}, 10.52$. Encontrado: $\mathrm{C}$, 76.88, H, 7.01, N, 10.61 .

\section{4-(((3-Metoxibencil)(metil)amino)metil)benzonitrilo (52)}

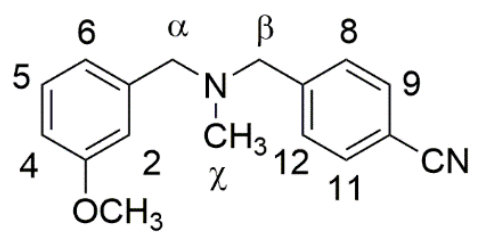

Siguiendo el procedimiento general, a partir de la 3metoxi-N-metilbencilamina (1.96 g, $14.3 \mathrm{mmol})$, y del 4bromometilbenzonitrilo (941 $\mathrm{mg}, 4.8 \mathrm{mmol}$ ) se aislaron $1.332 \mathrm{~g}(77 \%)$ de $\mathbf{5 1}$ como un aceite .HPLC: pureza (100\%). MS: $\mathrm{m} / \mathrm{z}=267[\mathrm{M}+\mathrm{H}]^{+} .{ }^{1} \mathrm{H}-\mathrm{RMN}\left(500 \mathrm{MHz}, \mathrm{CDCl}_{3}\right), \delta(\mathrm{ppm}): 7.52\left(\mathrm{~d}, 2 \mathrm{H}_{9,11}\right.$, $\mathrm{J}=8.4), 7.41\left(\mathrm{~d}, 2 \mathrm{H}_{8,12}, \mathrm{~J}=8.4\right), 7.18\left(\mathrm{t}, 1 \mathrm{H}_{5}, \mathrm{~J}=8.1\right), 6.88\left(\mathrm{~s}, 1 \mathrm{H}_{2}\right), 6.87\left(\mathrm{dd}, 1 \mathrm{H}_{4}, \mathrm{~J}=8.1\right.$, $\mathrm{J}=1.7), 6.74\left(\mathrm{dd}, 1 \mathrm{H}_{6}, \mathrm{~J}=8.1, \mathrm{~J}=1.7\right), 3.74\left(\mathrm{~s}, 3 \mathrm{H}, \mathrm{OCH}_{3}\right), 3.47\left(\mathrm{~s}, 2 \mathrm{H}_{\beta}\right), 3.45\left(\mathrm{~s}, 2 \mathrm{H}_{\alpha}\right)$, $2.12\left(\mathrm{~s}, 3 \mathrm{H}_{\chi}\right) \cdot{ }^{13} \mathrm{C}-\mathrm{RMN}\left(125 \mathrm{MHz}, \mathrm{CDCl}_{3}\right), \delta(\mathrm{ppm}): 159.5$ (C), 145.2 (C), $140.4(\mathrm{C})$, $131.9(2 \mathrm{CH}), 129.2(\mathrm{CH}), 129.1(2 \mathrm{CH}), 120.9(\mathrm{CH}), 118.9(\mathrm{C}), 114.2(\mathrm{CH}), 112.2(\mathrm{CH})$, $110.5(\mathrm{C}), 61.8\left(\mathrm{CH}_{2}\right), 61.0\left(\mathrm{CH}_{2}\right), 55.1\left(\mathrm{CH}_{2}\right) 42.3\left(\mathrm{CH}_{3}\right)$. Análisis (\%): Calculado para $\mathrm{C}_{17} \mathrm{H}_{18} \mathrm{~N}_{2} \mathrm{O}$ : C, 76.66, H, 6.81, N, 10.52. Encontrado: C, 76.71, H, 6.69, N, 10.33

\subsubsection{Procedimiento general para la síntesis de los ácidos precursores 53-57}

Sobre una disolución del nitrilo $(3.8 \mathrm{mmol})$ en $6 \mathrm{~mL}$ de dioxano se añadieron $29 \mathrm{~mL}$ de una disolución de $\mathrm{NaOH} 2 \mathrm{M}$, y la mezcla se calentó a reflujo durante 4 horas. Después de enfriar a temperatura ambiente, se gotea $\mathrm{HCl}$ concentrado hasta $\mathrm{pH}$ ácido. Se dejó unas horas en el frígorifico y se filtró, obteniéndose el ácido deseado como un sólido blanco. 


\section{Ácido 4-((bencil(metil)amino)metil)benzoico (53)}<smiles>[Y]c1cc(C(=O)O)ccc1CN(C)Cc1ccccc1</smiles>

Siguiendo el procedimiento general, a partir del 4((bencil(metil)amino)metil)benzonitrilo (898 $\mathrm{mg}, 3.8$ mmol) se aislaron $726.8 \mathrm{mg}(75 \%)$ de $\mathbf{5 3}$ como un sólido blanco (hidrocloruro) p. f. $230-231^{\circ} \mathrm{C}$ HPLC: pureza (99\%). MS: m/z = $256[\mathrm{M}+\mathrm{H}]^{+} .{ }^{1} \mathrm{H}-\mathrm{RMN}\left(300 \mathrm{MHz}, \mathrm{CD}_{3} \mathrm{OD}\right), \delta(\mathrm{ppm}): 8.00$ (d, 2 $\mathrm{H}_{9,11}$, $\mathrm{J}=8.2), 7.49\left(\mathrm{~d}, 2 \mathrm{H}_{8,12}, \mathrm{~J}=8.2\right), 7.39(\mathrm{~m}, 5 \mathrm{H}), 3.98\left(\mathrm{~s}, 2 \mathrm{H}_{\beta}\right), 3.95\left(\mathrm{~s}, 2 \mathrm{H}_{\alpha}\right), 2.43\left(\mathrm{~s}, 3 \mathrm{H}_{\chi}\right)$. ${ }^{13} \mathrm{C}-\mathrm{RMN}\left(75 \mathrm{MHz}, \mathrm{CD}_{3} \mathrm{OD}\right), \delta(\mathrm{ppm}): 172.0$ (CO), 139.2 (C), 135.7 (C), 135.4 (C), $131.3(2 \mathrm{CH}), 131.0(2 \mathrm{CH}), 130.9(2 \mathrm{CH}), 129.8(2 \mathrm{CH}), 129.7(\mathrm{CH}), 61.8\left(\mathrm{CH}_{2}\right), 61.3$ $\left(\mathrm{CH}_{2}\right), 41.0\left(\mathrm{CH}_{3}\right)$. Análisis (\%): Calculado para $\mathrm{C}_{16} \mathrm{H}_{18} \mathrm{ClNO}_{2}$ : C, 65.96, H, 6.22, N, 4.80. Encontrado: C, 66.31, H, 6.35, N, 4.92.

\section{Ácido 4-(((2-clorobencil)(metil)amino)metil)benzoico (54)}

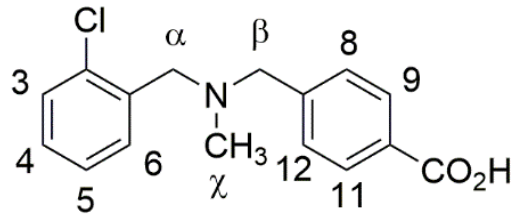

Siguiendo el procedimiento general, a partir del 4-(((2Clorobencil)(metil)amino)metil)benzonitrilo $\quad(1.03 \mathrm{~g}$, $3.8 \mathrm{mmol})$ se aislaron $967.4 \mathrm{mg}(88 \%)$ de $\mathbf{5 4}$ como un sólido blanco. p. f. $44-46^{\circ} \mathrm{C}$ HPLC: pureza (99\%). MS : $\mathrm{m} / \mathrm{z}=290[\mathrm{M}+\mathrm{H}]^{+} .{ }^{1} \mathrm{H}-\mathrm{RMN}\left(400 \mathrm{MHz}, \mathrm{CD}_{3} \mathrm{OD}\right), \delta(\mathrm{ppm}): 8.00\left(\mathrm{~d}, 2 \mathrm{H}_{9,11}, \mathrm{~J}=8.4\right), 7.57$ $\left(\mathrm{dd}, 1 \mathrm{H}_{3}, \mathrm{~J}=7.0, \mathrm{~J}=2.4\right) 7.51\left(\mathrm{~d}, 2 \mathrm{H}_{8,12}, \mathrm{~J}=8.4\right), 7.41\left(\mathrm{dd}, 1 \mathrm{H}_{6}, \mathrm{~J}=7.3, \mathrm{~J}=2.0\right), 7.33$ (dd, $\left.1 \mathrm{H}_{4}, \mathrm{~J}=7.3, \mathrm{~J}=2.0\right), 7.30\left(\mathrm{dd}, 1 \mathrm{H}_{5}, \mathrm{~J}=7.3, \mathrm{~J}=2.4\right), 3.91\left(\mathrm{~s}, 4 \mathrm{H}_{\alpha \beta},\right), 2.38\left(\mathrm{~s}, 3 \mathrm{H}_{\chi}\right) .{ }^{13} \mathrm{C}-$

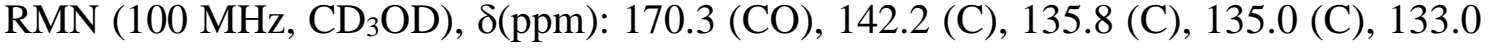
$(\mathrm{CH}), 132.8(\mathrm{CH}), 130.9(2 \mathrm{CH}), 130.8(2 \mathrm{CH}), 130.7(2 \mathrm{CH}), 128.3(\mathrm{CH}), 62.2\left(\mathrm{CH}_{2}\right), 58.9$ $\left(\mathrm{CH}_{2}\right), 41.9\left(\mathrm{CH}_{3}\right)$. Análisis (\%): Calculado para $\mathrm{C}_{16} \mathrm{H}_{16} \mathrm{ClNO}_{2}: \mathrm{C}, 66.32, \mathrm{H}, 5.57, \mathrm{~N}, 4.83$. Encontrado: C, 66.11, H, 5.49, N, 4.92.

\section{Ácido 4-(((3-clorobencil)(metil)amino)metil)benzoico (55)}

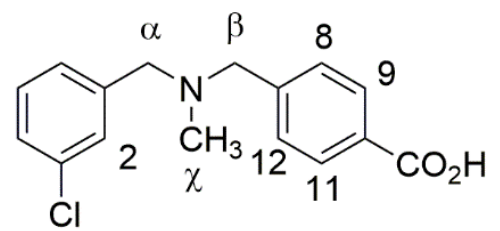

Siguiendo el procedimiento general, a apartir del 4-(((3Clorobencil)(metil)amino)metil)benzonitrilo (1.03 g, 3.8 mmol) se aislaron $1.068 \mathrm{~g}(97 \%)$ de bl175 (hidrocloruro) como un sólido blanco. p. f. 140-142 ${ }^{\circ} \mathrm{C}$ HPLC: pureza (100\%). MS : m/z = $290[\mathrm{M}+\mathrm{H}]^{+} .{ }^{1} \mathrm{H}-\mathrm{RMN}\left(400 \mathrm{MHz}, \mathrm{CD}_{3} \mathrm{OD}\right), \delta(\mathrm{ppm}): 8.13(\mathrm{~d}$, 
$\left.2 \mathrm{H}_{9,11}, \mathrm{~J}=8.4\right), 7.64\left(\mathrm{~d}, 2 \mathrm{H}_{8,12}, \mathrm{~J}=8.4\right), 7.61\left(\mathrm{~s}, 1 \mathrm{H}_{2}\right), 7.51(\mathrm{~m}, 3 \mathrm{H}), 4.48\left(\mathrm{~s}, 2 \mathrm{H}_{\beta}\right), 4.42(\mathrm{~s}$, $\left.2 \mathrm{H}_{\alpha}\right), 2.73\left(\mathrm{~s}, 3 \mathrm{H}_{\chi}\right) .{ }^{13} \mathrm{C}-\mathrm{RMN}\left(100 \mathrm{MHz}, \mathrm{CD}_{3} \mathrm{OD}\right), \delta(\mathrm{ppm}): 167.5(\mathrm{CO}), 135.0(\mathrm{C}), 134.1$ (C), $132.6(\mathrm{C}), 131.6(\mathrm{C}), 131.3(2 \mathrm{CH}), 131.1(\mathrm{CH}), 130.8(\mathrm{CH}), 130.4(2 \mathrm{CH}), 130.3$ $(\mathrm{CH}), 129.6(\mathrm{CH}), 59.3\left(\mathrm{CH}_{2}\right), 59.1\left(\mathrm{CH}_{2}\right), 38.6\left(\mathrm{CH}_{3}\right)$. Análisis $(\%)$ : Calculado para $\mathrm{C}_{16} \mathrm{H}_{17} \mathrm{Cl}_{2} \mathrm{NO}_{2}$ : C, 58.91, H, 5.25, N, 4.29. Encontrado: C, 59.42, H, 5.47, N, 4.63.

\section{Ácido 4-(((2-metoxibencil)(metil)amino)metil)benzoico (56)}

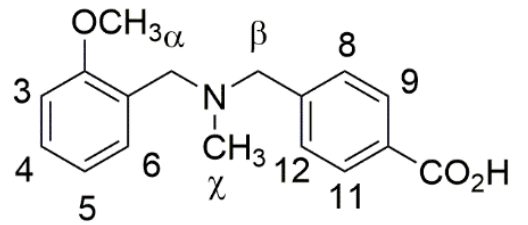

Siguiendo el procedimiento general, a partir del 4-(((2Metoxibencil)(metil)amino)metil)benzonitrilo (1.01 g, $3.8 \mathrm{mmol})$ se aislaron $1.051 \mathrm{~g}(97 \%)$ de $\mathbf{5 6}$ como un sólido blanco. p. f. $64-66^{\circ} \mathrm{C}$ HPLC: pureza (99\%). MS : $\mathrm{m} / \mathrm{z}=286[\mathrm{M}+\mathrm{H}]^{+} .{ }^{1} \mathrm{H}-\mathrm{RMN}\left(400 \mathrm{MHz}, \mathrm{CD}_{3} \mathrm{OD}\right), \delta(\mathrm{ppm}): 8.11\left(\mathrm{~d}, 2 \mathrm{H}_{9,11}, \mathrm{~J}=8.4\right), 7.69$

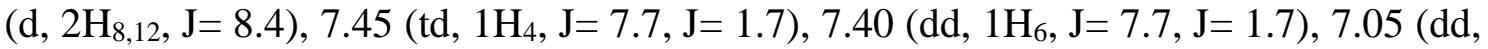
$\left.1 \mathrm{H}_{3}, \mathrm{~J}=7.7, \mathrm{~J}=0.9\right), 7.00\left(\mathrm{td}, 1 \mathrm{H}_{5}, \mathrm{~J}=7.7, \mathrm{~J}=0.9\right), 3.80\left(\mathrm{~s}, 3 \mathrm{H}, \mathrm{OCH}_{3}\right), 3.29\left(\mathrm{~s}, 2 \mathrm{H}_{\beta}\right), 3.23$ $\left(\mathrm{s}, 2 \mathrm{H}_{\alpha}\right), 2.81\left(\mathrm{~s}, 3 \mathrm{H}_{\chi}\right) \cdot{ }^{13} \mathrm{C}-\mathrm{RMN}\left(100 \mathrm{MHz}, \mathrm{CD}_{3} \mathrm{OD}\right), \delta(\mathrm{ppm}): 168.8(\mathrm{CO}), 159.4(\mathrm{C})$, $135.8(\mathrm{C}), 133.6(\mathrm{C}), 133.5(\mathrm{CH}), 132.4(2 \mathrm{CH}), 131.4(2 \mathrm{CH}), 129.5(\mathrm{CH}), 122.1(\mathrm{CH})$, $118.9(\mathrm{C}) 62.2\left(\mathrm{CH}_{2}\right), 60.7\left(\mathrm{CH}_{3}\right), 56.1\left(\mathrm{CH}_{2}\right), 55.9\left(\mathrm{CH}_{2}\right)$ ) $41.2\left(\mathrm{CH}_{3}\right)$. Análisis (\%): Calculado para $\mathrm{C}_{17} \mathrm{H}_{19} \mathrm{NO}_{3}$ : C, 71.56, H, 6.71, N, 4.91. Encontrado: C, 71.12, H, 6.56, N, 4.83.

\section{Ácido 4-(((3-metoxibencil)(metil)amino)metil)benzoico (57)}

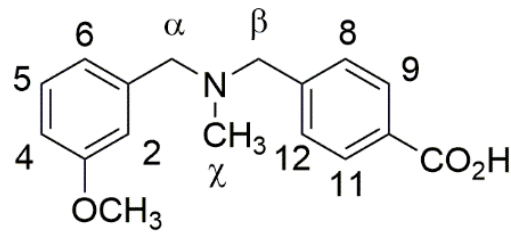

Siguiendo el procedimiento general, a partir del 4-(((3Metoxibencil)(metil)amino)metil)benzonitrilo (1.01 g, $3.8 \mathrm{mmol})$ se aislaron $748.2 \mathrm{mg}(69 \%)$ de 57 como un sólido blanco. p. f. $100-102^{\circ} \mathrm{C}$ HPLC: pureza (99\%). MS : m/z $=286[\mathrm{M}+\mathrm{H}]^{+} .{ }^{1} \mathrm{H}-\mathrm{RMN}\left(400 \mathrm{MHz}, \mathrm{CD}_{3} \mathrm{OD}\right), \delta(\mathrm{ppm}): 8.00\left(\mathrm{~d}, 2 \mathrm{H}_{9,11}, \mathrm{~J}=\right.$ 8.3), $7.47\left(\mathrm{~d}, 2 \mathrm{H}_{8,12}, \mathrm{~J}=8.3\right), 7.31\left(\mathrm{t}, 1 \mathrm{H}_{5}, \mathrm{~J}=7.9\right), 7.00\left(\mathrm{~s}, 1 \mathrm{H}_{2}\right), 6.95$ (m, 2H), 3.92 (s, $\left.2 \mathrm{H}_{\beta}\right), 3.87\left(\mathrm{~s}, 2 \mathrm{H}_{\alpha}\right), 3.80\left(\mathrm{~s}, 3 \mathrm{H}, \mathrm{OCH}_{3}\right), 2.41\left(\mathrm{~s}, 3 \mathrm{H}_{\chi}\right) .{ }^{13} \mathrm{C}-\mathrm{RMN}\left(100 \mathrm{MHz}, \mathrm{CD}_{3} \mathrm{OD}\right)$, $\delta(\mathrm{ppm}): 161.5$ (CO), $139.8(\mathrm{C}), 137.3(\mathrm{C}), 135.4(\mathrm{C}), 130.9$ (2CH), 130.8 (2CH), 130.7 $(\mathrm{CH}), 123.2(\mathrm{CH}), 122.9(\mathrm{C}), 116.5(\mathrm{CH}), 115.0(\mathrm{CH}), 62.0\left(\mathrm{CH}_{2}\right), 61.5\left(\mathrm{CH}_{2}\right), 55.7$ 
$\left(\mathrm{CH}_{3}\right), 41.3\left(\mathrm{CH}_{3}\right)$. Análisis (\%): Calculado para $\mathrm{C}_{17} \mathrm{H}_{19} \mathrm{NO}_{3}$ : C, 71.56, H, 6.71, N, 4.91. Encontrado: C, 71.33, H, 6.48, N, 4.77.

\subsubsection{Sintesis de $N$-(4-(aminometil)bencil)- $N$-metil-1-fenilmetanamina (58)}<smiles>[Y]c1ccc(CN(C)Cc2ccccc2)cc1</smiles>

A una disolución del 4-((bencil(metil)amino)metil)benzonitrilo $(2.11 \mathrm{mmol})$ en THF anhidro y bajo atmósfera de $\mathrm{N}_{2}$, se añadieron $6.33 \mathrm{mmol} \mathrm{de} \mathrm{LiAlH}_{4}$. La reacción se mantiene a reflujo durante 3 horas. Después de enfriar con baño de hielo a $0{ }^{\circ} \mathrm{C}$, se añade gota a gota una disolución de $\mathrm{NaOH} 2 \mathrm{M}$ hasta $\mathrm{pH}$ alcalino. Se extrajo la amina con éter dietílico $(3 \times 30 \mathrm{ml})$, y los extractos orgánicos se secaron sobre $\mathrm{Na}_{2} \mathrm{SO}_{4}$, se filtraron y el disolvente se evaporó a sequedad, obteniéndose un aceite que se purificó mediante columna cromatografica a presión sobre gel de sílice empleando como eluyente mezclas de polaridad creciente de AcOEt: $\mathrm{MeOH}: \mathrm{NH}_{3}$. Se aislaron $334.0 \mathrm{mg}(66 \%)$ de $\mathbf{5 2}$ como un aceite. Se prepara el hidrocloruro borboteando $\mathrm{HCl}$ (gas), obteniendo un sólido blanco. p. f. $230-231^{\circ} \mathrm{C}$ HPLC: pureza (99\%). MS: $\mathrm{m} / \mathrm{z}=241[\mathrm{M}+\mathrm{H}]^{+} .{ }^{1} \mathrm{H}-\mathrm{RMN}\left(300 \mathrm{MHz}, \mathrm{CDCl}_{3}\right), \delta(\mathrm{ppm}): 7.30\left(\mathrm{~d}, 2 \mathrm{H}_{9,11}\right.$, $\mathrm{J}=7.9), 7.26(\mathrm{~m}, 5 \mathrm{H}), 7.23\left(\mathrm{~d}, 2 \mathrm{H}_{8,12}, \mathrm{~J}=7.9\right), 3.81\left(\mathrm{~s}, 2 \mathrm{H}_{\delta}\right), 3.48\left(\mathrm{~s}, 4 \mathrm{H}_{\alpha, \beta}\right), 2.14\left(\mathrm{~s}, 3 \mathrm{H}_{\chi}\right)$, 1.61(s, $\left.\mathrm{NH}_{2}\right) .{ }^{13} \mathrm{C}-\mathrm{RMN}\left(75 \mathrm{MHz}, \mathrm{CDCl}_{3}\right), \delta(\mathrm{ppm}): 141.9(\mathrm{C}), 139.2(\mathrm{C}), 137.8(\mathrm{C})$, $129.1(2 \mathrm{CH}), 128.9(2 \mathrm{CH}), 128.2(2 \mathrm{CH}), 126.9(2 \mathrm{CH}), 126.8(\mathrm{CH}), 61.7\left(\mathrm{CH}_{2}\right), 61.5$ $\left(\mathrm{CH}_{2}\right), 46.2\left(\mathrm{CH}_{2}\right), 42.2\left(\mathrm{CH}_{3}\right)$. Análisis (\%): Calculado para $\mathrm{C}_{16} \mathrm{H}_{21} \mathrm{Cl} \mathrm{N}_{2}$ : C, 69.42, $\mathrm{H}$, 7.65, N, 10.12. Encontrado: C, 69.61, H, 7,55, N, 10.32.

\subsubsection{Síntesis de los híbridos N,N-dibencil(N-metil)amina - neuroaminas (59-68) y} $N, N$-dibencil(N-metil)amina - piridina / piridinol (69-76). Procedimiento general

A una disolución del ácido $(0.5 \mathrm{mmol})$ en DMF $(8 \mathrm{~mL})$ se añadieron los reactivos en el siguiente orden: trietilamina $(1.2 \mathrm{mmol})$, pyBOP $(0.6 \mathrm{mmol})$, y por último la correspondiente amina $(0.5 \mathrm{mmol})$. La mezcla se dejó agitando a temperatura ambiente entre 18-24 horas. Transcurrido este tiempo, se eliminó la DMF, y el aceite resultante se disolvió en $\mathrm{CH}_{2} \mathrm{Cl}_{2}$. Se lavó con una disolución de $\mathrm{NaHCO}_{3}(3$ x $10 \mathrm{~mL})$, y los extractos orgánicos se secaron sobre sulfato sódico, se filtraron y el disolvente se evaporó a presión reducida. El residuo resultante se purificó mediante columna de cromatografía a presión sobre gel de sílice empleando como eluyente mezclas de AcOEt :hexano. 


\section{$N$-(4-((Bencil(metil)amino)metil)bencil)-3,4,5-trimetoxibenzamida (59)}<smiles>[Y2]CN(Cc1ccccc1)Cc1ccc(CNC(=O)c2cc(OC)c(OC)c(OC)c2)cc1</smiles>

Siguiendo el procedimiento general, a partir del ácido 3,4,5-trimetoxibenzoico (106.1 mg, $0.5 \mathrm{mmol})$, pyBOP (312.2 mg, $0.6 \mathrm{mmol}), \mathrm{N}$-(4-(Aminometil)bencil)- $N$ metil-1-fenilmetanamina (138.4 mg, $0.5 \mathrm{mmol})$ y Et ${ }_{3} \mathrm{~N}(156 \mu \mathrm{L}, 1.2 \mathrm{mmol})$, se aislaron $132.5 \mathrm{mg}(61 \%)$ de 59 como un sólido amarillo p. f. $115-117^{\circ} \mathrm{C}$ HPLC: pureza (99\%). MS: $\mathrm{m} / \mathrm{z}=435[\mathrm{M}+\mathrm{H}]^{+} .{ }^{1} \mathrm{H}-\mathrm{RMN}\left(400 \mathrm{MHz}, \mathrm{CDCl}_{3}\right), \delta(\mathrm{ppm}): 7.34\left(\mathrm{~d}, 2 \mathrm{H}_{9,11}, \mathrm{~J}=8.0\right)$, $7.29\left(\mathrm{~d}, 2 \mathrm{H}_{8,12}, \mathrm{~J}=8.0\right), 7.27(\mathrm{~m}, 5 \mathrm{H}), 7.00\left(\mathrm{~s}, 2 \mathrm{H}_{2}{ }^{\prime}, 6^{\circ}\right), 6.43$ (t, NH, J= 5.0), 4.59 (d, 2H $\delta$, $\mathrm{J}=5.7), 3.86(\mathrm{~s}, 3 \mathrm{H}), 3.85(\mathrm{~s}, 6 \mathrm{H}), 3.52\left(\mathrm{~s}, 2 \mathrm{H}_{\beta}\right), 3.51\left(\mathrm{~s}, 2 \mathrm{H}_{\alpha}\right), 2.17\left(\mathrm{~s}, 3 \mathrm{H}_{\chi}\right) \cdot{ }^{13} \mathrm{C}-\mathrm{RMN}$ (100 MHz, $\left.\mathrm{CDCl}_{3}\right), \delta(\mathrm{ppm}): 167.0(\mathrm{CONH}), 153.1$ (3C), 136.9 (C), $129.8(\mathrm{C}), 129.4$ (2CH), $129.3(\mathrm{C}), 128.9(2 \mathrm{CH}), 128.3(2 \mathrm{CH}), 128.2(\mathrm{C}), 127.9(2 \mathrm{CH}), 127.1(\mathrm{CH}), 104.2$ (2CH), $61.7\left(\mathrm{CH}_{2}\right), 61.3\left(\mathrm{CH}_{2}\right), 60.9\left(\mathrm{CH}_{3}\right), 56.3\left(2 \mathrm{CH}_{3}\right) 44.0\left(\mathrm{CH}_{2}\right), 42.1\left(\mathrm{CH}_{3}\right)$. Análisis (\%): Calculado para $\mathrm{C}_{26} \mathrm{H}_{30} \mathrm{~N}_{2} \mathrm{O}_{4}: \mathrm{C}, 71.87, \mathrm{H}, 6.96, \mathrm{~N}, 6.45$. Encontrado: C, 70.20, H, $7,05, \mathrm{~N}, 6.38$.

\section{$N$-(4-((Bencil(metil)amino)metill)bencil)-3-(3,4-dimeoxyfenil)propanamida (60)}<smiles>[Y2]CN(Cc1ccccc1)Cc1ccc(CNC(=O)CC(=O)c2ccc(OC)c(OC)c2)cc1</smiles>

Siguiendo el procedimiento general, a partir del ácido 3-(3,4dimetoxifenil)propanoico (105.1 $\mathrm{mg}, 0.5 \mathrm{mmol})$, pyBOP (312.2 $\mathrm{mg}$,

$0.6 \mathrm{mmol}), \mathrm{N}$-(4-(Aminometil)bencil)- $N$-metil-1-fenilmetanamina (138.4 mg, $0.5 \mathrm{mmol}$ ) y Et $3 \mathrm{~N}(156 \mu \mathrm{L}, 1.2 \mathrm{mmol})$ se aislaron $153.6 \mathrm{mg}$ (71\%) de $\mathbf{6 0}$ como un sólido blanco p. f. $65-67^{\circ} \mathrm{C}$ HPLC: pureza (99\%). MS : m/z $=433[\mathrm{M}+\mathrm{H}]^{+} .{ }^{1} \mathrm{H}-\mathrm{RMN}\left(400 \mathrm{MHz}, \mathrm{CDCl}_{3}\right)$, $\delta(\mathrm{ppm}): 7.28(\mathrm{~m}, 5 \mathrm{H}), 7.27\left(\mathrm{~d}, 2 \mathrm{H}_{9,11}, \mathrm{~J}=8.1\right), 7.09\left(\mathrm{~d}, 2 \mathrm{H}_{8,12}, \mathrm{~J}=8.1\right), 6.71(\mathrm{~m}, 3 \mathrm{H}), 5.70$ (t, NH, J= 5.0), $4.35\left(\mathrm{~d}, 2 \mathrm{H}_{\delta}, \mathrm{J}=5.7\right), 3.82(\mathrm{~s}, 3 \mathrm{H}), 3.81(\mathrm{~s}, 3 \mathrm{H}), 3.48\left(\mathrm{~s}, 2 \mathrm{H}_{\beta}\right), 3.47(\mathrm{~s}$, $\left.2 \mathrm{H}_{\alpha}\right), 2.91\left(\mathrm{t}, 2 \mathrm{H}_{\phi}, \mathrm{J}=7.6\right), 2.46\left(\mathrm{t}, 2 \mathrm{H}_{\varepsilon}, \mathrm{J}=7.6\right), 2.14\left(\mathrm{~s}, 3 \mathrm{H}_{\chi}\right) \cdot{ }^{13} \mathrm{C}-\mathrm{RMN}(100 \mathrm{MHz}$, $\left.\mathrm{CDCl}_{3}\right), \delta(\mathrm{ppm}): 171.9(\mathrm{CONH}), 148.8(\mathrm{C}), 147.4(\mathrm{C}), 139.1(\mathrm{C}), 138.5(\mathrm{C}), 136.7(\mathrm{C})$, $133.3(\mathrm{C}), 129.1(2 \mathrm{CH}), 128.8(2 \mathrm{CH}), 128.2(2 \mathrm{CH}), 127.6(2 \mathrm{CH}), 126.9(\mathrm{CH}), 120.1$ $(\mathrm{CH}), 111.6(\mathrm{CH}), 111.2(\mathrm{CH}), 61.3\left(\mathrm{CH}_{2}\right), 61.7\left(\mathrm{CH}_{2}\right), 55.8\left(2 \mathrm{CH}_{3}\right), 43.3\left(\mathrm{CH}_{2}\right), 42.1$ 
$\left(\mathrm{CH}_{3}\right), 38.7\left(\mathrm{CH}_{2}\right), 31.3\left(\mathrm{CH}_{2}\right)$. Análisis (\%): Calculado para $\mathrm{C}_{27} \mathrm{H}_{32} \mathrm{~N}_{2} \mathrm{O}_{3}: \mathrm{C}, 74.97, \mathrm{H}$, 7.46, N, 6.48. Encontrado: C, 74.92, H, 7,46, N, 6.21.

\section{4-((Bencil(metil)amino)metil)-N-(3,4-dimetoxifenetil)benzamida (61)}<smiles>[Y2]C(CN(C)Cc1ccccc1)c1ccc(C(=O)NCCc2ccc(OC)c(OC)c2)cc1</smiles>

Siguiendo el procedimiento general, a partir del ácido 4-((bencil(metil)amino)metil)benzoico (127.6 mg, 0.5 $\mathrm{mmol})$, pyBOP (312.2 mg, $0.6 \mathrm{mmol})$, 2-(3,4-dimetoxifenil)etanamina (90.6

$\mathrm{mg}, 0.5 \mathrm{mmol})$ y Et $\mathrm{t}_{3} \mathrm{~N}(156 \mu \mathrm{L}, 1.2 \mathrm{mmol})$ se aislaron $127.7 \mathrm{mg}(61 \%)$ de 61 como un sólido blanco. p. f. $84-86^{\circ} \mathrm{C}$ HPLC: pureza (99\%). MS : m/z $=419[\mathrm{M}+\mathrm{H}]^{+} .{ }^{1} \mathrm{H}-\mathrm{RMN}$

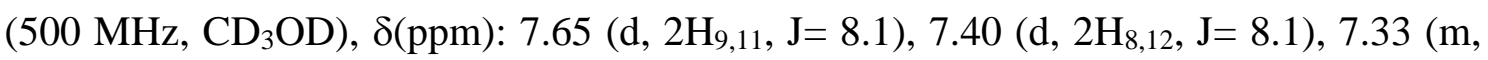
4H), $7.25(\mathrm{~m}, 1 \mathrm{H}), 6.82\left(\mathrm{~d}, 1 \mathrm{H}_{5}, \mathrm{~J}=8.1\right), 6.76\left(\mathrm{~d}, 1 \mathrm{H}_{6}, \mathrm{~J}=8.1\right), 6.75\left(\mathrm{~s}, 1 \mathrm{H}_{2}\right), 6.22(\mathrm{t}$, $1 \mathrm{NH}, \mathrm{J}=5.6), 3.86(\mathrm{~s}, 3 \mathrm{H}), 3.83(\mathrm{~s}, 3 \mathrm{H}), 3.68\left(\mathrm{c}, 1 \mathrm{H}_{\delta}, \mathrm{J}=6.7\right), 3.54\left(\mathrm{~s}, 2 \mathrm{H}_{\beta}\right), 3.52\left(\mathrm{~s}, 2 \mathrm{H}_{\alpha}\right)$, $2.87\left(\mathrm{t}, 1 \mathrm{H}_{\varepsilon}, \mathrm{J}=6.7\right), 2.18\left(\mathrm{~s}, 3 \mathrm{H}_{\chi}\right) .{ }^{13} \mathrm{C}-\mathrm{RMN}\left(125 \mathrm{MHz}, \mathrm{CD}_{3} \mathrm{OD}\right), \delta(\mathrm{ppm}): 167.3(\mathrm{CO})$, 149.0 (C), 147.6 (C), 143.0 (C), 138.8 (C), 133.3 (C), 131.4 (C), 128.9 (2CH), 128.8 $(2 \mathrm{CH}), 128.2(2 \mathrm{CH}), 127.1(\mathrm{CH}), 126.7(2 \mathrm{CH}), 120.9(\mathrm{CH}), 112.2(\mathrm{CH}), 111.6(\mathrm{CH})$, $62.1\left(\mathrm{CH}_{2}\right), 61.5\left(\mathrm{CH}_{2}\right), 56.1\left(2 \mathrm{CH}_{3}\right), 42.5\left(\mathrm{CH}_{3}\right), 41.5\left(\mathrm{CH}_{2}\right), 35.5\left(\mathrm{CH}_{2}\right)$.. Análisis $(\%)$ : Calculado para $\mathrm{C}_{26} \mathrm{H}_{30} \mathrm{~N}_{2} \mathrm{O}_{3}$ : C, 74.61, H, 7.22, N, 6.69. Encontrado: C, 72.65, H, 7.27, $\mathrm{N}, 6.55$.

\section{4-((Bencil(metil)amino)metil)-N-fenetilbenzamida (62)}<smiles>[Y]c1ccc(C(=O)NC(=O)Cc2ccccc2)cc1</smiles>

Siguiendo el procedimiento general, a partir del ácido 4-((bencil(metil)amino)metil)benzoico (127.6 mg, $0.5 \mathrm{mmol})$, pyBOP (312.2 $\mathrm{mg}, 0.6 \mathrm{mmol})$, 2-feniletanamine (78.8 $\mathrm{mg}, 0.5$

mmol) y Et $3 \mathrm{~N}(156 \mu \mathrm{L}, 1.2 \mathrm{mmol})$ se aislaron $159.9 \mathrm{mg}(87 \%)$ de 62 como un sólido blanco. p. f. $72-74^{\circ} \mathrm{C}$ HPLC: pureza (99\%). MS : m/z = $359[\mathrm{M}+\mathrm{H}]^{+} .{ }^{1} \mathrm{H}-\mathrm{RMN}(400$ $\left.\mathrm{MHz}, \mathrm{CD}_{3} \mathrm{OD}\right), \delta(\mathrm{ppm}): 7.74\left(\mathrm{~d}, 2 \mathrm{H}_{9,11}, \mathrm{~J}=8.4\right), 7.43\left(\mathrm{~d}, 2 \mathrm{H}_{8,12}, \mathrm{~J}=8.4\right), 7.27(\mathrm{~m}, 10 \mathrm{H})$, $3.59\left(\mathrm{t}, 2 \mathrm{H}_{\delta}, \mathrm{J}=7.4\right), 3.55\left(\mathrm{~s}, 2 \mathrm{H}_{\beta}\right), 3.51\left(\mathrm{~s}, 2 \mathrm{H}_{\alpha}\right), 2.91\left(\mathrm{t}, 1 \mathrm{H}_{\varepsilon}, \mathrm{J}=7.4\right), 2.16\left(\mathrm{~s}, 3 \mathrm{H}_{\chi}\right) \cdot{ }^{13} \mathrm{C}$ -RMN (100 MHz, CD 3 OD), $\delta(\mathrm{ppm}): 170.1$ (CONH), 144.0 (C), 140.6 (C), 139.8 (C), $134.7(\mathrm{C}), 130.3(2 \mathrm{CH}), 130.2(2 \mathrm{CH}), 129.9(2 \mathrm{CH}), 129.5(2 \mathrm{CH}), 129.3(2 \mathrm{CH}), 128.3$ 
$(\mathrm{CH}), 128.2(2 \mathrm{CH}), 127.4(\mathrm{CH}), 62.8\left(\mathrm{CH}_{2}\right), 62.2\left(\mathrm{CH}_{2}\right), 42.7\left(\mathrm{CH}_{2}\right), 42.5\left(\mathrm{CH}_{2}\right), 36.6$ $\left(\mathrm{CH}_{3}\right)$. Análisis (\%): Calculado para $\mathrm{C}_{24} \mathrm{H}_{26} \mathrm{~N}_{2} \mathrm{O}$ : C, 80.41, H, 7.31, N, 7.81. Encontrado: C, 80.33, H, 7.29, N, 7.66.

\section{4-(((2-Metoxibencil)(metil)amino)metil)-N-fenetilbenzamida (63)}

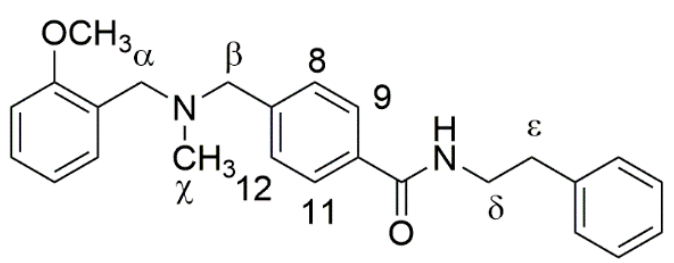

Siguiendo el procedimiento general, a partir del ácido 4-(((2-metoxibencil)(metil)amino)metil)benzoico (142.7 mg, $0.5 \mathrm{mmol})$, pyBOP (312.2 mg, $0.6 \mathrm{mmol}), 2$-feniletanamine (78.8 $\mathrm{mg}, 0.5 \mathrm{mmol})$ y Et ${ }_{3} \mathrm{~N}(156 \mu \mathrm{L}, 1.2 \mathrm{mmol})$ se aislaron $122.4 \mathrm{mg}(63 \%)$ de $\mathbf{6 3}$ como un sólido amarillo. p. f. $60-62^{\circ} \mathrm{C}$ HPLC: pureza (100\%). MS : m/z $=389[\mathrm{M}+\mathrm{H}]^{+} .{ }^{1} \mathrm{H}-\mathrm{RMN}$ (400 MHz, $\left.\mathrm{CDCl}_{3}\right), \delta(\mathrm{ppm}): 7.64\left(\mathrm{~d}, 2 \mathrm{H}_{9,11}, \mathrm{~J}=8.6\right), 7.42\left(\mathrm{~d}, 2 \mathrm{H}_{8,12}, \mathrm{~J}=8.6\right), 7.41(\mathrm{~m}, 1 \mathrm{H})$, $7.28(\mathrm{~m}, 6 \mathrm{H}), 6.94(\mathrm{td}, 1 \mathrm{H}, \mathrm{J}=7.4, \mathrm{~J}=0.8), 6.86(\mathrm{dd}, 1 \mathrm{H}, \mathrm{J}=7.4, \mathrm{~J}=0.8), 6.16(\mathrm{t}, \mathrm{NH}, \mathrm{J}=$ 5.5), $3.80\left(\mathrm{~s}, 3 \mathrm{H}, \mathrm{OCH}_{3}\right), 3.71\left(\mathrm{c}, 2 \mathrm{H}_{\delta}, \mathrm{J}=6.9\right), 3.59\left(\mathrm{~s}, 2 \mathrm{H}_{\beta}\right), 3.56\left(\mathrm{~s}, 2 \mathrm{H}_{\alpha}\right), 2.93\left(\mathrm{t}, 2 \mathrm{H}_{\varepsilon}\right.$, $\mathrm{J}=6.9), 2.21\left(\mathrm{~s}, 3 \mathrm{H}_{\chi}\right) .{ }^{13} \mathrm{C}-\mathrm{RMN}\left(100 \mathrm{MHz}, \mathrm{CDCl}_{3}\right), \delta(\mathrm{ppm}): 167.4(\mathrm{CONH}), 157.7(\mathrm{C})$, $143.4(\mathrm{C}), 138.9(\mathrm{C}), 133.1(\mathrm{C}), 130.3(\mathrm{CH}), 129.0(2 \mathrm{CH}), 128.8(2 \mathrm{CH}), 128.7(2 \mathrm{CH})$, $128.0(\mathrm{CH}), 126.9(\mathrm{C}), 126.7(2 \mathrm{CH}), 126.5(\mathrm{CH}), 120.3(\mathrm{CH}), 110.3(\mathrm{CH}), 61.7\left(\mathrm{CH}_{2}\right)$, $55.3\left(\mathrm{CH}_{2}\right), 55.2\left(\mathrm{CH}_{3}\right), 42.4\left(\mathrm{CH}_{3}\right), 41.1\left(\mathrm{CH}_{2}\right), 35.7\left(\mathrm{CH}_{3}\right)$. Análisis (\%): Calculado para $\mathrm{C}_{25} \mathrm{H}_{28} \mathrm{~N}_{2} \mathrm{O}$ : C, 77.29, H, 7.26, N, 7.21. Encontrado: C, 77.18, H, 7.21, N, 7.24.

\section{4-((Bencil(metil)amino)metil)-N-(4-hidroxifenetil)benzamida (64)}

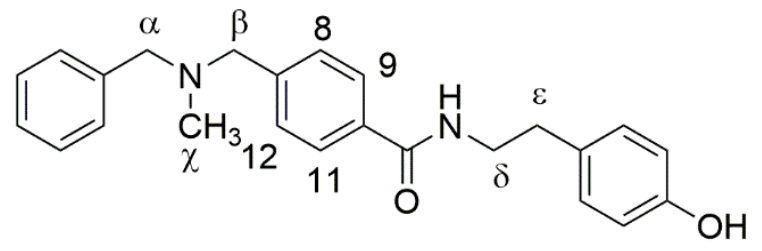

Siguiendo el procedimiento general, a partir del ácido 4-((bencil(metil)amino)metil)benzoico (127.6 $\mathrm{mg}, 0.5 \mathrm{mmol}$ ), pyBOP (312.2 $\mathrm{mg}, 0.6 \mathrm{mmol}), 4-(2-$ aminoetil)fenol (86.8 mg, $0.5 \mathrm{mmol}) \mathrm{y}$

$\mathrm{Et}_{3} \mathrm{~N}(156 \mu \mathrm{L}, 1.2 \mathrm{mmol})$ se aislaron $159.2 \mathrm{mg}(85 \%)$ de 64 como un sólido blanco. p. f. 33-35 ${ }^{\circ} \mathrm{C}$ HPLC: pureza (100\%). MS : m/z = $375[\mathrm{M}+\mathrm{H}]^{+} .{ }^{1} \mathrm{H}-\mathrm{RMN}\left(400 \mathrm{MHz}, \mathrm{CD}_{3} \mathrm{OD}\right)$, $\delta(\mathrm{ppm}): 7.73\left(\mathrm{~d}, 2 \mathrm{H}_{9,11}, \mathrm{~J}=8.4\right), 7.40\left(\mathrm{~d}, 2 \mathrm{H}_{8,12}, \mathrm{~J}=8.4\right), 7.27(\mathrm{~m}, 5 \mathrm{H}), 7.05\left(\mathrm{~d}, 2 \mathrm{H}_{2}{ }^{\prime}, 6^{\prime}, \mathrm{J}=\right.$ 8.6), $6.71\left(\mathrm{~d}, 2 \mathrm{H}_{3}, .5\right.$, J = 8.6), $3.51\left(\mathrm{~s}, 2 \mathrm{H}_{\beta}\right), 3.50\left(\mathrm{t}, 2 \mathrm{H}_{\delta}, \mathrm{J}=7.6\right), 3.48\left(\mathrm{~s}, 2 \mathrm{H}_{\alpha}\right), 3.13$ (s, $\left.3 \mathrm{H}_{\chi}\right), 2.79$ (t, $\left.2 \mathrm{H}_{\varepsilon}, \mathrm{J}=7.6\right) .{ }^{13} \mathrm{C}-\mathrm{RMN}\left(100 \mathrm{MHz}, \mathrm{CD}_{3} \mathrm{OD}\right), \delta(\mathrm{ppm}): 168.9(\mathrm{CONH}), 155.8$ (C), $142.8(\mathrm{C}), 138.5(\mathrm{C}), 133.5(\mathrm{C}), 130.2(\mathrm{C}), 129.7(2 \mathrm{CH}), 129.2(2 \mathrm{CH}), 129.1(2 \mathrm{CH})$, 
128.2 (2CH), $127.1(\mathrm{CH}), 127.1(2 \mathrm{CH}), 115.1(2 \mathrm{CH}), 61.6\left(\mathrm{CH}_{2}\right), 61.0\left(\mathrm{CH}_{2}\right), 41.8\left(\mathrm{CH}_{2}\right)$, $41.3\left(\mathrm{CH}_{3}\right), 34.6\left(\mathrm{CH}_{2}\right)$ Análisis (\%): Calculado para $\mathrm{C}_{24} \mathrm{H}_{26} \mathrm{~N}_{2} \mathrm{O}_{2}: \mathrm{C}, 76.98, \mathrm{H}, 7.00, \mathrm{~N}$, 7.48. Encontrado: C, 77.01, H, 7.10, N, 7.52.

\section{4-(((2-Clorobencil)(metil)amino)metil)-N-(4-hidroxifenetil)benzamida (65)}

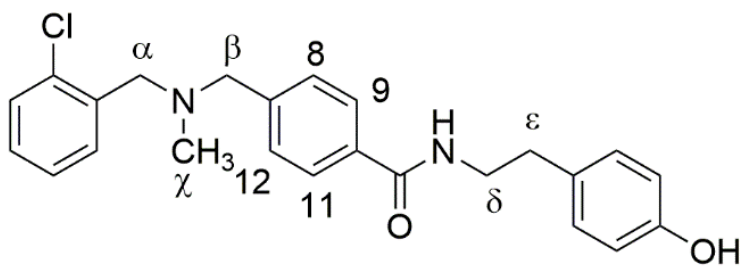

Siguiendo el procedimiento general, a partir del ácido 4-(((2-clorobencil)(metil)amino)metil)benzoico (144.9 $\mathrm{mg}, 0.5$ $\mathrm{mmol})$, pyBOP (312.2 $\mathrm{mg}, 0.6 \mathrm{mmol}), 4-$ (2-aminoetil)fenol ( $86.8 \mathrm{mg}, 0.5 \mathrm{mmol})$ y Et $3 \mathrm{~N}(156 \mu \mathrm{L}, 1.2 \mathrm{mmol})$ se aislaron $141.1 \mathrm{mg}$ (69\%) de 65 como un sólido amarillo. p. f. $34-36^{\circ} \mathrm{C}$ HPLC: pureza (100\%). MS : m/z = $409[\mathrm{M}+\mathrm{H}]^{+} .{ }^{1} \mathrm{H}-\mathrm{RMN}\left(400 \mathrm{MHz}, \mathrm{CD}_{3} \mathrm{OD}\right), \delta(\mathrm{ppm}): 7.71$ (d, 2 $\mathrm{H}_{9,11}, \mathrm{~J}=8.2$ ), 7.52 (dd, $\left.1 \mathrm{H}_{3}, \mathrm{~J}=7.6, \mathrm{~J}=1.8\right), 7.43\left(\mathrm{~d}, 2 \mathrm{H}_{8,12}, \mathrm{~J}=8.2\right), 7.35\left(\mathrm{dd}, 1 \mathrm{H}_{6}, \mathrm{~J}=7.6, \mathrm{~J}=1.4\right), 7.27\left(\mathrm{td}, 1 \mathrm{H}_{4}\right.$,

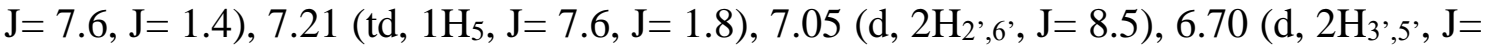
8.4), $3.63\left(\mathrm{~s}, 2 \mathrm{H}_{\beta}\right), 3.61\left(\mathrm{~s}, 2 \mathrm{H}_{\alpha}\right), 3.52\left(\mathrm{t}, 2 \mathrm{H}_{\delta}, \mathrm{J}=7.6\right), 2.80\left(\mathrm{t}, 2 \mathrm{H}_{\varepsilon}, \mathrm{J}=7.6\right), 2.17\left(\mathrm{~s}, 3 \mathrm{H}_{\chi}\right)$. ${ }^{13} \mathrm{C}-\mathrm{RMN}$ (100 MHz, CD $\left.3 \mathrm{OD}\right), \delta(\mathrm{ppm}): 170.1$ (CONH), $156.9(\mathrm{C}), 144.1(\mathrm{C}), 137.5(\mathrm{C})$, $133.5(\mathrm{C}), 134.7(\mathrm{C}), 132.3(\mathrm{CH}), 131.4(\mathrm{C}), 130.8(2 \mathrm{CH}), 130.5(\mathrm{CH}), 130.1(2 \mathrm{CH})$, 129.6 (CH), $128.2(2 \mathrm{CH}), 127.9(2 \mathrm{CH}), 116.2(2 \mathrm{CH}), 62.6\left(\mathrm{CH}_{2}\right), 59.4\left(\mathrm{CH}_{2}\right), 43.0\left(\mathrm{CH}_{2}\right)$, $42.5\left(\mathrm{CH}_{3}\right), 35.7\left(\mathrm{CH}_{2}\right)$ Análisis (\%): Calculado para $\mathrm{C}_{24} \mathrm{H}_{25} \mathrm{ClN}_{2} \mathrm{O}_{2}$ : C, 70.49, H, 6.16, N, 6.85. Encontrado: C, 70.42, H, 6.21, N, 6.77.

\section{4-(((3-Clorobencil)(metil)amino)metil)-N-(4-hidroxifenetil)benzamida (66)}<smiles>Cc1cccc(Cl)c1</smiles>

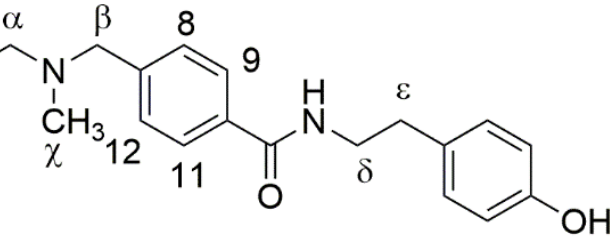

Siguiendo el procedimiento general, a partir del ácido 4-(((3-clorobencil)(metil)amino)metil)benzoico $\quad(144.9 \mathrm{mg}, 0.5$ $\mathrm{mmol})$, pyBOP (312.2 mg, $0.6 \mathrm{mmol})$, 4-

(2-aminoetil)fenol ( $86.8 \mathrm{mg}, 0.5 \mathrm{mmol})$ y Et ${ }_{3} \mathrm{~N}(156 \mu \mathrm{L}, 1.2 \mathrm{mmol})$ se aislaron $186.1 \mathrm{mg}$ (91\%) de 66 como un sólido blanco. p. f. $31-33^{\circ} \mathrm{C}$ HPLC: pureza (100\%). MS : m/z = 409 $[\mathrm{M}+\mathrm{H}]^{+} .{ }^{1} \mathrm{H}-\mathrm{RMN}\left(400 \mathrm{MHz}, \mathrm{CD}_{3} \mathrm{OD}\right), \delta(\mathrm{ppm}): 7.73\left(\mathrm{~d}, 2 \mathrm{H}_{9,11}, \mathrm{~J}=8.2\right), 7.40\left(\mathrm{~d}, 2 \mathrm{H}_{8,12}\right.$, $\mathrm{J}=8.2), 7.34\left(\mathrm{~s}, 1 \mathrm{H}_{2}\right), 7.24(\mathrm{~m}, 3 \mathrm{H}), 7.04\left(\mathrm{~d}, 2 \mathrm{H}_{2}{ }^{\prime}, 6^{\prime}, \mathrm{J}=8.4\right), 6.71\left(\mathrm{~d}, 2 \mathrm{H}_{3}, 5^{\prime}, \mathrm{J}=8.4\right), 3.52$ $\left(\mathrm{s}, 2 \mathrm{H}_{\beta}\right), 3.46\left(\mathrm{~s}, 2 \mathrm{H}_{\alpha}\right), 3.42\left(\mathrm{t}, 2 \mathrm{H}_{\delta}, \mathrm{J}=7.4\right), 2.79\left(\mathrm{t}, 2 \mathrm{H}_{\varepsilon}, \mathrm{J}=7.4\right), 2.12\left(\mathrm{~s}, 3 \mathrm{H}_{\chi}\right) .{ }^{13} \mathrm{C}-\mathrm{RMN}$ (100 MHz, CD $\left.{ }_{3} \mathrm{OD}\right), \delta(\mathrm{ppm}): 170.0(\mathrm{CONH}), 156.9$ (C), 143.8 (C), 142.5 (C), 135.2 (C), 
$134.7(\mathrm{C}), 131.3(\mathrm{C}), 131.4(\mathrm{C}), 130.8(\mathrm{CH}), 130.7(2 \mathrm{CH}), 130.1(2 \mathrm{CH}), 129.9(\mathrm{CH})$, $128.4(2 \mathrm{CH}), 128.3(2 \mathrm{CH}), 116.2(2 \mathrm{CH}), 62.3\left(\mathrm{CH}_{2}\right), 62.0\left(\mathrm{CH}_{2}\right), 43.0\left(\mathrm{CH}_{2}\right), 42.4\left(\mathrm{CH}_{3}\right)$, $35.7\left(\mathrm{CH}_{2}\right)$ Análisis (\%): Calculado para $\mathrm{C}_{24} \mathrm{H}_{25} \mathrm{ClN}_{2} \mathrm{O}_{2}$ : C, 70.49, H, 6.16, N, 6.85. Encontrado: C, 70.52, H, 6.26, N, 6.81.

\section{$N$-(4-Hidroxifenetil)-4-(((2-metoxibenzil)(metil)amino)metil)benzamida (67)}<smiles>[Y2]CN(Cc1ccc(C(=O)NCCc2ccc(O)cc2)cc1)Cc1ccccc1OC</smiles>
Siguiendo el procedimiento general, a partir del ácido 4-(((2-metoxibencil)(metil)amino)metil)benzoico $\quad(142.7 \quad \mathrm{mg}, \quad 0.5$ $\mathrm{mmol})$, pyBOP (312.2 mg, $0.6 \mathrm{mmol}), 4-(2-$ aminoetil)fenol ( $86.8 \mathrm{mg}, 0.5 \mathrm{mmol})$ y $\mathrm{Et}_{3} \mathrm{~N}(156 \mu \mathrm{L}, 1.2 \mathrm{mmol})$ se aislaron $145.6 \mathrm{mg}$ (72\%) de 67 como un sólido blanco. p. f. $46-48^{\circ} \mathrm{C}$ HPLC: pureza (100\%). MS : m/z $=405$ $[\mathrm{M}+\mathrm{H}]^{+} .{ }^{1} \mathrm{H}-\mathrm{RMN}\left(400 \mathrm{MHz}, \mathrm{CD}_{3} \mathrm{OD}\right), \delta(\mathrm{ppm}): 7.43$ (d, 2H $\left.\mathrm{H}_{9,11}, \mathrm{~J}=8.3\right), 7.41\left(\mathrm{~d}, 2 \mathrm{H}_{8,12}\right.$, $\mathrm{J}=8.3), 7.30\left(\mathrm{dd}, 1 \mathrm{H}_{6}, \mathrm{~J}=7.8, \mathrm{~J}=1.7\right), 7.22\left(\mathrm{td}, 1 \mathrm{H}_{5}, \mathrm{~J}=7.8, \mathrm{~J}=1.7\right), 7.04\left(\mathrm{~d}, 2 \mathrm{H}_{2}{ }^{\prime} .6^{\prime}, \mathrm{J}=\right.$ 8.6), $6.91\left(\mathrm{td}, 1 \mathrm{H}_{4}, \mathrm{~J}=7.8, \mathrm{~J}=1.7\right), 6.88\left(\mathrm{dd}, 1 \mathrm{H}_{3}, \mathrm{~J}=7.8, \mathrm{~J}=1.7\right), 6.70\left(\mathrm{~d}, 2 \mathrm{H}_{3}{ }^{\prime} .5^{\prime}, \mathrm{J}=8.6\right)$, $3.55\left(\mathrm{~s}, 2 \mathrm{H}_{\beta}\right), 3.52\left(\mathrm{t}, 2 \mathrm{H}_{\delta}, \mathrm{J}=7.5\right), 3.51\left(\mathrm{~s}, 2 \mathrm{H}_{\alpha}\right), 2.79\left(\mathrm{t}, 2 \mathrm{H}_{\varepsilon}, \mathrm{J}=7.5\right), 2.15\left(\mathrm{~s}, 3 \mathrm{H}_{\chi}\right) \cdot{ }^{13} \mathrm{C}$ -RMN (100 MHz, CD 3 OD), $\delta(\mathrm{ppm}): 168.9$ (CONH), 158.2 (C), 156.3 (C), 142.7 (C), $133.5(\mathrm{C}), 130.9(\mathrm{C}), 129.8(\mathrm{C}), 129.6(2 \mathrm{CH}), 129.2(2 \mathrm{CH}), 128.6(\mathrm{CH}), 127.0(2 \mathrm{CH})$, $125.9(\mathrm{CH}), 120.1(\mathrm{CH}), 115.3(2 \mathrm{CH}), 110.4(\mathrm{CH}), 61.4\left(\mathrm{CH}_{2}\right), 54.9\left(\mathrm{CH}_{2}\right), 54.5\left(\mathrm{CH}_{3}\right)$, $41.9\left(\mathrm{CH}_{2}\right), 41.5\left(\mathrm{CH}_{3}\right), 34.6\left(\mathrm{CH}_{2}\right)$ Análisis (\%): Calculado para $\mathrm{C}_{25} \mathrm{H}_{28} \mathrm{~N}_{2} \mathrm{O}_{3}$ : $\mathrm{C}, 74.23$, H, 6.98, N, 6.93. Encontrado: C, 74.42, H, 7.18, N, 6.89. 


\section{$N$-(4-hidroxifenetil)-4-(((3-metoxibenzil)(metil)amino)metil)benzamida (68)}<smiles>CCc1cccc(OC)c1</smiles><smiles></smiles>

Siguiendo el procedimiento general, a partir del ácido 4-(((3-metoxibencil)(metil)amino)metil)benzoico (142.7 $\mathrm{mg}$, $0.5 \mathrm{mmol})$, pyBOP (312.2 mg, $0.6 \mathrm{mmol})$, 4-(2-aminoetil)fenol (86.8 mg, $0.5 \mathrm{mmol}) \mathrm{y} \mathrm{Et}_{3} \mathrm{~N}(156 \mu \mathrm{L}, 1.2 \mathrm{mmol})$ se aislaron 163.8 mg $(81 \%)$ de 68 como un sólido amarillo. p. f. $36-38^{\circ} \mathrm{C}$ HPLC: pureza (99\%). MS : m/z $=405[\mathrm{M}+\mathrm{H}]^{+} .{ }^{1} \mathrm{H}-\mathrm{RMN}\left(400 \mathrm{MHz}, \mathrm{CD}_{3} \mathrm{OD}\right), \delta(\mathrm{ppm}): 7.72\left(\mathrm{~d}, 2 \mathrm{H}_{9,11}, \mathrm{~J}=8.2\right), 7.39(\mathrm{~d}$, $\left.2 \mathrm{H}_{8,12}, \mathrm{~J}=8.2\right), 7.19\left(\mathrm{t}, 1 \mathrm{H}_{5}, \mathrm{~J}=8.2\right), 7.04\left(\mathrm{~d}, 2 \mathrm{H}_{2}{ }^{\prime} .6^{\prime}, \mathrm{J}=8.4\right), 6.90\left(\mathrm{dd}, 1 \mathrm{H}_{6}, \mathrm{~J}=8.2, \mathrm{~J}=2.4\right)$, $6.87\left(\mathrm{~s}, 1 \mathrm{H}_{2}\right), 6.78\left(\mathrm{dd}, 1 \mathrm{H}_{4}, \mathrm{~J}=8.2, \mathrm{~J}=2.4\right), 6.72\left(\mathrm{~d}, 2 \mathrm{H}_{3}{ }^{\prime}, 5^{\prime}, \mathrm{J}=8.4\right), 3.74\left(\mathrm{~s}, 3 \mathrm{H}, \mathrm{OCH}_{3}\right)$, $3.51\left(\mathrm{t}, 2 \mathrm{H}_{\delta}, \mathrm{J}=7.8\right), 3.50\left(\mathrm{~s}, 2 \mathrm{H}_{\beta}\right), 3.44\left(\mathrm{~s}, 2 \mathrm{H}_{\alpha}\right), 2.79\left(\mathrm{t}, 2 \mathrm{H}_{\varepsilon}, \mathrm{J}=7.8\right), 2.13\left(\mathrm{~s}, 3 \mathrm{H}_{\chi}\right) \cdot{ }^{13} \mathrm{C}$ -RMN (100 MHz, CD 3 OD), $\delta(\mathrm{ppm}): 168.9$ (CONH), 161.1 (C), 156.8 (C), 143.8 (C), $141.3(\mathrm{C}), 134.6(\mathrm{C}), 131.3(\mathrm{C}), 130.8(2 \mathrm{CH}), 130.3(\mathrm{CH}), 130.2(2 \mathrm{CH}), 128.2(2 \mathrm{CH})$, $122.4(\mathrm{CH}), 116.2(2 \mathrm{CH}), 115.6(\mathrm{CH}), 113.7(\mathrm{CH}), 62.7\left(\mathrm{CH}_{2}\right), 62.1\left(\mathrm{CH}_{2}\right), 55.6\left(\mathrm{CH}_{3}\right)$, $42.9\left(\mathrm{CH}_{2}\right), 42.5\left(\mathrm{CH}_{3}\right), 35.7\left(\mathrm{CH}_{2}\right)$ Análisis (\%): Calculado para $\mathrm{C}_{25} \mathrm{H}_{28} \mathrm{~N}_{2} \mathrm{O}_{3}: \mathrm{C}, 74.23$, H, 6.98, N, 6.93. Encontrado: C, 74.28, H, 7.08, N, 6.96.

\section{4-((Bencil(metil)amino)metil)- $N$-(3-hidroxipiridin-2-il)benzamida (69)}<smiles>[Y2]CN(Cc1ccccc1)Cc1ccc(C(=O)Nc2ncccc2O)cc1</smiles>

6'

Siguiendo el procedimiento general, a partir del ácido 4-((bencil(metil)amino)metil)benzoico (127.6 mg, $0.5 \mathrm{mmol}$ ), pyBOP (312.2 $\mathrm{mg}, 0.6$ $\mathrm{mmol})$, 2-amino-3-hidroxipiridina $(55.1 \mathrm{mg}, 0.5$ mmol) y $\mathrm{Et}_{3} \mathrm{~N}(156 \mu \mathrm{L}, 1.2 \mathrm{mmol})$ se aislaron $83.4 \mathrm{mg}(\%)$ de 69 como un aceite. HPLC: pureza (100\%). MS : m/z $=348[\mathrm{M}+\mathrm{H}]^{+} .{ }^{1} \mathrm{H}$ -RMN (400 MHz, CD $\left.{ }_{3} \mathrm{OD}\right), \delta(\mathrm{ppm}): 7.98\left(\mathrm{~d}, 2 \mathrm{H}_{9,11}, \mathrm{~J}=8.0\right), 7.90\left(\mathrm{dd}, 1 \mathrm{H}_{6}, \mathrm{~J}=4.7, \mathrm{~J}=\right.$ 1.2), $7.49\left(\mathrm{~d}, 2 \mathrm{H}_{8,12}, \mathrm{~J}=8.0\right), 7.32(\mathrm{~m}, 5 \mathrm{H}), 7.23(\mathrm{~m}, 1 \mathrm{H}), 7.17\left(\mathrm{dd}, 1 \mathrm{H}_{5}, \mathrm{~J}=8.2, \mathrm{~J}=4.7\right)$, $3.56\left(\mathrm{~s}, 2 \mathrm{H}_{\beta}\right), 3.52\left(\mathrm{~s}, 2 \mathrm{H}_{\alpha}\right), 2.16\left(\mathrm{~s}, 3 \mathrm{H}_{\chi}\right) \cdot{ }^{13} \mathrm{C}-\mathrm{RMN}\left(100 \mathrm{MHz}, \mathrm{CD}_{3} \mathrm{OD}\right), \delta(\mathrm{ppm}): 169.3$ (CONH), $148.0(\mathrm{C}), 145.2(\mathrm{C}), 141.5(\mathrm{C}), 139.7$ (C), $139.3(\mathrm{CH}), 133.3(\mathrm{C}), 130.4(2 \mathrm{CH})$, $130.3(2 \mathrm{CH}), 129.3(2 \mathrm{CH}), 129.1(\mathrm{CH}), 128.3(\mathrm{CH}), 127.3(2 \mathrm{CH}), 124.0(\mathrm{CH}), 62.8$ $\left(\mathrm{CH}_{2}\right), 62.2\left(\mathrm{CH}_{2}\right), 42.5\left(\mathrm{CH}_{3}\right)$. Análisis (\%): Calculado para $\mathrm{C}_{21} \mathrm{H}_{21} \mathrm{~N}_{3} \mathrm{O}_{2}: \mathrm{C}, 72.60, \mathrm{H}$, 6.09, N, 12.10. Encontrado: C, 72.49, H, 5.89, N, 12.36 . 


\section{4-(((2-Clorobencil)(metil)amino)metil)- $N$-(3-hidroxipiridin-2-il)benzamida (70)}<smiles>[Y20]Cc1ccc(C(=O)N(C)Cc2ccccc2Cl)cc1</smiles>
Siguiendo el procedimiento general, a partir del ácido 4-(((2-clorobencil)(metil)amino)metil)benzoico (135.4 mg, $0.5 \mathrm{mmol})$, pyBOP (312.2 mg, 0.6 mmol), 2-amino-3-hidroxipiridina $(55.1 \mathrm{mg}, 0.5$ mmol) y Et ${ }_{3} \mathrm{~N}(156 \mu \mathrm{L}, 1.2 \mathrm{mmol})$ se aislaron $110.7 \mathrm{mg}$ (58\%) de 84 como un aceite. HPLC: pureza (100\%). MS: m/z = $382[\mathrm{M}+\mathrm{H}]^{+} .{ }^{1} \mathrm{H}-\mathrm{RMN}\left(400 \mathrm{MHz}, \mathrm{CD}_{3} \mathrm{OD}\right), \delta(\mathrm{ppm})$ : $7.94\left(\mathrm{~d}, 2 \mathrm{H}_{9,11}, \mathrm{~J}=8.2\right), 7.88\left(\mathrm{~m}, 1 \mathrm{H}_{6}{ }^{\prime}\right), 7.51(\mathrm{~m}, 1 \mathrm{H}), 7.48\left(\mathrm{~d}, 2 \mathrm{H}_{8,12}, \mathrm{~J}=8.2\right), 7.32(\mathrm{~m}$, 2H), $7.20(\mathrm{~m}, 3 \mathrm{H}), 3.61\left(\mathrm{~s}, 2 \mathrm{H}_{\beta}\right), 3.60\left(\mathrm{~s}, 2 \mathrm{H}_{\alpha}\right), 2.15\left(\mathrm{~s}, 3 \mathrm{H}_{\chi}\right) \cdot{ }^{13} \mathrm{C}-\mathrm{RMN}(100 \mathrm{MHz}$, CD $\left.{ }_{3} \mathrm{OD}\right), \delta(\mathrm{ppm}): 169.3(\mathrm{CONH}), 148.0(\mathrm{C}), 145.4(\mathrm{C}), 141.4(\mathrm{C}), 139.3(\mathrm{CH}), 137.5$ (C), $135.4(\mathrm{C}), 133.2(\mathrm{C}), 132.2(\mathrm{CH}), 130.5(\mathrm{CH}), 130.2(2 \mathrm{CH}), 129.6(\mathrm{CH}), 129.1$ $(2 \mathrm{CH}), 127.9(\mathrm{CH}), 127.3(\mathrm{CH}), 124.0(\mathrm{CH}), 62.6\left(\mathrm{CH}_{2}\right), 59.4\left(\mathrm{CH}_{2}\right), 42.5\left(\mathrm{CH}_{3}\right)$. Análisis (\%): Calculado para $\mathrm{C}_{21} \mathrm{H}_{20} \mathrm{ClN}_{3} \mathrm{O}_{2}$ : C, 66.05, H, 5.28, N, 11.00. Encontrado: $\mathrm{C}$, $66.13, \mathrm{H}, 5.09, \mathrm{~N}, 10.74$

\section{4-(((3-Clorobencil)(metil)amino)metil)- $N$-(3-hidroxipiridin-2-il)benzamida (71)}<smiles>[Y2]CN(Cc1cccc(Cl)c1)Cc1cccc(C(=O)Nc2ncccc2O)c1</smiles>

6

Siguiendo el procedimiento general, a partir del ácido 4-(((3-clorobencil)(metil)amino)metil)benzoico (135.4 mg, $0.5 \mathrm{mmol}$ ), pyBOP (312.2 mg, $0.6 \mathrm{mmol}), 2$-amino-3-hidroxipiridina $(55.1 \mathrm{mg}$, $0.5 \mathrm{mmol})$ y $\mathrm{Et}_{3} \mathrm{~N}(156 \mu \mathrm{L}, 1.2 \mathrm{mmol})$ se aislaron $126.0 \mathrm{mg}(66 \%)$ de 71 como un aceite. HPLC: pureza (100\%). MS : m/z = $382[\mathrm{M}+\mathrm{H}]^{+}$. ${ }^{1} \mathrm{H}-\mathrm{RMN}\left(400 \mathrm{MHz}, \mathrm{CD}_{3} \mathrm{OD}\right), \delta(\mathrm{ppm}): 7.97$ (d, 2H $\mathrm{H}_{911}, \mathrm{~J}=8.4$ ), 7.90 (dd, 1H $\mathrm{H}_{6}, \mathrm{~J}=4.8, \mathrm{~J}=$ 1.5), $7.48\left(\mathrm{~d}, 2 \mathrm{H}_{8,12}, \mathrm{~J}=8.4\right), 7.37\left(\mathrm{~s}, 1 \mathrm{H}_{2}\right), 7.34\left(\mathrm{dd}, 1 \mathrm{H}_{4}, \mathrm{~J}=8.1, \mathrm{~J}=1.5\right), 7.24(\mathrm{~m}, 3 \mathrm{H})$, $7.17\left(\mathrm{dd}, 1 \mathrm{H}_{5}, \mathrm{~J}=8.1, \mathrm{~J}=4.8\right), 3.56\left(\mathrm{~s}, 2 \mathrm{H}_{\beta}\right), 3.48\left(\mathrm{~s}, 2 \mathrm{H}_{\alpha}\right), 2.14\left(\mathrm{~s}, 3 \mathrm{H}_{\chi}\right) \cdot{ }^{13} \mathrm{C}-\mathrm{RMN}(100$ $\left.\mathrm{MHz}, \mathrm{CD}_{3} \mathrm{OD}\right), \delta(\mathrm{ppm}): 169.2(\mathrm{CONH}), 148.0(\mathrm{C}), 145.2(\mathrm{C}), 142.5(\mathrm{C}), 141.4(\mathrm{C}), 139.3$ (CH), $135.2(\mathrm{C}), 133.3(\mathrm{C}), 130.8(\mathrm{C}), 130.3(2 \mathrm{CH}), 129.9(\mathrm{CH}), 129.2(2 \mathrm{CH}), 128.4$ $(\mathrm{CH}), 128.3(\mathrm{CH}), 127.3(\mathrm{CH}), 124.0(\mathrm{CH}), 62.2\left(\mathrm{CH}_{2}\right), 62.1\left(\mathrm{CH}_{2}\right), 42.5\left(\mathrm{CH}_{3}\right)$. Análisis (\%): Calculado para $\mathrm{C}_{21} \mathrm{H}_{20} \mathrm{ClN}_{3} \mathrm{O}_{2}$ : C, 66.05, H, 5.28, N, 11.00. Encontrado: C, 66.37, $\mathrm{H}, 5.42, \mathrm{~N}, 11.44$ 


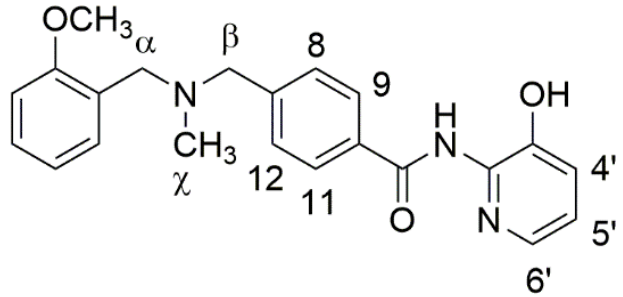

Siguiendo el procedimiento general, a partir del ácido 4-(((2-metoxibencil)(metil)amino)metil)benzoico (142.7 mg, $0.5 \mathrm{mmol})$, pyBOP (312.2 $\mathrm{mg}, 0.6 \mathrm{mmol})$, 2-amino-3-hidroxipiridina (55.1 $\mathrm{mg}, 0.5 \mathrm{mmol})$ y $\mathrm{Et}_{3} \mathrm{~N}(156 \mu \mathrm{L}, 1.2 \mathrm{mmol})$ se aislaron $67.9 \mathrm{mg}(36 \%)$ de 72 como un aceite. HPLC: pureza (100\%). MS : $\mathrm{m} / \mathrm{z}=378$ $[\mathrm{M}+\mathrm{H}]^{+} .{ }^{1} \mathrm{H}-\mathrm{RMN}\left(400 \mathrm{MHz}, \mathrm{CD}_{3} \mathrm{OD}\right), \delta(\mathrm{ppm}): 7.98\left(\mathrm{~d}, 2 \mathrm{H}_{9,11}, \mathrm{~J}=8.6\right), 7.90$ (dd, 1H${ }_{6}$, $\mathrm{J}=4.7, \mathrm{~J}=1.6), 7.51\left(\mathrm{~d}, 2 \mathrm{H}_{8,12}, \mathrm{~J}=8.6\right), 7.34(\mathrm{~m}, 2 \mathrm{H}), 7.23(\mathrm{td}, 1 \mathrm{H}, \mathrm{J}=7.8, \mathrm{~J}=1.6), 7.17$ $\left(\mathrm{dd}, 1 \mathrm{H}_{4}, \mathrm{~J}=8.2, \mathrm{~J}=4.7\right), 6.92(\mathrm{~m}, 2 \mathrm{H}), 3.78\left(\mathrm{~s}, 3 \mathrm{H}, \mathrm{OCH}_{3}\right), 3.63\left(\mathrm{~s}, 2 \mathrm{H}_{\beta}\right), 3.57\left(\mathrm{~s}, 2 \mathrm{H}_{\alpha}\right)$, $2.21\left(\mathrm{~s}, 3 \mathrm{H}_{\chi}\right) \cdot{ }^{13} \mathrm{C}-\mathrm{RMN}\left(100 \mathrm{MHz}, \mathrm{CD}_{3} \mathrm{OD}\right), \delta(\mathrm{ppm}): 169.2(\mathrm{CONH}), 159.4(\mathrm{C}), 148.3$ (C), $144.9(\mathrm{C}), 141.6(\mathrm{C}), 139.1(\mathrm{CH}), 133.4(\mathrm{C}), 132.0(\mathrm{C}), 130.5(2 \mathrm{CH}), 129.8(\mathrm{CH})$, $129.1(2 \mathrm{CH}), 127.2(\mathrm{CH}), 126.9(\mathrm{CH}), 124.0(\mathrm{CH}), 121.3(\mathrm{CH}), 111.6(\mathrm{CH}), 62.5\left(\mathrm{CH}_{2}\right)$, $56.1\left(\mathrm{CH}_{2}\right), 55.7\left(\mathrm{CH}_{3}\right), 42.6\left(\mathrm{CH}_{3}\right)$. Análisis (\%): Calculado para $\mathrm{C}_{22} \mathrm{H}_{23} \mathrm{~N}_{3} \mathrm{O}_{3}: \mathrm{C}, 70.01$, H, 6.14, N, 11.13. Encontrado: C, 70.42, H, 6.36, N, 11.23

\section{$N$-(3-Hidroxipiridin-2-il)-4-(((3-metoxibencil)(metil)amino)metil)benzamida (73)}

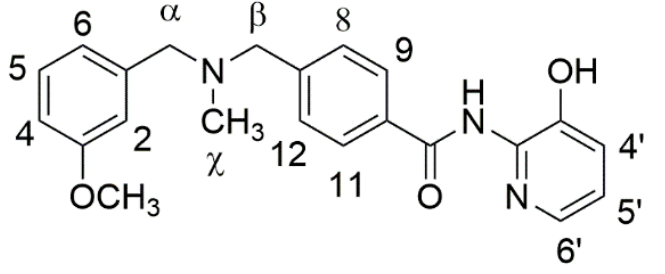

Siguiendo el procedimiento general, a partir del ácido 4-(((3-metoxibencil)(metil)amino)metil)benzoico (142.7 mg, $0.5 \mathrm{mmol})$, pyBOP (312.2 $\mathrm{mg}, \quad 0.6 \mathrm{mmol}), \quad$ 2-amino-3-hidroxipiridina (55.1 mg, $0.5 \mathrm{mmol})$ y Et ${ }_{3} \mathrm{~N}(156 \mu \mathrm{L}, 1.2 \mathrm{mmol})$

se aislaron $54.7 \mathrm{mg}$ (29\%) de 73 como un aceite. HPLC: pureza (100\%). MS : m/z = 378 $[\mathrm{M}+\mathrm{H}]^{+} .{ }^{1} \mathrm{H}-\mathrm{RMN}\left(400 \mathrm{MHz}, \mathrm{CD}_{3} \mathrm{OD}\right), \delta(\mathrm{ppm}): 7.99\left(\mathrm{~d}, 2 \mathrm{H}_{9,11}, \mathrm{~J}=8.6\right), 7.91\left(\mathrm{dd}, 1 \mathrm{H}_{6}\right.$, $\mathrm{J}=4.7, \mathrm{~J}=1.6), 7.52\left(\mathrm{~d}, 2 \mathrm{H}_{8,12}, \mathrm{~J}=8.6\right), 7.35\left(\mathrm{dd}, 1 \mathrm{H}_{4}, \mathrm{~J}=8.2, \mathrm{~J}=1.6\right), 7.23\left(\mathrm{dd}, 1 \mathrm{H}_{5}, \mathrm{~J}=\right.$ 8.2, J= 7.8), 7.19 (dd, 1 $\left.\mathrm{H}_{5}, \mathrm{~J}=8.2, \mathrm{~J}=4.7\right), 6.94\left(\mathrm{~m}, 1 \mathrm{H}_{6}\right), 6.92\left(\mathrm{~d} ; \mathrm{J}=0.8,1 \mathrm{H}_{2}\right), 6.82$ (ddd, $\left.1 \mathrm{H}_{4}, \mathrm{~J}=8.2, \mathrm{~J}=2.3, \mathrm{~J}=0.8\right), 3.78\left(\mathrm{~s}, 3 \mathrm{H}, \mathrm{OCH}_{3}\right), 3.59\left(\mathrm{~s}, 2 \mathrm{H}_{\beta}\right), 3.52\left(\mathrm{~s}, 2 \mathrm{H}_{\alpha}\right), 2.19(\mathrm{~s}$, $\left.3 \mathrm{H}_{\chi}\right) \cdot{ }^{13} \mathrm{C}-\mathrm{RMN}\left(100 \mathrm{MHz}, \mathrm{CD}_{3} \mathrm{OD}\right), \delta(\mathrm{ppm}): 169.3(\mathrm{CONH}), 161.2(\mathrm{C}), 148.2(\mathrm{C}), 145.1$ (C), $141.5(\mathrm{C}), 141.3(\mathrm{C}), 139.3(\mathrm{CH}), 133.4(\mathrm{C}), 130.4(2 \mathrm{CH}), 130.3(\mathrm{CH}), 129.1(2 \mathrm{CH})$, $127.2(\mathrm{CH}), 124.0(\mathrm{CH}), 122.5(\mathrm{CH}), 115.6(\mathrm{CH}), 113.8(\mathrm{CH}), 62.8\left(\mathrm{CH}_{2}\right), 62.1\left(\mathrm{CH}_{2}\right)$, 55.6 $\left(\mathrm{CH}_{3}\right), 42.6\left(\mathrm{CH}_{3}\right)$. Análisis (\%): Calculado para $\mathrm{C}_{22} \mathrm{H}_{23} \mathrm{~N}_{3} \mathrm{O}_{3}: \mathrm{C}, 70.01, \mathrm{H}, 6.14, \mathrm{~N}$, 11.13. Encontrado: C, 70.44, H, 6.43, N, 11.51 


\section{4-((Bencil(metil)amino)metil)- $N$-(piridin-2-il)benzamida (74)}<smiles>[Y]N(Cc1ccccc1)C([Y20])(F)Cc1ccccc1</smiles>

$6^{\prime}$

Siguiendo el procedimiento general, a partir del ácido 4-((bencil(metil)amino)metil)benzoico (127.6 mg, $0.5 \mathrm{mmol})$, pyBOP (312.2 $\mathrm{mg}, 0.6$ mmol), 2-aminopiridina (47.1 $\mathrm{mg}, 0.5 \mathrm{mmol}) \mathrm{y}$ $\mathrm{Et}_{3} \mathrm{~N}(156 \mu \mathrm{L}, 1.2 \mathrm{mmol})$ se aislaron $58.0 \mathrm{mg}$ (35\%) de 74 como un aceite. HPLC: pureza (100\%). MS : m/z $=332[\mathrm{M}+\mathrm{H}]^{+} .{ }^{1} \mathrm{H}-\mathrm{RMN}$ (400 MHz, $\left.\mathrm{CD}_{3} \mathrm{OD}\right), \delta(\mathrm{ppm}): 8.34\left(\mathrm{~m}, 1 \mathrm{H}_{6}{ }^{\prime}\right), 8.16\left(\mathrm{dt}, 1 \mathrm{H}_{3}, \mathrm{~J}=8.4, \mathrm{~J}=0.9\right), 7.94\left(\mathrm{~d}, 2 \mathrm{H}_{9,11}\right.$, $\mathrm{J}=8.3), 7.83\left(\mathrm{ddd}, 1 \mathrm{H}_{4}, \mathrm{~J}=8.4, \mathrm{~J}=7.3, \mathrm{~J}=1.8\right), 7.52\left(\mathrm{~d}, 2 \mathrm{H}_{8,12}, \mathrm{~J}=8.3\right), 7.33(\mathrm{~m}, 4 \mathrm{H}), 7.25$ (m, 1H), $7.17\left(\mathrm{ddd}, 1 \mathrm{H}_{5}, \mathrm{~J}=7.3, \mathrm{~J}=4.9, \mathrm{~J}=1.1\right), 3.61\left(\mathrm{~s}, 2 \mathrm{H}_{\beta}\right), 3.56\left(\mathrm{~s}, 2 \mathrm{H}_{\alpha}\right), 2.19$ (s, $\left.3 \mathrm{H}_{\chi}\right) \cdot{ }^{13} \mathrm{C}-\mathrm{RMN}\left(100 \mathrm{MHz}, \mathrm{CD}_{3} \mathrm{OD}\right), \delta(\mathrm{ppm}): 168.7(\mathrm{CONH}), 153.1(\mathrm{C}), 149.1(\mathrm{CH})$, $144.7(\mathrm{C}), 139.7(\mathrm{CH}), 134.4(\mathrm{C}), 130.5(2 \mathrm{CH}), 130.3(2 \mathrm{CH}), 129.3(2 \mathrm{CH}), 128.7(2 \mathrm{CH})$, $128.3(\mathrm{CH}), 127.3(\mathrm{C}), 121.4(\mathrm{CH}), 116.3(\mathrm{CH}), 62.7\left(\mathrm{CH}_{2}\right), 62.0\left(\mathrm{CH}_{2}\right), 42.4\left(\mathrm{CH}_{3}\right)$.. Análisis (\%): Calculado para $\mathrm{C}_{21} \mathrm{H}_{21} \mathrm{~N}_{3} \mathrm{O}: \mathrm{C}, 76.11, \mathrm{H}, 6.39, \mathrm{~N}, 12.68$. Encontrado: $\mathrm{C}$, $72.56, \mathrm{H}, 6.26, \mathrm{~N}, 12.41$

\section{4-(((2-Clorobencil)(metil)amino)metil)- $N$-(piridin-2-il)benzamida (75)}<smiles>[Y20]Cc1ccc(C(=O)Nc2ccccc2)cc1</smiles>

Siguiendo el procedimiento general, a partir del ácido 4-(((2-clorobencil)(metil)amino)metil)benzoico (135.4 mg, $0.5 \mathrm{mmol})$, pyBOP (312.2 $\mathrm{mg}, 0.6 \mathrm{mmol}), 2$-aminopiridina $(47.1 \mathrm{mg}, 0.5$ mmol) y $\mathrm{Et}_{3} \mathrm{~N}(156 \mu \mathrm{L}, 1.2 \mathrm{mmol})$ se aislaron

$27.4 \mathrm{mg}(15 \%)$ de 75 como un aceite. HPLC: pureza (100\%). MS : m/z = $366[\mathrm{M}+\mathrm{H}]^{+}$. ${ }^{1} \mathrm{H}$-RMN (400 MHz, $\left.\mathrm{CD}_{3} \mathrm{OD}\right), \delta(\mathrm{ppm}): 8.32\left(\mathrm{~m}, 1 \mathrm{H}_{6}\right.$ ), 8.21 (dt, $1 \mathrm{H}_{3}, \mathrm{~J}=8.6, \mathrm{~J}=1.2$ ), $7.92\left(\mathrm{~d}, 2 \mathrm{H}_{9,11}, \mathrm{~J}=8.6\right), 7.81\left(\mathrm{ddd}, 1 \mathrm{H}_{4}, \mathrm{~J}=8.6, \mathrm{~J}=7.4, \mathrm{~J}=2.0\right), 7.54\left(\mathrm{dd}, 1 \mathrm{H}_{3}, \mathrm{~J}=7.8, \mathrm{~J}=\right.$ 2.0), $7.52\left(\mathrm{~d}, 2 \mathrm{H}_{8,12}, \mathrm{~J}=8.6\right), 7.36\left(\mathrm{dd}, 1 \mathrm{H}_{6}, \mathrm{~J}=7.8, \mathrm{~J}=1.6\right), 7.28\left(\mathrm{td}, 1 \mathrm{H}_{4}, \mathrm{~J}=7.8, \mathrm{~J}=1.6\right)$, $7.23\left(\mathrm{td}, 1 \mathrm{H}_{5}, \mathrm{~J}=7.8, \mathrm{~J}=2.0\right), 7.13\left(\mathrm{ddd}, 1 \mathrm{H}_{5}, \mathrm{~J}=7.8, \mathrm{~J}=5.1, \mathrm{~J}=1.2\right), 3.65\left(\mathrm{~s}, 2 \mathrm{H}_{\beta}\right), 3.64$ (s, 2H $\left.\mathrm{H}_{\alpha}\right), 2.19\left(\mathrm{~s}, 3 \mathrm{H}_{\chi}\right) \cdot{ }^{13} \mathrm{C}-\mathrm{RMN}\left(100 \mathrm{MHz}, \mathrm{CD}_{3} \mathrm{OD}\right), \delta(\mathrm{ppm}): 168.3(\mathrm{CONH}), 153.3$ (C), $149.1(\mathrm{C}), 145.1(\mathrm{C}), 139.6(\mathrm{CH}), 137.6(\mathrm{C}), 135.5(\mathrm{C}), 133.4(\mathrm{CH}), 132.2(\mathrm{CH})$, $130.5(\mathrm{CH}), 130.3(2 \mathrm{CH}), 129.6(\mathrm{CH}), 128.8(2 \mathrm{CH}), 1227.9(\mathrm{CH}), 121.2(\mathrm{CH}), 116.2$ $(\mathrm{CH}), 62.6\left(\mathrm{CH}_{2}\right), 59.5\left(\mathrm{CH}_{2}\right), 42.5\left(\mathrm{CH}_{3}\right)$. Análisis (\%): Calculado para $\mathrm{C}_{21} \mathrm{H}_{21} \mathrm{~N}_{3} \mathrm{O}: \mathrm{C}$, 76.11, H, 6.39, N, 12.68. Encontrado: C, 72.56, H, 6.26, N, 12.41 


\section{4-(((3-Clorobencil)(metil)amino)metil)- $N$-(piridin-2-il)benzamida (76)}

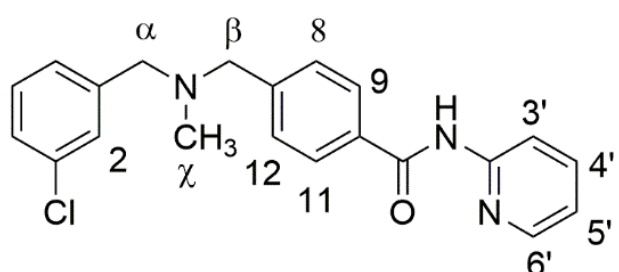

$6^{\prime}$

Siguiendo el procedimiento general, a partir del ácido 4-(((3-clorobencil)(metil)amino)metil)benzoico (135.4 mg, $0.5 \mathrm{mmol})$, pyBOP (312.2

$\mathrm{mg}, 0.6 \mathrm{mmol}), 2$-aminopiridina $(47.1 \mathrm{mg}, 0.5$ mmol) y Et $3 \mathrm{~N}(156 \mu \mathrm{L}, 1.2 \mathrm{mmol})$ se aislaron 31.1 mg $(17 \%)$ de 76 como un aceite. HPLC: pureza (100\%). MS: $\mathrm{m} / \mathrm{z}=366[\mathrm{M}+\mathrm{H}]^{+} .{ }^{1} \mathrm{H}-$

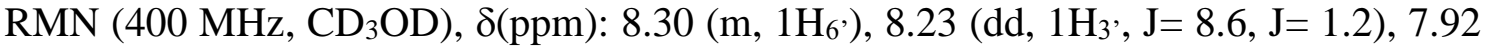
$\left(\mathrm{d}, 2 \mathrm{H}_{9,11}, \mathrm{~J}=8.6\right), 7.81\left(\mathrm{ddd}, 1 \mathrm{H}_{4}, \mathrm{~J}=8.6, \mathrm{~J}=7.4, \mathrm{~J}=2.0\right), 7.60\left(\mathrm{~s}, 1 \mathrm{H}_{2}\right), 7.50(\mathrm{~m}, 3 \mathrm{H})$, $7.52\left(\mathrm{~d}, 2 \mathrm{H}_{8,12}, \mathrm{~J}=8.6\right), 7.13\left(\mathrm{ddd}, 1 \mathrm{H}_{5}, \mathrm{~J}=7.8, \mathrm{~J}=5.1, \mathrm{~J}=1.2\right), 3.64\left(\mathrm{~s}, 2 \mathrm{H}_{\beta}\right), 3.62\left(\mathrm{~s}, 2 \mathrm{H}_{\alpha}\right)$, $2.19\left(\mathrm{~s}, 3 \mathrm{H}_{\chi}\right) \cdot{ }^{13} \mathrm{C}-\mathrm{RMN}\left(100 \mathrm{MHz}, \mathrm{CD}_{3} \mathrm{OD}\right), \delta(\mathrm{ppm}): 168.5(\mathrm{CONH}), 135.0(\mathrm{C}), 139.6$ $(\mathrm{CH}), 134.4(\mathrm{CH}), 134.1(\mathrm{C}), 132.6(\mathrm{C}), 131.6(\mathrm{C}), 131.3(2 \mathrm{CH}), 131.1(\mathrm{CH}), 130.8(\mathrm{CH})$, $130.4(2 \mathrm{CH}), 130.3(\mathrm{CH}), 129.6(\mathrm{CH}), 121.2(\mathrm{CH}), 116.3(\mathrm{CH}), 59.3\left(\mathrm{CH}_{2}\right), 59.1\left(\mathrm{CH}_{2}\right)$, 38.6 $\left(\mathrm{CH}_{3}\right)$. Análisis (\%): Calculado para $\mathrm{C}_{21} \mathrm{H}_{21} \mathrm{~N}_{3} \mathrm{O}$ : C, 76.11, H, 6.39, N, 12.68. Encontrado: C, 76.24, H, 6.57, N, 12.66 


\subsubsection{Síntesis de los híbridos $N, N$-dibencil( $N$-metil)amina - melatonina (77-90)}

El procedimiento general para la síntesis de los híbridos $N, N$-dibencil( $N$-metil)amina - melatonina (77-90) es el mismo que el descrito en el apartado 2.7.2.4.

\section{$N$-(2-(1H-Indol-3-il)etil)-4-((bencil(metil)amino)metil)benzamida (77)}

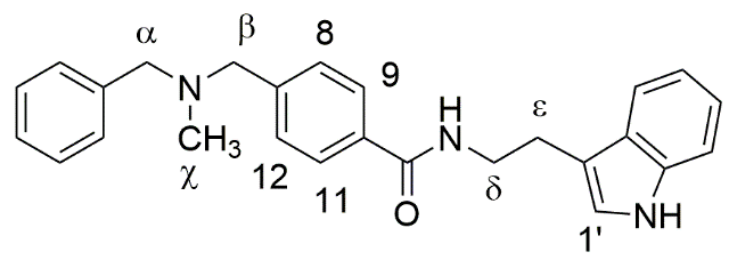

Siguiendo el procedimiento general, a partir del ácido 4-((bencil(metil)amino)metil)benzoico (127.6 mg, $0.5 \mathrm{mmol})$, pyBOP (312.2 mg, $0.6 \mathrm{mmol})$, triptamina $(80.1 \mathrm{mg}$, $0.5 \mathrm{mmol})$ y Et $3 \mathrm{~N}(156 \mu \mathrm{L}, 1.2 \mathrm{mmol})$ se aislaron $91.4 \mathrm{mg}$ (46\%) de 77 como un sólido amarillo. p. f. $94-96^{\circ} \mathrm{C}$ HPLC: pureza (99\%). MS : m/z = $398[\mathrm{M}+\mathrm{H}]^{+} .{ }^{1} \mathrm{H}-\mathrm{RMN}(400$ $\left.\mathrm{MHz}, \mathrm{CDCl}_{3}\right), \delta(\mathrm{ppm}): 8.20(\mathrm{~s}, \mathrm{NH}), 7.65\left(\mathrm{~s}, 1 \mathrm{H}_{1}\right), 7.62$ (d, 2 $\left.\mathrm{H}_{9,11}, \mathrm{~J}=8.2\right), 7.37\left(\mathrm{~d}, 2 \mathrm{H}_{8,12}\right.$, $\mathrm{J}=8.2), 7.33(\mathrm{~m}, 5 \mathrm{H}), 7.25(\mathrm{~m}, 1 \mathrm{H}), 7.21(\mathrm{td}, 1 \mathrm{H}, \mathrm{J}=7.1, \mathrm{~J}=1.0), 7.12(\mathrm{td}, 1 \mathrm{H}, \mathrm{J}=7.9, \mathrm{~J}=$ 1.0), $7.05(\mathrm{~m}, 1 \mathrm{H}), 6.22(\mathrm{t}, \mathrm{NH}, \mathrm{J}=5.4), 3.79\left(\mathrm{c}, 2 \mathrm{H}_{\delta}, \mathrm{J}=6.6\right), 3.53\left(\mathrm{~s}, 2 \mathrm{H}_{\beta}\right), 3.51\left(\mathrm{~s}, 2 \mathrm{H}_{\alpha}\right)$, $3.09\left(\mathrm{t}, 2 \mathrm{H}_{\varepsilon}, \mathrm{J}=6.6\right), 2.16(\mathrm{~s}, 3 \mathrm{H}) .{ }^{13} \mathrm{C}-\mathrm{RMN}\left(100 \mathrm{MHz}, \mathrm{CDCl}_{3}\right), \delta(\mathrm{ppm}): 167.4(\mathrm{CONH})$, $142.9(\mathrm{C}), 138.8(\mathrm{C}), 136.4(\mathrm{C}), 133.4(\mathrm{C}), 128.9(2 \mathrm{CH}), 128.9(2 \mathrm{CH}), 128.3(2 \mathrm{CH}), 127.3$ (C), $127.1(\mathrm{CH}), 126.8(2 \mathrm{CH}), 122.2(\mathrm{CH}), 122.1(\mathrm{CH}), 119.5(\mathrm{CH}), 118.7(\mathrm{CH}), 113.0$ (C), $111.3(\mathrm{CH}), 61.8\left(\mathrm{CH}_{2}\right), 61.3\left(\mathrm{CH}_{2}\right), 42.2\left(\mathrm{CH}_{3}\right), 40.2\left(\mathrm{CH}_{2}\right), 25.3\left(\mathrm{CH}_{2}\right)$ Análisis (\%): Calculado para $\mathrm{C}_{26} \mathrm{H}_{27} \mathrm{~N}_{3} \mathrm{O}: \mathrm{C}, 78.56, \mathrm{H}, 6.85, \mathrm{~N}, 10.57$. Encontrado: C, 78.95, H, $7.20, \mathrm{~N}, 10.48$.

\section{4-((Bencil(metil)amino)metil)-N-(2-(5-hidroxi-1H-indol-3-il)etil)benzamida (78)}

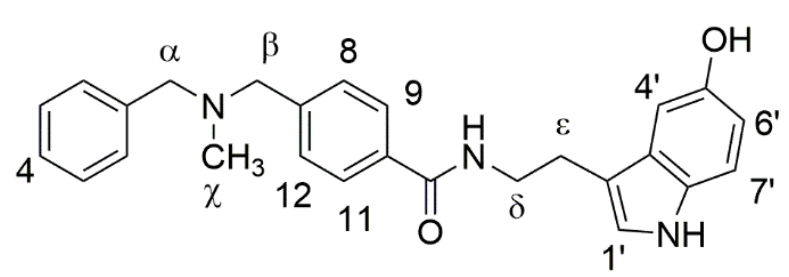

Siguiendo el procedimiento general, a partir del ácido 4-((bencil(metil)amino)metil)benzoico (127.6 $\mathrm{mg}, 0.5 \mathrm{mmol})$, pyBOP (312.2 mg, $0.6 \mathrm{mmol}), 5-$ hidroxitriptamina $(88.0 \mathrm{mg}, 0.5 \mathrm{mmol})$

y Et ${ }_{3} \mathrm{~N}(156 \mu \mathrm{L}, 1.2 \mathrm{mmol})$ se aislaron $62.0 \mathrm{mg}(30 \%)$ de 78 como un sólido blanco. p. f. 75-77 $\mathrm{C}$ HPLC: pureza (99\%). MS : m/z = $414[\mathrm{M}+\mathrm{H}]^{+} .{ }^{1} \mathrm{H}-\mathrm{RMN}\left(500 \mathrm{MHz}, \mathrm{CD}_{3} \mathrm{OD}\right)$, $\delta(\mathrm{ppm}): 7.74\left(\mathrm{~d}, 2 \mathrm{H}_{9,11}, \mathrm{~J}=8.2\right), 7.41\left(\mathrm{~d}, 2 \mathrm{H}_{8,12}, \mathrm{~J}=8.2\right), 7.32(\mathrm{~m}, 4 \mathrm{H}), 7.24\left(\mathrm{t}, 1 \mathrm{H}_{4}, \mathrm{~J}=\right.$ 7.1), $7.15\left(\mathrm{~d}, 1 \mathrm{H}_{7^{\prime}}, \mathrm{J}=8.5\right), 7.03\left(\mathrm{~s}, 1 \mathrm{H}^{1}\right), 6.99\left(\mathrm{~d}, 1 \mathrm{H}_{4}, \mathrm{~J}=2.2\right), 6.66\left(\mathrm{dd}, 1 \mathrm{H}_{6}, \mathrm{~J}=8.5\right.$, 
$\mathrm{J}=2.2), 3.63(\mathrm{~d}, 2 \mathrm{H} \delta, \mathrm{J}=7.4), 3.54(\mathrm{~s}, 2 \mathrm{H} \beta), 3.51(\mathrm{~s}, 2 \mathrm{H} \alpha), 2.98\left(\mathrm{t}, 2 \mathrm{H}_{\varepsilon}, \mathrm{J}=7.4\right), 2.16(\mathrm{~s}$, $3 \mathrm{H} \chi) .{ }^{13} \mathrm{C}-\mathrm{RMN}\left(125 \mathrm{MHz}, \mathrm{CD}_{3} \mathrm{OD}\right), \delta(\mathrm{ppm}): 170.6$ (CONH), $151.7(\mathrm{C}), 144.2(\mathrm{C})$, $140.1(\mathrm{C}), 135.3(\mathrm{C}), 133.6(\mathrm{C}), 130.8(2 \mathrm{CH}), 130.7(2 \mathrm{CH}), 130.0(\mathrm{C}), 129.8(2 \mathrm{CH}), 128.8$ $(\mathrm{CH}), 128.7(2 \mathrm{CH}), 124.7(\mathrm{CH}), 113.2(\mathrm{CH}), 113.1(\mathrm{C}), 112.9(\mathrm{CH}), 104.1(\mathrm{CH}), 63.3$ $\left(\mathrm{CH}_{2}\right), 62.7\left(\mathrm{CH}_{2}\right), 42.9\left(\mathrm{CH}_{3}\right), 42.5\left(\mathrm{CH}_{2}\right), 26.8\left(\mathrm{CH}_{2}\right)$ Análisis (\%): Calculado para $\mathrm{C}_{26} \mathrm{H}_{27} \mathrm{~N}_{3} \mathrm{O}_{2}$ : C, 75.52, H, 6.58, N, 10.16. Encontrado: C, 75.12, H, 6.37, N, 9.93.

\section{4-((Bencil(metil)amino)metil)-N-(2-(5-metoxi-1H-indol-3-il)etil)benzamida (79)}

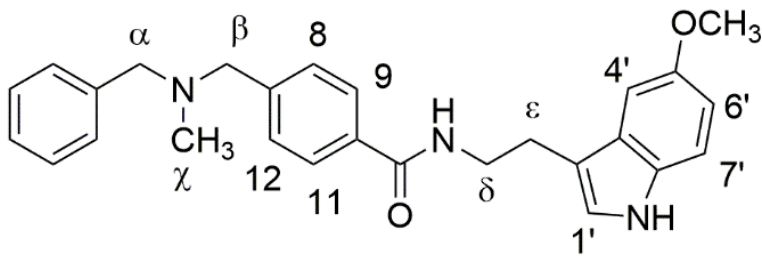

metoxitriptamina (95.12 mg, $0.5 \mathrm{mmol})$ y $\mathrm{Et}_{3} \mathrm{~N}(156 \mu \mathrm{L}, 1.2 \mathrm{mmol})$ se aislaron $153.9 \mathrm{mg}$ (72\%) de 79 como un sólido amarillo. p. f.102-103 ${ }^{\circ} \mathrm{C}$ HPLC: pureza (98\%). MS : m/z = $428[\mathrm{M}+\mathrm{H}]^{+} .{ }^{1} \mathrm{H}-\mathrm{RMN}\left(400 \mathrm{MHz}, \mathrm{CDCl}_{3}\right), \delta(\mathrm{ppm}): 8.68(\mathrm{~s}, \mathrm{NH}), 7.66\left(\mathrm{~d}, 2 \mathrm{H}_{9,11}, \mathrm{~J}=\right.$

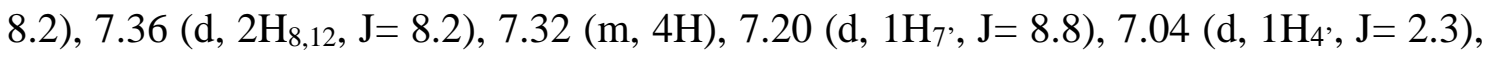
$6.95\left(\mathrm{~d}, 1 \mathrm{H}_{1}, \mathrm{~J}=2.3\right), 6.84\left(\mathrm{dd}, 1 \mathrm{H}_{6}, \mathrm{~J}=8.8, \mathrm{~J}=2.3\right), 6.52(\mathrm{t}, \mathrm{NH}, \mathrm{J}=5.5), 3.75\left(\mathrm{c}, 2 \mathrm{H}_{\delta}\right.$, $\mathrm{J}=6.7), 3.74\left(\mathrm{~s}, 3 \mathrm{H}, \mathrm{OCH}_{3}\right), 3.51\left(\mathrm{~s}, 4 \mathrm{H}_{\alpha, \beta}\right), 3.03\left(\mathrm{t}, 2 \mathrm{H}_{\varepsilon}, \mathrm{J}=6.7\right), 2.16\left(\mathrm{~s}, 3 \mathrm{H}_{\chi}\right) .{ }^{13} \mathrm{C}-$ RMN (100 MHz, $\mathrm{CDCl}_{3}$ ), $\delta(\mathrm{ppm}): 167.4$ (CONH), 153.8 (C), 143.0 (C), 138.8 (C), 133.1 (C), $131.5(\mathrm{C}), 128.8(2 \mathrm{CH}), 128.8(2 \mathrm{CH}), 128.2(2 \mathrm{CH}), 127.6(\mathrm{C}), 127.0(\mathrm{CH}), 126.8$ $(2 \mathrm{CH}), 123.0(\mathrm{CH}), 112.3(\mathrm{C}), 112.2(\mathrm{CH}), 112.1(\mathrm{CH}), 100.2(\mathrm{CH}), 61.7\left(\mathrm{CH}_{2}\right), 61.1$ $\left(\mathrm{CH}_{2}\right), 55.6\left(\mathrm{CH}_{3}\right), 42.1\left(\mathrm{CH}_{3}\right), 40.4\left(\mathrm{CH}_{2}\right), 25.2\left(\mathrm{CH}_{2}\right)$ Análisis (\%): Calculado para $\mathrm{C}_{27} \mathrm{H}_{29} \mathrm{~N}_{3} \mathrm{O}_{2}$ : C, 75.85, H, 6.84, N, 9.83. Encontrado: C, 76.13, H, 7.12, N, 10.15.

\section{4-((Bencil(metil)amino)metil)- $N$-(2-(6-metoxi-1H-indol-3-il)etil)benzamida (80)}

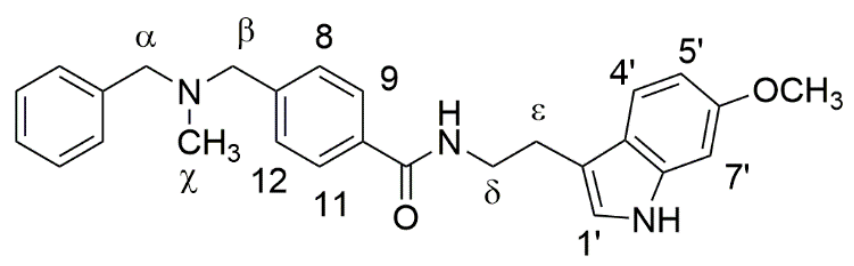

Siguiendo el procedimiento general, a partir del ácido 4((bencil(metil)amino)metil)benzoico (127.6 $\mathrm{mg}, 0.5 \mathrm{mmol})$, pyBOP (312.2 mg, $0.6 \mathrm{mmol}), 6$-metoxitriptamina (95.12 mg, $0.5 \mathrm{mmol})$ y Et ${ }_{3} \mathrm{~N}(156 \mu \mathrm{L}$, $1.2 \mathrm{mmol})$ se aislaron $139.0 \mathrm{mg}(65 \%)$ de 80 como un sólido amarillo. p. f.119-121 ${ }^{\circ} \mathrm{C}$ HPLC: pureza (99\%). MS : m/z $=428[\mathrm{M}+\mathrm{H}]^{+} .{ }^{1} \mathrm{H}-\mathrm{RMN}\left(400 \mathrm{MHz}\right.$, acetona-d ${ }_{6}$ ), 


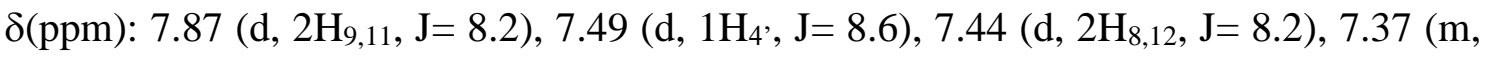
2H), $7.31(\mathrm{~m}, 2 \mathrm{H}), 7.23(\mathrm{~m}, 1 \mathrm{H}), 7.05\left(\mathrm{~s}, 1 \mathrm{H}_{1}\right), 6.90\left(\mathrm{~d}, 1 \mathrm{H}_{7}, \mathrm{~J}=2.2\right), 6.68\left(\mathrm{dd}, 1 \mathrm{H}_{5}, \mathrm{~J}=\right.$ 8.6, J=2.2), $3.76(\mathrm{~s}, 3 \mathrm{H}), 3.69(\mathrm{t}, 2 \mathrm{H}, \mathrm{J}=7.4), 3.54(\mathrm{~s}, 2 \mathrm{H}), 3.51(\mathrm{~s}, 2 \mathrm{H}), 3.02(\mathrm{t}, 2 \mathrm{H}, \mathrm{J}=$ 7.4), 2.12 (s, 3H). ${ }^{13} \mathrm{C}-\mathrm{RMN}(100 \mathrm{MHz}$, acetona-d 6 ), $\delta(\mathrm{ppm}): 167.2(\mathrm{CONH}), 157.2(\mathrm{C})$, $143.7(\mathrm{C}), 140.2(\mathrm{C}), 138.2(\mathrm{C}), 134.7(\mathrm{C}), 129.5(2 \mathrm{CH}), 129.3(2 \mathrm{CH}), 129.0(2 \mathrm{CH}), 127.9$ (2CH), $127.7(\mathrm{CH}), 122.9(\mathrm{C}), 121.7(\mathrm{CH}), 119.9(\mathrm{CH}), 113.4(\mathrm{C}), 109.6(\mathrm{CH}), 95.2(\mathrm{CH})$, $62.3\left(\mathrm{CH}_{2}\right), 61.9\left(\mathrm{CH}_{2}\right), 55.6\left(\mathrm{CH}_{3}\right), 42.3\left(\mathrm{CH}_{3}\right), 41.2\left(\mathrm{CH}_{2}\right), 26.3\left(\mathrm{CH}_{2}\right)$ Análisis $(\%)$ : Calculado para $\mathrm{C}_{27} \mathrm{H}_{29} \mathrm{~N}_{3} \mathrm{O}_{2}$ : C, 75.85, H, 6.84, N, 9.83. Encontrado: C, 75.77, H, 6.95, N, 9.78 .

\section{4-((Bencil(metil)amino)metil)- $N$-(2-(6-fluoro- $1 H$-indol-3-il)etil)benzamida (81)}

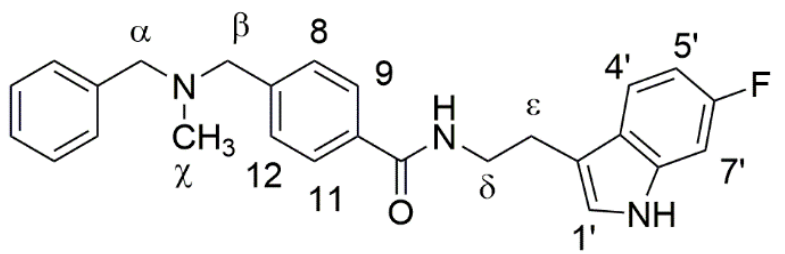

Siguiendo el procedimiento general, a partir del ácido 4-((bencil(metil)amino)metil)benzoico (127.6 $\mathrm{mg}, 0.5$ mmol), pyBOP (312.2 $\mathrm{mg}, 0.6 \mathrm{mmol})$,

6-fluorotriptamina ( $89.0 \mathrm{mg}, 0.5 \mathrm{mmol})$ y Et ${ }_{3} \mathrm{~N}(156 \mu \mathrm{L}, 1.2 \mathrm{mmol})$ se aislaron $135.0 \mathrm{mg}$ (65\%) de 81 como un sólido amarillo. p. f. $83-85^{\circ} \mathrm{C}$ HPLC: pureza (98\%). MS : m/z = 416 $[\mathrm{M}+\mathrm{H}]^{+} .{ }^{1} \mathrm{H}-\mathrm{RMN}\left(400 \mathrm{MHz}, \mathrm{CDCl}_{3}\right), \delta(\mathrm{ppm}):$ 8.63(s, NH), $7.63\left(\mathrm{~d}, 2 \mathrm{H}_{9,11}, \mathrm{~J}=8.2\right.$ ), $7.49(\mathrm{dd}, 1 \mathrm{H}, \mathrm{J}=9.0, \mathrm{~J}=5.2), 7.36\left(\mathrm{~d}, 2 \mathrm{H}_{8,12}, \mathrm{~J}=8.2\right), 7.32(\mathrm{~m}, 4 \mathrm{H}), 7.24(\mathrm{~m}, 1 \mathrm{H}), 6.99$ $(\mathrm{dd}, 1 \mathrm{H}, \mathrm{J}=9.7, \mathrm{~J}=2.3), 6.96\left(\mathrm{~d}, 1 \mathrm{H}_{7}, \mathrm{~J}=2.3\right), 6.84(\mathrm{td}, 1 \mathrm{H}, \mathrm{J}=9.0, \mathrm{~J}=2.3), 6.40(\mathrm{t}, 1 \mathrm{NH}$, $\mathrm{J}=5.7), 3.74\left(\mathrm{c}, 2 \mathrm{H}_{\delta}, \mathrm{J}=6.7\right), 3.24\left(\mathrm{~s}, 2 \mathrm{H}_{\beta}\right), 3.51\left(\mathrm{~s}, 2 \mathrm{H}_{\alpha}\right), 3.02\left(\mathrm{t}, 2 \mathrm{H}_{\varepsilon}, \mathrm{J}=6.7\right), 2.16(\mathrm{~s}$, $\left.3 \mathrm{H}_{\chi}\right) \cdot{ }^{13} \mathrm{C}-\mathrm{RMN}\left(100 \mathrm{MHz}, \mathrm{CDCl}_{3}\right), \delta(\mathrm{ppm}): 167.5(\mathrm{CONH}), 161.1(\mathrm{C}), 158.8(\mathrm{C}), 143.0$ (C), $138.7(\mathrm{C}), 136.3(\mathrm{C}, \mathrm{J}=12.2), 128.9(2 \mathrm{CH}), 128.8(2 \mathrm{CH}), 128.3(2 \mathrm{CH}), 127.1(\mathrm{CH})$, $126.8(2 \mathrm{CH}), 123.9(\mathrm{C}), 122.4(\mathrm{CH}), 122.3(\mathrm{CH}), 119.4(\mathrm{C}), 119.3(\mathrm{CH}), 112.8(\mathrm{CH})$, $108.0(\mathrm{CH}, \mathrm{J}=24.4), 97.6(\mathrm{CH}, \mathrm{J}=25.9), 61.8\left(\mathrm{CH}_{2}\right), 61.2\left(\mathrm{CH}_{2}\right), 42.1\left(\mathrm{CH}_{3}\right), 40.2\left(\mathrm{CH}_{3}\right)$, $25.2\left(\mathrm{CH}_{2}\right)$ Análisis (\%): Calculado para $\mathrm{C}_{26} \mathrm{H}_{26} \mathrm{FN}_{3} \mathrm{O}: \mathrm{C}, 75.16, \mathrm{H}, 6.31, \mathrm{~N}, 10.11$. Encontrado: C, 74.83, H, 5.96, N, 9.86. 


\section{$N$-(2-(1H-Indol-3-il)etil)-4-(((3-clorobencil)(metil)amino)metil)benzamida (82)}

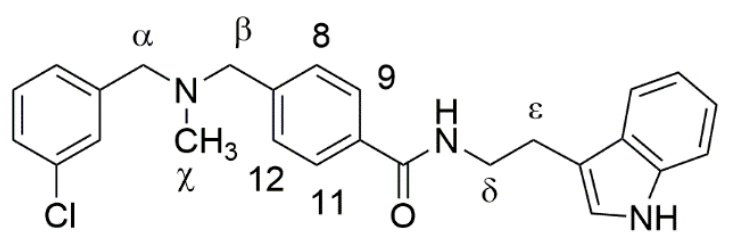

Siguiendo el procedimiento general, a partir del ácido 4-(((3-clorobencil)(metil)amino)metil)benzoico (135.4 $\mathrm{mg}, \quad 0.5 \mathrm{mmol})$, pyBOP (312.2 $\mathrm{mg}, 0.6 \mathrm{mmol})$, triptamina

(80.1 mg, $0.5 \mathrm{mmol})$ y Et ${ }_{3} \mathrm{~N}(156 \mu \mathrm{L}, 1.2 \mathrm{mmol})$ se aislaron $118.8 \mathrm{mg}(55 \%)$ de 82 como un sólido blnco. p. f. $110-112^{\circ} \mathrm{C}$ HPLC: pureza (100\%). MS: $\mathrm{m} / \mathrm{z}=432[\mathrm{M}+\mathrm{H}]^{+} .{ }^{1} \mathrm{H}-$ RMN (400 MHz, $\left.\mathrm{CDCl}_{3}\right), \delta(\mathrm{ppm}): 8.21(\mathrm{~s}, \mathrm{NH}), 7.64\left(\mathrm{~d}, 2 \mathrm{H}_{9,11}, \mathrm{~J}=8.3\right), 7.64(\mathrm{~m}, 1 \mathrm{H})$, $7.37\left(\mathrm{~d}, 2 \mathrm{H}_{8,12}, \mathrm{~J}=8.3\right), 7.37(\mathrm{~m}, 2 \mathrm{H}), 7.23(\mathrm{~m}, 4 \mathrm{H}), 7.13(\mathrm{td}, 1 \mathrm{H}, \mathrm{J}=7.5, \mathrm{~J}=1.0), 7.06(\mathrm{~d}$, $1 \mathrm{H}, \mathrm{J}=2.5), 6.23(\mathrm{t}, \mathrm{NH}, \mathrm{J}=5.5), 3.80\left(\mathrm{c}, 2 \mathrm{H}_{\delta}, \mathrm{J}=6.7\right), 3.52\left(\mathrm{~s}, 2 \mathrm{H}_{\beta}\right), 3.46\left(\mathrm{~s}, 2 \mathrm{H}_{\alpha}\right), 3.09$ $\left(\mathrm{t}, 2 \mathrm{H}_{\varepsilon}, \mathrm{J}=6.7\right), 2.16\left(\mathrm{~s}, 3 \mathrm{H}_{\chi}\right) \cdot{ }^{13} \mathrm{C}-\mathrm{RMN}\left(100 \mathrm{MHz}, \mathrm{CDCl}_{3}\right), \delta(\mathrm{ppm}): 167.4(\mathrm{CONH})$, 142.8 (C), $141.3(\mathrm{C}), 136.4(\mathrm{C}), 134.2$ (C), $133.5(\mathrm{C}), 129.5(\mathrm{CH}), 128.8(2 \mathrm{CH}), 128.7$ $(2 \mathrm{CH}), 127.3(\mathrm{C}), 127.2(\mathrm{CH}), 126.9(2 \mathrm{CH}), 122.2(\mathrm{CH}), 122.1(\mathrm{CH}), 119.5(\mathrm{CH}), 118.7$ $(\mathrm{CH}), 113.0(\mathrm{C}), 111.3(\mathrm{CH}), 61.4\left(\mathrm{CH}_{2}\right), 61.2\left(\mathrm{CH}_{2}\right), 42.3\left(\mathrm{CH}_{3}\right), 40.2\left(\mathrm{CH}_{2}\right), 25.3\left(\mathrm{CH}_{2}\right)$ Análisis (\%): Calculado para $\mathrm{C}_{26} \mathrm{H}_{26} \mathrm{ClN}_{3} \mathrm{O}: \mathrm{C}, 72.29, \mathrm{H}, 6.07, \mathrm{~N}, 9.73$. Encontrado: $\mathrm{C}$, 72.31, H, 6.13, N, 9.81 .

\section{4-(((3-Clorobencil)(metil)amino)metil)- $N$-(2-(5-metoxi-1H-indol-3-}

il)etil)benzamida (83)

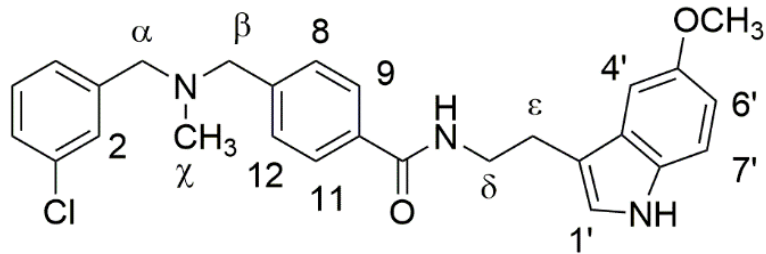

Siguiendo el procedimiento general, a partir del ácido 4-(((3clorobencil)(metil)amino)metil)benzoico (135.4 mg, $0.5 \mathrm{mmol})$, pyBOP (312.2 $\mathrm{mg}, \quad 0.6 \mathrm{mmol})$, 5-

metoxitriptamina $(95.1 \mathrm{mg}, 0.5 \mathrm{mmol}) \mathrm{y} \mathrm{Et}_{3} \mathrm{~N}(156 \mu \mathrm{L}, 1.2 \mathrm{mmol})$ se aislaron $189.4 \mathrm{mg}$ (82\%) de 83 como un sólido amarillo. p. f. $108-110^{\circ} \mathrm{C}$ HPLC: pureza $(100 \%)$. MS: m/z = $462[\mathrm{M}+\mathrm{H}]^{+} .{ }^{1} \mathrm{H}-\mathrm{RMN}\left(400 \mathrm{MHz}, \mathrm{CDCl}_{3}\right), \delta(\mathrm{ppm}): 8.15(\mathrm{~s}, \mathrm{NH}), 7.62\left(\mathrm{~d}, 2 \mathrm{H}_{9,11}, \mathrm{~J}=\right.$ 8.3), $7.35\left(\mathrm{~d}, 2 \mathrm{H}_{8,12}, \mathrm{~J}=8.3\right), 7.34\left(\mathrm{~s}, 1 \mathrm{H}_{2}\right), 7.25$ (d, $\left.1 \mathrm{H}_{7}, \mathrm{~J}=8.6\right), 7.22(\mathrm{~m}, 3 \mathrm{H}), 7.03$ (s. $\left.1 \mathrm{H}_{1}{ }^{\prime}\right), 6.85\left(\mathrm{dd}, 1 \mathrm{H}_{6}, \mathrm{~J}=8.6, \mathrm{~J}=2.3\right), 6.27(\mathrm{t}, \mathrm{NH}, \mathrm{J}=5.6), 3.77(\mathrm{c}, 2 \mathrm{H} \delta, \mathrm{J}=6.5), 3.76$ (s, $\left.3 \mathrm{H}_{,} \mathrm{OCH}_{3}\right), 3.51\left(\mathrm{~s}, 2 \mathrm{H}_{\beta}\right) 3.45\left(\mathrm{~s}, 2 \mathrm{H}_{\alpha}\right), 3.04\left(\mathrm{t}, 2 \mathrm{H}_{\varepsilon}, \mathrm{J}=6.5\right), 2.14\left(\mathrm{~s}, 3 \mathrm{H}_{\chi}\right) \cdot{ }^{13} \mathrm{C}-\mathrm{RMN}(100$ $\left.\mathrm{MHz}, \mathrm{CDCl}_{3}\right), \delta(\mathrm{ppm}): 167.6(\mathrm{CONH}), 154.3(\mathrm{C}), 143.1(\mathrm{C}), 141.5(\mathrm{C}), 134.4(\mathrm{C}), 133.6$ (C), $131.7(\mathrm{C}), 129.8(\mathrm{CH}), 129.1(2 \mathrm{CH}), 129.0(2 \mathrm{CH}), 127.9(\mathrm{C}), 127.5(\mathrm{CH}), 127.2$ 
$(2 \mathrm{CH}), 123.2(\mathrm{CH}), 113.0(\mathrm{C}), 112.8(\mathrm{CH}), 112.3(\mathrm{CH}), 100.5(\mathrm{CH}), 61.7\left(\mathrm{CH}_{2}\right), 61.4$ $\left(\mathrm{CH}_{2}\right), 56.0\left(\mathrm{CH}_{3}\right), 42.5\left(\mathrm{CH}_{3}\right), 40.5\left(\mathrm{CH}_{2}\right), 25.5\left(\mathrm{CH}_{2}\right)$ Análisis $(\%)$ : Calculado para $\mathrm{C}_{27} \mathrm{H}_{28} \mathrm{ClN}_{3} \mathrm{O}_{2}$ : C, 70.19, H, 6.11, N, 9.10. Encontrado: C, 70.11, H, 6.09, N, 9.31.

\section{4-(((3-Clorobencil)(metil)amino)metil)- $N$-(2-(6-metoxi-1H-indol-3- il)etil)benzamida (84)}<smiles>[Y2]CN(Cc1cccc(Cl)c1)Cc1cccc(C(=O)NCCc2[nH]c3cc(OC)ccc3c2[Y])c1</smiles>

pyBOP (312.2 mg, $0.6 \mathrm{mmol}), 6$-metoxitriptamina (95.1 mg, $0.5 \mathrm{mmol})$ y Et ${ }_{3} \mathrm{~N}(156 \mu \mathrm{L}$, $1.2 \mathrm{mmol})$ se aislaron $189.4 \mathrm{mg}(82 \%)$ de 84 como un sólido amarillo. p. f. 58-60 $\mathrm{C}$ HPLC: pureza (100\%). MS: m/z = $462[\mathrm{M}+\mathrm{H}]^{+} .{ }^{1} \mathrm{H}-\mathrm{RMN}\left(400 \mathrm{MHz}, \mathrm{CDCl}_{3}\right), \delta(\mathrm{ppm}): 8.31$ (s, $\mathrm{NH}), 7.65\left(\mathrm{~d}, 2 \mathrm{H}_{9,11}, \mathrm{~J}=8.4\right), 7.48(\mathrm{~d}, 1 \mathrm{H}, \mathrm{J}=8.6), 7.36\left(\mathrm{~d}, 2 \mathrm{H}_{8,12}, \mathrm{~J}=8.4\right), 7.35\left(\mathrm{~s}, 1 \mathrm{H}_{2}\right)$, $7.23(\mathrm{~m}, 3 \mathrm{H}), 6.91(\mathrm{~d}, 1 \mathrm{H}, \mathrm{J}=2.2), 6.84(\mathrm{~d}, 1 \mathrm{H}, \mathrm{J}=2.2), 6.78(\mathrm{dd}, 1 \mathrm{H}, \mathrm{J}=8.6, \mathrm{~J}=2.2), 6.35$ (t, NH, J= 5.6), $3.81\left(\mathrm{~s}, 3 \mathrm{H}, \mathrm{OCH}_{3}\right), 3.75(\mathrm{c}, 2 \mathrm{H} \delta, \mathrm{J}=6.6), 3.52\left(\mathrm{~s}, 2 \mathrm{H}_{\beta}\right) 3.46\left(\mathrm{~s}, 2 \mathrm{H}_{\alpha}\right), 3.03$ $\left(\mathrm{t}, 2 \mathrm{H}_{\varepsilon}, \mathrm{J}=6.6\right), 2.15\left(\mathrm{~s}, 3 \mathrm{H}_{\chi}\right) \cdot{ }^{13} \mathrm{C}-\mathrm{RMN}\left(100 \mathrm{MHz}, \mathrm{CDCl}_{3}\right), \delta(\mathrm{ppm}): 167.4(\mathrm{CONH})$, 156.5 (C), 142.7 (C), 141.2 (C), 137.2 (C), 134.1 (C), 133.4 (C), 129.85 (CH), 128.8 (2CH), $128.7(2 \mathrm{CH}), 127.2(\mathrm{CH}), 126.9(2 \mathrm{CH}), 121.6(\mathrm{C}), 120.9(\mathrm{CH}), 119.3(\mathrm{C}), 112.7$ (C), $109.4(\mathrm{CH}), 94.7(\mathrm{CH}), 61.4\left(\mathrm{CH}_{2}\right), 61.2\left(\mathrm{CH}_{2}\right), 55.6\left(\mathrm{CH}_{3}\right), 42.2\left(\mathrm{CH}_{3}\right), 40.2\left(\mathrm{CH}_{2}\right)$, $25.3\left(\mathrm{CH}_{2}\right)$ Análisis (\%): Calculado para $\mathrm{C}_{27} \mathrm{H}_{28} \mathrm{ClN}_{3} \mathrm{O}_{2}$ : C, 70.19, H, 6.11, N, 9.10. Encontrado: C, 70.06, H, 6.13, N, 9.23.

\section{$N$-(2-(1H-Indol-3-il)etil)-4-(((3-metoxibencil)(metil)amino)metil)benzamida (85)}

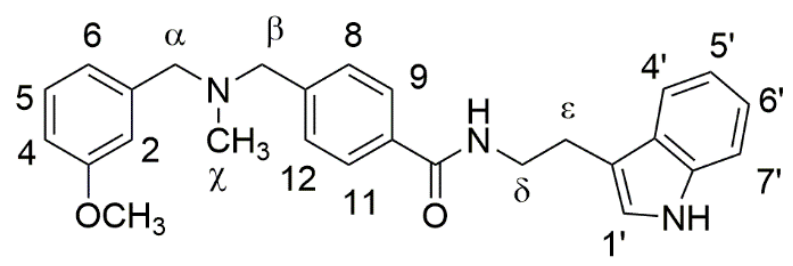

Siguiendo el procedimiento general, a partir del ácido 4-(((3metoxibencil)(metil)amino)metil)benzoico (142.7 mg, $0.5 \mathrm{mmol})$, pyBOP (312.2 mg, $0.6 \mathrm{mmol})$, triptamina $(80.1$

$\mathrm{mg}, 0.5 \mathrm{mmol})$ y Et ${ }_{3} \mathrm{~N}(156 \mu \mathrm{L}, 1.2 \mathrm{mmol})$ se aislaron $166.7 \mathrm{mg}(78 \%)$ de 85 como un sólido amarillo. p. f. $81-83^{\circ} \mathrm{C}$ HPLC: pureza (99\%). MS : m/z $=428[\mathrm{M}+\mathrm{H}]^{+} .{ }^{1} \mathrm{H}-\mathrm{RMN}$ (400 MHz, $\left.\mathrm{CD}_{3} \mathrm{OD}\right), \delta(\mathrm{ppm}): 7.74$ (d, 2 $\mathrm{H}_{9,11}, \mathrm{~J}=8.4$ ), 7.60 (dd, $\left.1 \mathrm{H}_{7}, \mathrm{~J}=8.1, \mathrm{~J}=1.0\right), 7.42$ 
$\left(\mathrm{d}, 2 \mathrm{H}_{8,12}, \mathrm{~J}=8.4\right), 7.32\left(\mathrm{dd}, 1 \mathrm{H}_{4}, \mathrm{~J}=8.1, \mathrm{~J}=1.0\right), 7.22\left(\mathrm{t}, 1 \mathrm{H}_{5}, \mathrm{~J}=8.1\right), 7.09\left(\mathrm{~s}, 1 \mathrm{H}_{1}\right.$ ) $), 7.06$ $\left(\mathrm{td}, 1 \mathrm{H}_{5}, \mathrm{~J}=8.1, \mathrm{~J}=1.0\right), 6.98\left(\mathrm{td}, 1 \mathrm{H}_{6}, \mathrm{~J}=8.1, \mathrm{~J}=1.0\right), 6.93\left(\mathrm{~d}, 1 \mathrm{H}_{2}, \mathrm{~J}=2.0\right), 6.91\left(\mathrm{~d}, 1 \mathrm{H}_{6}\right.$, $\mathrm{J}=8.1), 6.80\left(\mathrm{dd}, 1 \mathrm{H}_{4}, \mathrm{~J}=8.1, \mathrm{~J}=2.0\right), 3.77\left(\mathrm{~s}, 3 \mathrm{H}, \mathrm{OCH}_{3}\right), 3.66(\mathrm{t}, 2 \mathrm{H} \delta, \mathrm{J}=7.4), 3.53(\mathrm{~s}$, $\left.2 \mathrm{H}_{\beta}\right) 3.48\left(\mathrm{~s}, 2 \mathrm{H}_{\alpha}\right), 3.05\left(\mathrm{t}, 2 \mathrm{H}_{\varepsilon}, \mathrm{J}=7.4\right), 2.16\left(\mathrm{~s}, 3 \mathrm{H}_{\chi}\right) \cdot{ }^{13} \mathrm{C}-\mathrm{RMN}\left(100 \mathrm{MHz}, \mathrm{CD}_{3} \mathrm{OD}\right)$,

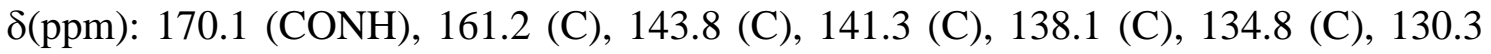
$(\mathrm{CH}), 130.3(2 \mathrm{CH}), 128.8(\mathrm{C}), 128.3(2 \mathrm{CH}), 123.4(\mathrm{CH}), 122.5(\mathrm{CH}), 122.3(\mathrm{CH}), 119.6$ $(\mathrm{CH}), 119.4(\mathrm{CH}), 115.7(\mathrm{CH}), 113.7(\mathrm{CH}), 113.4(\mathrm{C}), 112.2(\mathrm{CH}), 62.7\left(\mathrm{CH}_{2}\right), 62.1$ $\left(\mathrm{CH}_{2}\right), 55.6\left(\mathrm{CH}_{3}\right), 42.5\left(\mathrm{CH}_{3}\right), 42.2\left(\mathrm{CH}_{2}\right), 26.3\left(\mathrm{CH}_{2}\right)$ Análisis $(\%)$ : Calculado para $\mathrm{C}_{27} \mathrm{H}_{29} \mathrm{~N}_{3} \mathrm{O}_{2}$ : C, 75.85, H, 6.84, N, 9.83. Encontrado: C, 75.66, H, 6.71, N, 9.81.

\section{$N$-(2-(5-Metoxi-1H-indol-3-yl)etil)-4-(((3-metoxibencil)(metil)amino)metil)}

\section{benzamida $(86)$}

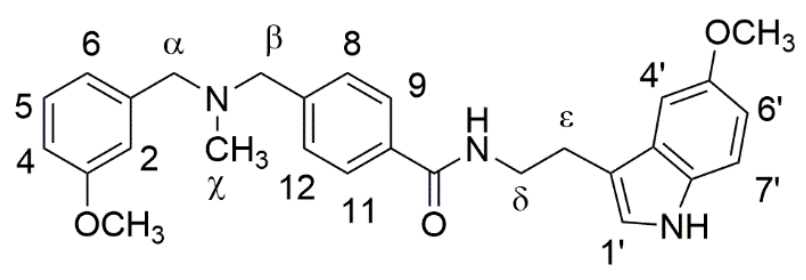

metoxitriptamina $(95.1 \mathrm{mg}, 0.5 \mathrm{mmol})$ y Et ${ }_{3} \mathrm{~N}(156 \mu \mathrm{L}, 1.2 \mathrm{mmol})$ se aislaron $144.1 \mathrm{mg}$ (63\%) de 86 como un sólido blanco. p. f. $82-84^{\circ} \mathrm{C}$ HPLC: pureza (100\%). MS : m/z $=458$ $[\mathrm{M}+\mathrm{H}]^{+} .{ }^{1} \mathrm{H}-\mathrm{RMN}\left(500 \mathrm{MHz}, \mathrm{CD}_{3} \mathrm{OD}\right), \delta(\mathrm{ppm}): 7.71\left(\mathrm{~d}, 2 \mathrm{H}_{9,11}, \mathrm{~J}=8.3\right), 7.38\left(\mathrm{~d}, 2 \mathrm{H}_{8,12}\right.$, $\mathrm{J}=8.3), 7.21\left(\mathrm{~d}, 1 \mathrm{H}_{7}, \mathrm{~J}=8.7\right), 7.20\left(\mathrm{t}, 1 \mathrm{H}_{5}, \mathrm{~J}=7.6\right), 7.06\left(\mathrm{~d}, 1 \mathrm{H}_{4}, \mathrm{~J}=2.4\right), 7.05\left(\mathrm{~s}, 1 \mathrm{H}_{1}{ }^{\prime}\right)$, $6.90\left(\mathrm{~d}, 1 \mathrm{H}_{2}, \mathrm{~J}=1.2\right), 6.88\left(\mathrm{~d}, 1 \mathrm{H}_{6}, \mathrm{~J}=7.6\right), 6.78\left(\mathrm{dd}, 1 \mathrm{H}_{4}, \mathrm{~J}=7.6, \mathrm{~J}=1.2\right), 6.72\left(\mathrm{dd}, 1 \mathrm{H}_{6}\right.$, $\mathrm{J}=8.7, \mathrm{~J}=2.4), 3.75\left(\mathrm{~s}, 3 \mathrm{H}, \mathrm{OCH}_{3}\right), 3.70\left(\mathrm{~s}, 3 \mathrm{H}, \mathrm{OCH}_{3}\right), 3.63(\mathrm{t}, 2 \mathrm{H} \delta, \mathrm{J}=7.3), 3.49(\mathrm{~s}$, $\left.2 \mathrm{H}_{\beta}\right) 3.44\left(\mathrm{~s}, 2 \mathrm{H}_{\alpha}\right), 3.02\left(\mathrm{t}, 2 \mathrm{H}_{\varepsilon}, \mathrm{J}=7.3\right), 2.13\left(\mathrm{~s}, 3 \mathrm{H}_{\chi}\right) \cdot{ }^{13} \mathrm{C}-\mathrm{RMN}\left(125 \mathrm{MHz}, \mathrm{CD}_{3} \mathrm{OD}\right)$, $\delta(\mathrm{ppm}): 170.0(\mathrm{CONH}), 161.2(\mathrm{C}), 154.9$ (C), 143.8 (C), 141.3 (C), 134.7 (C), 133.3 (C), $130.3(\mathrm{CH}), 130.2(2 \mathrm{CH}), 129.2(\mathrm{C}), 128.3(2 \mathrm{CH}), 124.2(\mathrm{CH}), 122.5(\mathrm{CH}), 115.6(\mathrm{CH})$, $113.7(\mathrm{CH}), 113.3(\mathrm{C}), 112.9(\mathrm{CH}), 112.7(\mathrm{CH}), 101.2(\mathrm{CH}), 62.7\left(\mathrm{CH}_{2}\right), 62.1\left(\mathrm{CH}_{2}\right), 56.1$ $\left(\mathrm{CH}_{3}\right), 55.6\left(\mathrm{CH}_{3}\right), 42.5\left(\mathrm{CH}_{2}\right), 42.3\left(\mathrm{CH}_{3}\right), 26.3\left(\mathrm{CH}_{2}\right)$ Análisis $(\%)$ : Calculado para $\mathrm{C}_{28} \mathrm{H}_{31} \mathrm{~N}_{3} \mathrm{O}_{3}$ : C, 75.50, H, 6.83, N, 9.18. Encontrado: C, 75.38, H, 6.78, N, 8.82. 


\section{$N$-(2-(1H-Indol-3-il)etil)-4-(((2-metoxibencil)(metil)amino)metil)benzamida (87)}<smiles>[Y]c1[nH]c2ccccc2c1CCNC(=O)c1ccc(CP(C)Cc2ccccc2OC)cc1</smiles>

Siguiendo el procedimiento general, a partir del ácido 4-(((2-metoxibencil)(metil)amino)metil)benzoico $\quad(142.7 \quad \mathrm{mg}, \quad 0.5$ $\mathrm{mmol}$ ), pyBOP (312.2 $\mathrm{mg}, 0.6 \mathrm{mmol})$, triptamina ( $80.1 \mathrm{mg}, 0.5 \mathrm{mmol}) \mathrm{y} \mathrm{Et}_{3} \mathrm{~N}(156$

$\mu \mathrm{L}, 1.2 \mathrm{mmol})$ se aislaron $130.4 \mathrm{mg}(61 \%)$ de 87 como un sólido blanco. p. f. $80-82^{\circ} \mathrm{C}$ HPLC: pureza (100\%). MS: m/z $=428[\mathrm{M}+\mathrm{H}]^{+} .{ }^{1} \mathrm{H}-\mathrm{RMN}\left(500 \mathrm{MHz}, \mathrm{CD}_{3} \mathrm{OD}\right), \delta(\mathrm{ppm})$ : $7.74\left(\mathrm{~d}, 2 \mathrm{H}_{9,11}, \mathrm{~J}=8.3\right), 7.60(\mathrm{~d}, 1 \mathrm{H}, \mathrm{J}=8.1), 7.42\left(\mathrm{~d}, 2 \mathrm{H}_{8,12}, \mathrm{~J}=8.3\right), 7.31(\mathrm{~m}, 2 \mathrm{H}), 7.24$ $(\mathrm{td}, 1 \mathrm{H}, \mathrm{J}=7.8, \mathrm{~J}=1.7), 7.09\left(\mathrm{~s}, 1 \mathrm{H}_{1}{ }^{\prime}\right), 7.06(\mathrm{~m}, 1 \mathrm{H}), 6.97(\mathrm{td}, 1 \mathrm{H}, \mathrm{J}=8.1, \mathrm{~J}=1.0), 6.93$ $(\mathrm{m}, 1 \mathrm{H}), 6.91(\mathrm{td}, 1 \mathrm{H}, \mathrm{J}=7.6, \mathrm{~J}=1.0), 3.78\left(\mathrm{~s}, 3 \mathrm{H}, \mathrm{OCH}_{3}\right), 3.66\left(\mathrm{t}, 2 \mathrm{H}_{\delta}, \mathrm{J}=7.4\right), 3.54(\mathrm{~s}$, $\left.2 \mathrm{H}_{\beta}\right) 3.34\left(\mathrm{~s}, 2 \mathrm{H}_{\alpha}\right), 3.06\left(\mathrm{t}, 2 \mathrm{H}_{\varepsilon}, \mathrm{J}=7.4\right), 2.18\left(\mathrm{~s}, 3 \mathrm{H}_{\chi}\right) \cdot{ }^{13} \mathrm{C}-\mathrm{RMN}\left(125 \mathrm{MHz}, \mathrm{CD}_{3} \mathrm{OD}\right)$, $\delta(\mathrm{ppm}): 170.1(\mathrm{CONH}), 159.4(\mathrm{C}), 143.7(\mathrm{C}), 138.1(\mathrm{C}), 134.7(\mathrm{C}), 132.1(\mathrm{CH}), 130.4$ $(2 \mathrm{CH}), 129.7(\mathrm{CH}), 128.8(\mathrm{C}), 128.2(2 \mathrm{CH}), 127.0(\mathrm{C}), 123.4(\mathrm{CH}), 122.3(\mathrm{CH}), 121.2$ $(\mathrm{CH}), 119.6(\mathrm{CH}), 119.4(\mathrm{CH}), 113.4(\mathrm{C}), 112.2(\mathrm{CH}), 111.6(\mathrm{CH}), 62.5\left(\mathrm{CH}_{2}\right), 56.0$ $\left(\mathrm{CH}_{3}\right), 55.7\left(\mathrm{CH}_{2}\right), 42.6\left(\mathrm{CH}_{3}\right), 42.2\left(\mathrm{CH}_{2}\right), 26.3\left(\mathrm{CH}_{2}\right)$ Análisis $(\%)$ : Calculado para $\mathrm{C}_{27} \mathrm{H}_{29} \mathrm{~N}_{3} \mathrm{O}_{3}$ : C, 75.85, H, 6.84, N, 9.83. Encontrado: C, 75.77, H, 6.81, N, 9.91.

\section{$N$-(2-(5-Metoxi-1H-indol-3-yl)etil)-4-(((2-metoxibencil)(metil)amino)metil)}

\section{benzamida (88)}

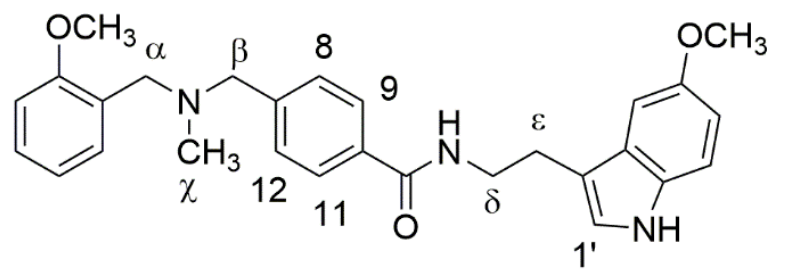

Siguiendo el procedimiento general, a partir del ácido 4-(((2metoxibencil)(metil)amino)metil)benzoico (142.7 mg, $0.5 \mathrm{mmol})$, pyBOP (312.2 mg, $0.6 \mathrm{mmol}$ ), 5-metoxitriptamina (95.1 mg, $0.5 \mathrm{mmol}^{2}$ y Et $\mathrm{Et}_{3} \mathrm{~N}(156 \mu \mathrm{L}, 1.2$ mmol) se aislaron $173.9 \mathrm{mg}(76 \%)$ de $\mathbf{8 8}$ como un sólido amarillo. p. f. 58-60 $\mathrm{C}$ HPLC: pureza (100\%). MS : m/z $=458[\mathrm{M}+\mathrm{H}]^{+} .{ }^{1} \mathrm{H}-\mathrm{RMN}\left(400 \mathrm{MHz}, \mathrm{CDCl}_{3}\right), \delta(\mathrm{ppm}): 8.18$ (s, NH), $7.62\left(\mathrm{~d}, 2 \mathrm{H}_{9,11}, \mathrm{~J}=8.6\right), 7.40(\mathrm{~m}, 1 \mathrm{H}), 7.39\left(\mathrm{~d}, 2 \mathrm{H}_{8,12}, \mathrm{~J}=8.6\right), 7.25(\mathrm{~d}, 1 \mathrm{H}, \mathrm{J}=$ 9.0), $7.22(\mathrm{td}, 1 \mathrm{H}, \mathrm{J}=7.7, \mathrm{~J}=2.0), 7.03(\mathrm{~m}, 2 \mathrm{H}), 6.94(\mathrm{td}, 1 \mathrm{H}, \mathrm{J}=7.7, \mathrm{~J}=1.0), 6.85(\mathrm{~m}$, 2H), 6.27 (t, NH, J= 5.6), $3.79\left(\mathrm{~s}, 3 \mathrm{H}, \mathrm{OCH}_{3}\right), 3.77\left(\mathrm{~s}, 3 \mathrm{H}, \mathrm{OCH}_{3}\right), 3.75$ (c, $\left.2 \mathrm{H} \delta, \mathrm{J}=6.6\right)$, $3.58\left(\mathrm{~s}, 2 \mathrm{H}_{\beta}\right) 3.55\left(\mathrm{~s}, 2 \mathrm{H}_{\alpha}\right), 3.05\left(\mathrm{t}, 2 \mathrm{H}_{\varepsilon}, \mathrm{J}=6.6\right), 2.20\left(\mathrm{~s}, 3 \mathrm{H}_{\chi}\right) \cdot{ }^{13} \mathrm{C}-\mathrm{RMN}(100 \mathrm{MHz}$, $\left.\mathrm{CDCl}_{3}\right), \delta(\mathrm{ppm}): 167.4(\mathrm{CONH}), 157.7(\mathrm{C}), 154.0(\mathrm{C}), 143.3(\mathrm{C}), 133.2$ (C), $131.5(\mathrm{C})$, 
$130.3(\mathrm{CH}), 128.9(2 \mathrm{CH}), 128.0(\mathrm{CH}), 127.7(\mathrm{C}), 126.8(\mathrm{C}), 126.7(2 \mathrm{CH}), 122.9(\mathrm{CH})$, $120.3(\mathrm{CH}), 112.8(\mathrm{C}), 112.5(\mathrm{CH}), 112.0(\mathrm{CH}), 110.3(\mathrm{CH}), 100.3(\mathrm{CH}), 61.7\left(\mathrm{CH}_{2}\right)$, $55.8\left(\mathrm{CH}_{2}\right), 55.3\left(\mathrm{CH}_{3}\right), 55.2\left(\mathrm{CH}_{3}\right), 42.4\left(\mathrm{CH}_{3}\right), 40.3\left(\mathrm{CH}_{2}\right), 25.3\left(\mathrm{CH}_{2}\right)$ Análisis $(\%)$ : Calculado para $\mathrm{C}_{28} \mathrm{H}_{31} \mathrm{~N}_{3} \mathrm{O}_{3}$ : C, 75.50, H, 6.83, N, 9.18. Encontrado: C, 75.61, H, 6.79, $\mathrm{N}, 9.12$.

\section{$N$-(2-(1H-Indol-3-il)etil)-4-(((2-clorobencil)(metil)amino)metil)benzamida (89)}<smiles>[Y]c1[nH]c2ccccc2c1CCNC(=O)c1ccc(CN(C)Cc2ccccc2Cl)cc1</smiles>

Siguiendo el procedimiento general, a partir del ácido 4-(((2-clorobencil)(metil)amino)metil)benzoico (135.4 $\mathrm{mg}, 0.5 \mathrm{mmol})$, pyBOP (312.2 $\mathrm{mg}, 0.6 \mathrm{mmol})$, triptamina (80.1 mg, $0.5 \mathrm{mmol})$ y $\mathrm{Et}_{3} \mathrm{~N}(156 \mu \mathrm{L}, 1.2$

mmol) se aislaron $105.8 \mathrm{mg}(49 \%)$ de 89 como un sólido blanco. p. f. 97-99 C HPLC: pureza (100\%). MS : m/z $=432[\mathrm{M}+\mathrm{H}]^{+} .{ }^{1} \mathrm{H}-\mathrm{RMN}\left(500 \mathrm{MHz}, \mathrm{CDCl}_{3}\right), \delta(\mathrm{ppm}): 8.20$ (s, NH), $7.65(\mathrm{~d}, 1 \mathrm{H}, \mathrm{J}=8.1), 7.62\left(\mathrm{~d}, 2 \mathrm{H}_{9,11}, \mathrm{~J}=8.3\right), 7.52(\mathrm{dd}, 1 \mathrm{H}, \mathrm{J}=7.6, \mathrm{~J}=1.2), 7.38$ $\left(\mathrm{d}, 2 \mathrm{H}_{8,12}, \mathrm{~J}=8.3\right), 7.37(\mathrm{~d}, 1 \mathrm{H}, \mathrm{J}=8.1), 7.34(\mathrm{dd}, 1 \mathrm{H}, \mathrm{J}=7.8, \mathrm{~J}=1.0) .7 .21(\mathrm{~m}, 4 \mathrm{H}), 7.13$ (t, 1H, J= 7.2), $7.06\left(\mathrm{~d}, 1 \mathrm{H}_{1} \mathrm{~J}=2.0\right), 6.23$ (t, NH, J= 5.4), 3.80 (c, 2H $\left.\mathrm{H}_{\delta}, \mathrm{J}=6.6\right), 3.63$ (s, $\left.2 \mathrm{H}_{\alpha}\right), 3.60\left(\mathrm{~s}, 2 \mathrm{H}_{\beta}\right), 3.09\left(\mathrm{t}, 2 \mathrm{H}_{\varepsilon}, \mathrm{J}=6.6\right), 2.19(\mathrm{~s}, 3 \mathrm{H} \chi) \cdot{ }^{13} \mathrm{C}-\mathrm{RMN}\left(125 \mathrm{MHz}, \mathrm{CDCl}_{3}\right)$, $\delta(\mathrm{ppm}): 167.3(\mathrm{CONH}), 143.0(\mathrm{C}), 136.5$ (C), $136.4(\mathrm{C}), 134.2$ (C), $133.4(\mathrm{C}), 130.6$ $(\mathrm{CH}), 129.4(\mathrm{CH}), 128.9(2 \mathrm{CH}), 128.1(\mathrm{CH}), 127.2(\mathrm{CH}), 126.8(2 \mathrm{CH}), 126.6(\mathrm{CH}), 122.2$ $(\mathrm{CH}), 122.1(\mathrm{CH}), 119.5(\mathrm{CH}), 118.7(\mathrm{CH}), 113.0(\mathrm{C}), 111.3(\mathrm{CH}), 61.7\left(\mathrm{CH}_{2}\right), 58.5$ $\left(\mathrm{CH}_{2}\right), 42.2\left(\mathrm{CH}_{3}\right), 40.2\left(\mathrm{CH}_{2}\right), 25.3\left(\mathrm{CH}_{2}\right)$ Análisis (\%): Calculado para $\mathrm{C}_{26} \mathrm{H}_{26} \mathrm{ClN}_{3} \mathrm{O}$ : C, 72.29, H, 6.07, N, 9.73. Encontrado: C, 72.42, H, 6.11, N, 9.77.

\section{4-(((2-Clorobencil)(metil)amino)metil)- $N$-(2-(5-metoxi-1H-indol-3-il)etil)benza- mida (90)}

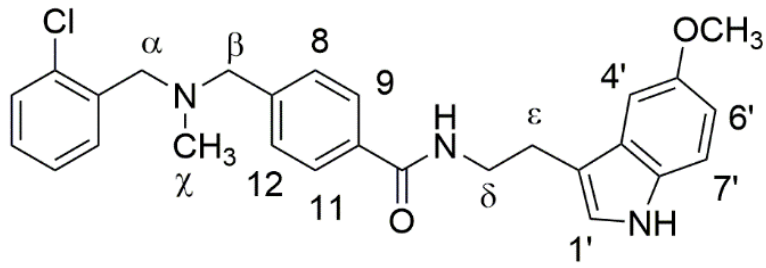

Siguiendo el procedimiento general, a partir del ácido 4-(((2clorobencil)(metil)amino)metil)benzoico (135.4 mg, $0.5 \mathrm{mmol})$, pyBOP (312.2 mg, $0.6 \mathrm{mmol}$ ), 5-metoxitriptamina (95.1 mg, $0.5 \mathrm{mmol})$ y Et $3 \mathrm{~N}(156 \mu \mathrm{L}, 1.2$ mmol) se aislaron $131.7 \mathrm{mg}$ (57\%) de 90 como un sólido blanco. p. f. 120-122 ${ }^{\circ} \mathrm{C}$ HPLC: 
pureza (99\%). MS : m/z $=462[\mathrm{M}+\mathrm{H}]{ }^{+} .{ }^{1} \mathrm{H}-\mathrm{RMN}\left(500 \mathrm{MHz}, \mathrm{CD}_{3} \mathrm{OD}\right), \delta(\mathrm{ppm}): 7.73$ $\left(\mathrm{d}, 2 \mathrm{H}_{9,11}, \mathrm{~J}=8.3\right), 7.54(\mathrm{~d}, 1 \mathrm{H}, \mathrm{J}=8.3), 7.46(\mathrm{~d}, 1 \mathrm{H}, \mathrm{J}=8.3), 7.44\left(\mathrm{~d}, 2 \mathrm{H}_{8,12}, \mathrm{~J}=8.3\right), 7.32$ $(\mathrm{d}, 1 \mathrm{H}, \mathrm{J}=8.3), 7.36(\mathrm{~m} ; 1 \mathrm{H}), 7.25\left(\mathrm{~d}, 1 \mathrm{H}_{4}, \mathrm{~J}=2.4\right) 7.21\left(\mathrm{~d}, 1 \mathrm{H}_{7}, \mathrm{~J}=8.8\right), 7.07\left(\mathrm{~s}, 1 \mathrm{H}_{1}{ }^{\prime}\right)$ $6.72\left(\mathrm{dd}, 1 \mathrm{H}_{6}, \mathrm{~J}=8.8, \mathrm{~J}=2.4\right), 3.72\left(\mathrm{~s}, 3 \mathrm{H}, \mathrm{OCH}_{3}\right), 3.66\left(\mathrm{~s}, 2 \mathrm{H}_{\beta}\right), 3.64\left(\mathrm{t}, 2 \mathrm{H}_{\delta}, \mathrm{J}=7.3\right)$, $3.63\left(\mathrm{~s}, 2 \mathrm{H}_{\alpha}\right), 3.03\left(\mathrm{t}, 2 \mathrm{H}_{\varepsilon}, \mathrm{J}=7.3\right), 2.20\left(\mathrm{~s}, 3 \mathrm{H}_{\chi}\right) \cdot{ }^{13} \mathrm{C}-\mathrm{RMN}\left(125 \mathrm{MHz}, \mathrm{CD}_{3} \mathrm{OD}\right), \delta(\mathrm{ppm})$ : 170.1 (CONH), 154.9 (C), 137.5 (C), 135.5 (C), 134.8 (C), 133.3 (C), 132.3 (C), 132.3 $(\mathrm{CH}), 130.5(\mathrm{CH}), 130.4(\mathrm{CH}), 130.3(\mathrm{C}), 130.2(2 \mathrm{CH}), 129.7(\mathrm{CH}), 129.2(\mathrm{C}), 128.3$ $(2 \mathrm{CH}), 113.3(\mathrm{C}), 112.9(\mathrm{CH}), 112.7(\mathrm{CH}), 101.2(\mathrm{CH}), 62.6\left(\mathrm{CH}_{2}\right), 59.4\left(\mathrm{CH}_{2}\right), 56.1$ $\left(\mathrm{CH}_{3}\right), 42.5\left(\mathrm{CH}_{2}\right), 42.3\left(\mathrm{CH}_{3}\right), 26.3\left(\mathrm{CH}_{2}\right)$ Análisis (\%): Calculado para $\mathrm{C}_{27} \mathrm{H}_{28} \mathrm{ClN}_{3} \mathrm{O}_{2}$ : C, 70.19, H, 6.11, N, 9.10. Encontrado: C, 70.42, H, 6.31, N, 9.43.

\subsubsection{Ensayos biológicos}

\subsubsection{Inhibición de AChE y BuChE}

Las medidas de inhibición de colinesterasas se realizaron siguiendo el método de Ellman ${ }^{127}$, en el Instituto de Química Médica. La solución de ensayo estaba formada por tampón fosfato 0,1 M a pH = 8, ácido 5,5'-ditiobisnitrobenzoico $200 \mu \mathrm{M}$ (DTNB, reactivo de Ellman), las enzimas acetilcolinesterasa o butirilcolinesterasa y yoduros de acetiltiocolina o de butiriltiocolina $(400 \mu \mathrm{M})$ como sustratos de las reacciones enzimáticas. Los compuestos a evaluar se preincubaron con la enzima durante 10 minutos a $30{ }^{\circ} \mathrm{C}$, se añadió el sustrato y se midieron los cambios de absorbancia a $412 \mathrm{~nm}$ cada 5 minutos en un espectrómetro UV/VIS Perkin Elmer 550 SE. Se compararon las velocidades de reacción y se calcularon los porcentajes de inhibición debidos a la presencia de los compuestos que se analizaban. El valor de $\mathrm{CI}_{50}$ se define como la concentración de compuesto que reduce en un 50\% la actividad enzimática.

\subsubsection{Ensayos de desplazamiento de propidio del PAS de la AChE}

A una disolución de AChE (Sigma Aldrich, se considera como tetrámero de peso molecular 260000) a la concentración de $5 \mu \mathrm{M}$ en tampón tris $0.1 \mathrm{mM}, \mathrm{pH}=8$, se añaden alícuotas de los compuestos a las concentraciones ensayadas. Las muestras se incuban 
primero a temperatura ambiente durante 6 horas y después durante 15 minutos con yoduro de propidio a la concentración final de $20 \mu \mathrm{M}$. La señal de fluorescencia se mide en un lector de fluorescencia Fluostar Optima a unas longitudes de absorción y emisión de 485 y $620 \mathrm{~nm}$ respectivamente.

\subsubsection{Evaluación de la capacidad antioxidante mediante el método ORAC}

La actividad antioxidante se determinó empleando el método ORAC-FL (Oxygen Radical Absorbance Capacity - Fluorescein) adaptando lo descrito por Dávalos y col ${ }^{190}$ El experimento se llevó a cabo en un fluorímetro Polarstar Galaxy con lector de placas (BMG Labtechnologies GMBH, Offenburg, Germany), controlado por el software Fluorostar Galaxy (versión 4.11-0) y dotado con filtros de excitación y de emisión a 485$\mathrm{P}$ y a 520-P, respectivamente. Los reactivos empleados, dihidrocloruro de 2,2'azobis(amidinopropano) (AAPH), ácido ( \pm )-6-hidroxi-2,5,7,8-tetrametilcromano-2carboxílico (trolox) y fluoresceína (FL), fueron adquiridos en Sigma-Aldrich. La reacción se llevó a cabo en tampón de fosfato $75 \mathrm{mM}(\mathrm{pH}$ 7.4) y la mezcla de reacción final fue de $200 \mu \mathrm{L}$. Se colocaron disoluciones de antioxidante $(20 \mu \mathrm{L})$ y FL $(120 \mu \mathrm{L} ; 70 \mathrm{mM}$, concentración final) en una microplaca negra de 96 pocillos ( $96 \mathrm{~F}$ sin tratamiento, Nunc). La mezcla se preincubó durante 15 min a $37^{\circ} \mathrm{C}$ y después se agregó rápidamente la disolución de AAPH ( $60 \mu \mathrm{L}, 12 \mathrm{mM}$, concentración final) usando una pipeta multicanal. La microplaca fue colocada inmediatamente en el lector, y se registró la fluorescencia cada minuto durante $80 \mathrm{~min}$. La microplaca fue automáticamente movida antes en cada lectura. Las muestras se midieron a ocho concentraciones diferentes $(0.1-1 \mu \mathrm{M})$. En cada ensayo se utilizó un blanco (FL + AAPH en tampón fosfato) y ocho disoluciones de calibración usando trolox $(1-8 \mu \mathrm{M})$. Todas las mezclas de reacción se prepararon por duplicado, y al menos se realizaron tres ensayos independientes para cada muestra. Los datos brutos se exportaron desde Fluostar Galaxy Software en una hoja de Excel para realizar los cálculos. Las curvas de fluorescencia frente al tiempo se normalizaron a la curva del blanco correspondiente al mismo ensayo, y se calculó el área bajo la curva de caída de fluorescencia (AUC). Las AUC netas correspondiente a cada muestra se calculó restando la AUC del blanco. Se calcularon las ecuaciones de regresión entre AUC neto y la concentración de antioxidantes para todas las muestras. Los valores ORAC-FL se expresaron como equivalentes trolox utilizando la curva estándar calculada para cada ensayo, donde el valor ORAC-FL de trolox se consideró igual a 1.0. 


\subsubsection{Cultivo de la línea celular de neuroblastoma humano SH-SY5Y}

La línea celular SH-SY5Y, entre los pasos entre 3 y 16 después de la descongelación, se mantuvieron en un medio modificado Eagle Dulbecco (DMEM) que contenía 15 aminoácidos no esenciales (NEAAs) y que se suplementó con $10 \%$ de suero de ternera fetal (FCS), $1 \mathrm{~mm}$ de glutamina, 50 unidades $/ \mathrm{ml}$ de penicilina y $50 \mu \mathrm{g} / \mathrm{ml}$ estreptomicina (reactivos GIBCO, Madrid, España). Los cultivos celulares se pusieron en frascos que contenían el medio suplementado y se mantuvieron a $37^{\circ} \mathrm{C}$ en un $5 \%$ de $\mathrm{CO}_{2} /$ aire humidificado. Los cultivos se pasaron 1:4 dos veces por semana. Para los experimentos de viabilidad celular/muerte celular, las células SH-SY5Y fueron subcultivadas en placas de 48 pocillos con una densidad de siembra de $10^{5}$ células por pocillo en DMEM libre de suero.

\subsubsection{Neuroprotección contra el estrés oxidativo}

Para estudiar la acción de protección de los compuestos contra la muerte celular inducida por $\mathrm{H}_{2} \mathrm{O}_{2}(60 \mu \mathrm{M})$ o por una mezcla de rotenona $(30 \mu \mathrm{M})$ y oligomicina $\mathrm{A}(10$ $\mu \mathrm{M})$, se administraron los fármacos a tiempo cero y se mantuvieron durante $24 \mathrm{~h}$. Después, los medios se sustituyeron por medios frescos que contenían el fármaco más el estímulo citotóxico y se dejó por un período adicional de 24 h. Posteriormente, se evaluó la supervivencia celular midiendo la actividad LDH o de MTT.

\subsubsection{Neuroprotección contra la sobrecarga de calcio}

Para evaluar el efecto neuroprotector de un compuesto contra la sobrecarga de $\mathrm{Ca}^{2+}$, las células SH-SY5Y se incubaron durante 24 h en un medio con una concentración de despolarización leve de $\mathrm{KCl}(20 \mathrm{mM})$ que contenía $\mathrm{CaCl}_{2}(5 \mathrm{mM})$ y FPL64176 $(0.3 \mu \mathrm{M})$, un antagonista de los canales de de $\mathrm{Ca}^{2+}$ de tipo L, lo que indujo una sobrecarga de $\mathrm{Ca}^{2+}$ y la consiguiente muerte celular ${ }^{203}$. El compuesto a ensayar fue administrado $24 \mathrm{~h}$ antes

\footnotetext{
${ }^{203}$ W. Zheng, D. Rampe, D. J. Triggle, Pharmacological, radioligand binding, and electrophysiological characteristics of FPL 64176, a novel non-dihydropyridine Ca channel activator, in cardiac and vascular preparations, Mol. Pharmacol. 1991, 40, 734-741.
} 
de la incubación de células con un tratamiento que consistió en $20 \mathrm{~K}^{+} / 5 \mathrm{Ca}^{2+} / \mathrm{FPL}$ que se mantuvo por un período adicional de $24 \mathrm{~h}$. Al final del experimento, se evaluó la viabilidad celular usando el método MTT.

\subsubsection{Neuroprotección contra la toxicidad inducida por $A \beta_{1-42}$}

Para evaluar el efecto neuroprotector de un determinado compuesto frente la toxicidad inducida por $\mathrm{A} \beta$, las células SH-SY5Y se preincubaron con el neuroprotector a las concentraciones indicadas durante $24 \mathrm{~h}$. Finalmente, se coincubaron por otro período de $24 \mathrm{~h}$ con el compuesto en presencia de $\mathrm{A} \beta_{1-42}(30 \mu \mathrm{M})$. Al final del experimento, se evaluó la viabilidad celular usando el método MTT.

\subsubsection{Neuroprotección contra la toxicidad inducida por ácido okadaico}

Para evaluar la neuroprotección contra la toxicidad inducida por ácido okadaico, se usó el siguiente protocolo: las células SH-SY5Y se expusieron durante $24 \mathrm{~h}$ a $30 \mathrm{nM}$ de ácido okadaico. El compuesto 61 se agregó en las concentraciones indicadas $24 \mathrm{~h}$ antes de la incubación de las células con el estímulo tóxico y se mantuvo todo el sistema durante un período adicional de $24 \mathrm{~h}$. Al final de los experimentos, se evaluó la muerte celular midiendo la actividad de lactato deshidrogenasa (LDH) liberada.

\subsubsection{Medida de la actividad de lactato deshidrogenasa (LDH)}

La actividad de LDH extracelular e intracelular se midió por UV-vis usando un kit de muerte celular por citotoxicidad (Roche-Boehringer. Mannheim, Alemania) empleando las indicaciones del fabricante. La actividad total de LDH se definió como la suma de la actividad de LDH intracelular y extracelular y la liberación de LDH se definió como el porcentaje de actividad extracelular comparado con la actividad total de LDH. Los datos se expresaron como media \pm SEM de al menos tres cultivos que se realizaron por cuadruplicado. Se calculó la liberación de LDH para cada experimento individual, considerando el $100 \%$ del LDH extracelular liberado por con respecto al total. Para 
determinar el \% de protección, la liberación de LDH se normalizó de la siguiente manera: en cada experimento por triplicado, la liberación de LDH obtenida en células no tratadas (basales) se restó de la LDH liberada en el tratamiento tóxico y se normalizó al $100 \%$. Este valor se restó de 100.

\subsubsection{Medida de la viabilidad celular mediante MTT}

La viabilidad celular (actividad mitocondrial de células vivas), se midió mediante el análisis colorimétrico cuantitativo con MTT (3-[4,5-dimetiltiazol-2-yl]-2,5diphenyltetrazolium bromuro, Sigma-Aldrich, Madrid, España), de acuerdo a lo descrito en la bibliografía ${ }^{204}$. Se agregó MTT a todos los pocillos (concentración final $0.5 \mathrm{mg} / \mathrm{ml}$ ) y se incubó en la oscuridad a $37^{\circ} \mathrm{C}$ durante $2 \mathrm{~h}$. El anillo tetrazolio del MTT puede ser abierto por las reductasas mitocondriales para producir un precipitado de un derivado del formazán. Después de $2 \mathrm{~h}$, el formazán producido se disolvió agregando $200 \mu \mathrm{L}$ de DMSO, dando como resultado un compuesto coloreado cuya densidad óptica se leyó con un lector de ELISA a una longitud de onda de $540 \mathrm{~nm}$. Todos los ensayos con MTT se realizaron por triplicado. Los valores de absorbancia obtenidos en las células de control no tratadas con el tóxico se consideraron células con una viabilidad del 100\%.

204 F. Denizot, R. Lang, Rapid colorimetric assay for cell growth and survival. Modifications to the tetrazolium dye procedure giving improved sensitivity and reliability, J. Immunol. Methods 1986, 89, 271-277. 
2.7.3.11. Preparación de rodajas de hipocampo de rata e inducción de toxicidad mediante la falta de oxígeno y glucosa seguida de re-oxigenación (OGD/Reox)

Todos los experimentos se realizaron utilizando ratas macho Sprague-Dawley adultas (275 - $325 \mathrm{~g})$, procedentes de una colonia de los animalarios de la Facultad de Medicina de la Universidad Autónoma de Madrid. Los experimentos se realizaron tras la aprobación del Protocolo del Comité de ética institucional. Se realizaron todos los esfuerzos conducentes a reducir el número de animales empleados en el experimento y a minimizar su sufrimiento.

El protocolo fue el mismo que el utilizado por Egea y col. ${ }^{205}$ Las ratas se decapitaron rápidamente bajo anestesia del pentobarbital del sodio $(60 \mathrm{mg} / \mathrm{kg}$, i.p. $)$, las partes delanteras del cerebro se diseccionaron rápidamente del cráneo y se colocaron en una disolución fría de tampón Krebs (pH 7.4), conteniendo $\mathrm{NaCl} 120 \mu \mathrm{M}, \mathrm{KCl} 2 \mu \mathrm{M}, \mathrm{CaCl}_{2}$ $0.5 \mu \mathrm{M}, \mathrm{NaHCO} 326 \mu \mathrm{M}, \mathrm{MgSO}_{4} 10 \mu \mathrm{M}, \mathrm{KH}_{2} \mathrm{PO}_{4} 1.18 \mu \mathrm{M}$, glucosa $11 \mu \mathrm{M}$ y sacarosa $200 \mu \mathrm{M}$. Las soluciones de la cámara se burbujearon con mezclas de gas $95 \% \mathrm{O}_{2} / 5 \% \mathrm{CO}_{2}$ ó 95\% $\mathrm{N}_{2} / 5 \% \mathrm{CO}_{2}, 45$ min antes de inmersión de las rodajas de cerebro, para asegurar la saturación de $\mathrm{O}_{2}$. Los hipocampos se disecaron rápidamente, y las rodajas (350 $\mu \mathrm{m}$ de espesor) se prepararon rápidamente usando un interruptor de tejido de McIlwain. Luego, las láminas de tejido se transfirieron a frascos de tampón de disección libre de sacarosa, burbujeando con $95 \% \mathrm{O}_{2} / 5 \% \mathrm{CO}_{2}$ en un baño de agua a temperatura ambiente durante 60 min para recuperarse del trauma de corte antes de comenzar los experimentos (período de equilibrado). Las láminas correspondientes al grupo control se incubaron 15 min en la misma solución de tampón Krebs y la solución se equilibró con una mezcla de 95\% $\mathrm{O}_{2} / 5 \%$ $\mathrm{CO}_{2}$. La privación de oxígeno y glucosa se indujo al incubar las rodajas de tejido durante un período de 15 minutos en una solución de Krebs libre de glucosa, equilibrada con una mezcla de gas de $\mathrm{CO}_{2}$ de $95 \% \mathrm{~N}_{2} / 5 \%$; la glucosa se substituyó por 2-desoxiglucosa. Después de este período de OGD, las láminas se introdujeron de nuevo en una solución normal oxigenada de Krebs que contenía glucosa (período de la re-oxigenación). Los experimentos se realizaron a $37^{\circ} \mathrm{C}$. Se incluyeron un grupo de control y OGD en todos los experimentos y se probaron cuatro concentraciones de fármacos en cada experimento.

\footnotetext{
${ }^{205}$ Egea, J.; Rosa, A. O.; Sobrado, M.; Gandia, L.; Lopez, M. G.; Garcia, A. G. Neuroprotection afforded by nicotine against oxygen and glucose deprivation in hippocampal slices is lost in alpha7 nicotinic receptor knockout mice. Neuroscience 2007, 145, 866-872.
} 


\subsubsection{Cuantificación de la viabilidad celular en rodajas de hipocampo por MTT}

La viabilidad celular en rodajas de hipocampo se determinó mediante la capacidad de estas células para reducir $\mathrm{MTT}^{206}$. Las láminas de hipocampo se cogieron inmediatamente después del período de reoxigenación y se incubaron con MTT (0.5 $\mathrm{mg} / \mathrm{ml}$ ) en solución tamponada de bicarbonato de Krebs durante 30 min a $37{ }^{\circ} \mathrm{C}$. El formazán producido se solubilizó agregando $200 \mu 1$ de DMSO, dando por resultado un compuesto coloreado cuya densidad óptica fue medida en un lector ELISA a $540 \mathrm{~nm}$.

\subsubsection{Estudios en un modelo in vivo de pérdida de memoria por escopolamina}

En estos experimentos se emplearon ratones suizos machos adultos (12-14 semanas de edad, con un peso de 35-40 g; Charles River, Wilmington, MA, USA) en la Facultad de Medicina de la Universidad Autónoma de Madrid. Los experimentos se realizaron tras la aprobación del Protocolo del Comité de ética institucional. Se realizaron todos los esfuerzos conducentes a reducir el número de animales empleados en el experimento y a minimizar su sufrimiento.

Los ratones se alojaron bajo condiciones de temperatura y iluminación controladas con alimentos y agua a demanda. Los ratones se colocaron durante 5 minutos en un lugar establecido (recinto de estructura de PVC con dimensiones 40 x $40 \times 40 \mathrm{~cm}$ ) durante 2 días antes del día de la prueba para reducir el estrés y la presencia de fobias. En el día de la prueba, los ratones $(\mathrm{n} \geq 9)$ se dividieron aleatoriamente en 5 grupos y se inyectaron con los fármacos requeridos. Los grupos experimentales, según las sustancias inyectadas, fueron: basal (salino), escopolamina, escopolamina + galantamina, escopolamina +2.5 $\mathrm{mg} / \mathrm{kg}$ compuesto $\mathbf{6 1}$, y escopolamina $+10 \mathrm{mg} / \mathrm{kg}$ de $\mathbf{6 1}$. En el recinto de los ratones se colocaron dos objetos idénticos (botellas cilíndricas de vidrio, lo suficientemente pesadas como para evitar que los ratones los desplazaran; altura, $22 \mathrm{~cm}$; diámetro, $9 \mathrm{~cm}$ ) y se permitió a los animales explorarlos durante 30 s (T1, ensayo de muestra). La exploración de los objetos se cronometraba cuando los ratones olfateaban, o miraban a los objetos desde no más de $2 \mathrm{~cm}$ de distancia. Después de 15 minutos, los ratones volvieron a

206 Denizot, F.; Lang, R. Rapid colorimetric assay for cell growth and survival. Modifications to the tetrazolium e procedure giving improved sensitivity and reliability. J Immunol Methods 1986, 89, 271277. 
colocarse en el recinto, pero uno de los dos objetos había sido trasladado a una nueva ubicación. El tiempo dedicado a explorar los objetos en las nuevas y antiguas localizaciones (T2, ensayo de reconocimiento) se observó y cronometró durante 3 minutos por un observador que desconocía los tratamientos. Todas las ubicaciones de los objetos se modificaron entre grupos, y los objetos y el campo se lavaron con ácido acético al $0.1 \%$ entre los ensayos para eliminar cualquier indicio olfativo. El tiempo medido fue considerado un comportamiento de exploración y se usó para calcular un índice de discriminación de memoria (DI) como se descrbió con anterioridad ${ }^{207}$ : DI $=(\mathrm{N}-\mathrm{F}) /(\mathrm{N}+$ $\mathrm{F}$ ), donde $\mathrm{N}$ es el tiempo dedicado a explorar el nuevo objeto, y $\mathrm{F}$ es el tiempo dedicado a explorar el objeto conocido. Un DI más alto se considera que refleja una mayor capacidad de memoria.

\subsubsection{Ensayos de Neurogénesis. Animales y cultivo de neuroesferas}

Estos ensayos se realizaron en el Instituto de Investigaciones Biomédicas “Alberto Sols" (CSIC), empleando ratas adultas Wistar macho (8-12 semanas de edad, $\mathrm{n}=6$ por grupo), que habían sido mantenidas en un ciclo de $12 \mathrm{~h}$ de luz-oscuridad. Todos los procedimientos con animales fueron aprobados específicamente por el Comité de Ética para Experimentación Animal del CSIC y llevados a cabo de conformidad con las recomendaciones nacionales (normativa 1201/2005), e internacionales (Directiva 2010/63 del Consejo de Comunidades Europeas). Se trató de minimizar en todo momento el sufrimiento de los animales.

Las neuroesferas (NS) se derivaron de la zona subgranular del giro dentado del hipocampo de ratas adultas Wistar, que fueron inducidas a proliferar usando métodos establecidos para lograr una expansión celular óptima según los protocolos publicados ${ }^{208}$. Las ratas fueron decapitadas y los cerebros diseccionados, obteniendo el hipocampo como se describe en la bibliografía ${ }^{209}$. Las células se sembraron en placas de 12 pocillos y se

${ }^{207}$ Blalock, E. M.; Chen, K. C.; Sharrow, K.; Herman, J. P.; Porter, N. M.; Foster, T. C.; Landfield, P. W. Gene microarrays in hippocampal aging: statistical profiling identifies novel processes correlated with cognitive impairment. J Neurosci 2003, 23, 3807-3819

208 Ferron, S. R.; Andreu-Agullo, C.; Mira, H.; Sanchez, P.; Marques-Torrejon, M. A.; Farinas, I. A combined ex/in vivo assay to detect effects of exogenously added factors in neural stem cells. Nat. Protoc. 2007, 2, 849-859.

${ }^{209}$ Morales-Garcia, J. A.; Luna-Medina, R.; Alfaro-Cervello, C.; Cortes-Canteli, M.; Santos, A.; GarciaVerdugo, J. M.; Perez-Castillo, A. Peroxisome proliferator-activated receptor gamma ligands regulate neural stem cell proliferation and differentiation in vitro and in vivo. Glia 2011, 59, 293-307. 
cultivaron en DMEM / F12 (1: 1, Invitrogen) que contienen $10 \mathrm{ng} \mathrm{mL}^{-1}$ del factor de crecimiento epidérmico (EGF, Peprotech, Londres, RU), $10 \mathrm{ng} \mathrm{mL} \mathrm{mL}^{-1}$ del factor de crecimiento de fibroblastos (FGF, Peprotech), y medio B27 (Gibco). Después de 3 días, los cultivos primarios de NS se trataron con diferentes compuestos. Para determinar el capacidad de los compuestos para inducir la diferenciación, los cultivos de NS de 10 días de edad fueron puestas en cubreobjetos recubiertos con poli-L-lisina de $100 \mu \mathrm{g} \mathrm{mL}^{-1}$ y se trataron durante $48 \mathrm{~h}$ en presencia de suero, pero en ausencia de factores de crecimiento exógenos.

\subsubsection{Inmunocitoquímica y determinaciones estadísticas}

Después del tratamiento, las células se procesaron para inmunocitoquímica con dos tipos de marcadores asociados a neurogénesis: anticuerpo anti- $\beta$-tubulina (clon TuJ1), asociado con etapas tempranas de neurogénesis, y MAP-2 (proteína 2 asociada a microtúbulos), un marcador de maduración neuronal. Como marcador nuclear se utilizó la tinción DAPI (4',6-diamidino-2-fenilindol). Los valores basales se obtuvieron en las mismas condiciones pero en ausencia de producto. Se utilizaron como controles melatonina (ligando endógeno de los receptores melatoninérgicos) y luzindol (antagonista melatoninérgico). Las imágenes se obtuvieron usando un microscopio de fluorescencia Nikon 90i que estaba acoplado a una cámara digital Qi. La configuración del microscopio se ajustó para producir la óptima relación señal / ruido. Para cuantificar el número de células señaladas por cada marcador, se contó la cantidad de células positivas en la neurosfera como se describió previamente ${ }^{210}$. El número de células se estimaron a partir de un total de cinco neuroesferas por condición en tres experimentos independientes.

Para el tratamiento estadístico se siguió el análisis “one-way ANOVA” para realizar las comparaciones entre diferentes tratamientos en NS, empleando el paquete de software estadístico SPSS (versión 20.0) para Windows (Chicago, IL), seguido del test de Student. Se consideró un valor estadísticamente significativo un valor de $\mathrm{p} \leq 0.05$.

\footnotetext{
${ }^{210}$ Morales-Garcia, J. A.; Luna-Medina, R.; Alonso-Gil, S.; Sanz-Sancristobal, M.; Palomo, V.; Gil, C.; Santos, A.; Martinez, A.; Perez-Castillo, A. Glycogen synthase kinase 3 inhibition promotes adult hippocampal neurogenesis in vitro and in vivo. ACS Chem. Neurosci. 2012, 3, 963-971.
} 


\subsection{TABLAS (DATOS DE ${ }^{1} \mathrm{H}-\mathrm{RMN} \mathrm{Y}^{13} \mathrm{C}-\mathrm{RMN}$ )}

Tabla I. Datos de ${ }^{1} \mathrm{H}-\mathrm{RMN}, \delta(\mathrm{ppm})$ y $J(\mathrm{~Hz})$ de 9-cloro-1,2,3,4-tetrahidroacridinas 1-4 $\left(\mathrm{CDCl}_{3}, 300 \mathrm{MHz}\right)$.

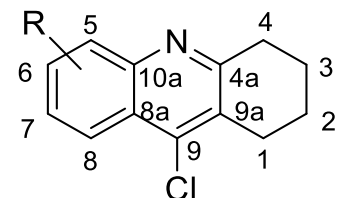

\begin{tabular}{|c|c|c|c|c|c|c|c|c|c|c|c|c|}
\hline \multirow[b]{2}{*}{ Comp. } & \multirow[b]{2}{*}{$\mathrm{R}$} & \multicolumn{7}{|c|}{$\delta(\mathrm{ppm})$} & \multicolumn{4}{|c|}{$J(\mathrm{~Hz})$} \\
\hline & & $\begin{array}{c}1 \\
(\mathrm{~m}) \\
\end{array}$ & $\begin{array}{l}2,3 \\
(\mathrm{~m}) \\
\end{array}$ & $\begin{array}{c}4 \\
(\mathrm{~m}) \\
\end{array}$ & $\begin{array}{c}5 \\
\text { (dd) } \\
\end{array}$ & $\begin{array}{c}6 \\
\text { (ddd) } \\
\end{array}$ & $\begin{array}{c}7 \\
\text { (ddd) } \\
\end{array}$ & $\begin{array}{c}8 \\
(\mathrm{dd}) \\
\end{array}$ & & $\begin{array}{l}5,6 \\
7,8 \\
\end{array}$ & $\begin{array}{l}5,7 \\
6,8 \\
\end{array}$ & 6,7 \\
\hline 1 & $\mathrm{H}$ & 3.03 & 1.96 & 3.15 & 7.98 & 7.67 & 7.54 & 8.16 & - & 8.3 & 1.2 & 6.9 \\
\hline 2 & $8-\mathrm{Cl}$ & 2.95 & 1.92 & 3.11 & 7.87 & $7.46(\mathrm{t})$ & 7.54 (dd) & - & & 8.2 & 1.2 & 8.2 \\
\hline 3 & 6,8-diCl & 2.90 & 1.89 & 3.01 & $7.81(\mathrm{~d})$ & - & $7.48(\mathrm{~d})$ & - & - & - & 2.2 & - \\
\hline 4 & 7-F & 3.00 & 1.94 & 3.08 & 7.95 & 7.41 & - & 7.75 & & 9.1 & 2.7 & \\
\hline
\end{tabular}

En el espectro de ${ }^{1} \mathrm{H}-\mathrm{RMN}$ del compuesto $4(\mathrm{R}=7-\mathrm{F})$ se observan las constantes de acoplamiento $J_{\mathrm{H}, \mathrm{F} .} .7 .95\left(\mathrm{dd}, 1 \mathrm{H}, J_{5, \mathrm{~F}}=5.3 \mathrm{~Hz}, J_{5,6}=9.1 \mathrm{~Hz}, \mathrm{H} 5\right) ; 7,75$ $\left(\mathrm{dd}, 1 \mathrm{H}, J_{6,8}=2.7 \mathrm{~Hz} ; J_{8, \mathrm{~F}}=9.7 \mathrm{~Hz}, \mathrm{H}_{8}\right) ; 7,41\left(\mathrm{ddd}, 1 \mathrm{H}, J_{6,8}=2.7 \mathrm{~Hz}, J_{6, \mathrm{~F}}=8.2 \mathrm{~Hz} ; J_{5,6}=9.1 \mathrm{~Hz}, \mathrm{H}_{6}\right)$.

Tabla II. Datos de ${ }^{13} \mathrm{C}-\mathrm{RMN}, \delta(\mathrm{ppm})$ de las 9-cloro-1,2,3,4-tetrahidroacridinas 1-4 $\left(\mathrm{CDCl}_{3}, 75 \mathrm{MHz}\right)$.

\begin{tabular}{ccccccccccccccccccc}
\hline Comp. & 1 & 2 & 3 & 4 & $4 a$ & 5 & 6 & 9 & 8 & $8 \mathrm{a}$ & 9 & $9 \mathrm{a}$ & $10 \mathrm{a}$ \\
\hline \hline $\mathbf{1}$ & 22.6 & 22.5 & 22.5 & 27.3 & 159.4 & 128.5 & 129.1 & 126.3 & 123.6 & 128.7 & 141.3 & 125.2 & 146.5 \\
$\mathbf{2}$ & 28.1 & 22.7 & 22.3 & 34.0 & 159.6 & 128.9 & 128.3 & 130.0 & 129.1 & 122.6 & 140.3 & 131.9 & 148.4 \\
$\mathbf{3}$ & 28.1 & 22.6 & 22.1 & 33.9 & 160.8 & 127.8 & 140.4 & 130.3 & 130.1 & 121.0 & 133.5 & 131.8 & 148.3 \\
$\mathbf{4}$ & 27.5 & 22.6 & 22.5 & 33.9 & 158.7 & 131.1 & 1194 & 160.6 & 107.4 & 126.1 & 143.7 & 129.6 & 140.6 \\
\hline
\end{tabular}

En el espectro de ${ }^{13} \mathrm{C}-\mathrm{RMN}$ del compuesto $4\left(\mathrm{R}=7\right.$-F) se observan las constantes de acoplamiento $J_{\mathrm{C}, \mathrm{F}}:$ : 160,6 $\left(J_{7, \mathrm{~F}}=245 \mathrm{~Hz}, \mathrm{C}_{7}\right) ; 158,7\left(J_{4 \mathrm{a}, \mathrm{F}}=\right.$ $\left.3,0 \mathrm{~Hz}, \mathrm{C}_{4 \mathrm{a}}\right) ; 140,6\left(J_{10 \mathrm{a}, \mathrm{F}}=5,0 \mathrm{~Hz}, \mathrm{C}_{10 \mathrm{a}}\right) ; 131,1\left(J_{5, \mathrm{~F}}=9,0 \mathrm{~Hz}, \mathrm{C} 5\right) ; 126,1\left(J_{8 \mathrm{a}, \mathrm{F}}=10 \mathrm{~Hz}, \mathrm{C}_{8 \mathrm{a}}\right) ; 119,4\left(J_{6, \mathrm{~F}}=26 \mathrm{~Hz}, \mathrm{C}_{6}\right) ; 107,4\left(J_{8, \mathrm{~F}}=24 \mathrm{~Hz}, \mathrm{C}_{8}\right)$. 
Tabla III. Datos de ${ }^{1} \mathrm{H}-\mathrm{RMN}, \delta(\mathrm{ppm})$ y $J(\mathrm{~Hz})$ de los ácidos 5-11 $\left(\mathrm{CD}_{3} \mathrm{OD}, 300 \mathrm{MHz}\right)$.

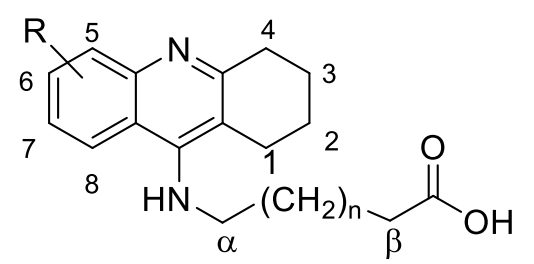

\begin{tabular}{|c|c|c|c|c|c|c|c|c|c|c|c|c|c|c|c|}
\hline \multirow[b]{2}{*}{$\mathrm{N}^{\circ}$} & \multirow[b]{2}{*}{$\mathrm{R}$} & \multirow[b]{2}{*}{$\mathrm{n}$} & \multicolumn{7}{|c|}{$\delta(\mathrm{ppm})$} & \multicolumn{4}{|c|}{$J$} & \multicolumn{2}{|c|}{$\delta(J)$} \\
\hline & & & $\begin{array}{c}1 \\
(\mathrm{t}) \\
\end{array}$ & $\begin{array}{l}2.3 \\
(\mathrm{~m}) \\
\end{array}$ & $\begin{array}{c}4 \\
(\mathrm{t}) \\
\end{array}$ & $\begin{array}{c}5 \\
(\mathrm{dd}) \\
\end{array}$ & $\begin{array}{c}6 \\
\text { (ddd) } \\
\end{array}$ & $\begin{array}{c}7 \\
\text { (ddd) } \\
\end{array}$ & $\begin{array}{c}8 \\
(\mathrm{dd}) \\
\end{array}$ & $\begin{array}{l}1.2 \\
3.4 \\
\end{array}$ & $\begin{array}{l}5.6 \\
7.8 \\
\end{array}$ & $\begin{array}{l}5.7 \\
6.8 \\
\end{array}$ & 6.7 & $\begin{array}{r}\alpha \\
(\mathrm{t}) \\
\end{array}$ & $\begin{array}{c}\beta \\
(\mathrm{t}) \\
\end{array}$ \\
\hline 5 & $\mathrm{H}$ & 3 & $2.88(\mathrm{~m})$ & 2.14 & $3.20(\mathrm{~m})$ & 7.94 & 8.01 & 7.78 & 8.56 & - & 8.3 & 1.4 & 6.8 & $4.14(7.3)$ & $2.44(7.3)$ \\
\hline 6 & $\mathrm{H}$ & 4 & $2.89(\mathrm{~m})$ & 2.15 & $3.20(\mathrm{~m})$ & 7.97 & 8.03 & 7.76 & 8.56 & - & 8.5 & 1.5 & 6.6 & $4.14(7.3)$ & $2.46(7.3)$ \\
\hline 7 & $\mathrm{H}$ & 5 & 2.88 & 2.16 & 3.20 & 7.95 & 8.04 & 7.77 & 8.58 & 5.4 & 8.4 & 1.2 & 7.1 & $4.14(7.2)$ & $2.45(7.3)$ \\
\hline 8 & $8-\mathrm{Cl}$ & 3 & 3.02 & 2.14 & 3.20 & 7.94 & $7.86(\mathrm{t})$ & $\begin{array}{l}7.73 \\
(\mathrm{dd})\end{array}$ & - & 6.2 & 8.0 & 1.8 & 8.0 & $3.94(7.0)$ & $2.48(7.0)$ \\
\hline 9 & 6.8-diCl & 3 & 2.97 & 2.05 & 3.17 & $7.92(\mathrm{~d})$ & - & 7.68 (d) & - & 6.4 & - & 2.2 & - & $3.67(7.1)$ & $2.34(7.1)$ \\
\hline 10 & 6.8-diCl & 5 & 2.97 & 2.09 & 3.19 & $7.98(\mathrm{~d})$ & - & 7.77 (d) & - & 6.4 & - & 2.3 & - & $3.81(7.2)$ & $2.39(7.3)$ \\
\hline 11 & $7-\mathrm{F}$ & 3 & $2.92(\mathrm{~m})$ & 2.13 & $3.22(\mathrm{~m})$ & 8.05 & 7.85 & - & 8.25 & - & 8.5 & 2.4 & - & $4.08(7.2)$ & $2.40(7.2)$ \\
\hline
\end{tabular}

Otros protones: 5: $\left(\mathrm{CH}_{2}\right)_{3}: 2.04(\mathrm{q}, 2 \mathrm{H}, J=7.3) ; 1.84(\mathrm{q}, 2 \mathrm{H}, J=7.3) ; 1.65(\mathrm{q}, 2 \mathrm{H}, J=7.3)$. 6: $\left(\mathrm{CH}_{2}\right) 4: 2.03(\mathrm{q}, 2 \mathrm{H}, J=7.3) ; 1.85(\mathrm{~m}, 4 \mathrm{H}) ; 1.60(\mathrm{q}, 2 \mathrm{H}, J=7.3)$.

7: $\left(\mathrm{CH}_{2}\right)_{5}: 2.02(\mathrm{q}, 2 \mathrm{H}, J=7.3) ; 1.77(\mathrm{q}, 2 \mathrm{H}, J=7.3) ; 1.58(\mathrm{~m}, 6 \mathrm{H}) .8:\left(\mathrm{CH}_{2}\right)_{3}: 1.91(\mathrm{q}, 2 \mathrm{H}, J=7.0) ; 1.75(\mathrm{q}, 2 \mathrm{H}, J=7.0) ; 1.48(\mathrm{q}, 2 \mathrm{H}, J=7.0) .9:\left(\mathrm{CH}_{2}\right)_{3}: 1.84$ $(\mathrm{q}, 2 \mathrm{H}, J=7.1) ; 1.74(2 \mathrm{H}, \mathrm{q}, J=7.1) ; 1.50(\mathrm{q}, 2 \mathrm{H}, J=7.1) .10:\left(\mathrm{CH}_{2}\right)_{5}: 1.87(\mathrm{q}, 2 \mathrm{H}, J=7.0) ; 1.72(\mathrm{q}, 2 \mathrm{H}, J=7.0) ; 1.46(\mathrm{~m}, 6 \mathrm{H}) .11:\left(\mathrm{CH}_{2}\right)_{3}: 2.02(\mathrm{q}, 2 \mathrm{H}, J=$ 7.2); 1.84 (q, $2 \mathrm{H}, J=7.2) ; 1.64(\mathrm{~m}, 2 \mathrm{H})$. Nota: En el espectro de ${ }^{1} \mathrm{H}-\mathrm{RMN}$ del compuesto $11(\mathrm{R}=\mathrm{F}): J_{\mathrm{F}, 5}=5.1 \mathrm{~Hz} ; J_{\mathrm{F}, 6}=10.0 \mathrm{~Hz} ; J_{\mathrm{F}, 8}=10.7 \mathrm{~Hz}$. 
Tabla IV. Datos de ${ }^{13} \mathrm{C}-\mathrm{RMN}, \delta$ (ppm) de los ácidos 5-11 ( $\left.\mathrm{CD}_{3} \mathrm{OD}, 75 \mathrm{MHz}\right)$.

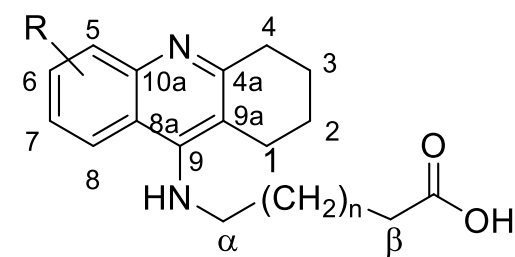

\begin{tabular}{cccccccccccccccccccc}
\hline $\mathrm{N}^{\mathrm{o}}$ & $\mathrm{R}$ & $\mathrm{n}$ & 1 & 2 & 3 & 4 & $4 \mathrm{a}$ & 5 & 6 & 7 & 8 & $8 \mathrm{a}$ & 9 & $9 \mathrm{a}$ & $10 \mathrm{a}$ & $\alpha$ & $\beta$ & $\mathrm{CO}$ \\
\hline \hline $\mathbf{5}$ & $\mathrm{H}$ & 3 & 24.8 & 23.0 & 21.8 & 29.9 & 151.7 & 120.2 & 133.9 & 126.5 & 126.3 & 117.9 & 157.9 & 112.8 & 139.8 & 48.6 & 36.4 & 179.7 \\
$\mathbf{6}$ & $\mathrm{H}$ & 4 & 24.9 & 23.0 & 21.8 & 29.3 & 151.6 & 120.2 & 134.0 & 126.8 & 126.5 & 116.9 & 157.8 & 112.7 & 139.6 & 49.1 & 34.8 & 176.3 \\
$\mathbf{7}$ & $\mathrm{H}$ & 5 & 24.8 & 22.9 & 21.8 & 29.4 & 151.7 & 120.1 & 134.1 & 126.5 & 126.3 & 117.1 & 158.1 & 112.9 & 139.8 & 49.1 & 34.8 & 177.5 \\
$\mathbf{8}$ & $8-\mathrm{Cl}$ & 3 & 27.5 & 23.2 & 22.1 & 31.6 & 158.2 & 121.3 & 132.6 & 129.2 & 130.5 & 115.9 & 154.4 & 115.7 & 143.0 & 50.7 & 37.4 & 180.7 \\
$\mathbf{9}$ & $6.8-\mathrm{diCl}$ & 3 & 26.9 & 23.5 & 22.7 & 32.0 & 158.0 & 123.4 & 136.0 & 128.4 & 131.4 & 116.1 & 156.2 & 118.3 & 146.4 & 50.9 & 37.6 & 179.4 \\
$\mathbf{1 0}$ & $6.8-\mathrm{diCl}$ & 5 & 27.4 & 23.2 & 22.5 & 32.5 & 158.8 & 123.4 & 136.0 & 128.4 & 131.7 & 116.5 & 155.1 & 118.8 & 146.8 & 50.4 & 36.0 & 178.9 \\
$\mathbf{1 1}$ & $7-\mathrm{F}$ & 3 & 25.3 & 23.0 & 21.8 & 29.5 & 152.3 & 123.1 & 123.3 & 160.5 & 110.4 & 118.1 & 157.1 & 113.0 & 136.7 & 48.6 & 36.6 & 179.9 \\
\hline
\end{tabular}

Otros carbonos: 5: $\left(\mathrm{CH}_{2}\right)_{3}: 31.2 ; 27.4 ; 26.2 .6:\left(\mathrm{CH}_{2}\right)_{4}: 31.3 ; 30.0 ; 29.7 ; 27.4 .7:\left(\mathrm{CH}_{2}\right)_{5}: 31.4 ; 29.9 ; 29.8 ; 27.5 ; 25.6 .8:\left(\mathrm{CH}_{2}\right)_{3}: 30.1 ; 26.8 ; 26.5 .9:\left(\mathrm{CH}_{2}\right)_{3}$ : 31.8; 27.7; 26.7. 10: $\left(\mathrm{CH}_{2}\right)_{5}: 31.9 ; 29.9 ; 30.0 ; 27.7 ; 25.8 .11:\left(\mathrm{CH}_{2}\right)_{3}: 31.3 ; 27.4 ; 26.2$. Nota: en el espectro de ${ }^{13} \mathrm{C}$ del compuesto $11(\mathrm{R}=\mathrm{F}): 160.5\left(\mathrm{~d},{ }^{1} J_{\mathrm{C}, \mathrm{F}}=\right.$ $245.2 \mathrm{~Hz}) ; 123.3\left(\mathrm{~d},{ }^{2} J_{\mathrm{C}, \mathrm{F}}=26.2 \mathrm{~Hz}\right) ; 123.1\left(\mathrm{~d},{ }^{3} J_{\mathrm{C}, \mathrm{F}}=9.0 \mathrm{~Hz}\right) ; 118.1\left(\mathrm{~d},{ }^{3} J_{\mathrm{C}, \mathrm{F}}=9.0 \mathrm{~Hz}\right) ; 110,4\left(\mathrm{~d},{ }^{2} J_{\mathrm{C}, \mathrm{F}}=25.7 \mathrm{~Hz}\right)$. 
Tabla $\boldsymbol{V}$. Desplazamientos químicos $\delta$ (ppm) de ${ }^{1} \mathrm{H}-\mathrm{RMN}$ registados en $\mathrm{CD}_{3} \mathrm{OD}$ (400 MHz) de los híbridos tacrina - fenol. Fragmento de tacrina.

Multiplicidades y constantes de acoplamiento $J$ indicadas en Herzios $(\mathrm{Hz})$

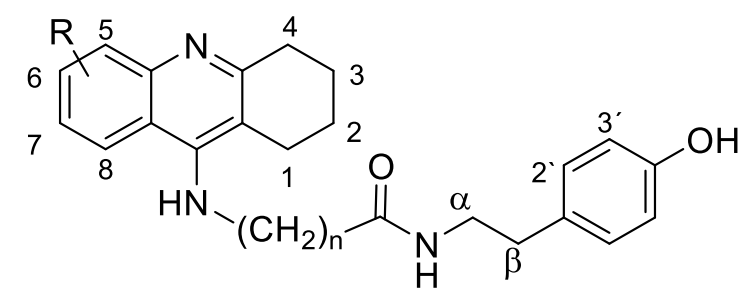

\begin{tabular}{|c|c|c|c|c|c|c|c|c|c|}
\hline & \multirow[b]{2}{*}{$\mathbf{R}$} & \multirow[b]{2}{*}{$\mathbf{n}$} & \multicolumn{7}{|c|}{ Fragmento de tacrina } \\
\hline & & & 1 & 2 & 4 & 5 & 6 & 7 & 8 \\
\hline \multirow[t]{2}{*}{12} & $\mathrm{H}$ & 5 & $2.89(\mathrm{~m})$ & $2.13(\mathrm{~m}) 2.13$ & $3.17(\mathrm{~m})$ & $7.94(\mathrm{dd})$ & 7.95 (ddd) & 7.70(ddd) & $8.48(\mathrm{ddd})$ \\
\hline & & & & & & \multicolumn{4}{|c|}{$J_{5.7}=J_{6.8}=1.1 ; J_{6.7}=7.0 ; J_{5.6}=J_{7.8}=8.5$} \\
\hline \multirow[t]{2}{*}{13} & $\mathrm{H}$ & 6 & $2.92(\mathrm{~m})$ & $2.12(\mathrm{~m}) 2.12$ & $3.18(\mathrm{~m})$ & $7.94(\mathrm{dd})$ & 7.87 (ddd) & $7.70(\mathrm{ddd})$ & $8.48(\mathrm{~d})$ \\
\hline & & & & & & \multicolumn{4}{|c|}{$J_{5.7}=J_{6.8}=1.5 ; J_{6.7}=6.9 ; J_{5.6}=J_{7.8}=8.5$} \\
\hline \multirow[t]{2}{*}{14} & $\mathrm{H}$ & 7 & $2.68(\mathrm{~m})$ & $1.87(\mathrm{~m}) 1.87$ & $2.94(\mathrm{~m})$ & $7.71(\mathrm{dd})$ & $7.58(\mathrm{ddd})$ & 7.65 (ddd) & $8.42(\mathrm{dd})$ \\
\hline & & & & & & \multicolumn{4}{|c|}{$J_{5.7}=J_{6.8}=1.2 ; J_{6.7}=6.9 ; J_{5.6}=J_{7.8}=8.5$} \\
\hline \multirow[t]{2}{*}{15} & $8-\mathrm{Cl}$ & 5 & $3.02(\mathrm{t})$ & $2.20(\mathrm{~m}) 2.00$ & $3.17(\mathrm{t})$ & $7.78(\mathrm{dd})$ & $7.89(\mathrm{t})$ & 7.38 (ddd) & $8.13(\mathrm{dd})$ \\
\hline & & & $J_{3.4}=5.9$ & & $J_{1.2}=5.9$ & \multicolumn{4}{|c|}{$J_{5.7}=1.5 ; J_{5.6}=J_{6.7}=8.1$} \\
\hline \multirow[t]{2}{*}{16} & 6.8-diCl & 5 & $2.94(\mathrm{t})$ & $2.12(\mathrm{~m}) 2.02$ & $3.14(\mathrm{t})$ & $7.85(d)$ & - & $7.82(\mathrm{dd})$ & - \\
\hline & & & $J_{1.2}=6.1$ & & $J_{3.4}=6.1$ & \multicolumn{4}{|c|}{$J_{5.7}=2.2$} \\
\hline \multirow[t]{2}{*}{17} & 6.8-diCl & 7 & $2.99(\mathrm{t})$ & $2.20(\mathrm{~m}) 2.00$ & $3.15(\mathrm{t})$ & $7.84(d)$ & - & $7.60(d)$ & - \\
\hline & & & $J_{1.2}=5.8$ & & $J_{3.4}=5.8$ & \multicolumn{4}{|c|}{$J_{5.7}=1.8$} \\
\hline \multirow[t]{2}{*}{18} & $7-\mathrm{F}$ & 5 & $2.88(\mathrm{~m})$ & $2.20(\mathrm{~m}) 2.03$ & $3.16(\mathrm{~m})$ & $7.95(\mathrm{dd})$ & 7.85 (ddd) & $7.82(\mathrm{~d})$ & - \\
\hline & & & & & & \multicolumn{4}{|c|}{$J_{5.6}=9.3 ; J_{5 . \mathrm{F}}=5.1 ; J_{6.8}=2.4 ; J_{6 . \mathrm{F}}=10.0 ; J_{8 . \mathrm{F}}=10.7$} \\
\hline
\end{tabular}


Tabla V (cont.) Desplazamientos químicos $\delta$ (ppm) de ${ }^{1} \mathrm{H}-\mathrm{RMN}$ registados en $\mathrm{CD}_{3} \mathrm{OD}(400 \mathrm{MHz})$ de los híbridos tacrina - fenol. Cadena intermedia y fragmento de fenol. Multiplicidades y constantes de acoplamiento $J$ indicadas en Herzios $(\mathrm{Hz})$

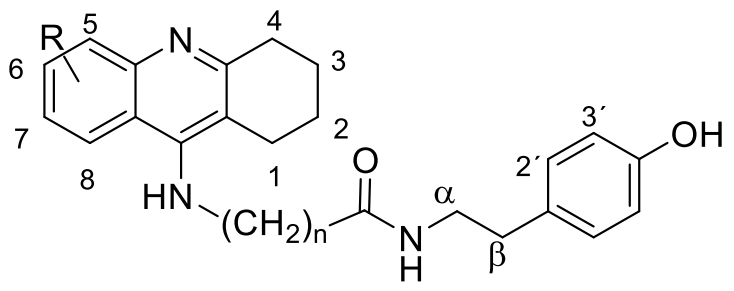

\begin{tabular}{|c|c|c|c|c|c|c|c|c|c|}
\hline & \multirow[b]{2}{*}{$\mathbf{R}$} & \multirow[b]{2}{*}{$\mathbf{n}$} & \multirow[b]{2}{*}{$\mathrm{NHC}_{2}$} & \multirow[b]{2}{*}{$\mathrm{CH}_{2} \mathrm{CO}$} & \multirow[b]{2}{*}{$\alpha$} & \multirow[b]{2}{*}{$\beta$} & \multicolumn{2}{|c|}{ Fenol } & \multirow[t]{2}{*}{ Otras señales: } \\
\hline & & & & & & & $2^{\prime}$ & $3^{\prime}$ & \\
\hline \multirow[t]{2}{*}{12} & $\mathrm{H}$ & 5 & $3.99(\mathrm{t})$ & $2.33(\mathrm{t})$ & $3.51(t)$ & $2.82(t)$ & $7.17(\mathrm{~d})$ & $6.85(\mathrm{~d})$ & $1.96(\mathrm{q}, 2 \mathrm{H}, J=7.5) ; 1.79(\mathrm{q}, 2 \mathrm{H}, J=$ \\
\hline & & & $J=7.2$ & $J=7.2$ & $J=7.2$ & $J=7.2$ & \multicolumn{2}{|c|}{$J=8.5$} & $7.5) ; 1.60-1.42(\mathrm{~m}, 2 \mathrm{H})$ \\
\hline \multirow[t]{2}{*}{13} & $\mathrm{H}$ & 6 & $3.91(\mathrm{t})$ & $2.34(\mathrm{t})$ & $3.52(t)$ & $2.84(t)$ & $7.18(\mathrm{~d})$ & $6.87(\mathrm{~d})$ & $1.90(\mathrm{q}, 2 \mathrm{H} . \mathrm{J}=7.2) ; 1.76(\mathrm{q}, 2 \mathrm{H} . J=$ \\
\hline & & & $J=7.2$ & $J=7.2$ & $J=7.2$ & $J=7.2$ & \multicolumn{2}{|c|}{$J=8.6$} & $7.2) ; 1.60-1.40(\mathrm{~m}, 4 \mathrm{H})$ \\
\hline \multirow[t]{2}{*}{14} & $\mathrm{H}$ & 7 & $3.60(\mathrm{t})$ & $2.08(\mathrm{t})$ & $3.30(t)$ & $2.65(\mathrm{t})$ & $6.96(d)$ & $6.66(\mathrm{~d})$ & $1.64(\mathrm{q} .2 \mathrm{H}, \mathrm{J}=7.3) ; 1.49(\mathrm{q}, 2 \mathrm{H}, \mathrm{J}=$ \\
\hline & & & $J=7.2$ & $J=7.2$ & $J=7.2$ & $J=7.2$ & \multicolumn{2}{|c|}{$J=8.5$} & $7.3) ; 1.38-1.18(\mathrm{~m}, 6 \mathrm{H})$ \\
\hline \multirow[t]{2}{*}{15} & $8-\mathrm{Cl}$ & 5 & $3.92(t)$ & $2.29(\mathrm{t})$ & $3.48(t)$ & $2.81(\mathrm{t})$ & $7.17(\mathrm{~d})$ & $6.85(\mathrm{~d})$ & $1.87(\mathrm{q}, 2 \mathrm{H}, J=7.4) ; 1.72(\mathrm{q}, 2 \mathrm{H} . J=$ \\
\hline & & & $J=7.0$ & $J=7.1$ & $J=7.2$ & $J=7.2$ & \multicolumn{2}{|c|}{$J=8.4$} & $7.4) ; 1.43-1.38(\mathrm{~m}, 2 \mathrm{H})$ \\
\hline \multirow[t]{2}{*}{16} & 6.8-diCl & 5 & $3.53(\mathrm{t})$ & $2.28(\mathrm{t})$ & $3.47(\mathrm{t})$ & $2.83(t)$ & $7.17(\mathrm{~d})$ & $6.86(\mathrm{~d})$ & $1.78(\mathrm{q}, 2 \mathrm{H}, J=7.3) ; 1.72(\mathrm{q}, 2 \mathrm{H}, J=$ \\
\hline & & & $J=7.1$ & $J=7.2$ & $J=7.2$ & $J=7.2$ & \multicolumn{2}{|c|}{$J=8.3$} & $7.3) ; 1.52 .1 .38(\mathrm{~m}, 2 \mathrm{H})$ \\
\hline \multirow[t]{2}{*}{17} & 6.8-diCl & 7 & $3.93(t)$ & $2.29(\mathrm{t})$ & $3.53(t)$ & $2.85(t)$ & $7.18(\mathrm{~d})$ & $6.85(\mathrm{~d})$ & $1.87(\mathrm{q}, 2 \mathrm{H}, J=7.2) ; 1.68(\mathrm{q}, 2 \mathrm{H}, J=$ \\
\hline & & & $J=7.1$ & $J=7.3$ & $J=7.2$ & $J=7.2$ & \multicolumn{2}{|c|}{$J=8.5$} & $7.2) ; 1.55-1.35(\mathrm{~m}, 6 \mathrm{H})$ \\
\hline \multirow[t]{2}{*}{18} & $7-\mathrm{F}$ & 5 & $4.07(\mathrm{t})$ & $2.35(\mathrm{t})$ & $3.52(t)$ & $2.78(t)$ & $7.16(d)$ & $6.84(\mathrm{~d})$ & $1.98(\mathrm{q}, 2 \mathrm{H}, \mathrm{J}=7.2) ; 1.80(\mathrm{q}, 2 \mathrm{H} . \mathrm{J}=$ \\
\hline & & & $J=7.2$ & $J=7.3$ & $J=7.2$ & $J=7.2$ & \multicolumn{2}{|c|}{$J=8.5$} & $7.2) ; 1.60-1.50(\mathrm{~m}, 2 \mathrm{H})$ \\
\hline
\end{tabular}


Tabla VI. Desplazamientos químicos $\delta(\mathrm{ppm})$ de ${ }^{13} \mathrm{C}-\mathrm{RMN}$ registados en $\mathrm{CD}_{3} \mathrm{OD}(100 \mathrm{MHz})$ de los híbridos tacrina - fenol. Fragmento de tacrina.

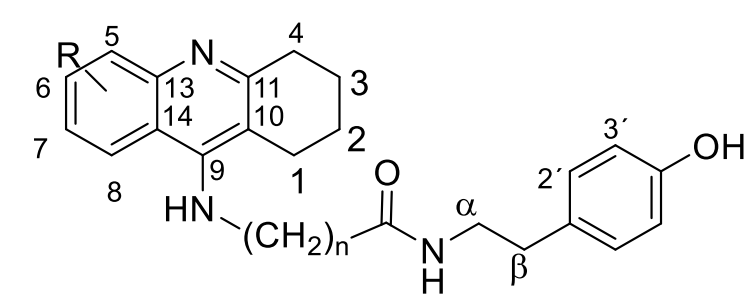

\begin{tabular}{|c|c|c|c|c|c|c|c|c|c|c|c|c|c|c|c|}
\hline & \multirow[b]{2}{*}{$\mathbf{R}$} & \multirow[b]{2}{*}{$\mathbf{n}$} & \multicolumn{13}{|c|}{ Fragmento de Tacrina } \\
\hline & & & 1 & 2 & 3 & 4 & 5 & 6 & 7 & 8 & 9 & 10 & 11 & 13 & 14 \\
\hline 12 & $\mathrm{H}$ & 5 & 25.2 & 23.3 & 22.4 & 30.8 & 122.5 & 132.7 & 125.8 & 125.8 & 156.2 & 114.0 & 153.9 & 142.3 & 118.4 \\
\hline 13 & $\mathrm{H}$ & 6 & 25.7 & 23.8 & 22.9 & 31.4 & 122.8 & 131.9 & 125.6 & 125.8 & 156.2 & 115.0 & 154.3 & 143.3 & 119.4 \\
\hline 14 & $\mathrm{H}$ & 7 & 26.2 & 24.2 & 23.7 & 33.3 & 126.3 & 131.6 & 125.6 & 125.5 & 157.4 & 116.1 & 155.0 & 146.2 & 120.6 \\
\hline 15 & $8-\mathrm{Cl}$ & 5 & 26.4 & 23.0 & 21.6 & 28.9 & 129.5 & 133.6 & 119.2 & 130.9 & 159.5 & 114.2 & 152.8 & 141.2 & 115.0 \\
\hline 16 & 6.8-diCl & 5 & 27.4 & 23.8 & 23.2 & 33.4 & 125.9 & 134.8 & 128.3 & 130.8 & 154.7 & 120.1 & 160.5 & 148.7 & 117.6 \\
\hline 17 & 6.8-diCl & 7 & 27.2 & 23.3 & 22.1 & 32.1 & 125.9 & 133.3 & 129.6 & 130.7 & 153.7 & 118.7 & 162.7 & 146.5 & 115.1 \\
\hline 18 & 7-F & 5 & 25.0 & 22.8 & 21.6 & 31.1 & 123.3 & 123.0 & 160.1 & 110.3 & 152.1 & 123.6 & 173.1 & 136.4 & 113.2 \\
\hline
\end{tabular}

Nota: en el espectro ${ }^{13} \mathrm{C}$ del compuesto 18: 160.1 (d, J=285.0), 123.0 (d, J=23.5), 110.3 (d, J= 22.5). 
Tabla VI (cont.) Desplazamientos químicos $\delta(\mathrm{ppm})$ de ${ }^{13} \mathrm{C}-\mathrm{RMN}$ registados en $\mathrm{CD}_{3} \mathrm{OD}(100 \mathrm{MHz})$ de los híbridos tacrina - fenol. Cadena intermedia y fragmento de fenol.

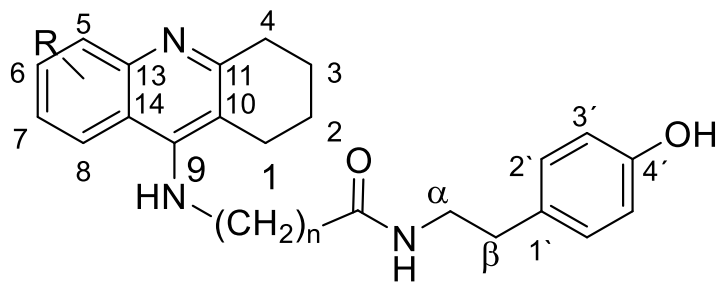

\begin{tabular}{|c|c|c|c|c|c|c|c|c|c|c|c|c|}
\hline & $\mathbf{R}$ & $\mathbf{n}$ & $\mathrm{NH}_{\underline{C}} \mathrm{H}_{2}$ & $\underline{\mathrm{C}}_{2} \mathrm{CO}$ & $\underline{\mathrm{CONH}}$ & $\alpha$ & $\beta$ & 1 & $2^{\prime}-6^{\prime}$ & $3^{\prime}-5$ & $4^{\prime}$ & Otras señales \\
\hline 12 & $\mathrm{H}$ & 5 & 49.4 & 36.8 & 175.8 & 42.1 & 35.7 & 131.2 & 130.7 & 116.2 & 156.9 & $\left(\mathrm{CH}_{2}\right)_{3}: 31.4 ; 26.5 ; 27.2$ \\
\hline 13 & $\mathrm{H}$ & 6 & 49.9 & 36.9 & 175.9 & 42.3 & 35.9 & 131.6 & 130.7 & 116.3 & 156.9 & $\begin{array}{c}\left(\mathrm{CH}_{2}\right)_{3}: 31.4 ; 30.9,26.5 \\
27.2\end{array}$ \\
\hline 14 & $\mathrm{H}$ & 7 & 50.1 & 37.4 & 176.6 & 42.6 & 36.1 & 131.4 & 131.2 & 116.1 & 157.4 & $\begin{array}{c}\left(\mathrm{CH}_{2}\right)_{5}: 32.5 ; 30.6 ; 30.5 \\
28.2 ; 27.4\end{array}$ \\
\hline 15 & $8-\mathrm{Cl}$ & 5 & 50.6 & 36.6 & 175.7 & 42.1 & 35.6 & 131.2 & 130.9 & 116.1 & 156.9 & $\left(\mathrm{CH}_{2}\right)_{3}: 31.4 ; 27.0 ; 26.7$ \\
\hline 16 & 6.8-diCl & 5 & 50.5 & 36.8 & 175.8 & 42.1 & 35.7 & 131.2 & 130.7 & 116.2 & 156.9 & $\left(\mathrm{CH}_{2}\right)_{3}: 31.7 ; 27.3 ; 26.6$ \\
\hline 17 & 6.8-diCl & 7 & 50.1 & 37.4 & 176.6 & 42.6 & 36.1 & 131.7 & 131.2 & 116.6 & 157.3 & $\begin{array}{c}\left(\mathrm{CH}_{2}\right)_{5}: 30.8 ; 30.2 ; 29.4 \\
27.8 ; 26.7\end{array}$ \\
\hline 18 & $7-\mathrm{F}$ & 5 & 49.7 & 36.8 & 175.9 & 42.1 & 35.6 & 131.2 & 131.2 & 116.1 & 156.8 & $\left(\mathrm{CH}_{2}\right)_{3}: 31.1 ; 26.5 ; 27.0$ \\
\hline
\end{tabular}


Tabla VII. Desplazamientos químicos $\delta$ (ppm) de ${ }^{1} \mathrm{H}-\mathrm{RMN}$ registrados en $\mathrm{CD}_{3} \mathrm{OD}(400 \mathrm{MHz})$ de híbridos tacrina - neuroamina. Fragmento de tacrina. Multiplicidades y constantes de acoplamiento $J$ indicadas en Herzios $(\mathrm{Hz})$

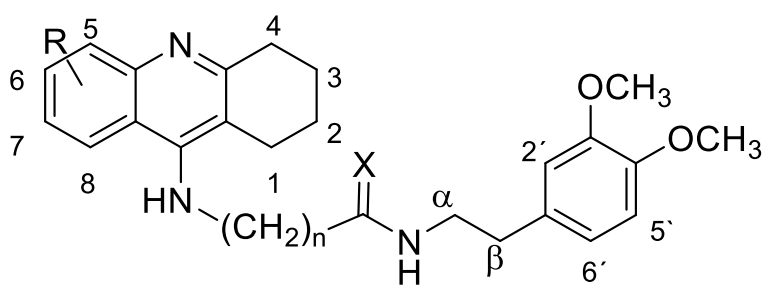

\begin{tabular}{|c|c|c|c|c|c|c|c|c|c|c|c|}
\hline & \multirow[b]{2}{*}{$\mathbf{R}$} & \multirow[b]{2}{*}{$\mathbf{X}$} & \multirow[b]{2}{*}{$\mathbf{n}$} & \multirow[b]{2}{*}{$\mathbf{R 2}$} & \multicolumn{7}{|c|}{ Fragmento de tacrina } \\
\hline & & & & & 1 & 2 & 4 & 5 & 6 & 7 & 8 \\
\hline \multirow[t]{2}{*}{19} & \multirow[t]{2}{*}{$\mathrm{H}$} & \multirow[t]{2}{*}{$\mathrm{O}$} & \multirow[t]{2}{*}{5} & \multirow{2}{*}{$\mathrm{OCH}_{3}$} & $2.90(\mathrm{~m})$ & \multirow[t]{2}{*}{$2.13(\mathrm{~m}) 2.03$} & \multirow[t]{2}{*}{$3.16(\mathrm{~m})$} & $7.94(\mathrm{dd})$ & 7.85 (ddd) & 7.64 (ddd) & $8.40(\mathrm{dd})$ \\
\hline & & & & & & & & \multicolumn{4}{|c|}{$J_{5.7}=J_{6.8}=1.2 ; J_{6.7}=7.0 ; J_{5.6}=J_{7.8}=8.4$} \\
\hline \multirow[t]{2}{*}{20} & \multirow[t]{2}{*}{$\mathrm{H}$} & \multirow[t]{2}{*}{$\mathrm{O}$} & \multirow[t]{2}{*}{6} & \multirow[t]{2}{*}{$\mathrm{OCH}_{3}$} & $2.96(\mathrm{~m})$ & \multirow[t]{2}{*}{$2.12(\mathrm{~m}) 2.08$} & $3.17(\mathrm{~m})$ & $7.95(\mathrm{dd})$ & 7.77 (ddd) & 7.58 (ddd) & $8.32(\mathrm{dd})$ \\
\hline & & & & & & & & \multicolumn{4}{|c|}{$J_{5.7}=J_{6.8}=1.1 ; J_{6.7}=6.9 ; J_{5.6}=J_{7.8}=8.4$} \\
\hline \multirow[t]{2}{*}{21} & \multirow[t]{2}{*}{$\mathrm{H}$} & \multirow[t]{2}{*}{$\mathrm{O}$} & \multirow[t]{2}{*}{7} & \multirow[t]{2}{*}{$\mathrm{OCH}_{3}$} & $2.89(\mathrm{~m})$ & \multirow[t]{2}{*}{$2.12(\mathrm{~m}) 2.02$} & \multirow[t]{2}{*}{$3.12(\mathrm{~m})$} & $7.93(\mathrm{dd})$ & 7.76 (ddd) & $7.56(\mathrm{ddd})$ & $8.30(\mathrm{dd})$ \\
\hline & & & & & & & & \multicolumn{4}{|c|}{$J_{5.7}=J_{6.8}=1.0 ; J_{6.7}=6.9 ; J_{5.6}=J_{7.8}=8.4$} \\
\hline \multirow[t]{2}{*}{22} & \multirow[t]{2}{*}{$8-\mathrm{Cl}$} & \multirow[t]{2}{*}{$\mathrm{O}$} & \multirow[t]{2}{*}{5} & \multirow[t]{2}{*}{$\mathrm{OCH}_{3}$} & $2.99(\mathrm{t})$ & \multirow[t]{2}{*}{$2.19(\mathrm{~m}) 2.05$} & $3.16(t)$ & $7.80(\mathrm{dd})$ & $7.85(t)$ & $7.72(\mathrm{dd})$ & - \\
\hline & & & & & $J_{1.2}=6.1$ & & $J_{3.4}=6.1$ & & $J_{5.7}=1.8$ & $=J_{6.7}=8.0$ & \\
\hline 23 & 6.8-diCl & $\mathrm{O}$ & 5 & $\mathrm{OCH}_{3}$ & $2.97(\mathrm{t})$ & $2.13(\mathrm{~m}) 2.04$ & $3.14(t)$ & $7.80(\mathrm{~d})$ & - & $7.72(\mathrm{~d})$ & - \\
\hline & & & & & $J_{1.2}=6.1$ & & $J_{3.4}=6.1$ & & & & \\
\hline 24 & $7-\mathrm{F}$ & $\mathrm{O}$ & 5 & $\mathrm{OCH}_{3}$ & $2.91(\mathrm{~m})$ & $2.18(\mathrm{~m}) 2.08$ & $3.17(\mathrm{~m})$ & $7.96(\mathrm{dd})$ & 7.87 (ddd) & - & $8.26(\mathrm{dd})$ \\
\hline & & & & & & & & $J_{5 . \mathrm{F}}=$ & $J_{5.6}=7.6 ; J_{6 .}$ & $5 ; J_{6 . \mathrm{F}}=9.3 ;$ & $=10.7$ \\
\hline 25 & $\mathrm{H}$ & $\mathrm{S}$ & 5 & $\mathrm{OCH}_{3}$ & $2.93(\mathrm{~m})$ & $2.16(\mathrm{~m}) 2.06$ & $3.16(\mathrm{~m})$ & $7.94(\mathrm{dd})$ & 7.77 (ddd) & $7.58(\mathrm{ddd})$ & $8.30(\mathrm{dd})$ \\
\hline & & & & & & & & & $J_{6.8}=1.0 ; J_{5}$ & $7.8=8.3 ; J_{6.7}$ & \\
\hline 26 & $\mathrm{H}$ & $\mathrm{S}$ & 7 & $\mathrm{OCH}_{3}$ & $2.91(\mathrm{~m})$ & $2.13(\mathrm{~m}) 2.04$ & $3.14(\mathrm{~m})$ & $7.94(\mathrm{dd})$ & 7.69 (ddd) & $7.51(\mathrm{ddd})$ & $8.21(\mathrm{dd})$ \\
\hline & & & & & & & & & $J_{6.8}=1.0 ; J_{\epsilon}$ & $5.9 ; J_{5.6}=J_{7.8}$ & \\
\hline
\end{tabular}


Tabla VII (cont.) Desplazamientos químicos $\delta(\mathrm{ppm})$ de ${ }^{1} \mathrm{H}-\mathrm{RMN}$ registrados en $\mathrm{CD}_{3} \mathrm{OD}(400 \mathrm{MHz})$ de híbridos tacrina - neuroamina. Cadena intermedia y fragmento de benceno. Multiplicidades y constantes de acoplamiento $J$ indicadas en Herzios $(\mathrm{Hz})$

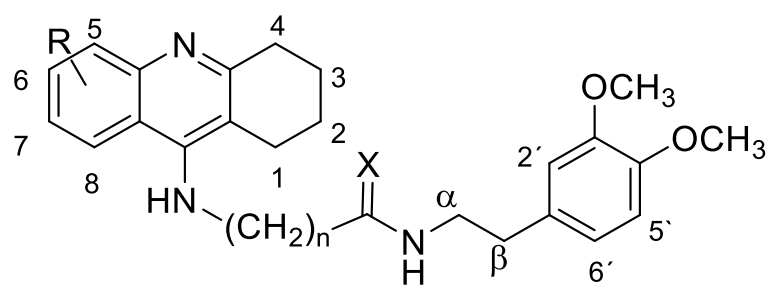

\begin{tabular}{|c|c|c|c|c|c|c|c|c|c|c|c|}
\hline & $\mathbf{R}$ & $\mathbf{n}$ & $\mathbf{x}$ & $\mathrm{NHC}_{\underline{H}}$ & $\mathrm{CH}_{2} \mathrm{CO}$ & $\alpha$ & $\beta$ & $\mathbf{2}^{\prime}$ & $5^{\prime}$ & $6^{\prime}$ & Otras señales \\
\hline \multirow[t]{2}{*}{19} & $\mathrm{H}$ & 5 & $\mathrm{O}$ & $3.87(\mathrm{t})$ & $2.34(t)$ & $3.55(t)$ & $2.88(\mathrm{t})$ & 9 (d) & $7.00(\mathrm{~d})$ & $6.89(\mathrm{dd})$ & $\mathrm{OCH}_{3}: 3.97(\mathrm{~s}, 3 \mathrm{H}) ; 3.93(\mathrm{~s}, 3 \mathrm{H}) ; 1.89(\mathrm{q}, 2 \mathrm{H}, J=$ \\
\hline & & & & $J=7.3$ & $J=7.2$ & $J=7.3$ & $J=7.3$ & \multicolumn{3}{|c|}{$J_{2.6}=1.9 ; J_{5.6}=8.0$} & $7.3) ; 1.77(\mathrm{q}, 2 \mathrm{H}, J=7.3) ; 1.55-1.50(\mathrm{~m}, 2 \mathrm{H})$ \\
\hline \multirow[t]{2}{*}{20} & $\mathrm{H}$ & 6 & $\mathrm{O}$ & $3.75(\mathrm{t})$ & $2.29(\mathrm{t})$ & $3.55(\mathrm{t})$ & $2.89(\mathrm{t})$ & 7.00 (d) & $7.01(\mathrm{~d})$ & $6.90(\mathrm{dd})$ & $\mathrm{OCH}_{3}: 3.99(\mathrm{~s}, 3 \mathrm{H}) ; 3.94(\mathrm{~s}, 3 \mathrm{H}) ; 1.82(\mathrm{q}, 2 \mathrm{H} . J=$ \\
\hline & & & & $J=7.2$ & $J=7.2$ & $J=7.2$ & $J=7.2$ & \multicolumn{3}{|c|}{$J_{2.6}=1.8 ; J_{5.6}=8.2$} & $7.2) ; 1.74(\mathrm{q}, 2 \mathrm{H}, J=7.2) ; 1.58-1.40(\mathrm{~m}, 4 \mathrm{H})$ \\
\hline \multirow[t]{2}{*}{21} & $\mathrm{H}$ & 7 & $\mathrm{O}$ & $3.75(\mathrm{t})$ & $2.29(\mathrm{t})$ & $3.56(t)$ & $2.85(\mathrm{t})$ & $6.99(\mathrm{~d})$ & $7.00(\mathrm{~d})$ & $6.90(\mathrm{dd})$ & $\mathrm{OCH}_{3}: 3.97(\mathrm{~s}, 3 \mathrm{H}) ; 3.93(\mathrm{~s}, 3 \mathrm{H}) ; 1.82(\mathrm{q}, 2 \mathrm{H} . J=$ \\
\hline & & & & $J=7.2$ & $J=7.3$ & $J=7.3$ & $J=7.3$ & \multicolumn{3}{|c|}{$J_{2.6}=1.9 ; J_{5.6}=8.0$} & $7.1) ; 1.69(\mathrm{q}, 2 \mathrm{H}, J=7.1) ; 1.54-1.38(\mathrm{~m}, 6 \mathrm{H})$ \\
\hline \multirow[t]{2}{*}{22} & $8-\mathrm{Cl}$ & 5 & $\mathrm{O}$ & $3.78(\mathrm{t})$ & $2.30(\mathrm{t})$ & $3.53(t)$ & $2.87(\mathrm{t})$ & 6.99 (d) & 7.01 (d) & $6.89(\mathrm{dd})$ & $\mathrm{OCH}_{3}: 3.97(\mathrm{~s}, 3 \mathrm{H}) ; 3.94(\mathrm{~s}, 3 \mathrm{H}) ; 1.84(\mathrm{q}, 2 \mathrm{H}, J=$ \\
\hline & & & & $J=7.0$ & $J=7.2$ & $J=7.2$ & $J=7.2$ & \multicolumn{3}{|c|}{$J_{2.6}=1.8 ; J_{5.6}=8.1$} & $7.3) ; 1.72(\mathrm{q}, 2 \mathrm{H}, J=7.3) ; 1.48-1.37(\mathrm{~m}, 2 \mathrm{H})$ \\
\hline \multirow[t]{2}{*}{23} & 6.8-diCl & 5 & $\mathrm{O}$ & $3.75(\mathrm{t})$ & $2.29(\mathrm{t})$ & $3.53(t)$ & $2.86(t)$ & 6.99 (d) & $7.00(\mathrm{~d})$ & $6.89(\mathrm{dd})$ & $\mathrm{OCH}_{3}: 3.98(\mathrm{~s}, 3 \mathrm{H}) ; 3.95(\mathrm{~s}, 3 \mathrm{H}) ; 1.83(\mathrm{q}, 2 \mathrm{H} . J=$ \\
\hline & & & & $J=7.2$ & $J=7.2$ & $J=7.3$ & $J=7.3$ & \multicolumn{3}{|c|}{$J_{2.6}=1.9 ; J_{5.6}=8.0$} & $7.3) ; 1.72(\mathrm{q}, 2 \mathrm{H}, J=7.3) ; 1.42(\mathrm{q}, 2 \mathrm{H}, \mathrm{J}=7.3)$ \\
\hline \multirow[t]{2}{*}{24} & $7-\mathrm{F}$ & 5 & $\mathrm{O}$ & $4.06(t)$ & $2.35(\mathrm{t})$ & $3.54(t)$ & $2.86(t)$ & $6.99(\mathrm{~d})$ & $7.00(\mathrm{~d})$ & $6.89(\mathrm{dd})$ & $\mathrm{OCH}_{3}: 3.97(\mathrm{~s}, 3 \mathrm{H}) ; 3.94(\mathrm{~s}, 3 \mathrm{H}) ; 1.97(\mathrm{q}, 2 \mathrm{H} . J=$ \\
\hline & & & & $J=7.3$ & $J=7.2$ & $J=7.2$ & $J=7.2$ & \multicolumn{3}{|c|}{$J_{2.6}=2.1 ; J_{5.6}=8.2$} & $7.3) ; 1.80(\mathrm{q}, 2 \mathrm{H}, J=7.3) ; 1.60-1.50(\mathrm{~m}, 2 \mathrm{H})$ \\
\hline \multirow[t]{2}{*}{25} & $\mathrm{H}$ & 5 & S & $3.99(\mathrm{t})$ & $2.73(t)$ & $3.75(t)$ & $3.03(\mathrm{t})$ & 6.99 (d) & $7.01(\mathrm{~d})$ & $6.90(\mathrm{dd})$ & $\mathrm{OCH}_{3}: 3.97(\mathrm{~s}, 3 \mathrm{H}) ; 3.92(\mathrm{~s}, 3 \mathrm{H}) ; 1.88(\mathrm{q}, 2 \mathrm{H} . J=$ \\
\hline & & & & $J=7.2$ & $J=7.2$ & $J=7.1$ & $J=7.2$ & \multicolumn{3}{|c|}{$J_{2.6}=1.9 ; J_{5.6}=8.3$} & $7.3) ; 1.83(\mathrm{q}, 2 \mathrm{H} . J=7.3) ; 1.54-1.44(\mathrm{~m}, 2 \mathrm{H})$ \\
\hline \multirow[t]{2}{*}{26} & $\mathrm{H}$ & 7 & $S$ & $3.89(\mathrm{t})$ & $2.74(\mathrm{t})$ & $3.76(t)$ & $2.99(\mathrm{t})$ & 6.99 (d) & $7.00(\mathrm{~d})$ & $6.90(\mathrm{dd})$ & $\mathrm{OCH}_{3}: 3.97$ (s. $\left.3 \mathrm{H}\right) ; 3.93$ (s. $\left.3 \mathrm{H}\right) ; 1.82$ (q, 2H. $J=$ \\
\hline & & & & $J=7.2$ & $J=7.2$ & $J=7.4$ & $J=7.2$ & \multicolumn{3}{|c|}{$J_{2.6}=1.8 ; J_{5.6}=8.1$} & $7.1) ; 1.71(\mathrm{q}, 2 \mathrm{H} . J=7.1) ; 1.54-1.41(\mathrm{~m}, 6 \mathrm{H})$ \\
\hline
\end{tabular}


Tabla VIII. Desplazamientos químicos $\delta$ (ppm) de ${ }^{13} \mathrm{C}-\mathrm{RMN}$ registrados en $\mathrm{CD}_{3} \mathrm{OD}$ (100 MHz) de híbridos tacrina - neuroamina. Fragmento de tacrina.

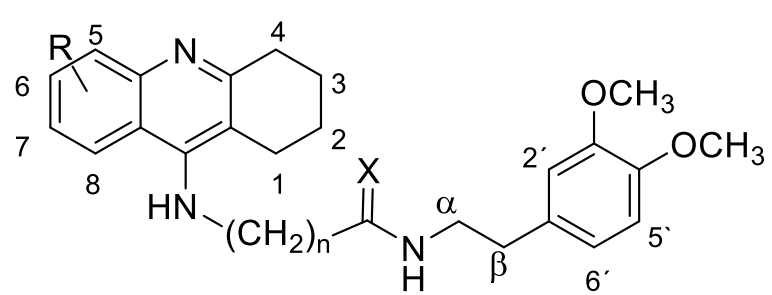

Fragmento de Tacrina

\begin{tabular}{|c|c|c|c|c|c|c|c|c|c|c|c|c|c|c|c|c|}
\hline & $\mathbf{R}$ & $\mathbf{n}$ & $\mathbf{X}$ & 1 & 2 & 3 & 4 & 5 & 6 & 7 & 8 & 9 & 10 & 11 & 13 & 14 \\
\hline 19 & $\mathrm{H}$ & 5 & $\mathrm{O}$ & 26.1 & 24.1 & 23.4 & 32.6 & 125.9 & 132.1 & 125.8 & 125.1 & 155.7 & 115.6 & 156.5 & 149.5 & 120.0 \\
\hline 20 & $\mathrm{H}$ & 6 & $\mathrm{O}$ & 25.8 & 23.9 & 23.9 & 32.1 & 123.7 & 132.8 & 126.1 & 126.0 & 155.2 & 114.9 & 156.5 & 143.6 & 119.9 \\
\hline 21 & $\mathrm{H}$ & 7 & $\mathrm{O}$ & 25.9 & 23.9 & 23.4 & 33.4 & 126.6 & 130.4 & 124.9 & 124.7 & 154.0 & 116.0 & 157.8 & 146.6 & 120.6 \\
\hline 22 & $8-\mathrm{Cl}$ & 5 & $\mathrm{O}$ & 26.5 & 23.3 & 22.1 & 30.2 & 129.3 & 132.5 & 121.6 & 130.4 & 158.0 & 115.9 & 154.8 & 143.3 & 116.1 \\
\hline 23 & 6.8-diCl & 5 & $\mathrm{O}$ & 27.1 & 23.2 & 22.1 & 31.5 & 121.0 & 137.3 & 128.7 & 131.9 & 157.6 & 115.1 & 155.8 & 144.2 & 116.7 \\
\hline 24 & $7-\mathrm{F}$ & 5 & $\mathrm{O}$ & 26.5 & 22.9 & 21.6 & 31.1 & 122.8 & 123.4 & 160.5 & 110.5 & 157.4 & 118.0 & 152.2 & 136.4 & 113.1 \\
\hline 25 & $\mathrm{H}$ & 5 & $\mathrm{~S}$ & 26.5 & 24.5 & 23.9 & 30.7 & 127.5 & 130.7 & 125.4 & 125.2 & 158.7 & 121.3 & 154.2 & 147.5 & 116.8 \\
\hline 26 & $\mathrm{H}$ & 7 & $\mathrm{~S}$ & 26.1 & 24.0 & 23.6 & 30.9 & 127.5 & 130.0 & 124.8 & 124.5 & 158.6 & 120.9 & 154.4 & 146.1 & 116.5 \\
\hline
\end{tabular}

Nota: en el espectro ${ }^{13} \mathrm{C}$ del compuesto 24: 160.5 (d, J=284.8), 123.4 (d, J=24.5), 110.5 (d, J=23.5). 
Tabla VIII (cont.) Desplazamientos químicos $\delta(\mathrm{ppm})$ de ${ }^{13} \mathrm{C}-\mathrm{RMN}$ registrados en $\mathrm{CD}_{3} \mathrm{OD}(400 \mathrm{MHz})$ de híbridos tacrina - neuroamina. Cadena intermedia y fragmento de benceno.

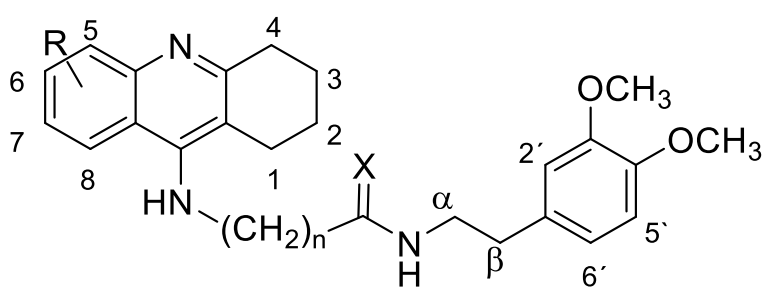

\begin{tabular}{|c|c|c|c|c|c|c|c|c|c|c|c|c|c|c|c|}
\hline & $\mathbf{R}$ & $\mathbf{n}$ & $\mathbf{X}$ & $\mathbf{N H C H}_{2}$ & $\underline{\mathrm{C}} \mathrm{H}_{2} \mathrm{CO}$ & $\underline{\mathrm{CONH}}$ & $\alpha$ & $\beta$ & 1 & 2 & 3 & 4 & 5 & 6 & Otras señales \\
\hline 19 & $\mathrm{H}$ & 5 & $\mathrm{O}$ & 49.2 & 37.4 & 176.4 & 42.4 & 36.5 & 133.9 & 114.3 & 150.9 & 149.5 & 113.6 & 122.7 & $\begin{array}{c}\mathrm{OCH}_{3}: 57.0 ; 56.9 ;\left(\mathrm{CH}_{2}\right)_{3}: \\
32.1 ; 27.8 ; 27.1\end{array}$ \\
\hline 20 & $\mathrm{H}$ & 6 & $\mathrm{O}$ & 49.1 & 37.4 & 176.5 & 42.3 & 36.5 & 133.9 & 114.3 & 150.8 & 149.5 & 113.6 & 122.6 & $\begin{array}{c}\mathrm{OCH}_{3}: 57.0 ; 56.9 ;\left(\mathrm{CH}_{2}\right)_{4}: \\
31.8 ; 28.0 ; 27.3\end{array}$ \\
\hline 21 & $\mathrm{H}$ & 7 & $\mathrm{O}$ & 49.2 & 37.0 & 176.1 & 41.9 & 36.0 & 133.3 & 113.7 & 150.4 & 148.9 & 113.0 & 122.1 & $\begin{array}{c}\mathrm{OCH}_{3}: 56.5 ; 56.4 ;\left(\mathrm{CH}_{2}\right)_{5}: \\
32.1 ; 30.1 ; 30.0 ; 27.7 ; \\
26.7\end{array}$ \\
\hline 22 & $8-\mathrm{Cl}$ & 5 & $\mathrm{O}$ & 50.5 & 36.9 & 175.7 & 41.8 & 36.0 & 133.4 & 113.8 & 150.4 & 149.0 & 113.1 & 122.1 & $\begin{array}{c}\mathrm{OCH}_{3}: 56.5 ; 56.4 ;\left(\mathrm{CH}_{2}\right)_{3}: \\
32.1 ; 27.8 ; 27.1\end{array}$ \\
\hline 23 & 6.8-diCl & 5 & $\mathrm{O}$ & 50.7 & 36.7 & 175.8 & 41.9 & 36.0 & 133.4 & 113.7 & 150.3 & 148.9 & 113.0 & 122.1 & $\begin{array}{c}\mathrm{OCH}_{3}: 56.5 ; 56.4 ;\left(\mathrm{CH}_{2}\right)_{3}: \\
31.5 ; 26.7 ; 26.5\end{array}$ \\
\hline 24 & 7-F & 5 & $\mathrm{O}$ & 49.8 & 36.8 & 175.8 & 41.9 & 36.0 & 133.4 & 113.7 & 150.3 & 148.9 & 113.1 & 122.1 & $\begin{array}{c}\mathrm{OCH}_{3}: 56.5 ; 56.4 ;\left(\mathrm{CH}_{2}\right)_{3}: \\
\quad 31.5 ; 26.7 ; 25.0\end{array}$ \\
\hline 25 & $\mathrm{H}$ & 5 & $S$ & 49.9 & 47.1 & 209.8 & 48.5 & 34.5 & 133.6 & 114.2 & 150.9 & 149.6 & 113.6 & 122.6 & $\begin{array}{c}\mathrm{OCH}_{3}: 56.9(2 \mathrm{C}) ;\left(\mathrm{CH}_{2}\right)_{3}: \\
34.5 ; 32.4 ; 27.4\end{array}$ \\
\hline 26 & $\mathrm{H}$ & 7 & $S$ & 49.2. & 47.1 & 209.6 & 48.2 & 34.6 & 133.4 & 114.3 & 150.3 & 149.1 & 113.1 & 122.3 & $\begin{array}{c}\mathrm{OCH}_{3}: 56.4 ; 56.3\left(\mathrm{CH}_{2}\right)_{5}: \\
32.2 ; 30.0 ; 27.7 ; 27.3 ; \\
26.9\end{array}$ \\
\hline
\end{tabular}


Tabla IX. Datos de ${ }^{1} \mathrm{H}-\mathrm{RMN}, \delta(\mathrm{ppm})$ y $J(\mathrm{~Hz})$ de $N$-(1,2,3,4-tetrahidroacridin-9-il)-1,n-alcanodiaminas $27-30\left(\mathrm{CD}_{3} \mathrm{OD}^{\mathrm{a}}\right.$ y $\left.\mathrm{CDCl}_{3}{ }^{\mathrm{b}}, 300 \mathrm{MHz}\right)$.

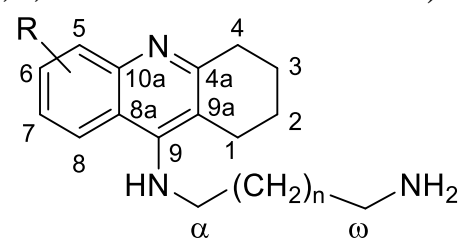

\begin{tabular}{|c|c|c|c|c|c|c|c|c|c|c|c|c|c|c|}
\hline \multirow[b]{2}{*}{ Comp. } & \multirow[b]{2}{*}{$\mathrm{R}$} & \multirow[b]{2}{*}{$\mathrm{n}$} & \multicolumn{7}{|c|}{$\delta(\mathrm{ppm})$} & \multicolumn{3}{|c|}{$J$} & \multicolumn{2}{|c|}{$\delta(J)$} \\
\hline & & & $\begin{array}{c}1 \\
(\mathrm{~m}) \\
\end{array}$ & $\begin{array}{l}2.3 \\
(\mathrm{~m}) \\
\end{array}$ & $\begin{array}{c}4 \\
(\mathrm{~m}) \\
\end{array}$ & $\begin{array}{c}5 \\
(\mathrm{dd}) \\
\end{array}$ & $\begin{array}{c}6 \\
(\mathrm{ddd}) \\
\end{array}$ & $\begin{array}{c}7 \\
\text { (ddd) } \\
\end{array}$ & $\begin{array}{c}8 \\
(\mathrm{dd}) \\
\end{array}$ & $\begin{array}{l}5.6 \\
7.8 \\
\end{array}$ & $\begin{array}{l}5.7 \\
6.8 \\
\end{array}$ & 6.7 & $\alpha$ & $\omega$ \\
\hline $27^{\mathrm{a}}$ & $\mathrm{H}$ & 4 & 2.69 & 1.91 & 3.03 & 7.90 & 7.54 & 7.33 & 7.94 & 8.5 & 1.0 & 7.0 & $3.48(7.2)$ & $2.65(7.0)$ \\
\hline $28^{a}$ & $\mathrm{H}$ & 5 & 2.94 & 2.11 & 3.17 & 7.96 & 7.77 & 7.58 & 8.32 & 8.6 & 1.2 & 7.0 & $3.77(7.2)$ & $2.93(7.2)$ \\
\hline $29^{a}$ & $\mathrm{H}$ & 6 & 2.94 & 2.10 & 3.17 & 7.95 & 7.75 & 7.58 & 8.30 & 8.5 & 1.0 & 7.0 & $3.77(7.2)$ & $2.93(7.2)$ \\
\hline $\mathbf{3 0}^{\mathrm{b}}$ & $\mathrm{H}$ & 7 & 2.94 & 2.11 & 3.17 & 7.94 & 7.74 & 7.56 & 8.26 & 8.5 & 1.0 & 7.0 & $3.72(7.0)$ & $2.79(7.2)$ \\
\hline
\end{tabular}

Otros protones: 27: $\left(\mathrm{CH}_{2}\right)_{4}: 1.62(\mathrm{~m}, 4 \mathrm{H}) ; 1.30(\mathrm{~m}, 4 \mathrm{H}) .28:\left(\mathrm{CH}_{2}\right)_{5}: 1.85(\mathrm{q}, 2 \mathrm{H}, J=7.2) ; 1.71(\mathrm{q}, 2 \mathrm{H}, J=7.2) ; 1.50(\mathrm{~m}, 6 \mathrm{H}) .29:\left(\mathrm{CH}_{2}\right) 6: 1.81(\mathrm{q}, 2 \mathrm{H}, J=$ 7.2); $1,71(\mathrm{~m}, 2 \mathrm{H}) ; 1.45(\mathrm{~m}, 8 \mathrm{H}) .30:\left(\mathrm{CH}_{2}\right)_{7}: 1.82(\mathrm{q}, 2 \mathrm{H}, J=7.2) ; 1.45(\mathrm{~m}, 12 \mathrm{H})$.

Tabla X. Datos de ${ }^{13} \mathrm{C}-\mathrm{RMN}, \delta$ (ppm) de $N$-(1,2,3,4-tetrahidroacridin-9-il)-1,n-alcanodiaminas 27-30 $\left(\mathrm{CD}_{3} \mathrm{OD}^{\mathrm{a}}\right.$ y $\mathrm{CDCl}_{3}^{\mathrm{b}}, 75 \mathrm{MHz}$.

\begin{tabular}{cccccccccccccccc}
\hline Comp. & 1 & 2 & 3 & 4 & $4 a$ & 5 & 6 & 7 & 8 & $8 \mathrm{a}$ & 9 & $9 \mathrm{a}$ & $10 \mathrm{a}$ & $\alpha$ & $\omega$ \\
\hline \hline $\mathbf{2 7}^{\text {a }}$ & 26.0 & 24.2 & 23.7 & 33.5 & 158.1 & 127.1 & 129.9 & 124.7 & 124.5 & 120.3 & 151.3 & 116.1 & 147.1 & 49.5 & 41.3 \\
$\mathbf{2 8}^{\text {a }}$ & 26.1 & 24.0 & 23.5 & 33.7 & 158.4 & 127.2 & 130.2 & 124.8 & 124.6 & 120.9 & 151.4 & 116.4 & 147.2 & 49.7 & 41.4 \\
$\mathbf{2 9}^{\text {a }}$ & 26.2 & 24.1 & 23.7 & 34.2 & 159.2 & 128.1 & 129.6 & 124.6 & 124.4 & 121.4 & 153.2 & 116.7 & 148.1 & 49.8 & 42.4 \\
$\mathbf{3 0}^{\text {b }}$ & 25.2 & 23.5 & 23.2 & 34.1 & 158.9 & 128.6 & 129.2 & 123.9 & 123.2 & 120.7 & 151.1 & 116.3 & 148.0 & 49.9 & 42.6
\end{tabular}

Otros carbonos: 27: $\left(\mathrm{CH}_{2}\right)_{4}: 32.0 ; 30.4 ; 29.9 ; 27.8 .28:\left(\mathrm{CH}_{2}\right)_{5}: 32.1 ; 30.7 ; 30.0 ; 27.8 ; 27.5 .29:\left(\mathrm{CH}_{2}\right)_{6}: 33.5 ; 32.3 ; 30.4 ; 30.3 ; 27.8 ; 26.2 .30:\left(\mathrm{CH}_{2}\right)_{7}: 32.2$, 
Tabla XI. Desplazamientos químicos $\delta(\mathrm{ppm})$ de ${ }^{1} \mathrm{H}-\mathrm{RMN}$ registrados en $\mathrm{CD}_{3} \mathrm{OD}$ (400 MHz) de híbridos tacrina - neuroamina. Multiplicidades y constantes de acoplamiento $J$ indicadas en Herzios $(\mathrm{Hz})$

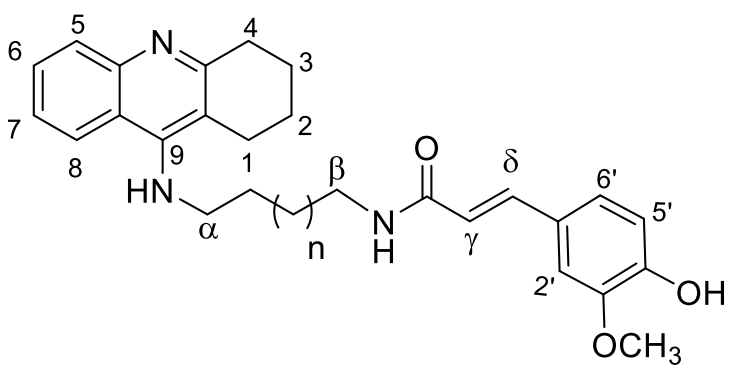

\begin{tabular}{|c|c|c|c|c|c|c|c|c|c|}
\hline & $\mathbf{n}$ & 1 & 2 & 3 & 4 & 5 & 6 & 7 & 8 \\
\hline \multirow[t]{2}{*}{31} & 6 & $2.73(\mathrm{~m})$ & $1.96(\mathrm{~m})$ & 1.92 & $2.98(\mathrm{~m})$ & $7.75(\mathrm{dd})$ & 7.64 (ddd) & 7.43 (ddd) & $8.20(\mathrm{dd})$ \\
\hline & & & & & & \multicolumn{4}{|c|}{$J_{5.7}=J_{6.8}=1.2 ; J_{6.7}=7.7 ; J_{5.6}=J_{7.8}=8.6$} \\
\hline \multirow[t]{2}{*}{32} & 7 & $2.72(\mathrm{~m})$ & $1.91(\mathrm{~m})$ & 1.89 & $2.97(\mathrm{~m})$ & $7.75(\mathrm{dd})$ & $7.58(\mathrm{ddd})$ & $7.38(\mathrm{ddd})$ & $8.12(\mathrm{dd})$ \\
\hline & & & & & & \multicolumn{4}{|c|}{$J_{5.7}=J_{6.8}=1.2 ; J_{6.7}=7.7 ; J_{5.6}=J_{7.8}=8.6$} \\
\hline \multirow[t]{2}{*}{33} & 8 & $2.72(\mathrm{~m})$ & $1.90(\mathrm{~m})$ & 1.89 & $2.96(\mathrm{~m})$ & $7.76(\mathrm{dd})$ & 7.57 (ddd) & 7.37 (ddd) & $8.11(\mathrm{dd})$ \\
\hline & & & & & & \multicolumn{4}{|c|}{$J_{5.7}=J_{6.8}=1.2 ; J_{6.7}=7.7 ; J_{5.6}=J_{7.8}=8.6$} \\
\hline
\end{tabular}

\begin{tabular}{|c|c|c|c|c|c|c|c|c|c|}
\hline & $\mathbf{n}$ & $\alpha$ & $\beta$ & $\gamma$ & $\delta$ & $\mathbf{2}^{\prime}$ & $\mathbf{5}^{\prime}$ & $6^{\prime}$ & Otras señales: \\
\hline \multirow[t]{2}{*}{31} & 6 & $3.69(\mathrm{t})$ & $3.27(\mathrm{t})$ & $6.40(d)$ & $7.42(d)$ & $7.10(d)$ & $6.79(d)$ & $7.01(\mathrm{dd})$ & $\mathrm{OCH}_{3}: 3.87(\mathrm{~s}, 3 \mathrm{H}) ; 1.73(\mathrm{q}, 2 \mathrm{H}, J=7.1) ; 1.55(\mathrm{q}, 2 \mathrm{H}$, \\
\hline & & $J=7.2$ & $J=7.0$ & \multicolumn{2}{|c|}{$J_{\gamma \delta}=15.8$} & \multicolumn{3}{|c|}{$J_{2.6}=1.7 ; J_{5.6}=8.1$} & $J=7.1) ; 1.36-1.48(\mathrm{~m}, 4 \mathrm{H})$ \\
\hline \multirow[t]{2}{*}{32} & 7 & $3.59(\mathrm{t})$ & $3.25(\mathrm{t})$ & $6.40(\mathrm{t})$ & $7.42(\mathrm{~d})$ & $7.09(\mathrm{~d})$ & $7.01(\mathrm{~d})$ & $6.78(\mathrm{dd})$ & $\mathrm{OCH}_{3}: 3.87(\mathrm{~s}, 3 \mathrm{H}) ; 1.66(\mathrm{q}, 2 \mathrm{H} . J=6.8) ; 1.51(\mathrm{q}, 2 \mathrm{H}$. \\
\hline & & $J=7.2$ & $J=7.1$ & \multicolumn{2}{|c|}{$J_{\gamma \delta}=15.7$} & \multicolumn{3}{|c|}{$J_{2.6}=1.8 ; J_{5.6}=8.3$} & $J=6.8) ; 1.33-1.37(\mathrm{~m}, 6 \mathrm{H})$ \\
\hline \multirow[t]{2}{*}{33} & 8 & $3.57(\mathrm{t})$ & $3.35(\mathrm{t})$ & $6.41(\mathrm{t})$ & $7.42(\mathrm{~d})$ & $7.08(\mathrm{~d})$ & $7.00(\mathrm{~d})$ & $6.77(\mathrm{dd})$ & $\mathrm{OCH}_{3}: 3.86(\mathrm{~s}, 3 \mathrm{H}) ; 1.65(\mathrm{q}, 2 \mathrm{H} . J=7.2) ; 1.51(\mathrm{q}, 2 \mathrm{H}$ \\
\hline & & $J=7.2$ & $J=7.1$ & \multicolumn{2}{|c|}{$J_{\gamma \delta}=15.7$} & \multicolumn{3}{|c|}{$J_{2.6}=1.9 ; J_{5.6}=8.1$} & $J=6.5) ; 1.31-1.38(\mathrm{~m}, 8 \mathrm{H})$ \\
\hline
\end{tabular}


Tabla XII. Desplazamientos químicos $\delta$ (ppm) de ${ }^{13} \mathrm{C}-\mathrm{RMN}$ registrados en $\mathrm{CD}_{3} \mathrm{OD}(100 \mathrm{MHz})$ de híbridos tacrina - neuroamina.

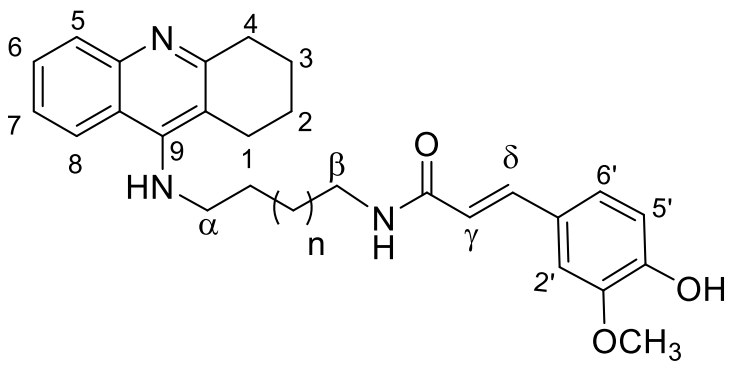

\begin{tabular}{cccccccccccccccc}
\hline & $\mathbf{R}$ & $\mathbf{n}$ & $\mathbf{1}$ & $\mathbf{2}$ & $\mathbf{3}$ & $\mathbf{4}$ & $\mathbf{5}$ & $\mathbf{6}$ & $\mathbf{7}$ & $\mathbf{8}$ & $\mathbf{9}$ & $\mathbf{1 0}$ & $\mathbf{1 1}$ & $\mathbf{1 3}$ & $\mathbf{1 4}$ \\
\hline $\mathbf{3 1}$ & $\mathrm{H}$ & 6 & 25.7 & 23.7 & 23.0 & 32.5 & 125.3 & 131.2 & 125.2 & 125.1 & 154.8 & 115.4 & 156.5 & 149.3 & 119.8 \\
$\mathbf{3 2}$ & $\mathrm{H}$ & 7 & 25.8 & 23.8 & 23.3 & 33.3 & 126.6 & 130.4 & 124.9 & 124.7 & 153.9 & 115.9 & 157.7 & 149.4 & 120.5 \\
$\mathbf{3 3}$ & $\mathrm{H}$ & 8 & 25.9 & 23.9 & 23.4 & 33.5 & 126.8 & 130.3 & 124.9 & 124.7 & 153.9 & 116.1 & 157.9 & 149.4 & 120.6 \\
\hline
\end{tabular}

\begin{tabular}{|c|c|c|c|c|c|c|c|c|c|c|c|c|c|c|}
\hline & $\mathbf{R}$ & $\mathbf{n}$ & $\alpha$ & $\beta$ & CONH & $\gamma$ & $\delta$ & 1 , & 2 & 3 , & 4, & 5, & 6 , & Otras señales \\
\hline 31 & $\mathrm{H}$ & 6 & 49.5 & 40.3 & 169.2 & 118.5 & 142.1 & 128.0 & 116.5 & 150.1 & 145.1 & 111.4 & 123.2 & $\begin{array}{c}\mathrm{OCH}_{3}: 56.3 ;\left(\mathrm{CH}_{2}\right)_{4}: 31.9 ; \\
30.3 ; 27.6,27.5\end{array}$ \\
\hline 32 & $\mathrm{H}$ & 7 & 48.5 & 40.4 & 169.1 & 118.4 & 142.0 & 127.7 & 116.6 & 150.5 & 146.5 & 111.3 & 123.3 & $\begin{array}{c}\mathrm{OCH}_{3}: 56.3 ;\left(\mathrm{CH}_{2}\right)_{5}: 32.1 ; \\
30.3,30.0,27.8,27.7\end{array}$ \\
\hline 33 & $\mathrm{H}$ & 8 & 49.6 & 40.5 & 169.1 & 118.5 & 142.0 & 127.8 & 116.6 & 150.4 & 146.7 & 111.3 & 123.2 & $\begin{array}{l}\mathrm{OCH}_{3}: 56.3 ;\left(\mathrm{CH}_{2}\right)_{6}: 32.1 ; \\
30.4 ; 30.3 ; 30.2,27.9 ; 27.8\end{array}$ \\
\hline
\end{tabular}

